Marius Hildebrand

Rechtspopulismus

und Hegemonie

Der Aufstieg der SVP und die diskursive Transformation der politischen Schweiz 
Marius Hildebrand

Rechtspopulismus und Hegemonie

Kultur und Kollektiv | Band 4 


\section{Editorial}

Die von der Forschungsstelle Kultur- und Kollektivwissenschaft der Universität Regensburg herausgegebene Schriftenreihe »Kultur und Kollektiv« veröffentlicht Monographien im Bereich der Kultur- und Kollektivwissenschaft, die aktuelle Themen auf einem innovativem Theorie-Niveau und in jargonfreier Sprache zur Darstellung bringen.

Von der Forschungsstelle wird ebenfalls die Zeitschrift für Kultur- und Kollektivwissenschaft herausgegeben.

Marius Hildebrand (Dr.) forscht an der Universität Hamburg in den Bereichen Politische Theorie und Ideengeschichte, Sozialtheorie, Rechtssoziologie, Populismusund Hegemonietheorie sowie Gouvernmentalitätsstudien. 
Marius Hildebrand

\section{Rechtspopulismus und Hegemonie}

Der Aufstieg der SVP und die diskursive Transformation der politischen Schweiz

[transcript] 


\section{(c) $(1) \Theta(\Theta)$}

Dieses Werk ist lizenziert unter der Creative Commons Attribution-NonCommercial-NoDerivs 4.0 Lizenz (BY-NC-ND). Diese Lizenz erlaubt die private Nutzung, gestattet aber keine Bearbeitung und keine kommerzielle Nutzung. Weitere Informationen finden Sie unter https://creativecommons.org/licenses/by-nc-nd/4.o/deed.de/.

Um Genehmigungen für Adaptionen, Übersetzungen, Derivate oder Wiederverwendung zu kommerziellen Zwecken einzuholen, wenden Sie sich bitte an rights@transcript-verlag.de

\section{(C) 2017 transcript Verlag, Bielefeld}

Die Verwertung der Texte und Bilder ist ohne Zustimmung des Verlages urheberrechtswidrig und strafbar. Das gilt auch für Vervielfältigungen, Übersetzungen, Mikroverfilmungen und für die Verarbeitung mit elektronischen Systemen.

\section{Bibliografische Information der Deutschen Nationalbibliothek}

Die Deutsche Nationalbibliothek verzeichnet diese Publikation in der Deutschen Nationalbibliografie; detaillierte bibliografische Daten sind im Internet über http://dnb.d-nb.de abrufbar.

Umschlagkonzept: Kordula Röckenhaus, Bielefeld

Satz: Marius Hildebrand

Druck: Majuskel Medienproduktion GmbH, Wetzlar

Print-ISBN 978-3-8376-3712-0

PDF-ISBN 978-3-8394-3712-4

Gedruckt auf alterungsbeständigem Papier mit chlorfrei gebleichtem Zellstoff. Besuchen Sie uns im Internet: http://www.transcript-verlag.de Bitte fordern Sie unser Gesamtverzeichnis und andere Broschüren an unter: info@transcript-verlag.de 


\section{Inhalt}

Prolog: Der Anti-Populismus-Reflex

oder die wissenschaftliche Konstitution

eines ungeliebten Forschungsgegenstandes | 11

\section{Einleitung | 19}

1. Der SVP Populismus und die Polarisierung der politischen Schweiz | 19

2. Theoretische Perspektive und Fragestellung | 24

3. Aufbau der Arbeit | 30

4. Forschungsüberblick | 33

\section{Erster Teil: Diskurs, Hegemonie, Populismus. ERNESTO LACLAUS POLITISCHE THEORIE DER GESELLSCHAFT}

1. Das ,Volk' als imaginäre und reale Identität |47

2. Populismusforschung als Parteienforschung: der Gelegenheitsstrukturansatz | 51

2.1 Das Erklärungsmodell und die theoretischen Prämissen des Gelegenheitsstrukturansatzes | 52

2.2 Populismusforschung ohne, Volk‘ Grenzen des Gelegenheitsstrukturansatzes | 57

2.3 Plädoyer für einen Paradigmenwechsel in der Erforschung populistischer Parteien | 60

3. Konzeptuelle Vorbemerkungen: Identität und Hegemonie |63

3.1 Der Forschungsgegenstand: Identität | 63

3.2 Der sozialtheoretische Scheinwerfer: Hegemonie | 66

3.3 Eine hegemonietheoretische Konzeption des Identitätsbegriffs | 69

4. Antagonistische Ordnungen. Ernesto Laclaus und Chantal Mouffes poststrukturalistische Diskurstheorie des Sozialen | 73

4.1 Theoretische Grundlagen I: Von performativen Sprachspielen und Sprechakten zu einer Diskurstheorie des Sozialen | 74

4.2 Theoretische Grundlagen II: Poststrukturalismus, discursive turn und postfundamentalistische Epistemologie | 79 
4.3 Eckpunkte einer poststrukturalistischen Diskurstheorie | 86

4.4 Die konzeptuellen Bausteine der Hegemonietheorie $\mid 88$

4.4.1 Artikulation, Diskurs, Knotenpunkte | 88

4.4.2 Antagonismus, Dislokation und das Subjekt als Mangel | 91

4.4.3 Die Subversion von Bedeutung: Die wechselseitige Kontamination von Äquivalenz- und Differenzlogik $\mid 98$

4.4.4 Leere Signifikanten und Hegemonie: Semantische Entleerungen als Möglichkeitsbedingung provisorischer Universalisierungen | 101

4.5 Die Unmöglichkeit von Gesellschaft und das Primat des Politischen | 106

4.6 Die politische Ethik der radikalen Demokratie | 111

5. Populismus als politisches Phänomen par excellence | 115

5.1 Die binäre Spaltung des Sozialen und die hegemoniale Konstruktion des, Volkes' | 116

5.2 Populismus als Königsweg des Politischen - und der Demokratie? | 122

6. Für eine Hegemonieanalyse rechtspopulistischer Diskurse | 127

\section{ZWEITER TEIL: VON DER THEORIE ZUR FORSCHUNGSSTRATEGIE}

1. Operationalisierung und Untersuchungsmaterial | 137

1.1 Wie sich die Fixierung von Sinn untersuchen lässt. Eine textanalytisch orientierte Operationalisierung der Hegemonietheorie | 137

1.2 Eine forschungspragmatische Auswahl von vier dislozierenden Ereignissen als Wegmarken der Hegemonieanalyse | 145

1.3 Untersuchungsmaterial | 147

\section{DritTER TeIL: Eine HegemonieAnalyse DES SVP-POPULISMUS}

1. No Country for Populist Leaders? | 151

1.1 Der ,konkordanzdemokratische Sonderfall'.

Zur hegemonialen Konstruktion der politischen Schweiz zwischen 1945 und 1990 | 152

1.2 Der SVP-Populismus und die Krise der konkordanzdemokratisch integrierten Schweiz | 163 
2. Blochers, Neue Mitte“ und die Radikalisierung des Zürcher Flügels: Von der klientelistischen Bauern- und Gewerbepartei zur neukonservativen Catch-All-Partei | 167

2.1 Die Pionierphase des SVP-Populismus: Die Zürcher Antwort auf die Krise der SVP | 168

2.2 Die Konstruktion einer liberalkonservativen Äquivalenz | 180

2.2.1 Neoliberalismus - die ordnungspolitische Offensive | 180

2.2.2 Konservatismus - die sicherheitspolitische Offensive | 183

3. Zwischenbilanz und Vorausblick: Von der subkulturellen Enklave zum nationalpopularen politischen Projekt | 193

4. Der populare Bruch: Der Konflikt um die europäische Integration und die Konstruktion eines nationalpopularen Neoliberalismus | 197

4.1 Das Nein zum Europäischen Wirtschaftraum. Ursachen und Folgen der Volksabstimmung vom 6. Dezember 1992 | 198

4.2 Einschub: Die Albisgüetli-Tagung der Zürcher SVP | 209

4.3 Die Albisgüetlirede von 1992 |211

4.4 Die EG als sozialistisches Rezidiv und die liberal-konservative Usurpation des ,Schweizer Sonderfalls، | 221

4.5 Missionarische Politik und popularer Bruch |229

4.6 Zusammenfassung: Die ,orientierungslose politische Klasse ‘ und die Überdeterminierung der popularen Äquivalenz | 236

5. Die Heydays des SVP-Populismus und die rechtspopulistische Hegemonisierung des nationalpopularen Imaginären | 241

5.1 Die Nationalratswahlen 1999 |241

5.2 Geschichtspolitik: Die Konstruktion eines Heartland | 248

5.2.1 Das Organische und das Zersetzende | 250

5.2.2 Blocher \& Co als Helden einer zyklisch-periodisch verlaufenden Geschichte. Von ,schweizerischen Gemeinschaften' und ,europäischen Massengesellschaften` | 258

5.2.3 Zusammenfassung: Die geschichtspolitische Hegemonisierung des ,Sonderfalls‘ | 277

5.3 Demokratie und Pluralismus. Zur semantischen Transformation identitätsstiftender Begriffe im SVP-Populismus | 279 
6. Gegenhegemonien: Swissness oder Sonderfall.

Post-politische Restauration der multikulturellen Schweiz oder linkspopulistische Gegenhegemonie | 285

7. ,Blocherismus' | 291

7.1 Das Ereignis: Die Nationalratswahlen 2007 und die Abwahl Christoph Blochers als Bundesrat $\mid 292$

7.2 Christoph Blocher: Bauer, Jurist, Oberst, Unternehmer, Kunstsammler. Die Karriere des politischen Versorgers und Gesetzgebers | 298

7.3 Der Abgewählte als verhinderter Heilsbringer.

Charisma, politische Repräsentation und missionarische Politik |307

8. Der Minarett-Streit. Der SVP-Populismus zwischen Zersplitterung und Hegemonisierung des demokratischen Imaginären | 311

8.1 Minarett-Streit und Minarett-Initiative $\mid 312$

8.2 Der Antiislamismus und die Europäisierung des popularen Bruchs | 321

8.3 Volkssouveränität gegen, fremdes Recht'.

Die populistische Generalisierung der Bedrohung und die Variation des, Sonderfalls‘ | 327

\section{SChluss: ANTIPOLITISCher Populismus}

1. Die Kontinuität des SVP-Populismus und die Externalisierung innerer Grenzen | 337

2. Popular-demokratischer oder autoritärer Populismus. Das ethische Moment der politischen Ontologie und die Grenzen des Formalismus | 347

Bibliographie | 353

Literatur | 353

Fragmente des SVP-Diskurses $\mid 388$

Danksagung | 397 
„,The people' is not something of the nature of an ideological expression, but a real relation between social agents.“

LACLAU 2005A: 73

„For the destruction of the racist complex presupposes not only the revolt of its victims, but the transformation of the racists themselves, and consequentially the internal decomposition of the community created by racism."

BALIBAR 1991: 18

„Man muss das Versagen der etablierten Politik diskutieren, anstatt alles mit dem Vorwurf des ,Populismus` zu dämonisieren, was sich dem traditionellen, rationalen Diskurs verschliesst.“ GUISSANI 1995: 226 



\section{Prolog: Der Anti-Populismus-Reflex oder die wissenschaftliche Konstitution eines ungeliebten Forschungsgegenstandes}

„Die Anhänger der SVP, die sind nicht so ganz
anders als ich.“

BICHSEL 2010

In einem Interview mit der Gewerkschaftszeitung Work identifiziert sich der Schweizer Schriftsteller und Linksintellektuelle Peter Bichsel mit den Anhängern einer rechtspopulistischen Partei. Die Aussage wird weder ein- noch ausgeleitet. Sie legt eine solitäre Spur, die Verwirrung stiftet, gilt der Populismus - zumal in seiner rechten Spielart - doch als ,,absolutes Übel “1 einer wohlgeordneten demokratischen Gesellschaft.

Einen ersten Eindruck vom schlechten Image des Populismus erhält, wer Lexika, Zeitungen und Magazine nach den geläufigen Attributen des politischen Phänomens durchsucht. Der Populismus wird als opportunistisch, emotionalisierend, ephemer, demagogisch, charismatisch, krude, brachial, markig, suggestiv, hysterisch, plump, simplifizierend, vulgär, manipulativ und demokratiegefähr-

1 Der Begriff stammt von Frantz Fanon (1981: 34). Für Fanon ist der Kolonisierte aus Sicht der Kolonialherren „der Feind der Werte, [...] das absolute Übel, ein zersetzendes Element, das alles, was mit ihm in Berührung kommt, zerstört, alles, was mit Ästhetik oder Moral zu tun hat, deformiert und verunstaltet, ein Hort unheilvoller Kräfte, ein unbewußtes und nicht faßbares Instrument blinder Gewalt.“ Hier und im Folgenden werden sowohl die alte Rechtschreibung, als auch die schweizerische Rechtschreibung im Rahmen von Zitationen beibehalten. 
dend qualifiziert. ${ }^{2}$ Das semantische Netz, das sich um den Begriff legt, lässt unschwer erkennen, dass es sich um einen politischen „Kampfbegriff ${ }^{{ }^{3} 3}$ handelt. Das Etikett ,populistisch“ fungiert in der Regel als stigmatisierende Fremdbeschreibung. Wer eine Partei, eine Politikerin, eine Ideologie oder eine Initiative als populistisch klassifiziert, zielt darauf, die politische Position des Anderen zu brandmarken und den eigenen Standpunkt mit den positiven Antonymen des Populismus zu schmücken, sich selbst als glaubwürdigen, rationalen und normalen Verantwortungsträger zu stilisieren.

Abgesehen von seiner pejorativen Konnotation bleibt der Populismusbegriff indes nebulös. Einig sind sich die politischen Kommentatoren lediglich darin, dass es sich um einen opportunistischen Politikstil handelt, der von einer akzeptablen Form der politischen Kontingenz- und Komplexitätsbewältigung $a b$ weicht. ${ }^{4}$ Das Problem mit derlei Kritiken des Populismus besteht darin, dass sich die Fragen, wann ein politischer Lösungsvorschlag zu simplifizierend und wann die Repräsentation des Mehrheitswillens lediglich eine skrupellose Strategie ist, nicht ohne Unterstellungen beantworten lassen. So überrascht es nicht, wenn der Populismusbegriff selbst unter Populismus-Verdacht gerät, wie Frank Decker, einer der führenden deutschsprachigen Populismusforscher einräumt. ${ }^{5}$

Nichtsdestotrotz vollziehen die gängigen wissenschaftlichen Populismustheorien dieselbe Operation. ${ }^{6}$ Zwar lehnen es die meisten Forscher/innen ab, den Populismus auf einen demagogischen politischen Stil zu reduzieren, ${ }^{7}$ doch treffen sie sich bezüglich der Stigmatisierung als anomales Phänomen mit dem medialen Diskurs. Angesichts der vermeintlichen Unmöglichkeit, den spezifischen Unterschied des Populismusbegriffs auf positive Weise zu bestimmen, wird die Abweichung von einer präsupponierten Normalität zum Definiens des Begriffs. Wenn der Aufstieg populistischer Parteien auf unaufgeklärte Teilgesellschaften, uneinsichtige Protestwähler/innen oder unzureichende politische Bildung zurückgeführt wird, ${ }^{8}$ die Wahlerfolge populistischer Parteien in Verbindung mit den Integrationsdefiziten der repräsentativen Demokratien und der Krise der

2 Vgl. stellvertretend für viele Jäger 2011; Nonnenmacher 2014; vor dem Hintergrund der italienischen Parlamentswahlen 2013 vgl. Hartleb 2013; vor dem Hintergrund des Wahlerfolges der griechischen Syriza-Partei vgl. Winkler 2015.

3 Vgl. Link 2008: 17.

4 Vgl. kritisch Rensmann 2006: 59ff.

5 Decker 2000: 23f.; vgl. auch Dahrendorf 2003: 156; sowie Helbing 2011: 13.

6 Einen ersten Eindruck vermittelt etwa Nohlen 2011: 489ff.

7 So etwa Priester 2011: 187; Decker/Lewandowsky 2009: 1.

8 Exemplarisch vgl. Spier 2010 sowie Jäger 2011. 
etablierten Parteiensysteme gebracht werden, ${ }^{9}$ wenn gefragt wird, ob der Populismus eher „Totengräber oder Korrektiv der Demokratie“"10 sei, wenn der Populismus als inkonsistente, unterentwickelte Ideologie konturiert wird, ${ }^{11}$ der Rechtspopulismus als moderate Form des Rechtsextremismus begriffen wird ${ }^{12}$ oder zum Krisenindikator eines postpolitischen Kosmopolitismus avanciert, ${ }^{13}$ dann wird das Phänomen ,Populismus` stets außerhalb des politischen Normalbetriebes und des ,eigentlichen' politischen Systems positioniert, um entweder als fremdartige Bedrohung oder als beunruhigendes Symptom tieferliegender soziopolitischer Pathologien sinnhaft gemacht zu werden. ${ }^{14}$ Während ein analytisch scharfer Populismusbegriff außer Reichweite bleibt, zieht sich der Topos der Devianz wie ein roter Faden durch den Populismusdiskurs des sozialwissenschaftlichen Mainstreams. ${ }^{15}$ Dabei erscheint das Phänomen zumeist als das antipodische Andere eines output-orientierten Demokratiediskurses, der die demokratischen Grundprinzipien Volkssouveränität und Partizipation den „Rationali-

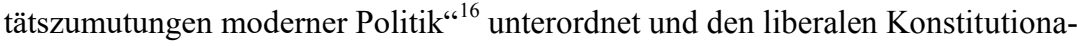
lismus als die einzig legitime Staatsform anerkennt.

So bespricht die Mainstream-Politologie den Erfolg populistischer Parteien entweder als politisch-ideologisches Oberflächenphänomen einer allgemeinen

9 Anstelle vieler vgl. Dahrendorf 2003 sowie Albertazzi/McDonnell 2008b.

10 So der Titel von Hartleb 2012. Auch andere Titel wie etwa „Populismus. Gefahr für die Demokratie oder nützliches Korrektiv?““ (Decker 2006) und „Populismus - Herausforderung oder Gefahr für die Demokratie“ (Sir Peter Ustinov Institut 2012) deuten darauf hin, dass die damit angerissene Frage (ob der Populismus eine Gefährdung der Demokratie darstellt oder ob die Demokratie angesichts der populistischen Herausforderung zu sich selbst zurückfinden könnte, indem die etablierten demokratischen Parteien ihre Responsivität wiederherstellten) die zentrale Fragestellung der Populismusforschung ist.

11 Vgl. Priester 2012a: 3; Mudde 2004: insb. 543.

12 So etwa von Philipp Becher (2013).

13 Vgl. Chantal Mouffes $(2005,2007,2011)$ Kritik an Kosmopolitismus (und Rechtspopulismus); Oudenampsen 2012; exemplarisch für das kosmopolitische Argument gegen den Populismus vgl. Pelinka 2012: insb. 17ff.

14 Die Titel „Populism and the Pathology of Representative Politics” (Taggart 2002); „Populism, or, Politics at the Edges of Democracy” (Arditi 2003) und „The Populist Radical Right: A Pathological Normalcy” (Mudde 2010) sind typische Zeugnisse dieser allgemeinen Stoßrichtung der Populismusforschung.

15 Vgl. Mény/Surel 2002: 2ff.

16 Buchstein/Jörke 2003: 476. 
Störung des gesellschaftlichen Normalzustandes oder aber als demagogische Strategie zur Mobilisierung ,bildungsferner Modernisierungsverlierer ${ }^{6}{ }^{17}$ Im ersten Fall wird dem Populismus eine Indikatorfunktion für gesellschaftspolitische Missstände zugebilligt: Sein Erfolg ist symptomatisch. Der Populismus drückt aus, was tiefer wurzelt: sei es das falsche Bewusstsein von Bevölkerungsteilen oder die desintegrativen Effekte der neoliberalen Globalisierung und die schwindende Legitimation ihrer Regierungssysteme. Der mahnende Appell richtet sich folglich an die etablierten Parteien. Es gelte, sich der veränderten politischen Nachfrage soweit als möglich anzupassen und die Responsivität des politischen Systems wiederherzustellen. ${ }^{18}$

Im zweiten Fall wird der Populismus als „schleichendes Gift“19 wahrgenommen: Populisten werden dafür gescholten, dass sie soziopolitische Missstände und rationale Interessengegensätze in „unechte“ oder „unteilbare Konflikte“ übersetzten. ${ }^{20}$ Die rechtspopulistische „Politik von Angst und Zugehörigkeit““21 wird als Gefahr für die Zivilgesellschaft und als „Hindernis für die politische Sozialisation ${ }^{\text {، } 22}$ wahrgenommen, da sie den soziomoralischen Fortschritt moderner Gesellschaften blockiere und die Integration durch Rationalität, Kompromiss und Konsens untergrabe. Die verordnete Therapie besteht folglich in verstärkter politischer Bildung. Letztere soll jene Bürger/innen aufklären, die den Authentizitätsbehauptung der populistischen „Pioniere der Anomie ${ }^{\text {“23 }}$ Glauben schenkten, ihren Heilsversprechen anheimfielen und die eigenen ,wahren Interessen aus den Augen verloren hätten. Dem „Bazillus des Populismus“ ${ }^{\text {(24 }}$ soll auf diese

17 Typisch für die Deutung als ideologischer Ausdruck von tieferliegenden Pathologien: Mény/Surel 2002: 7; Dahrendorf 2003; Taggart 2002 u. 2004; Rosanvallon 2008; Dorna 2003: 4; Mudde 2010; Decker 2012 u. 2013; Mouffe 2005 u. 2011. Typisch für die Deutung als ideologisch unbestimmte, opportunistische Strategie mit dem Ziel der schlichten Machtmaximierung: Weyland 2001: insb. 12ff.; Mair 2002; Barr 2009; Werz 2011. Zur Modernisierungsverliererthese vgl. bspw. Spier 2006 u. 2010; sowie Rydgren 2004.

18 Vgl. exemplarisch Mény/Surel 2002: 21.

19 Decker/Lewandowsky 2009: 3.

20 Die Unterscheidung von echten und unechten Konflikten geht zurück auf Coser 1972. Zur Unterscheidung von teilbaren und unteilbaren Konflikten vgl. Hirschmann 1994: $302 \mathrm{ff}$.

21 Hoheneder 2012.

22 Hartleb 2005.

23 Rosenberger 2001: 103.

24 Dahrendorf 2003. 
Weise gewissermaßen der soziokulturelle „Nährboden“ ${ }^{\text {‘25 }}$ entzogen werden, um die gesellschaftliche Normalität eines gemäßigt pluralistischen status quo ante zu restaurieren. ${ }^{26}$

Der Krankheitstopos, der den Populismus in diesen Diskursen als Symptom anomaler Verhältnisse rahmt, induziert eine pathogenetische, normativistische und a priori populismuskritische Perspektive. Der Populismus erscheint als Phänomen, das es eigentlich gar nicht geben dürfte, als politischer Fortsatz irrationaler Abstiegsängste, als Folgeerscheinung der mangelhaften Responsivität der etablierten Parteien oder als Epiphänomen antipluralistischer Einstellungen, die anschlussfähig sind für die populistischen Kernstrategien der Pauschalisierung, der Skandalisierung und des scape goating. ${ }^{27}$ Somit zeigt sich in der sozialwissenschaftlichen Behandlung des Populismus in exemplarischer Weise, wie ,sich das zwischen Rationalität und Irrationalität strukturierende Vorurteil noch zusätzlich mit Vorstellungen des Pathologischen auf[lädt] und somit mindestens implizit Heilung durch Rückkehr zum rationalen Modell [verspricht] “28

Kritikwürdig an dieser Perspektivierung ist, dass juridische Normen innerhalb der entworfenen pathogenetischen Ursache-Wirkungs-Szenarien zu sozialwissenschaftlichen Leitdifferenzen mutieren, ohne dass ihr politischer Charakter thematisiert werden würde. Die Populismusforschung lässt damit nicht nur die elitäre Angst vor der Politisierung einer ,,verstockten Masse ${ }^{\text {‘29 }}$ nachhallen. Indem sie eine liberaldemokratische Normalität und Teleologie präsupponiert und ihren Gegenstand anhand dieses Regulativs als pathologische Abweichung klassifiziert, reproduziert sie auch das Normalitätsdispositiv einer rationalisierten Demokratie. Das normativistische Vorurteil strukturiert die wissenschaftliche Analyse und substituiert die politische Auseinandersetzung. ${ }^{30}$

Diese Form der Kritik konnte die Konjunktur des Populismus indes nicht aufhalten. ${ }^{31}$ Während in Lateinamerika überwiegend linkspopulistische Projekte

25 Hoheneder 2012.

26 Vgl. Jäger 2011; Patzelt 1999. Pointiert kritisch zu diesem rationalisierenden Gestus seines Faches äußert sich der Politikwissenschaftler Michael Th. Greven (1999: insb. 13f.).

27 Vgl. etwa Priester 2012a: 6.

28 Greven 1999: 14.

29 Ortega y Gasset 1957: 49.

30 Vgl. Mouffe 2007a: 100.

31 Ob diese Form der Kritik den Aufstieg populistischer Parteien eher forciert als bremst, bleibt spekulativ (Vgl. zu dieser Frage Mudde 2004; Taguieff 1995). Jedoch lässt sich beobachten, dass Populisten diese Form der Kritik keineswegs ignorieren, sondern in 
mit weitreichenden Umverteilungsversprechen reüssieren, ${ }^{32}$ sind in Europa überwiegend rechtspopulistische Parteien erfolgreich. Seit Mitte der 1990er Jahre haben sie sich nicht nur in vielen osteuropäischen Transformationsgesellschaften etabliert, auch in konsolidierten, westlichen Demokratien dürfen sie sich zu einem festen Bestandteil des Parteienspektrums rechnen. ${ }^{33}$ Entsprechend hat sich auch die sozialwissenschaftliche Einordnung dieser Parteien verschoben: Während ihre ersten politischen Erfolge noch als ephemere Protestphänomene trivialisiert werden konnten, entpuppte sich diese Einschätzung angesichts der Häufung und Verstetigung ihrer Wahlerfolge als falsche Hoffnung. ${ }^{34}$ Sozialwissenschaftler/innen mussten anerkennen, dass die Wahl rechtspopulistischer Parteien nicht mehr als sporadische Protestwahl abgetan werden konnte, sondern in zunehmendem Maße als ideologisch motivierte Wahlentscheidung zu begreifen ist. $^{35}$

Die erfolgreichen rechtspopulistischen Parteien zeichnen sich dadurch aus, dass sie im Unterschied zu sogenannten single-issue-Bewegungen ein umfassendes politisches Programm liefern. Sie opponieren gegen die zunehmende Macht

die eigenen ideologischen Narrative integrieren und als weiteres Indiz für die postulierte Kluft zwischen ,Establishment' und den ,einfachen Leuten' sinnhaft machen. So lässt sich festhalten, dass der rationalistische Anti-Populismus-Reflex zumindest Gefahr läuft, sich politisch kontraproduktiv auszuwirken. - Zumal dieser Form der Kritik des Populismus kein Rezept liefert, wie sich die Sorgen, Befindlichkeiten und Unrechtserfahrungen der Anhänger politischer Parteien anders artikulieren ließen.

32 Für einen Überblick über die jüngsten politischen Erfolge populistischer Bewegungen in Lateinamerika vgl. Werz 2011.

33 Einen Überblick über die Stimmanteile der bedeutendsten rechtspopulistischen Parteien bei den Parlamentswahlen in Westeuropa findet sich bei Lochocki 2012: 31. Zum Aufstieg populistischer Parteien in postsozialistischen Staaten vgl. exemplarisch Segert 2011.

34 Vgl. Decker 2006c: 4. Darüber hinaus darf nicht vergessen werden, dass der Einfluss rechtspopulistischer Parteien auch dort, wo ihre Erfolge von kurzer Dauer sind - sei es aufgrund des Mangels an qualifiziertem Personal, sei es, weil ihre weitreichenden Forderungen und Versprechungen im Fall einer Regierungsbeteiligung nicht erfüllt werden können, mit ihrer wahlpolitischen Niederlage niemals gänzlich endet. Vielmehr hinterlassen ihre Agenden und Deutungsangebote ideologische Spuren auf den politischen Feldern, denen die etablierten politischen Parteien programmatisch folgen müssen, wollen sie die verlorenen Wählerstimmen zurückgewinnen (vgl. Minkenberg 2001; Geden 2005b: 69).

35 Vgl. van der Brug/Meindert/Tillie 2000; Helbing 2011:12. 
internationaler Organisationen, gegen transnational agierende Unternehmen, gegen ausufernde Bürokratien, steigende Sozialabgaben und gegen eine als zu liberal und zu lax empfundene Migrations- und Sicherheitspolitik. Der Krise des Wohlfahrtsstaates treten sie mit wohlfahrtschauvinistischen Forderungen nach Steuersenkungen für ,Inländer“ entgegen; die politische Repräsentationskrise beantworten sie mit einer allgemeinen Kritik an einer , abgehobenen Parteiendemokratie'; und die Identitätskrise, in die westliche Gesellschaften nach dem Ende des Ost-West-Konfliktes gerieten, kurieren sie mit neo-rassistischen Selbstvergewisserungen $^{36}$ und ethnonationalistischen Konzeptionen von Staatsbürgerschaft. $^{37}$

Im Unterschied zur extremen Rechten handelt es sich in der Regel nicht um offen verfassungsfeindliche Gruppierungen. Eines ihrer Erfolgsgeheimnisse liegt vielmehr darin begründet, dass sie sich als Erben der Verfassungsväter, als Restauratoren eines depravierten Gemeinwesens und Erneuerer der Demokratie gerieren. ${ }^{38}$ Und in der Tat schalten sich auch rechtspopulistische Parteien in den Konflikt ein, welcher der liberalen Demokratie verfassungsmäßig eingeschrieben ist. Sie zielen darauf, das etablierte Verhältnis zwischen der liberalen Tradition und der demokratischen Tradition zugunsten der letzteren zu korrigieren. Im Konfliktfall privilegieren sie das Volkssouveränitäts- und Mehrheitsprinzip gegenüber dem Rechtsstaatsprinzip des liberalen Konstitutionalismus. ${ }^{39}$ Oftmals wird dieses Primat des Mehrheitsprinzips verknüpft mit dem ethnopluralistischen Dogma der Unvereinbarkeit unterschiedlicher, in sich homogener kultureller Entitäten, ${ }^{40}$ mit dem der rechtskommunitaristische Intellektuelle Alain de Benoist ${ }^{41}$ eine neue Rechte in Stellung gegen die Hegemonie des multikulturalis-

36 Der Begriff Neo-Rassismus wurde von Etienne Balibar (1991a) geprägt. Er bezeichnet eine politische Ideologie, die soziale Verhältnisse nicht aus biologisch determinierten Rassenunterschieden ableitet, sondern auf eine historisch gewachsene und damit quasi-natürliche ethnische Diversität rekurriert, welche dieselben diskriminierenden Ressentiments und Praktiken nach sich zieht, wie der biologische Rassismus.

37 Vgl. Decker 2006c: 10; zur ethnischen Begründung von Volk und Nation vgl. Betz 2001 u. 2003; Betz/Johnson 2004.

38 Das gilt vor allem für die besonders erfolgreichen rechtspopulistischen Parteien, so etwa für die niederländische Partei für die Freiheit oder die Schweizerische Volkspartei. (vgl. allgemein auch Betz 2004; Mény/Surel 2002: insb. 21).

39 Mény/Surel 2002: 7ff.

40 Vgl. Bornschier 2010: 2f.; auch Betz 2001 u. 2003; Betz/Johnson 2004.

41 Das von de Benoist (1985) begründete Projekt der neuen ,post-rassistischen“ Rechten kann als Versuch verstanden werden, die alte (radikale) Rechte aus der ideologischen 
tischen Kosmopolitismus brachte. Indem rechtspopulistische Parteien dieses Deutungsschema mit neo-rassistischen Stereotypen (,faulen Ausländern', ,extremistischen Moslems', , dealenden Asylanten', etc.) politisch zuspitzen und gegenüber Migranten eine von Misstrauen und Verdacht geprägte Stimmung kultivieren, konnten sie ein politisch unbestimmtes gesellschaftliches Unbehagen programmatisch engführen und zu wirkmächtigen Antipoden des Parteienkonsenses avancieren.

Isolation $\mathrm{zu}$ befreien, indem man sich von nationalsozialistischen, biorassistischen Motiven, Inhalten und Positionen distanziert und stattdessen jene Forderungen und Ideologien reformuliert, die von den etablierten politischen Kräften nicht (mehr) glaubwürdig repräsentiert werden (vgl. Kaindl 2013: 24). Das Kernstück, das diesen Forderungen Kohärenz verleiht, ist die ethnopluralistische Vorstellung, die Welt setzte sich aus unterschiedlichen Völkern mit jeweils organisch gewachsenen, monolithischen kulturellen Identitäten zusammen (vgl. exemplarisch und grundlegend für diese Argumentation Benoist 1985: 53ff.). 


\section{Einleitung}

\section{Der SVP-Populismus Und die Polarisierung DER POLITISCHEN SCHWEIZ}

Die Schweizerische Volkspartei (SVP) kann trotz der stimmenmäßigen Stagnation der vergangenen Jahre als eine der „erfolgreichsten rechtspopulistischen Parteien "1 in Westeuropa gelten. Die Partei, die im Ausland insbesondere mit ihren streitbaren Plakatkampagnen und ihren überraschenden Erfolgen bei Volksabstimmungen für Aufsehen sorgte, lässt sich als prototypische Vertreterin der rechtspopulistischen Parteienfamilie klassifizieren. ${ }^{2}$ Sie politisiert gegen die europäische Integration, gegen den ,Parteienfilz', gegen die Personenfreizügigkeit, gegen die ,Islamisierung' der Schweiz, für eine härtere Bestrafung von Delinquenten, gegen die staatliche Bürokratie, gegen ,Masseneinwanderung' sowie gegen ,Asyl- und Sozialmissbrauch ‘ und für das ,werktätige Volk` und die ,einfachen Leute'.

Im Unterschied zu den meisten ihrer europäischen Verwandten handelt es sich bei der SVP jedoch nicht um eine neugegründete, sondern um eine alteingesessene und zu Beginn keineswegs populistische Partei. Bis in die 1990er Jahre war die SVP eine im protestantisch-ruralen Milieu der Deutschschweiz verankerte Klientelpartei, die sich im Wesentlichen darauf konzentrierte, Subventionen für die Landwirtschaft zu generieren. Auf allen anderen Politikfeldern politisierte sie als kollegialer Juniorpartner der beiden großen bürgerlichen Parteien. Erst unter dem wachsenden Einfluss des sogenannten Zürcher Flügels um Christoph Blochers entwickelte sich die Bauernpartei zu einer catch-all-Partei und zu „der

1 Betz 2012.

2 Zur Positionierung der SVP im Vergleich zu anderen europäischen Parteien vgl. Ladner 2010 u. 2013; Ladner u.a. 2010. 
Oppositionspartei“33 schlechthin. Gemessen an den Nationalratswahlen konnte sie ihren Stimmanteil von 11,9 Prozent im Jahr 1991 sukzessive auf bis zu 28,9 Prozent im Jahr 2007 steigern, ehe sie 2011 erstmals Wählerstimmen einbüßte, sich mit 26,6 Prozent aber erneut als deutlich stärkste politische Kraft behaupten konnte. ${ }^{4}$

Diese politischen Erfolge mögen im internationalen Vergleich keineswegs ungewöhnlich erscheinen, vor dem Hintergrund des ,festgefrorenen Parteiensystems ${ }^{\text {" }}$ der Schweiz ist die Karriere der Partei jedoch sehr bemerkenswert. Seit der Einführung des Proporzsystems im Jahr 1919 war es keiner Partei gelungen, derartige Stimmzuwächse für sich zu verbuchen. Und rechtspopulistische Bewegungen wie die Nationale Aktion (NA), die Schweizer Demokraten (SD), die Wachsamen oder die Auto-Partei (AP) waren bis dahin immer single-issueBewegungen geblieben. Trotz einigen politischen Achtungserfolgen konnte sich auf Bundesebene keine von ihnen dauerhaft etablieren. ${ }^{6}$

Der Aufstieg der SVP geht einher mit einer programmatischen und strategischen Radikalisierung, die ihren Ausgang Ende der 1990er Jahre im Kanton Zürich nahm. Damals brach die von Blocher geführte Kantonssektion mit der traditionellen pragmatisch-kompromissorientierten Strategie der Parteiführung. Die Zürcher SVP-Sektion konnte lange Zeit als kantonaler Sonderfall und als ,populistisches Einsprengsel in das Konkordanzsystem “7 bagatellisiert werden. Diese Einstufung musste jedoch spätestens Mitte der 1990er Jahre korrigiert werden. In Folge der Volksabstimmung über den Beitritt zum Europäischen Wirtschaftsraum im Jahr 1992 gewannen Blocher \& Co die Oberhand über den gemäßigten

3 Mazzoleni 2003: 10.

4 Einbußen erlitten insbesondere die sogenannten staatstragenden Parteien der bürgerlichen Mitte. Der Stimmanteil der Freisinnigen-demokratischen Partei (FDP) und der Christlichdemokratischen Volkspartei (CVP) schmolz auf der nationalen Ebene kontinuierlich von zusammengenommen über 40 Prozent in den achtziger Jahren auf unter 30 Prozent in 2011. Das linke Lager aus SP und Grünen überstand den Aufstieg der SVP stimmenmäßig unbeschadet. Zur Karriere der SVP vgl. Mazzoleni 2003; Kriesi 2005; Linder/Steffen 2006, Hennecke 2003; Geden 2005a; Betz 2012; Longchamp u.a. 2003.

5 Kriesi 2005: 3; im Anschluss an die berühmte frozen-party-systems-These von Martin Lipset und Stein Rokkan (1967), nach der es seit dem Ende des Zweiten Weltkrieges dieselben Konfliktlinien sind, welche die Parteienlandschaften und den politischen Prozess in den meisten westeuropäischen Staaten strukturieren.

6 Gentile/Kriesi 1999; Skenderovic 2009.

7 Armingeon 1996: 72. 
Berner Flügel und prägten in zunehmendem Maße die politische Ausrichtung der SVP Schweiz. Die „neue SVP“" ${ }^{8}$ scherte aus der Mitte der bürgerlichen Parteien aus. Neben den traditionellen Partei-Domänen der Agrar- und Verteidigungspolitik formulierte sie eigenständige Positionen in der Wirtschafts- und Finanzpolitik sowie in der Migrations- und der Außenpolitik, um sich mit einer „Kombination aus Marktliberalismus, gesellschaftspolitischem Konservatismus und außenpolitischem Neutralismus“ ${ }^{\text {(9 }}$ auf nahezu allen Politikfeldern von den übrigen drei Bundesratsparteien abzugrenzen. Mit der neuen Akzentuierung ihres politischen Profils absorbierte sie nicht nur eine Reihe subalterner Positionen, die zuvor lediglich von marginalen Kleinparteien am rechten Rand des politischen Spektrums aggregiert wurden. ${ }^{10}$ Der SVP gelang es auch, die einst stabilen Bindungen zwischen Wählergruppen und Parteien zu rekonfigurieren und einstige Stammwähler der konkurrierenden Parteien an sich zu binden.

Der Erfolg dieser dealignment-realignment-Strategie ${ }^{11}$ basiert auf einem scheinbar paradoxalen, aber äußerst integrativen Programm, das einem rückwärtsgewandten, patriotisch-folkloristischen Konservatismus mit einer zukunftsorientierten, neoliberalen Deregulierungspolitik kombiniert. ${ }^{12}$ Gestützt auf ihr „historisches Kapital“"13 als verantwortungsvolle Regierungspartei vereinigte die SVP mit dieser programmatischen Mixtur ihre Stammwählerschaft aus Bauern und Gewerblern mit sozial Schwachen und Verunsicherten auf der einen sowie mit sozialen Aufsteigern auf der anderen Seite und kanalisierte die politischen Forderungen ihrer heterogenen Anhängerschaft in einer Bewegung. Dabei nutzte sie die Besonderheiten des politischen Systems der Schweiz, um zwischen kollegialer Regierungsarbeit und volksnaher Opposition $\mathrm{zu}$ changieren und trotz gleichzeitiger Regierungsbeteiligung mit Volksinitiativen gegen die sogenannte ,Koalition der Vernunft ${ }^{6}$ (aus SP, CVP und FDP) zu politisieren. ${ }^{14}$ Auf diese

8 So die deutsche Übersetzung des Titels von Mazzoleni 2003.

9 Hennecke 2003: 146.

10 Vgl. Mazzoleni 2003: 13ff. Diese rechten Klein- und Kleinstparteien, die bei den Nationalratswahlen von 1991 zusammen genommen noch zehn Prozent erreichten, sind heute entweder vollkommen verschwunden oder nahezu bedeutungslos geworden.

11 Allgemein zur konzeptuellen Trias alignment, dealignment, realignment vgl. Martin 2000. In Verknüpfung mit dem Aufstieg der SVP vgl. Bornschier/Helbing 2005: insb. 31.

12 Vgl. Buomberger 2004: 210.

13 Skenderovic 2007b: 58.

14 Vgl. Mazzoleni 2003: 99ff. 
Weise setzte sich die Partei als ,gemeinschaftsstabilisierende Kraft“"15 und als der einzig verbliebene Vertrauensanker des ,einfachen, hart arbeitenden Volkes“ in Szene, die von einer ,abgehobenen Classe politique ' und deren Klientel nicht nur im Stich gelassen, sondern auch verraten und ausgenützt würden.

Flankiert wurde diese symbolische Zweiteilung des politischen Raumes durch eine in der Schweiz einmalige Personenzentrierung der politischen Debatte auf Christoph Blocher. Die Führungsfigur der SVP stand im Mittelpunkt so vieler Kontroversen, dass nahezu alle politischen Entscheidungen gleichbedeutend waren mit der Entscheidung ,pro oder contra Blocher'. Unentschiedenheit oder Gleichgültigkeit scheint es in puncto Blocher bis heute nicht zu geben. ${ }^{16}$ Dabei verweben sowohl seine Kritiker als auch seine Befürworter die BlocherFrage mit der Frage der nationalen Identität. Seine Gegner bezichtigen den charismatischen Führer der SVP der politischen Brandstiftung, des Rassismus und der Demagogie. ${ }^{17}$ Für sie ist Blocher das erste Symptom einer tieferliegenden Identitätskrise der Schweiz. ${ }^{18}$ Aufgrund seiner Aggressivität und seiner polarisierenden Rhetorik gilt er ihnen als „demagogischer Neinsager“"19 und als Bedrohung der , ausgeklügelten Gleichgewichte der politischen Schweiz ${ }^{60}$ oder kurzum als „unschweizerisches Phänomen““21. Seine Anhänger sehen in dem „konservativen Revolutionär ${ }^{\text {“22 }}$ und Selfmademan dagegen die Verkörperung der Schweiz. Für sie ist der gelernte Landwirt, Offizier und promovierte Jurist mit seinem „spezifisch schweizerischen Charisma“" ${ }^{\text {23 }}$ und seiner bodenständigen Art der standhafteste Verteidiger der außenpolitischen Neutralität, des Föderalismus, des Kleinstaates und der direkten Demokratie, der entschlossenste Verfechter des Marktliberalismus und der couragierteste Ankläger eines etatistischgleichmacherischen Eurozentrismus. Sie sehen in ihm den Prototyp des homo nationalis, den tapferen Patrioten, der für genuin schweizerische Traditionen und

15 Skenderovic 2013: 68.

16 Vgl. exemplarisch Hubacher 2014: 79.

17 Vgl. Bürgi 1997.

18 Altwegg 2004: 87ff.

19 Scharsach 2002: 140.

20 So der FDP-Bundesrat Pascal Couchepin in einem Duell mit Blocher (Blocher/ Couchepin 2013).

21 Gsteiger 2002; Hämmerle 2011: 9ff.; Schilling 1994.

22 So der treffende Titel der Blocher-Biographie von Markus Somm (2009).

23 Somm 2009: 10. 
Werte einsteht, die von den ,geschichtsvergessenen Eliten“ an die ,Imperialisten aus Brüssel, Paris und Berlin' verkauft würden. ${ }^{24}$

So sorgte die „nationalkonservative Revolte in Gestalt der SVP“25 für ein „véritable changement de l'équilibre politique“"26. Sie löste eine im europäischen Vergleich antizyklische Entwicklung aus. Denn während die führenden Parteien der meisten west- und mitteleuropäischen politischen Systeme sich seit Ende des Ost-West-Konfliktes einander annäherten, den einst prägenden Links-RechtsGegensatz als anachronistisch verwarfen, lässt sich in der Schweiz das Gegenteil konstatieren: Hier wurde die einst mittezentrierte, konkordanzdemokratisch geprägte politische Landschaft durch einen populistischen Diskurs überprägt und nach einem dichotomen Schema reinstituiert. Die anhaltende Resonanz dieser Rhetorik führte zu einer ungekannten „Politisierung und Polarisierung der Bevölkerung ${ }^{\text {‘ } 27}$, in deren Folge auch das Schweizerische Parteiensystem, ${ }^{28}$ das aufgrund stabiler Parteibindungen und konstanter Wahlergebnisse als „scheinbar unwandelbar ${ }^{629}$ galt, in Bewegung geriet. ${ }^{30}$ Der Aufstieg der SVP von der kleinsten Kraft des bürgerlichen Lagers zur deutlich stärksten Partei des Landes wirbelte aber nicht nur das Parteiensystem durcheinander. Er stellte auch die institutionelle Apparatur des konkordanzdemokratischen politischen Systems zur Disposition. $^{31}$ Denn durch den reklamierten Alleinvertretungsanspruch auf das Schweizervolk stellte die Partei auch die kulturellen Gemeinschaftssemantiken

24 Vgl. kritisch Hennecke 2003: 145.

25 Longchamp 2000.

26 Mazzoleni 2004: 9. In der deutschen Übersetzung: „wahrhaftigen Veränderung des politischen Gleichgewichts“. Vgl. auch Longchamp 2000; Hennecke 2003.

27 Vgl. Longchamp/Rousselot 2010.

28 Vgl. Mazzoleni/Meuwly 2013: 12; Betz 2012: $92 \mathrm{f}$.

29 Mazzoleni/Meuwly 2013: 11.

$30 \mathrm{Zu}$ Kontinuität und Wandel des Schweizer Parteiensystems vgl. Ladner 2001 u. 2004. Zur zunehmenden und im europäischen Vergleich starken Polarisierung des Parteiensystems vgl. Ladner 2010 u. 2013; Ladner 2010 u. a.. Zur Charakterisierung des Schweizer Parteiensystems als gemäßigt pluralistisches Parteiensystems vgl. die bekannte Typologie Giovanni Sartoris (1976), die den polarisierten Pluralismus, den gemäßigten Pluralismus, das Zwei-Parteiensystem und Parteiensysteme mit einer klar dominanten Partei unterscheidet.

31 Zum Zusammenhang des Aufstiegs der SVP und der Krise des Konkordanzsystems vgl. Mazzoleni/Skenderovic 2007; Longchamp/Rousselot 2010; Longchamp u.a. 2003; Ladner 2004; Ladner u.a. 2010; Betz 2012. 
infrage, von denen die Legitimität der kompromissorientierten Entscheidungsverfahren des Konkordanzsystems zehrt.

\section{Theoretische Perspektive und Fragestellung}

Vor diesem Hintergrund macht es sich die vorliegende Arbeit zur Aufgabe, in einer kritischen Distanzierung vom Populismusdiskurs des sozialwissenschaftlichen Mainstreams den SVP-Populismus als Phänomen einer „,multiplen Moderne ${ }^{\text {‘32 }}$ in den Blick zu nehmen, um deren Repräsentation vielfältige politische Projekte ringen. Der SVP-Populismus wird dabei weder als politische Folge noch als Widerspruch der schweizerischen Gesellschaft konstituiert, sondern als eine ,politische Technologie ${ }^{\text {‘33 }}$ zur Konstruktion einer widerständischen popularen Identität verstanden. Untersucht werden sollen daher die mit dem Aufstieg und der Radikalisierung der Partei verbundenen Politisierungs- und Polarisierungsprozesse der Schweizer Gesellschaft. Schließlich zielt die Arbeit auf eine Kritik des SVP-Populismus, die nicht auf die wirklichkeitsverzerrende, sondern auf die wirklichkeitskonstitutive Dimension dieses Diskurses abhebt.

Meine Analyse des Schweizer Populismus lässt sich daher von einem Populismuskonzept leiten, das mit dem eingangs skizzierten Anti-Populismus-Reflex der Forschung des Mainstreams bricht und populistische Bewegungen nicht als pathologische Folgeerscheinungen krisenhafter Verhältnisse, sondern als politische Projekte sui generis begreift: dem Populismuskonzept des argentinischen Gesellschafts- und Politiktheoretikers Ernesto Laclau. ${ }^{34}$ Diese Populismustheorie verhält sich in dreifacher Hinsicht antithetisch zur Populismusforschung des Mainstreams: Erstens verlagert Laclau mittels einer Aufwertung des Rhetorischen das Erkenntnisinteresse auf die soziale Produktivität des Populismus. Der Populismus wird nicht als politischer Ausdruck eines gegebenen Kollektivs, sondern als performativ wirksamer Diskurs gedacht, der die politische Einheit, die er rhetorisch imaginiert, erst konstruiert. Der Bezug auf ein ,Volk' erscheint daher nicht als Oberflächenphänomen falschen Bewusstseins. Populismus bezeichnet vielmehr eine Form der Modellierung und Strukturierung des Sozialen, die in

32 Eisenstadt 2006.

33 Vgl. Reinfeldt 2013: 138.

34 Vgl. Laclau 1981, 2005a, 2005b u. 2006. Der Titel von Laclaus zweitem Populismusbuch On Populist Reason (2005a), das meine Analyse theoretisch anleitet, verweist auf diese antithetische Position. 
einer binären Gruppendifferenzierung resultiert. Zweitens entwickelt Laclau ausgehend von einem diskurstheoretisch begründeten Konstruktivismus eine streng formale Populismustheorie, die das marginalisierte Phänomen zur politischen Erscheinung par excellence erhebt. ${ }^{35}$ Aus einer Laclau'schen Perspektive liefert ausgerechnet der vermeintlich pathologische Populismus einen privilegierten Einblick in den kontingenten und machtgeladenen Prozess der Konstruktion sozialer Identitäten. Drittens verschiebt der politische Theoretiker die übliche Perspektive auf das Verhältnis von Demokratie und Populismus. Der Populismus wird weder als äußerliche Gefährdung noch als pathologisches Symptom krisengeschüttelter demokratischer Regierungssysteme, sondern als notwendiges Moment der Demokratisierung einer Gesellschaft dargestellt. ${ }^{36}$

Grundlage dieser dreifachen Rehabilitation des Populismus ist die Hegemonietheorie, die Laclau in Hegemony and Socialist Strategy ${ }^{37}$ gemeinsam mit Chantal Mouffe aus einer Dekonstruktion des orthodox-marxistischen Klassenessentialismus formulierte. Durch die Kombination der Hegemonietheorie Antonio Gramscis und poststrukturalistischer Denkfiguren überführen die beiden politischen Theoretiker die Diskurstheorie in eine allgemeine Gesellschaftstheorie. ${ }^{38}$ Die Quintessenz ihres Theorieprojekts besteht darin, dass es das diskursive „meaning-making ${ }^{\text {(39 }}$, die Fixierung von Bedeutung, Sinn und Identität, an die Konstruktion symbolischer Antagonismen koppelt. Kollektive Identitäten und soziale Ordnungen sind demnach auf kontingente, macht- und entscheidungsimmanente Grenzziehungen zu einem bedrohlichen Anderen angewiesen, um sich provisorisch zu schließen und als Totalitäten zu konstituieren. Mit dieser Verschränkung von Macht und Objektivität beziehen Laclau und Mouffe eine postfundamentalistische Position, die den Entscheidungscharakter der vielfältigen Strategien sichtbar macht, das Soziale auf eine unhintergehbare Instanz zu

35 Vgl. Laclau 2005a: 67.

36 Vgl. Laclau 2005a: 168ff.; Laclau 2006.

37 Laclau/Mouffe 2006 [1985].

38 Wegweisend für dieses Unterfangen ist ein Begriff des Diskursiven, der Foucaults Unterscheidung von diskursiven (sprachlichen) und nicht-diskursiven (nicht-sprachlichen) Praktiken aufhebt und insofern nicht auf eine Sphäre des Sozialen beschränkt wird, sondern das „Ensemble der gesellschaftlichen Sinnproduktion, das eine Gesellschaft als solche begründet“ (Laclau 1981: 176) bezeichnet (vgl. Auer 2008: 249; Nonhoff 2007b: 9).

39 Fairclough 2007: 10. 
gründen. ${ }^{40}$ Die differenztheoretische Denkfigur des Antagonismus liefert somit den Grundstein für die Dekonstruktion gegebener und naturalisierter Ordnungen sowie philosophisch deduzierter Normen. Im Gegenzug postuliert sie einen Universalitätsanspruch des Politischen, der einer konfliktiven, demokratischen Selbstinstituierung der Gesellschaft den Weg ebnen soll. ${ }^{41}$

Vor diesem theoretischen Hintergrund ist Populismus weit mehr als eine strategische ,Volkstümelei“ oder eine „schlaue Verrenkung““42, mittels derer ein charismatischer Politikunternehmer versucht, eine ungedeckte politische Nachfrage zu saturieren. Genauso wenig sind irrationale und unrealistische politische Forderungen, Inhalte oder Weltbilder per se populistisch. Der Populismusbegriff Laclaus bezeichnet vielmehr eine Form der Artikulation heterogener Elemente, die sich dadurch auszeichnet, dass sie auf eine gesamtgesellschaftliche FreundFeind-Unterscheidung abzielt, indem sie eine partikulare Wir-Sie-Differenz zu universalisieren versucht. Als populistisch wird insofern jede Diskurspraxis verstanden, die Forderungen, Erwartungen, Hoffnungen und Missachtungserfahrungen innerhalb eines bipolaren Szenarios synchronisiert.

Der springende Punkt dieses differenztheoretischen Konstruktivismus besteht darin, dass er diese Freund-Feind-Unterscheidung nicht als Politisierung, Mobilisierung oder Erweckung vorgängiger Identitätsgruppen, sondern als eine kontingente, sozial produktive Wir-Sie-Unterscheidung vorstellt. Das bedeutet, dass jene Identitäten, die qua Antagonismus gegeneinander konturiert werden, durch diese Unterscheidung erst produziert werden. ${ }^{43}$ An der rhetorischen Ima-

40 Vertreter einer postfundamentalistischen Ontologie wenden sich gegen die Vorstellung, soziale Bedeutung, kollektive Identitäten und gesellschaftliche Ordnungen gründeten auf einem vordiskursiven Wesenskern und betonen im Gegenzug, dass Sinn und Bedeutung erst durch die Performativität eines einschlägigen Diskurses geschaffen werden und nicht etwa in einer biologisch, ethnisch, ökonomisch, anthropologisch oder sprachphilosophisch fixierten Essenz fundiert liegen. Zum Postfundamentalismusbegriff vgl. Marchart 2007a u. 2010.

41 Hierin besteht ihre Anschlussfähigkeit für ethische und demokratietheoretische Fragestellungen, die vor allem Mouffe (2008) weiterverfolgt, aber auch von Laclau (2007: 104ff.) thematisiert werden und die insbesondere in der Sekundärliteratur intensiv debattiert werden (vgl. etwa Rüdiger 1996; Norval 2000; Smith 1998; Critchley 2004; Devenney 2004; Sigglow 2009).

42 Bürgi 1999.

43 Diese Position basiert auf der (post-)strukturalistischen Prämisse, dass Sprache nicht als eine Abbildung einer vorgängigen, natürlichen oder objektiven Diversität zwischen Dingen, Konzepten und Gruppen von Menschen betrachtet werden darf, son- 
gination eines ,Volkes' lässt sich daher exemplarisch beobachten, was aus einem hegemonietheoretischen Blickwinkel für jede soziale Entität gilt: Da ein ,Volk“ auf eine Gegen-Gemeinschaft angewiesen ist, um sich als Kollektiv zu konstituieren, muss es als negative Einheit gedacht werden. ${ }^{44}$ In anderen Worten: der populistische Gegensatz zwischen ,Volk‘ und ,Establishment` ist nicht etwa der ideologisch verzerrte Ausdruck grundlegender Interessen- und Wertgegensätze zwischen zwei konfligierenden Entitäten. Er ist die ontologische Ermöglichungsbedingung einer sozialen Objektivität, deren Kontingenz und Machtimmanenz er gleichzeitig bezeugt. Infolgedessen avanciert der Populismus zum paradigmatischen Studienobjekt einer Politik- und Gesellschaftstheorie, die soziale Ordnungen als Sedimente antagonistischer Deutungskämpfe begreift und dem Politischen die Rolle einer prinzipiell ubiquitären und originären Instanz einräumt. ${ }^{45}$

Wegweisend für die vorliegende Arbeit ist die diskurstheoretisch begründete Entscheidung, populistische Politik als einen performativ wirksamen Diskurs zu fassen, der die Positionsdifferenzen, die Konflikten scheinbar ursächlich zugrunde liegen, erst herstellt und die Wir-Gruppe, deren Interessen er zu repräsentieren vorgibt, erst konstituiert. ${ }^{46}$ Aus dieser Perspektive erscheint das ,Volk' weder als naturwüchsige Einheit noch als irrationale Referenz, sondern als bedeutungsoffener Signifikant. Ähnlich dem Nationenkonzept der sozialkonstruktivistischen Nationalismus-Forschung wird es als eine „,vorgestellte Gemeinschaft“" ${ }^{\text {*7 }}$ aufge-

dern als ein autonomes Differenzsystem gedacht werden muss, das die Differenzen zwischen Dingen, Konzepten und Gruppen in einer kontingenten Struktur (vorläufig) fixiert (vgl. de Saussure 2001). Zur epistemologisch begründeten Unterscheidung von Differenz und Diversität vgl. Bhabha 2000: insb. 51f.

44 Hierin liegt auch der Unterschied zwischen Laclaus differenztheoretischem Konzept des Politischen und Carl Schmitts (2009 [1932]) ,Begriff des Politischen“. Schmitts Freund-Feind-Unterscheidung ist im Gegensatz zu jener Laclau/Mouffes streng genommen nicht politisch konstruiert, sondern besteht lediglich in der politischen Aufwertung präexistenter Oppositionen. Vgl. Mouffe insb. 2008: 64, sowie Baschek 2011, der im Unterschied zu Mouffe die These vertritt, dass der Freund-FeindUnterscheidung Carl Schmitts notwendig ein substantieller Volksbegriff zugrunde liegt.

45 Vgl. insb. Laclau 2005a: 67; Laclau 1990: 34ff.

46 Ähnliche Konzeptionen kollektiver Identitäten entwerfen neben anderen Homi K. Bhabha (2000) und Stuart Hall (exemplarisch 1994a u. 1994b) sowie Shmuel Eisenstadt (2006 u. 2009) im Rahmen seiner Konzeption einer multiplen Moderne.

47 Anderson 1996; vgl. auch Hobsbawm 1991; Gellner 1991; für eine konzise Zusammenfassungen dieser konstruktivistischen Theorien der Nation vgl. Hall 1994c: 199ff. 
fasst, deren Identität „durch die Konfiguration verschiedener Dissens-Szenarien ${ }^{\text {“48 }}$ diskursiv geformt wird.

So gehe ich mit Laclau davon aus, dass der politische Aufstieg der SVP auf der diskursiven Konstruktion einer popularen Wir-Gruppe basiert, deren Identität nicht aus strukturellen Verhältnissen abgeleitet werden kann. ${ }^{49}$ Die Zurückweisung einer sozialstrukturell fundierten Bedingungsfaktorenanalyse bedeutet natürlich nicht, dass der SVP-Populismus jenseits eines gesellschaftlichen Kontextes gedacht werden soll. Die hegemonietheoretische Perspektive macht lediglich deutlich, dass der Populismus nicht auf einen machtpolitischen Opportunismus verkürzt werden kann, der von einer milieu- oder schichtenspezifischen politischen Kultur profitiert, sondern als sozialproduktive Kraft zu verstehen ist, die sich zwar in eine soziale Konstellation einschreibt und an sedimentierte Identitäten anknüpft, diese jedoch in spezifischer Weise reartikuliert und remodelliert. In den Fokus der Analyse rücken damit jene Willens- und Identitätsbildungsprozesse, die Populismusforscher/innen in der Regel voraussetzen, die den Erfolgen populistischer Parteien aber insofern zeitlich und logisch vorgeschaltet sind, als sie die politischen Kollektive hervorbringen, die den populistischen Authentizitätsbehauptung Glauben schenken.

Anstatt einem Marktmodell politischer Repräsentation zu folgen, nach dem eine in sozialen Identitäten geronnene gesellschaftliche Präferenzstruktur eine mehr oder minder deckungsgleiche politische Parteienlandschaft bedingt, stülpe ich das Verhältnis von Gesellschaft und Politik gewissermaßen um: Es geht ge-

In Analogie zu Ernest Gellners Diktum, nach dem „,[n]icht die Bestrebungen von Nationen den Nationalismus schaffen“, sondern „sich der Nationalismus seine Nationen [schafft]“ (zit. nach Wehler 2011: 9) ließe sich sagen, dass nicht ein vorgängiges Volk den Populismus hervorbringt, sondern der Populismus ein Volk.

48 Die Formulierung stammt von Jacques Rancière (2007).

49 Dass der Erfolg populistischer Parteien nicht als Folge spezifischer soziopolitischer Bedingungen, sondern als Effekt einer diskursiven Reorganisation politischer Identitäten betrachtet wird, bedeutet nicht, ihn für voraussetzungslos zu erklären und zu behaupten, ein populistisches Projekt entstünde in einem politischen und gesellschaftlichen Vakuum. Es heißt lediglich, nicht vorhandene Kollektivakteure mit fixierten Identitäten (gegebenen Einstellungen, Werten und Präferenzen) zum Ausgangspunkt der Analyse zu erklären, sondern die kleinste Analyseeinheit auf einer anderen Ebene zu bestimmen (vgl. Laclau 2005a: 73f.). 
rade nicht um die ,politischen Folgen nationaler Identität“"50, sondern darum, Identität als Folge politisch konstruierter Identitäten zu lesen. Folglich richtet sich mein Forschungsinteresse auf die symbolische Repräsentationsleistung des SVP-Projekts, die das ,Schweizervolk‘ als ein klassen-, schichten- und milieuübergreifendes politisches Kollektiv instituiert. Es soll analysiert werden, wie aus einer Gesellschaft, die sich als soziokulturell segmentierte, multikulturelle, pluralistische und konkordanzdemokratisch integrierte „Ausgleichsgesellschaft ${ }^{\text {“51 }}$ beschreibt, ein ,Volk' entsteht, das sich in binär teilungsbetonten Repertoires als homogenes politisches Kollektiv identifiziert.

Meine Forschungsfrage bezieht sich auf das Verhältnis von Populismus und Pluralismus. Dieses Verhältnis, das die Populismusforschung des Mainstreams als Widerspruch wahrnimmt und durch den Rückgriff auf das ,falsche Bewusstsein' unaufgeklärter Bevölkerungsteile aufzulösen versucht, ${ }^{52}$ entpuppt sich aus hegemonietheoretischer Sicht als irreduzibles Spannungsverhältnis, das in den konkurrierenden Selbstbeschreibungen der Gesellschaft fortlaufend verhandelt wird. Mein primäres Erkenntnisinteresse lässt sich daher als analytischdeskriptiv bezeichnen. Es richtet sich auf die Wirkungsweise und die Funktionslogik des SVP-Populismus. Untersucht wird, wie dieser Diskurs eine vorhandene Gruppendifferenzierung subvertiert, die gemäßigt pluralistische Struktur des politischen Raumes in einen scharfen bipolaren Antagonismus transformiert, singuläre Unrechtserfahrungen zu einem manichäischen Gesellschaftsbild verknüpft, und wie er die Identitäten der Subjekte innerhalb einer dichotomen Matrix fixiert, die zwischen einem ,gesunden, nützlichen und organischen Wir ${ }^{6}$ auf der einen und einem ,depravierten, schädlichen und künstlichen Sie‘ auf der anderen Seite unterscheidet.

Zudem soll erklärt werden, warum sich Subjekte mit der so geschaffenen Projektionsfläche leidenschaftlich identifizieren. Dabei gilt es herauszuarbeiten, dass die affektive Komponente des SVP-Populismus, die sich etwa in der Verehrung Christoph Blochers manifestiert, nicht etwa als außerdiskursives Komplement, sondern als Effekt der populistischen Repräsentation der Gesellschaft zu verstehen ist. In diesem Zusammenhang liegt ein weiteres Augenmerk auf der herausgehobenen Stellung Blochers. Ich fokussiere indes nicht Blochers virtu, das Talent und natürliche Charisma des politischen Genies. Vielmehr führe ich

50 So der Haupttitel von Hanspeter Kriesis (2002) Aufsatz, in dem er am Beispiel der eidgenössischen Wahlen deutlich macht, inwiefern das Ergebnis als Folgephänomen der nationalen Identität gelesen werden kann.

51 Rehberg 2007.

52 Vgl. exemplarisch Decker/Lewandowsky 2009. 
die Tatsache, dass er zum ,politischen und psychologischen Rettungsanker““53 derjenigen avancieren konnte, die andernorts als ,bildungsferne Modernisierungsverlierer ${ }^{54}$ etikettiert werden, auf seine Funktion für die Kohäsion des popularen Lagers zurück. Es soll gezeigt werden, dass der Signifikant ,Blocher die fiktive Einheit des ,Schweizervolkes‘ symbolisch zum Ausdruck bringt, indem er zum emblematischen Schnittpunkt jener Diskursstränge avancierte, aus deren Artikulation dieses politische Kollektiv hervorgeht.

Indem ich mit Hilfe des Laclau'schen Ansatzes eine Lektüre des SVPPopulismus vorschlage, welche die Kontingenz, Historizität und Machtimmanenz von Identität unterstreicht, lege ich zugleich den Grundstein für die Dekonstruktion der Identitätspolitik der SVP. Gleichzeitig jedoch lässt sich anhand des kontinuierlichen SVP-Populismus exemplarisch beobachten, wie die Dissolution des theoretisch als prekär gefassten ,Schweizervolkes' abgewendet wird. Denn der SVP-Diskurs schließt die genuin populistischen, semantisch leeren Kategorien des Popularen durch einen geschichtspolitisch begründeten ,differentialistischen Nativismus ${ }^{65}$. Auf diese Weise gelingt es ihm, die Kontingenz der symbolisch errichteten Ordnung partiell zu löschen und das politisierende und demokratisierende Moment des Populismus zu unterminieren. Vor dem Hintergrund der Analyse des SVP-Populismus möchte ich daher abschließend versuchen, die Grauzone zwischen radikaldemokratischer und populistischer Politik zu explorieren, die Laclau in On Populist Reason entstehen lässt. ${ }^{56}$

\section{Aufbau der Arbeit}

Auf das Einleitungskapitel folgt ein Theorieteil (I). Dieser zielt weder auf eine vollständige Darstellung der Hegemonietheorie noch auf eine historischgenealogische Rekapitulation ihrer Komplettierung. ${ }^{57}$ Vielmehr soll das begriff-

53 Lang 2000: 97.

54 Vgl. Spier 2006 u. 2010.

55 Betz 2003: 195; vgl. auch Mudde 2007: 18ff.

56 Laclau 2005a: insb. 169.

57 Vgl. hierfür etwa Stäheli 2001; Bech Dyrberg 1998; Moebius 2003; Nonhoff 2007b; zur kontinuierlichen Ergänzung und Weiterentwicklung der Hegemonietheorie durch Laclau und Mouffe vgl. Torfing 2005: insb. 159ff.; Howarth 2007. Einen guten Überblick über die frühe, postmarxistische Rezeption Laclau/Mouffes liefert Rüdiger 1996: $137 \mathrm{ff}$. 
liche Instrumentarium eingeführt werden, das die Analyse des SVP-Populismus anleitet. Im Mittelpunkt steht daher die Verknüpfung hegemonietheoretischer und poststrukturalistisch-differenztheoretischer Denkfiguren, die eine dekonstruktivistische Lektüre der Identitätspolitik des SVP-Populismus ermöglichen soll. Ferner wird das hegemonietheoretische Forschungsprogramm akzentuiert, indem der Erkenntnisgewinn der Laclau'schen Perspektive gegenüber den gängigen Ansätzen der Populismusforschung herausgearbeitet wird. Die theoretische Vorbereitung schließt damit, dass einige etablierte Konzepte aus der Populismusforschung, die im Hinblick auf die Analyse des SVP-Populismus hilfreich erscheinen, hegemonietheoretisch reformuliert werden.

Im Methodenteil (II) schlage ich vor, die methodisch nach wie vor unterentwickelte Hegemonietheorie ${ }^{58}$ mit Analysekategorien der kritischen Diskursanalyse nach Ruth Wodak und Norman Fairclough zu ergänzen. ${ }^{59}$ Auf diese Weise wird die hegemonietheoretisch-deduktive Kodierung der Artikulationen des SVP-Populismus mit einer induktiv gewonnenen Kodierung der bedeutungsfixierenden Praktiken vervollständigt, sodass der hegemonietheoretische Fokus auf die Funktionsweise des populistischen Diskurses durch ontische Analysekategorien, insbesondere durch diskursstabilisierende Topoi ergänzt und zu einem flexiblen Analyserahmen zusammengefügt wird. Ferner wird im Methodenkapitel die Zusammenstellung des Diskurskorpus begründet. Der Herausforderung eines 30 Jahre umfassenden Untersuchungszeitraumes begegne ich, indem ich empirische ,Tiefenbohrungen“ um vier ausgewählte Kernereignisse (die EWRAbstimmung von 1992, die Nationalratswahlen 1999, Blochers Abwahl als Bundesrat 2007 und die Minarett-Abstimmung 2009) lanciere, die ich als „Dislokationen ${ }^{\text {“60 }}$ der politischen Schweiz rekonstruiere.

58 Vgl. Keller 2005: 162ff.; Versuche, die Hegemonietheorie zu operationalisieren, finden sich u. a. bei Glasze 2007; Nonhoff 2006 u. 2010. Die meisten Hegemonieanalysen verzichten aber auf, ,jegliche Methodologie“ (Casula 2012: 73) und lassen lediglich eine dekonstruktivistische Analysestrategie erkennen, die Diskursfragmente als Belege für die deduktiv angelegten theoretischen Konzepte handhabt (vgl. kritisch Keller 2005: 162f.).

59 Wodak u.a. 1998; Wodak 2001; Wodak/Fairclough 1997; Fairclough 1995. Diese Verknüpfung wird auch von David Rear (o.J.) vorgeschlagen.

60 Zur theoretischen Grundlegung des Konzepts der Dislokation vgl.: Laclau 1990: 39ff.; für eine empirische Anwendung vgl. Stavrakakis 2000, wo der Aufschwung der Grünen Parteien in Westeuropa aus einer doppelten Disklokation des Sozialismus erklärt wird. 
Der analytische Hauptteil (III) beginnt mit einer hegemonietheoretischen Lektüre der konkordanzdemokratischen Integration der multikulturellen Bevölkerung der Schweiz im Rahmen einer gemäßigt pluralistischen „Ausgleichsgesellschaft ${ }^{\text {“61 }}$. Dabei wird gezeigt, wie der konkordanzdemokratische Diskurs durch die Konstruktion peripherer Antagonismen gegenüber ,unvernünftigen, extremistischen Kräften' die konsens- und kompromissorientierte Politik der Mitte vernunftrechtlich nobilitiert und den ,konkordanzdemokratischen Sonderfall Schweiz‘ zwischen 1945 und 1990 gegen alle populistischen Spaltungsversuche immunisieren konnte.

Darauf aufbauend wird analysiert, wie der SVP-Populismus die konkordanzdemokratische Hegemonisierung des Sonderfalls schrittweise erodiert und ab etwa Mitte der 1990er Jahre im Rahmen der eigenen politischen Ideologie fixiert. Die Analyse beginnt mit der Geschichte der Radikalisierung des Zürcher Flügels in den 1970er und 1980er Jahren, die sich retrospektiv als Pionierphase des SVP-Populismus verstehen lässt. Danach folgen die um die Kernereignisse zentrierten Hauptkapitel. Sie unterliegen jeweils einer kohärenten Struktur: Nach einer kurzen Einführung, die kapitelinterne Fragestellungen und Ziele formuliert, erfolgt eine knappe Rekonstruktion des jeweiligen Ereignisses, seines Kontextes und seiner Ursachen. Im Anschluss wird gezeigt, wie der SVP-Diskurs das Ereignis absorbiert und im Rahmen einer bipolar-populistischen Matrix sinnhaft macht. Es wird jeweils herausgearbeitet, welche Artikulationen, Signifikanten und Bedeutungsfixierungen konstitutiv für die Vergemeinschaftung und Stabilisierung der popularen Identität sind und welche Ausschlüsse diesen Sinnstabilisierungen zugrunde liegen.

Im Mittelpunkt steht die äquivalentielle Konstruktion des ,genuin Schweizerischen'. So wird erklärt, wie die SVP den ,Sonderfall Schweiz' und seine Knotenpunkte wie beispielsweise direkte Demokratie, Freiheit, Neutralität und Pluralismus hegemonisiert. Dabei liegen die Hauptaugenmerke auf der programmatischen und elektoralen Kontinuität, die den SVP-Populismus auszeichnet, auf der Funktion des Signifikanten ,Blocher' als dem kohäsionsstiftenden Knotenpunkt der Äquivalenz sowie auf der Bedeutung des „differenzialistischen Nativismus“62 und seiner Topoi für die Schließung der ,liberalkonservativen“, ,selbstverantwortlichen' popularen Äquivalenz gegenüber ,ökologischen', ,rechtsextremen', ,wohlfahrtsstaatlichen' und ,konkordanzdemokratischen' Elementen.

Vor dem Hintergrund der relativen Stabilität des SVP-Populismus diskutiere ich im Schlussteil (IV) die Grenzen der formalen Populismustheorie Laclaus im 
Hinblick auf die Unterscheidung zwischen einem demokratischen und einem autoritären Populismus. Dabei wird keineswegs die klassische Dichotomie zwischen populistisch-autoritärer Politik und demokratisch-pluralistischer Politik erneuert, sondern für eine partielle Ergänzung der streng ontologischen Konzeption politischer Phänomene bei Laclau argumentiert.

\section{FORSCHUNGSÜBERBLICK}

Die Arbeit lässt sich nicht innerhalb eines scharf umrissenen Forschungsfeldes einordnen, sondern tangiert vielmehr drei unterschiedliche, sich partiell überschneidende Felder: (1) die Populismustheorie und das Verhältnis von Demokratie, Pluralismus und Populismus, (2) die Rechtspopulismusforschung im Allgemeinen und die Erforschung des SVP-Populismus im Spezifischen und (3) die hegemonietheoretisch fundierte Diskursanalyse im Anschluss an Laclau und Mouffe.

\section{(1) Populismustheorie und das Verhältnis von Demokratie, Pluralismus und Populismus}

Obwohl der von Frank Decker diagnostizierte „Boom in der Populismusforschung ${ }^{\text {،63 }}$ angesichts der anhaltenden Mobilisierungserfolge populistischer Parteien anhält, liegt bisher keine allgemein akzeptierte Definition vor, die in der Lage wäre, den Populismus in positiven Begriffen zu bestimmen.${ }^{64}$ Folglich beginnen empirische Analysen populistischer Parteien in der Regel mit einem Lamento über ein vermeintlich undefinierbares politisches Phänomen. ${ }^{65}$ Sie disku-

63 Decker 2006c: 1.

64 Für eine Problematisierung der Definitionsangebote vgl. Taguieff 1995; Müller 2015. Dass die diagnostizierte Konjunktur des Populismus als Gegenstand der Forschung nach wie vor anhält, wird durch die Vielzahl jüngerer Forschungen zum Thema belegt. Exemplarisch sei hier auf folgende verwiesen: Albertazzi/McDonnell 2008a; Tanneberg/Rovira Kaltwasser 2011; Sir Peter Ustinov Institut 2012; Decker 2013; Heinrich-Böll-Stiftung 2012; Müller 2015.

65 Angesichts dessen plädieren einige Forscher/innen dafür, den Begriff als Analysekategorie zu verabschieden und durch Konzepte wie Demagogie oder Extremismus zu ersetzen (vgl. etwa Bathke/Hoffstadt 2013). 
tieren einige Merkmale des Phänomens, weichen einer allgemeinen Definition jedoch aus und versuchen, ihren Untersuchungsgegenstand zeitlich, räumlich oder inhaltlich einzugrenzen. ${ }^{66}$ So arbeitet Frank Decker beispielsweise mit dem Konzept des „neuen Rechtspopulismus“67. Neben der Unterscheidung von Links- und Rechtspopulismus ${ }^{68}$ finden sich auch schichtenbasierte Typologien. Torcuato S. di Tella differenziert etwa zwischen „multiclass integrative parties“, „middle class populist parties“, „,working-class-populist parties“ und „,social revolutionary parties" ${ }^{69}$ Magret Canovan unterscheidet einen agrarischen und einen politischen Populismus. $^{70}$

All diese Ansätze leisten aber nicht mehr als eine „Synopse der Bedeutungsvarianten" ${ }^{\text {"71 }}$ des Populismus. Was das spezifisch populistische an den zusammengestellten Phänomenen ist, können diese Ansätze nicht klären. ${ }^{72}$ Daher machen es sich andere Populismusforscher/innen zur Aufgabe, einen Kern des Populismus zu identifizieren. ${ }^{73}$ Dabei lassen sich zwei Ansätze unterscheiden: Der eine insbesondere von den Politologen Cas Mudde ${ }^{74}$ und Paul Taggart ${ }^{75}$ vertretene Ansatz begreift den Populismus im Anschluss an Michael Freedens Nationalismustheorie ${ }^{76}$ als eine „dünne Ideologie“. ${ }^{77}$ Im Unterschied zu Liberalismus und Sozialismus sei der Populismus nicht als „Substanzbegriff“, sondern als „Relationsbegriff“ zu verstehen, denn ihm fehle ein „,beharrender Träger (Substanz) seiner Akzidenzien““ ${ }^{78}$ Der Populismus sei ,inhärent unvollständig“'79, er habe „ein leeres Herz" ${ }^{\text {“80 }}$ und könne sich daher gleich einem „Chamäleon“" ${ }^{\star 81}$ an unterschiedliche Gegebenheiten anpassen und sich zu ihnen in eine „Anti-

66 Vgl. Decker 2006c: 3.

67 Decker 2004 u. 2006c.

68 Vgl. exemplarisch Priester 2012a: 3.

69 Tella 1995.

70 Canovan 1981: 13.

71 Dorna 2003: 1.

72 Vgl. Laclau 2005a : 9; Panizza 2005: 2; Priester 2011: 186; Mény/Surel 2002: 20.

73 Vgl. für eine Zusammenfassung Rovira Kaltwasser 2011; Priester 2011.

74 Mudde 2004, 2007 u. 2010.

75 Taggart 2000 u. 2004.

76 Freeden 1998.

77 Vgl. Mudde 2004, 2007 u. 2010; sowie Stanley 2008; Priester 2011.

78 Priester 2012a: 3.

79 Taggart 2004: 274.

80 Taggart 2004: 275.

81 Taggart 2000: 4; Taggart 2004: 275. 
Beziehung ${ }^{682}$ setzen. Der andere Ansatz fasst den Populismus im Anschluss an Kurt Weyland $^{83}$ als eine demagogische Strategie, die eine politisch entfremdete Gruppe zu mobilisieren versucht. ${ }^{84}$

Allerdings geraten auch diese Ansätze in ein Dilemma. Einer knappen Merkmalsliste gelingt es nicht, ein analytisch gehaltvolles Populismuskonzept zu generieren. Eine umfassende Merkmalsliste dagegen bringt ein vermeintlich scharfes Populismuskonzept hervor, doch müssen empirische Studien, die sich einer solchen Liste bedienen, vielfältige Einschränkungen und Gewichtungen vornehmen. ${ }^{85}$ Um dieses Dilemma zu lösen, schlägt die Politologin Karin Priester vor, den Populismus als „radiale Kategorie“ zu verstehen und zwischen „einem prototypischen ,genuinen“ [...] Fall und seiner strahlenförmigen Erweiterung um weniger typische Fälle" zu unterscheiden. ${ }^{86}$ Dieses Vorgehen bietet jedoch auch keine Abhilfe, da auch hier Kriterien fehlen, die es erlauben würden, die entscheidende Auswahl des prototypischen Falls zu begründen. Infolgedessen erschöpfen sich die meisten Definitionsangebote in clusterartigen Zusammenstellungen, die unterschiedliche Gesichtspunkte des Populismus auflisten, aber nicht in der Lage sind, die Interaktionslogik der enummerierten Aspekte im Rahmen eines analytisch gehaltvollen Populismuskonzepts zu integrieren.

Die Schwäche dieser Ansätze liegt darin begründet, dass der vertikale Konflikt zwischen ,Volk' und ,Elite' als genuin populistisch identifiziert wird, dieser zentrale Aspekt jedoch untertheoretisiert bleibt. Wenn etwa Karin Priester stellvertretend für viele Populismusforscher/innen ${ }^{87}$ - postuliert, Populismen würden die Achse ,Volk-Elite“ nicht anhand ,politischer“, sondern anhand „,mo-

82 Priester 2012a: 3.

83 Weyland 2001; ein derartiger Populismusbegriff wird auch zugrunde gelegt, wenn der Populismus als Reaktion auf die Post-Demokratisierungstendenzen in westlichen Gesellschaften geltend gemacht wird vgl. Mair 2002: 4; Jun 2006: 234; Mouffe 2005 u. 2011; Decker 2012.

84 Quer zu diesen beiden Hauptansätzen liegt der von José Pedro Zúquete eingebrachte vielversprechende Vorschlag, den Populismus im Anschluss an Emilio Gentiles und Roger Griffins Konzept der „missionarischen Politik“ als einen Diskurs zu verstehen, der bestimmte Motive (Erlösung, Außenseitertun, charismatische Führerschaft, Verschwörungstheorie) kombiniert und ein emphatisches Politikverständnis transportiere.

85 Vgl. Laclau 2005a: 9; Rovira-Kaltwasser 2011: 5; sowie Priester 2011: 189; MénySurel 2002: 2.

86 Priester 2011: 189.

87 Vgl. auch Müller 2015; Mudde 2004: insb. 543. 
ralischer" Vorstellungen kreieren, dann bleiben zwei Fragen offen: ${ }^{88}$ Ist die Unterscheidung zwischen einer moralischen, legitimen Sphäre und einer amoralischen, illegitimen Sphäre wirklich spezifisch populistisch - und nicht notwendiger Bestandteil jedes politischen Projekts und jedes politischen Regimes? (2) Inwiefern ist diese moralische Achse nicht politisch und inwiefern sind andere Teilungs- und Organisationsprinzipien von Gesellschaft politisch? Darüber können diese Ansätze keine Aussagen treffen. Stattdessen wird das bestehende Repräsentationssystem als ,politisch' nobilitiert und der populistische Widerstand als ,moralisierend“ verworfen. So läuft das theoretische Unterfangen Gefahr, in einen normativistischen „Bewahrungsdiskurs“69 ${ }^{6 u}$ kippen, der darauf abzielt, den pathologischen Regimetyp ,Populismus` vom gesunden Regimetyp ,liberale Demokratie‘ $z$ unterscheiden. $^{90}$

Die Devianz von einer vorgestellten Normalität bestimmt auch die wissenschaftliche Debatte um das Verhältnis zwischen Demokratie und Populismus. Die meisten Forscher/innen deuten den Populismus entweder als externe Bedrohung $^{91}$ oder als Korrektiv ${ }^{92}$ der Demokratie. Dabei zeigt sich, dass die positive Konzeption des Populismus mit einem radikalen Demokratiebegriff korreliert, der Demokratie und Liberalismus theoretisch getrennt hält und Demokratie als umkämpfte Selbstinstituierung von Gesellschaft begreift, wohingegen diejenigen, die dem Populismus destruktive oder (bestenfalls) die Selbstheilungskräfte der Demokratie aktivierende Wirkungen zuschreiben, den Demokratiebegriff auf die liberaldemokratischen Repräsentativsysteme nach nordatlantischem Vorbild reduzieren. $^{93}$

Die sozialtheoretische Grundlage dieser negativen Konzeption des Populismus lässt sich als differenzierungstheoretischer Realismus bezeichnen. Dieser Deutungsrahmen, der etwa in den Pluralismustheorien Ernst Fraenkels und Ralf Dahrendorfs sowie der Cleavage-Theorie Seymour Martin Lipsets und Stein Rokkans entworfen wird, ${ }^{94}$ stellt moderne Gesellschaften als „multichrome Mo-

88 Priester 2012a: 4.

89 Vgl. Rosa 1999: 449.

90 Vgl. Laclau 2005a: 15; Seyd 2014; Link 2008.

91 Vgl. exemplarisch Taggart 2002; Rosanvallon 2008; Müller 2015. Forscher/innen, die den Populismus als intrinsisches, potentiell demokratisierendes Moment ins Auge fassen, sind dagegen in der Minderheit. Neben Ernesto Laclau (2005a) sei hier insbesondere auf Margaret Canovan (1999; 2002) verwiesen.

92 Vgl. exemplarisch etwa Decker 2011; Mény/Surel 2002.

93 Vgl. Rovira Kaltwasser 2011: 9.

94 Dahrendorf 1972; Fraenkel 2011; Lipset/Rokkan 1976. 
saike aus monochromen [...] Blöcken“"95 vor. Dabei werden die empirisch diagnostizierbaren Pluralisierungs- und Ausdifferenzierungsprozesse, die in Form dieser Mosaike sedimentieren, als gegeben konzipiert. Infolgedessen erscheinen bestimmte soziale Kollektive (etwa Schichten, Lebensstilgruppen, Ethnien, Generationen und Milieus) als objektive Entitäten und andere Entitäten (Nationen und Völker beispielsweise) als ideologische, bloß vorgestellte Gemeinschaften. Mithilfe der Leitdifferenz ,real vs. imaginär' sorgt der differenzierungstheoretische Realismus dafür, dass die politischen Referenzen auf die ,objektiven Kollektive‘ als intelligibel, aufgeklärt und rational begrüßt werden, während die populistischen Anrufungen eines unterdrückten ,Volkes‘ als Ausdruck ,falschen Bewusstsein' geltend gemacht werden. Die Politisierung der ersteren wird daher als Eponym einer lebendigen pluralistischen Zivilgesellschaft geadelt; die Identifikation eines unterdrückten ,Volkes‘ dagegen als antipluralistisches Relikt vormoderner Identitätssemantiken verworfen. ${ }^{96}$

Ein erstes Forschungsdesiderat besteht folglich darin, die poststrukturalistische Populismustheorie Laclaus gegen diese normativistischen Populismustheorien zu konturieren. Herausgearbeitet werden soll indes nicht nur der Mehrwert der Laclau'schen Perspektive gegenüber den herkömmlichen Konzeptionen des Phänomens. Es geht auch darum, die Merkmale des Populismus, die phänomenologische Ansätze anbieten, innerhalb des Theorierahmens von Laclau so zu reformulieren, dass sie die Hegemonieanalyse des SVP-Populismus ergänzen können. ${ }^{97}$

Mit dem Ziel, die Entstehung und die Persistenz populistischer Protestphänomene in modernen pluralistischen Gesellschaften $\mathrm{zu}$ begreifen, ohne auf fixierte ,bildungsferne, uneinsichtige Gruppenidentitäten` zu rekurrieren, soll das Verhältnis von Pluralismus und Populismus nicht als inkompatibler Gegensatz gedacht werden, sondern mithilfe einer Theorie dynamisiert werden, die bei der Dekonstruktion eines monistisch vorgestellten Volkes und eines faktischen Pluralismus ansetzt. Schließlich soll vor dem Hintergrund der Analyse des SVPPopulismus auch das allgemeine Verhältnis von Demokratie und Populismus mit

95 Brubaker 2007: 18.

96 Exemplarisch etwa bei Decker/Lewandowsky 2009: 1; diese Kritik des Populismus ließe sich im Anschluss an Jacques Rancière (2002: 90ff.) und ganz im Sinne Laclaus als metapolitische Suspension des Politischen bezeichnen (vgl. auch Marchart 2010: 182).

97 Dabei wird insbesondere an die „dünne Ideologie“ (Mudde 2004), die „missionarische Politik“ (Zúquete 2011) und die „Heartand-Politik“ (Taggart 2000 u. 2004) angeknüpft. 
Laclau und gegen Laclau diskutiert werden. In diesem Zusammenhang wird deutlich, dass die einschlägigen Passagen aus On Populist Reason eine implizite Normativität bergen, die dazu tendiert, den Populismusbegriff auf linke und demokratische Populismen zu verengen und Gefahr läuft, den Allgemeinheitsanspruch der Populismustheorie Laclaus zu unterminieren.

\section{(2) Die Rechtspopulismusforschung und die Erforschung des SVP-Populismus}

Methodisch korrespondiert die skizzierte Pathologisierung des Populismus mit dem Gelegenheitsstrukturansatz, den Populismusforscher/innen der Parteiensystemforschung entliehen haben. ${ }^{98}$ Gelegenheitsstrukturtheoretiker/innen verfolgen ein nomothetisches Erkenntnisinteresse. Auf Grundlage eines Marktmodells von Politik zielen sie auf die Erfolgsbedingungen von Protestphänomenen. Demzufolge stoßen erfolgreiche populistische Politikunternehmer mit einer programmatischen winning formula ${ }^{99}$ in die Lücke von politischem Angebot und politischer Nachfrage. Ihre Rhetorik erscheint dabei als kognitive Vermittlungsinstanz, als ein Medium zum matching von politischen Erwartungen und Einstellung der ,Bürgerklienten ' auf der einen und dem programmatischen Angebot der Populisten auf der anderen Seite.

Mithilfe dieses Ansatzes wurde der Aufstieg rechtspopulistischer Parteien in den 1990er Jahren im Wesentlichen auf sozioökonomische Desintegrationsprozesse zurückgeführt. ${ }^{100}$ Die Globalisierung produziere sogenannte ,Modernisierungsverlierer', die in den rechten Protestparteien ein neues politisches Zuhause fänden. Dieser Zusammenhang zwischen sozialem Abstieg oder Abstiegsangst und der Wahl rechtspopulistischer Parteien lässt sich in allen westeuropäischen Ländern empirisch nachweisen. ${ }^{101}$ Vor diesem Hintergrund stellt sich der Auf-

98 Der Gelegenheitsstrukturansatz wird zu Beginn des folgenden Theoriekapitels exploriert und hier daher nur grob skizziert. Vgl. grundlegend: Kitschelt/McGann 1995; Koopmanns/Statham 2000; Kriesi 1999. Exemplarische Anwendungen des Gelegenheitsstrukturansatzes auf den französischen Front National und die schweizerische SVP finden sich beispielsweise bei Schmidtke 1996; Rydgren 2004 bzw. Mazzoleni 2003; Lachat/Selb 2005 und (sehr elaboriert) bei Bornschier 2010. Auf diesen Ansatz wird im Theoriekapitel zu Beginn ausführlich eingegangen.

99 Kitschelt/McGann 1995.

100 Vgl. etwa Betz 1994; Kitschelt/McGann 1995; Kriesi 1999a.

101 Vgl. Spier 2006; 2010; mit Blick auf die Schweiz und die SVP Lachat/Selb 2005. 
stieg rechtspopulistischer Parteien auch als Folge der „Entideologisierung“102 der sozialdemokratischen und christlich-konservativen Volksparteien dar, deren ehemalige Stammwähler sich von den etablierten Parteien nicht mehr wahrgenommen fühlten. ${ }^{103}$

Obwohl diese Perspektive plausible Erklärungen für den Erfolg rechtspopulistischer Parteien bietet, lässt sich beobachten, dass der sozioökonomisch fundierte Ansatz angesichts der elektoralen Persistenz des Rechtspopulismus in den 2000er Jahren zugunsten eines soziokulturellen Ansatzes zurücktritt, welcher der Tatsache gerecht zu werden versucht, dass der Aufstieg rechtspopulistischer Parteien die ,längerfristige Neustrukturierung des politischen Raumes in Westeuropa widerspiegelt“104. So postuliert etwa der Politologe Simon Bornschier: „It seems that it is not the sociostructural roots per se, but rather antagonistically related collective identities that stabilize party systems. The subcultures created by conflicts therefore constitute the durable basis of cleavages, and not their immutable bases. “105 Demnach profitieren rechtspopulistische Parteien von der kulturellen Cleavage zwischen „Öffnung und Schließung“"106 respektive zwischen „Integration und Exklusion“"107, welche die tradierten politischen Konfliktlinien überpräge und neue kollektive Identitäten hervorbringe. ${ }^{108}$ Im Zuge dieser Verschiebung innerhalb des Erklärungsmodells betonen einige Forscher/innen, dass rechtspopulistische Parteien nicht nur von der kulturell geprägten „IntegrationsExklusions-Cleavage“"109 profitierten, sondern die Konjunktur kultureller Themen auch forcierten. ${ }^{110}$ Damit wird der Gelegenheitsstrukturansatz zwar nicht grundlegend verabschiedet, aber doch an seine Grenzen geführt, da die politischen Akteure nicht nur aus spezifischen Gegebenheiten Profit schlagen und spezifische Konfliktlinien politisieren, sondern dieser Gegebenheiten und diese

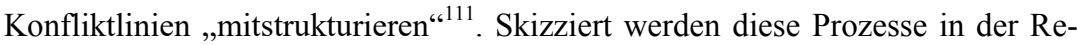

102 Decker 2012: 6.

103 Vgl. Decker 2012: 5ff.; Dorna 2004.

104 Helbing 2011: 12.

105 Bornschier 2010: 14.

106 Vgl. mit Blick auf die Schweiz vgl. Brunner/Sciarini 2002; Bornschier/Helbing 2005: insb. 32ff..

107 Helbing 2011.

108 Vgl. grundlegend zur Restrukturierung von Cleavages in Westeuropa Kriesi u.a. 2008.

109 Helbing 2011; vgl. auch Bornschier 2009 u. 2010.

110 Vgl. Hellbing 2011; Bornschier 2009: 2010.

111 Vgl. Hellbing 2011: 14. 
gel mithilfe von Pierre Martins ${ }^{112}$ Weiterentwicklung der Cleavage-Theorie als dealignment-realignment, d.h. als Lösung und Reorganisation der etablierten Partei-Wählerbindungen. ${ }^{113}$ Wie sich diese politischen Willens- und Identitätsbildungsprozesse vollziehen, bleibt indes im Verborgenen. Die politische Virulenz spezifischer Konfliktlinien wird empirisch diagnostiziert, historisch kontextualisiert und anhand von Parteiprogrammen belegt. Eine Analyse der Instituierung dieser identitätsstiftenden Konfliktlinien lässt die theoretische Perspektive aber nicht zu.

In diesem Forschungszusammenhang lassen sich einige Arbeiten verorten, die der Deutungsmacht rechtspopulistischer Parteien mit Hilfe der Wissenssoziologischen Diskursanalyse nach Reiner Keller auf den Grund gehen. ${ }^{114}$ Dabei wird Gesellschaft nicht konsequent diskurstheoretisch gedacht. ${ }^{115}$ Vielmehr wird sowohl das Struktur-Akteur-Modell als auch das Marktmodell von Politik beibehalten. ${ }^{116}$ Ausgestattet mit diskurstheoretischen Analysebegriffen wird die Angebotsseite respektive die Rhetorik der strategisch intervenierenden Akteure untersucht, die auf bestimmte gesellschaftliche Diskurse und Deutungsmuster zurückgreifen, um ihre Ziele zu erreichen. ${ }^{117}$ Im Fokus der Analyse steht die rhetorische Produktion der Wissensbestände ${ }^{118}$, auf die Individuen oder bestimmte soziale Gruppen zurückgreifen, wenn sie politisch handeln.

Indes führt die Repräsentation dieser Individuen und Gruppen als Entitäten mit festen Identitäten dazu, dass die populistische Identitätspolitik als eine wenn nicht notwendige, kausal-determinierte, so doch als ein in einer objektiven Struktur begründetes Phänomen gelesen wird. Somit droht die Gefahr, dass die

112 Martin 2000.

113 Mit Blick auf die Schweiz und die SVP vgl. Bornschier/Helbing 2005.

114 Vgl. exemplarisch mit Fokus auf die SVP und die FPÖ Geden 2006; mit Fokus auf die SVP respektive die Volksabstimmung über demokratische Einbürgerungen Elliker 2011.

115 Zur Unterscheidung dieser Form der Diskursanalyse von einer diskurstheoretischen Lektüre des Sozialen vgl. Pieper 2006.

116 Vgl. Geden 2006.

117 Für eine Kritik dieser Perspektive anhand der Arbeit Gedens (2005) vgl. Jäger 2007.

118 In erster Linie beziehen sich diese Arbeiten zumeist auf den von Hans-Georg Betz (2002 u. 2004) diagnostizierten „differenzialistischen Nativismus“ und die damit verbundene Konfliktlinie zwischen einem liberalen Kosmopolitismus und einem populistischen, ethnisch fundierten Kommunitarismus (Betz 2004). 
Identitätspolitik einer populistischen Partei schlichtweg affirmiert wird. ${ }^{119} \mathrm{Im}$ Gegensatz zu diesen sozialstrukturell fundierten Analysen kann das Soziale mit Laclau als Feld konzipiert werden, auf dem Identitäten politisch gebildet werden, um die untertheoretisierte Instituierung des diagnostizierten Bruchs zwischen ,Öffnung und Schließung' konsequent diskurstheoretisch in den Blick zu nehmen.

Wenngleich zur SVP auch viele idiographische Arbeiten entstanden sind, ${ }^{120}$ ist auch die Erforschung dieser Partei in erster Linie durch den nomothetisch orientierten Gelegenheitsstrukturansatz geprägt. ${ }^{121}$ Wählersoziologische Untersuchungen stützen die Modernisierungsverlierer-These. ${ }^{122}$ Denn neben den SVPStammwählern aus dem agrarischen Milieu der protestantischen Landesteile sind es insbesondere „Erwerbstätige in traditionellen Berufen und ungelernte Arbeiter, die eine hohe Wahlwahrscheinlichkeit für die SVP“"123 haben. Ferner zeigen demoskopische Analysen, dass der Aufstieg der SVP vor dem Hintergrund einer zunehmenden politischen Polarisierung des Parteiensystems und der Bevölkerung seit den 1990er Jahren zu verstehen ist. ${ }^{124}$

Im Zentrum der Forschung stehen aber die durch das politische System induzierten Gelegenheitsstrukturen. Wohingegen in den 1990er Jahren noch davon ausgegangen wurde, dass polarisierende politische Projekte angesichts der Verankerung des Konkordanzprinzips in der politischen Kultur der gemäßigt pluralistischen Gesellschaft keine Erfolgschancen hätten, ${ }^{125}$ betonen neuere For-

119 Der Wahlerfolg der SVP erscheint dann beispielsweise als ,politische Folge“ (Kriesi 2002) einer fixierten nationalen Identität, die in bestimmten Milieus besonders verankert ist. Für eine ausführlichere Kritik vgl. auch Kapitel 5.1 des analytischen Hauptteils.

120 Mit Fokus auf die Erosion der Konkordanz durch die SVP vgl. Mazzoleni/ Skenderovic 2007; parteigeschichtlich u. mit Fokus auf die Entstehung des Zürcher Flügels vgl. Hartmann/Horvath 1995; mit Fokus auf den „differenzialistischen Nativismus“ als Kernstück der Ideologie vgl. Betz 2012; wissenssoziologisch vgl. Zollinger 2002 u. 2004; ideengeschichtlich und mit Verweis auf die ideologische Kontinuität der vermeintlich neuen SVP vgl. Lang 2000; Skenderovic 2009 u. 2013; diskursanalytisch: Geden 2006 u. Elliker 2011.

121 Vgl. Mazzoleni 2003; Bornschier 2010; Albertazzi 2008.

122 Vgl. exemplarisch Longchamp 2000.

123 Lachat/Selb 2005: 57.

124 Ladner 2010 u. 2013; Ladner u.a. 2010; Longchamp/Rousselot 2010.

125 So behauptete der Politologe Ludger Helms (1996) etwa, dass die konsensorientierte, gemäßigt pluralistische politische Kultur der Schweiz der Entfaltung des SVP- 
schungen, dass Konkordanzdemokratien im Allgemeinen und die schweizerische Konkordanzdemokratie mit ihrem Proporzsystem und den direktdemokratischen Institutionen im Spezifischen besonders günstige Voraussetzungen für Populismen bieten. ${ }^{126}$ Der konkordanzdemokratisch induzierte Elitenkonsens versorge das populistische Verschwörungsszenario eines „homogenen Bevormundungskartells“'127 mit Nahrung, während die direkte Demokratie der SVP ermögliche, fallweise als Oppositionspartei zu agieren. ${ }^{128}$ Indes verschwindet in dieser ,genuin politologischen 'Analyse das ehedem zentrale Argument der Kongruenz von politischem System und politischer Kultur, nach dem populistische Projekte in der Schweiz keine Chance hätten. ${ }^{129}$

Dieses Dilemma versucht die Arbeit zu lösen, indem sie sich zunächst auf das kulturalistische Argument einlässt, um es im Anschluss zu dekonstruieren. Die Interaktion von Konkordanz, gemäßigtem Pluralismus und politischer Kultur zwischen 1945 und 1990 wird dabei als hegemoniale Fixierung des ,Sonderfall Schweiz' gelesen, um danach zu zeigen, wie der SVP-Diskurs diese Hegemonie herausfordert und einen anderen ,Sonderfall Schweiz‘ kreiert. Ich knüpfe hierbei an bereits existierende politologische, wissenssoziologische, phänomenologi-

Populismus enge Grenzen setze. Zur konsensorientierten politischen Kultur der Schweiz als Bastion gegen extremistische Bewegungen vgl. auch Armingeon 1995. Kritisch zu dieser Diagnose äußert sich Damir Skenderovic (2007b: 45): Um das Diktum des ,Schweizer Sonderfalls‘ als konkordanzdemokratisch integrierter, multikultureller Willensnation aufrecht zu erhalten, so der Historiker, sei die Präsenz wirkmächtiger rechtspopulistischer Bewegungen auf der Bühne der Schweizer Politik auch dadurch verdeckt worden, dass sie schlicht anders benannt wurden. Allgemein zur konsens- und kompromissorientierten politischen Kultur vgl. MeierDallach 1988, Rehberg 2007 u. Imhof 2007.

126 Allgemein vgl. Taggart 1996: 113ff.; Caramani/Mény 2005: 41ff.; vergleichend anhand der Beispielländer Österreich, Schweiz und den Niederlanden Fröhlich-Steffen 2006; mit Fokus auf die Schweiz vgl. Papadopoulos 2005; Albertazzi 2008. Insofern ließe sich schlussfolgern, dass der Konkordanzdemokratie die programmatische Mitte-Orientierung der etablierten Parteien als wichtige Voraussetzung für den Aufstieg des Rechtspopulismus in Westeuropa bereits eingebaut ist (vgl. Decker 2012).

127 Vgl. Priester 2012a: 9.

128 Vgl. die zwischen Österreich und der Schweiz vergleichende Arbeit Oliver Gedens (2006).

129 Dagegen konstatiert etwa Kurt Imhof, die SVP laufe Gefahr, den populistischen Bogen zu überspannen und an der Privilegierung der Konkordanz in der Bevölkerung zu scheitern (Imhof 2007: 28). 
sche, partei- und ideengeschichtliche sowie diskursanalytische Arbeiten ${ }^{130}$ an und versuche deren Ergebnisse im Rahmen einer hegemonietheoretischen Lektüre zu integrieren. Dadurch wird beispielsweise analysiert, wie die Partei in die ,bürgerliche Mitte' vordringen und gleichzeitig ehemalige Stammwähler/innen rechtsextremistischer Kleinstparteien absorbieren konnte, ${ }^{131}$ indem sie den ,Sonderfall Schweiz‘ und seine Knotenpunkte im Rahmen des eigenen politischen Projekts hegemonisierte. ${ }^{132}$

\section{(3) Hegemonieanalyse}

Obwohl die Theorie Laclau/Mouffes durchaus als Gesellschaftstheorie gewürdigt wird, ${ }^{133}$ werden im deutsch- und englischsprachigen Raum in erster Linie ihre philosophischen sowie ihre politik- und demokratietheoretischen Implikationen diskutiert. ${ }^{134}$ Empirische Anwendungen der Hegemonietheorie sind dagegen nach wie vor selten. ${ }^{135}$ Die zurückhaltende Indienstnahme Laclau/Mouffes für analytische Zwecke, liegt u.a. darin begründet, dass Laclau und Mouffe sich kaum zur empirischen Umsetzungen der Hegemonietheorie äußern, geschweige denn selbst eine prototypische Hegemonieanalyse entworfen haben. ${ }^{136}$

So verzichten auch die empirischen Arbeiten, die aus der von Laclau gegründeten Essex School hervorgegangen sind, auf eine Methodologie im strengen Sinn. ${ }^{137}$ Stattdessen werden etwa Reden von Parteiführern mit hegemonietheoretischen Analysebegriffen gelesen, um die politische Logik herauszuarbei-

130 Mazzoleni/Skenderovic 2007; Hartmann/Horvath 1995; Betz 2012; Zollinger 2002 u. 2004; Lang 2000; Skenderovic 2007b, 2009 u. 2013; Geden 2006; Elliker 2011.

131 Vgl. Mazzoleni 2003: 17.

132 Die Arbeit kann insofern auch als theoretisch innovativer Beitrag zur SonderfallDebatte gelesen werden (vgl. Eberle/Imhof 2007).

133 Vgl. exemplarisch Stäheli 2001; Nonhoff 2007b, Reckwitz 2006.

134 Vgl. Rüdiger 1996; Marchart 1998; Flügel u.a. 2004; Critchley/Marchart 2004; Nonhoff 2007a; für eine äußerst kritische Rezeption vgl. Priester 2012b.

135 Verwiesen sei hier auf Nonhoff 2006; Casula 2012; Howarth u.a. 2000; Norval 1996.

136 Vgl. auch Glasze 2007: 11.

137 Vgl. exemplarisch Norval 1996; Martin Nonhoffs (2006) streng formalisierte Hegemonieanalyse bildet insofern eher eine Ausnahme. 
ten, die diskursiven Sinnfixierungen zugrunde liegt. ${ }^{138}$ Dieses deduktive Vorgehen läuft indes Gefahr, soziale Wirklichkeit lediglich als Beleg für die Validität der eigenen abstrakten Konzepte zu missbrauchen, wie der Begründer der Wissenssoziologischen Diskursanalyse Reiner Keller anmerkt. ${ }^{139}$

Die deduktive Herangehensweise prägt auch die vorliegende Arbeit. Sie trägt der von Keller skizzierten Gefahr jedoch insofern Rechnung, als sie die Hegemonietheorie mit induktiv gewonnen, intermediären Analysebegriffen ergänzt und innerhalb eines Rahmens für die Analyse rechtspopulistischer Diskurse integriert. ${ }^{140}$ Die Hegemonieanalyse wird somit an eine textanalytisch orientierte Diskursanalyse angeschlossen, die nach den Regeln der Sinnproduktion fragt, ohne ihre grundlegende politische Funktionslogik aus dem Blick zu verlieren.

138 Philipp Casula (2012: 79) spricht in diesem Zusammenhang treffend von einer ,impliziten Analysestrategie“, der die Arbeiten der Essex School folgten.

139 Vgl. Keller 2005: 164ff.; Howarth/Stavrakakis 2004: 4; sowie das Methodenkapitel dieser Arbeit.

140 Ich bediene mich hierbei in erster Linie im Arsenal der Kritischen Diskursanalyse nach Ruth Wodak und Norman Fairclough (Wodak u.a. 1998; Wodak 2001; Wodak/Fairclough 1997; Fairclough 1995). 


\section{Erster Teil:}

Diskurs, Hegemonie, Populismus. Ernesto Laclaus politische Theorie der Gesellschaft 



\title{
1. Das ,Volk‘ als imaginäre und reale Identität
}

\begin{abstract}
„It is as if, in other words, what we call people was actually not a unitary subject but rather a dialectical oscillation between two opposite poles: on the one hand, the ,People' as a whole and as an integral body politic and, on the other hand, the ,people' as a subset and as fragmentary multiplicity of needy and excluded bodies; on the one hand, an inclusive concept that pretends to be without remainder while, on the other hand, an exclusive concept known to afford no hope; at one pole, the total state of the sovereign and integrated citizens and, at the other pole, the banishment - either court of miracles or camp of the wretched, the oppressed, and the vanquished."
\end{abstract}

AGAMBEN 2004

Die vorliegende Arbeit behandelt die diskursive Konstruktion des Schweizervolkes durch den SVP-Populismus. Im Folgenden erarbeite ich hierfür einen Volksbegriff, der sowohl der ethno-essentialistischen Identitätspolitik der SVP als auch den objektivistischen, differenzierungstheoretischen Ansätzen widerspricht, die im Rahmen moderner pluralistischer Gesellschaften jeden politischen Bezug auf ein ,Volk' entweder als völkisch-heterodoxen Anachronismus oder in Begriffen von ,Stil' und ,Strategie“ als machtmaximierende Geste diffamieren. ${ }^{1}$

1 Vgl. die Rekapitulation solcher Ansätze im Einleitungskapitel der vorliegenden Arbeit. 
Es geht um die Konzeption eines Volksbegriff, der das ,Volk' als vorgestellte und reale politische Identität begreift. Ein ,Volk' bezeichnet demnach nicht etwa einen substantiellen ,gesellschaftlichen Körper“淿 oder eine originäre Positivität, sondern ein Artefakt, das durch wiederholte „Anrufungen“汭, in einem kontingenten „System kultureller Repräsentation““4 geschaffen wird. So wird das ,Volk‘ hier - zunächst ganz im Sinne Jacques Rancières - als eine „durch Subjektivierungsformen, durch die Konfiguration verschiedener Dissens-Szenarien geschaffen[e] kollektive Identität ${ }^{* 5}$ gedacht, die insofern reale politische Effekte zeitigt, als sie subjektiven Unrechtserfahrungen eine politische Projektionsfläche bietet.

Ein ,Volk' fordert die Struktur des „politischen Feldes“ ${ }^{\text {“6 }}$ heraus. Denn es stellt die grundlegende Distinktion des Feldes zwischen den , legitimerweise beherrschten Laien' und den , legitimerweise herrschaftsausübenden Berufspolitikern` zur Disposition. Die Konstruktion eines, Volkes' impliziert aber nicht nur eine Rebellion gegen eine ,dysfunktionale Elite', sondern subvertiert auch die bestehende Gruppendifferenzierung einer Gesellschaft. Dadurch dass die Rede von einem ,Volk' eine übergeordnete Egalität präsupponiert, welche die inkludierten Differenzen (Milieus, Schichten, Klassen, Geschlechter, Minderheiten, Altersgruppen, etc.) transzendiert, bricht es mit der „polizeilichen Verteilung der Anteile, die verschiedenen Teilen der Gesellschaft zugestanden werden“"7.

Dabei ist das ,Volk ${ }^{\star}$ im Unterschied zu anderen Subjektivierungsformen nicht etwa auf spezifische Teilbereiche der Gesellschaft wie Produktionsverhältnisse, Rassenverhältnisse, Geschlechterverhältnisse und die jeweiligen Ungleichheiten limitiert. Der Volksbegriff zeichnet sich dadurch aus, dass er prinzipiell in der Lage ist, Ungerechtigkeitserfahrungen aus allen Teilbereichen auf einen Nenner zu bringen und als Teilaspekte eines tieferliegenden, allgemeinen Unterdrückungsverhältnisses zu subsumieren. Infolgedessen stört ein ,Volk ${ }^{`}$ die reibungslose Reproduktion der herrschenden Verhältnisse. Es stellt metaphysisch oder funktional begründete Hierarchien infrage. Im Unterschied zu anderen kollektiven Identitäten, die ja ebenfalls Verschiebungen in der symbolischen Repräsentation der Gesellschaft bewirken, zielt es auf eine grundlegende politische Desorganisation. Denn einerseits handelt es sich um ein exklusives Konzept. Das

2 Rancière 2007: 6.

3 Zum Konzept der Anrufung vgl. Althusser 1977.

4 Hall 1994c: 200.

5 Vgl. Rancière 2007: 6.

6 Vgl. Bourdieu 2001.

7 Vgl. Rancière 2007: 6. 
,Volk‘ bezeichnet nicht die gesamte Bevölkerung, sondern nur einen subjektiv marginalisierten Bevölkerungsteil. Es meint die partikulare Entität der plebs, die einfachen, hart arbeitenden, politisch und gesellschaftlich jedoch marginalisierten Leute. Andererseits wohnt dem Volksbegriff ein Moment der Universalität inne. ${ }^{8}$ Das Volk ist der demos, die Gesamtheit der Staatsbürger, deren Willen seit den demokratischen Revolutionen im 18. Jahrhundert als universelle Quelle politischer Souveränität konstruiert wird. Populistische politische Projekte wie jenes der SVP rekurrieren auf diese Ambiguität des Volksbegriffs. Sie führen seine partikulare und seine universelle Konnotation im Rahmen einer synekdochischen Logik zusammen. Denn sie postulieren, dass allein ein unterdrückter, moralisch integrer Teil der Bevölkerung das Ganze repräsentiert.

Indes verfügen demokratische politische Projekte entgegen der Politiktheorie Rancières keineswegs über eine privilegierte Stellung, diese universalisierende Operation zu bewerkstelligen und die Identität des ,Volkes' in Analogie zu ihrem politischen Programm zu fixieren. Dass ein ,Volk` durch liberale, egalitäre und emanzipatorische und nicht durch ethnonationalistische und autoritäre Projekte hegemonisiert wird, kann nicht theoretisch deduziert, sondern nur politisch erkämpft werden. ${ }^{9}$

Diesen Volksbegriff und die diskursive Logik seiner Konstruktion werde ich in den folgenden Kapiteln aus der Hegemonie- und Populismustheorie Ernesto Laclaus und Chantal Mouffes entwickeln. Um diese theoretische Perspektive zu schärfen, werde ich mit dem Gelegenheitsstrukturansatz zunächst jenes Forschungsprogramm vorstellen, das der konventionellen Populismusforschung zugrunde liegt. Im Anschluss werde ich das Modell an seine Grenzen führen und für einen Paradigmenwechsel in der Erforschung populistischer Parteien plädieren, der die populistischen Rekurse auf das ,Volk' nicht per se als pathologische Abweichungen klassifiziert, sondern als genuin politische und potentiell demokratisierende Operationen begreift. Im darauffolgenden Kapitel werde ich nach einer kurzen Einführung zu den erkenntnisleitenden Begriffen Identität und Hegemonie die epistemologischen Grundlagen der Diskurstheorie Laclau/Mouffes darlegen und die Hegemonie- und Populismustheorie sowie deren Analysebegriffe entfalten. Am Ende des Theoriekapitels konturiere ich die hegemonietheoretische Konzeption des Populismus gegen die Konstitution des Populismus im Gelegenheitsstrukturansatz sowie gegen phänomenologisch gewonnene Popu-

$8 \mathrm{Zu}$ dieser Doppeldeutigkeit des Volksbegriffs vgl. neben Laclau 2005: insb. 244ff. auch Canovan 2004: 249 u. Agamben 2004.

9 Zur Kritik an Rancière vgl. Laclau 2005: 244ff.; sowie im Anschluss an die politische Ontologie Laclaus vgl. Marchart 2011. 
lismusbegriffe und exponiere das Erkenntnispotential der Laclau'schen Perspektive für die Erforschung rechtspopulistischer Bewegungen. 


\section{Populismusforschung als Parteienforschung: der Gelegenheitsstrukturansatz}

Der Gelegenheitsstrukturansatz ist der dominante Theorieansatz der Populismusforschung. ${ }^{1}$ Der von Herbert Kitschelt und Anthony J. McGann zur Erforschung von Protestbewegungen ausgearbeitete und vielfach verfeinerte Ansatz schließt die Populismusforschung an die Parteiensystemforschung an. Er rekurriert insbesondere auf die Cleavage-Theorie von Martin S. Lipset und Stein Rokkan ${ }^{2}$ sowie auf den Dealignment-realignment-Ansatz von Pierre Martin ${ }^{3}$. Die Quintessenz des Ansatzes besteht darin, dass er makrosoziologische bzw. strukturtheoretische und mikrologische bzw. akteurtheoretische Perspektiven innerhalb eines Modells kombiniert, das die Variabilität der Mobilisierungserfolge populistischer Parteien zu erklären versucht.

1 Kitschelt 1986; Kitschelt/McGann 1995. Exemplarisch für Verfeinerungen vgl. Kriesi 1999a; Koopmans/Statham 2000; Rydgren 2004; Bornschier 2009 u. 2010. Mich interessieren hier weniger die vielfältigen Feinjustierungen des Gelegenheitsstrukturansatzes, die vor dem Hintergrund empirischer Analyseergebnisse vorgenommen wurden, sondern insbesondere seine theoretischen Prämissen und deren Konsequenzen für die Konzeption und die Erforschung des Populismus.

2 Lipset/Rokkan 1967.

3 Martin 2000; sowie Bornschier 2009. 


\subsection{DAS ERKLÄRUNGSMODELL UND DIE THEORETISCHEN PRÄMISSEN DES GELEgENHEITSSTRUKTURANSATZES}

Grundlage des Gelegenheitsstrukturansatzes ist ein Marktmodell von Politik. ${ }^{4}$ Nach diesem Modell agieren die Wähler/innen als zweckrationale, interessenmaximierende Politik-Konsumenten; die Parteien als zweckrationale und interessenmaximierende, d.h. machtstrebende Politik-Anbieter. ${ }^{5}$ Auf der Nachfrageseite fordern Wähler/innen mit gruppenspezifischen Präferenzen nach bestimmten Politikangeboten; ${ }^{6}$ auf der Angebotsseite werben politische Parteien mit ihren Programmen um die Gunst der Wähler/innen. Ihre Repräsentationsfunktion ist darauf beschränkt, eine als gegeben betrachtete Nachfrage zu saturieren. Da die Parteien darauf abzielen, ihre Macht zu maximieren und politische Macht in demokratischen Regierungssystemen an Wählerstimmen gekoppelt ist, werden sie versuchen, die Präferenzen möglichst vieler Bürgerinnen und Bürger programmatisch zu aggregieren.

Die Konkurrenzsituation und der Wiederwahlmechanismus bewirken, dass sich die Parteien auch nach der Wahl responsiv gegenüber den Wünschen und Forderungen der Wähler/innen verhalten. Auf diese Weise entsteht mittelfristig ein dynamisches Gleichgewicht, ein matching zwischen Parteiensystem und Wählergruppen. Das Parteiensystem repräsentiert die Einstellungen und Forderungen der Bürger/innen; seine Komposition spiegelt die Gruppendifferenzierung und die Konfliktlinien der repräsentierten Gesellschaft. Lediglich das Wahlsystem verzerrt diese Spiegelung mehr oder weniger, da es die politischen Akteure dazu zwingt, Koalitionen einzugehen und gruppenübergreifende Allianzen zu schmieden, um mehrheits- bzw. regierungsfähig zu werden.

Gestört wird das Parteiensystem durch Umwelteinflüsse, gesellschaftliche Ereignisse oder Prozesse, die entweder die Präferenzen der sozialen Gruppen verändern oder aber neue Gruppen mit neuen Präferenzen hervorbringen. Wenn es dem etablierten Parteiensystem aufgrund seiner strukturell bedingten relativen Trägheit nicht gelingt, diese neuen Präferenzen programmatisch zu absorbieren,

4 Grundlegend vgl. Downs 1968.

5 Vgl. Kitschelt/McGann 1995: viii.

6 Der Präferenzbegriff bezeichnet in diesem Zusammenhang das Ensemble der politisch relevanten Einstellungen, Ideologien, Forderungen, Ängsten und Hoffnungen, anhand derer Menschen und Gruppen von Menschen ihre politischen Wahlentscheidungen treffen. 
entstehen sogenannte Gelegenheitsstrukturen. Darunter werden „specific configurations of resources, institutional arrangements and historical precedents for social mobilization, which facilitate the development of protest movements ${ }^{\text {“7 }}$ verstanden. Gelegenheitsstrukturen fungieren als Marktlücken. Sie bieten kleineren oder neugegründeten Parteien die Chance, sich mit einer programmatischen „winning formula" ${ }^{68}$ die Unterstützung derjenigen zu sichern, die sich von den etablierten Parteien nicht mehr repräsentiert fühlen.

Ausschlaggebend für den Erfolg rechtspopulistischer Parteien ist aus Sicht der Vertreter des Gelegenheitsstrukturansatzes daher das Zusammenspiel von vier Variablen, die sich zu folgendem Analyserahmen fügen.

Der Analyserahmen des Gelegenheitsstrukturansatzes ${ }^{9}$

\begin{tabular}{|c|c|c|}
\hline & Nachfrage & Angebot \\
\hline Mikroebene & Wähler (1) & $\begin{array}{l}\text { Politische } \\
\text { Parteien (3) }\end{array}$ \\
\hline Makroebene & $\begin{array}{l}\text { Gesellschaftliche } \\
\text { Strukturen (2) }\end{array}$ & $\begin{array}{l}\text { Parteien- } \\
\text { System (4) }\end{array}$ \\
\hline
\end{tabular}

Die einschlägigen Forschungsfragen beziehen sich folglich erstens auf die Wähler, ihre Ideologien, Einstellungen, Stereotype, Interessen und Deutungsschemata, die sie zu bestimmten Wahlentscheidungen bewegen. Zweitens fragen Vertreter des Gelegenheitsstrukturansatzes nach gesellschaftlichen Strukturen, der Erosion sozialer Milieus, der Krise fordistischer Produktionsverhältnisse, dem Übergang zu postindustriellen Wissensgesellschaften und der Entfremdung von politischen Institutionen, unter deren Einwirkung sich sowohl die Interessen als auch die ideologischen Wissensbestände und Deutungsmuster der Wähler transformieren. Drittens interessieren sie sich für Parteien, die sie als ideologisch begründete, aber strategisch handelnde Organisationen betrachten, sowie für die sogenannte ,Gewinnerformel', die sie aus politischen Programmen und Reden herauszudestillieren versuchen. Viertens fragen Gelegenheitsstrukturtheoreti-

7 Kitschelt 1986: 58.

8 Kitschelt/McGann 1995.

9 In Anlehnung an Rydgren 2004: 28. 
ker/innen nach den Parteiensystemen, den Beziehungen zwischen den Parteien, aber auch nach den Wahlgesetzen, welche die Entstehung neuer Parteien bedingen. ${ }^{10}$

Wenngleich die Vertreter des Gelegenheitsstrukturansatzes allen vier Variablen Einfluss auf das Wahlergebnis einräumen, favorisiert der Ansatz eine wählersoziologische Perspektive und räumt den gesellschaftlichen Strukturen eine privilegierte Stellung ein. Denn aus Sicht von Gelegenheitsstrukturtheoretikern resultieren die Präferenzen der Wählerinnen und Wähler aus ihrer Klassen-, Schichten- oder Milieuzugehörigkeit. weswegen die Parteiensysteme die einschlägigen makrosoziologischen Cleavages zwischen Arbeit und Kapital, Stadt und Land, Peripherie und Zentrum sowie zwischen Religion und Laizismus reflektieren. Somit repräsentieren die politischen Parteien die gesellschaftlichen Konfliktparteien und es bilden sich stabile Bindungen zwischen den Parteien und den Wählergruppen (alignment). Diese Bindungen erodieren, wenn gesellschaftliche Prozesse bestimmte soziale Gruppen marginalisieren und auf diese Weise politische Marktlücken schaffen (dealigment), in die neue Politikunternehmer hineinstoßen, um neue politische Bindungen zu kreieren (realigment). ${ }^{11}$

Obwohl Gelegenheitsstrukturtheoretiker/innen einräumen, dass Strukturwandelprozesse sich nicht unmittelbar auf Politik auswirken und betonen, dass gesellschaftliche und kulturelle Trennungslinien erst dann zu politischen Konflikten werden, wenn sie politisiert werden, ${ }^{12}$ gehen sie doch davon aus, dass Strukturwandelprozesse neue politische Cleavages erzeugen und neue DealignmentRealigment-Prozesse auslösen. Der Strukturwandel ist die notwendige Bedingung für die Entstehung einer Gelegenheitsstruktur, die sich ein neuer Politikanbieter zunutze machen kann:

„Social movements are ultimately based on social and cultural cleavages. In other words, they have their origin in broad societal transformations that oppose social groups for structural and cultural reasons. These societal transformations determine structural and cultural potentials for mobilization by social movements. [...] Structure and culture do not impinge directly on politics. Social and cultural dividing lines - societal cleavages - only result in political cleavages, if they are politicized.“13

10 Vgl. ebd.: $27 \mathrm{ff}$.

11 Vgl. Martin 2000.

12 Vgl. Kriesi 1999a: 399.

13 Ebd. 
Damit ist die Makroebene der Mikroebene und die Nachfrageseite der Angebotsseite logisch vorgeordnet. Auf der Angebotsseite wird davon ausgegangen, dass ohne die entsprechende Marktlücke selbst der rhetorisch versierteste Populist keine Mobilisierungserfolge erzielen wird; auf der Nachfrageseite werden die politischen Präferenzen der Wähler aus der Zugehörigkeit zu sozialen Gruppen abgeleitet. Für Vertreter des Gelegenheitsstrukturansatzes lautet die zentrale Frage daher, durch welche übergeordneten gesellschaftlichen Prozesse, auf welchen Politikfeldern und anhand welcher Konfliktlinien sich jene Wählergruppe ausbildet, die sich von den etablierten Parteien entfremdet und nach dem Politikangebot der Populisten fragt.

Trotz der prinzipiellen Offenheit des Erklärungsmodells sind es aus Sicht der meisten Gelegenheitsstrukturtheoretiker/innen primär die wirtschaftliche Globalisierung und die Entstehung eines postindustriellen Kapitalismus, die den Mobilisierungserfolgen rechtspopulistischer Parteien zugrunde liegen. Die Gelegenheitsstrukturen resultieren also nicht aus dem politischen Prozess selbst, sondern aus vor- oder unpolitischen Vorgängen, die politische Systeme irritieren. So schaffe die Erosion nationaler Grenzen sogenannte ,Modernisierungsverlierer", soziale Gruppen, deren Marktposition sich verschlechtert hat und die sich als (potentielle) Verlierer wahrnehmen und pessimistisch, besorgt oder angstvoll in die Zukunft blicken. ${ }^{14}$ Angesichts der zunehmenden internationalen Konkurrenz fürchteten sie um ihre Arbeitsplätze, die Immigration ethnischer Minderheiten stelle ihre traditionellen Lebensstile in Frage, der Verlust nationalstaatlicher Autonomie und die Abgabe von Souveränitätsrechten an internationale Organisationen werde von ihnen als Bedrohung erfahren, da sie sich positiv mit dem Nationalstaat identifizierten. In einer Welt, in der nationalstaatliche Grenzen an Bedeutung verlören und die Nationalstaaten ihre Gestaltungsfähigkeit und Autonomie einbüßten, erhöhe sich das Mobilisierungspotential der nationalen Identität. ${ }^{15}$ Dabei sind es für Kitschelt und McGann in der Regel ältere blue-collarworker, Landwirte und Kleinunternehmer, die aufgrund ihrer berufsspezifischen Kommunikationserfahrungen und der Schwächung ihrer Marktposition in postfordistischen Gesellschaften dazu prädestiniert sind, rechtspopulistische Politikangebote nachzufragen. ${ }^{16}$

14 Zur Modernisierungsverliererthese vgl. Spier 2006 u. 2010.

15 Vgl. Kriesi 2002: 566.

16 Kitschelt und McGann postulieren, dass sich jene Berufsgruppen, die ihre Zukunft durch Modernisierungsprozesse des globalen Kapitalismus bedroht sehen, gegen einen aktiven Wohlfahrtsstaat sind, wohingegen jene Berufsgruppen, die optimistisch in die Zukunft blicken, Umverteilungspolitiken befürworten. Die Marktposition bestimmt 
In partieller Konkurrenz zu diesem sozioökonomisch fundierten Erklärungsansatz, führen jüngere Forschungsansätze den Aufstieg rechtspopulistischer Parteien auf die Tatsache zurück, dass die prägende ideologische Konfliktlinie westlicher Gesellschaften nicht mehr dem durch liberalkonservative und sozialdemokratische Volksparteien verkörperten Links-Rechts-Gegensatz folgt, sondern in zunehmendem Maße kulturell verfasst ist und zwischen einem libertäruniversalistischen Kosmopolitismus und einem traditionalistisch-partikularen Ethnonationalismus verläuft. ${ }^{17}$ Wie sich diese Verschiebung vollzieht, können diese Ansätze jedoch nicht erklären. Wenngleich sie angesichts der Persistenz dieser Konfliktlinie die Bedeutung der politischen Akteure gegenüber der gesellschaftlichen Struktur betonen, fungieren die vermeintlich vorpolitischen Prozesse innerhalb der gesellschaftlichen Basis nach wie vor als unabhängige Variable, von der sich politische Prozesse als mehr oder weniger verzerrte Oberflächenbewegungen ableiten. ${ }^{18}$

In beiden Ansätzen ist die diagnostizierte Lücke zwischen dem politischen Angebot und einer als gegeben erachteten politischen Nachfrage ausschlaggebend. Diese Lücke vergrößert sich, wenn die etablierten Parteien ideologisch und programmatisch konvergieren und beispielsweise darüber übereinkommen, dass die Globalisierung als quasi naturgegeben hinzunehmen sei, um allenfalls noch darüber zu streiten, wie ihre negativen Konsequenzen abzufedern seien. Besonders günstige Gelegenheiten bieten daher korporatistische und konkordanzdemokratische politische Systeme wie etwa die Niederlande, Belgien, Österreich

also über die Einstellung gegenüber der wohlfahrtstaatlichen Umverteilungspolitik. Die Kommunikationserfahrungen und -fähigkeiten korrelieren mit zwei entgegengesetzten Konzeptionen von Staatsbürgerschaft und zwei entgegengesetzten Modi kollektiver Entscheidungsfindung: Wohingegen sich kommunikative Berufsgruppen eher mit universalistisch-kosmopolitischen Staatsbürgerschaftskonzepten und egalitärdemokratischen Entscheidungsverfahren identifizierten, begrüßten weniger kommunikative Berufsgruppen partikular-kulturelle, identitäre und parochiale Staatsbürgerschaftskonzepte und hierarchisch-autoritäre Entscheidungsverfahren (Kitschelt/ McGann 1995: 46ff.).

17 Vgl. Taguieff 1994; zur wachsenden Prägekraft dieser von der Neuen Rechten in Anschlag gebrachten Konfliktlinie vgl. Betz 2003 u. 2004; Betz/Johnson 2004; Helbing 2011; sowie Bornschier 2010. In der Politologie ist in diesem Zusammenhang auch häufig von der Konfliktlinie „Öffnung vs. Abgrenzung“ die Rede (mit Bezug auf die Schweiz vgl. Brunner/Sciarini 2002; Bornschier/Helbing 2005: 32ff.).

18 Vgl. Bornschier 2009 u. 2010; Helbing 2011. 
oder eben die Schweiz, deren Funktionslogik die Kompromissfindung der politischen Eliten forciert. ${ }^{19}$

\title{
2.2 Populismusforschung OHNe, VolK'. GRENZEN DES GELEGENHEITSSTRUKTURANSATZES
}

\author{
„Die politische Wissenschaft wird aus einem \\ Willen zur ,Objektivierung' geboren, der ver- \\ gisst, dass es keine Elemente oder Elementar- \\ strukturen, keine Wesenheiten (Klassen oder \\ Klassensegmente), keine gesellschaftlichen Be- \\ ziehungen, keine ökonomische und technische \\ Bestimmung gibt, die ,vor' ihrer Formgebung \\ existierten.“
}

LEFORT 1990: 284

Die Stärke des Gelegenheitsstrukturansatzes besteht darin, dass er Makro- und Mikroebene aufeinander bezieht. Wenngleich Vertreter des Gelegenheitsstrukturansatzes von der Makroebene ausgehen, bringen sie keineswegs einen rigiden Strukturalismus in Anschlag, der den Aufstieg einer populistischen Partei deterministisch aus der Entstehung neuer Milieus, Schichten oder Klassen ableitet. Politik, der manifeste Konflikt zwischen zwei oder mehr kollektiven Identitäten, erscheint keineswegs als unmittelbare Folge beispielsweiser ökonomisch bedingter Entwicklungen und der latenten Interessengegensätzen, die sie hervorbringen. ${ }^{20}$ Der Gelegenheitsstrukturansatz legt vielmehr ein probabilistisches Modell zugrunde. Eine gesellschaftliche Gelegenheitsstruktur ist eine Marktlücke, die ein politischer Akteur programmatisch ausfüllen, aber eben auch verfehlen kann. Demnach ist der Erfolg einer populistischen Partei keine notwendige Folge, sondern eine ergriffene Chance. Denn um die Marktlücke auszunutzen, muss die sozialstrukturell bedingte Nachfrage auf Seiten der Wählerinnen und Wähler und das Angebot auf Seiten der politischen Herausforderer übereinstimmen oder zur Übereinstimmung gebracht werden. Den letzten Ausschlag gibt also die Ange-

19 Vgl. Taggart 1996; Decker 2012; mit Blick auf die Schweiz Geden 2006.

20 Zur Unterscheidung von „latenten Interessengegensätzen“ und „manifesten Konflikten“ vgl. Dahrendorf 1972: 47ff. 
botsseite - das politische Geschick, das rhetorische Talent und das Charisma der politischen Herausforderer.

Das Struktur-Akteurs-Modell ermöglicht somit eine gewisse Flexibilität in der Analyse politischer Phänomene. Wenn die Gelegenheitsstrukturen günstig sind und dennoch keine machtvollen populistischen Parteien entstehen, dann mangelt es den Herausforderern an politischem Geschick. Wenn trotz vergleichsweise ungünstiger Gelegenheitsstrukturen populistische Parteien reüssieren, dann ist dies dem außerordentlichen Talent ihrer Führungsfiguren geschuldet. Anstatt das unerwartete Scheitern respektive den überraschenden Erfolg einer populistischen Partei genauer zu analysieren, wird den Akteuren mehr Bedeutung zugesprochen. Dabei bedienen sich Gelegenheitsstrukturtheoretiker/innen meist des Konzepts der charismatischen Herrschaft, um die in ihrem Modell unerklärten Aspekte populistischer Erfolge zu begreifen. Sie führen damit ein Konzept ein, das nicht weiter erläuterungsbedürftig scheint, im Grunde aber inkompatibel mit dem zugrunde gelegten Marktmodell von Politik und seinem axiomatischen Ausgangspunkt, dem rationalen, nutzenmaximierenden Wähler ist.

Das Problem mit dieser Perspektivierung des Populismus besteht nicht darin, dass sich hierfür keine empirischen Indizien finden ließen. Sozioökonomische Transformationsprozesse stellen eine wichtige Vorbedingung des Populismus dar. Der ökonomische Strukturwandel schafft neues Protestpotential. Er marginalisiert ehedem privilegierte soziale Gruppen und sorgt für soziale Unzufriedenheit und Selbstwertverlust bei den Betroffenen. Folglich sind bestimmte Schichten und Milieus in der Wählerschaft rechtspopulistischer Parteien überproportional häufig vertreten. ${ }^{21}$ Dass sich die Unterstützung rechtspopulistischer Bewegungen als politische Reaktion derjenigen verstehen lässt, die als Verlierer aus Postindustrialisierungsprozessen hervorgehen, konnte vielfach empirisch belegt werden. ${ }^{22}$ Dass der Aufstieg des Rechtspopulismus mit der Virulenz eines kulturell geprägten Konfliktes zwischen einem kosmopolitischen Liberalismus und einem kommunitaristischen Ethnonationalismus in Verbindung steht, konnte ebenfalls gezeigt werden. ${ }^{23}$

Die Defizite des Gelegenheitsstrukturansatzes sind theoretischen Ursprungs. Sie gründen darin, dass der Populismus als „Ideologie oder Mobilisierungstyp einer bereits existierenden Gruppe ${ }^{624}$ gerahmt wird. Zwar begreifen Gelegen-

21 Vgl. etwa Rydgren 2004; Spier 2006 u. 2010.

22 Vgl. exemplarisch die Arbeiten des Politologen Tim Spier (2006 u. 2010).

23 Vgl. Betz 2004.

24 Laclau 2005a: 72. 
heitsstrukturtheoretiker/innen politische Phänomene nicht kausaldeterministisch, als notwendige Folgen basaler gesellschaftlicher Entwicklungen, doch lesen sie diese als Folgen tieferliegender gesellschaftlicher Ursachen, die von ihrer oberflächlichen, politisch-ideologischen Form, dem Phänomen Populismus, zu unterscheiden sind. Diese rigide Trennung zwischen einer objektiven sozialstrukturellen Basis (den sozialen Klassen, Ethnien, Geschlechtern, Schichten, den vielfältigen Milieus und Lebensstilgruppen mit ihren disparaten Präferenzen) und der politisch-ideologischen Form (der rhetorisch imaginierten Scheinwelt des, Volkes', der ,einfachen Leute' und des ,kleinen Mannes') läuft darauf hinaus, dass das politische Phänomen ,Populismus' und seine Anrufung eines klassen-, schichten- und milieuübergreifenden popularen Kollektivs nur als ideologische Verzerrung konzipiert werden kann. ${ }^{25}$ Angesichts der empirisch diagnostizierten Pluralisierungs- und Differenzierungsprozesse moderner Gesellschaften kann die Quintessenz des Populismus, der diskursiv konstruierte Gegensatz zwischen ,Volk' und ,Establishment', der in Form einer polarisierten Gesellschaft sedimentiert, nur als anachronistisches Zerrbild wahrgenommen werden, das die vielfältigen echten Konflikte zwischen den objektiven Gruppen der Gesellschaft in einen unechten Konflikt transformiert. ${ }^{26}$ Die Marginalisierung des Populismus gründet also auf der normativistischen Setzung ,,archimedischer Punkte ${ }^{\text {(27 }}$, die legitime, pluralistische von illegitimen, dichotomisierenden Formen der politischen Repräsentation von Gesellschaft unterscheiden und den Populismus als das deviante, irrationale und pathologische Andere der Politik der etablierten Parteien erscheinen lassen.

„If populism is described merely in terms of ,vagueness', ,imprecision', ,intellectual poverty', purely ,transient', as a phenomenon, ,manipulative“ in its procedures, and so on, there is no way of determining its differentia specifica in positive terms. The whole exercise seems to aim, in the contrary, at separating what is rational and conceptually compre-

25 Kritisch zur Abwesenheit des Volkes in der Politischen Theorie vgl. Canovan $1999 \mathrm{u}$. 2004: insb. 247.

26 So postuliert etwa Oliver Schmidtke (1996: 46) im Rahmen seiner Analyse des politischen Aufstieges der Lega Nord und der Südtiroler Volkspartei, dass „die populistische Agenda als solche über keinen tragbaren Vorschlag verfüge, wie man erfolgreich mit der Komplexität moderner Gesellschaft umzugehen hat“. Die Unterscheidung zwischen echten und unechten Konflikten geht zurück auf Coser 1972.

27 Marchart 2007: 155. 
hensible in political action from its dichotomic opposite: a populism conceived as irrational and indefinable. “28

Der Populismus verweist auf die Grenze des differenzierungstheoretischen Realismus $^{29}$ und des einschlägigen aggregativen Politikmodells, das die Form politischer Kämpfe aus ,objektiven' gesellschaftlichen Strukturen und gruppenspezifischen Interessen- und Wertgegensätzen ableitet. Wenn dieses Basis-ÜberbauModell wie im Fall des Populismus an der Erklärung der politischen Wirklichkeit scheitert, dann ist nicht das Politik- und Gesellschaftsmodell das Problem, sondern das Phänomen, das die Grenzen dieses Modells vor Augen führt.

\subsection{Plädoyer für einen Paradigmenwechsel IN DER ERFORSCHUNG POPULISTISCHER PARTEIEN}

Folglich blockiert die Konzeption von Politik in Analogie zum Markt nicht nur die Formulierung eines positiven Populismusbegriffs. Anhand populistischer Projekte lässt sich auch zeigen, inwiefern ein markttheoretisches, aggregatives Politikmodell daran scheitert, eine adäquate Vorstellung von Politik und politischer Repräsentation zu generieren. Zwar räumen Gelegenheitsstrukturtheoretiker/innen ein, dass populistische Parteien an der Restrukturierung politischer Räume und der Konstruktion neuer gesellschaftlicher Konfliktlinien beteiligt sind, ${ }^{30}$ doch sind sie nicht in der Lage, diese sozial performative Dimension des Populismus zu erfassen.

Das Angebot-Nachfrage-Modell entbehrt einer Theorie, die politische Willens- und Identitätsbildungsprozesse in den Blick zu nehmen vermag. Es erfasst nicht, wie populistische Bewegungen den Willen einer sozial heterogenen Wählerschaft artikulieren, wie sie gesellschaftliche Cleavages modellieren und neue politische Identitäten schaffen. ${ }^{31}$ Es ist zwar richtig, dass der Aufstieg populisti-

28 Laclau 2005a: 15.

29 Diesen Begriff habe ich bereits im Einleitungskapitel eingeführt.

30 Vgl. exemplarisch Helbing 2011: insb. 14f.

31 Willens- und Identitätsbildungsprozesse werden von Gelegenheitsstrukturtheoretiker/innen wenn überhaupt in implizitem Anschluss an den Erfahrungsbegriff der mikrosoziologischen Interaktionstheorie Randall Collins (2000, zsf. Rössel 2008) theoretisiert. So erklären beispielsweise Herbert Kitschelt und Anthony McGann (1995) die Korrelation zwischen der Präferenz gegenüber autoritären Politikangeboten und soge- 
scher Parteien nicht ohne Gelegenheiten gedacht werden kann. Der Versuch, den Populismus sozialstrukturell zu definieren und den Antagonismus zwischen ,Volk` und ,Establishment‘ auf grundlegende Interessen- und Wertgegensätze zwischen präkonstituierten Gruppen zurückzuführen, scheitert jedoch. Um diese Blockade zu lösen, muss das Verhältnis zwischen gesellschaftlichen Gruppen und politischer Repräsentation in anderer Weise konzipiert werden.

Das bedeutet nicht, dass diese Perspektive aufgegeben werden sollte. Wer ein nomothetisches Erkenntnisinteresse verfolgt und nach den Bedingungen für die anhaltenden Wahlerfolge rechtspopulistischer Parteien fragt, wird auf marginalisierte Gruppen und neue Konfliktlinien stoßen, von denen diese Parteien profitieren. Das Erkenntnispotential des Gelegenheitsstrukturansatzes ist jedoch limitiert. Denn einer wählersoziologischen Perspektive, die gruppenspezifische Einstellungen als kleinste Analyseeinheiten zugrunde legt, entgehen die Konstruktionen der Konfliktlinien, die für populistische Konfigurationen konstitutiv sind.

Ein adäquates Verständnis dieser Konstruktionen lässt sich nur entwickeln, indem der Populismus im Rahmen eines kultursoziologischen Forschungsprogramms betrachtet wird, das Identitäten nicht als fixierte Essentiale und vorgängige Ausgangspunkte politischer Diskurse, sondern als deren Effekte betrachtet. $^{32}$ Aus einer solchen Perspektive entspringt der populare Widerstand nicht einer gegebenen, politisch erweckten Identität. Eine widerständige populare Identität ist vielmehr das Produkt politischer Artikulationen. Demnach spiegelt die Unterscheidung zwischen ,Volk' und ,Establishment‘ nicht etwa eine vorperforierte Konfliktlinie zwischen ökonomisch, ethnisch oder religiös definierten Identitäten. Die Konfliktlinie ,Volk/Establishment‘ muss als Subjektivierungsleistung eines performativ wirksamen Diskurses verstanden werden, der die potentiell antagonistischen Differenzen zwischen Klassen, Geschlechtern, Generationen, Milieus, Schichten und Lebensstilgruppen provisorisch transzendiert,

nannten blue-collar-Berufen aus deren arbeitsweltlichen Kommunikationserfahrungen. Willens- und Identitätsbildung werden hier nicht als kontingente (und infolgedessen macht- und entscheidungsimmanente) Prozesse theoretisiert. Vielmehr wird das strukturalistische Modell mikrosoziologisch unterfüttert und als Kristallisationspunkt von Interaktionsritualen betrachtet.

32 Für eine Grundlegung dieses Forschungsprogramms vgl. Hall 1994b; Marchart 2008; Moebius 2009; Reckwitz 2000; Wimmer 2005. 
indem er ein vermeintlich tieferliegendes, originäres Konfliktverhältnis konstruiert. $^{33}$

Infolgedessen ist die kulturelle Cleavage zwischen einem libertären Kosmopolitismus und einem ethnisch geprägten Kommunitarismus, mit der rechtspopulistische Parteien politisieren, nicht einfach ein gegebenes Faktum, eine unabhängige Variable, sondern das Resultat eines politischen Projekts. Aus dieser Perspektive lässt sich beschreiben, wie diese kulturalistische Cleavage zu einer der prägenden Konfliktlinien westlicher Gesellschaften avancierte, auf welche Weise sie die Differenzen anderer Konfliktlinien synthetisiert, wie aus diesem Prozess der Desartikulation-Reartikulation von Gesellschaft ein bestimmtes ,Volk' hervorgeht und welche alternativen Konstruktionen des ,Volkes' ausgeschlossen werden.

33 So wird die soziale Ungleichheit, die im Diskurs der Modernisierungsverliererthese etwa als „Modernitätsrückstand“ oder als „,soziales Kompetenzdefizit“ definiert wird (Kaschuba 1995: 83), in populistischen Diskursen als Symptom eines allgemeinen Unterdrückungsverhältnisses diskursiviert. 


\section{Konzeptuelle Vorbemerkungen: Identität und Hegemonie}

Die Vertreter des Gelegenheitsstrukturansatzes behandeln soziale Identitäten als explanans von Politik. Identität wird entweder aus sozialpsychologischen Willensbildungsprozessen erklärt, aus basalen Klassen- oder Schichtenzugehörigkeiten abgeleitet oder aber als empirisch beobachtbare Tatsache schlichtweg vorausgesetzt. Demgegenüber begreife ich soziale Identität als explanandum. Ich interessiere mich für die diskursive Konstruktion einer kollektiven Identität, die sich in Opposition zu einem ,Establishment" wahrnimmt und in der SVP die Repräsentantin ihres Willens erkennt. Es geht um die ideologische Führung, um die von Blocher \& $\mathrm{Co}^{1}$ ausgeübte Hegemonie, die in einer bestimmten Identität des Schweizervolkes kristallisiert.

Die beiden konzeptuellen Eckpfeiler meiner Populismusanalyse lauten also Identität und Hegemonie, wobei der Identitätsbegriff den Forschungsgegenstand definiert, der Hegemoniebegriff einen theoretischen Scheinwerfer liefert, der diesen Gegenstand auf spezifische Weise ausleuchtet. Bevor ich meine theoretische Perspektive systematisch entfalte, möchte ich daher einige Vorbemerkungen zu den beiden Schlüsselbegriffen Identität und Hegemonie vorausschicken.

\subsection{DER ForsChUNGSgEgENSTAND: IDENTITÄT}

Unter Identität wird im Allgemeinen eine relativ dauerhafte Instanz verstanden, die ,disparate Selbst- und Welterfahrungen, Selbst- und Fremdentwürfe, Erwar-

1 Um Missverständnisse zu vermeiden, sei hier gleich erwähnt, dass auch diese Führungsfiguren als Führungsfiguren diskursiv konstruiert sind und keineswegs den Diskurs von außen organisieren. 
tungen und kulturelle Rollenvorgaben“" ${ }^{2}$ homologisiert und auf diese Weise ein konstantes und kohärentes Selbstbild herstellt. Während die dominanten soziologischen Identitätstheorien bis etwa 1970 den Identitätsbegriff als „konstante Subjektstruktur ${ }^{\text {‘s }}$ konzipierten, wird der Begriff heute in der Regel konstruktivistisch verstanden. Identität bezeichnet ein kontingentes, regelhaftes Selbstverstehen. Diese Bedeutungsverschiebung basiert darauf, dass Identität nicht mehr an die Vorstellung eines invariablen, essentiellen Kerns geknüpft, sondern als sozial konstruierte, prozesshafte Institution gedacht wird. ${ }^{4}$ Eine Identität ist ein veränderbarer und sich permanent verändernder „Entwurf ${ }^{45}$, der nicht etwa auf Einheitlichkeit gründet, sondern Einheitlichkeit schafft, indem er fortlaufend unterschiedliche Merkmale zueinander in Beziehung setzt und sinnhaft ordnet. Identitäten erscheinen als ,instabile Identifikationspunkte“6 eines Selbst; es handelt sich um temporäre „Nahtstellen, die innerhalb des Diskurses über Geschichte und Kultur gebildet werden“"

Die Entstehung und Modifikation von Identitäten lassen sich zwar an gewisse Ereignisse rückkoppeln, doch sind Identitäten weder ephemere noch situative Phänomene. Trotz ihrer Wandelbarkeit zeichnen sie sich durch eine gewisse Kontinuität aus. Identität verweist auf eine ,gewisse Selbigkeit im Lauf der Zeit, eine gewisse Dauerhaftigkeit [...], während andere Dinge sich verändern“ ${ }^{\star 8}$. Dabei ist der Identitätsbegriff nicht auf konstante Semantiken beschränkt. Denn identitäre Selbstbeschreibungen sind nicht zwangsläufig stabil; Subjekte können sich auch als Teile einer veränderbaren, sich entwickelnden Gemeinschaft oder als Avantgarde einer dialektisch voranschreitenden Geschichte identifizieren. ${ }^{9}$

Kollektive Identitäten vermitteln ein situationsenthobenes, mitunter belastbares Zugehörigkeitsgefühl, einen robusten „Gemeinsamkeitsglauben“"10, der sich in Form affektiv besetzter Welt- und Selbstanschauungsgemeinschaften manifes-

2 Vgl. Horatschek 2005: 71. Für eine allgemeine Bestimmung des Identitätsbegriff vgl. Rosa 2007; kritisch vgl. Brubaker/Cooper (2007), die das Allzweckwort ob seiner hoffnungslosen Vieldeutigkeit zurückweisen und durch eine (inter-)subjektive bzw. handlungszentrierte Begriffsarchitektur ergänzen wollen.

3 Vgl. Reckwitz 2001: 29 u. 33.

4 Vgl. Rosa 2007: 47ff.

5 Hall 1994c: 182.

6 Hall 1994a: 30.

7 Ebd.

8 Brubaker/Cooper 2007: 62.

9 Vgl. Reckwitz 2010: 46.

10 Weber 1972: 237. 
tiert. Im Unterschied zu sozialen Gruppen setzen sich Identitäten weder aus konkreten Individuen zusammen, noch geht ein Individuum in einer kollektiven Identität vollkommen auf. Individuen bzw. Subjekte sind vielmehr von vielfältigen, mitunter konkurrierenden oder gar widersprüchlichen Identitäten durchzogen, die in spezifischen Kontexten handlungswirksam werden. ${ }^{11}$

Gesellschaftlich und politisch relevant sind Identitäten, weil sie als kontingenz- und komplexitätsbewältigende „Sinnplombe[n]“12 fungieren. Identitäten beziehen spezifische Forderungen, Erwartungen, Traditionen, Interessen, Ziele und Ideologien aufeinander. Sie plausibilisieren bestimmte Denk- und Handlungsweisen und blenden mögliche Alternativen aus. Identitäten implizieren Ideologien und Deutungsmuster, die nicht nur unsere Perzeptionswirklichkeit im engen Sinn, das Wissen über die Gegenstände und Zusammenhänge unserer Umwelt, sondern auch das Wissen über uns selbst und unsere Stellung in der Welt organisieren. ${ }^{13}$ So vermitteln Identitäten spezifische Formen der Selbsthermeneutik, regelhafte Modi des Selbstverstehens, die soziales Handeln informieren, sinnhaft anleiten, normieren und bestimmte Erwartungen und Erwartungssicherheiten etablieren. ${ }^{14}$ Subjekten dienen sie als Schablonen, durch die sich diese als kohärente, selbst identische Individuen vorstellen. Sie sorgen dafür, dass sich Subjekte mit den einen dissoziieren, mit den anderen assoziieren und auf diese Weise stabile und solidarische Kollektive konstituieren.

Demzufolge wirken Identitäten praxisleitend. Jedoch handelt es sich bei dem Zusammenhang von Identität und Praxis keineswegs um ein Bedingungsverhältnis zwischen einer unabhängigen Variablen (der Identität X) und einer abhängigen Variablen (Handlung Y). Identitäten und soziale Praktiken konstituieren sich wechselseitig. Denn, wie wir noch sehen werden, sollten Identitäten nicht als vollkommen fixierte Einheiten vorgestellt werden. Vielmehr werden sie durch soziale Praktiken angeeignet, reproduziert und stabilisiert oder aber irritiert, verschoben und modifiziert.

11 Vgl. Rosa 2007: 49ff.

12 Claussen 1993: 5.

13 Zum Begriff der Perzeptionswirklichkeit vgl. Patzelt 2003: 42.

14 Den Begriff der Selbsthermeneutik übernehme ich an dieser Stelle von Andreas Reckwitz (2010: 45f. u. 2001: 31), der diesen als Definiens des Identitätsbegriffs im Anschluss an Charles Taylor einführt. 


\subsection{Der sozialtheoretische Scheinwerfer: HEGEMONIE}

Unter Hegemonie wird im Allgemeinen ein Herrschaftsverhältnis verstanden, das nicht primär auf physisch-materieller Überlegenheit, sondern auf Deutungsmacht beruht. Im Unterschied zu Herrschaftsformen, die auf Gewalt und Zwang gründen, zehren hegemoniale Verhältnisse vom Legitimationsglauben der Untergeordneten. Das Konzept wurde in erster Linie durch den italienischen Marxisten Antonio Gramsci begründet. In den 1970er Jahren avancierte es zu einer zentralen Analysekategorie des sogenannten Kulturmarxismus und der entstehenden Cultural Studies, fand aber auch Eingang in die Internationale Politik. ${ }^{15}$

Entgegen der mit Machiavelli, Hobbes und Weber assoziierten Tradition konzipiert Gramscis Hegemoniebegriff Herrschaft nicht als repressive, asymmetrische Institution, sondern als konsensuales, intersubjektives Verhältnis. Diese Konzeption von Herrschaft impliziert zwei fundamentale Aspekte: Zum einen ist Hegemonie im Unterschied zu Sanktionsmacht, die sich monopolisieren lässt, niemals absolut und unangefochten, sondern immer graduell und umkämpft. Hegemonie kann man nicht besitzen. Der Begriff bezeichnet ein „Verhältnis““16, innerhalb dessen man sich positionieren und Stellung beziehen kann. Zum anderen zeichnet sich ein hegemoniales Verhältnis dadurch aus, dass die Beherrschten dem Hegemon nicht etwa aus Furcht vor Strafe, sondern aus freien Stücken, als ,überzeugte Anhänger' folgen. Hegemonie meint daher weniger Beherrschung, als vielmehr Führung und Erziehung zur Folgsamkeit. Sie wird nicht in erster Linie durch Institutionen der politischen Gesellschaft im engen, gewaltmonopolistischen Sinn, sondern innerhalb der Zivilgesellschaft (durch Intellektuelle, Journalisten, Schulen, Kirchen, Gewerkschaften, Vereine, Künstler und Blogge-

15 Exemplarisch für die Gramsci-Rezeption und die Reartikulation des Hegemoniebegriffs der Cultural Studies vgl. Hall 2002; sowie Marchart 2008: 76ff. Zur Einbettung des Hegemoniebegriffs in die Internationale Politik vgl. Keohane/Nye 1977: insb. 44; Keohane 1984: 44f. Die beiden US-amerikanischen Politologen leiten aus dem Hegemoniebegriff ihre Konzeption von soft power ab. Wie ein hegemoniales Verhältnis gründet weiche Macht nicht auf militärischer und wirtschaftlicher Überlegenheit bzw. Zwangsgewalt, sondern auf der Anerkennung und freiwilligen Aneignung der Werte und Lebensstile, die der Hegemon repräsentiert.

16 Marchart 2008: 79. Insofern ist dem Hegemoniebegriff Gramscis dieselbe Stoßrichtung immanent wie dem Machtbegriff Foucaults (vgl. hierzu Mouffe 1979: insb. 201). 
rinnen) ausgeübt. ${ }^{17}$ Als hegemonial lässt sich eine Herrschaftsform dann bezeichnen, wenn es ihr gelingt, die ideologischen Ressourcen, von denen ihre Legitimität abhängt, $\mathrm{zu}$ reproduzieren und $\mathrm{zu}$ naturalisieren. Hierfür wiederum muss sie gegenhegemoniale Interventionen peripherisieren, als illusorisch, irrational und kurzsichtig brandmarken und schließlich undenkbar machen.

Damit nimmt Gramsci zwei grundlegende Verschiebungen innerhalb der marxistischen Theoriebildung vor: ${ }^{18}$ Erstens denkt er die Zivilgesellschaft als eine weitgehend autonome Sphäre und distanziert sich somit von der materialistischen Sozialtheorie des orthodoxen Marxismus, die den ideologisch-politischen Überbau kausaldeterministisch aus der ökonomischen Basis ableitet. Zweitens räumt er innerhalb des Überbaus der ,weichen', zivilgesellschaftlichen Willensbildung ein Primat gegenüber der ,harten“ Zwangsgewalt der repressiven politischen Gesellschaft ein. ${ }^{19}$

Die insbesondere für die Cultural Studies wegweisende Innovation seines Denkens besteht indes darin, dass hegemoniale Verhältnisse im Unterschied zu schlichten Allianzen sozialtransformativ wirken. Dadurch dass sie eine Vielzahl heterogener Willen auf ein und dasselbe Ziel vereinen, verformen sie die Identitäten der involvierten Gruppen. ${ }^{20}$ Sie verschweißen singuläre, „korporatistische“

17 Gramsci Staatsbegriff unterscheidet zwischen der politischen Gesellschaft (società politica), den machtmonopolistischen staatlichen Institutionen einerseits und der Zivilgesellschaft (società civile), in der argumentativ um Konsens und Zustimmung gekämpft wird, andererseits. Aus seiner Sicht waren staatliche Zwangsgewalt und zivilgesellschaftliche Ideologie in den hochindustrialisierten Staaten West- und Mitteleuropas (im Unterschied zum vorrevolutionären, zaristischen Russland) zu ,integralen Staaten“, d.h. konsolidierten, soliden Herrschaftskomplexen verschmolzen. Zum Staatsbegriff Antonio Gramscis vgl. Demirovic 2007; Bieling 2006.

18 Vgl. Bobbio 1988: 85f. u. 88f.

19 Diese Sensiblität für die kulturelle Komponente der bürgerlichen Herrschaft sollte die Fortschreibung der marxistischen Theoriebildung in der zweiten Hälfte des 20. Jahrhunderts nachhaltig beeinflussen. In der Tradition Gramscis steht etwa Louis Althusser in seinem berühmten Aufsatz „Ideologie und ideologische Staatsapparate“ (1977), in dem er die Frage nach der ideologischen „Reproduktion der Produktionsbedingungen" stellt und insbesondere die Schule als Ort der bürgerlichen Sozialisation in den Blick nimmt.

20 Für einen sozialwissenschaftlich anschlussfähigen Transzendenzbegriff vgl. Patzelt 2013a u 2013b. Transzendenz wird dort, in impliziter Analogie zum Hegemoniebegriff Laclau/Mouffes, als allgemeines Konstruktionsprinzip von Gemeinsinn konzipiert. 
Interessen zu „,historischen Blöcken“, zu sozialen Formationen, die sich anhand „organischer Ideologien“ als homogene, politisch handlungsfähige Kollektivakteure identifizieren. Diese Blöcke zielen darauf, das „Nationalpopulare“ synekdochisch zu repräsentieren, die Identität von Nation und Volk nach ihrem ideologischem Vorbild zu hegemonisieren. ${ }^{21}$

Zentral für den Hegemoniebegriff Gramscis sind insofern zwei Aspekte: Erstens verschmelzen hegemoniale Prozesse partikulare Interessen mit universellen, allgemeingültigen Zielen: Eine politische Partei zielt etwa darauf, Universalien wie Fortschritt, Emanzipation, Vernunft, Gerechtigkeit, Nachhaltigkeit, Freiheit, Gleichheit oder ,das Volk` zu repräsentieren. Hegemonietheoretische Perspektiven denken das Partikulare und das Universelle daher nicht als separierte Sphären, die „durch die erlösende Rationalität der Aufhebung und der Transzendenz ${ }^{622}$ zusammenzuführen seien. Sie positionieren sich in einen Zwischenraum und fragen nach dem umkämpften Verhältnis des Partikularen und des Universellen sowie nach dem Gewordensein universeller und partikularer Semantiken. ${ }^{23}$ Wenn im Folgenden von universellen Semantiken, Universalisierungsleistungen oder -prozessen die Rede ist, wird damit nicht auf eine grundlegende oder übergeordnete Ebene angespielt, die der gesellschaftlichen Aktualität zugrunde läge und durch Abstrahierungen zu erreichen sei, sondern auf eine pragmatische und graduelle Universalität, die beispielsweise die allgemeinere Bedeutung einer konkreten Situation fixiert, indem sie ein ursächliches Übel konstruiert.

Zweitens bezeichnet Hegemonie ein Prinzip sozialer Ordnungsstiftung, in dem Herrschaft und Konsens fusionieren. Der Begriff unterläuft insofern die klassische machttheoretische Unterscheidung zwischen einer befähigenden ,power to', der Arendt'sche Tradition, und einer sanktionierenden ,power over', der Weber'schen Tradition. ${ }^{24}$ Während diese Klassifikation zwischen einer symmetrischen, konsensual organisierten Macht, die es ermöglicht, gemeinsame Ziele zu erreichen, und einer asymmetrischen, auf physischer Superiorität gegründeten Macht, die der Durchsetzung partikularer Interessen dient, unterscheidet, verschränkt der Hegemoniebegriff Macht und Herrschaft mit Konsens und Legitimität. ${ }^{25}$ Macht und Konsens werden nicht als zwei diametral entgegenge-

21 Vgl. Marchart 2008: 81.

22 Bhabha 2000: 39.

23 Vgl. exemplarisch Laclau 2007a: 45ff.

24 Vgl. Lluis Martell 2013: 20, FN 16; zur Unterscheidung zwischen ,power to“ und ,power over' vgl. Imbusch 1998: 10ff.

25 So argumentiert etwa Mouffe (2008: 102) gegen Habermas, „dass es keinen unüberwindbaren Graben zwischen Macht und Legitimität gibt - offensichtlich nicht in dem 
setzte Modi sozialer Ordnungsstiftung konzipiert: Macht beginnt nicht dort, wo Konsensualität aufhört; Konsensualität ist niemals frei von Macht. Hegemonietheoretische Ansätze blenden Macht und Konsens ineinander. ${ }^{26}$ Ihnen geht es um die konsensuale Organisation von Machtverhältnissen und die machtvolle Organisation von Konsensualität. Sie führen zu Politik- und Machtbegriffen, die sich weder auf die repressiven Mittel der Staatsgewalt noch auf ein autopoietisches Subsystem der Gesellschaft reduzieren lassen, sondern - im Sinne Foucaults alle Ebenen und Teilgebiete des Sozialen durchziehen. ${ }^{27}$

\subsection{EINE HEgEMONIETHEORETISCHE KONZEPTION DES IDENTITÄTSBEGRIFFS}

Die dominanten Wissensbestände und Deutungsmuster, anhand derer Subjekte sich selbst identifizieren, müssen folglich als kontingente Produkte einer produktiven Macht dechiffriert werden. Der Hegemoniebegriff bricht mit konventionellen Identitätssemantiken. ${ }^{28}$ Soziale Identitäten werden weder nach orthodox marxistischen oder biologistischen Mustern aus einer basalen oder natürlichen Essenz deduziert, noch als Ausdruck einer mikrologischen, „interpretativreflexiven Selbstrepräsentation“ ${ }^{29}$ vorgestellt und auch nicht als Ergebnis einer intersubjektiven, konsensorientierten Verständigung einer Diskursgemeinschaft gedacht. Vielmehr werden Identitäten als temporäre Effekte von Repräsentationsleistungen rekonstruiert, die bestimmte Identitätsangebote plausibilisieren oder gar universalisieren, andere dagegen negieren. So wird beispielsweise das ,Schweizervolk،, auf dessen Identität das Authentizitätspostulat der SVP grün-

Sinne, dass alle Macht automatisch legitim wäre, sondern in dem Sinne, dass (a) jede Macht, die sich durchzusetzen imstande war, dies deshalb konnte, weil sie von manchen Gruppen als legitim anerkannt wurde; und (b) jede Legitimität, insofern sie auf keinen aprioristischen Grund basiert, auf irgendeiner Form erfolgreicher Macht basiert."

26 Hierin gründet die Antinomie zwischen der deliberativen Demokratietheorie Jürgen Habermas' und der agonistischen Demokratietheorie Chantal Mouffes (vgl. Mouffe 2008: 85).

27 Zur Wahlverwandtschaft des Foucault'schen Machtbegriffs und der Hegemonietheorie Gramscis vgl. Mouffe 1979: insb. 201.

28 Für einen Überblick über konkurrierende Identitätssemantiken vgl. Reckwitz 2001.

29 Vgl. Reckwitz 2008a: 80. 
det, nicht als objektiv gegebene Entität, sondern als hybride Identität vorgestellt, die vielfältige Elemente, Diskursstränge und Traditionen zusammenfügt und andere verwirft. ${ }^{30}$ Gesellschaften entpuppen sich somit gerade nicht als willfährig pluralistisch. Stattdessen heben hegemonietheoretisch inspirierte Arbeiten hervor, dass jenseits eines oberflächlichen Werte- und Interessenpluralismus die Kontingenz möglicher Identifikationen machtvoll begrenzt wird.

Damit setzt das Hegemoniekonzept Politik und Identität in ein reziprokes Verhältnis. Identitäten erscheinen nicht nur als politisch relevante Gegenstände, wie etwa in der traditionellen Erforschung politischer Kulturen, ${ }^{31}$ sondern auch als politisch geformte Gegenstände - und zwar gerade dann, wenn sie von ihren Trägerinnen und Trägern als unverfälschter Ausdruck tiefster Individualität oder eines unerschütterlichen, natürlichen Wesens konzipiert werden.

Im Rahmen einer hegemonietheoretischen Perspektive fungiert der Identitätsbegriff somit als „,sekundärer Schlüsselbegriff ‘ ${ }^{32}$. Identitäten sind „Fluchtpunkte ${ }^{633}$, auf die Hegemonien abzielen. Um möglichst breite Kollektive wie Nationen, Völker oder Milieus zu konstituieren, verflechten Hegemonien unterschiedliche Elemente zu kohärenten Einheiten. Die Stärke des Hegemoniebegriffs besteht somit darin, dass er ein nicht-substantialistisches und dennoch starkes Konzept von Identität auf den Weg bringt. Er erlaubt es, Kollektividentitäten zu denken, die von Subjekten als Heimstätten ihrer selbst wahrgenommen, angeeignet, affektiv besetzt und verteidigt werden, ohne in Gefahr zu geraten, deren innere Differenzen a priori als oberflächlich, nachgeordnet oder transient zu marginalisieren. Der Hegemoniebegriff versetzt uns daher in die Lage, sowohl die Robustheit und die Kontinuation als auch die Dissolution und die Reorganisation sozialer Identitäten zu analysieren.

Seine volle theoretische Tragweite und sein analytisches Potential entfaltet der Hegemoniebegriff indes erst dadurch, dass Laclau und Mouffe ihn mit einem poststrukturalistischen Diskursbegriff verknüpfen. Denn erst im Zuge dieser Verknüpfung gelingt es, die „Reziprozität von Identität und Alterität bei der Genese kollektiver Identität in den Blick zu nehmen ${ }^{\text {‘34 }}$ und Identitäten als Effekte von Macht und Ausschluss zu dechiffrieren. Vor diesem Hintergrund ist Identitätspolitik nicht bloß die Aggregation einer vorgängigen, wesenhaften Diversität,

30 Zum Konzept der Hybridität vgl. Bhabha 2000: insb. 29ff.; Reckwitz 2010: insb. 81ff.

31 Vgl. Almond/Verba 1963; eine prägnante Einführung in dieses Konzept politischer Kultur findet sich etwa bei Patzelt 2003: 325ff.

32 Reckwitz 2008a: 80.

33 Reckwitz 2006: 346.

34 Horatschek 2005: 71. 
sondern eine politische „Positionierung ${ }^{\text {(35 }}{ }^{3}$ innerhalb einer kontingenten, machtvoll instituierten Struktur, die eine vermeintlich vorgängige, wesenhafte Diversität als Differenz erst herstellt. ${ }^{36}$

35 Vgl. Hall 1994a: 30. Hall spricht von Identitätspolitik genau genommen als einer „Politik der Positionierung".

36 Zur konzeptionellen Unterscheidung von Diversität und Differenz vgl. Bhabha 2000: $51 \mathrm{f}$. 



\section{Antagonistische Ordnungen. Ernesto Laclaus und Chantal Mouffes poststrukturalistische Diskurstheorie des Sozialen}

Laclau und Mouffe überführen die Diskurstheorie in eine allgemeine Sozialtheorie, die einen außer-diskursiven Referenzpunkt als Fundament von Gesellschaft und Politik negiert. ${ }^{1}$ Anstatt einen Grund zu präsupponieren, von dem sich allgemeingültige Teilungs- und Organisationsprinzipien des Sozialen ableiten ließen, postulieren sie, dass kontingente Wir-Sie-Unterscheidungen konstitutiv für die Hervorbringung und Stabilisierung sozialer Ordnungen sind. Ihre theoretische Perspektive emergiert am Schnittpunkt von Poststrukturalismus und Kulturmarxismus. So werden Antonio Gramscis Hegemoniebegriff, die Semiotik de Saussures, der Diskursbegriff Foucaults, die Dekonstruktion Derridas und die psychoanalytische Subjekttheorie Lacans in einer antiessentialistischen Begriffsarchitektur zusammengefügt, die auf die Irreduzibilität der Macht- und Konfliktgeladenheit von sozialen Ordnungen insistiert.

Das folgende Kapitel führt in die zentralen Grundannahmen und Schlüsselbegriffe dieser Theoriearchitektur ein. Die Rekonstruktion der Hegemonie- und Populismustheorie Laclaus und Mouffes ordnet deren Komplexität dem Ziel unter, sie für eine Analyse des SVP-Populismus fruchtbar zu machen. In erster Linie geht es darum, das begriffliche Instrumentarium einzuführen, das die Analyse des SVP-Populismus anleitet. Das impliziert selektive Vereinfachungen und Verkürzungen. Allenfalls gestreift werden beispielsweise der historische Hintergrund, auf den Laclau/Mouffes gemeinsames Hauptwerk Hegemony and Socia- 
list Strategy ${ }^{2}$ antwortet, sowie ihre Gramsci-Lektüre und die Post-MarxismusDebatte, die im Anschluss an ihre Dekonstruktion des Marxismus entbrannte. ${ }^{3}$ Anstelle einer historisch-genealogischen Rekonstruktion der Theorie Laclau/Mouffes stelle ich die Verknüpfung poststrukturalistisch-differenztheoretischer und hegemonietheoretischer Denkfiguren in den Mittelpunkt. ${ }^{4}$ Denn aus dieser Verknüpfung entsteht eine Gesellschafts- und Politiktheorie, die mich in die Lage versetzen soll, die Identitätspolitik der SVP zu rekonstruieren und an ihre Grenzen zu führen, ohne eine ,privilegierte epistemologische Stel$1 e^{\text {“5 }}$ in Anschlag zu bringen, die, wirkliche Identitäten', ,tatsächliche Interessen oder ,echte Konflikte' präsupponiert und der populistischen Konstruktion eines Volkes a priori für die Verzerrung dieser basalen Gegebenheiten verurteilt.

\subsection{THEORETISCHE GRUNDLAGEN I: VON PERFORMATIVEN SPRACHSPIELEN UND SPRECHAKTEN ZU EINER DISKURSTHEORIE DES SOZIALEN}

Den Ausgangspunkt dieses theoretischen Unterfangens bildet ein Begriff des Diskursiven, der an das antihumanistische Diskurskonzept Foucaults anschließt, ${ }^{6}$

2 Laclau/Mouffe 2006 [1985].

3 So der deutsche Untertitel des gemeinsamen Hauptwerkes Laclau/Mouffes (2006) [1985]. Zur Post-Marxismus-Debatte vgl. die von Norman Geras (1987) und von Michael Rustin (1988) vorgebrachte Laclau/Mouffe-Kritik sowie die Antwort von Laclau und Mouffe (1990).

4 Einen guten Überblick über die frühe, postmarxistische Rezeption Laclau/Mouffes liefert Rüdiger 1996: 137ff. Zur kontinuierlichen Ergänzung und Weiterentwicklung der Hegemonietheorie durch Laclau und Mouffe vgl. Torfing 2005: insb. $159 \mathrm{ff}$.

5 Laclau/Mouffe 2006 [1985]: 28.

6 Zur anti-humanistischen Verve des Foucault'schen Diskurskonzepts vgl. exemplarisch Foucault 1988: 22ff. Mit Anti-Humanismus ist in diesem Zusammenhang selbstverständlich nicht gemeint, Foucault würde sich gegen die Werte des Humanismus oder gegen ein ,menschliches‘ Miteinander aussprechen. Anti-Humanismus meint, dass Foucault gegen Anthropologien argumentiert, die ein mit sich selbst identisches, rationales Subjekts als logischen Ausgangspunkt von Sozialität, Handeln und Geschichte denken und faktische oder denkbare Gesellschaftsordnungen aus dieser unumstößlichen Verfasstheit des Menschen deduzieren. 
dessen Unterscheidung von diskursiven und nicht-diskursiven Praktiken zugunsten eines alle sozialen Praktiken umfassenden Begriffs des Diskursiven jedoch verwirft. ${ }^{7}$ Wie dem Diskurskonzept Foucaults liegen auch jenem Laclau/Mouffes einerseits die strukturale Sprach- und Zeichentheorie des Linguisten Ferdinand de Saussure und andererseits Ludwig Wittgensteins Konzept des Sprachspiels sowie die Sprechakttheorien von John Austin und John Searle zugrunde. ${ }^{8}$ Wenngleich sich Laclau und Mouffe (anders als etwa Judith Butler ${ }^{9}$ ) weniger mit Sprechakten als mit der Semiotik de Saussures auseinandersetzen, wirkt das Bewusstsein für die Performativität von Sprache gleichwohl weichenstellend für die Diskurstheorie Laclau/Mouffes.

Im Anschluss an die sprachphilosophischen Überlegungen Wittgensteins, Austins und Searles wenden sich Laclau und Mouffe gemeinsam mit anderen Diskurstheoretiker/innen gegen die Vorstellung, Aussagen und Diskurse könnten als nicht-invasive Repräsentationen einer außersprachlichen Wirklichkeit oder als Abbilder einer subjektiven oder intersubjektiven Wirklichkeitswahrnehmung gedacht werden. ${ }^{10}$ Anstatt Sprache auf ihre Abbildfunktion zu reduzieren und nach der Wirklichkeitsadäquanz von Aussagen zu fragen, fokussieren sie die wirklichkeitskonstitutive und handlungsäquivalente Dimension von Sprechakten.

Aus diesem Blickwinkel sind Diskurse weder auf ihren semantischen Gehalt noch auf semiotische Aspekte zu reduzieren. Sie sind vielmehr, ,als Praktiken zu behandeln, die systematisch die Gegenstände bilden, von denen sie sprechen“"11. Das Verhältnis zwischen Sprache und sozialer Wirklichkeit wird umgedreht: Es sind demnach gerade nicht die Gegenstände, welche die einschlägigen Diskurse hervorbringen, sondern die Diskurse, die diese Gegenstände formieren. Indem die Diskurse über die Gegenstände sprechen, verorten sie diese in Sinnzusam-

7 Zur Differenzierung von diskursiven und nicht-diskursiven Praktiken vgl. Foucault 1988: 231ff. Zur Kritik dieser Differenzierung vgl. Laclau/Mouffe 2006 [1985]: 143f.; Laclau 1982: 14; Wrana/Langer 2007.

8 Vgl. den programmatischen Titel von Austins Hauptwerk „How to do things with words" (1972); zur analytischen Unterscheidung von konstatierenden (lokutionären) und performativen (illokutionären) Äußerungen vgl. Austin 1968; Searle 1969; zu Wittgensteins Sprachspielbegriff vgl. Mouffe 2008: 69ff.

9 Für Butlers Auseinandersetzung mit Austins Konzept der Performativität vgl. Butler 1997: 35ff.

10 Vgl. Bachmann-Medick 2006: 36; auch Torfing 2005: 153.

11 Foucault 1988: 74; vgl. auch die Definition von Sprechakten bei Butler (1993: 123f.): „Eine performative Handlung ist eine solche, die das, was sie benennt, hervorruft oder in Szene setzt und so die konstitutive oder produktive Macht der Rede unterstreicht.“ 
menhängen und bringen diese als sinnhafte Entitäten hervor. Sie bestimmen, was gesagt und gedacht werden kann, ,was als wahr erkannt und als falsch verworfen wird“"12.

Im Unterschied zur Diskurstheorie Jürgen Habermas' erscheinen Argumentationen nicht etwa als prozesshafte, intersubjektive Annäherungsversuche an eine zu entdeckenden Wahrheit, sondern als soziale Konstruktionen von Wahrheit ${ }^{13}$, die sich als kontingentes „,meaning making “14 vollziehen. Die Serialität und Regelhaftigkeit (die taxonomischen Ordnungen, die binären Unterscheidungen, Korrelationen, Kausalbeziehungen und Tabuisierungen), die Diskurse auszeichnen, entstehen weder auf Grundlage des Bezugsgegenstandes noch auf Grundlage einer konstanten Rationalität, sondern dadurch, dass Diskurse spezifischen Formationsregeln folgen, die sie diskursintern perpetuieren, indem sie die Menge an intelligiblen Aussagen limitieren. ${ }^{15}$ Diskurse sind insofern machtvolle und produktive Regelsysteme, „Sinngeneratoren für Ordnungen des Denkbaren und Sagbaren ${ }^{\text {“16. Sie produzieren „(allgemeinverbindliche) Wahrheiten“17 }}$ und bringen „,mehr oder weniger kontinuierliche und diskontinuierliche Ordnungen“"18 hervor, die Objekte und Subjekte auf spezifische Weise formieren. ${ }^{19}$

Subjekte imaginieren Diskurstheorien somit weder als sinnstiftende und selbstreflexive Autoren des Diskurses noch als strategisch-intervenierende Akteure. ${ }^{20}$ Das Subjekt geht dem Diskurs nicht voraus. Gleich den Objekten sind

12 Hirseland/Schneider 2011: 402.

13 Ich paraphrasiere hier Laclaus (1989: 79) paradigmatische Unterscheidung von ,arguments as discovery“ und ,arguments as social construction“. Zur Unterscheidung der Diskursbegriffe von Jürgen Habermas einerseits und von Foucault und Laclau/Mouffe andererseits vgl. Nonhoff 2004.

14 Fairclough 2007: 10.

15 Vgl. exemplarisch Foucault 1991 u. 1988: 58 u. 92; erläuternd Moebius 2009: $91 \mathrm{ff}$.

16 Reckwitz 2008b: 193

17 Bublitz u.a. 1999: 11.

18 Keller 2005: 125.

19 So lassen sich Diskurse verstehen als „Praktiken der Repräsentation, das heißt Praktiken, in denen sich Objekte, Subjekte und Zusammenhänge auf eine bestimmte, regulierte Weise dargestellt werden und in dieser Darstellung als spezifische Beobachterkategorie erst produziert werden“ (Reckwitz 2008b: 203).

20 Hierin besteht der zentrale Unterschied zu einem wissenssoziologischen Konstruktivismus (vgl. Berger/Luckmann 2010). Für eine Verknüpfung von Wissenssoziologie und Diskursanalyse plädieren insbesondere die Vertreter der sogenannten Wissenssoziologischen Diskursanalyse, die gerade vonseiten der Politologie stark rezipiert wird 
Subjekte mitsamt ihren Interessen, Einstellungen und Motiven die Effekte diskursiver „Anrufung “21 durch den Diskurs ${ }^{\text {‘2 }}$, der die Bedingungen einer anerkennungswürdigen Subjektivität diktiert. $^{23}$

Diskursanalysen haben insofern einen ,de-ontologisierenden Charakter“"24: Es geht nicht oder nicht in erster Linie um die empirisch beobachtbare Faktizität sozialer Institutionen und menschlicher Handlungsweisen, sondern darum jene Epistemologien infrage zu stellen, die diese Institutionen und Handlungsweisen normalisieren und etwaige Alternativen pathologisieren. Die kritischemanzipatorische Stoßrichtung, die mit dieser Gesellschafts- und Subjektanalytik verbunden ist, zielt folglich nicht auf die Verwirklichung einer machtfreien, ,wahrhaft menschlichen' Utopie, sondern auf eine Politik der Entunterwerfung. Es geht darum, Gegendiskurse zu initiieren, Handlungsspielräume zu eröffnen und „Formen der Subjektivität ${ }^{\text {“25 }}$ zu entwerfen, die etablierte Vorstellungen von Notwendigkeit, Normalität und Rationalität konterkarieren. ${ }^{26}$

Dieses im Wesentlichen durch Foucault geprägte Diskurskonzept liegt auch der Hegemonietheorie Laclau/Mouffes zugrunde. Im Unterschied zur Foucault'schen Tradition ${ }^{27}$ ist das Diskursive für Laclau und Mouffe jedoch

(vgl. Keller 2005; für die politologische Adaption vgl. etwa Nullmeier 2006). Insofern dieser Ansatz die strategisch motivierten, ,intentionalen Deutungsaktivitäten politischer AkteurInnen und deren Produktion politikrelevanten Wissens“ (Pieper 2006: 275) fokussiert, führt er ein Akteurskonzept in die Foucault'sche Diskurstheorie ein, das nicht kompatibel mit dessen anti-humanistischem Impetus ist.

21 Der Begriff der Anrufung bzw. der Interpellation stammt von Louis Althusser (1977).

22 Reckwitz 2006: 341; Laclau 1989: 80.

23 Vgl. Laclau 2003: 431; Reckwitz 2000: 16. Für Judith Butler wird die „Unterwerfung unter die akzeptablen Formen von Subjekthaftigkeit“ infolgedessen zur begehrten „Voraussetzung von Subjektivität“ (Reckwitz 2008a: 81). Für diesen simultanen Prozess von Werden und Unterordnen, der mit der diskursiven Subjektivierung einhergeht, prägte sie den Begriff ,,asujetissement“ (Butler 2001: 81ff.; vgl auch Moebius 2009: 153ff.).

24 Bublitz u.a. 1999: 13.

25 Foucault 1987: 250.

26 Vgl. Butler 2002.

27 In diese Tradition stellen sich insbesondere die mit Rainer Keller assoziierte Wissenssoziologische Diskursanalyse (kurz: WDA), die ,Foucault‘ mit der Wissenssoziologie Berger/Luckmanns und deren Akteurskonzept zu verbinden versucht (vgl. Keller 2005), und die Critical Discourse Analysis (kurz: CDA), die insbesondere von Ruth 
nicht auf eine sprachlich vermittelte Ideen- und Wissenssphäre beschränkt. Bei Laclau und Mouffe bezeichnet es vielmehr die allgemeine Konstitutionsebene des Sozialen, „das Ensemble der Phänomene gesellschaftlicher Sinnproduktion, das eine Gesellschaft als solche begründet ${ }^{\text {‘28 }}$.

Diese Verschiebung ermöglicht Laclau und Mouffe, das Soziale mit dem Diskursiven gleichzusetzen und die Unterscheidung „einer sozial-strukturellen, materialen und einer kulturellen, diskursiven Ebene ${ }^{، 29}$ zu unterminieren. Diskurse sind nicht, ,aus anderem Stoff ${ }^{\mathrm{r} 30}$ gemacht als soziale Praktiken im herkömmlichen Sinn; sie umfassen nicht bloß „mentale oder textuelle Phänomene, sondern tatsächlich materiale, sinnhaft konstituierte Komplexe von Praktiken “31. Als Stätte der Bedeutungsproduktion umfasst das Diskursive also sowohl sprachliche als auch nicht-sprachliche Praktiken. ${ }^{32}$ Denn nicht nur eine sprachlich vermittelte Ideenwelt, sondern ,[a]uch Objekte, Subjekte, Zustände und Praktiken ergeben erst im sozialen Relationsgefüge einen je spezifischen Sinn ${ }^{\text {‘33 }}$ und können daher diskurstheoretisch gelesen werden.

$\mathrm{Zu}$ behaupten, dass es ,nichts Gesellschaftliches [gibt], das außerhalb des Diskursiven “34 läge, bedeutet keineswegs, die Existenz einer nicht-diskursiven Umwelt des Sozialen zu negieren. So existiert beispielsweise das Hochgebirge, das einen Großteil des schweizerischen Staatsgebietes ausmacht, unabhängig da-

Wodak und Norman Fairclough vorangetrieben wurde (vgl. etwa Fairclough/Wodak 1997). Sowohl Keller als auch Fairclough und Wodak machen die Unterscheidung von Diskursiven und Nicht-Diskursivem stark und unterscheiden zwischen einer sozial-strukturellen und einer ideologisch respektive wissensmäßig organisierten Sphäre von Gesellschaft. Die Kritische Diskursanalyse Siegfried und Margarethe Jägers (Jäger/Jäger 2007) arbeitet sich zwar ebenfalls in erster Linie an Foucault ab. Jedoch äußert sich Siegried Jäger kritisch gegenüber dem „stark im Verbalen verfangenen Diskursbegriff" Foucaults und weist insofern bereits in Richtung des umfassenden Begriffs des Diskursiven bei Laclau und Mouffe (vgl. Wrana/Langer 2007).

28 Laclau 1981: 169; vgl. auch Laclau 1982: 15; Laclau/Mouffe 1990: 100ff.

29 Stäheli 2001: 200.

30 Reckwitz 2008b: 204.

31 Reckwitz 2006: 342.

32 Der Diskursbegriff unterläuft damit die binäre Unterscheidung zwischen einer idealistischen Vorstellungswelt der Sprache und einer materiellen Welt der harten Fakten. Aussagen sind genauso real wie Taten, weil beide Wirklichkeit schaffen (vgl. Laclau/Mouffe 1990: 102; sowie Reckwitz 2006: 342).

33 Nonhoff 2007a: 9.

34 Auer 2008: 249. 
von, ob es als agrarischer Ungunstraum, Verkehrshindernis, Wasserschloss, militärisches Réduit, Natur- oder Kulturraum, Freizeitpark oder als Ursprungs- und Kraftort eines homo nationalis besprochen oder behandelt wird. Die Identität der Alpen changiert jedoch, je nachdem ob man primär Ackerbau zu betreiben versucht, sie durchqueren möchte, Staudämme oder Bunkeranlagen errichtet, die ursprüngliche Naturlandschaft wiederherstellen oder die traditionelle Kulturlandschaft erhalten will, sie für den Wintermassentourismus erschließt oder zum prägenden Stammland des Schweizervolkes stilisiert. ${ }^{35}$

Das Beispiel macht deutlich, dass die Trennung zwischen „Materialität“ und „Ideenwelt“ hinfällig ist. Die Bedeutung auch der materiell-physischen Umwelt wird erst durch ein Geflecht von Praktiken konstituiert, das Objekte, Handlungen und Aussagen zueinander in Beziehung setzt und auf diese Weise Subjektpositionen bereitstellt, mit denen sich soziale Akteure identifizieren. ${ }^{36}$ Infolgedessen kann das Soziale mit dem Diskursiven identifiziert werden und die Diskurstheorie als allgemeine Sozialtheorie reformuliert werden, ohne einem Idealismus zu huldigen, der die materiellen Aspekte von Gesellschaft aus den Augen verlieren würde. ${ }^{37}$

\subsection{Theoretische GrundLagen II: POSTSTRUKTURALISMUS, DISCURSIVE TURN UND POSTFUNDAMENTALISTISCHE EPISTEMOLOGIE}

Während Foucault sowohl in seinen archäologischen als auch in seinen genealogischen Arbeiten primär auf eine Historisierung der Regime anthropologischen Wissens zielt, die subjektive Identifikationsmöglichkeiten konstituieren und begrenzen, entwickeln Laclau und Mouffe auf Grundlage dieses umfassenden Diskursbegriffs eine allgemeine Sozialtheorie, die Gesellschaft als Effekt konkurrierender hegemonialer Projekte lesbar macht und Möglichkeiten der Infragestellung sozialer Verhältnisse auslotet. Hierfür knüpfen Laclau und Mouffe an die

35 Ähnliches gilt beispielsweise auch für den ,Deutschen Wald‘, dem die diskursiven Praktiken von Heimatschützern ebenfalls einen anderen Sinn verleihen als jene der Holzindustrie, oder für die Pflastersteine, die normalerweise als Bürgersteig dienen, im Rahmen einer Demonstrationen jedoch in Schaufenster geworfen werden (vgl. Nonhoff 2004: 76f.).

$36 \mathrm{Vgl}$. Howarth/Stavrakakis 2000: 3.

37 Vgl. Laclau/Mouffe 1990. 
strukturale Linguistik Ferdinand de Saussures und den Dekonstruktivismus Jacques Derridas an.

Wie alle semiotisch begründeten Varianten des Poststrukturalismus präsupponieren Laclau und Mouffe, dass das Soziale wie eine Sprache strukturiert ist. ${ }^{38}$ In Analogie zum Begriff der langue definieren Laclau und Mouffe einen Diskurs als übersubjektives, konventionalisiertes und singulären Sprechakten (paroles) vorstehendes Differenzsystem aus arbiträren Zeichen. ${ }^{39}$ Wie eine Sprache ist ein Diskurs nicht als eine „Nomenklatur“ zu verstehen, deren Begriffe gleich Etiketten, den Gegenständen und Konzepten anhefteten, die sie bezeichnen. ${ }^{40}$ Die Signifikanten, aus denen sich Sprachen und Diskurse zusammensetzen, symbolisieren nicht gegebene Objekte oder vorsprachliche Ideen. ${ }^{41}$ Ihre Bedeutung entsteht vielmehr aus der Differenzrelation zu anderen Signifikanten innerhalb des Systems. ${ }^{42}$ Die Arbitrarität der Zeichen bedeutet nicht nur, dass die Beziehung zwischen Signifikant und Signifikat kontingent ist, sondern auch, dass dem Bezeichneten kein Wesen innewohnt, das es erlauben würde, es als kohärente, der Bezeichnung vorgängige Einheit zu begreifen. Sinn entsteht nicht retroaktiv, durch Referenz auf eine gegebene Essenz des Bezeichneten, sondern systemimmanent und ex negativo, indem Zeichen oder Elemente auf kontingente Weise zueinander in Beziehung gesetzt und voneinander unterschieden werden. ${ }^{43}$ Übertragen auf die Gesellschaftstheorie, heißt das, dass

„Gesellschaft nicht aus ,Letztelementen“ wie z. B. Individuen oder auch einzelne Handlungen besteht, die miteinander Verbindungen eingehen. Vielmehr entstehen die einzelnen ,Elemente' erst in einem Beziehungsgeflecht. Erst durch die Position in einem derartigen Gewebe, und somit durch die Abgrenzung von anderen Positionen, kommen ,Elemente“

38 Vgl. Moebius 2009: 96f.; sowie Bachmann-Medick 2006: 36.

39 Vgl. Saussure 1967: 76ff. u. 132ff. bzw. Laclau/Mouffe 2006 [1985]: 142ff. In Analogie zur Unterscheidung von langue und parole bei Saussure werden Laclau und Mouffe von Diskurs und Artikulation sprechen (s.u.). Der Artikulationsbegriff taucht bereits bei Saussure (1967: 12 u. 134) auf.

40 Vgl. ebd.: 76.

41 Vgl. ebd.: 133; sowie erläuternd Howarth 2000: 19.

42 Vgl. Saussure 1967: 132.

43 „In der Sprache gibt es nur Verschiedenheiten ohne positive Einzelglieder“ und „die Sprache ist eine Form und nicht eine Substanz", so die einschlägigen Axiome des „Cours de Linguistique Générale“. Ebd.: 143 u. 146. 
zustande. Wenn also kein Element aus sich heraus bestimmt werden kann, dann bekommt die Beziehung zu dem, was es nicht ist, eine zentrale Bedeutung.“ ${ }^{44}$

Die Objektivität eines Elements entsteht also erst dadurch, dass es auf bestimmte Art und Weise besprochen wird, innerhalb eines „kulturellen Differenzsystems ${ }^{\text {“45 }}$ positioniert und zu anderen Elementen in Beziehung gesetzt wird, wobei diese Differenzbeziehungen nicht einer wesenhaften Diversität entspringen, sondern sozial konstruiert, kontingent und historisch geworden sind. ${ }^{46}$

Saussures Vorstellung einer bedeutungskonstitutiven Differenz legt den Grundstein für eine konstruktivistische Gesellschaftstheorie, in der kein Element vor seiner relationalen Positionierung als selbstidentisches „Letztelement“47 existiert. Soziale Ordnung wird nicht auf unhintergehbare Essenzen zurückgeführt, sondern als Effekt kontingenter und regelhafter Repräsentationen vorgestellt, die Entitäten zueinander in Beziehung setzen, voneinander unterscheiden und erst dadurch konstituieren. Sinnzusammenhänge, Bedeutungen, Identitäten und Gesellschaften entstehen erst aus der relationalen Fixierung von Elementen im Rahmen konventionalisierter Differenzsysteme. Da keine soziale Entität ihre Bedeutung aus einer ihr innewohnenden Essenz heraus erlangt, sondern nur in Differenz zu anderen Elementen erhält, lässt sich auf Grundlage des Cours de Linguistique générale eine dezidiert sozialkonstruktivistische Position beziehen, die gegen die unterschiedlichen Varianten der Verdinglichung und Naturalisierung gesellschaftlicher Verhältnisse polemisiert.

Die Theorien de Saussures, Lévi-Strauss', Althussers und anderer Strukturalisten bergen jedoch die Gefahr, die Essentialismen anderer Sozialtheorien durch einen Essentialismus geschlossener Systeme zu substituieren. Denn ihre strukturalistischen Modelle legen nahe, dass die starre Struktur des Systems jede soziale Praxis determiniert. ${ }^{48}$ Wenn dem so wäre, würde jede Handlung notwendig ,dem

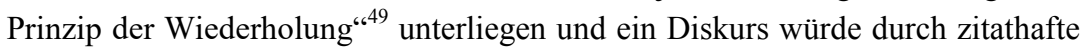

44 Stäheli 2000: 9.

45 Reckwitz 2008a: 80.

46 Vgl. Laclau 1982: 15.

47 Stäheli 2000: 9.

48 Vgl. Howarth 2000: 28. Wenngleich bereits bei Saussure die Beziehungen zwischen den Signifikanten dem sozial konstruierten Charakter der Struktur logisch nachgeordnet sind, sorgt die Geschlossenheit der Struktur doch dafür, dass soziales Handeln nur als Repetition und nicht als Variation oder Verschiebung von Struktur gedacht werden kann.

49 Laclau/Mouffe 2006 [1985]: 143. 
Reproduktionen der Differenzrelationen erstarren. Das strukturalistische Axiom geschlossener Systeme muss sich daher für ein dynamisierendes Moment öffnen, ohne den Dualismus von Struktur und Handlung zu erneuern und durch die Einführung eines planvoll intervenierenden Subjekts in Widerspruch zum Paradigma generativer, vorsubjektiver Regelsysteme zu geraten. ${ }^{50}$

Um zu erfassen, wie die Signifikationssysteme de Saussures variiert werden, schließen Laclau und Mouffe an Derridas Dekonstruktion an. Derrida löst die Zuordnung zwischen Signifikant und Signifikat und fasst die von Saussure als stabiles Differenzsystem konzipierte langue als azentrische und daher unabschließbare „Spielbewegung ${ }^{\text {c551 }}$, in der Differenzen fortlaufend kreiert werden. In diesem Spiel entbehren die Zeichen nicht nur eine ursprüngliche, sondern auch eine ultimativ konventionalisierte Differenz (Identität). Sie zeigen lediglich Spuren einer mitschwingenden Bedeutungsgeschichte, auf der ihre Iterabilität, ihre Wiederholbarkeit und ihr Wiedererkennungswert in unterschiedlichen Kontexten und Diskursen gründen. ${ }^{52}$

Anstelle des klassischen Dualismus von (objektiver) Struktur und (subjektiver) Handlung, in dem erstere die stabilen, zweitere die dynamischen Aspekte von Gesellschaft erklärt, verwandelt sich die Struktur in ein rhizomatisches Geflecht aus bedeutungstragenden Elementen, das selbst brüchig, dynamisch und ereignishaft ist. Die relative Stabilität von Sinnzusammenhängen ist nicht mehr durch eine geschlossene Struktur determiniert, sondern ein möglicher Effekt der performativen Hervorbringung, die sich in Form von Wiederholungen vollzieht. ${ }^{53}$ Es gibt keinen unverrückbaren Identitätskern und kein basales Original, die an einer gesellschaftlichen Oberfläche als mehr oder weniger stark verzerrte Kopien zum Ausdruck kämen, sondern nur Zitationen diskursiv erzeugter Sinnzusammenhänge, die zu imaginären Originalen sedimentieren und als Identifikationsschablonen angeeignet werden. ${ }^{54}$

Wegweisend für diese Überwindung der Stabilitätszentrierung des Strukturalismus ist die Gleichzeitigkeit von Verschiebung und Unterscheidung, die Derrida mit dem polysemischen Neologismus der différance ${ }^{55}$ bezeichnet. Denn durch

50 Vgl. Reckwitz 2006: 342.

51 Derrida 1990a: 89.

52 Zum Konzept der Iterabilität vgl. Howarth 2000: $41 \mathrm{ff}$.

53 Diese Vorstellung einer durch performative Wiederholung hervorgebrachte, und später naturalisierte Struktur, ist zugleich der Dreh- und Angelpunkt der Gendertheorie Judith Butlers (exemplarisch Butler 1997: 35ff. sowie zsf. Schäfer 2013: 195ff.).

54 Moebius 2009: 155.

55 Zum Konzept der différance vgl. Derrida 1990a: 83. 
die différance halten Derrida und seine Schüler an Saussures Paradigma ,Identität $=$ Differenz' fest, betonen jedoch entgegen der statischen Strukturalität des Modells des Genfer Linguisten, dass sich Bedeutungen prozedural, durch ein kontextuelles Different-Werden der Zeichen vollzieht. Die binären Begriffspaare, von denen strukturalistische Theoretiker/innen wie Lévi-Strauss oder Althusser ausgingen, existieren als sozial strukturierende Ordnungen nach wie vor, doch sind diese Ordnungen keineswegs starr, wie das Modell der strukturalen Linguistik suggeriert, sondern auf die stetige und potentiell alternierende Aktualisierung ihrer selbst angewiesen.

Infolgedessen erscheint das von Althusser geprägte und für den frühen Kulturmarxismus zentrale Konzept der Überdeterminierung nicht mehr als ontisches Phänomen bzw. als erklärungsbedürftige, empirische Tatsache, nach der sich bei der Bildung gesellschaftlicher Strukturen vielfältige Faktoren überlagern, sondern als ontologische Konstitutionsbedingung des Sozialen. ${ }^{56}$ Wenn keine Differenz auf ein begründendes Original verweist, das ihre Adäquanz verbürgen könnte, sondern aus dem unabschließbaren Spiel der différance hervorgeht, dann wohnt den Beziehungen zwischen den Differenzen eine Unentscheidbarkeit inne, die deren Stabilität unterwandert. Folglich ist jede Identität kontingent und resignifizierbar. Kontingenz und Resignifizierbarkeit beziehen sich nicht bloß auf einen ideologisch verfassten, superstrukturellen Teilbereich von Gesellschaft, der sich von einem anderen (ökonomisch, funktional oder natürlich) determinierten Bereich unterscheiden ließe; sie avancieren selbst zur irreduziblen Wurzel des Sozialen.

Gesellschaft wird nicht mehr von einer „privilegierten epistemologischen Stelle ${ }^{\text {“57 }}$ (sei es Gott, die Natur des Menschen, die Produktionsverhältnisse oder ein universelles Konzept von Vernunft) deduziert. Stattdessen wird ,infolge der Abwesenheit eines Zentrums oder eines Ursprungs alles zum Diskurs [...], das heißt zum System, in dem das zentrale, originäre oder transzendentale Signifikat niemals absolut, außerhalb des Systems von Differenzen, präsent ist ${ }^{\text {“ }}{ }^{58}$. Aus der Absenz eines transzendentalen Signifikats folgt, dass sich das „Spiel des Bezeichnens ins Unendliche ${ }^{\text {c59 }}$ erweitert und dass dieses Spiel als „eine Reihe ei-

56 Zur poststrukturalistischen Radikalisierung des Begriffs der Überdeterminierung vgl. Laclau/Mouffe 2006 [1985]: 140f.

57 Ebd.: 28.

58 Derrida 1990b: 117.

59 Ebd. 
nander substituierender Zentren, als Verkettung von Bestimmungen des Zentrums gedacht werden ${ }^{\text {“60 }}$ muss.

Die Negation eines Ursprungs, der die Reproduktion eines Diskurses determinieren würde, impliziert nicht nur die Unabschließbarkeit des Spiels. Die différance sorgt auch dafür, dass jeder Spielzug, jede performative Sinnselektion, die in der fortlaufenden Realisierung spezifischer Bedeutungen (Differenzen) vollzogen wird, mit der Negation von Alternativen einhergeht, sodass jedem Diskurs ein Moment der Unentscheidbarkeit immanent ist, der verhindert, dass er sich als geschlossene Totalität konstituieren kann.

Wenn Bedeutung nur ex negativo, durch eine unentscheidbare Entscheidung hergestellt werden kann, dann „kann das Sein eines Objekts niemals als reine ,Präsenz' oder ,Objektivität' konzipiert werden “61. Jede Identität und jede Gesellschaft wird stets durch ein diskursives Außen geformt und unterminiert, das sie verwirft, um sich zu konstituieren - ein Gedanke, den Derrida in der Figur des konstitutiven Außen zum Ausdruck bringt. ${ }^{62}$

„Jede Anordnung, jede zeit-räumliche, soziale oder symbolische Ordnung und Struktur, jeder Diskurs, jede Identität, jede Institution bzw. jeder Kontext grenzt sich von einem Anderen, einem Außen ab, auf das er jedoch angewiesen ist, um sich (begrenzend) zu schließen und um existieren zu können. “63

Demnach ist die Vorstellung einer wesenhaften Substanz respektive eines Grundes, welcher der symbolischen Repräsentation zugrunde liegt, als Effekt zu dechiffrieren, der in einem Außen diskursiv hervorgebracht wird. ${ }^{64}$ Die Denkfigur des konstitutiven Außens macht darauf aufmerksam, dass Zugehörigkeit und Kohäsion erst durch die Produktion und den Ausschluss eines Fremden hergestellt werden können. Sie postuliert eine ,irreduzible Verschränkung ${ }^{\text {“65 }}$ des Anderen und des Eigenen: „The ,other' is never outside or beyond us; it emerges forcefully, within cultural discourse, when we think we speak most intimately

60 Ebd.: 116.

61 Mouffe 2008: 36

62 Für eine kompakte Darstellung der Denkfigur des konstitutiven Außen und der damit verbundenen Radikalisierung des Strukturalismus bei Derrida vgl. Howarth 2000:35ff.; sowie Moebius 2009: 149ff.

63 Moebius 2009: 151.

64 Vgl. Schäfer 2013: 218.

65 Moebius 2009: 151. 
and indigenously ,between ourselves‘ “66 ${ }^{66}$ Die Konstruktion von Zugehörigkeit und Nicht-Zugehörigkeit verläuft demnach simultan und reziprok. Man verwirft eine innere Differenz und stilisiert sie zu dem Unterschied schlechthin, zu einer inkompatiblen Differenz zwischen sich und einem Anderen. Kollektivierende Anrufungsbegriffe wie Proletariat, Volk, Sozialdemokraten, juste milieu und Neue Mitte, alle Begriffe, die ein metonymisches ,Wir' realisieren, sind stets mit einem Anderen, einem ,Sie‘ konfrontiert, das sie zwar bezeichnen müssen, aber eigentlich nicht bezeichnen können, da es sich nicht etwa um eine schlichte Differenz innerhalb des Diskurses, sondern um ein verworfenes Anderes der Identität handelt.

Wenn eine soziale Formation aus kontingenten Grenzziehungen hervorgeht, wird die Grenze zu einer eigentümlichen Institution: Sie ist konstitutiv für die Form und die Kohäsion einer Identität und zeigt gleichzeitig an, dass es sich um ein prekäres Verhältnis handelt. Die Grenzziehung gegenüber dem Anderen impliziert eine dialektische Beziehung von Kontingenz und Notwendigkeit. Auf der einen Seite ist das Andere unentbehrlich für die Einheit des Diskurses. Es ist die notwendige Bedingung seiner Objektivität, dasjenige, was ,ausgeschlossen werden muss, damit die symbolische Ordnung sich ihrer [...] ,inneren Reinheit ${ }^{\star}$ versichern kann“67. Auf der anderen Seite bezeugt es die Unentscheidbarkeit der Struktur. In der Irreduzibilität des Anderen manifestiert sich die Unvollständigkeit innerer Einheit; seine Präsenz unterminiert die Versuche finaler Schließungen des Diskurses.

Die Dekonstruktion fokussiert die ,permanente Destabilisierung [...] kultureller Signifikationssysteme, Identitäten und Wissensordnungen, die Brüchigkeit von Sinnzusammenhängen, aber auch die Produktion von neuartigen, unberechenbaren Sinnelementen“"68. Während der Strukturalismus die Stabilität sozialer Beziehungen überstilisierte und daran scheiterte, Wandel und Diskontinuität zu theoretisieren, laufen die Denkfiguren der Dekonstruktion Gefahr, die Instabilität und Veränderbarkeit sozialer Ordnungen überzustrapazieren. ${ }^{69}$ Für sich genommen würde das poststrukturalistische Axiom radikaler Kontingenz in der Tat auf

66 Bhabha 1990: 4.

67 Moebius/Reckwitz 2008: 16.

68 Moebius 2009: 152.

69 Aus einer von Derrida informierten Perspektive wohnt jeder Wiederholung eine Modifikation respektive eine Bedeutungsverschiebung inne, da der Kontext, der die Bedeutung der wiederholenden Sprechhandlung mitkonstituiert, nie absolut identisch ist. Auf dieser Überlegung gründet die Formulierung einer poststrukturalistischen Praxeologie Hilmar Schäfers (2013). 
die gesellschaftsanalytisch stumpfe Annahme hinauslaufen, dass Differenzen fortwährend verschoben und alle Identitäten gleichermaßen resignifiziert werden können. Um diesem Fallstrick zu entgehen, muss das Konzept der différance durch eine Theorie ergänzt werden, die analysieren kann, wie die gleitenden Signifikanten provisorisch arretiert und wie die „Signifikationssequenzen ${ }^{\text {“70 }}$ und Grenzziehungen, durch die sich Diskurse, Identitäten und Gesellschaften konstituieren, temporär stabilisiert werden. Der theoretische Ausgangspunkt der Unentscheidbarkeit muss durch eine Theorie der Entscheidung ergänzt werden, die zu erfassen vermag, wie bestimmte ,Texte' konserviert werden und zumindest zeitweise als plausibel, legitim oder alternativlos anerkannt werden. Denn nur so lässt sich beschreiben, wie soziale Identitäten entgegen ihrer prinzipiellen Kontingenz erfolgreich konventionalisiert werden, wie sie ihre Selbstverständlichkeit verlieren, in Frage gestellt und neu organisiert werden. Auf derlei Fragen, die mit Derrida zwar angeschnitten, aber nicht ausreichend theoretisiert werden können, antwortet die Hegemonietheorie von Laclau und Mouffe, indem sie ein Begriffsinstrumentarium entwirft, das die Möglichkeit und Notwendigkeit von Sinnfixierungen auslotet, aber auch ihre Grenze und ihr Scheitern ins Visier nimmt.

\subsection{ECKPUNKTE EINER POSTSTRUKTURALISTISCHEN DISKURSTHEORIE}

Ehe ich mich auf die Theorie Laclau/Mouffe konzentriere, seien folgende drei Pointen einer poststrukturalistischen Diskurstheorie nochmals festgehalten: Erstens wird die im Strukturalismus apostrophierte Stabilität der Differenzen prozeduralisiert. Vor dem Hintergrund der infiniten Aufgeschobenheit und des Gleitens der Differenzen erscheinen Diskurse nicht als geschlossene Totalitäten, sondern als ,incomplete linguistic systems that are produced by the ,play of differences ${ }^{\text {“ } 671}$. Das Soziale wird nicht mehr auf eine basale Instanz, ein Fundament oder ein Zentrum zurückgeführt, das die Positionen, mit denen sich Subjekte identifizieren, prädeterminierte. Stattdessen wird es als unabschließbares Spiel konzipiert wird und als Möglichkeitsraum vorgestellt, der durch diskursive Sinnfixierungen und die ihnen immanenten Ausschlüsse provisorisch strukturiert 
wird. ${ }^{72}$ Daher kann Gesellschaft auch nicht als „einheitliches Objekt“" gedacht werden, das ,ihre eigenen partialen Prozesse begründen“ könnte. ${ }^{73}$ Gesellschaft gibt es nur als Zwischenergebnis von mehr oder weniger erfolgreichen Repräsentationsleistungen von Gesellschaft, die immer mit den Bedeutungsüberschüssen der différance konfrontiert sind.

Die Dekonstruktion dechiffriert soziale Identitäten und die ihnen immanenten Wissensordnungen als kontingente Produkte einer Geschichte der Macht, in der um grundbegriffliche Hierarchien, anerkennungswürdige Subjektpositionen und Herrschaftsverhältnisse gerungen wird. ${ }^{74}$ Indem sie der jeweils formierten Objektivität eine irreduzible Unentscheidbarkeit entgegenhält und die Kontingenz und Machtimmanenz von Sinnselektionen ontologisch verankert, entfaltet sie zweitens eine politische Logik. ${ }^{75}$

Drittens ist der poststrukturalistischen Diskurstheorie ein ethisches Moment immanent. Es handelt sich um eine „Praxis der Lektüre“"76, die dazu auffordert, Diskurse mit ihrem verworfenen Anderen zu konfrontieren. Sie forciert eine Ethik, die sich kritisch gegenüber universalistischen Erzählungen verhält, ihr Ziel aber nicht darin erkennt, diese Erzählungen und die darin eingebetteten gesellschaftlichen (Herrschafts-)Verhältnisse von einem Ort jenseits der Macht zu kritisieren und schließlich zu überwinden, sondern für eine dauerhafte Politisierung zu öffnen.

72 In „Hegemonie und radikale Demokratie“ bezeichnen Laclau und Mouffe diesen Möglichkeitsraum als Feld der Diskursivität (Laclau/Mouffe 2006 [1985]: 149) - ein Begriff, der in späteren Arbeiten nicht mehr auftaucht.

73 Laclau 1990b: 90.

74 Vgl. Sigglow 2009: 30f.

75 Entsprechend konstatiert Derrida: „Die Tatsache aber, dass die Dekonstruktion scheinbar politisch neutral ist, erlaubt uns einerseits eine Reflexion über das Wesen des Politischen und andererseits, und das ist es was mich an der Dekonstruktion interessiert, eine Hyperpolitisierung. [...] Dekonstruktion ist Hyperpolitisierung“ (Derrida 1999: 189). Es ist insbesondere dieses Denken des Politischen, das die Hegemonietheorie Laclau/Mouffes radikalisieren und begrifflich engführen wird (Vgl. exemplarisch Mouffe 1999: 14).

76 Moebius/Quadflieg 2006: 299. 


\subsection{Die konzeptuellen Bausteine DER HEgEMONIETHEORIE}

Wie Derrida beziehen Laclau und Mouffe eine postfundamentalistische Positi$o n^{77}$ : Die Vorstellung, Gesellschaft ließe sich von universellen Geltungskriterien ableiten und ein für alle Mal als objektive, gerechte oder rationale Ordnung begründen, wird zurückgewiesen. Die mittels des Konzepts der différance vollzogene Dekonstruktion der Geschlossenheits- und Stabilitätsannahme der synchron orientierten Linguistik de Saussures rekonzipiert Sprache als unendliches Spiel, in dem Differenzen fortlaufend verschoben und modifiziert werden. So können Laclau und Mouffe im Anschluss an Derrida, das Diskursive als unentscheidbares Terrain denken, auf dem jede Fixierung von Sinn und somit jede stabilisierte Gesellschaftsform unterwandert wird.

Dieses radikal kontingente Terrain ist das Spielfeld der Hegemonie. Denn wenngleich es unmöglich ist, Sinn im Rahmen einer geschlossenen Totalität zu fixieren, sind provisorische Sinnstabilisierungen möglich. Diese prekären Stabilisierungen von Sinnzusammenhängen bezeichnet der Hegemoniebegriff. Hegemoniale Projekte - man denke etwa an den Marxismus, den Fordismus, die Soziale Marktwirtschaft, den Neoliberalismus oder die ,Modernisierung' der Sozialdemokratie durch Toni Blair und Gerhard Schröder mit dem Projekt des Dritten Weges - zielen darauf, historisch-spezifische Diskurse als allgemeingültig und alternativlos zu universalisieren. Die genannten Beispiele machen deutlich, dass es sich bei hegemonialen Diskursen nicht nur um politische Strategien zum Gewinn von Mehrheiten handelt. Hegemoniale Projekte wirken operativ in der Gesellschaft, indem sie die prinzipielle Unbestimmtheit des Sozialen vorübergehend kompensieren und bestimmte Identitäten als anerkennungswürdig und begehrenswert präsentieren. ${ }^{78}$

\subsubsection{Artikulation, Diskurs, Knotenpunkte}

Um zu beschreiben, wie Hegemonien etabliert, konsolidiert und infrage gestellt werden, führen Laclau und Mouffe die grundlegende Unterscheidung zwischen Artikulation und Diskurs respektive zwischen Elementen und Momenten ein. Unter Artikulation verstehen sie

77 Vgl. zum Begriff Marchart 2007.

78 Vgl. Reckwitz 2006: 343. 
,jede Praxis, die eine Beziehung zwischen Elementen so etabliert, dass ihre Identität als Resultat einer artikulatorischen Praxis modifiziert wird. Die aus der artikulatorischen Praxis hervorgehende strukturierte Totalität nennen wir Diskurs. Die differentiellen Positionen, insofern sie innerhalb eines Diskurses artikuliert erscheinen, nennen wir Momente. Demgegenüber bezeichnen wir jede Differenz, die nicht diskursiv artikuliert ist, als Element." 79

Artikulationen sind also Praktiken, die Elemente zueinander in Beziehung setzen und dadurch Sinn generieren. Sie verknüpfen flottierende Signifikanten und verwandeln sie durch die Institution von so genannten Knotenpunkten in partiell fixierte Momente eines Diskurses. ${ }^{80}$ Unter Knotenpunkten werden Signifikanten verstanden, die Elemente in ein Beziehungsgeflecht integrieren und ihre Differenz/Identität provisorisch arretieren. ${ }^{81}$ Knotenpunkte schaffen ,operative Paradigmen $^{\text {“82. }}$. Sie kreieren stabile Ensembles aufeinander bezogener Aussagen und Konzepte, die durch ihre Iteration als diskursiv-normative Anweisungsstrukturen fungieren und auf diese Weise bestimmte Regelmäßigkeiten und Normalitäten hervorbringen.

Welche Signifikanten als Knotenpunkte instituiert werden und welche Sinnzusammenhänge dadurch hergestellt werden, ist kontingent. Denn Artikulationen sind streng postfundamentalistisch zu denken. Sie besitzen „,keine Konstitutionsebene vor oder außerhalb der Verstreuung der artikulierten Elemente" ${ }^{\text {"83 }}$. Artikulationen werden also nicht etwa durch eine ihnen vorgeordnete Instanz prädeterminiert und dürfen daher auch nicht als Nachbildungen eines außerdiskursiven Bauplanes missverstanden werden. Es handelt sich um hegemoniale, so oder anders mögliche Verknüpfungen, die sich in hybriden, aus unterschiedlichen Ele-

79 Laclau/Mouffe 2006 [1985]: 141.

80 Vgl. ebd.: 151.

81 Vgl. Moebius 2003: 170.

82 Der Begriff operatives Paradigma stammt von Sheldon Wolin (1968: 183ff.). Operative Paradigmen präjudizieren, welchen Phänomenen potentiell welche Bedeutung zugeschrieben werden kann. Politik- oder gesellschaftstheoretische Analysekategorien sind demnach nicht als abstrakte, streng propositionale Aussagen, sondern als performative Sprechakte und Denkfiguren zu lesen (vgl. dazu auch Skinner 1969, Asbach 2002). Sie wirken „operativ in der Gesellschaft [...], indem sie Institutionen und Praktiken ihren Platz, Charakter und Bedeutung verleihen und dabei handlungsleitend wirken“ (Rosa 1994: 199f.). Es handelt sich um idées-forces (Bourdieu), Konzepte mit identitätsstiftendem und mobilisierendem Potential.

83 Laclau/Mouffe 2006 [1985]: 146. 
menten zusammengefügten Identitäten niederschlagen. Folglich können die daraus hervorgehenden Diskurse nur als unsichere Einheiten existieren. So versucht zwar jeder Diskurs, sich als Totalität zu konstituieren, „das Feld der Diskursivität zu beherrschen [und] das Fließen der Differenzen aufzuhalten“" ${ }^{\text {" }}$, doch muss jeder dieser Anläufe an den polysemischen Spuren der différance scheitern. Infolgedessen ist die kontingente Praxis der Artikulation der beständigen Struktur des Diskurses logisch vorgeordnet: Diskurse (und die durch sie konstituierten Sinnzusammenhänge und gesellschaftlichen Formationen) werden erst durch kontingente Artikulationen konstituiert. Sie sind „Produkte“ ${ }^{\text {85 }}$ von Artikulationen.

Allerdings operieren artikulatorische Praktiken nicht in einem luftleeren Raum, sondern auf einem hegemonial verfassten Terrain, d.h. auf einem Feld, auf dem vielfältige Diskurse sedimentiert sind und bestimmte Vorstellungen, Wissensbestände Normen, Erwartungen, Traditionen und Subjektpositionen instituiert haben. ${ }^{86}$ Diese historisch spezifischen Konstellationen konstituieren das Ausgangsmaterial und die Ausgangssituation für artikulatorische Praktiken. ${ }^{87}$ Sie lösen gewisse Pfadabhängigkeiten ${ }^{88}$ aus, indem sie dafür sorgen, dass in einem spezifischen gesellschaftlichen Kontext bestimmte Artikulationen wahrscheinlicher werden als andere.

84 Laclau/Mouffe 2006 [1985]: 150.

85 Vgl. Akerstrom Andersen 2003: 50.

86 Zum Konzept der Sedimentation von Hegemonien vgl. Laclau 1990a: 34; sowie daran anschließend das von Joscha Wullweber (2012: 36) entworfene „Schichtmodell Sedimentation und Reaktivierung“. Dieses Terrain werden Laclau und Mouffe als das Soziale bezeichnen (vgl. Laclau 1990a: 34).

87 Laclau und Mouffe grenzen sich damit gegen die „postmoderne Konzeption einer unbegrenzten Fragmentierung des Sozialen ab, die sich weigert, den Fragmenten irgendeine Art relationaler Identität zu geben“ (Laclau/Mouffe 2006 [1985]: 25, vgl. auch Sigglow 2009: 38). Im Gegensatz zu dieser „Pulverisierung des Sozialen“ (Laclau/Mouffe 2006 [1985]: 140) im Rahmen eines unbegrenzten Pluralismus fordert die Theoriearchitektur Laclau/Mouffes dazu auf, die Faktizität und die Notwendigkeit diskursiver Sinnstabilisierungen und die ihnen immanenten Ausschlüsse anzuerkennen.

88 Grundlegend zum Konzept der Pfadabhängigkeit vgl. Pierson 2004; für eine Anwendung auf den ,Schweizer Sonderfall‘ vgl. Imhof 2007. 


\subsubsection{Antagonismus, Dislokation und das Subjekt als Mangel}

„Ce qui constitue une République, c'est la destruction totale de ce qui lui est opposé.“

SAINT-JUST 1957: 117F.

Bei Derrida zeigte sich das Scheitern des Diskurses, sich als geschlossene Totalität zu konstituieren, in der Irreduzibilität des konstitutiven Außen. Demnach konstituiert ein Diskurs zwar eine relationale, aus aufeinander bezogenen Differenzen bestehende Totalität, doch setzt dieses System, um sich selbst als Ganzheit zu konstituieren, eine weitere Differenz voraus, die nicht Bestandteil des Ganzen, sondern von diesem verschieden sein muss. In anderen Worten, als artikuliertes System von Differenzen kann sich ein Diskurs nur konstituieren, indem es eine Differenz exterritorialisiert.

Diesen Gedanken radikalisieren Laclau und Mouffe mittels des Konzepts des Antagonismus zu einer innovativen Konflikttheorie. Wohingegen die Konflikttheorien des sozialwissenschaftlichen Mainstreams fragen, worauf Konfliktbeziehungen gründen, wie Konfliktbeziehungen entstehen und überwunden werden können, fokussiert der Antagonismusbegriff, was ein Konfliktverhältnis eigentlich ausmacht. ${ }^{89}$ Grundlage dieser Verschiebung ist, dass Antagonismen nicht mit Interessen- oder Wertkonflikten zwischen präexistenten Identitätsgruppen gleichgesetzt werden. Antagonismen sind weder Widersprüche noch Realoppositionen. ${ }^{90}$ Die Konstruktion eines Antagonismus repliziert nicht etwa eine vorgängige Kontraritätsbeziehung zwischen zwei präkonstituierten, vollen Entitäten und politisiert diesen Gegensatz. Diese Möglichkeit, die Carl Schmitts FreundFeind-Unterscheidung zugrunde liegt, wurde mit Derrida und de Saussure als essentialistisch verworfen. ${ }^{91}$ Vielmehr bezeichnet der Antagonismusbegriff eine Operation, welche die beiden Entitäten erst herstellt, indem sie diese voneinander abgrenzt.

Ein Antagonismus ist eine kontingente, sozial performative Wir-SieUnterscheidung. Welche Differenz als antagonistisches Anderes fungiert, kann nur als Effekt einer unentscheidbaren Entscheidung gedacht werden. Differenz respektive Identität ist insofern nicht bloß politisierbar, sondern per se politisch.

89 Zur Unterscheidung des Antagonismusbegriffs und konventionellen Konfliktbegriffen vgl. Auer 2008: insb. 252.

90 Von diesen beiden Begriffen grenzen Laclau und Mouffe (2006 [1985]: 161ff.) ihr Konzept des Antagonismus ab.

91 Schmitt 1991. 
Dass dies den Subjekten als Trägern von Identität in actu in der Regel nicht bewusst ist, ist Ausdruck einer sedimentierten Hegemonie, eines Diskurses, dem es gelungen ist, die Kontingenz seiner antagonistischen Grundlegung zu verschleiern.

Die sozialtheoretische Perspektive, die sich im Antagonismusbegriff verdichtet, lässt sich als dezisionistischer Konstruktivismus bezeichnen. Im Hinblick auf die Untersuchung gesellschaftlicher Konflikte verschiebt diese Perspektive das Erkenntnisinteresse von den Ursachen sozialer Konfliktbeziehungen zu deren praktischer Instituierung. Sie fordert dazu auf, zu untersuchen, auf welche Weise Konfliktkonstellationen modelliert werden und wie sozialstrukturell heterogene Elemente (sedimentierte Identifikationsbegriffe, unerfüllte Forderungen und subjektive Unrechtserfahrungen) in den Identitäten der Konfliktparteien fusionieren.

Antagonismen instituieren eine Demarkationslinie ,zwischen dem, was legitimerweise ,innerhalb“ der intelligiblen Sphäre der Gesellschaft verläuft, und dem, was als bedrohliches, inakzeptables und kaum begreifbares Anderes außerhalb der Grenzen der Gesellschaft [...] situiert ist ${ }^{، 92}$. Entscheidend ist, dass das Diesseits und das Jenseits der Demarkationslinie, das Innen und Außen des Diskurses, nicht unabhängig voneinander existieren. Denn ein antagonistisches „Verhältnis entsteht nicht aus vollen Totalitäten, sondern aus der Unmöglichkeit ihrer Konstitution ${ }^{\text {‘93 }}$. Die Konfliktualität resultiert also daraus, dass mein antagonistisches Gegenüber mich daran hindert, meine volle Identität zu verwirklichen. Diese Pointe des Antagonismusbegriffs exemplifiziert Slavoj Žižek anhand des Klassenkonfliktes:

„The relation between the two classes is antagonistic in the Laclau/Mouffe sense of the term, i.e. it is neither contradiction nor opposition but the ,impossible' relationship between the two terms: each of them is preventing the other from achieving its identity with itself, to become what it really is. As soon as I recognize myself, in an ideological interpellation, as a ,proletarian', I am engaged in the social reality, fighting against the ,capitalist" who is preventing me from realizing fully my human potential, blocking my full development. “94

Die Präsenz der Kapitalisten als parasitäres Anderes ist einerseits die notwendige Konstitutionsbedingung des kommunistischen Diskurses und der darin geschöpf-

92 Reckwitz 2006: 345.

93 Laclau/Mouffe 2006 [1985]: 164.

94 Žižek 1990: 251. 
ten proletarischen Identität. Andererseits sorgt ihre Präsenz dafür, dass die imaginäre Fülle der kommunistischen Gesellschaft versperrt ist.

Dasselbe antagonistische Konstruktionsprinzip wohnt etwa dem von Anthony Giddens theoretisch entwickelten und von Toni Blair und Gerhard Schröder politisch forcierten Projekt des ,Dritten Weges“ inne, nur dass sich Blairs und Schröders Diskurs der ,Neuen Mitte“ nicht durch die Einrichtung eines zentralen Antagonismus, sondern durch die Konstruktion peripherer Antagonismen konstituiert. Hierzu wird der binäre Antagonismus zwischen links und rechts als anachronistisch verworfen, um die jeweiligen Identifikationsbegriffe im Rahmen des eigenen politischen Projekts zu synthetisieren. Die Synthese linker und rechter Positionen, die sich etwa im Slogan ,Fordern und Fördern“ verdichtet, setzt jedoch die Negation eines antagonistischen Lagers aus ,Ewiggestrigen und Uneinsichtigen“ voraus. Denn nur mit dem Verweis auf das ideologisch verbrämte Andere lassen sich neoliberale und sozialdemokratische Momente zu einer vermeintlich universellen „Lebenspolitik““95 verbinden, die den Widerspruch zwischen sozialer Gleichheit und ökonomischer Dynamik im Rah-

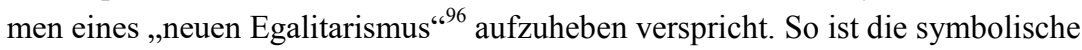
Repräsentation derjenigen, die das politische Projekt nicht anerkennen, einerseits unabdingbar für seine Konstitution. Andererseits verweist dieses Andere auf das Scheitern des Dritten Weges, sich zu universalisieren und seine Identität als vollkommen inklusives Projekt $\mathrm{zu}$ verwirklichen. ,Die Uneinsichtigen und Ewiggestrigen der bildungsfernen Milieus' manifestieren den exklusiven Charakter der eigenen Identität. ${ }^{97}$

Wie jedes andere politische Projekt setzt die „Erneuerung der Sozialdemokratie ${ }^{\text {998 }}$ ein Anderes voraus, das sie zugleich blockiert. Dieses antagonistische Andere ist einerseits Konstitutionsbedingung des Diskurses, andererseits dessen „absolutes Übel“" ${ }^{\text {,99 }}$, die externe Projektionsfläche, die dafür verantwortlich gemacht wird, dass die post-politische Utopie der erneuerten Sozialdemokratie sich nicht vollkommen verwirklichen kann. Die Irreduzibilität dieser nicht-

95 Giddens 1991: 156.

96 Giddens 2007: xii; kritisch Watson/Hay 2004; für eine hegemonietheoretisch informierte Kritik an Giddens‘ Begründung des Dritten Weges vgl. Mouffe 2005, 2007a u. 2011; auch Hildebrand/Lluis Martell 2012.

97 Damit korrespondiert die Tatsache, dass in der Regel bildungsferne Modernisierungsverlierer für das Erstarken jener politischen Projekte verantwortlich gemacht werden, die den Konsens der, Neuen Mitte' infrage stellen (Vgl. exemplarisch Spier 2010).

98 Giddens 1998.

99 Fanon 1981: 34. 
integrierbaren und bedrohlichen Kräfte zeigt, dass die Vision eines „Staates ohne

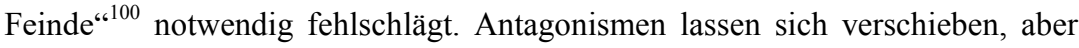
der antagonistische Charakter von Gesellschaft kann nicht überwunden werden. Die Ausprägung der Antagonismen ist kontingent, ihre ontologische Existenz aber notwendig.

Der Antagonismus spielt somit eine paradoxale Doppelrolle. Er konstituiert Objektivität und blockiert sie zugleich. Da jede Artikulation von Differenzen innerhalb eines Diskurses nur im Verhältnis zu einem Außen erzeugt werden kann, jedes ,Wir' ein inkompatibles ,Nicht-Wir' voraussetzt, ist das antagonistische Andere die notwendige Bedingung von Objektivität. Gleichzeitig markiert es deren Grenze. Seine untilgbare Präsenz bezeugt das letztendliche Scheitern von Identität. Es zeigt, dass jede soziale Ordnung von einer ,traumatischen Unmöglichkeit ${ }^{\star 101}$ unterwandert wird und jede Begründung von Identität und Gesellschaft in ihrem universellen Geltungsanspruch unterminiert ist.

Der Antagonismus ist der Schlüsselbegriff zur politischen Theorie Laclau/Mouffes. Er oszilliert zwischen der ontologischen und der ontischen Ebene. ${ }^{102}$ Einerseits meint der Antagonismusbegriff die ontologische Irreduzibilität des ultimativen Scheiterns sozialer Ordnung, andererseits bezeichnet er ontische, historisch-spezifische Konfliktbeziehungen, an denen sich dieses Scheitern manifestiert. In späteren Schriften ergänzt Laclau den Antagonismusbegriff durch den Begriff der Dislokation. ${ }^{103}$ Der Dislokationsbegriff bezeichnet fortan die unhintergehbare, ontologisch begründete Unentscheidbarkeit, die jedem Dis-

100 Giddens 1998: 77.

101 Žižek 1990: 249.

102 Laclau unterscheidet streng zwischen diesen Ebenen, da die Differenzierung grundlegend für seinen konsistenten Postfundamentalismus ist, der sich gegen Derrida aber auch gegen Mouffe konturieren lässt (vgl. Marchart 2004; Marchart 2007; für die Gegenüberstellung von Laclau und Mouffe vgl. Hildebrand/Séville 2015).

103 Zur Einführung des Begriffs der Dislokation vgl. Laclau 1990a: 39 ff. u. 72ff. Eine konzise Erläuterung des Begriffs findet sich bei Stavrakakis 2000: insb. 105f. Dort wird das Konzept vorgestellt, um die Erfolgsbedingungen der ökologischen Parteien in Westeuropa zu erfassen. Neben der konsequenten Trennung von Ontologie und Ontik bietet der hinzugefügte Begriff der Dislokation den analytischen Vorteil, das Potential gegenhegemonialer Projekte und die Möglichkeiten neuer Antagonismen vor deren tatsächlicher Konstruktion aufmerksam zu machen (Stavrakakis 1998: 184). 
kurs aufgrund der untilgbaren Präsenz des Anderen innewohnt, ${ }^{104}$ wohingegen der Antagonismusbegriff die ontische, konkret identifizierbare Demarkationslinie meint, die Freund und Feind in einem Diskurs voneinander unterscheidet. Das bedeutet, dass die Konstruktion eines antagonistischen Freund-FeindVerhältnisses als Reaktion auf den grundlegenden, dislozierten Charakter von Identität verstanden werden kann, insofern der konkrete, identifizierbare Feind für das unvermeidliche Scheitern voller Identität verantwortlich gemacht wird.

Aus dem dislozierten Charakter von Identität schließt Laclau auf eine zweifache Subjektkonzeption, anhand der er den Handlungsspielraum des Subjekts theoretisch auszuloten vermag. In seinen frühen Schriften führt Laclau einen an Foucault geschulten Subjektbegriff. Subjekte gehen aus den Positionen hervor, die ihnen Signifikationssysteme zuweisen. Sie sind „Effekt[e] der strukturalen Determination [...] - es gibt kein substantielles Bewusstsein, das sich außerhalb der Struktur konstituiert“"105. Diesem klassisch diskurstheoretischen Subjektbegriff setzt Laclau im Anschluss an Slavoj Žižeks Kritik der Reduktion des Subjekts auf strukturell fixierte Positionen eine zweite Subjektkonzeption hinzu: das Subjekt als Mangel. ${ }^{106}$ Wenn das Subjekt diskursiv und antagonistisch konstituiert ist, so das von Žižek nahegelegte, in New Reflections erstmals formulierte und in Minding the Gap gemeinsam mit Lilian Zac präzisierte Argument, ist es auch vom Scheitern geschlossener Diskurse betroffen. ${ }^{107}$

„The structure will obviously not be able to determine me, not because I have an essence independent from the structure, but because the structure has failed to constitute itself fully and thus to constitute me as a subject as well. [...] I am condemned to be free, not because I have no structural identity as the existentialist asserts, but because I have a failed structural identity. “ 108

Dieses notwendige Scheitern konfrontiert das Subjekt mit der Erfahrung des Realen, eines inkommensurablen Mangels, den es nicht etwa passiv erduldet, sondern $\mathrm{zu}$ kompensieren versucht, indem es sich für das symbolisch generierte Identifikationsangebot eines Diskurs entscheidet und seinem Versprechen, eine

104 Entsprechend heißt es bei Laclau (1990a: 39): „Every identity is dislocated insofar as it depends on an outside which both denies that identity and provides the condition of possibility at the same time".

105 Laclau 1999: 126.

106 Žižek 1990.

107 Vgl. Laclau 1990a: insb. 41ff.; Laclau/Zac 1994; auch Stavrakakis 1998.

108 Laclau 1990a: 44. 
abwesende Fülle zu erreichen, Glauben schenkt. ${ }^{109}$ Das Subjekt geht also nicht in seiner diskursiven Subjektivierung auf. Es erscheint als vordiskursive ,psychi-

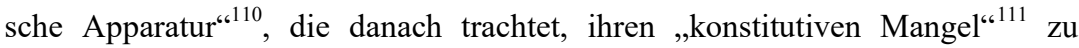
überwinden, indem es sich mit dem Symbolischen einer diskursiven Anrufung identifiziert. Der Mangel und das Begehren des Subjekts wurzeln in der ontologisch gesetzten, antagonistischen Selbstblockade von Identität und avancieren somit zu einer post-essentialistischen conditio humana. ${ }^{12}$

Diese Bedingung menschlichen Seins zeigt sich in exemplarischer Weise in sogenannten dislozierenden Ereignissen. Darunter werden krisenhafte Ereignisse verstanden, die gesellschaftliche Transformationsprozesse auslösen können. Dislozierende Ereignisse sind destruktiv und konstruktiv zugleich, da die Krise der hegemonialen Formation gegenhegemonialen Diskursen die Möglichkeit bietet, die ehedem fixierten Momente anders zu artikulieren. ${ }^{113}$ Zunächst wird in dislozierenden Ereignissen jedoch die Brüchigkeit der Ordnung manifest, weil sie durch die bestehende hegemoniale Formation nicht ohne weiteres integriert werden können. ${ }^{114}$ Gegenhegemonialen Diskursen bieten solche Ereignisse die Gelegenheit, sich die flottierenden Elemente einzuverleiben und ihnen eine neue Bedeutung zuzuweisen. Zunächst aber werden die Subjekte aus ihren struktural determinierten Positionen freigesetzt, so dass sich ihr Entscheidungsspielraum erhöht. Indes wird diese Freiheit nicht zwangsläufig als Befreiung aus einem

109 Vgl. Laclau/Zac 1994: hier 35 sowie Hildebrand/Séville 2015: 31, wo die psychoanalytische Ergänzung der Subjekttheorie durch Laclau als Beleg für die Differenz zwischen Laclau und Mouffe angeführt wird.

110 Reckwitz 2006: 346.

111 Laclau/Zac 1994: 23.

112 Bei dieser allgemeinen Bedingung des Menschseins handelt es sich nicht um einen neuen Fundamentalismus, der eine konkrete Form gesellschaftlichen Zusammenlebens als wahrhaft menschliche universalisieren würde. Nach wie vor gibt es keine „privilegierte epistemologische Stelle“ (Laclau/Mouffe 2006 [1985]: 28), die das Begehren der Subjekte in allgemeingültige Bahnen lenken würde. Die Identitäten, auf die sich die Affekte der Subjekte richten, werden diskursiv generiert und sind daher als radikal kontingente Institutionen zu denken.

113 Zur Produktivität dislozierender Ereignisse vgl. Stavrakakis 1998: 106.

114 In diesem Sinn begreift etwa Philip Casulas (2012) Hegemonieanalyse des russischen Nationalismus unter Vladimir Putin das Ende der Sowjetunion und die darauffolgende Krise der russischen Identität in der Jelzin-Ära als dislozierenden Ausgangspunkt für die hegemoniale Restauration des nationalen Imaginären durch den Diskurs von Putin. 
identitären Korsett, sondern als Identitätskrise empfunden, die das Subjekt durch die Identifikation mit alternativen hegemonialen Identifikationsangeboten $\mathrm{zu}$ kompensieren versucht.

Der Moment des Subjekts besteht folglich keineswegs in der Entscheidung selbst - nach wie vor gibt es keine Subjektivität vor oder jenseits des Diskurses. Sein Moment ist der Augenblick vor der Entscheidung, der Moment, bevor es sich mit einem Diskurs identifiziert und eine partiell fixierte Position einnimmt. ${ }^{115}$ Insofern wohnt der zweifachen Subjektkonzeption keineswegs eine Aporie inne. Die Vorstellung von strukturell determinierten Subjektpositionen einerseits und dem zu Identifikationen gezwungenen Subjekt als Mangel andererseits stehen vielmehr in einem gesellschaftsanalytisch produktiven Spannungsverhältnis: Eine Identifikation mit einem Diskurs und den einschlägigen Positionen (als Mann, Frau, Bürgerin, Liberale oder Konservative, Linker oder Rechter, als Europäer, Deutscher oder Schweizer) ist eine radikal kontingente Selbstbegründung des Subjekts; sie führt zur Festigung einer Subjektposition und damit zur provisorischen Aufhebung des Moments des Subjekts. ${ }^{116}$ Dagegen folgt aus dem dislozierten Charakter der Struktur und den darin eingeschriebenen Subjektpositionen, dass der Mangel des Subjekts irreduzibel ist, neue Situationen der Unentscheidbarkeit und somit neue Momente des Subjekts entstehen, die die getroffenen Entscheidung unterlaufen. ${ }^{117}$

Die Komplettierung des Subjektbegriffs durch die Lacan'sche Triebtheorie spitzt die Bedeutung hegemonialer Diskurse in spezifischer Weise zu: Aus Laclaus Sicht oktroyieren Hegemonien nicht nur bestimmte Subjektpositionen; sie stellen auch subjektiv begehrte Projektionsflächen bereit. Infolgedessen wird die Tatsache, dass Subjekte ihrer Identität mitunter leidenschaftlich verhaftet

115 Vgl. Laclau 1999: 128.

$116 \mathrm{Zu}$ diesem Wechselspiel zwischen Subjektposition und dem Subjekt als Mangel vgl. Laclau 1990a: 61sowie Stäheli 2001: 209.

117 Laclau schlägt damit einen „Mittelweg“ zwischen zwei kritischen Extrempositionen ein, der von Slavoj Žižek vertretenen psychoanalytischen Subjekttheorie einerseits und der etwa von Peter Osborne vertretenen strukturalistischen Subjekttheorie andererseits (Howarth 2004: 264). Wenn Žižek (1990: 250f.) Laclau vorwirft, er reduziere Subjektivität auf diskursiv fixierte Subjektpositionen, und Osborne (1991: hier 210) der Ansicht ist, Laclau vernachlässige die strukturelle Bedingtheit des Subjekts, privilegiere die Logik der Kontingenz und suggeriere, dass „beinahe alles möglich“ sei, dann synthetisiert Laclau diesen Widerspruch, indem er mithilfe der zweifachen Subjektkonzeption über die Situationen und die Prozesse des Verschwindens/Erscheinens des Moments des Subjekts nachdenkt (vgl. Howarth 2004: 264). 
sind, bei Laclau (anders als etwa bei Judith Butler) nicht damit begründet, dass die Inszenierung und Inkorporierung dieser Identität die Voraussetzung dafür ist, als vollwertiges und normales Mitglied der Gemeinschaft anerkannt zu werden. ${ }^{118}$ Subjekte identifizieren sich mit einem hegemonialen Projekt, weil es ihren untilgbaren Mangel aufzuheben verspricht. Gleichzeitig projizieren sie ihren Hass auf das antagonistische Andere, das die Erfüllung dieses Identitätsversprechens blockiert und zur symbolischen Projektionsfläche vielfältiger Frustrationserfahrungen wird. ${ }^{119}$ Damit schafft Laclau Raum für eine strategische Essentialisierung politischer Identitäten. ${ }^{120}$

\subsubsection{Die Subversion von Bedeutung: Die wechselseitige Kontamination von Äquivalenz- und Differenzlogik}

Im vorangegangenen Unterkapitel habe ich rekapituliert, wie sich Diskurse provisorisch zu Totalitäten schließen, indem sie eine Differenz exkludieren. Diskursiv erzeugte Identitäten sind nicht substantiell begründet, sondern antagonistisch organisiert: „An objective identity is not a homogeneous point but an articulated set of elements. But as this articulation is not a necessary articulation, its characteristic structure, its ,essence ' depends entirely on that which it denies.“" ${ }^{121}$ Die innere Kohäsion eines Diskurses kann nur durch die symbolische Repräsentation eines Außen erzielt werden, das der imaginierten Einheit feindlich gegenübersteht. Denn nur durch den Verweis auf einen Widerpart können die Differenzen im Innen aufeinander bezogen werden und als Momente einer Totalität erscheinen. Der Wegfall dieses antagonistischen Gegenübers führt zu einer Identitätskrise, in deren Folge eine Identität durch die Konstruktion eines neuen Antagonismus eine semantische Transformation erfährt. ${ }^{122}$

Ein Antagonismus „absorbiert gleichsam alle interne Differenz“, indem er den rein differentiellen Charakter der Elemente sublimiert; er sorgt für „das ten-

118 Zu dieser Differenz zwischen Butler und Laclau vgl. Diestelhorst 2007: insb. 267ff.; auch Moebius 2009: 161.

119 Vgl. Reckwitz 2006: 347; auch Sarasin (2001), der diese Überlegungen an die Rassismusanalyse anschließt.

120 Vgl. Hildebrand/Séville 2015: 34.

121 Laclau 1990a: 32.

122 Vgl. Laclau/Mouffe 2006 [1985]: 187. 
denzielle Verschwinden der Differenzbeziehung“. ${ }^{123}$ Die einzelnen Momente sind immer noch voneinander verschieden, doch sind sie zumindest in einer Hinsicht gleichartig, nämlich in Bezug auf dieses antagonistische Andere. Diese antagonistisch generierte Subversion der Differenz nennen Laclau und Mouffe Logik der Äquivalenz. Diese Logik der Äquivalenz steht in einem Spannungsverhältnis zur grundlegenden Logik der Differenz von Signifikationssystemen. ${ }^{124}$ Wohingegen die Logik der Differenz die Bedeutung diskursiver Momente fixiert, indem sie sie voneinander unterscheidet, konterkariert die Logik der Äquivalenz diese Bedeutungsfixierungen, indem sie die Differenzen gegen ein antagonistisches Außen in Stellung bringt und auf diese Weise gleichsetzt. Gleich einer Metapher instituiert die Logik der Äquivalenz ein wechselseitiges Substitutionsverhältnis: Eine Differenz repräsentiert die andere, alle bezeichnen dasselbe. ${ }^{125}$ Die Logik der Äquivalenz intensiviert die paradigmatische Dimension der Sprache; sie erweitert die einander substituierenden Elemente und verknappt auf diese Weise die Anzahl der Positionen, die differentiell artikuliert werden können. Dagegen forciert die Logik der Differenz die syntagmatische Dimension der Sprache; sie erweitert die Positionen, die zueinander in Beziehung gesetzt werden können. ${ }^{126}$ Das bedeutet, „dass die Logik der Äquivalenz eine Logik der Vereinfachung des politischen Raumes ist, während die Logik der Differenz eine Logik seiner Erweiterung und zunehmender Komplexität ist" ${ }^{\text {"127 }}$.

Jedoch bedingen sich die beiden Logiken trotz ihrer entgegengesetzten Stoßrichtung wechselseitig: Nur wenn etwas nicht im Grunde identisch, sondern verschieden ist, kann es überhaupt äquivalent gesetzt werden und zu sogenannten Äquivalenzketten verknüpft werden; und erst wenn das, was einst verschieden war, als Teil einer Kette artikuliert werden kann, die ein gemeinsames Anliegen konstituiert, ist es möglich, dass sich die strukturell arretierten Differenzen verflüssigen. Der im Poststrukturalismus apostrophierte Antiessentialismus wird durch die wechselseitige Kontamination von Differenz- und Äquivalenzlogik erneut aufgefangen und in gesellschaftsanalytische Begriffe übersetzt. Zurückgewiesen wird nämlich sowohl die Idee eines tieferliegenden Wesens, das den $\mathrm{Zu}$ sammenhang der äquivalentiell artikulierten Elemente begründen könnte, als auch die multikulturelle Vorstellung, die Elemente besäßen eine „fixierte, der

123 Vgl. Sarasin 2001: 36

124 Vgl. Laclau 2005a: 80.

125 Zur Analogie zwischen Metapher und Logik der Äquivalenz vgl. Moebius 2003: 181.

126 Laclau/Mouffe 2006 [1985]: 171

127 Ebd.: 171. 
kontingenten und pragmatischen Form ihrer Artikulation vorausgehende Identität “' ${ }^{128}$, welche die Autonomie ihres Kampfes begründen könnte.

Es ist weder ein Diskurs denkbar, der ausschließlich differenzlogisch komponiert wäre, da jedes Moment in einem solchen Signifikationssystem nur eine invariable Bedeutung hätte, noch lässt sich ein ausschließlich äquivalenzlogisch komponierter Diskurs vorstellen, da die Momente in einem solchen Diskurs alle ein- und dasselbe bezeichnen würden, d.h. die Zugehörigkeit zu einem Diskurs. ${ }^{129}$ Folglich vereint jeder Diskurs sowohl äquivalenz- als auch differenzlogische Aspekte, sodass lediglich von einer graduellen Dominanz der einen oder der anderen Logik gesprochen werden kann. Dabei zielt ein äquivalenzlogisch dominierter Diskurs wie etwa jener des revolutionären Sozialismus auf eine binäre Spaltung der Gesellschaft, indem er eine Differenz, die zuvor Teil des Systems war, als antagonistische Differenz ausschließt und vielfältige Elemente (unerfüllte Forderungen, Subjektpositionen und singuläre Unrechtserfahrungen) gegen dieses absolutes Übel artikuliert. Dagegen versucht ein differenzlogisch dominierter Diskurs wie jener des Dritten Weges eine dichotome Struktur zu transzendieren und die Elemente im Rahmen eines vermeintlich teilungsfreien Ganzen zu absorbieren; im Fall des Erfolges sedimentiert er etwa in Form einer moderat pluralistischen Ausgleichsgesellschaft mit einer starken, konsensual integrierten Mitte und peripheren Antagonismen gegenüber subalternen, nichtkonsensfähigen Positionen, die als ,Extremisten` ausgeschlossen werden. ${ }^{130}$

128 Ebd.: 25.

129 Vgl. Stäheli 2001: 200; Moebius 2003: 180.

130 Laclau und Mouffe (2006 [1985]: 170f.) exemplifizieren die entgegengesetzte Strukturierung der Gesellschaft, die mit der Dominanz der Äquivalenz- respektive der Differenzlogik einhergehen, anhand der millenaristischen Bewegung einerseits und Disraelis Vorstellung der geeinten Nation andererseits. Im millenaristischen Diskurs „zerfällt die Welt durch ein System parataktischer Äquivalenzen in zwei Lager: in die ländliche Kultur, die die Identität der Bewegung repräsentiert, und die städtische Kultur, die das Böse verkörpert“. Disraelis Diskurs versucht dagegen die diagnostizierte Spaltung der französischen Gesellschaft des 19. Jahrhunderts in Arm und Reich rückgängig zu machen, die äquivalentiell artikulierten Elemente in ,objektive Differenzen“ innerhalb eines Systems, einer Nation, zu transformieren. Für Laclau und Mouffe begründete Disraeli damit die illusionäre Agenda des neokorporatistischen Wohlfahrtsstaates, ,der zufolge das Ganze des Sozialen in das intelligible und geordnete Gefüge der Gesellschaft aufgenommen werden“ (ebd.: 171) könne. 


\subsubsection{Leere Signifikanten und Hegemonie: Semantische Entleerungen als Möglichkeitsbedingung provisorischer Universalisierungen}

Wie wir gesehen haben, findet jede Totalität ihre Grenze in einem antagonistischen Anderen. Sie kann nicht als Positivität, sondern nur als Mangel repräsentiert werden, der aus dem notwendig fehlschlagenden Versuch der Schließung resultiert. Gleichwohl existiert eine Möglichkeit, den Diskurs auf imaginäre Weise zu schließen und seine Einheit zum Ausdruck zu bringen. Diese Möglichkeit entfaltet das Konzept des leeren Signifikanten. ${ }^{131}$ Der Begriff antwortet auf die Frage, wie ein Diskurs die Illusion von Originalität und Organizität erzeugt, wenn ein gemeinsamer Ursprung oder Wesenskern, d.h. ein Signifikat, das den systemischen Zusammenhang der artikulierten Momente begründen könnte, ausgeschlossen ist.

Leere Signifikanten entstehen dadurch, dass ein Element der Äquivalenzkette sich seiner spezifischen Bedeutung entledigt. Es entleert sich und befreit sich von seiner partikularen Semantik, um die äquivalentiell artikulierten Elemente in sich aufnehmen zu können. Die Rede von leeren Signifikanten bedeutet daher mitnichten, dass diese nichts mehr repräsentieren würden. Im Gegenteil, leere Signifikanten verkörpern den Zusammenhang der expandierenden Äquivalenz; sie ,bezeichnen, was eigentlich nicht bezeichnet werden kann: die Identität des Diskurses“"132. Ein leerer Signifikant führt eine primordiale Differenz ein, die anderen, bloß sekundären Differenzen übergeordnet ist, und schafft auf diese Weise Ordnung und Kohäsion im kontingenten Feld des Sozialen. ${ }^{133}$ Insofern fungieren leere Signifikanten als ,gemeinsame Nenner“"134. Sie heben die Differenzbeziehungen der Elemente symbolisch auf, sodass diese zu Momenten einer imaginären Einheit fusionieren und als Facetten oder Teilaspekte ein- und desselben Ganzen perzipiert werden.

131 Vgl. auch Laclau 2007a: 65-78 u. 2007b: insb. 30; erläuternd Stäheli 2001: 201f.; Bonacker 2008: 37ff.

132 Stäheli 2001: 201.

133 Ich gebrauche den Begriff der primordialen Differenz in Anlehnung an Shmuel Eisenstadts (2009) Konzept der Primordialität.

134 Laclau 2005a: 95. 
Ein leerer Signifikant begründet das synekdochische Repräsentationsverhältnis, das hegemoniale Beziehungen kennzeichnet. ${ }^{135}$ Durch eine semantische Entleerung transzendiert eine partikulare Differenz ihre begrenzte Bedeutung und wird zum Repräsentanten eines gemeinschaftlichen Anliegens. Die von ihrer konkreten Bedeutung gereinigte Differenz erzeugt „die Illusion einer Synthesis durch Totalisierung ${ }^{\text {“136. Sie wird zum „Jenseits aller Differenz }}{ }^{\text {“137 }}$ und kann die Äquivalenzkette bündeln und programmatisch ausrichten. Folglich ist es die Beziehung zwischen den äquivalentiell artikulierten Differenzen der Kette und dem übergeordneten leeren Signifikanten, die ein hegemoniales Verhältnis ausmacht. „Die Präsenz leerer Signifikanten [...] ist die eigentliche Bedingung für Hegemonie.“138 Nur indem ein Element der Kette sich seiner singulären Bedeutung entledigt, kann es hegemonial werden, die äquivalentielle Verbindung symbolisieren und einen universellen Geltungsanspruch formulieren.

Im leeren Signifikanten durchdringen das Universelle und das Partikulare einander, ohne je identisch zu werden. Einerseits transzendiert die durch die Entleerung erwirkte Universalisierung die partikulare Bedeutung des Signifikanten. ${ }^{139}$ Andererseits ist „das Universelle nichts anderes als zu einem bestimmten Zeitpunkt dominant gewordenes Partikulares“' ${ }^{\text {140 }}$, sodass Universalität immer nur als pragmatisches und prekäres Repräsentationsverhältnis existiert. ${ }^{141}$

Ein leerer Signifikant kann weder das Spiel der différance beenden und das Flottieren der Signifikanten arretieren, noch kann er seine antagonistische Konstruktionslogik abstreifen. Insofern ist ein Ende von Geschichte in Form der vollen Realisierung einer universellen Teleologie theorieimmanent ausgeschlossen. Eine vollständige Hegemonie ist nicht möglich: Der Übergang vom partikularen Mythos - der politischen Vision einer idealen Gesellschaft, die den Mangel der Gegenwart zu überwinden verheißt und aufgrund dessen als kohäsive Einschrei-

135 Zur Synekdoche als der für hegemoniale Beziehungen konstitutiven Trope vgl. Laclau 2000: 57; erläuternd Sigglow 2009: 51.

136 Paul de Man, zitiert nach Laclau 2001: 156.

137 Laclau 2007a: 74.

138 Ebd.

139 Entsprechend hält Laclau fest: „No particularity can become political without becoming the locus of universalizing effects“ (Laclau 2000: 56).

140 Laclau 2007a: 52.

141 Vgl. ebd.: 148. 
befläche der defizitären Elemente fungiert - zum universellen sozialen Imaginären als der einzig denkbaren Ordnung kann niemals vollständig gelingen. ${ }^{142}$

Mit der polysemischen Überdeterminierung des leeren Signifikanten legt Laclau den Grundstein für einen antitotalitären, pluralismuskompatiblen und politisch prozeduralisierenden Universalismus. Die Offenheit leerer Signifikanten versetzt diese nämlich in die Lage, als identitätsstiftende Bezugspunkte zu fungieren und politische Debatten zu kanalisieren, ohne im Stile der Leitkulturdebatte eine spezifische Identifikation als einzig legitime vorzuschreiben. Die Vagheit identitätsstiftender Begriffe ist daher nichts defizitäres, sondern die notwendige Bedingung der universalisierende Operation, die den Zusammenhang der äquivalentiell artikulierten Differenzen ausdrückt. Nur aufgrund ihrer Vagheit können Signifikanten wie Gerechtigkeit, Demokratie oder Fortschritt zum Schnittpunkt widerstreitender Diskurse und zur potentiellen Einschreibungsfläche heterogener Identitäten werden.

Jedoch darf Vagheit nicht mit Beliebigkeit verwechselt werden. ${ }^{143}$ Vielmehr hallt die dem Hegemoniebegriff inhärente Macht- und Ordnungsorientierung im leeren Signifikanten wider. Denn ein leerer Signifikant führt keineswegs zu einem grenzenlosen Pluralismus. Leere Signifikanten sind niemals vollkommen leer und können daher auch nicht beliebig befüllt und resignifiziert werden. Vielmehr instituiert ein leerer Signifikant einen zentralen Bezugspunkt in der Konstruktion einer ,abwesenden Totalität“"144 und marginalisiert dadurch zugleich alternative Konstruktionen. ${ }^{145}$

142 Laclau (1990a: 60f.) führt die konzeptuelle Differenz zwischen Mythos und sozialem Imaginären ein, um zwischen erfolgreichen und weniger erfolgreichen politischen Projekten zu unterscheiden. Mythen fungieren als hegemoniale Projektionsfläche für die äquivalentiell artikulierten Elemente (Howarth/Stavrakakis 2000: 15). Für den Fall ihres Erfolges avancieren sie zu einem sozialen Imaginären. Als solches konstituieren sie einen Horizont, „der ein Feld der Intelligibilität strukturiert“ (Laclau 1990a: 64), d.h. darüber bestimmt, welche gesellschaftlichen Probleme als politisch relevant und welche politischen Lösungen als legitim und denkbar erachtet werden (vgl. Marchart 2002: 813). Im Unterschied zu konventionellen Konzeptualisierungen des Mythosbegriffs (vgl. etwa Heer 2013: 107) in den Sozialwissenschaften ist jene von Laclau nicht notwendige vergangenheitsorientiert und auch nicht notwendig narrativ strukturiert.

143 Karin Priesters (2012b) vehemente Kritik der Populismustheorie Laclaus gründet u.a. auf diesem Missverständnis.

144 Laclau 2007a: 73.

145 Vgl. Sarasin 2001: 37. 
Moderne und plurale Gesellschaften verfügen über eine Vielzahl leerer Signifikanten, die sich überschneiden und miteinander konkurrieren. $\mathrm{Zu}$ analytischen Zwecken lassen sich sedimentierte von innovativen leeren Signifikanten unterscheiden. Als sedimentierte leere Signifikanten begreife ich etablierte identitätsstiftende Begriffe wie Freiheit, Gleichheit, Demokratie, Gerechtigkeit, Abendland oder Fortschritt, aber auch primordiale Kategorien ${ }^{146}$ wie Ethnizität, Religion, Klasse oder Geschlecht. Diese leeren Signifikanten konstituieren symbolische Ressourcen von Politik. Aufgrund ihrer semantischen Offenheit können sie von unterschiedlichen politischen Projekten hegemonisiert werden. Dagegen verstehe ich unter innovativen leeren Signifikanten solche, die (zunächst) nur im Rahmen eines politischen Projekts artikuliert werden. Dabei handelt es sich beispielsweise um Slogans oder die Namen von Führungsfiguren politischer Protestbewegungen. So steht etwa die polnische Gewerkschaft Solidarnosc nicht nur für die partikularen Forderungen von Danziger Werftarbeitern, sondern verkörpert den Widerstand gegen den sowjetischen Imperialismus; der Slogan ,Freiheit für Nelson Mandela' beinhaltet nicht nur die Forderung nach der Freilassung des inhaftierten politischen Aktivisten, sondern bündelt den Widerstand gegen das Apartheidsystem und imaginiert die zukünftige Prosperität eines demokratischen Südafrikas; und der Name der verstorbenen Eva Peron meint nicht nur das Schicksal der argentinischen Präsidentengattin, sondern avanciert zum Repräsentanten des argentinischen Volkes. ${ }^{147}$ Sedimentierte leere Signifikanten und innovative leere Signifikanten sind nicht rigide voneinander getrennt; vielmehr gehen erstere aus letzteren hervor. So hat sich beispielsweise Solidarnosc in einen leeren Bezugspunkt des politischen Imaginären postsozialistischer Gesellschaften verwandelt, auf den sich nahezu alle politischen Kräfte beziehen.

In der Regel ist die Instituierung leerer Signifikanten ein langwieriges politisches Unterfangen. In extremen Fällen entstehen sie jedoch binnen Stunden. So ließ sich nach den terroristischen Anschlägen auf das französische Satiremagazin Charlie Hebdo im Januar 2015 beobachten, wie die Selbstbeschreibung ,Je suis Charlie', die zunächst ein Ausdruck der Anteilnahme und allenfalls als entschlossenes Votum für die Vorrangstellung der Presse- und Meinungsfreiheit gegenüber religiösen Gefühlen war, sich innerhalb kürzester Zeit zu einem leeren Signifikaten entwickelte, mit dem sich die Französische Nation und die gesamte ,zivilisierte Welt‘ identifizierte. ,Je suis Charlie' stand nicht nur für Meinungs- und Pressefreiheit, sondern für ein überdeterminiertes ,Wir', um dessen

146 Eisenstadt 2009.

147 Das Solidarnosc-Beispiel stammt von Laclau (2005a: 81 u. 2006: 652f.); das Mandela-Beispiel von Oliver Marchart (2005: 267). 
konkrete Bedeutung laizistische, sozialdemokratische, kulturrassistische, antisemitische, antiimperialistische und kosmopolitische Diskurse rangen, indem sie unterschiedliche Antagonisten und unterschiedliche Äquivalenzketten konstruierten.

Welcher Signifikant sich in einen leeren Signifikanten verwandelt und die abwesende Totalität repräsentiert, ist prinzipiell unentscheidbar. Dass in einer spezifischen gesellschaftlichen Konstellation beispielsweise der Signifikant ,good governance' bessere Chancen hat, sich zu entleeren als der Signifikant ,Demokratie‘, gründet allein in der aus sedimentierten hegemonialen Auseinandersetzungen resultierenden „Unebenheit des Sozialen“148. Gleich Knotenpunkten und Antagonismen reflektieren leere Signifikanten keineswegs ein grundsätzliches Organisationsprinzip oder eine übergeordnete Teleologie. Sie lassen sie sich weder von einer metaphysischen Instanz deduzieren noch von einer ontologischen Basis herleiten, sondern sind als Effekte kontingenter Artikulationen zu begreifen. Als solche entspringen sie nicht der deduktiven Logik der Abstraktion, sondern einem „radikalen Investment" ${ }^{\text {149 }}$, das nicht philosophisch begründet, sondern nur politisch getätigt werden kann. Die jeweils konstituierte Universalität ist nicht ,wahr' oder ,falsch' respektive ,objektiv“ oder ,ideologisch", sondern ,leer' und infolgedessen politisch besetzbar.

Folglich kann Laclau mit dem leeren Signifikanten gegen Claude Lefort argumentieren, dass der leere Ort der Macht nach dem Verlust transzendentaler Legitimationsquellen von Herrschaft zwar niemals vollkommen ausgefüllt werden kann, hegemoniale Verkörperungen des legitimitätsstiftenden Grundes aber möglich und politisch notwendig sind. ${ }^{150}$ Aus Laclaus Sicht zielen politische Projekte also darauf, die abwesende Fülle der Gemeinschaft zu resignifizieren. Hierzu konstruieren sie ein antagonistisches Außen, das für den Mangel in Haftung genommen wird, und verwandeln ihre Knotenpunkte in leere Signifikanten, sodass die Subjekte des Mangels ihre libidinösen Energien auf eben diese Signifikanten projizieren. ${ }^{151}$

148 Laclau 2007a: 73.

149 Laclau 2005a: 71, 97 u. 110.

150 Im Unterschied zur Demokratietheorie Claude Leforts ist der Ort der Macht bei Laclau nicht leer. Vielmehr müssen sich die Subjekte, die darauf abzielen, den Ort der Macht zu okkupieren, partiell entleeren (vgl. ebd.: 166).

151 So ist es etwa dem politischen Projekt der Grünen gelungen, den sedimentierten leeren Signifikanten ,Fortschritt‘ durch den grünen Knotenpunkt ,Nachhaltigkeit` zu ersetzen, indem der Signifikant ,Nachhaltigkeit‘ von seiner partikularen Bedeutung als ökologisches Waldbewirtschaftungsprinzip befreit wurde und sich in ein allge- 


\subsection{Die UnMöglichKeIt VON GeSELLSChAFT UND das PRimat des Politischen}

Die Begriffe Antagonismus, Dislokation, leerer Signifikant, Äquivalenz- und Differenzlogik und das Wechselspiel zwischen struktural determinierten Subjektpositionen und dem Subjekt als Mangel bilden das konzeptuelle Gerüst, mit dem Laclau und Mouffe beschreiben, auf welche Weise die „Anatomie der sozi-

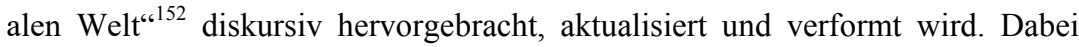
liegt das Hauptaugenmerk der Hegemonietheorie darauf, dass die Konjunkturen spezifischer Selbstbeschreibungen von Gesellschaft nicht etwa als Realisierung basaler Teilungsprinzipien, einer vordiskursiven Teleologie oder als Siegeszug des besseren Arguments, sondern als Resultat politischer, d.h. radikal kontingenter, macht- und entscheidungsimmanenter Bedeutungsfixierungen rekonstruiert werden.

Grundlage dieser Perspektive auf Gesellschaft ist der auf die Dekonstruktion rekurrierende Postfundamentalismus Laclau/Mouffes, der jeden denkbaren Grund verabschiedet, von dem aus Sinn, Identität und Ordnung als notwendige, natürlich bedingte oder legitime Institutionen rekonstruiert werden könnten. Bei Laclau und Mouffe wird somit deutlich, dass die Dekonstruktion keineswegs in einem gesellschaftsanalytisch gehaltlosen und politisch handlungsunfähigen $\mathrm{An}$ tifundamentalismus mündet, der sich in einer notorischen Kritik sozialer Institutionen erschöpft, sondern eine Perspektive ermöglicht, die soziale Ordnungen als Effekte politischer Fixierung von Sinn liest. ${ }^{153}$

Im Unterschied zu Derrida, der die Dekonstruktion durch eine Ethik der Anerkennung des Anderen supplementiert, indem er aus seiner unhintergehbaren Präsenz auf die ethischen Prinzipien von Freundschaft und Verantwortung schließt, fokussieren die beiden nicht in erster Linie die ethischen, sondern die gesellschafts- und politiktheoretischen Implikationen des Poststrukturalismus. ${ }^{154}$

meines Prinzip rationalen und moralischen Regierens verwandelt hat. - Freilich zu dem Preis, dass die politischen Mitbewerber den Signifikanten ebenfalls artikulierten und ihrem Diskurs einverleiben, sodass der Nachhaltigkeitsbegriff seine ,politische Farbe‘ verlor und mit ihm die Grüne Partei ihre binär-antagonistische Position gegenüber dem Status quo.

152 Vgl. Laclau 2005a: 110.

153 Vgl. Marchart 2007: 11ff. u. 155.

154 Zur „Politik der Freundschaft“ und der poststrukturalistischen Begründung der ethischen Prinzipien Anerkennung und Verantwortung vgl. Derrida 2000 sowie (im An- 
Angesichts der apostrophierten Unendlichkeit des Spiels der Differenzen und der antagonistischen Selbstblockade des Diskurses kann es die Gesellschaft im Sinne einer vollständig konstituierten Totalität nicht geben. Zurückgewiesen wird jedoch nicht die Idee, dass Gesellschaft begründet werden kann, sondern nur die fundamentalistische Setzung eines transzendentalen Grundes, von dem aus die Gesellschaft als objektive Ordnung deduziert werden könnte. Daher ersetzen Laclau und Mouffe den Gesellschaftsbegriff durch den Begriff des Sozialen. Das Soziale bezeichnet bei Laclau und Mouffe einen Zwischenraum, der durch eine Pendelbewegung zwischen Öffnung und Schließung charakterisiert ist. Das Soziale oszilliert zwischen dem unendlichen Spiel der Differenzen als ontologischer Möglichkeitsbedingung von Wandel und der aktualen Begrenztheit dieses Spiels, die sich in der ontischen, relativen Stabilität gesellschaftlicher Formationen niederschlägt: „Auch wenn das Soziale sich nicht in den intelligiblen und instituierten Formen einer Gesellschaft zu fixieren vermag, so existiert es doch nur als Anstrengung, dieses unmögliche Objekt zu konstruieren. ${ }^{155}$ Hier wird deutlich, dass die politische Ontologie den Gesellschaftsbegriff nicht zum Verschwinden bringt. Gesellschaft besteht, aber sie „besteht immer nur aus fehlgeschlagenen Versuchen, sich selbst als universalen und hegemonialen Horizont zu etablieren“" ${ }^{\text {156 }}$. Dadurch dass die Gesellschaft nicht bezeichnet werden kann, aber dennoch bezeichnet werden muss, entsteht soziale Ordnung im Widerstreit hegemonialer Diskurse. In anderen Worten, die Unmöglichkeit, Gesellschaft als Totalität zu instituieren, ist die Ermöglichungsbedingung für unterschiedliche Totalisierungen dieses Objekts (etwa als Erlebnisgesellschaft, postmoderne Gesellschaft, Risikogesellschaft, spätkapitalistische Gesellschaft, Prekariatsgesellschaft oder als spezifisch schweizerische Gesellschaft). Gerade weil die Gesellschaft nicht existiert, existieren multiple Selbstbeschreibungen von Gesellschaft, die darum konkurrieren, diese unmögliche Totalität herzustellen und das Soziale zu fixieren, indem sie sich begrenzend schließen und eine Differenz als antagonistisches Anderes exterritorialisieren.

Da diese antagonistischen Schließungen nicht aus fundamentalen Ordnungsprinzipien deduziert werden können, ist das Soziale als „Effekt von Macht und

schluss an Derrida und Emmanuel Lévinas) Critchley 2008; Moebius 2003. Laclau (2007a) steht dieser Verbindung von Poststrukturalismus und Ethik kritisch gegenüber. Für eine Gegenüberstellung der Positionen Derridas und Laclau/Mouffes in Bezug auf das Verhältnis zwischen Ethik und Politik vgl. Sigglow 2009: insb. 65ff.

155 Laclau/Mouffe 2006 [1985]: 150.

156 Stäheli 2000: 34. 
nichts als Macht ${ }^{\text {“157 }}$ zu lesen. Es „kann [...] nur in den Formen einer Macht bestehen, welche die Spuren ihrer Kontingenz verwischt hat ${ }^{\text {"“158 }}$. Macht darf daher auch nicht mit Weber auf eine repressive Instanz zur Einschränkung der Handlungsmöglichkeiten des anderen verkürzt werden. Wie bei Foucault ist Macht für Laclau und Mouffe kein empirisches, sondern ein ontologisches Konzept: Macht ist das logische Komplement der radikalen Kontingenz. Sie ist sozialen Identitäten nicht äußerlich, sondern vorgängig. ${ }^{159}$

Indem Laclau und Mouffe die machtvolle Instituierung antagonistischer Beziehungen als irreduzibles Konstitutivum sozialer Ordnung denken, proklamieren sie ein Primat des Politischen gegenüber dem Sozialen. ${ }^{160}$ Das Politische lässt sich weder als schlichte Folge präkonstituierter Identitätsgruppen mit divergierenden Interessen und Werten denken, noch lässt es sich durch die liberale Unterscheidung zwischen öffentlich und privat erfassen. ${ }^{161}$ Es bezeichnet weder ein begrenztes Feld noch ein gesellschaftliches Funktionssystem, das nach dem binären Code ,Machtgewinn-Machtverlust' kommuniziert, sondern die antagonistische Logik, die der Instituierung des Sozialen zugrunde liegt. ${ }^{162}$ Diese Logik

157 Vgl. Marchart 2008: 169 sowie zum Primat der Macht gegenüber der Identität die vielzitierte Formulierung Laclaus (1990a: 31): „The constitution of social identity is an act of power and [...] identity as such is power.“

158 Laclau 2007a: 149.

159 Vgl. Laclau/Mouffe 2006 [1985]: 27.

160 Vgl. Laclau 1990a: 36.

161 Aus einer hegemonietheoretischen Perspektive wird vielmehr deutlich, dass die Trennung zwischen öffentlichen und demzufolge politischen bzw. politisierbaren Angelegenheiten auf der einen und privaten und demzufolge nicht-politischen bzw. nicht-politisierbaren Angelegenheiten auf der anderen Seite eine grundlegende politische Operation ist, die dafür sorgt, dass die im privaten oikos verorteten Herrschaftsverhältnisse von der Selbstinstituierung der polis ausgeklammert bleiben (vgl. Laclau/Mouffe 2006 [1985]: 229).

162 Aufgrund der Zentralität des Antagonismus ist Laclau/Mouffes Begriff des Politischen in der „dissoziativen“, von Carl Schmitt geprägten Begriffstradition und nicht in der ,assoziativen“ Tradition Hannah Arendts zu verorten (vgl. Marchart 2007a: 38ff.). Schließlich resultiert die Kommunalität zwischen Freunden, auf der ihre Fähigkeit zum gemeinsamen Handeln gründet, auf der Konstruktion eines inkommensurablen und bedrohlichen Feindes. Indes übersehen diejenigen, die Laclau/Mouffe auf ein Rezidiv eines Schmitt'schen Dezisionismus reduzieren (so etwa die Politologin Karin Priester 2012b), dass die beiden - ganz im Gegensatz zu Schmitt - Gesellschaft und Politik differenztheoretisch denken und daher nicht von vorgängigen Kol- 
emergiert am Schnittpunkt von Unentscheidbarkeit und Entscheidung. Sie reflektiert die Tatsache, dass die Oszillation zwischen Kontingenz und Strukturalität, die das Soziale auszeichnet, nur als Effekt vorläufiger Grenzziehungen und pragmatischer Universalisierungen gedacht werden kann. Das Politische ist ein Terrain der Unentscheidbarkeit, das durch antagonistische Schließungen begrenzt wird und diese kontingenten Entscheidungen zugleich unterläuft. Es bezeichnet ein quasi-transzendentales Phänomen, das sich in der „Unmöglichkeit [manifestiert], das Soziale als objektive Ordnung einzurichten“"163.

Politik erschöpft sich vor diesem Hintergrund nicht darin, für die Interessen präkonstituierter Identitäten zu kämpfen. Politik bedeutet, ,jene Identitäten in einem prekären und jederzeit anfechtbaren Terrain zu konstituieren“164. Sie spielt nicht bloß eine beigeordnete Rolle bei der Konstruktion von Ordnung. Politik ist die konkrete „Praxis des Erzeugens, der Reproduktion und Transformation sozialer Verhältnisse“"165. Sie übernimmt die Aufgabe, eine temporäre Ordnung in der allgemeinen Unordnung der Welt zu erschaffen. ${ }^{166}$ Sie versucht, die différance im Rahmen eines Netzes aus Differenzen zu arretieren oder aber dieses Netz aus Differenzen herauszufordern, indem sie antagonistische Grenzen einrichtet oder verschiebt.

Politische Projekte zielen darauf, dem Sozialen einen Grund zu verleihen, der es erlaubt, bestimmte Positionen als objektiv und legitim zu zertifizieren und andere als ideologisch und illegitim zu dezertifizieren. ${ }^{167}$ Da es keine vorpolitischen Kriterien gibt, die spezifische Begründungen, Grenzziehungen und Zertifizierungen-Dezertifizierungen privilegieren würden, ist Politik prinzipiell als dezisionistische „creatio ex nihilo“168 zu denken. Das meint jedoch nicht, dass Politik in einem struktur- und formlosen Raum operieren würde. Es heißt, dass das Soziale als spezifisch strukturierter und geformter Raum ein Resultat historisch-politischer Formgebungen ist, dass soziale Identitäten als Resultate politischer Entscheidungen begriffen werden müssen und daher politisch reaktiviert

lektiven ausgehen können (vgl. bereits Kapitel 4.2.3 des Theorieteils; Baschek 2010 insb. 45).

163 Laclau 1990a: 16.

164 Laclau/Mouffe 2006 [1985]: 26.

165 Ebd.: 193.

166 Vgl. Bech Dyrberg 1998: 43.

167 Zum Begriffspaar Zertifizierung-Dezertifizierung vgl. McAdam/Tarrow/Tilly 2008: 121, 157 ff. u 204.

168 Laclau 1990a: 184. 
werden können. ${ }^{169}$ Politik kann daher als das ontische Pendant der politischen Ontologie gedacht werden. Wenn das Politische den irreduziblen „Spalt“ zwischen der Unentscheidbarkeit und der Entscheidung bezeichnet, den keine soziale Konfiguration final schließen kann, dann werden unter Politik die Anläufe verstanden, diesen Spalt durch hegemoniale Universalisierungsleistungen „provisorisch aufzufüllen “' ${ }^{\text {170 }}$.

Da jeder dieser Versuche, jede (faktische und denkbare) Universalisierungsleistung, auf ein verworfenes „Anderes jenseits der Universalität“" ${ }^{\text {“171 }}$ verweist, um sich zu konstituieren, geht es gerade nicht darum, der Partikularität politischideologischer Repräsentationen ,impartiale Maßstäbe“ oder die ,tatsächlichen Verhältnisse einer objektiv gegebenen Realität‘ entgegenzuhalten. Aus der politischen Ontologie lässt sich keineswegs eine Parteinahme für ein spezifisches politisches Projekt oder eine bestimmte politische Ordnung ableiten. Laclau argumentiert konsequent postfundamentalistisch: Wie mit der irreduziblen Offenheit umgegangen wird, welche sozialen Normen und welche politischen Institutionen der Unmöglichkeit von Gesellschaft antworten sollen, kann nicht philosophisch begründet, sondern nur politisch entschieden werden. ${ }^{172}$ Die politische Ontologie fordert lediglich anzuerkennen, dass es kein ,Jenseits des Antagonismus' gibt und dass das Partikulare und das Universelle weder zusammenfallen, noch rigide voneinander getrennt werden können, sondern durch leere Signifikanten und die ihnen immanenten Ausschlüsse politisch vermittelt sind. ${ }^{173}$

169 Laclau/Mouffes Konzeption von Politik und dem Politischen deckt sich weitgehend mit jener Claude Leforts (1990a: insb. 284), der Politik ebenfalls als grundlose und formgebende Instanz vorstellt.

170 Vgl. Bech Dyrberg 1998: 24.

171 Reckwitz 2006: 345.

172 Das zeigt sich insbesondere darin, dass das Prinzip der Unabschließbarkeit aus Laclaus Sicht keineswegs dazu auffordert, die Unabschließbarkeit im Rahmen einer démocratie à venir zu kultivieren und dem verworfenen Anderen gewisse Rechte zuzubilligen (vgl. Laclau 2007a: insb. 117f.). Laclau vertritt somit auch im Unterschied zu Mouffe eine konsequent postfundamentalistische Position (vgl. Hildebrand/Séville 2015: hier 27 u. 35), die sich einer „Ethisierung“ (Laclau 1999: 134f.; Stäheli 2001: 222) der dekonstruktivistischen Ontologie verwehrt.

173 Laclau (1999: 136) spricht in diesem Zusammenhang von einer „wechselseitigen Kontamination“ des Universellen und des Partikularen. Indem die Hegemonietheorie universelle Kategorien als temporäre Effekte antagonistisch organisierter Diskurse rekonstruiert, zitiert sie die postmoderne Universalismuskritik, vermeidet es aber, universelle Ordnungsbegriffe a priori als totalitär zu verwerfen. 
Infolgedessen muss auch der Ideologiebegriff reformuliert werden. ${ }^{174}$ Wenn jede Form von Objektivität und Legitimität von einem antagonistisch instituierten Wahrheitsregime abhängt, verliert der marxistisch geprägte und alltagssprachlich sedimentierte Ideologiebegriff den Boden. Wenn es vor respektive jenseits der kontingenten Form des Antagonismus keinen wahrheitsverbürgenden Standpunkt gibt, dann lässt sich ideologisches und vermachtetes Wissen auch nicht von wahrem, macht- und ideologiefreiem Wissen unterscheiden. Ideologie lässt sich daher nicht in den objektivistischen Kategorien von Verzerrung, Entstellung, Täuschung etc. konzipieren, sondern muss als streng deskriptive Kategorie in der Linie von Stabilisierung-Destabilisierung respektive Desorganisation-Reorganisation gedacht werden. Laclaus Ideologiebegriff ist folglich keineswegs pejorativ konnotiert. ${ }^{175}$ Ideologie ist das Kernstück eines jeden politischen Projekts. Sie perpetuiert ein Ensemble von Schlussfolgerungsregeln, welche die Welt nicht nur sinnhaft ordnen, ihre ,wirkliche Beschaffenheit' definieren, Zusammenhänge, Ursachen und Folgewirkungen festlegen und etwaige Lösungen plausibilisieren, indem sie dieses Ordnungssystem mit einem Grund versieht. Dieser Grund schirmt eine Gesellschaft zeitweilig vor ihrer Infragestellung $\mathrm{ab}$, indem er die geschöpften Identitäten naturalisiert und so den unentscheidbaren Charakter ihrer Instituierung verschleiert. Ideologie ist der notwendige und notwendig scheiternde Versuch, durch Schließungen einen Horizont des Sagbaren zu konstruieren, der einen gegenhegemonialen Mythos zu einem zeitweise unhintergehbaren sozialen Imaginären avancieren lässt.

\subsection{Die politische Ethik DER RAdikalen DEMOKRATIE}

Demokratie und Emanzipation können infolgedessen auch nicht als Überwindung von Macht und Ideologie gedacht werden. ${ }^{176}$ Es geht gerade nicht darum, Macht und Ideologie aus politischen Willens- und Identitätsbildungsprozessen zu eliminieren und einen wahrheitsverbürgenden ultimativen Grund von Gesellschaft freizulegen. Um das demokratische Ideal einer nicht-determinierten und konfliktiven Selbstinstituierung von Gesellschaft anvisieren zu können, muss po-

174 Vgl. Laclau 1997; erläuternd Hirseland/Schneider 2011; zum Ideologiebegriff einer marxistisch begründeten Ideologiekritik Eagleton 1993.

175 Vgl. zu Laclaus Ideologiebegriff Laclau 1997 u. 2007b: 38f.

176 Vgl. exemplarisch Laclau/Mouffe 2006 [1985]: 26. 
litische Willensbildung als phronesis konzipiert werden, d.h. als macht- und ideologieimmanente Herstellung von Plausibilität, die auf die Einrichtung eines provisorischen, politisch anfechtbaren Grundes abzielt. ${ }^{177}$ Dieses Prinzip der Willensbildung setzt seinerseits ein soziales Imaginäres voraus, das die Geltung von Freiheits- und Gleichheitsrechten sowie ein Bewusstsein für die Kontingenz der eigenen Identität als unbedingte Bezugspunkte von Politik verankert.

Somit entgeht die Hegemonietheorie dem Relativismus-Vorwurf, mit dem postmoderne und poststrukturalistische Theorien notorisch konfrontiert werden. ${ }^{178}$ Es ist zwar richtig, dass sich aus der ontologisch gesetzten Unentscheidbarkeit keine normativen Kriterien ableiten lassen, die bestimmte politische Inhalte vorschreiben würden. Jedoch manifestiert sich in dem theorieimmanenten Ausschluss des Phantasmas einer versöhnten Gesellschaft ein antitotalitäres „ethisches Apriori“179. Laclau/Mouffes Entscheidung für Poststrukturalismus und Hegemonietheorie ist insofern durchaus als „,normative Stellungnahme“"180 zu begreifen. Schließlich fordert ihr Theorieprojekt dazu auf, das paradoxale Verhältnis von Unentscheidbarkeit und Entscheidung sichtbar zu machen und als ethischen Horizont von Politik und Gesellschaft präsent zu halten, anstatt fundamentale Gerechtigkeitsprinzipien zu ermitteln und in eine normative Ordnung zu gießen, über die erhabene Letztinstanzen bestimmen.

Die postfundamentalistisch begründete Differenz zwischen Politik (dem Ensemble der getroffenen Entscheidungen) und dem Politischen (dem negativen Hintergrund der Unentscheidbarkeit, der Entscheidungen erfordert) erweist sich insofern selbst als demokratietheoretisch relevant. Das Spezifikum demokratischer und pluralistischer Gesellschaften besteht nämlich darin, dass sie den Spalt zwischen den getroffenen politischen Entscheidungen und dem negativen Horizont der Unentscheidbarkeit präsent halten. ${ }^{181}$ Der ethisch-politische Auftrag lautet daher, die Spuren der Macht, die historische Entscheidungen hinterlassen haben, lesbar zu machen und ein Bewusstsein für die politischen Ausschlüsse zu schaffen, die jeder sozialen Ordnung innewohnen. Entsprechend zeichnet sich das von Laclau und Mouffe favorisierte politische Projekt der radikalen und pluralen Demokratie weder dadurch aus, dass es besonders gute, gerechte oder ver-

177 Zur Adaption des aristotelischen Konzepts der phronesis vgl. Laclau 1989: 79.

178 Für eine besonders scharfe Neuauflage dieser Kritik vgl. etwa Priester 2012b.

179 Aronowitz 1989: 52.

180 Hildebrand/Séville 2015: 40 sowie Brodocz 2000: 39.

181 Insofern eine hegemonietheoretisch informierte Gesellschaftsanalyse genau hierauf abzielt, lässt sie sich als ,performativ radikaldemokratisch“ bezeichnen (vgl. Hildebrand/Séville 2015: 39). 
nünftige Outputs produziert, noch dass es den Zugang zu politischer Macht an die objektive Repräsentation vorgängiger Interessen koppelt. Vielmehr zielt es darauf, die Kontingenz der getroffenen Entscheidungen und der sozialen Identitäten zu visibilisieren, politisch zu prozeduralisieren und die ihnen eingeschriebenen Herrschaftsverhältnisse mit einem liberaldemokratischen Imaginären zu konfrontieren, das die Geltung von Freiheits- und Gleichheitsrechten als unhintergehbaren Horizont von Politik verankert. 



\title{
5. Populismus als politisches Phänomen par excellence
}

\begin{abstract}
„Wenn man den privilegierten Stand wegnähme, wäre die Nation nicht etwas weniger, sondern etwas mehr. Also, was ist der dritte Stand? Alles, aber ein gefesseltes und unterdrücktes Alles. Was wäre er ohne den privilegierten Stand? Alles, aber ein freies und blühendes Alles. Nichts kann ohne ihn gehen; alles ginge unendlich besser ohne die anderen."
\end{abstract}

SIEYÈS 2010: 114

Die Hegemonietheorie sensibilisiert für den politischen Charakter des Sozialen. Sie fokussiert die Kontingenz, Macht und Konfliktualität, die jeder sozialen Konfiguration inhärent ist. Im Hinblick auf die Erforschung kollektiver Identitäten stellt sie aus, dass die Vorstellung kohäsiver Organizität das „stigmatisierende Konstrukt einer kollektiven Alterität " ${ }^{11}$ voraussetzt. Indes beschränkt sich die Hegemonietheorie nicht auf Identitätspolitik im engeren Sinn. Sie erlaubt es vielmehr, jede Form von Subjektivität und Gesellschaft als antagonistisch geschöpfte, reversible und anfechtbare Struktur zu rekonstruieren. Politik ist daher nicht das mehr oder weniger verzerrte oberflächliche Abbild tieferliegender sozialer Verhältnisse oder Prozesse, sondern das Ensemble der artikulatorischen Praktiken, die diese Verhältnisse und Prozesse instituieren. Doch welche Konsequenzen ergeben sich aus dieser Perspektivierung von Politik und Gesellschaft für eine Theorie des Populismus? Welchen Blickwinkel eröffnet das Primat des Politischen auf populistische Phänomene?

1 Horatschek 2005: 71. 
Wenn Gesellschaften und soziale Identitäten erst durch hegemoniale Repräsentationsleistungen instituiert werden, ist der erkenntnistheoretische Dualismus zwischen Realismus und Idealismus, zwischen gesellschaftlicher Objektivität und politischer Ideologie, den sozialstrukturell definierbaren Identitätsgruppen auf der einen und der politisch-ideologischen Artikulation des, Volkes' auf der anderen Seite, hinfällig. Die erste Konsequenz der hegemonietheoretischen Perspektivierung des Populismus ist damit eine Negation konventioneller Populismuskonzepte. Sie entzieht den ideologiekritischen und normativistischen Konzeptionen des Phänomens den Grund, indem sie deren scheinbar objektivistische Urteilsmaßstäbe dekonstruiert. Wenn soziale Objektivität durch ideologische Schließungen konstituiert wird, dann kann der Populismus weder als politischideologisches Zerrbild einer gegebenen (pluralistischen) Gesellschaftsstruktur noch als oberflächlicher Ausdruck zugrundeliegender gesellschaftlicher Desintegrationsprozesse gelesen werden, die sich etwa durch die empirisch messbare überproportionalen Repräsentation von bildungsfernen Modernisierungsverlierern und Wohlfahrtschauvinisten innerhalb der Wählerschaft populistischer Parteien belegen ließen. Der präsupponierte Widerspruch zwischen der objektiven Sozialstruktur der pluralistischen Gesellschaft und der rhetorisch-ideologischen Repräsentation dieser Gesellschaft als binär gespaltenem Raum im Populismus löst sich in dem Moment auf, in dem wir das ontologische Primat der politischen Praxis gegenüber den sozialen Akteuren und der sozialen Struktur akzeptieren. Denn auch die vermeintlich objektive Selbstbeschreibung der pluralistischen Gesellschaft als Mosaik aus vielfältigen (multikulturellen) Gruppen ist als hegemoniale Konstruktion zu begreifen.

\subsection{Die binäre SPALtUng des SozIALEN UND diE HEGEMONIALE KONSTRUKTION DES ,VOLKES“}

Das postfundamentalistische Postulat der politischen Verfasstheit sozialer Ordnung unterläuft die herkömmliche normativistisch-ideologiekritische Konzeption des Populismus und schafft Raum für eine deskriptive Konzeption, die das Phänomen nicht in Begriffen von Verzerrung, Anomie und Devianz, sondern streng formal in Begriffen von Transformation, Desorganisation und Restrukturierung 
denkt und den vereinfachenden Gegensatz von ,Volk‘ und ,Establishment ${ }^{\text {‘ als }}$ mögliche politische Operation anerkennt. ${ }^{2}$

Für Laclau zeugt die populistische Anrufung eines, Volkes‘ daher nicht von einer inhaltlich definierten Verfallsform von Politik. Sie instituiert vielmehr eine „reale Verbindung zwischen sozialen Akteuren“"3. Populismus ist nicht mehr und nicht weniger als ,eine Möglichkeit die Einheit einer Gruppe herzustellen“" ${ }^{*}$. Es handelt sich um einen sozialstrukturell unbestimmten Modus der Instituierung des Sozialen, der Versatzstücke unterschiedlicher ideologischer Provenienz miteinander kombiniert. ${ }^{5}$ Das Spezifische des populistischen Modus besteht darin, dass er auf eine binäre Spaltung des Sozialen hinwirkt. Populistische Projekte propagieren ein manichäisches Teilungsprinzip, das anderweitige Gruppendifferenzierung überprägt und im Rahmen des Gegengensatzes von ,Volk‘ und ,Establishment" transzendiert. Sie zeichnen sich dadurch aus, dass sie eine grundlegende antagonistische Differenz zu instituieren versuchen, welche die etablierten Antagonismen der ,politischen Richtungstraditionen“6 in schlichte Differenzen ein und desselben Bedrohungskomplexes verwandelt. Dabei ist die Vagheit der beiden antagonistischen Pole, wie sie sich in dem Gegensatzpaar ,einfache Leute' vs. ,politische Klasse' offenbart, nicht Ausdruck eines unaufrichtigen Opportunismus auf Seiten des populistischen Politikunternehmers, sondern die notwendige Bedingung der binären Spaltung der Gesellschaft, die alle sozialen Felder und Gruppenidentitäten zu erfassen versucht. Das Wesen des Populismus liegt demnach in einer dichotomisierenden Rhetorik begründet, die nicht etwa sozialstrukturell vorperforierte Konfliktlinie zwischen vorgängigen, verfeindeten Gruppen nachzeichnet, sondern diese Differenzen absorbiert und regruppiert. Der Populismus resultiert nicht aus den Identitäten der Konfliktparteien, sondern stellt diese erst her.

Folglich muss die ,kleinste Analyseeinheit“" ${ }^{\text {"7 }}$ unterhalb der Ebene sozialer Gruppen gewählt werden. So geht Laclau in On Populist Reason anstelle von

2 Zum Formalismus des Laclau'schen Populismusbegriffs vgl. auch Stavrakakis 2004: insb. $262 \mathrm{ff}$.

3 Vgl. Laclau 2005a: 73.

4 Ebd.

5 Es macht aus Laclaus Sicht insofern auch gar keinen Sinn, den Populismus a priori gegen den Liberalismus zu konturieren, da liberale Forderungen wie Menschenrechte, Presse- und Meinungsfreiheit auch als Elemente eines populistischen Projekts artikuliert werden können.

6 Dubiel 1986: 47.

7 Laclau 2005a: 70. 
Elementen oder Differenzen von Forderungen (demands) respektive von demokratischen Forderungen (democratic demands) aus. ${ }^{8}$ Die Formulierung ist erläuterungsbedürftig: Gemeint ist nicht, es gäbe Forderungen, die notwendig oder wahrscheinlich innerhalb eines demokratischen Regimes artikuliert werden, da sie nur dort ihre wahre Bedeutung verwirklichen könnten. ${ }^{9}$ Wie Elemente sind Forderungen keineswegs selbstidentisch und in sich geschlossen, sondern überdeterminiert. ${ }^{10}$ Das Attribut ,demokratisch ' bedeutet daher lediglich, dass diese Forderungen ein demokratisch-egalitäres Imaginäres voraussetzen, um überhaupt gegen ein Herrschaftsverhältnis in Stellung gebracht werden zu können.

Demokratische Forderungen können aus konkreten Missständen, Abstiegsängsten, enttäuschten Erwartungen oder subjektiven Ungerechtigkeitserfahrungen resultieren. Man denke etwa an eine dysfunktionale öffentliche Infrastruktur, Arbeitslosigkeit, mangelhafte Kriminalitätsbekämpfung, eine inadäquate Entlohnung von bestimmten Berufsgruppen, Korruption, ethnische Diskriminierung, steigende Preise oder zunehmend steuerliche Belastungen. Sie können aber auch die Verwirklichung abstrakter Prinzipien wie Gewaltenteilung, Pressefreiheit, Volkssouveränität und Gleichberechtigung oder die Restauration eines sozialen Imaginären zum Ziel haben, das sich mit sedimentierten leeren Signifikanten wie Sicherheit, Freiheit, Gleichheit, Gerechtigkeit, Demokratie oder Heimat bezeichnet. Demokratische Forderungen müssen also nicht zwangsläufig zukunftsorientiert sein; sie können auch auf eine ,gute alte Zeit' rekurrieren. Entscheidend ist lediglich, dass sie gegen einen als defizitär erlebten Status quo gerichtet sind.

$\mathrm{Zu}$ Beginn unterscheidet sich die Populismustheorie Laclaus nicht von den Ansätzen des Mainstreams: Der „populistische Moment““11 entspringt einer „,desorganisierten Unzufriedenheit ${ }^{\text {“12. }}$. Er resultiert aus einer Krise eines etablierten Repräsentationsregimes. Es existieren vielfältige Missstände und diese Miss-

8 Vgl. ebd.: 72ff. bzw. 125ff.; Laclau 2005b: 34ff.

9 Diese teleologische Präsupposition implizierte eine deterministisch-essentialistische Annahme, die mit der postfundamentalistischen Position Laclaus unvereinbar wäre. Für Laclau können demokratische Forderungen sowohl in einem faschistischen als auch in einem liberaldemokratischen Diskurs artikuliert werden. Welcher Diskurs sich durchsetzt und den allgemeinen Mangel bezeichnet, kann nur politisch entschieden werden.

10 Dagegen warnt Johannes Angermüller (2007b), der Forderungsbegriff würde in einen Essentialismus der kleinsten Analyseeinheit umschlagen und somit hinter die eigene differenztheoretische Epistemologie zurückfallen.

11 Goodwyn 1978.

12 Hall 1986: 91. 
stände werden weder unmittelbar behoben, noch als solitäre Differenzen (,Herausforderungen' oder ,zu lösende Probleme') systemisch absorbiert. Die etablierte Ordnung ist nicht in der Lage, die vakanten Forderungen differenzlogisch zu artikulieren, sodass sie ,aus den etablierten Diskursen und Legitimationsmustern gleichsam herausfallen und den Status vagabundierender Potentiale gewinnen“"13. Infolgedessen teilen diese frei flottierenden Elemente,,jenseits ihrer positiven differentiellen Natur ${ }^{\text {“14 }}$ die negative Eigenschaft, dass es sich um Elemente eines als illegitim empfundenen Mangels handelt. Dies ist die Grundvoraussetzung für das populistische Dissens-Szenario. Denn nur wenn die heterogenen Defizite des Status quo als Folge eines Unterdrückungsverhältnisses konstruiert werden können und nicht etwa als Ausdruck eines metaphysisch oder funktional begründeten Unterordnungsverhältnisses, können sie überhaupt gemeinsam artikuliert werden, ihre partielle Bedeutung transzendieren und sich in Momente eines popularen Kollektivs verwandeln. ${ }^{15}$

Um diese Metamorphose zu initiieren, vollziehen populistische Diskurse drei miteinander verknüpfte Operationen: Die disparaten Elemente werden gegen ein antagonistisches Außen in Stellung gebracht, auf diese Weise zu einer Äquivalenzkette verknüpft und schließlich unter dem Dach eines leeren Signifikanten subsumiert, der das Begehren der Subjekte kanalisiert. ${ }^{16}$ Webers Gemeinsamkeitsglaube, der als konstitutives Merkmal politischer Kollektividentitäten bestimmt wurde, gründet nicht auf einer positiven geteilten Eigenschaft. Vielmehr wird er im Verhältnis zu einem antagonistischen „Gegenpol“ erzeugt, „der selbst aus Äquivalenzen des Widerständigen konstruiert werden muss“. ${ }^{17}$ So werden vielfältige Elemente (,Oligarchen', ,Washington Insiders', ,gierige Banker', die ,Sozialindustrie', Professoren, die Kulturschaffenden, privilegierte und marginalisierte ethnische Minderheiten) zu einem parasitären Bedrohungskomplex verschmolzen, der für die Defizite des Status quo haftet und die Entfaltung der Prosperität des ,Volkes“ hemmt. Den ,,primär Schuldigen“ werden „sekundär Schuldige“" an die Seite gestellt, indem das absolute Übel mit protegierten und protegierenden Elementen assoziiert wird. ${ }^{18}$ Dabei changiert die Identität dieses

13 Dubiel 1986: 47.

14 Vgl. Laclau 2005b: 37.

15 Zur Unterscheidung von Unterordnungs- und Unterdrückungsverhältnis vgl. Laclau/ Mouffe 2006 [1985]: 194.

16 Laclau 2005a: 77.

17 Nonhoff 2010: 314.

18 Pelinka 2012: 17. 
,Volkes' je nach dem welcher Aspekt des Bedrohungskomplexes in den Vordergrund gerückt wird.

In jedem Fall aber erwirkt der Antagonismus einen popularen Bruch. Eine ehedem differenzlogisch komponierte Ordnung zerfällt in zwei Äquivalenzketten, deren Elemente ihre differentielle Bedeutung abstreifen und als Teilaspekte ein- und desselben Unterdrückungsverhältnisses absorbiert werden. Die AntiEstablishment-Rhetorik des Populismus ist folglich nicht bloßes Mittel, um aus den Ressentiments eines bestimmten Milieus politisches Kapital zu schlagen. Sie ist vielmehr konstitutiv für die Konstruktion eines ,Volkes', da sie erst die gemeinsame Negativität begründet, auf der die populare Identität beruht. Ein populistisches Projekt versucht also,

„den gesamten diskursiven Raum entzweizuteilen, um letztlich auf der einen Seite der antagonistischen Grenze [...] alle Elemente des Mangels, der Lethargie und des Widerstands miteinander zu artikulieren und auf der anderen Seite $[\ldots]$ alle Forderungen, die nach der Überwindung dieser negativen Kräfte streben.“`19

Aus Laclaus Sicht reicht die äquivalenzlogisch erwirkte Substitutionslogik jedoch nicht über ein ,vages Gefühl von Solidarität“ ${ }^{20}$ hinaus. Damit aus diesem Gefühl ein ,Volk‘ im Sinne eines politisch handlungsfähigen Kollektivsubjekts entsteht, müssen die beiden antagonistischen Pole bezeichnet werden: ,[D]as Äquivalenzverhältnis muss in einer bestimmten diskursiven Identität kristallisieren, die die [...] Forderungen nicht mehr nur als äquivalent, sondern die äquivalentielle Verbindung als solche repräsentiert. “21 Diese Aufgabe übernimmt ein leerer Signifikant. Er erwirkt eine imaginäre Schließung, indem er der Äquivalenzkette einen Namen gibt. Dadurch transformiert sich die negativ konstituierte Äquivalenz in das vermeintlich positive Fundament der antagonistischen Kämpfe. „Eine populare Identität fungiert als ein tendenziell leerer Signifikant ${ }^{422}$ und je erfolgreicher diese Identität ist, je mehr vagabundierende Forderungen und flottierende Elemente der Äquivalenzkette einverleibt werden, desto stärker müssen sich die Slogans, Bilder und Führungsfiguren, die diese Identität symbolisieren, entleeren. ${ }^{23}$

19 Nonhoff 2010: 314.

20 Laclau 2005a: 93.

21 Ebd.

22 Ebd.: 96.

23 An dieser Stelle sei daran erinnert, dass leere Signifikaten nicht mit abstrakten Begriffen zu verwechseln sind. Leere Signifikanten lassen sich nicht logisch begründen, 
Typischerweise bekleidet ein Führer die repräsentative Funktion des leeren Signifikanten. Sein Name steht für das Versprechen, die Negativität aufzuheben, die der antagonistisch verhinderten Identität des Volkes anhaftet. ${ }^{24}$ Daher projizieren sich die libidinösen Energien der Subjekte auch auf den Führer und das Machtkartell, das seine Machtergreifung verhindert oder die volle Verwirklichung seiner Ziele sabotiert. Das Charisma des Führers, auf dem seine herausgehobene Stellung als Versorger, Gesetzgeber und Held des Volkes gründet, entspringt nicht etwa seiner virtù im Sinne seines politischen Talents zur Massenmobilisierung. ${ }^{25}$ Sein Charisma resultiert vielmehr aus einem Prozess der semantischen Entleerung. Denn nur wenn der Führer nichts Konkretes signifiziert, kann er alles bedeuten und ein interaktives Repräsentationsverhältnis begründen, in dem sein Name oder sein Bild vielfältige (subjektiv) marginalisierte Gruppen zu einem Kollektiv zusammenschließt. Populistische Führer fungieren als objets $a$, als symbolisch generierte und tendenziell universelle Bezugspunkte, auf die die Frustrierten ihre Wünsche und Erwartungen projizieren, weil sie sich davon eine Kompensation ihres irreduziblen Mangels versprechen. ${ }^{26}$ Die Affekte, die der charismatische Führer (und seine Gegenspieler) evozieren, sind folglich kein emotionales Surplus, das sich zum Diskursgeschehen hinzugesellt. Sie sind nicht als Manifestationen irrationaler Subjekte oder als Ausdruck des autoritären Charakters eines unaufgeklärten Bevölkerungsteils zu lesen. Für Laclau ist die affektive Komponente diskursiv erzeugt. ${ }^{27}$ Sie rührt daher, dass bestimmte Symbole, Bilder oder Personen auf eine Art besprochen und in Szene gesetzt werden, dass sie die abwesende Universalität symbolisieren, die das ,Volk‘ identifiziert. Dem-

sondern nur performativ erzeugen. Dass unter einem Slogan wie ,Freiheit, Gleichheit und Brüderlichkeit‘ all die Forderungen, die gegen das Ancien Régime vorgebracht wurden, zu einem historischen Akteur verschmolzen wurden, liegt keineswegs in der Natur der Begriffe, sondern resultiert aus der hegemonialen Operation ihrer semantischen Entleerung, durch die sie zum Repräsentanten einer abwesenden Fülle und zu einer nachhaltig wirksamen, affektiv besetzten Ressource des sozialen Imaginären liberaldemokratischer Gesellschaften avanciert sind.

24 Das Theorem des naming (ebd.: 101ff.) lässt sich Synonym zum Theorem leerer Signifikanten lesen.

25 Vgl. hierzu auch Ron van Doorens (1994) interaktive Theorie politischen Charismas, die das Charisma politischer Führer im Rückgriff auf die psychoanalytisch begründeten Charisma-Theorien von Orrin E. Klapp (1964), Daniel Katz (1973) und Eric Hoffer (1966) als Effekt dieser dreifachen Repräsentationsfunktion erklärt.

26 Vgl. Hoffer 1966: 105.

27 Vgl. Laclau 2004: insb. 326. 
zufolge ist der für viele populistische Bewegungen kennzeichnende Bonapartismus - die zentrale Stellung eines Führers, auf den sich die Hoffnungen seiner Anhänger projizieren - Effekt einer semantischen Entleerung, durch die eine Figur vielfältige, subalterne Forderungen eine Stimme verleiht.

\title{
5.2 Populismus als Königsweg des Politischen - UND DER DEMOKRATIE?
}

\author{
„Populism is the royal road to understanding \\ something about the ontological constitution of \\ the political as such.“ \\ LACLAU 2005A: 67
}

Populistische Diskurse lassen sich nicht nur hegemonietheoretisch beschreiben; sie sind nicht nur ein Extrembeispiel für äquivalenzlogisch dominierte Diskurse. Für Laclau ist der Populismus eine theoriegetreue Umsetzung seiner Konzeption von Politik. In seiner marginalen Stellung im Diskurs der MainstreamPolitologie manifestiert sich deren Unfähigkeit, die politische Verfasstheit von Gesellschaft in den Blick zu nehmen. ${ }^{28}$

Populistische Diskurse zeigen, dass ein vollkommen differenzlogisch komponierter Diskurs, der jeder Differenz den für sie vorgesehenen Platz einräumt und die Konfliktualität des Sozialen in Form einer post-politischen Gesellschaft transzendiert, unrealisierbar ist. Auch differenzlogisch dominierte Diskurse sind, wie am Beispiel des Dritten Weges deutlich wurde, nicht frei von der Dimension des Antagonismus. Ihr Postulat einer inklusiven Mitte, die jede Alterität absorbieren würde, erodiert lediglich den ehemals zentralen Links-RechtsAntagonismus, ist jedoch nicht in der Lage, den Antagonismus als solchen zu überwinden. Der von Giddens \& Co apostrophierte Staat ohne Feinde ${ }^{29}$ gründet nämlich auf dem Ausschluss nicht-konsensfähiger Kräfte. Der politische Gehalt dieser Exklusion wird lediglich mit dem Vokabular von Einsicht und Vernunft invisibilisiert, sodass die Kritik an diesem politischen Projekt als ,unaufgeklärt‘, 
,gestrig ${ }^{6}$ und infolgedessen als illegitim peripherisiert werden kann. ${ }^{30}$ Aus Sicht von Laclau und insbesondere von Mouffe indiziert der Aufstieg gegenhegemonialer populistischer Projekte nun, dass diese technokratischen Versuche, das Politische zu sublimieren und die Form der Gesellschaft rational zu begründen, allenfalls kurzzeitig Erfolg haben können. Wenn politischen Konflikten die Legitimität aberkannt wird und politische Arenen keinen Raum für Antagonismen bereithalten, so brechen diese von den Rändern in die post-politische Vision der versöhnten Gesellschaft ein. ${ }^{31}$ Die ,rationale Alternativlosigkeit‘ der etablierten Parteien wird mit einer ,irrationalen Alternative' des populistischen Herausforderers konfrontiert, der die verworfenen Elemente als legitime Momente des eigentlichen demokratischen Souveräns rezertifiziert und gegen den Konsens der Mitte in Stellung bringt. ${ }^{32}$

Der Populismus indiziert aber nicht nur die Grenzen von Post-Politik und Postdemokratie sowie von Sachzwang und Alternativlosigkeit. Insofern sich populistische Diskurse nicht homolog zu sedimentierten Gruppendifferenzierungen verhalten, zeigen sie in exemplarischer Weise, dass politische Konfliktkonstellationen nicht zwangsläufig vorgezeichneten Cleavages folgen und Ideologie und Rhetorik nicht auf bloße Oberflächenphänomene vorgängiger Gruppen mit konkurrierenden Einstellungen zu reduzieren sind, sondern sozialtranformativ wirken. Populistische Projekte desartikulieren eine etablierte symbolische Ordnung und reartikulieren deren Elemente im Rahmen des Gegensatzes von ,Volk' und ,Establishment‘. Das ,Volk‘ ist insofern der Effekt einer Repräsentationsleistung der Gesellschaft: Differente Missstände, die andere Diskurse als singulär, heterogen, privat oder naturgegeben besprechen, werden auf die Präsenz ein und derselben, moralisch korrumpierten Minderheit zurückgeführt, die für die antagonistische (Selbst-)Blockade der popularen Prosperität diskriminiert wird.

30 Vgl. Kapitel 2.3.2 des Theorieteils, sowie für eine allgemeine Kritik der Rationalisierung der Demokratie und der Demokratietheorie vgl. Buchstein/Jörke 2003; mit Fokus auf den Dritten Weg vgl. Mouffe 2005, 2007a, 2011 u. Hildebrand/Lluis Martell 2012.

31 Vgl. Mouffe 2005, 2007a u. 2011; Decker 2012, der sich Mouffes Deutung in diesem Punkt anschließt, aber für einen, realistischere‘ Einschätzung der Gestaltungmöglichkeiten von Politik eintritt.

32 Damit korrespondiert die Tatsache, dass Konkordanzdemokratien besonders gute Bedingungen für die Entstehung populistischer Parteien bieten (vgl. Taggart 1996: $113 \mathrm{ff}$.). Und in der Tat lässt sich gerade in neokorporatistischen Konkordanzdemokratien wie etwa in Österreich (vgl. siehe Mouffe 2005 u. 2007a: 85ff.), den Niederlanden und eben in der Schweiz exemplarisch beobachten, wie die normalisierende Wirkung von Konsens, Kompromiss und Pragmatismus erfolgreich herausgefordert wird. 
In diesem Modus der Identitätskonstruktion entfaltet sich Laclaus Totalisierungs- und Universalisierungstheorem. ${ }^{33}$ Wie wir gesehen haben, konstituiert sich die populare Äquivalenzkette, indem sie ein antagonistisches Außen konstruiert. Sie kristallisiert zu einer belastbaren Kollektividentität, indem eines der äquivalentiell artikulierten Elemente seine partikulare Bedeutung ablegt und sich in einen tendenziell leeren Signifikanten verwandelt, der die Implosion der Kette verhindert, indem er ihr einen Namen gibt und sie symbolisch vereint. Die populare Einheit entsteht also in einem antagonistisch verfassten Repräsentationsverhältnis, in dem der Repräsentant das Repräsentierte retroaktiv konstituiert. ${ }^{34}$ Indes ist dieses Repräsentationsverhältnis zwischen den äquivalentiell artikulierten Elementen und dem leeren Signifikanten keineswegs einseitig, sondern interaktiv: Denn je vielfältiger die äquivalentiell artikulierten Forderungen, je stärker die Universalitätsbehauptung, je mehr Elemente dem popularen Lager einverleibt werden und je mehr die plebs sich dem populus annähert, desto leerer muss der Signifikant werden, der diese expandierende Totalität bezeichnet. Und je ambitionierter die Universalitätsbehauptung, je länger die Äquivalenzkette und je leerer ihr Repräsentant, desto wahrscheinlicher ist, dass die Äquivalenzkette an einer Stelle abreißt, dass etwa Parteiflügel oder gar neue Parteien entstehen, die den leeren Signifikanten neu zu befüllen versuchen oder sich unter einem neuen, innovativen leeren Signifikanten zusammenfinden. Folglich werden populistische Diskurse bei Laclau als hochdynamisch gedacht.

Laclau behauptet natürlich nicht, dass jeder Populismus demokratisch sei. Aber populistische Politik steht keineswegs in einem per se antithetischen Verhältnis zur modernen Demokratie. Populismus und Pluralismus sind nämlich keineswegs inkompatibel. Ein populistischer Diskurs zielt darauf, vielfältige demokratische Kämpfe zu einem einzigen popularen Kampf zusammenzuschlieBen. Hierzu versucht er, möglichst alle Differenzen entweder ,dem Volk' oder ,der Herrscherkaste‘ zuzuordnen. Der Populismus erwirkt somit eine Überdeterminierung der vielfältigen Forderungen einer pluralistischen Gesellschaft, ohne die eine gegen den Status quo gerichtete Politik, die sich nicht in single-issues erschöpft, sondern eine gesellschaftliche Alternative zu begründen versucht, die auf eine sektorielle Ausweitung und inhaltliche Vertiefung von Gleichheitseffekten abzielt, überhaupt nicht gedacht werden kann.

Wenn politische Konfliktkonstellationen nicht perforierten Linien zwischen vordiskursiv verfassten Kollektiven mit konfligierenden Interessen folgen, sondern diskursiv verfasst sind, dann ist die Konstruktion einer binär antagonistisch

33 Vgl. Laclau 2005a: 224ff. u. 2000; auch Sigglow 2009: 53, FN 242.

34 Laclau 2005a: 108 u. 2007b: 33. 
geschöpften Matrix, die vielfältige Forderungen gegen den Status quo artikuliert, der einzige Weg, um ein gegenhegemoniales Projekt mehrheitsfähig zu machen. Und wenn Macht, Wissen und Recht, die einst im Körper des absolutistischen Erbmonarchen symbolisch zusammenflossen, seit den demokratischen Revolution des 18. Jahrhunderts voneinander geschieden sind und die legitime Form der Gesellschaft nur auf der leeren Identität des Volkes begründet werden kann, so ist der (notwendig scheiternde) Versuch, diesen leeren Ort der Macht zu besetzen und die Identität des Volkes zu fixieren, weit davon entfernt, eine deviante Form von Politik zu sein. ${ }^{35}$ Vielmehr setzen sich die Demokratie und der Populismus wechselseitig voraus: ohne Demokratie kein Populismus und ohne Populismus keine Demokratie. Unter den Bedingungen eines demokratischen sozialen Imaginären ist jedes gegenhegemoniale Projekt notwendig populistisch. Es stellt sich nur die Frage, welchen Grad dieser Populismus erreicht - und dies lässt sich nicht anhand ideologischer Inhalte, sondern nur diskurstheoretisch, anhand der relativen Dominanz der Äquivalenz- gegenüber der Differenzlogik eruieren. ${ }^{36}$

Eine Typologie populistischer Diskurse im Sinne Laclaus zielt daher nicht auf eine Differenzierung unterschiedlicher ideologischer Ausprägungen des Populismus. Anstatt populistische Projekte anhand externer Maßstäbe zu kategorisieren und den Grad der Abweichung von einer liberaldemokratischen Normalität zu bestimmen, schlägt Laclau vor, jene „,internen Regeln“ zu erfassen, die bestimmte „Trends“ auslösen. ${ }^{37}$ Es gilt, in anderen Worten, die diskursiv perpetuierten Entwicklungslogiken zu erfassen, welche die jeweiligen Konjunkturen populistischer Projekte bedingen. So ließe sich etwa ein expandierender, relativ offener und dynamischer Populismus von einem saturierten, relativ geschlossenen und statischen Populismus unterscheiden.

35 Vgl. Laclau 2005a: 164f. Laclau schließt hier an Claude Leforts Analyse der symbolischen Transformation von Legitimität an, die mit dem Übergang von der absolutistischen zur demokratischen Gesellschaft verbunden ist. Die gottgegebene Einheit von Macht, Recht und Wissen, die im Körper des Königs zum Ausdruck kam, wird durch dessen Guillotinierung symbolisch zerschlagen und weicht einer neuen Gesellschaftsform, deren Charakteristikum darin besteht, dass sie sich „,dadurch instituiert und erhält, dass sie die Grundlagen aller Gewissheit auflöst“ (Lefort 1990: 296).

36 Vgl. Laclau 2005b: 45 u. 46.

37 Laclau 2005a: 175. 



\section{Für eine Hegemonieanalyse rechtspopulistischer Diskurse}

Mit Laclau wird der populistische Rekurs auf ein ,Volk' weder als Ausdruck einer vorgegebenen Diversität zwischen einem substantiellen Körper und inkompatiblen Fremdkörpern noch als Zerrbild einer gesellschaftlichen Konfliktlinie perspektiviert, sondern im Rahmen eines differenztheoretisch fundierten Antiessentialismus erschlossen. Dies ebnet den Weg für einen prozeduralen Zugang, der sich für die innere Kompositionslogik populistischer Diskurse interessiert. Laclau vermeidet es, dem Populismus bestimmte Etiketten aufzukleben und fokussiert stattdessen die Logik der Bedeutungskonstitution, die populistische Diskurse erwirken.

Das ,Volk' erscheint infolgedessen als hybride, politisch artikulierte Identifikationsschablone. Wie für die meisten Populismusforscher/innen basiert ein populistischer Diskurs aus Laclaus Sicht auf einer ,vereinfachenden, diffamatorischen Abgrenzung von Freund-Feind“, wodurch „Meinungspluralismus und Kritik in Polarisierung transformiert [werden]". ${ }^{1}$ Indes ist entscheidend, dass diese Vereinfachung nicht als illegitime, per se demokratiegefährdende Operation begriffen wird. Im Gegenteil: Laclau postuliert, dass die populistische Entzweiung der Gesellschaft mit Universalisierungseffekten verbunden ist, ohne die Demokratisierungsprozesse nicht möglich sind. Kern dieser Überlegung ist, dass die Integrationsfähigkeit populistischer Diskurse davon abhängt, ob es ihnen gelingt, ihre Knotenpunkte in leere Signifikanten zu verwandeln. Denn nur wenn identitätsstiftende Begriffe ihre partikulare Bedeutung abstreifen und zu Platzhaltern eines abwesenden Allgemeinen werden, sind sie in der Lage, der gemeinsamen Negativität der äquivalentiell artikulierten Elemente Ausdruck zu verleihen. In- 
konsistenz und Vagheit sind folglich keine Zeichen von Unreife, sondern strukturelle Notwendigkeiten dieser hochdynamischen, integrativen Diskurse.

Gleich Hegemony and Socialist Strategy lässt sich On Populist Reason nicht nur als Theoriebuch, sondern auch als strategische Intervention innerhalb eines linken politischen Diskurses lesen. Hierzu wird rund um den leeren Signifikanten ein Modell politischer Repräsentation konzipiert, das Repräsentation weder als top-down- noch als bottom-up-Prozess, sondern als interaktives Machtverhältnis konzipiert. Insofern ist es nicht überraschend, dass sich die vielfältigen politischen Projekte, auf die Laclau zurückgreift, um seine Populismustheorie zu veranschaulichen, eher dem linken politischen Spektrum zuordnen lassen und sich insbesondere auf lateinamerikanische Erfahrungen beziehen. ${ }^{2}$ Rekurse auf Rechtspopulismen in ,etablierten Demokratien' finden sich dagegen keine. ${ }^{3}$ Laclau setzt sich lediglich an einer Stelle mit den ethnonationalistischen Projekten im ehemaligen Jugoslawien auseinander und argumentiert, dass diese Diskurse nicht auf die Konstruktion einer „,inneren Grenze“, sondern auf die Konstruktion der „Grenzen der Gemeinschaft“ zielten und es sich bei ihnen gerade nicht um genuin populistisch geprägte, sondern, im Gegenteil, um differenzlogisch dominierte Diskurse handle. ${ }^{4}$ Die universalisierende Logik des Populismus werde hier unterminiert, da der leere Signifikant, der die populare Gemeinschaft bezeichnet, von Beginn an nur spezifische Elemente absorbieren könne, während andere a priori ausgeschlossen seien. ${ }^{5}$ Diese oberflächliche Abhandlung des jugoslawischen Ethnonationalismus liefert zwar einige wichtige Hinweise für eine Hegemonieanalyse rechtspopulistischer Diskurse, doch handelt es sich bei den jugoslawischen Populismen um extreme Beispiele. Denn auch rechtspopulisti-

2 Neben dem Peronismus, der sein theoretisches Denken nach eigenen Angaben maßgeblich prägte, insinuiert Laclau die lateinamerikanischen Linkspopulismen, insbesondere den Kirchnerismus, mit dem er in den letzten Jahren seines Lebens sympathisierte (vgl. Laclau/Mouffe 2009 u. Laclau 2010). Die spanische Podemos-Bewegung ist ebenfalls maßgeblich durch Laclaus Populismustheorie informiert (vgl. Errejón/ Mouffe 2015).

3 In On Populist Reason setzt sich Laclau kurz mit dem Regionalismus der Lega Nord und Berlusconis Forza Italia auseinander. Mouffe beschäftigt sich dagegen ausführlicher mit dem europäischen Rechtspopulismus, untersucht diesen jedoch nicht als Projekt sui generis, sondern beschäftigt sich mit dessen Ursachen, der Postdemokratie, der unangefochtenen Hegemonie des Neoliberalismus sowie der demokratietheoretisch problematischen Reduktion von Politik auf Gouvernance (vgl. Mouffe 2005).

4 Laclau 2005a: 196f.

5 Ebd. 
sche Projekte konstituieren ihr ,Volk' nicht ausschließlich durch ,externe', ethnisch definierte Grenzen, sondern durch komplexe Artikulationen innerer und äußerer Feinde. ${ }^{6}$

Um die Populismustheorie Laclaus für die Analyse rechtspopulistischer Diskurse anschlussfähig zu machen, soll sie im Folgenden an die phänomenologische Rechtspopulismusforschung angeschlossen werden. Hierzu werden einige Wesensmerkmale populistischer Politik im Allgemeinen und rechtspopulistischer Politik im Spezifischen hegemonietheoretisch reformuliert.

\section{Commonsense}

Der typisch populistische Bezug auf einen Commonsense ist aus einer Laclau'schen Perspektive auch in komplexen, modernen und pluralistischen Gesellschaften keineswegs ein illegitimer rhetorischer Handgriff. Vielmehr verbirgt sich hinter dem Begriff die Vorstellung einer antagonistisch blockierten Universalität, die es erlaubt, Macht im Arendt'schen Sinne zu generieren und eine Vorstellung des Gemeinwohls gegen ein expertokratisches, outputzentriertes Politikverständnis in Stellung zu bringen. Der Commonsense-Begriff ist ideologisch vage respektive inhaltlich leer. Er lässt sich prinzipiell sowohl gegen Managergehälter und die kapitalistische Wachstumslogik, als auch gegen Umweltauflagen, Arbeitnehmerrechte und den Schutz von Konsumenten artikulieren. Aufgrund dieser Offenheit ist er in der Lage, die vakanten Forderungen der popularen Äquivalenz zu absorbieren und gegen die herrschenden Verhältnisse in Stellung zu bringen.

\section{Dünne Ideologie}

In eine ähnliche Richtung deutet die von Cas Mudde im Anschluss an Michael Freeden postulierte These, dass der Populismus als „dünne Ideologie، ${ }^{67} \mathrm{zu}$ verstehen sei, die gleich dem Nationalismus an konsistentere, elaboriertere „Wirtsideologien “8 andockt. Im Unterschied zu den Hochideologien Liberalismus und Sozialismus zeichnen sich populistische Diskurse dadurch aus, dass sie weder über eine programmbildende Gesellschafts- und Geschichtstheorie verfügen, noch auf eine sozialstrukturell definierbare Gruppe als substantiellen Ausgangs-

6 Außerdem ist die Imagination einer originären, wesenhaft begründeten Gemeinschaft mit externen Grenzen gegenüber grundlegend verschiedenen Gruppen keineswegs ein Spezifikum rechtspopulistischer Diskurse, sondern lässt sich auch in den von Laclau anvisierten linkspopulistischen Diskursen beobachten.

7 Freeden 1998; Mudde 2004 u. 2007; vgl. auch Stanley 2008; Priester 2012a: 3.

8 Priester 2012a: 3. 
und Referenzpunkt ihres politischen Projekts rekurrieren. ${ }^{9}$ Ihrer ideologischen Schlichtheit entsprechen die vagen Begriffe, welche die beiden antagonistisch gruppierten Pole eines populistischen Diskurses bezeichnen: „[D]as ,wahre Volk' und ,die korrupte Elite“ [erweisen] sich als leere Signifikanten“"10, wie Cristóbal Rovira-Kaltwasser im Anschluss an Mudde schlussfolgert, ohne an dieser Stelle explizit an Laclau anzuschließen.

Die Konzeption des Populismus als dünne Ideologie wird der Tatsache gerecht, dass es sich beim Populismus um ein programmatisches „Chamäleon““11 handelt, das sich einer inhaltlichen Definition entzieht. ${ }^{12}$ Doch muss diese Definition des Populismus präzisiert werden. Der Populismus verhält sich nämlich nicht komplementär zu anderen Ideologien. Die Inkohärenz, die populistische Diskurse auszeichnet, ist nicht etwa eine originäre Eigenschaft einer unterentwickelten Ideologie oder eines archaischen Regimetyps, sondern Produkt einer semantischen Entleerung, durch die eine abwesende Universalität erst bezeichnet werden kann. Dieser Prozess der Universalisierung durch Entleerung und nicht sein Resultat, die inhaltliche Leere selbst, ist das Kernstück des Populismus. Damit ist die Vagheit populistischer Slogans auch nicht als intellektuelle Rückständigkeit, sondern Universalisierungsmechanismus partikularer Positionen zu verstehen.

\section{Missionarische Politik}

Auch José Pedro Zúquetes Populismuskonzeption ist anschlussfähig für eine hegemonietheoretische Reformulierung. ${ }^{13}$ Zúquete versucht, den Populismus im Anschluss an Emilio Gentile und Roger Griffin mit Hilfe des Begriffs der missionarischen Politik zu begreifen. ${ }^{14}$ Missionarische Politik ist ein idealtypisches „Cluster-Konzept ${ }^{\text {“15 }}$ und bezeichnet

„das dynamische Wechselspiel zwischen einer charismatischen Führerschaft, einem Erlösungsnarrativ, Außenseitertum und Ritualisierung, sowie der Schaffung einer Wertge-

9 Vgl. ebd.

10 Rovira Kaltwasser 2011: 9.

11 Taggart 2000: 2; Taggart 2004: 275.

12 Vgl. Canovan 1999: 3.

13 Zúquete 2011.

14 Ebd.; Griffin 2005; Gentile 2006.

15 Zúquete 2011: 93. 
meinschaft, die mit der kollektiven Mission ausgestattet ist, gegen verschwörerische Feinde zu kämpfen und die Nation von ihrer vermeintlichen Krise zu erretten.“" ${ }^{16}$

Missionarische Politik betont den emphatischen Politikbegriff des Populismus: „Politik wird nicht als kleinteilige und bürokratische Angelegenheit betrachtet; im Gegenteil, sie gilt als [...] als ein Werkzeug des radikalen, totalen und holistischen Wandels. “17 In einem populistischen Diskurs erscheint Politik daher nicht als ein pragmatisches von Fall-zu-Fall-Entscheiden. Vielmehr steht jede politische Entscheidung pars pro toto für die falsche oder die richtige Richtung, die sie einschlägt.

Das ,Wechselspiel' aus Verschwörungstheorie, charismatischer Führerschaft, Erlösungsnarrativ und der Schaffung einer Wertegemeinschaft, das missionarische Politik inszeniert, erwirkt demnach eine Politisierung, die aus der Generalisierung von singulären Momenten resultiert. Die Logik, die diese Generalisierung auslöst, lässt sich mit Laclau als Zusammenwirken von Äquivalenz, leerem Signifikant und Antagonismus entschlüsseln: Die singulären Entscheidungen werden äquivalentiell artikuliert, indem sie unter leeren Signifikanten subsumiert und als Teilaspekte eines tieferliegenden Antagonismus besprochen werden. Im manifesten politischen Kampf zwischen dem ,Establishment' und dem ,popularen Führer', welcher der negativen popularen Äquivalenz eine positive Form verleiht, steht nicht bloß ein Austausch der Funktionselite auf dem Spiel. Die Moralisierung der Konfliktparteien schöpft vielmehr ein manichäisches Szenario und erzeugt die eschatologische Illusion einer post-politischen Gesellschaft, in der die Elemente der popularen Äquivalenz ihre antagonistische Blockade überwinden.

\section{Heartland}

Jedoch lässt sich insbesondere in konservativen, rechtspopulistischen Diskursen beobachten, dass diese zukunftsorientierte Politisierung durch eine vergangenheitsorientierte Anti-Politisierung flankiert wird, die der Populismusforscher Paul Taggart als „Heartland-Politik ${ }^{\text {“18 }}$ bezeichnet. Ein Heartland, das etwa in Konzepten wie ,la France profonde‘, ,Padanien“ oder ,den Schweizer Alpen“ zum Ausdruck kommt, propagiert ein bedrohtes Stammland, das zugleich als Ursprungs- und Sehnsuchtsort fungiert. Es imaginiert das vorpolitische Ideal einer

16 Ebd.: 93.

17 Ebd.: 97.

18 Taggart 2000 u. 2004: insb. $278 \mathrm{ff}$. 
ursprünglichen, organisch gewachsenen, kulturell autonomen und ökonomisch autochthonen Gemeinschaft, die sich einer feindlichen Welt gegenübersieht:

„Das heartland steht als lokaler Topos für die Peripherie gegen das (Macht-)Zentrum, als mentaler Topos für den comon sense gegen die Wissenseliten, als kultureller Topos für die unhinterfragbare, aber von innen und außen bedrohte lebensweltliche Tradition und als politischer Topos für den Freiheitsbegriff des Frühliberalismus im Gegensatz zu ökonomischen, sozialen und kulturellen ,Bevormundung' des Volkes durch Agenten des sozialen Wandels. “19

Die geschichtspolitische Retrospektive erfüllt die Aufgabe, dem offenen Volksbegriff bestimmte politische Konturen zu verleihen. ${ }^{20}$ Zum ,Volk‘ gehören eben nur jene Elemente, die zum Heartland gehören. Anhand des Codes ,zugehörigorganisch/fremd-künstlich“ entscheidet das Heartland über die Legitimität politischer Forderungen. Auf diese Weise erzeugt es die Illusion einer unhintergehbaren Diversität zwischen zwei klar umrissenen, in sich homogenen Gruppen.

Die Quintessenz des Heartland besteht jedoch in einer tribalistisch begründeten antipolitischen Grundhaltung. ${ }^{21}$ Eine Heartland-Gemeinschaft bedarf keinerlei intermediärer Institutionen oder intersubjektiver Prozesse, um einen gemeinsamen politischen Willen zu bilden. Ihre Identität wurzelt in einer gemeinsamen Lebens- und Erfahrungswelt. Der Mythos organischer Einheit transportiert einen Antipluralismus, der nur jene politischen Programme als legitim anerkennt, die sich als restauratives Unterfangen diskursivieren und den Normen der originären Gemeinschaft folgen. Umgekehrt wird nicht nur die Politik des ,Establishments', sondern jeder Vorschlag und jede politische Initiative, die den Prinzipien des Heartland zuwiderläuft, zum Bestandteil des Bedrohungskomplexes.

Mit Laclau lässt sich der Bezug auf ein Heartland als ,strategischer Essentialismus، ${ }^{\text {222 }}$ lesen. Heartland-Begriffe wie ,Heimat', ,Padanien“ oder ,la France profonde" fungieren als bedeutungsstabilisierende Knotenpunkte. Sie verleihen dem Volksbegriff einen Grund und begrenzen das Spektrum möglicher Artikulationen. Ein Heartland-Mythos propagiert eine arche-politische ${ }^{23}$ Vorstellung. Er

19 Priester 2011: 196.

20 Vgl. Taggart 2004: 278.

21 Vgl. zur tribalistischen Komponente des Populismus Antonio 2000.

22 Spivak 1996.

23 Der kursiv gesetzte arche-politisch ist eine Adjektivierung des Begriffs Arche-Politik (arche-politics), den ich an dieser Stelle von Slavoj Žižek (1999: 28f.) übernehme. 
imaginiert einen vorpolitischen und wohlgeordneten Ursprungsort und immunisiert die populare Identität gegen alternative, gegenhegemoniale Reartikulationen. Gleichzeitig müssen sich Heartland-Begriffe von ihrer konkreten Bedeutung befreien, wenn sie die multiplen Elemente der popularen Äquivalenzkette gegen den Status quo in Stellung bringen sollen. Auch ein Heartland ist darauf angewiesen, sich in eine leere Hülle zu verwandeln, die sich mit unterschiedlichen Inhalten befüllen lässt. Die hegemonietheoretische Dialektik zwischen Vagheit, Leere und Universalisierung auf der einen und Fixierung, Partikularität und Schließung auf der anderen Seite bestimmt demnach auch die Logik des Heartland.

Indes ist der Rekurs auf ein Heartland keineswegs eine spezifische Differenz des Populismus. Im Gegenteil auch differenzlogisch dominierte Diskurse können auf ein Heartland verweisen, um populistische Gegenhegemonien im Keim zu ersticken. Heartland-Begriffe wirken der äquivalenzlogisch konstruierten Instabilität populistischer Diskurse entgegen. Sie schließen den Diskurs, indem sie die Lebenswelt einer vermeintlich originären Gemeinschaft als unhinterfragbaren Gradmesser von Plausibilität, Akzeptabilität und Legitimität verankern. Die Verschleierung der Kontingenz dieser Operation erweist sich dabei als Erfolgsbedingung. ${ }^{24}$ Das exkludierte Andere bleibt als Bedrohung der inneren Einheit präsent, wird jedoch als dinghafte, vordiskursive Diversität besprochen. Die bipolare Struktur bleibt bestehen, die Unentscheidbarkeit, die sich in der Vagheit der Signifikanten der beiden Pole widerspiegelt, wird jedoch durch das archepolitische Moment des Heartland-Mythos sublimiert. So ermöglicht das Heartland eine Politisierung nach Außen bei gleichzeitiger Entpolitisierung und Antipolitisierung im Innen und verweist damit auf die Grenzen der Analogisierung von Populismus und Demokratisierung, die von Laclau selbst nicht weiter reflektiert werden.

Ich gehe davon aus, dass dieses Problem in der Analyse rechtspopulistischer Diskurse wie jenem der SVP besonders virulent wird. Denn der doppelte Antagonismus gegenüber sozial privilegierten Gruppen (den ökonomischen, kulturel-

24 Zur Imagination von Organizität und Originalität als Logiken kultureller Gründungserzählungen vgl. Koschorke 2007. Slavoj Žižek (2005: 183ff.) greift diesen Aspekt in seiner Kritik der Hegemonietheorie Laclau/Mouffes ebenfalls auf. Der Philosoph diagnostiziert einen Bruch zwischen der Hegemonietheorie als Herrschaftstheorie, in der Macht und Entscheidung auf Verschleierungen angewiesen seien, und der radikaldemokratischen Ethik Laclau/Mouffes, die eine Visibilisierung von Macht und Unentscheidbarkeit verlange (vgl. zu diesem Spannungsverhältnis auch Hildebrand/ Séville 2015). 
len und politischen Eliten) und sozial marginalisierten Gruppen (Sozialhilfeempfängern, Migranten oder Asylsuchende), der rechtspopulistische Projekte charakterisiert, wird in diesen Diskursen durch ethnokulturell begründete Heartlands plausibilisiert. Diese Heartlands propagieren einen „differentialistischen Nativismus $^{\text {“25, }}$, der alles Nicht-Indigene a priori vom Volk ausschließt. So sind den oben exemplarisch angeführten Heartland-Begriffen trotz ihrer relativen Vagheit bestimmte Ausschlüsse eingeschrieben: Drogenabhängige passen nicht zum idyllischen Topos der Schweizer Alpen, süditalienische Arbeitsmigranten gehören nicht nach Padanien, und antipatriotische Kommunisten haben im tiefen Frankreich genauso wenig verloren wie Menschen maghrebinischer Herkunft.

Obwohl die Konstruktion eines Heartland hegemonietheoretisch analysiert werden kann, deuten die vielfältigen rhetorischen Rekurse auf diesen vorpolitischen Horizont in populistischen Diskursen auf ein Problem der Populismustheorie von Laclau hin. Wie ich gezeigt habe, basiert Laclaus demokratietheoretische Würdigung des Populismus darauf, dass er den Bruch mit dem Status quo und die Entstehung einer gegenhegemonialen Äquivalenz als Kernstück des Populismus fokussiert und den Populismus damit nicht nur als destabilisierenden, fundamentaloppositionellen, sondern auch als notwendig instabilen und folglich pluralismuskompatiblen Diskurs vorstellt. ${ }^{26}$ Dagegen nimmt der HeartlandBegriff das stabilisierende Moment der Schließung der popularen Äquivalenz ins Visier und liefert somit einen vielversprechenden Ansatz, um die außergewöhnliche Kontinuität und Stabilität des SVP-Populismus zu verstehen und ein Defizit der Populismustheorie Laclaus zu diskutieren. Denn mithilfe des Heartland lässt sich analysieren, wie die von Laclau als prekär und provisorisch gefassten Schließungen populistischer Diskurse stabilisiert werden, indem sie ihren politischen Charakter leugnen und zu vermeintlich natürlichen Originalen sedimentieren. $^{27}$

25 Taguieff 1994; Betz 2003: 195; vgl. auch Mudde 2007: 18ff.

26 Seine interne Dynamik liegt darin begründet, dass die populistische Äquivalenzkette mit der differenzlogischen Fixierung der Elemente bricht. Dadurch dass sie die Differenzen in untergeordnete Teilaspekte der polysemischen Negativität des Status quo verwandelt, steht eine Differenz für die andere.

27 Diese Problematik des Laclau'schen Populismusbegriffs werde ich nach der Analyse des SVP-Diskurses im Schlusskapitel diskutieren. 


\section{Zweiter Teil:}

\section{Von der Theorie}

zur Forschungsstrategie 



\section{Operationalisierung und Untersuchungsmaterial}

Im vorangegangen Kapitel wurde die Hegemonie- und Populismustheorie Ernesto Laclaus an die konventionelle Populismusforschung angeschlossen und für die Erforschung rechtspopulistischer Parteien im Allgemeinen differenziert. Nun soll darauf aufbauend ein Forschungsdesign für eine hegemonietheoretisch informierte Analyse des Aufstiegs der SVP entworfen werden. Hierzu wird zunächst ein Analyserahmen entfaltet, der das abstrakte hegemonietheoretische Begriffsinstrumentarium mit induktiv gewonnen Analysebegriffen ergänzt. Im Anschluss lege ich dar, wie ich mit der forschungspragmatischen Herausforderung eines sehr langen Untersuchungszeitraumes umgegangen bin. Abschließend erläutere und begründe ich die Auswahl der zu analysierenden Diskursfragmente.

\subsection{WIE SICH DIE FIXIERUNG VON SINN UNTERSUCHEN LÄSST. EINE TEXTANALYTISCH ORIENTIERTE OPERATIONALISIERUNG DER HEgEMONIETHEORIE}

Im Unterschied zu anderen Diskurstheorien und den daran anknüpfenden diskursanalytischen Schulen, die sich in erster Linie für die strukturellen Regelmäßigkeiten eines Diskurses oder die diskursive Konstruktion intersubjektiv geteilten Wissens interessieren, fokussiert die Hegemonietheorie die allgemeine Funktionslogik politischer Diskurse. ${ }^{1}$ „Es geht [...] nicht primär um diskursive Inhal-

1 Einen Überblick über unterschiedliche Ansätze der sozialwissenschaftlichen Diskursanalyse liefert etwa Johannes Angermüller (2007a: 99ff.). Dort werden drei Ansätze gegeneinander konturiert: eine an Foucaults Archäologie des Wissens orientierte 
te, sondern um diskursive Funktionen, oder genauer, um die Hegemoniefunktion von politischen Diskursen. ${ }^{\prime 2}$ Um diese Funktionsmechanismen zu analysieren, stellt sie ein Ensemble von Begriffen bereit, das die diskursive Konstruktion von Sinn als politischen, mit Kontingenz und Macht assoziierten Prozess begreift. Die Hegemonietheorie legt somit, im Unterschied zu den an Foucault orientierten, zumeist induktiv vorgehenden Diskursanalysen, ein deduktives Vorgehen nahe, in dem bestimmten Signifikanten spezifische Funktionen zugewiesen werden: Begriffe werden so artikuliert, dass sie als Knotenpunkte, leere Signifikanten oder als antagonistisches Anderes fungieren.

Obwohl in den vergangenen 20 Jahren Hegemonieanalysen zu vielfältigen politischen Phänomenen angefertigt wurden, steckt die Operationalisierung der abstrakten Theoriearchitektur Laclau/Mouffes nach wie vor in den Kinderschuhen. ${ }^{3}$ Die Hegemonieanalysen, die aus der sogenannten Essex School hervorgegangen sind, verzichten zumeist auf methodologische Vorarbeiten, ${ }^{4}$ wodurch sie Gefahr laufen, die hegemonietheoretischen Begriffe gleich Etiketten den Diskursfragmenten aufzukleben und den Forschungsgegenstand lediglich als Beweis für die Validität des Begriffsinstrumentariums zu gebrauchen, wie die LaclauSchüler David Howarth und Yannis Stavrakakis einräumen. ${ }^{5}$ Auf diese Problematik macht auch Reiner Keller aufmerksam. Aus Sicht des Begründers der Wissenssoziologischen Diskursanalyse weichen die hegemonietheoretisch informierten Arbeiten, die aus der Essex School hervorgegangen sind, Fragen einer Operationalisierung der Hegemonietheorie aus. ${ }^{6}$ Die Problematik besteht für Keller darin, dass sie das Untersuchungsmaterial lediglich als „Illustration der theoretischen Zusammenhänge“ behandeln, anstatt es als „eigenständige Ebene der Theoriebildung“ miteinzubeziehen. ${ }^{7}$ „Die empirische Anwendung der Dis-

strukturanalytische Diskursanalyse, eine hermeneutische, an den Wissensbegriff Berger/Luckmanns anschließende Diskursanalyse sowie eine hegemonietheoretische, auf Laclau/Mouffe zurückgehende Diskursanalyse.

2 Nonhoff 2010: 300f.

3 Vgl. Glasze 2007: 11.

4 Vgl. exemplarisch Smith 1994 u. Norval 1996.

5 Howarth/Stavrakakis 2000: 4f.

6 Vgl. Keller 2005: 162f. sowie Glasze 2007: 11, auch Casula 2012: 76. Kellers Kritik bezieht sich hierbei im Wesentlichen auf die Diskursanalysen, die aus der Essex School hervorgegangen sind, so etwa auf den von David Howarth, Aletta Norval und Yannis Stavrakakis (2000) herausgegebenen Sammelband „Discourse Theory and Political Analysis. Identities, Hegemonies and Social Change“.

7 Keller 2005: 162. 
kurstheorie von Laclau und Mouffe“, fokussiere ,allein [...] den Nachweis des Vorkommens und die konkrete Erfüllung derjenigen ,Zeichenfunktionen“, denen ihre Aufmerksamkeit" gelte, wodurch die diskursiv perpetuierte Regelhaftigkeit der ,,von Foucault anvisierten Wissensformationen aus dem Blick“ gerate. ${ }^{8}$

Wenngleich Kellers Grundsatzkritik am deduktiven Forschungsprogramm von Hegemonieanalysen über das Ziel hinausschießt, erwies sich der von Keller monierte Schwachpunkt in den Pilot-Analysen von Diskursfragmenten, die ich zu Beginn des Forschungsprozesses anzufertigen versuchte, als virulent. So war es zwar möglich, den theoretisch postulierten Zeichenfunktionen bestimmte Signifikanten zuzuordnen, doch fehlten intermediäre Analysebegriffe, die eine Beschreibung der diskursiv perpetuierten Regeln erlaubten, die äquivalentielle, differentielle, antagonistische oder repräsentative Relationen herstellen und stabilisieren. Es fehlten induktiv gewonnene Begriffe, die das genauer zu beschreiben vermögen, was Laclau und Mouffe unter der Einrichtung von Knotenpunkten als grundlegende Operation hegemonialer Sinnfixierungen verstehen.

Um dieses Problem zu lösen, ergänze ich das abstrakte hegemonietheoretische Begriffsinstrumentarium durch induktiv gewonnene Analysekategorien. Ich bediene mich dabei einer Reihe von Begriffen der Kritischen Diskursanalyse, die Ruth Wodak und Norman Fairclough in erster Linie zur Untersuchung nationalistischer und kulturrassistischer Diskurse konzipiert haben. ${ }^{9}$ Zwar unterscheiden sich Wodak/Faircloughs und Laclau/Mouffes Positionen im Hinblick auf die Frage, ob eine soziale Wirklichkeit jenseits diskursiver Repräsentationen existiert und erfasst werden kann, doch lassen sich die textanalytisch-orientierten Analysebegriffe der Kritischen Diskursanalyse mit dem Begriffsinstrumentarium der Hegemonietheorie kombinieren und zu einem effektiven Analyserahmen zusammenfügen, der die diskursiv perpetuierten Regeln der artikulatorischen Sinnproduktion stärker in den Blick nimmt als die hegemonietheoretische Begriffsapparatur allein. ${ }^{10}$ Neben der Hegemoniefunktion, die bestimmte Elemente des SVP-Diskurses ausüben, werden somit auch die regelhaften Plausibilisierungsund Legitimierungspraktiken in den Blick genommen, die den Diskurs von Innen stabilisieren.

Die Regeln, die den Diskurs von Innen organisieren, unterminieren keineswegs die hegemonietheoretisch begründete Irreduzibilität des Antagonismus. Dass diskursiv perpetuierte Regeln Elemente zueinander in Beziehung setzen,

8 Ebd.

9 Fairclough/Wodak 1997; Wodak u. a. 1998; Wodak 2001.

10 Vgl. Rear [o.J.]: 2 u. 12f.; David Rear versucht ebenfalls, die Diskurstheorie Laclau/ Mouffes mit der Kritischen Diskursanalyse Faircloughs zu verbinden. 
Taxonomien einrichten und Teilungskriterien instituieren, meint keineswegs, dass diese Regeln jenseits der antagonistischen Verfasstheit des Sozialen existierten. Vielmehr muss analytisch herausgearbeitet werden, dass die regelgeleitete Stabilisierung der Bedeutungsproduktion im Innen des Diskurses auf ein antagonistisches Außen angewiesen ist, das die Universalität der Regel unterläuft. Das heißt, dass die Regel, die der Artikulation zugrunde liegt, ihrerseits auf einem Antagonismus basiert. Ihr hegemonialer Geltungsanspruch gründet auf der Verwerfung eines Anderen, das sich der Regel entzieht und zugleich die Grenze ihrer Geltung markiert. Auf diese Weise soll verhindert werden, dass die mitunter kleinteiligen Analysen einzelner Diskursfragmente die politische Funktionslogik von Diskursen aus dem Blick verliert. ${ }^{11}$

Der Analyserahmen, den ich aus der Kombination von Hegemonietheorie und Kritischer Diskursanalyse gewinne, unterscheidet neben der relationalen Bedeutungsgeneration, die ich mit den hegemonietheoretischen Begriffen Differenz, Äquivalenz, Antagonismus und Repräsentation bezeichne, drei weitere Analyseebenen: diskursive Praktiken (1), Topoi und Argumentationsmuster (2) sowie Realisierungsformen (3). ${ }^{12}$

(1) Unter diskursiven Praktiken verstehe ich wiederkehrende (Sprech-) Handlungen, die differentielle, äquivalentielle, antagonistische oder repräsentative Relationen zwischen Elementen herstellen. ${ }^{13}$ Die einschlägigen Analysebegriffe sollen präzisieren, welche Praktiken bei der Konstruktion des populisti-

11 Hiervor warnt etwa Philipp Casula (2012: 72f.).

12 Vgl. Wodak u.a. 1998.

13 Wodak u.a. (1998: 73ff.) sprechen nicht von diskursiven Praktiken, sondern von diskursiven Strategien. Sie grenzen sich zwar (mit Bourdieu) von einem Strategiebegriff $\mathrm{ab}$, der ein kalkulatorisch intervenierendes Individuum suggeriert, und betonen, dass Strategien unbewusst und automatisiert zu Anwendung kommen können, halten aber (gegen Bourdieu) an der Trennung der praktischen Handlungsebene und der planerischen Strategieebene fest: Strategien stecken demnach „hinter beziehungsweise in“ (Wodak u.a. 1998: 74) den Handlungen, sodass die Rekonstruktion von ,oberflächlichen Handlungen` Rückschlüsse auf die ,tieferliegenden Strategien` zulässt, die die Handlungen gleich sozialen Normen oder subjektiven Intentionen organisieren. Mit diesem Strategiebegriff wird meines Erachtens ein schwaches Basis-Überbau-Modell und ein schwaches Konzept von Intentionalität eingeführt, die inkompatibel mit der postfundamentalistischen Diskurstheorie Laclau/Mouffes sind. Um diesen Unterschied deutlich zu machen, spreche ich anstelle von diskursiven Strategien lieber von diskursiven Praktiken. 
schen Dissens-Szenarios involviert sind bzw. wie die bedeutungsstiftenden Relationen eingerichtet werden.

(2) Das Herzstück des Analyserahmens bildet der Toposbegriff, wie ihn Wodak u.a. zur Erforschung der „diskursiven Konstruktion nationaler Identität“"14 entwickelten. Der Begriff stammt aus der Argumentationstheorie und bezeichnet wiederkehrende und komplexitätsreduzierende Schlussfolgerungsregeln, die einen Sinnzusammenhang zwischen zwei oder mehr Phänomenen herstellen, ohne diesen Zusammenhang notwendig ausbuchstabieren zu müssen. Topoi sind Deutungsmodelle der Wirklichkeit. Dabei kann es sich um Ursache-WirkungsZusammenhänge oder Wenn-Dann-Aussagen, die bestimme Gesetzmäßigkeiten oder Korrelationen postulieren, aber auch um Metaphern oder Schlagworte handeln, die bestimmte Schlussfolgerungen nahelegen oder bestimmte Assoziationsketten anstoßen. Entscheidend ist, dass Topoi Weltwahrnehmungen konstituieren und stabilisieren. Topoi bringen Knotenpunkte hervor, die spezifische Differenzrelationen perpetuieren, indem sie eine Regel formulieren, nach der Elemente zueinander in Beziehung gesetzt werden. So wird zum Beispiel im SVPDiskurs durch den konservativen Topos der Masse ${ }^{15}$ in einem europäischsozialistischen Außen eine Äquivalenz von Vereinzelung (Individualisierung, Vereinsamung, Anonymität, Egoismus) und Vermassung (Konformitätsdruck, Mittelmaß, Kollektivdenken, wohlfahrtsstaatliche Gleichmachung) vorgestellt, die es ermöglicht, kommunitaristische Gemeinschaftssemantiken mit dem neoliberalen Prinzip der Selbstverantwortung des Einzelnen zu artikulieren und diverse flottierende Elemente entweder einem liberalkonservativen ,Wir ${ }^{6}$ oder einem sozialistisch-massengesellschaftlichen ,Sie‘ zuzuordnen.

(3) Unter Realisierungsformen werden die rhetorischen Mittel verstanden, die diese Topoi verwirklichen. Sie dienen an dieser Stelle lediglich der Erläuterung der diskursiven Praktiken und der Topoi, werden in der Hegemonieanalyse aber genauer untersucht.

Während ich die Hegemonietheorie als vorgefasste Begriffsarchitektur zugrunde lege und deduktiv an meinen Forschungsgegenstand anlege, verfährt die vorgeschlagene Ergänzung durch die drei weiteren Analyseebenen nach Maßgabe der Grounded Theory. ${ }^{16}$ Das heißt, dass dem Untersuchungsmaterial respektive seiner Interpretation die Funktion zukommt, analytische Konzepte zu generieren. Folglich handelt es sich bei dem auf den folgenden Seiten in tabellarischer Form kondensierten Analyserahmen bereits um ein analytisch gewonnenes Er-

14 Wodak u. a. 1998.

15 Thies 2013.

16 Glaser/Strauss 1967. 
gebnis. Der Rahmen wurde als offenes Set angelegt. Er wurde zunächst anhand von Pilot-Analysen einzelner Diskursfragmente entworfen und im Laufe des Forschungsprozesses adjustiert.

Zum besseren Verständnis dieses Analyserahmens sei hier folgende Anmerkung vorausgeschickt. Anders als es die statische tabellarische Darstellungsform suggeriert, ist das Verhältnis zwischen den vier unterschiedenen Analyseebenen (Relationen, Praktiken, Topoi und Realisierungsformen) weder exklusiv noch erschöpfend. Bei den Praktiken, Topoi und den Realisierungsformen handelt es sich vielmehr um solche, die für die Konstruktion der jeweiligen Relation typisch sind. Das heißt beispielweise, dass ein- und dieselbe Praxis oder ein- und dieselbe Metapher gleichzeitig eine Differenz- und eine Äquivalenzbeziehung sowie einen Antagonismus und ein Repräsentationsverhältnis herstellen kann. Wenn Christoph Blocher sich zum Beispiel als ,Kopf einer Bewegungspartei beschreibt und erklärt, dass es nur folgerichtig sei, dass die „Attacken“ der politischen Klasse „,vor allem“ ihm gelten, da „die Partei geköpft werden müsse, da ohne Kopf nicht einmal eine Partei [lebt]", so bespricht der metaphorisch realisierte Topos des Organischen die Wir-Gruppe als funktional differenzierten und hierarchisch gegliederten Körper. ${ }^{17}$ Er stellt eine natürliche Einheit vor, die von einem Außen angegriffen, durch einen Kopf gesteuert wird und sich auf eine „kampferprobte“ und „standfeste Basis“ verlassen kann. ${ }^{18}$ Zwischen den Gliedern des Körpers realisiert die Metapher also sowohl eine Differenz- als auch eine Äquivalenzrelation; gleichzeitig begründet sie aber auch ein antagonistisches Verhältnis zu all jenen, die der Partei den Kopf abschlagen wollen, sowie ein synekdochisches Repräsentationsverhältnis, das Blocher als Kopf eine primusinter-pares-Position zuschreibt.

Ähnliches gilt beispielsweise auch für die Praxis der Skandalisierung. In einem Skandal avanciert ein Sachverhalt, der sich differenzlogisch als begrenzte Ungerechtigkeit oder als singulärer Ausrutscher artikulieren ließe, zur ,Spitze des Eisberges'. So steht beispielsweise die ,skandalöse Abwahl ${ }^{19}$ Blochers als Bundesrat im Jahr 2007 für die allgemeine Dekadenz der politischen Klasse, wodurch Blocher als deren Gegenspieler und Opfer zum Repräsentanten einer autochthonen, antagonistisch blockierten Gemeinschaft wird.

17 Blocher 2000a: 5.

18 Ebd.

19 Blocher 2008: 5. 
Ein Analyserahmen zur Erforschung des SVP-Populismus

\begin{tabular}{|c|c|c|c|}
\hline $\begin{array}{l}\text { Bedeutungs- } \\
\text { generieren- } \\
\text { de Relation } \\
\text { Welche Re- } \\
\text { lation wird } \\
\text { hergestellt? }\end{array}$ & $\begin{array}{l}\text { Zentrale diskursive } \\
\text { Praktiken } \\
\text { Durch welche Prakti- } \\
\text { ken werden die je- } \\
\text { weiligen Relationen } \\
\text { instituiert? }\end{array}$ & $\begin{array}{l}\text { Wiederkehrende } \\
\text { Topoi zur Begrün- } \\
\text { dung der Relation } \\
\text { Welchen Argumenta- } \\
\text { tionsmustern folgen } \\
\text { die jeweiligen artiku- } \\
\text { latorischen Prakti- } \\
\text { ken? }\end{array}$ & $\begin{array}{l}\text { Exemplarische Rea- } \\
\text { lisierungsformen } \\
\text { Was sind typische } \\
\text { Realisierungsformen } \\
\text { der jeweiligen Rela- } \\
\text { tion? }\end{array}$ \\
\hline \multirow{3}{*}{$\begin{array}{l}\text { Differenz } \\
\text { a ist anders } \\
\text { als } b, b \text { an- } \\
\text { ders als } c, c \\
\text { anders als } d \text {, } \\
\text { etc. }\end{array}$} & $\begin{array}{l}\text { Assimilation/ } \\
\text { Inklusion: } \\
\text {,Alle-in-einem-Boot- } \\
\text { Bild‘ }\end{array}$ & $\begin{array}{l}\text { Interdependenz- und } \\
\text { Komplexitätstopos } \\
\text { Topos der Balance } \\
\text { Lösungsorientierung } \\
\text { Similaritäts- und An- } \\
\text { passungstopos } \\
\text { Normalitätstopos }\end{array}$ & $\begin{array}{l}\text { Ausbalancierung und } \\
\text { Integration von Inte- } \\
\text { ressen als überle- } \\
\text { benswichtige Strate- } \\
\text { gien } \\
\text { Holistische und in- } \\
\text { tegrative Metaphern } \\
\text { (Schiff, Netz) } \\
\text { Übergeordnete, ,im- } \\
\text { partiale Sprecherpo- } \\
\text { sitionen }\end{array}$ \\
\hline & $\begin{array}{l}\text { Kontinuation: } \\
\text { Präsupposition von } \\
\text { positiver Kontinuität } \\
\text { resp. Negation von } \\
\text { Diskontinuität }\end{array}$ & $\begin{array}{l}\text { Topos der Entwick- } \\
\text { lung und des Lernens } \\
\text { Alternativlosigkeit } \\
\text { Historischer Topos }\end{array}$ & $\begin{array}{l}\text { Integration qua Kon- } \\
\text { sens } \\
\text { Zitationen }\end{array}$ \\
\hline & $\begin{array}{l}\text { Autonomisierung bei } \\
\text { gleichzeitiger Ver- } \\
\text { netzung: } \\
\text { Betonung von Eigen- } \\
\text { gesetzlichkeit }\end{array}$ & Komplexitätstopos & $\begin{array}{l}\text { Holistische Meta- } \\
\text { phern (Netz) }\end{array}$ \\
\hline $\begin{array}{l}\text { Äquivalenz } \\
\text { a geht Hand } \\
\text { in Hand mit } \\
b, c \text { und } d \text {. }\end{array}$ & $\begin{array}{l}\text { Singularisierung bei } \\
\text { gleichzeitiger Kon- } \\
\text { trastierung: } \\
\text { Betonung von Ein- } \\
\text { zigartigkeit (und } \\
\text { Vorbildlichkeit) }\end{array}$ & $\begin{array}{l}\text { Kontrastiver Ver- } \\
\text { gleich }\end{array}$ & $\begin{array}{l}\text { Lexeme mit singula- } \\
\text { risierender Semantik } \\
\text { Miranda, positive ge- } \\
\text { teilte Attribute }\end{array}$ \\
\hline
\end{tabular}




\begin{tabular}{|c|c|c|c|}
\hline & $\begin{array}{l}\text { Imagination von Au- } \\
\text { tarkie durch ein- } \\
\text { schlägige Prädikati- } \\
\text { vierungen }\end{array}$ & $\begin{array}{l}\text { Locus amoenus: } \\
\text { Fülle }\end{array}$ & $\begin{array}{l}\text { Pleonasmen } \\
\text { Parallelismen }\end{array}$ \\
\hline & $\begin{array}{l}\text { Kohäsivierung: } \\
\text { Betonung von Ge- } \\
\text { meinsamkeiten } \\
\text { Warnung vor dem } \\
\text { Verlust von Autarkie }\end{array}$ & $\begin{array}{l}\text { Bedrohungstopos } \\
\text { Historischer Topos } \\
\text { Kausalitätstopos } \\
\text { Topos der Organizi- } \\
\text { tät }\end{array}$ & $\begin{array}{l}\text { Kollektivierung } \\
\text { durch Ethnonyme } \\
\text { und Relationyme } \\
\text { Metonymisches und } \\
\text { historisches ,Wir‘ } \\
\text { Relationyme (,der } \\
\text { Fähigste‘) }\end{array}$ \\
\hline \multirow{4}{*}{$\begin{array}{l}\text { Antagonis- } \\
\text { mus } \\
\text { y bedroht } a, \\
b, c \text { und } d .\end{array}$} & $\begin{array}{l}\text { Externalisierung von } \\
\text { Schuld und Verant- } \\
\text { wortung: } \\
\text { Zweifel streuen } \\
\text { scapegoating } \\
\text { Differenzierung und } \\
\text { gemeinsame Artiku- } \\
\text { lation von primär und } \\
\text { sekundär Schuldigen }\end{array}$ & $\begin{array}{l}\text { Sinnverkehrungsto- } \\
\text { pos } \\
\text { Belastungs- und } \\
\text { Missbrauchstopos } \\
\text { Sündenfall und Dep- } \\
\text { ravation }\end{array}$ & $\begin{array}{l}\text { Metaphorik des Para- } \\
\text { sitären } \\
\text { Deiktika: ,Wir‘, } \\
\text { „Sie', ,die da oben“ }\end{array}$ \\
\hline & $\begin{array}{l}\text { Exklusion und Dis- } \\
\text { kontinuation: } \\
\text { Betonung inhaltlicher } \\
\text { und temporaler Dif- } \\
\text { ferenz }\end{array}$ & $\begin{array}{l}\text { Locus terribilis } \\
\text { Kritische Kreu- } \\
\text { zungspunkte } \\
\text { Periodizität }\end{array}$ & $\begin{array}{l}\text { Antimiranda, pejora- } \\
\text { tive Attribute } \\
\text { Diskontinuität und } \\
\text { Ereignishaftigkeit } \\
\text { ausdrückende Le- } \\
\text { xeme (indes, jedoch) }\end{array}$ \\
\hline & $\begin{array}{l}\text { Dissimilation: } \\
\text { Betonung einer in- } \\
\text { komatiblen, überge- } \\
\text { ordneten Differenz } \\
\text { gegenüber einem } \\
\text { Anderen }\end{array}$ & $\begin{array}{l}\text { Gefährdungstopos } \\
\text { Kausalitätstopos } \\
\text { Geschichtstopos }\end{array}$ & $\begin{array}{l}\text { Metaphorik des Or- } \\
\text { ganischen }\end{array}$ \\
\hline & $\begin{array}{l}\text { Polarisierung und } \\
\text { Spaltung: } \\
\text { Schwarz-Weiß- } \\
\text { Differenzierung mit }\end{array}$ & $\begin{array}{l}\text { Kontrastiver Ver- } \\
\text { gleichstopos (locus } \\
\text { amoenus vs. locus } \\
\text { terribilis) }\end{array}$ & $\begin{array}{l}\text { Kontrastierung von } \\
\text { Miranda und Antimi- } \\
\text { randa } \\
\text { expliziter Tabubruch }\end{array}$ \\
\hline
\end{tabular}




\begin{tabular}{|c|c|c|c|}
\hline & $\begin{array}{l}\text { pejorativer Fremd- } \\
\text { und positiver Selbst- } \\
\text { darstellung }\end{array}$ & $\begin{array}{l}\text { Verschwörungstopos } \\
\text { Topos der Masse }\end{array}$ & offene Parteinahme \\
\hline \multirow[t]{4}{*}{$\begin{array}{l}\text { Repräsenta- } \\
\text { tion } \\
\text { a steht für } b \text {, } \\
c \text { und } d \text {. }\end{array}$} & Stilisierung & $\begin{array}{l}\text { Primus inter pares } \\
\text { Heldentopos } \\
\text { Bescheidenheitstopos } \\
\text { Auftragstopos }\end{array}$ & $\begin{array}{l}\text { Synekdoche, bspw. } \\
\text { die SVP als Körper } \\
\text { mit Blocher als Kopf }\end{array}$ \\
\hline & $\begin{array}{l}\text { Emotionalisierung } \\
\text { und Skandalisierung }\end{array}$ & $\begin{array}{l}\text { Topos der verhinder- } \\
\text { ten Fülle }\end{array}$ & $\begin{array}{l}\text { Involvierte Sprecher- } \\
\text { position } \\
\text { offene Parteinahme } \\
\text { explizite Tabubruch }\end{array}$ \\
\hline & $\begin{array}{l}\text { Universalisierung } \\
\text { durch semantische } \\
\text { Entleerung }\end{array}$ & $\begin{array}{l}\text { Generalisierung } \\
\text { Vagheit }\end{array}$ & Naming \\
\hline & $\begin{array}{l}\text { Kontinuation } \\
\text { Präsupposition von } \\
\text { Kontinuität }\end{array}$ & Periodizität & $\begin{array}{l}\text {,David gegen Goli- } \\
\text { ath'-Szenario } \\
\text { Zyklisch-periodische } \\
\text { Geschichtsphilosphie }\end{array}$ \\
\hline
\end{tabular}

\subsection{EINE FORSCHUNGSPRAGMATISCHE AUSWAHL VON VIER DISLOZIERENDEN EREIGNISSEN ALS WegmaRKEN DER HEgEMONIEANALYSE}

Die zentrale forschungspragmatische Herausforderung für die vorliegende Arbeit bestand darin, dass es sich beim SVP-Populismus im Gegensatz zu vielen anderen populistischen Parteien und Bewegungen nicht etwa um ein ephemeres Protestphänomen, sondern um ein politisches Projekt mit einer fortwährenden Erfolgsgeschichte handelt. Die kontinuierliche Radikalisierung und der simultane Aufstieg der SVP erstrecken sich auf über 20 Jahre. Nimmt man den Beginn der innerparteilichen Spaltung zwischen dem ehemals dominanten pragmatischklientelistischen Berner Flügel und dem oppositionellen Zürcher Flügel hinzu, so reicht die Geschichte des SVP-Populismus gar bis in die 1970er Jahre und den damaligen Grundsatzstreit über die zukünftige Ausrichtung der kriselnden Partei zurück.

Der Versuch, die Karriere der ehemaligen Mitte-Partei diskursanalytisch zu rekapitulieren, wäre verbunden mit einer nicht zu bewältigenden Materialfülle. 
Daher greife ich auf den Vorschlag zurück, den unter anderen der Soziologe Rogers Brubaker und die Kritischen Diskursforscher Margarete und Siegfried Jäger zur Analyse ethnischer Identitäten respektive diskriminierender Diskurse unterbreiten: Anstelle von sozialen Gruppen, gehe ich von Ereignissen aus, in deren Folge sedimentierte Wissensbestände und Normalitätsvorstellungen desartikuliert und reartikuliert werden. ${ }^{20}$

Ich habe vier Ereignisse ausgewählt: die Volksabstimmung über den Beitritt zum EWR, in der die Zürcher SVP im Alleingang gegen die etablierten Repräsentationsorgane der politischen Schweiz den EWR-Beitritt abwehren konnte (1); die Nationalratswahlen von 1999, in denen die SVP erstmals stärkste politische Kraft wurde (2); die Abwahl Christoph Blochers als Justizminister im Jahr 2007 und die darauffolgende Abspaltung der neugegründeten BDP von der SVP (3); die Minarettinitiative von 2009, mit der die SVP nicht nur gegen den Bau von Minaretten, sondern auch gegen das Primat von Völker- und Menschenrechten gegenüber dem demokratischen Prinzip der Volkssouveränität opponierte (4). Bei den Ereignissen handelt es sich um Ereignisse unterschiedlicher Art, insofern die Nationalratswahlen von 1999 und die Abwahl Blochers prinzipiell politikfeldübergreifende, die anderen beiden Ereignisse dagegen prinzipiell thematisch eingegrenzte Entscheidungen sind. Jedoch versucht die Hegemonieanalyse zu zeigen, wie der SVP-Populismus die Differenz von Politikfeldern aufhebt, indem er eine integrative Wir-Sie-Matrix herstellt, die in der Lage ist, heterogene Elemente zu absorbieren und in Momente eines übergeordneten Konfliktes zu verwandeln.

Hierzu werden die vier Ereignisse jeweils vorgestellt, kontextualisiert und als Dislokationen der konkordanzdemokratisch integrierten Schweiz interpretiert. Aus einer Kritik der Ursachenanalysen konventioneller Erklärungsansätze leite ich sodann konkrete Forschungsdesiderata ab, die ich hegemonieanalytisch zu beantworten versuche. Dabei ist zu beachten, dass die ausgewählten Ereignisse nicht als Folge einer vorgängigen Identität, sondern zugleich als Effekt und als Gelegenheit der rhetorischen Neufixierung von Sinn durch den SVP-Populismus zu lesen sind. Sowohl die Ereignisse als auch die Kontexte werden daher als diskursive Elemente betrachtet, die ihre Bedeutung erst erhalten, indem sie auf spezifische Art und Weise besprochen werden.

20 Vgl. Brubaker 2007; Jäger/Jäger 2007. 


\subsection{UNTERSUCHUNGSMATERIAL}

Die ausgewählten Ereignisse fungieren als Wegmarken der Hegemonieanalyse. Um sie herum werden jeweils Tiefenbohrungen lanciert, durch die ich relevante Texte als Fragmente des zu analysierenden Diskurses erschließe. ${ }^{21}$ Das bedeutet, dass die Zusammenstellung der zu analysierenden Texte nicht systematischen Kriterien, sondern meinem Erkenntnisinteresse folgt. Ausgewählt werden Texte, die in Zusammenhang mit einem der vier ausgewählten Ereignisse stehen und eine Beantwortung der forschungsleitenden Frage nach der sozialen Performativität der SVP-Rhetorik ermöglichen.

Es sei daher darauf hingewiesen, dass die Zusammenstellung der zu analysierenden Texte keineswegs einen Anspruch auf Vollständigkeit erhebt. Vielmehr sollen die ausgewählten Texte typisch respektive symptomatisch für die Repräsentation der Gesellschaft im SVP-Populismus sein. Ein typischer respektive symptomatischer Text lässt sich nicht a priori eruieren. Die Qualifikation als typisch oder symptomatisch ist vielmehr bereits ein Forschungsergebnis, das es in der Analyse zu untermauern gilt, indem die intertextuellen Bezüge des jeweiligen Fragments herausgearbeitet werden. Gleichzeitig basiert die Einstufung auf dem forschungspragmatischen Urteil, den Diskurs so weit erfasst zu haben, dass bei weiterer Recherche und Lektüre keine neuartigen Artikulationen aufgefunden werden würden.

Von besonderer Relevanz sind Texte, die Politikfelder und Forderungen miteinander verknüpfen. Um die äquivalentielle Artikulation und die Bündelung von Elementen durch leere Signifikanten zu analysieren, sind enumerative Formate wie Parteiprogramme und politikfeldspezifische Positionspapiere, die Forderungen und Standpunkte listenartig aneinanderreihen, weniger zielführend als Plakate, Reden, Leitartikel und Kommentare sowie feuilletonistische und essayistische Texte von Parteiführern und SVP-nahen Intellektuellen, die sich als komplexe Verknüpfungen von disparaten Elementen lesen lassen.

21 Wie wir gesehen haben, inkludiert Laclau/Mouffes Diskursbegriff sowohl sprachliche als auch nicht-sprachliche Handlungen. Jedes Handeln wird als sinnkonstituierend gefasst und insofern als diskursives Handeln analysiert. Wenn hier und im Folgenden daher von Texten die Rede ist, so geschieht dies gemäß des Derrida'schen Diktums „There is nothing outside the text“ (Derrida 1974: 158). Als Texte werden daher nicht nur Reden, Reformpakete und Zeitungsartikel, sondern auch Werbeplakate und Gesetzesbeschlüsse gelesen. 
Die vorliegende Arbeit konzentriert sich auf den SVP-Populismus. Dieser Diskurs umfasst nicht nur Artikulationen von Politiker/innen der radikalen Zürcher Sektion, sondern auch Artikulationen, die sich der um die Kantonssektion entstandenen Formation zuordnen lassen. Während zur Rekonstruktion der Ereignisse Primär- und Sekundärtexte konkurrierender politischer Diskurse hinzugezogen werden, rekurriert die Analyse im Wesentlichen auf Texte, die SVPnahen Quellen entstammen. ${ }^{22}$ Dazu gehören Artikel aus der von Ulrich Schlüer herausgegebenen nationalkonservativen Zeitung Schweizerzeit, in der neben rechtskonservativen Intellektuellen hauptsächlich SVP-Politiker publizieren, Aufsätze aus der in unregelmäßigen Abständen erscheinenden SchweizerzeitSchriftenreihe, Artikel aus dem Zürcher Boten, dem wöchentlich erscheinenden Publikationsorgan der Zürcher SVP, Artikel aus der AUNS-Klartext, dem Publikationsorgan der von Christoph Blocher, Otto Fischer und anderen namhaften Konservativen 1986, im Vorfeld der Abstimmung über den UNO-Beitritt, als überparteiliche Organisation gegründeten Aktion für eine unabhängige und neutrale Schweiz, Artikel aus der Zeitung der SVP Schweiz SVP-ja (ab 2007 SVPKlartext) sowie Artikel aus der Weltwoche, die seit ihrer Übernahme durch Roger Köppel auf SVP-Linie politisiert und wie die Schweizerzeit als intellektuelles Laboratorium der SVP fungiert. Die herausgehobene Stellung Blochers wird anhand von Blocher-freundlichen und Blocher-feindlichen biographischen Texten untersucht. Als Schlüsseltexte werden die Albisgüetli-Reden Christoph Blochers gehandhabt. ${ }^{23}$ Diese Schlüsseltexte werden detailliert untersucht und mit weiteren Textanalysen kombiniert.

Von Interesse sind des Weiteren die politischen Slogans der SVP, die als identitätsstiftende Verdichtungspunkte gelesen werden, die Requisiten und die Orte von SVP-Veranstaltungen, sowie die Abstimmungsplakate der Partei. Denn diese Plakate wollen nicht sympathisch-lächelnde oder vertrauenserweckendstaatsmännisch dreinblickende Kandidaten anpreisen. Die Plakate der SVP zielen vielmehr darauf, Missstände anzuprangern, Wir-Sie-Unterscheidungen auf den Punkt zu bringen und eine Diskussion auszulösen, die die binäre Struktur der eigenen Kampagne repliziert.

22 Eine Zusammenstellung des konkreten Textkorpus findet sich im Literaturverzeichnis.

23 Auf die Albisgüetli-Tagung wird im folgenden dritten Teil, in Kapitel 4.2 detailliert eingegangen. 


\section{Dritter Teil:}

Eine Hegemonieanalyse des SVP-Populismus 



\section{No Country for Populist Leaders?}

In den vorangegangenen beiden Kapiteln wurden die theoretischen und methodischen Grundpfeiler für die Hegemonieanalyse des SVP-Populismus errichtet. Um diesen Diskurs auf seine identitätsstiftenden Effekte hin zu befragen, gilt es nun zuerst die politische Kultur zu beschreiben, in deren Kontext er operiert und die er auf spezifische Weise verformt. Meine Analyse zielt jedoch nicht auf eine vollständige Darstellung der politischen Kultur der Schweiz. Vielmehr sollen jene artikulatorischen Praktiken rekonstruiert werden, die für die Struktur und die außergewöhnliche Stabilität der politischen Schweiz maßgeblich waren. Ich möchte zeigen, wie die kompromissorientierten Willensbildungs- und Entscheidungsprozesse des schweizerischen Konkordanzsystems ein soziales Imaginäres hervorbrachten, das in Form einer konsensorientierten, gemäßigt pluralistischen und insofern populismusresistenten politischen Kultur sedimentierte. ${ }^{1}$ So verfügt die Schweiz zwar über eine wirkmächtige Tradition der nationalen Selbstvergewisserung, doch wurde diese seit dem Ende des Kulturkampfes zwischen einem ultramontanen, innerschweizerischen Katholizismus und einem nationalliberalen, mittelländischen Protestantismus Mitte des 19. Jahrhunderts nicht durch binäre, populistisch-äquivalenzlogische, sondern überwiegend durch neokorporatistische, differenzlogisch dominierte Diskurse geprägt.

1 Ich folge hierbei Oliver Marchart (2002), der das Konzept des hegemonialen Imaginären zur Beschreibung des österreichischen Neokorporatismus nutzt und zeigt, inwiefern der Aufstieg der FPÖ dieses hegemoniale Imaginäre erschüttert (vgl. auch Marchart 2000). 


\subsection{DER ,KONKORDANZDEMOKRATISCHE SONDERFALL‘. ZUR HEGEMONIALEN KONSTRUKTION DER POLITISCHEN SCHWEIZ ZWISCHEN 1945 UND 1990}

Vor der populistischen Wende der SVP spielten populistische Diskurse in der Schweiz eine weitgehend marginale Rolle. ${ }^{2}$ Seitdem die Sozialdemokratische Partei (SP) im Nachgang des ersten und letzten Generalstreiks im Jahr 1918 die Proporzwahl für den Nationalrat erkämpfen konnte, ab 1959 zwei Bundesratssitze erhielt und fortan - trotz signifikanter Positionsdifferenzen - zumeist als kompromissbereiter Partner der bürgerlichen Mehrheit agierte, kannte das politische System der Schweiz über drei Jahrzehnte keine machtvolle systematische Oppositionspartei. ${ }^{3}$ Mit Ausnahme der Grünen, denen es gelang, die postmateriellen Einstellungen der Neuen Sozialen Bewegungen zu bündeln, scheiterten alle politischen Initiativen, sich nachhaltig mit einem Programm links oder rechts der durch die vier Bundesratsparteien verkörperten politischen Mitte zu etablieren. ${ }^{4}$

Auf der linken Seite des politischen Spektrums disqualifizierte sich die Nachfolgepartei der verbotenen Kommunistischen Partei der Schweiz (KPS), die Partei der Arbeit (PdA), durch ihr Bekenntnis zu den imperialistischen Interventionen der Sowjetunion in Osteuropa und konnte sich in den 1960er und 1970er Jahren lediglich in ein paar Hochburgen in den westschweizerischen Industriezentren behaupten. Da die Sozialpartnerschaft, der Arbeitsfrieden und die politische Integration der SP den Klassenkonflikt wirksam dämpften, ${ }^{5}$ konnten die inzwischen zersplitterten politischen Bewegungen links der mitregierenden SP ihren Einfluss nicht über diese wenigen roten Inseln hinaus ausdehnen. ${ }^{6}$

Auf der rechten Seite des politischen Spektrums hingegen konnte die von dem charismatischen Verleger James Schwarzenbach geführte Nationale Aktion in den 1970er Jahren für Aufsehen sorgen, als die Volksinitiativen gegen Überfremdung, mit denen die Partei gegen die Wirtschafts- und Migrationspolitik des

2 Vgl. für einen Überblick Altermatt u.a. 1994.

3 Zur Geschichte der SP vgl. Degen 1993.

4 Zur Geschichte der Grünen in der Schweiz vgl. Seitz 2008.

5 Zur Geschichte des Arbeitsfriedens vgl. Degen 1991.

6 Zur Entstehung der Sozialpartnerschaft vgl. ebd.; für eine kompakte Darstellung der politischen Parteien und Bewegungen links der SP vgl. Studer 2010; detailliert Rauber 2003. 
Bundesrates politisierte, nur knapp scheiterten. ${ }^{7}$ Gegen die kulturrassistisch begründete Migrationspolitik der Nationalen Aktion verbündeten sich die großen Parteien, die Kulturschaffenden, die Medien, die Kirchen, die Wirtschaftsverbände und die Gewerkschaften. Gleichzeitig erwies sich der Überfremdungsbegriff, mit dem die Partei hantierte, aber als geeigneter politischer Kampfbegriff, um diesen deutungsmächtigen politischen Kräften die Stirn zu bieten und ein insbesondere im Arbeiter- und Bauernmilieu verbreitetes Unbehagen gegenüber dem Strukturwandel, den Industrialisierungs- und Modernisierungsprozessen und der damit verbundenen Arbeitsmigration aus Südeuropa zu kanalisieren.

Schwarzenbachs vehemente Kritik an der ,materialistischen Maßlosigkeit der Moderne“" ${ }^{\text {, }}$, die heraufbeschworene Bedrohung durch die „kommunistischen Arbeitsmigranten“" ${ }^{\text {"9 }}$ und die skizzierte Alternative einer kleinräumigen, religiös und rural geprägten Schweiz waren indes inkompatibel mit den Lebenswirklichkeiten einer zunehmend urban und suburban geprägten Gesellschaft. Zumal sich die von „Blochers Vorläufer“"10 geschürte Angst vor Arbeitslosigkeit und Lohnsenkungen für die meisten Bürger/innen als unbegründet erwies. Der EthnoPopulismus Schwarzenbachs scheiterte daran, sich neue Forderungen einzuverleiben, um die in den Volksabstimmungen erzielte Polarisierung der Gesellschaft zu aktualisieren. In den 1980er Jahren mutierte er schließlich zu einer subalternen kulturellen Enklave, einer folkloristischen „Volkstumsschwärmerei“"11, die fortan lediglich eine Stammwählerschaft von zwei bis drei Prozent zu mobilisieren vermochte. So blieb der Überfremdungsdiskurs der Nationalen Aktion ein heftiges, aber zeitlich begrenztes „Strohfeuer“12. Die Partei geriet in eine Krise, ehe sie in unterschiedliche Faktionen zersplitterte. ${ }^{13}$ Ihre wichtigste Nachfolgepartei, die Schweizer Demokraten, konnte die Mobilisierungserfolge Schwarzenbachs nicht annähernd wiederholen.

Ähnlich erging es anderen politischen Projekten der extremen Rechten: Die Genfer Partei Vigilance blieb ein kantonales Phänomen; die Auto-Partei, die sich in erster Linie als liberale Steuersenkungspartei profilierte und nebenbei Ressen-

7 Zum Überfremdungsdiskurs und der politischen Karriere Schwarzenbachs vgl. Drews 2005; Skenderovic 2003; Buomberger 2003 u. 2004.

8 Drews 2005: 272.

9 Zur Artikulation von Migration und Kommunismus zu einem bedrohlichen Kollektiv im Diskurs Schwarzenbachs vgl. exemplarisch Schwarzenbach 1974: 75ff.

10 Buomberger 2003.

11 von Salis, zit. in: Buomberger 2004: 205.

12 Buomberger 2004: 205.

13 Vgl. Drews 2005: 82ff. 
timents gegen Ausländer kultivierte, stagnierte auf konstant niedrigem Niveau. ${ }^{14}$ Trotz einiger Achtungserfolge bei Referenden über migrations- und sicherheitspolitische Fragen scheiterten alle Tentativen rechts der drei bürgerlichen Großparteien daran, politische Projekte zu entwerfen, die diverse Unrechtserfahrungen integrieren, um als gegenhegemoniale Alternative der vier Bundesratsparteien wahrgenommen zu werden. ${ }^{15}$

Zudem entstanden trotz der kulturellen Diversität der Schweiz und zunehmender sozioökonomischer Disparitäten zwischen Peripherien und Zentren auch keine einflussreichen Regionalparteien, die erfolgreich gegen das Berner Quadrumvirat politisierten. ${ }^{16}$ Konflikte zwischen ökonomisch prosperierenden und strukturschwachen Kantonen, katholischen und protestantischen Gegenden, zwischen Stadt und Land oder den romanischen Teilen des Landes und der Majorität der Deutschschweizer lassen sich anhand der unterschiedlichen Stimmverteilungen in den Kantonen zwar mitunter ablesen, die Responsivität des konkordanzdemokratischen politischen Systems, die breite Akzeptanz des ausgeprägten Wettbewerbsföderalismus der Kantone und der schwach ausgeprägte Parteienwettbewerb verhinderten jedoch, dass diese Differenzen mit nachhaltigem Erfolg gegen die Berner Allparteienregierung gewendet werden konnten. ${ }^{17}$ So sind in der Schweiz bis heute zwar alle vier klassischen Konfliktlinien politisch virulent, ${ }^{18}$ doch intensivierte sich vor 1990 keine dieser Konfliktlinien zu einem

14 Zur Programmatik und Entwicklung der Auto-Partei vgl. Altermatt/Furrer 1994.

15 Zur relativen Schwäche der extremen Rechten in der Schweiz vgl. Gentile/Kriesi 1998; Skenderovic 2007a u. 2009.

16 Die Lega dei Ticinesi entstand erst 1991. Zur programmatischen und strategischen Ausrichtung der Partei und ihrer Stellung innerhalb des Parteiensystems vgl. Mazzoleni (2005), der die Partei als ethnische Überprägung des sozioökonomisch gelagerten Konflikts zwischen Peripherie und Zentrum deutet.

17 Eine Ausnahme bildet der Kanton Jura. Die stark mehrheitlich französischsprachige Region spaltete sich im Jahr 1979 nach einem langen ethnisch gelagerten Konflikt vom deutschsprachigen Kanton Bern ab (vgl. Ganguillet 1986; Linder 1994: 25f. u. 2012: 49ff.). Zur friedlichen Konfliktbearbeitung der regionalen Disparitäten durch das Konkordanzprinzip vgl. Steiner 1970; Linder 2012: $29 \mathrm{ff}$.

18 Mit den vier klassischen Konfliktlinien sind die persistenten Gegensätze zwischen Stadt und Land, Arbeit und Kapital, Laizismus und Kirchenbindung sowie zwischen Zentrum und Peripherie gemeint, die Seymour M. Lipset und Stein Rokkan (1967) als strukturbildende Konflikte westlicher Gesellschaften und ihrer Parteiensysteme konzipieren. 
Freund-Feind-Gegensatz, der die Konkordanz gefährdet oder zumindest das Parteiensystem dynamisiert hätte.

Im Gegenteil, aufgrund der Kontinuität der Vier-Parteien-Regierung, der geringen Volatilität des Parteiensystems und der Beständigkeit des alignment zwischen den Wählergruppen und den vier Bundesratsparteien konnte sich die Schweiz bis zum Beginn der 1990er Jahre als Hort politischer Stabilität par excellence auszeichnen. Diese außerordentliche Stabilität des politischen Systems gründet auf einem konkordanzdemokratischen nationalen Imaginären, dessen Funktionslogik ich im Folgenden hegemonietheoretisch beschreiben werde.

Die vorherrschende Selbstinterpretation der Eidgenossenschaft ist geprägt durch das Diktum des Politologen Karl W. Deutsch. Demnach konstituiert die multikulturelle Nation einen ,paradigmatischen Fall politischer Integration“19. Der Glaube an den ,Schweizer Sonderfall ${ }^{\circ 2}$ und die ,,schweizerische Gegenläufigkeit“ ${ }^{21}$ stilisierte die pluralistische, ,hoch über der blossen Bluts- und Sprachverwandtschaft ${ }^{\text {‘22 }}$ umliegender Kulturnationen stehende Willensgemeinschaft nicht nur zum Ideal einer nach republikanischen Idealen verfassten Nation. ${ }^{23}$ Das hegemoniale Imaginäre der politischen Schweiz koppelt das Gelingen des Gemeinwesens zugleich an die konkordanzdemokratischen Konfliktregelungsmechanismen des politischen Systems. ${ }^{24}$ Wenngleich zum ,Sonderfall Schweiz auch direkte Demokratie, außenpolitische Neutralität, Föderalismus und Subsidiarität gehörten, so das zentrale Argument, liege der Grundstein für den Zusammenhalt der heterogenen Nation doch in politischen Institutionen begründet, die nicht den Willen einer Mehrheit umsetzen, sondern strukturelle Minderheiten integrieren, die politischen Faktionen zu mitunter langwierigen Kompromissbil-

19 Deutsch 1976; vgl. hierzu auch Andreas Wimmers (2011) Studie zum multiethnischen Schweizer Nationalismus, sowie die einleitenden Bemerkungen zur Entstehung des Schweizer Nationalismus der Historiker Urs Altermatt, Catherine Bosshart-Pfluger und Albert Tanner (1998).

20 Zum Topos des Sonderfalls als der nach wie vor ,verbreitetste[n] kollektive[n] Identitätskonstruktion“"vgl. Eberle 2007: 7.

21 Schmid 1998 [1957].

22 Hilty 1875: 29; exemplarisch für die Aktualisierung der Selbstbeschreibung als exzeptionelle Willensnation vgl. Koller 1995: 11; Altermatt/Bosshart-Pfluger/Tanner 1998.

23 Vgl. Tanner 2002: 179f.; im Anschluss an Ernest Renan, der die Schweiz 1832 als ,la nation de l'Europe la plus légitimement composée“ bezeichnete (zit. in: ebd.).

24 So argumentieren beispielsweise die Politologen Wolf Linder (1994), Werner Seitz (2006) und Ulrich Klöti (2001) sowie der FDP-Politiker Kaspar Villiger (2008: 202ff.). 
dungen zwingen und daher kollektiv verbindliche Entscheidungen fällen, die von allen als vernünftig, unterstützenswert, akzeptabel oder zumindest tragbar erachtet werden. Der ,Schweizer Sonderfall“ als „Geschichte einer gelungenen In-

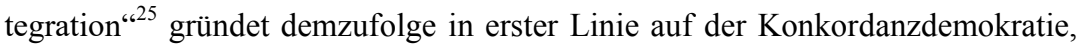
die als spezifisch schweizerische, anderen Ordnungen überlegene politische Ordnung präsentiert wird. ${ }^{26}$ Bestätigt durch die außergewöhnliche Stabilität des Parteiensystems galt die Konkordanz für lange Zeit als die Erfolgsgarantin der kulturell heterogenen Willensnation.

Wenngleich auch der Föderalismus und die Milizarmee als „Schule der Nation $^{\text {‘27 }}$ die Integration der multikulturellen Bevölkerung im Rahmen einer Willensnation begünstigt hätten, sei die konkordanzdemokratische Norm des ,gütlichen Einvernehmens ${ }^{\text {‘28 }}$ die eigentliche Ermöglichungsbedingung des politischen Gemeinwesens. ${ }^{29}$ Die konsensorientierten Konfliktregelungsmechanismen des politischen Systems (die proporzmäßige und machtteilende Bestellung der Regierung nach der sogenannten Zauberformel, die in der Verfassung verankerte Kollegialität des Bundesrates in der Kommunikation nach außen, die notwendige Kompromissbildung in einer regierungstragenden Koalition aus vier großen Parteien, die runden Tische und die daraus resultierende Vernetzung der gesellschaftlichen Eliten) hätten entscheidend dazu beigetragen, die soziokulturellen und sozioökonomischen Differenzen der multiethnischen Schweiz politisch zu integrieren. ${ }^{30}$ Sie hätten ein republikanisches Staatsbürgerschaftskonzept hervorgebracht, mit dem sich die Bürger nicht als Politikabnehmer gegenüber dem Staat, sondern als Akteure im Staat wahrnähmen und sich auch dann noch mit der politischen Gemeinschaft identifizierten, wenn deren Entscheidungen zu ihren Ungunsten ausfielen. ${ }^{31} \mathrm{Im}$ Windschatten dieser vorbildlichen civic culture ${ }^{32}$

25 Altermatt/Bosshart-Pfluger/Tanner 1998.

26 Vgl. Widmer 2008: 184, Imhof 2007; kritisch zum Glauben an den konkordanzdemokratischen Sonderfall vgl. die ländervergleichende Studie von Armingeon 1996.

27 Als solche bezeichnete der Bundesrat die Armee noch im Jahr 1989 im Bericht an den Nationalrat, als das Parlament über die Abschaffungsinitiative abstimmte (vgl. Hubacher 2014: 142).

28 Lehmbruch 1967: 8.

29 Vgl. etwa Imhof 2007.

30 Vgl. exemplarisch Meier-Dallach 1988: 104ff. sowie zu Multikulturalismus und Konkordanz vgl. Neidhart 2002: 118ff.; Linder 2012: 29ff.

31 Vgl. Meier-Dallach 1988: 105. 
sei ein „demokratischer Nationalismus ${ }^{\text {‘33 }}$ entstanden, der auf den Vorrang individueller Freiheitsrechte und die Anerkennung von Diversität insistiere.

In partieller Konkurrenz zu diesem sendungsbewussten liberaldemokratischen Nationalismus, der die Schweiz als „europäische Pioniernation“"34 und „aufgeklärte Musterrepublik“635 bespricht, war nach dem Scheitern des Völkerbundes, in der Zwischenkriegszeit, mit der Idee der geistigen Landesverteidigung ein isolationistische Variante des Schweizer Nationalismus wiederbelebt worden, welche die Schweiz vor dem Hintergrund der Bedrohung durch den deutschen und italienischen Faschismus in der Tradition des Rütli-Mythos als „heile Insel in einer heillosen Welt ${ }^{\star 36}$ besprach. Als deutungsoffener, parteienund ideologieübergreifender Minimalkonsens schuf der sogenannte ,LandiGeist' in der ersten Hälfte des 20. Jahrhunderts ein Bewusstsein für die besondere Verfasstheit der von fremden Mächten umstellten „Alpenfestung“637 Schweiz und propagierte die Notwendigkeit einer ideologisch geeinten und militärisch wehrhaften Nation, die ihren Ausdruck in der bewaffneten Neutralität und einer konsensualen Außenpolitik fand. ${ }^{38}$ Eine wichtige Rolle für die Plausibilisierung dieser „nationalpädagogischen Staatsideologie ${ }^{\text {(39 }}$ spielte die „Vorstellung der Prägekraft des Bodens ${ }^{\text {“40 }}$ : Der freiheitsliebende und unbeugsame ,homo alpinus helveticus ${ }^{\text {“41 }}$ avancierte zur Verkörperung des bedrohten liberaldemokratischen Kleinstaates. Mit dem Beginn des Kalten Krieges wurden diese Ideen von bürgerlich-konservativen Kräften hegemonisiert und als „antitotalitärer Basiskom-

32 Das Konzept stammt von den Gründervätern der vergleichenden politischen Kulturforschung Gabriel Almond und Sydney Verba (1963) und bezeichnet einen Typus politischer Kultur, der der liberalen Demokratie am besten entspricht.

33 Kohn 1956: 77.

34 Küng 1992: 96.

35 Langejürgen 1993: 17.

36 Ebd.

37 Küng 1992: 96.

38 Zum sogenannten ,Landi-Geist` vgl. Jorio 2006; zur sendungsbewussten und isolationistischen Variante des Schweizer Nationalismus und ihren historischen Konjunkturen vgl. auch Widmer 2008: 22.

39 Guggenbühl 1998: 45.

40 Sarasin u.a. 1998: 28.; zur Semantisierung der Alpen als Kernstück der nationalen Identitätskonstruktion vgl. Marchal 1992.

41 Sarasin u.a. 1998: 28. 
promiss $^{\text {“42 }}$ gegen (vermeintliche) Sympathisanten des expansiven SowjetKommunismus gewendet.

Damit antwortet der Schweizer Nationalismus, ähnlich dem US-amerikanischen, auf die Herausforderung, eine ethnisch, sprachlich und kulturell heterogene Bevölkerung zu integrieren, mit einer „Überhöhung und Sakralisierung des Volkes als einig Volk von Bürgern“43. Und wie der US-amerikanische Nationalismus kann auch der Schweizer Nationalismus, insbesondere in seiner protektionistisch-isolationistischen Variante, den Individuen mitunter große Opfer abverlangen, weil er als singuläre und vermeintlich letzte Bastion von Freiheit, Souveränität und Humanität erscheint. Obwohl die Bindungskraft dieses Basiskompromiss zwischen den 1960er und 1980er Jahren nachließ und mit dem Untergang des realexistierenden Sozialismus sein konstitutives Anderes verlor, verfügt die politische Schweiz in Form dieses Exzeptionalismus über eine starke Tradition der nationalen Selbstvergewisserung, die dem SVP-Populismus vielfältige Anknüpfungspunkte bot. ${ }^{44}$

Jedoch folgt das hegemoniale Imaginäre, das diese Sonderstellung lange Zeit unterfütterte und die Möglichkeiten der nationalen Selbstbeschreibung begrenzte,${ }^{45}$ traditionellerweise nicht populistisch-binären bzw. äquivalenzlogisch dominierten Diskursen. Vielmehr schuf die anhaltende Aktualisierung ,ganzheitlicher

42 So die Formulierung des Schweizer Soziologen Kurt Imhof (Imhof 1996b, Jost/Imhof 1998: 371). Diese würdigende Deutung der Geistigen Landesverteidigung ist allerdings umstritten; vgl. dazu das Streitgespräch zwischen Hans-Ulrich Jost und Kurt Imhoff (1998).

43 Altermatt/Bosshart-Pfluger/Tanner 1998: 12; Tanner 2002: 180.

44 So fand das Nationale Forschungsprogramm „Kulturelle Vielfalt und nationale Identität“ zu Beginn der 1990er Jahre heraus, dass das intersubjektive Bewusstsein für das politisch-kulturelle Alleinstellungsmerkmal in der Schweizer Bevölkerung nach wie vor weit verbreitet ist: Wohingegen die meisten Schweizer/innen ihre Alltags- und Lebenskultur oder die Produkte ihrer Höhenkammkultur nicht für besonders originell halten, so der Abschlussbericht der Studie, sei die starke Mehrheit überzeugt, dass „die Schweiz insgesamt [...] eine eigene politische Kultur habe und diese von ethisch hohem Niveau sei, dass sie sich darum von den politischen Kulturen anderer Gesellschaften abhebe und für die eigene Gesellschaft eine täglich verpflichtende Vorgabe sei“ (Kreis 1993: 141).

45 Zur Kontingenzbegrenzung durch Sonderfalldiskurse vgl. Imhof 2007: 27, der die Wirkungsweise der Sonderfall-Ideologie mithilfe des Konzepts der Pfadabhängigkeit begründet. 
und teilungsfreier Repertoires“"46 von Seiten einer kollegial handelnden politischen Elite eine Gemeinschaft, die sich als multikulturelle, gemäßigt pluralistische und konkordanzdemokratisch integrierte „Ausgleichsgesellschaft ${ }^{\text {“47 }}$ identifiziert. Die Hegemonie der Konkordanz und des Neokorporatismus nobilitierte das gemäßigte juste milieu als staatstragende, verantwortungsvolle Kraft. Sie schuf eine differenzlogisch komponierte politische Landschaft und ließ eine politische Kultur entstehen, die sich an der politischen Mitte orientiert. So wurden die Ergebnisse des konkordanzdemokratischen Elitenkonsenses nicht als Symptom eines klüngelnden politischen Establishments, sondern als Ergebnis langwieriger Aushandlungsprozesse politischer Repräsentanten interpretiert, die der Fragilität der pluralistischen Schweizer Gesellschaft in idealer Weise Rechnung tragen.

Durch das Initiativ- und Referendumsrecht ist der Verfassung zwar ein konkurrenzdemokratisches Gegengewicht zum Parteienkonsens eingebaut, insofern diese Institutionen den Regierungsparteien erlauben, aus einer ,fallweisen Opposition“48 zu politisieren. Jedoch gilt die direkte Demokratie lange Zeit als Supplement und keineswegs als Kernstück der politischen Schweiz. So darf die Tatsache, dass diese plebiszitären Instrumente oftmals erfolgreich genutzt wurden, um gegen Bundesrat und die regierungstragenden Fraktionen zu mobilisieren, nicht darüber hinwegtäuschen, dass es den etablierten politischen Kräften im Anschluss an die Abstimmungen stets gelang, derlei Forderungen entweder zu peripherisieren und als das bedrohliche Andere des ,konkordanzdemokratischen Sonderfalls ${ }^{`} \mathrm{zu}$ dezertifizieren oder aber zu beschwichtigen und der Verhandlungsdemokratie einzuverleiben. ${ }^{49}$

Als Meisterin dieses doppelten Spiels erwiesen sich insbesondere die Freisinnigen. Sobald sich eine Opposition rührte und die Hegemonie des liberalen Nationalismus gefährdete, machte die FDP diese unschädlich, indem sie sie entweder als unpatriotisch diffamierte oder aber so viele Konzessionen gewährte, bis jede fundamentaloppositionelle Strategie weder glaubwürdig noch attraktiv

46 Meier-Dallach 1988: 127 u. Meier-Dallach u.a. 1980: 44ff.

47 Rehberg 2007.

48 Linder/Steffen 2006: 27.

49 So stellt der Journalist Thomas Küng (2014: 169) fest: „Wenn also das Parlament [...] eine Volksinitiative zu Fall bringen will, so bastelt es am besten einen Gegenvorschlag, ein Kompromissangebot, das die Engagierten von den Mitläufern scheiden soll. Standardäusserung der Politiker: ,Das Ansinnen ist durchaus berechtigt. Die Initiative schiesst aber über das Ziel hinaus. ““ 
war. ${ }^{50}$ Entsprechend konstatierte der Schweizer Soziologe Hans-Peter MeierDallach im Jahr 1988:

„In der politischen Kultur der Schweiz haben Politiker, Ideologen und Projekte wenig Legitimität, die alternative, utopische oder schwarzweiß polarisierte Zukunftserwartungen akzentuieren und dadurch das Bild der Gegenwart und der Vergangenheit drastisch in Frage stellen." ${ }^{\text {51 }}$

Und der Politologe und Jurist Kris W. Kobach postulierte selbst im Jahr 1993 noch: „A fundamental and traditional aspect of Swiss traditional political culture is its distaste for popular leaders. “52 Wer als verantwortungsbewusste, an konstruktiven Lösungen interessierte politische Kraft wahrgenommen werden wollte, musste sich folglich sowohl programmatisch als auch strategisch innerhalb einer konkordanzdemokratisch integrierten politischen Mitte verorten. „Wer gegen sie [die Konkordanz, M.H.] verstößt, wird politisch bestraft, wer sie betont oder gar fördert, wird politisch belohnt. ${ }^{\text {“53 }}$ Demnach portraitiert sich der homo helveticus politicus als Teil eines maßvollen Ganzen, dessen innere Meinungsverschiedenheiten und Interessenkonflikte mit Hilfe kompromissorientierter institutioneller Mechanismen kontinuierlich moderiert und austariert werden. Die volonté générale der Willensnation entspringt nicht einem homogenen, organisch gewachsenen Volkskörper, sondern ausgeklügelten Institutionen, die diesen Willen konsensual prozeduralisieren und auch strukturelle Minderheiten integrieren.

Die Befolgung konkordanzdemokratischer Spielregeln gilt jedoch nicht nur als strategische Notwendigkeit angesichts der inneren Heterogenität des Vielvölkerstaates. Indem Konkordanz und Aufklärung miteinander assoziiert werden, wird der Output des politischen Systems zusätzlich vernunftrechtlich nobilitiert.

„Wer vernünftig ist, der streitet auf Biegen, nie aber auf Brechen! Tatsächlich liegen die Bedeutungen der Vernunftidee der Aufklärung und der Vernunftidee der Konkordanz sehr nahe beisammen. Konkordanz ist Deliberation. Der ,Austritt aus der selbstverschuldeten

50 Vgl. Somm 2009: 134. „Schlimmeres verhüten und referendumsfähige Gegner in die Regierung einbinden“, diagnostizierte der langjährige CVP-Generalsekretär Iwan Rickenbacher (zit. in: Somm 2009: 134) im Jahr 1998 trefflich, ,ist seither eines der Erfolgsrezepte der über hundertjährigen FDP geworden“.

51 Meier-Dallach 1988: 113.

52 Kobach 1993: 180.

53 Imhof 2007: 28. 
Unmündigkeit' beruht auf freier öffentlicher Kommunikation und diese, so die Kernüberzeugung der Aufklärungsphilosophie, führt zu Vernunft und Tugend. [...] Konkordanz wird damit zum Habitus der Aufgeklärten, das Verhandeln von Ideen und Interessen zur sittlichen Forderung an die Akteure in Problemlösungsprozessen. Konkordantes Handeln verschafft in der politischen Kultur der Schweiz Status. Umgekehrt wird weltanschauliche Reinheit zum Dogmatismus, zur Zwängerei, zum Unschweizerischen und führt zu Statusverlust. “54

Kurt Imhofs skandierende Merksätze machen deutlich, dass die Konkordanzdemokratie nicht bloß ein neutraler, streng propositionaler Analysebegriff der Vergleichenden Regierungslehre ist, sondern als operatives Paradigma fungiert. ${ }^{55}$ Die Konkordanz arbeitet ,operativ in der Gesellschaft [...], indem sie Institutionen und Praktiken ihren Platz, Charakter und Bedeutung verleih[t] und dabei handlungsleitend wirk $[\mathrm{t}]^{\text {‘56 }}$. Es handelt sich um ein Set von Ordnungsbegriffen mit normierender und identitätsstiftender Kraft. In der Schweiz ist Konkordanz für lange Zeit nicht nur ein Verfahren der politischen Entscheidungsfindung, sondern auch eine Lebensform.

Die Macht dieser Selbstbeschreibung manifestiert sich in der Behandlung gegenhegemonialer binärer Diskurse: „,[U]m Kultur und Staatswesen deckungsgleich zu machen ${ }^{657}$, die konkordanzdemokratischen Paradigmen des politischen Systems zum Pendant eines genuin schweizerischen soziokulturellen Substrats zu stilisieren, sind die konkordanzdemokratischen Gemeinschaftssemantiken auf antagonistischen Grenzziehungen gegenüber einem bedrohlichen homo externus angewiesen. $^{58}$

54 Ebd.: 36.

55 Im Theoriekapitel habe ich dieses Konzept im Anschluss an Sheldon Wolin (1968: insb. 183ff.) als „Ensemble aufeinander bezogener Aussagen und Konzepte, die durch ihre Iteration als diskursiv-normative Anweisungsstruktur fungieren" definiert.

56 Rosa 1994: 199f.

57 Hall 1994a: 204.

58 Imhof (2007: 35f.) weist darauf hin, dass sich dies exemplarisch anhand der Auslandsberichterstattung der Schweizer Medien belegen ließe: Nicht nur, dass man der offene Austragung oder gar die gewaltsame Eskalation ideologischer Konflikte mit Unverständnis begegne; ,wenn die Schweiz [...] politisch oder wirtschaftlich tangiert war, dann wurde immer die Hoffnung geäußert, die Kontrahenten mögen doch noch zur Vernunft finden“. 
„In dem Masse, wie sich die Schweiz unter dem Druck der tiefgreifenden ökonomischen Krisenauswirkungen und den ebenso bedrohlichen wie fundamentalen Veränderungen in ihren Nachbarländern als Schicksalsgemeinschaft und Willensnation entdeckte, wurden die Trägerorganisationen und -bewegungen klassenantagonistischer, ständestaatlich-autoritärer und rassistischer ideologischer Konstrukte peripherisiert, wurde [...] die Integration der Sozialdemokratie eingeleitet, der Korporatismus erweitert und die Umrisse einer Agrar-, Wirtschafts- und Sozialpolitik festgelegt, auf denen eine wieder berechenbare Zukunft angegangen werden konnte. ${ }^{\text {59 }}$

Demnach läuft die (Re-)Produktion der konkordanzdemokratisch integrierten Gemeinschaft parallel zur Dezertifizierung binärer Diskurse und ihrer ,weltanschaulichen Ausschließlichkeitsfixierungen "60, welche die unheilvolle Geschichte des „Zeitalters der Extreme“61 ${ }^{\text {}}$ prägten. ${ }^{62}$ Erst der Antagonismus gegenüber dem locus terribilis, den ,bornierten Dogmatikern', ,ideologischen Scharfmachern' und den ,extremistischen Kritikern' des Parteien- und Verbändekonsenses begründet das juste milieu als locus amoenus und einzig legitimen Repräsentanten der Schweizer Gesellschaft. ${ }^{63}$ Die diskursive Repräsentation eines inkommensurablen, radikalen Anderen lässt die Konkordanz zum Erfolgsgaranten der multikulturellen Willensgemeinschaft avancieren. Die Präsenz dieses bedrohlichen Außen sorgt für die Perpetuierung der kompromiss- und konsensorientierten Spielregeln des politischen Systems und initiiert ein symbiotisches, wechselseitig positives Feedback von ,politics“ (der Reproduktion des Kompromissprinzips von Seiten der politischen Akteure), ,policy` (den verfassungsmäßig induzierten konkordanzdemokratischen Spielregeln) und politischer Kultur (der Nobilitierung der konkordanzdemokratischen Konfliktbearbeitung als genuin schweizerisch und vernünftig), das über mehrere Jahrzehnte kaum gestört wurde. So entstand ein gemäßigt pluralistischer politischer Raum mit vielfältigen schwachen Antagonismen im Innern und starken peripheren Antagonismen, der bis in die 1990er Jahre gegen alle binären Spaltungsversuche immun schien.

59 Imhof 1996a: 35.

60 Imhof 2007: 36.

61 Hobsbawm 1995.

62 Vgl. Imhof 2007: 32 u. 35.

63 Vgl. für eine derartige Selbstvergewisserung etwa Armingeon 1995. 


\subsection{DER SVP-POPULISMUS UND DIE KRISE DER KONKORDANZDEMOKRATISCH INTEGRIERTEN SCHWEIZ}

Erst dem SVP-Populismus gelang es, die glatte Reproduktion dieses differenzlogisch komponierten Raumes nachhaltig zu stören. Die Strategie des konkordanzdemokratischen Elitenkonsenses, jede Form der Polarisierung als ,unvernünftig und ,unschweizerisch“ zu diffamieren und fundamentaloppositionelle Projekte im Keim zu ersticken oder zumindest mittelfristig zu unterminieren, sollte im Kampf gegen Blochers SVP scheitern.

Die von der Zürcher Kantonssektion um Christoph Blocher vorangetriebene programmatische und strategische Radikalisierung befreite die ehemalige Bauern-, Gewerbe- und Bürgerpartei (BGB) aus dem „Korsett der Konkordanz “64. Während die BGB und die ,alte SVP' als klientelistisch orientierter, kompromissbereiter Partner innerhalb der bürgerlichen Allianz politisierten, artikulierte Blochers „neue SVP“65 das heterogene Andere des konkordanzdemokratischkorporatistischen Elitenkonsenses und eilte fortan mit einer gegen ,Classe politique" und ,Establishment' gerichteten Rhetorik von Wahlerfolg zu Wahlerfolg. Gemessen an den Nationalratswahlen konnte sie ihren Stimmenanteil von 11,9 im Jahr 1991 sukzessive auf 28,9 Prozent im Jahr 2007 steigern. ${ }^{66} 2011$ erlitt sie einen kleinen Einbruch und erhielt lediglich 26,4 Prozent, ehe sie 2015 ein vorläufiges Rekordergebnis von 29,4 Prozent einfuhr.

Die Offensive der SVP erschütterte indes nicht nur das ehemals „festgefrorene ${ }^{667}$ Vierparteiensystem, sondern führte auch zu einer verstärkten Politisierung und Polarisierung der Bevölkerung, die nicht nur das etablierte Parteiensystem, sondern auch das Konkordanzprinzip affizierte. ${ }^{68}$ Da die Vertiefung der ideolo-

64 Altermatt 1994.

65 Mazzoleni 2003.

66 Bei den Wahlen von 2011 erhielt die SVP zwar nur 26,6 Prozent, war damit jedoch erneut die deutlich stärkste politische Kraft.

67 Kriesi 2005: 4; im Anschluss an die frozen-party-systems-These der Politologen Martin Lipset und Stein Rokkan (1967), nach denen es seit dem Ende des Zweiten Weltkrieges dieselben Konfliktlinien sind, welche die Parteienlandschaften und die politische Prozesse in den meisten westeuropäischen Staaten strukturieren.

68 Auf der Ebene des Parteiensystems äußert sich diese Polarisierung in zweierlei Hinsicht: Zum einen lässt sich anhand der Wahlergebnisse eine Stärkung der Ränder bei gleichzeitiger Schwächung der staatstragenden politischen Mitte ausmachen. Zum an- 
gischen Gräben zwischen den politischen Lagern die Reproduktion kooperativer und kollegialer Normen erschwert und die Konkordanzdemokratie sich schwertut, widerstreitende Standpunkte und Positionsdifferenzen politisch zu repräsentieren, löste der Aufstieg und die Radikalisierung der SVP auch eine Krise des politischen Systems aus. ${ }^{69}$ Seine politischen Protagonisten, die staatstragenden Mitte-Parteien FDP und CVP, verloren an Zustimmung. ${ }^{70}$ Um ihren hegemonialen Repräsentationsanspruch zu wahren, versuchten sie zwar, den Antagonismus zu den ökologischen und sozialdemokratischen Linksparteien zu betonen, doch wurden die vielfältigen, konkordanzdemokratisch moderierten Antagonismen des Links-Rechts-Kontinuums sukzessive durch den von der SVP akzentuierten, ,tieferliegenden' populistischen Antagonismus zwischen einem ,unschweizerischen, korrumpierten Machtblock` und einem, schweizerischen, moralisch integren underdog` überprägt.

Die Effektivität dieses Diskurses manifestiert sich u.a. darin, dass sich heute alle wichtigen politischen Kräfte zum ,Sonderfall Schweiz‘ bekennen, die Debatten über die Bedeutung und Hierarchisierung der einschlägigen Normen jedoch kontrovers verlaufen. Die dominante Selbstbeschreibung der politischen Schweiz folgt nicht mehr der konkordanzdemokratisch-korporatistischen Gemeinschaftsideologie, sondern in zunehmendem Maße einem binären Modell. Nicht nur in den Verlautbarungen von Blocher und seinen Anhänger/innen, sondern auch in jenen seiner politischen Gegner/innen weichen die Iterationen des gemäßigten Pluralismus dichotomen Freund-Feind-Unterscheidungen. So entspricht die von den politischen Kontrahenten der radikalisierten SVP ins Leben gerufene „Koalition der Vernunft" ${ }^{\text {“71 }}$, was die evozierte Strukturierung des politi-

deren haben sich die Parteien in ihren Positionen jeweils radikalisiert, sodass das Parteiensystem inzwischen nicht nur fragmentierter, sondern weitaus polarisierter ist als der europäische Durchschnitt (vgl. Ladner u.a. 2010; Ladner 2010; Ladner 2013).

69 Vgl. zur Krise der Konkordanzdemokratie Mazzoleni/Skenderovic 2007; Hennecke 2003; Steppacher 2012.

70 Während die SP sich im Zeitraum zwischen 1991 und 2007 im Bereich von etwa 20 Prozent stabilisierte, büßten die bürgerlichen Parteien FDP und CVP im selben Zeitraum jeweils sechs Prozent ein und verloren bei den Nationalratswahlen von $2011 \mathrm{mit}$ 15,1 Prozent (FDP) und 12,3 (CVP) erneut an Terrain.

71 Die sogenannte „Koalition der Vernunft“ (aus FDP, CVP und SP) wurde von der sozialdemokratischen Parteichefin Ursula Koch nach den Nationalratswahlen von 1999 ins Leben gerufen und gegen die ,unvernünftige SVP“ gewandt (Koch zit. in Bürgi 1999: 182). Der Begriff stammt eigentlich von 1991, als SP und FDP sich in Zürich zusammentaten, um gegen die SVP die staatlich kontrollierte Abgabe von Heroin an 
schen Raumes betrifft, dem von Blocher propagierten Szenario eines binären Antagonismus zwischen der SVP und den „Sozialisten in allen Parteien“72 bzw. seiner Prognose, die Schweiz steuere auf ein Zweiparteiensystem aus einer zentralistischen ,vereinigten Linken“ auf der einen und einer freiheitlichen SVP auf der anderen Seite hin. ${ }^{73}$

Insofern handelt es sich bei dem um die SVP zentrierten Populismus nicht nur um einen Krisenindikator oder einen schlichten Agenda Setter. Der SVPDiskurs thematisiert nicht nur vernachlässigte und tabuisierte Probleme und Forderungen, welche die staatstragenden Kräfte aufgreifen müssen, um die Responsivität des ,eigentlichen“ politischen Systems wiederherzustellen. Vielmehr führt die populistische Konstruktion einer Demarkationslinie zwischen einem ,unschweizerischen Sie ‘ und einem ,urschweizerischen Wir` zu einer Reorganisation des politischen Raumes. Die Quintessenz und der Erfolg des SVP-Populismus gründen darauf, dass er die vielfältigen Konfliktlinien der multikulturellen Gesellschaft durch eine tieferliegenden Grundkonflikt ersetzt und das Universelle (die Identität der Schweizer Nation) mit dem Partikularen (der eigenen politischen Agenda) verflechtet.

Es wäre folglich zu kurz gegriffen, den SVP-Populismus auf eine politische Folgeerscheinung gegebener sozialer Verhältnisse zu reduzieren. Er ist vielmehr als hegemonialer Diskurs zu begreifen, an dessen antagonistischen Grenzen die politisch maßgeblichen Identitäten und Selbstbeschreibungen der Schweizer/innen kristallisieren. Es handelt sich eben nicht bloß um ein politisches Epiphänomen der Legitimationskrise des politischen Systems, sondern um einen performativen Diskurs, der diese Krise mitauslöst, indem er zentrale Funktionsprinzipien der Konkordanz (die korporatistische Elitenvernetzung, die Kompromissfähigkeit der politischen Akteure, das Kollegialitätsprinzip, die geringe Dissens-Toleranz und die Tabuisierung fundamentaloppositioneller Alternativen) unterminiert.

Diese soziale und politische Produktivität des SVP-Populismus soll im Folgenden hegemonieanalytisch offengelegt werden. Dabei möchte ich nachzeich-

Abhängige durchzusetzen. 1999 wurde die Koalition der Vernunft nationalisiert, auf alle Politikfelder ausgedehnt und avancierte in der Folge sowohl bei Anhängern der SVP als auch bei ihren Gegnern zum geflügelten Wort.

72 Blocher 2000a.

73 Blocher 1999a: 17f. Die Vertreter der sogenannten bürgerlichen Mitte, CVP, FDP und auch einzelne aus der heutigen SVP würden zu einer „Wischi-Waschi-Partei“ fusionieren, der Blocher ob ihrer Profillosigkeit jegliche politische Existenzberechtigung abspricht. 
nen, wie der SVP-Diskurs die etablierte, verhandlungsdemokratische politische Kultur desartikuliert, indem er die schwachen Antagonismen zwischen den Faktionen des politischen Spektrums durch einen vermeintlich tieferliegenden, binär strukturierten Antagonismus ersetzt, der die vielfältigen Differenzen der multikulturellen Schweiz transzendiert. 


\title{
2. Blochers ,Neue Mitte" und
}

\author{
die Radikalisierung des Zürcher Flügels: \\ Von der klientelistischen Bauern- und \\ Gewerbepartei zur neukonservativen \\ Catch-All-Partei
}

Ehe ich die Funktionsweise des SVP-Populismus anhand der vier ausgewählten Kernereignissen detailliert untersuche, rekonstruiere ich zunächst den parteiinternen Richtungsstreit zwischen dem gemäßigten Berner Flügel der SVP und dem radikalen Zürcher Flügel als hegemonialen Kampf um die DesartikulationReartikulation der identitätsstiftenden Signifikanten ,Mitte' und ,Mittelstand“ (3.1). Im Anschluss werde ich zeigen, wie Christoph Blocher und andere Exponenten der SVP diesen traditionellen Identifikationsbegriffen der SVP neue politische Konturen verliehen (3.2). ${ }^{1}$ Die parteiinterne Auseinandersetzung um die Fixierung der Signifikanten ,Mitte' und ,Mittelstand', so die grundlegende These der beiden Unterkapitel, kann als Pilotprojekt eines expansiven populistischen Diskurses verstanden werden, der in den 1990er Jahren einen ,phänomenalen Spagat“ vollführt, indem „er [...] eine „patriotisch-nationalkonservative Haltung mit einem dezidiert neoliberalen Deregulierungskurs ${ }^{\text {“ } 2}$ verbindet. Die Kompositionslogik dieser Artikulation werde ich hegemonietheoretisch entschlüsseln. Ich möchte zeigen, inwiefern die erfolgreiche Dekonstruktion-Rekonstruktion der

1 Dieses Kapitel stützt sich insbesondere auf die Quellenarbeit der Historiker Hans Hartmann und Franz Horvath, die sie in ihrer Monographie „Die Erfolgsstory der Zürcher SVP“ (1995) darlegen. Zur Persistenz und Wirkmächtigkeit der Mittelstandsideologie vgl. Skenderovic 2013.

2 Buomberger 2004: 210. 
Begriffe ,Mitte ' und ,Mittelstand` die Voraussetzung für die Verknüpfung des konservativ-ständischen Parteiprofils mit neoliberalen Forderungen nach Steuersenkungen und Bürokratieabbau darstellt. Dabei soll unterstrichen werden, dass die Repräsentation der ,Neuen Mitte' auf die Konstruktion und Aktualisierung eines Antagonismus zu einem hybriden Anderen angewiesen ist, dessen interne Kohärenz in erster Linie durch den Knotenpunkt des ,kriminellen Ausländers ${ }^{6}$ imaginiert wird.

\subsection{Die Pionierphase des SVP-PopUlismus: DIE ZÜRCHER ANTWORT AUF DIE KRISE DER SVP}

Der politische Richtungsstreit zwischen dem hegemonialen Berner Parteiflügel und den Herausforderern aus Zürich entstand im Kontext der Krise, in welche die SVP im Verlauf der 1970er Jahre geraten war. Bereits bei den Nationalratswahlen von 1971 hatte die Partei einen historischen Tiefstand von elf Prozent erreicht; vier Jahre danach büßte sie weitere Stimmen ein und fiel unter die zehn Prozentmarke. Durch den Bedeutungsverlust der kleinbäuerlichen, traditionellen Landwirtschaft war ihre Stammwählerschaft geschwunden. Bei der wichtigsten Wählergruppe der Arbeitnehmer/innen war die Partei deutlich unterrepräsentiert.

Die Krise ließ sich jedoch nicht allein auf sozialstrukturelle Transformationen zurückführen; die ehemalige BGB, die in den Nachkriegsjahren trotz ihres relativ geringen Wähleranteils das nationale Sendungsbewusstsein der Bauern kultivierte, war auch in ideologischer Hinsicht in die Defensive geraten. Der Strukturwandel stellte das politische Selbstbewusstsein der Partei zur Disposition. Die Stilisierung eines bodenständigen, „traditions- und naturverbundenen“ Bauernstandes als Garanten eines „gesunden Volkes“, das von „entwurzelten Asphaltmenschen“ und dem „eitlen Flitterkram“ der Städter bedroht werde, mit welcher der bedeutende BGB-Ideologe Kurt Guggisberg in seiner Programmschrift Grundzüge des mittelständischen Denkens im Jahr 1961 operierte, hafteten zu Beginn der 1970er Jahre anachronistische Züge an. ${ }^{3}$ Die Beschwörungen des „Authentischen, Ländlichen und Bodenständigen“4 ${ }^{4}$ und die rhetorischen Reminiszenzen an das Bäuerliche als „Archetyp des Schweizerischen“"5, auf denen das Selbstvertrauen und die hegemonialen Ansprüche des Bauern- und Ge-

3 Guggisberg, zit. in: Skenderovic 2013: 59.

4 Skenderovic 2013: 69.

5 Scheidegger 2012: 138. 
werbestandes einst gründeten, wirkten in einer modernen, urban und suburban geprägten Schweiz als folkloristisches, anachronistisches und nicht-politikfähiges Relikt. Die traditionelle Ausrichtung der BGB hatte keine Zukunft.

$\mathrm{Zu}$ diesem Ergebnis kamen nicht nur parteiexterne politische Beobachter, sondern auch die SVP selbst. ${ }^{6}$ Eine Arbeitsgruppe, die von dem damaligen Generalsekretär Peter Schmid ins Leben gerufen und von Parteipräsidenten Fritz Hofmann geleitet wurde, forderte, die SVP müsse sich von einer klientelistisch orientierten „Standespartei zu einer geistig wie personell breit gefächerten Volkspartei wandeln“" ${ }^{\text {“7 }}$ Dieser Empfehlung folgte die nationale Delegiertenversammlung im ,Aktionsprogramm ' $79{ }^{\circ} .{ }^{8}$ Unter der Führung der traditionell starken Berner und Bündner Kantonssektionen beschloss die SVP Schweiz, mit der ständisch-klientelistischen Tradition zu brechen, um sich zur Arbeitnehmerseite hin zu öffnen und sich auf ,ein breites, alle Interessengruppierungen umfassen-

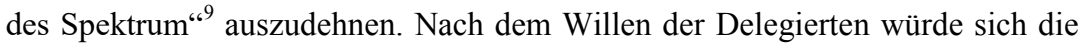
SVP in Zukunft an „Arbeitnehmer und Arbeitgeber, Mieter und Vermieter, Junge und Betagte, Protestanten und Katholiken, Arbeiter und Akademiker, also Frauen und Männer aller Altersgruppen und Einkommensklassen“" ${ }^{10}$ wenden. Die Partei sollte sich in der Mitte des politischen Spektrums positionieren und als integrative Catch-All-Partei agieren.

Programmatisch orientierten sich die Reformer am sozialliberalen Zeitgeist der 70er Jahre. Hofmann sprach von einer „,sozialverpflichteten Marktwirtschaft $^{\text {“11 }}$. Mit dem Ziel, sich responsiv gegenüber den postmateriellen Forderungen der 1970er Jahre zu verhalten, thematisierte die Partei neue Politikfelder wie Menschenrechte, Umwelt- und Verbraucherschutz. ${ }^{12}$ So wurde unter anderem beschlossen, sich in Zukunft für eine verbesserte Bankenaufsicht, eine „menschliche Ausländerpolitik“, eine Neufinanzierung der AHV sowie für „den stufenweisen Abbau der Höchstarbeitszeit und der Erweiterung der minimalen Ferienansprüche“ einzusetzen. ${ }^{13}$ Die neugegründete SVP sollte sich als progressive, ar-

6 Vgl. Hartmann/Horvath 1995: 40.

7 Hofmann, zit. in: ebd.: 41.

8 Ebd.: 41.

9 Reichling 1979, zit. in: Hartmann/Horvath 1995: 42.

10 [o.A.] Zürcher Bauer vom 28.9.1971, zit. in: Skenderovic 2013: 62.

11 Hofmann, zit. in: Somm 2009: 220.

12 Vgl. SVP-Aktionsprogramm 1979, zit. in: Skenderovic 2013: 62.

13 [o.A.] Die Mitte 6/1997 und [o.A.] Die Mitte 49/1977, zit. in: Hartmann/Horvath 1995: 41f. 
beitnehmerfreundliche und sozialverantwortliche Alternative zur FDP profilieren.

Die programmatische Erneuerung sollte jedoch ein Projekt der nationalen Parteiführung bleiben. Viele Kantonssektionen und insbesondere die Mitglieder an der Basis begegneten den Reformen mit Zurückhaltung und Skepsis. ${ }^{14}$ Auf manifeste Gegenwehr stießen die Ideen der Parteizentrale aber vor allem im Kanton Zürich. Mit dem von der Bundespartei eingeschlagenen Modernisierungskurs positionierte sich die SVP aus Sicht der Zürcher Kantonssektion viel zu weit links. ${ }^{15}$ Bereits 1977 hatte die Zürcher SVP mit Christoph Blocher einen erfolgreichen Industrieunternehmer zu ihrem Präsidenten gewählt, der im Unterschied zu seinem Gegenkandidaten Hans Frei die sozialliberale Neuausrichtung der SVP Schweiz ablehnte. Während alle Parteien in die Mitte rückten, sollte die Zürcher SVP unter Blochers Führung rechts der drei anderen Bundesratsparteien politisieren. Mit dem Ziel, neue gesellschaftliche Milieus zu erschließen und den nationalen Repräsentationsanspruch der BGB zu erneuern, verpflichtete Blocher seine Partei auf den Kampf gegen den sozialliberalen Parteienkonsens und die ,politische Klasse'.

Bereits in seiner Antrittsrede stellte der neue Zürcher Kantonalpräsident klar, dass er die Krise auf andere Weise kurieren wollte als die nationale Führungsriege. Eine Partei, so Blocher, werde immer an der Qualität ihres „Ideengutes“ bemessen. Es käme darauf an, dass die SVP sich mit ihrem „Gedankengut“ „hinauswage ins Volk“ und es „offen, ehrlich und glaubwürdig“ vertrete. ${ }^{16}$ Eine erste vehemente Attacke auf die nationale Parteiführung erfolgte Ende des Jahres, als Blocher in der Parteizeitung Die Mitte auf sein erstes Jahr als Präsident der Zürcher SVP zurückblickte. Die „kopflose Flucht nach vorne“ der Parteiführung und ihr „schief geratenes Programm“ gefährde die tief verankerten, „soliden Grundsätze“ - „Freiheit zur individuellen Entwicklung, Wirtschaft als Grundlage für materielle Sicherheit, staatliche Unabhängigkeit" - und damit ausgerechnet jene Prinzipien, für die die eigene Partei eigentlich stehe. ${ }^{17}$ Während er in „unserem Volke“ den Willen zur „Umkehr“ ausmachte, beschuldigte er die eigene Parteispitze, mit dem Sozialliberalismus zu paktieren, dessen Ziele und Annahmen der SVP und der Schweiz gleichermaßen fremd seien. ${ }^{18}$

14 Vgl. ebd.: 42f.

15 Vgl. ebd.: 43.

16 Blocher 1977, zit. in: Skenderovic 2013: 63.

17 Blocher 1977, zit. in: Hofmann/Horvath 1995: 52.

18 Ebd. 
Bereits diese frühe Intervention Blochers wird durch drei Topoi strukturiert, die für den gegenhegemonialen Befreiungsmythos des Zürcher Flügels prägend werden sollten. ${ }^{19}$ Die Geschichte handelt von einem selbstgenügsamen, unterprivilegierten ,Volk', das über Jahrzehnte einer orientierungslosen, hinterhältigen sozialliberalen politischen Klasse untergeordnet war, sich nun aber, wo die Entfremdung von Bürgern und politischen Repräsentanten ein ungekanntes Ausmaß erreicht hat (Dekadenz) und die Gemeinschaft und ihre Werte durch feindliche Mächte im Außen und Innen bedroht werden (Apokalypse), unter der Führung einer wahren, führungsstarken Elite (Heroismus) als politische Bewegung zusammenschließt. Es bekämpft seine Unterdrücker und verwirklicht seine Prosperität und Eigenständigkeit in einer anderen, vermeintlich ursprünglichen und authentischen Ordnung. Die durch die Trias „Dekadenz, Apokalypse und Heroismus ${ }^{\text {“20 }}$ strukturierte Dramaturgie entfaltet ein missionarisches Weltbild und evoziert eine eschatologische Sehnsucht nach der „Wiederkehr einer verjüngten, heilen Welt ${ }^{\text {‘21 }}$ - einer vollen, inhaltlich jedoch vagen Heartland-Gemeinschaft, die frei von inneren Antagonismen sei.

Im Kontext dieses Befreiungs- und Erlösungsmythos entfaltet der von Blocher geführte Begriff der ,Umkehr' seine spezifische Bedeutung. Im Unterschied zu Schwarzenbach favorisierte die Zürcher-SVP weder eine antimoderne Politik der Reaktion - weswegen die in Anschlag gebrachte ,Umkehr' auch nicht als Rückkehr zu vorindustriellen Lebensformen missverstanden werden darf, noch plädierte sie für ein Festhalten an der ständischen Klientelpolitik der Vergangenheit. Dem Zürcher Flügel war bewusst, dass man durch eine im engen Sinn konservative Idee von Umkehr die Gefahr der ständischen Isolation nicht abwenden können würde. Folglich stimmte man mit der Analyse der nationalen Parteiführung überein: Wenn die SVP nicht untergehen wolle, müsse sie sich zur Mitte öffnen und neue Wählerschichten ansprechen. Indes hatten die radikalen Zürcher/innen um Blocher von Beginn an eine andere Mitte im Sinn. Sie wollten die SVP nicht im Herzen der Konkordanz, als programmatischen Brückenkopf zwischen liberaler und sozialdemokratischer Ordnungspolitik sehen, sondern als wirtschaftspolitisch liberal, kultur- und sicherheitspolitisch jedoch konservativ orientierte Volkspartei etablieren, die gegen die Hegemonie des Sozialliberalismus politisiert. Wohingegen die nationale Parteiführung der Gefahr der ständischen Isolation entgegenwirken wollte, indem sie sich in der Mitte eines gegebenen politischen Raums positioniert, schärfte der radikale Flügel um Blocher das

19 Exemplarisch für diesen Mythos vgl. Blocher 2002.

20 Lenk 2005: 50.

21 Ebd.: 56. 
liberal-konservative Profil der Partei, um nicht länger als ergänzende, sondern als alternative bürgerliche Kraft wahrgenommen zu werden. Die Partei sollte auf möglichst vielen Politikfeldern gegen den sozialliberalen Kompromiss der Bundesratsparteien politisieren, wozu der ständisch-konservativen Ideologie der Partei neue politische Forderungen einverleibt werden mussten.

Folglich übernahm Blocher im Unterschied zur Parteiführung weder den landläufigen, sozioökonomischen Begriff der gesellschaftlichen Mitte im Sinne der sozialen Schicht mit mittleren Einkommen noch den Begriff der politischen Mitte im Sinne einer moderaten Position, die von sich behauptete, die weltanschaulichen Gegensätze zwischen links und rechts miteinander zu versöhnen. Stattdessen greift Blocher im Vorfeld der Kantons- und Regierungsratswahlen von 1979 einen ,ideologischen“ Mittelstandsbegriff auf, der sich nach eigenem Bekunden nicht vom Einkommen her begrenzen ließe, sondern „weit über den materiellen Bereich ${ }^{، 22}$ hinausreiche. ${ }^{23}$ Während sich die nationale Parteiführung im Zuge der programmatischen Neuausrichtung also dafür entschied, den ständischen Mittelstandsbegriff zugunsten eines politischen Mittebegriffs zu verwerfen, ${ }^{24}$ sollte die Hegemonisierung des Mittelstandsbegriffs dem Zürcher Flügel gestatten, Vergangenheit, Gegenwart und Zukunft der Partei zu synchronisieren.

Mit diesem Ziel artikulierten Blocher \& Co den zentralen Identifikationsbegriff der BGB mit einer neoliberalen Reformideologie. Der Mittelstandsbegriff wurde resignifiziert, indem er mit dem „,werktätigen Volk ${ }^{\text {‘25 }}$ und der „Einstellung zum freien demokratischen Staate“ ${ }^{26}$ verbunden wurde. Alle Bürger/innen, die „von ihrer tagtäglichen Arbeit leben“ und sich „,zum Grundsatz der Eigenverantwortung, der persönlichen Initiative und des Selbstbehauptungswillens bekennen und die nicht alles Heil vom Staat erwarten", subsumierte Blocher unter dem Mittelstandskonzept. ${ }^{27}$ Entscheidend für die sozialtransformative Wirkung des Begriffs ist, dass der einschlägige Wir-Sie-Gegensatz nicht als materieller Interessenkonflikt, sondern als „diffuse“ ${ }^{28}$ ethisch-moralische Positionsdifferenz geframed wird. Blochers Mittelstand handelt als prinzipientreue Willensgemeinschaft, deren politische Überzeugungen die Partikularinteressen eines bloß durch

22 Blocher 1979, zit. in: Hartmann/Horvath 1995: 60.

23 Zur Bedeutung der Mittelstandsideologie in der Pionierphase des Zürcher Flügels vgl. Jost 2007: insb. 37.

24 Vgl. Hartmann/Horvath 1995: 55.

25 Blocher 1979, zit. in: Hartmann/Horvath 1995: 55.

26 Bolliger [o.J.], zit. in: ebd.: 59.

27 Blocher 1979, zit. in: ebd.: 55.

28 Jost 2007: 37. 
gemeinsame Klassen- oder Schichteninteressen geeinten Kollektivs transzendieren. Dass die Leistungsbereiten ihr Eigentum gegen den wohlfahrtsstaatlichen „Raubzug auf das persönliche Eigentum““29 verteidigen möchten, ist daher auch nicht Ausdruck eines egoistischen Eigeninteresses, sondern grundlegender, politisch-ideologischer Natur.

Anstelle der sozioökonomischen Gruppendifferenzierung und des Paradigmas des Interessenkonfliktes, welche die nationale Parteileitung mit dem sozialliberalen Projekt der Öffnung zur Arbeitnehmerseite hin aktualisiert, postuliert Blochers Neuauflage der Mittelstandsideologie ein binäres Ordnungsmodell, das eine eigenverantwortliche, genügsame und autochthone Wir-Gruppe von einer parasitären, unersättlichen und fremden Sie-Gruppe unterscheidet und alle Konfliktlinien, die dieses Schema unterlaufen, in einfache Differenzen der einen oder der anderen Gruppe zu transformieren vermag. Wohingegen der moderate Berner Diskurs eine politische Mitte anruft, die sich zwischen dem Sozialismus der SP und dem Liberalismus der FDP positioniert, handelt es sich im Diskurs der Zürcher keineswegs um eine empirische Bezugsgruppe, die sich als ein Mittelwert der Summe gegebener politischer Präferenzen ermitteln ließe. Die von Blocher aktualisierte Mittelstandsideologie stilisiert den Mittelstand zum vitalen Teil einer Gesellschaft, die am expansiven Parasitismus der ,politischen Klasse“ und ihrer sozial bedürftigen Klientel krankt. Sie verleiht ihm ein ideologisches Rückgrat, das ihn nicht nur von der sozialliberalen Wirtschafts-, Sozial-, Kulturund Bildungspolitik des Bundesrates und der Berner Parteiführung dissoziiert, sondern auch die konkordanzdemokratisch integrierte Differenzordnung sprengen sollte.

In diesem Zusammenhang wird deutlich, dass die Vagheit des Mittelstandsbegriffs weder als Zeichen ideologischer Unreife noch als Ausdruck blanken Opportunismus missverstanden werden darf, sondern die conditio sine qua non des expandierenden Universalismus des politischen Projekts ist. Die Leere bedingt die Extension der Äquivalenz. Denn nur wenn der identitätsstiftende Begriff sich entleert, kann er neue Forderungen absorbieren und die differenten Milieus, die die Zürcher SVP für sich zu gewinnen versucht, symbolisch vereinen.

Exemplarisch illustrieren lässt sich die Artikulation dieses leeren Identifikationsbegriffs anhand der Jubiläumsfeier „60 Jahre SVP“, zu der die Zürcher Sektion im Vorfeld der Nationalratswahlen von 1979 anlässlich des erstmaligen Einzugs von Zürcher Bauernparlamentariern in den Nationalrat im Jahr 1919 einlud. $^{30}$ In den Feierlichkeiten verdichtet sich die hegemoniale Strategie, die

29 Blocher 1997c.

30 Vgl. Hartmann/Horvath 1995: 56f. 
der Kantonssektion erlaubt, die ständische Parteitradition und die vorangetriebene neoliberale Profilierung im Rahmen einer neukonservativen politischen Ideologie zu vernähen.

Der Festzug ruft zunächst historische Motive auf. Der Umzug wird von einer Reitertruppe mit Bezirksstandarten angeführt. Man trifft sich am Wehrmännerdenkmal auf der Forch und erinnert damit die Zürcher Soldaten, die während des Ersten Weltkrieges für die Schweiz ihr Leben ließen. Ort und Inszenierung stellen die Zürcher SVP in die Tradition der militärischen und geistigen Wehrhaftigkeit der Schweiz. ${ }^{31}$ Blochers Festrede führt diese Tradition und die gegenwärtige politische Positionierung der Partei zusammen. Blocher beginnt mit einer Rekonstruktion der Gründungsphase der BGB. Um 1900 habe sich der Mittelstand durch die voranschreitende Technisierungs- und Industrialisierungsprozesse wirtschaftlich, kulturell und politisch in einer Krise befunden. Die etablierten politischen Kräfte hätten seine Interessen nicht mehr ausreichend repräsentiert, weswegen Bauern und Gewerbetreibende beschlossen hätten, eine eigene Partei zu gründen. Zu dieser Partei habe sich in den zwanziger Jahren ,weiteres mittelständisch denkendes Volk“ gesellt, um die „linksextreme Flut“ abzuwehren. Die junge BGB, deren Flugblätter aus dem Wahlkampf von 1919 man auch heute noch ,fast unverändert“ verwenden könne, sei in der Folge „,zur entscheidenden Stütze der Staatsordnung überhaupt“ aufgestiegen. Sie hätte die „Gratwanderung zwischen sozialistischer Verstaatlichung und ungehemmtem Laisser-faire des Liberalismus" gemeistert und sei von Beginn an - hier zitiert Blocher eine Parteischrift aus dem Jahr 1920 - mitten im ,arbeitssamen, sittlich starken Zürcher Volk“ gestanden. Dank dieses, „fundierten ideologischen Unterbaus“, schließt Blocher, sei es der SVP in den vergangenen Jahren gelungen, sich von den Verbänden zu emanzipieren und neue Wählerschichten anzusprechen. ${ }^{32}$

Blochers ,kleine Geschichte der SVP' verleiht dem von ihm favorisierten politischen Kurs historische Kontinuität. Dabei erscheint das ideologische Erbe der Mittelstandspartei keineswegs als Bürde oder als Hindernis für eine überfällige sozialliberale Modernisierung, sondern als historisch gewachsene Basis politischer Erfolges. Den Mittelstand, den die Partei traditionell zu repräsentieren beansprucht, stellt Blocher in eine dezidiert antisozialistische Traditionslinie und rückt damit den Antikommunismus der BGB in den Vordergrund. Die historische Zusammenkunft des „,mittelständisch denkenden Volkes“, von der Blocher

31 Zur Idee der geistigen Landesverteidigung vgl. Jorio 2006 sowie das Streitgespräch zwischen dem Historiker Hans-Ulrich Jost und dem Soziologen Kurt Imhof (1998).

32 Die Zitate des Abschnitts entstammen [o.A.] Die Mitte 37/1979, zit. in: Hartmann/ Horvath 1995: 56f. 
berichtet, ereignet sich vor dem Hintergrund einer sozialistischen Bedrohung, die metaphorisch als „linksextreme Flut“ vorgestellt wird. Die Flutmetaphorik präsentiert den politischen Gegner als übermächtige, nicht-menschliche und fremde Kraft, die ein wohlgeordnetes Innen, das tüchtige „Zürcher Volk“ und die „Staatsordnung überhaupt“, bedroht. ${ }^{33}$ Die Metapher imaginiert ein kriegsähnliches Bedrohungsszenario. Sie verknüpft Blochers Erzählung mit dem RedouteMythos und aktualisiert die Vorstellung, die Schweiz sei von Feinden umstellt und verdanke ihre politische Unabhängigkeit ihrer militärischen und geistigen Wehrhaftigkeit. Blocher fixiert die Identität der eigenen politischen Ordnung nicht nur als eine gegen den Sozialismus errichtete. Er stilisiert den Mittelstand und seine politischen Stellvertreter zur ,konservativen Avantgarde' des nationalen Kollektivs. Als politischer Arm des Mittelstandes erweist sich die frühe BGB - und nicht etwa die beiden großen bürgerlichen Parteien FDP und CVP - als die eigentlich staatstragende politische Kraft.

Blocher knüpft damit an den nationalen Repräsentationsanspruch des Bauern- und Gewerbestandes an, der im Selbstverständnis des BGB tief verankert war. ${ }^{34}$ Indem Blocher die antisozialistische Ausrichtung des BGB in den Vordergrund rückt und die etatistischen Forderungen, welche die Bauernpartei gegen den Marktliberalismus des Freisinns artikulierte, übergeht, synthetisiert er die Parteitradition und seine Zukunftsvision. Wie der BGB verpflichtet sich sein neukonservatives Sammlungsprojekt dem Kampf gegen den Sozialismus, den Blocher jedoch weniger mit dem proletarischen Internationalismus oder der Sowjetunion, sondern in erster Linie mit der EU, der Bürokratie, Steuererhöhungen und Zentralismus assoziieren wird. Unter Verweis auf einen transhistorischen sozialistischen Bedrohungskomplex wird das identitätsstiftende „Amalgam aus Mittelstand und Mitte, Volk und Nation“"35 in einem zukunftsorientierten, neoliberalen politischen Projekt reartikuliert werden.

Der Synthetisierung von Geschichte, Gegenwart und Zukunft in Blochers Jubiläumsrede liegt eine antagonistische Logik zugrunde. Konstitutiv für die Äquivalenzkette aus der neoliberalen Agenda der Zürcher SVP, dem traditionellen BGB und der nationalen politischen Gemeinschaft ist nicht etwa eine positive Gemeinsamkeit der artikulierten Traditionen, sondern die antagonistische Grenze gegenüber dem sozialistischen Außen. Der Ausschluss des bedrohlichen Anderen ermöglicht die Artikulation der Differenzen zu einer imaginären politi-

33 Ebd.

34 Vgl. Skenderovic 2013.

35 Skenderovic 2013: 69. 
schen Einheit und begründet zugleich den hegemonialen Führungsanspruch der Zürcher SVP als antisozialistische Avantgarde des bürgerlichen Lagers.

Obwohl der Schwerpunkt von Blochers Narration auf der Abgrenzung zum Sozialismus und der Konstruktion einer antisozialistischen Äquivalenz von Tradition und Neoliberalismus liegt, rekonstruiert Blocher die Parteigeschichte als Geschichte eines zweifachen Antagonismus. ,Blochers Mitte' identifiziert sich nicht nur in Abgrenzung zur „sozialistischen Verstaatlichung“, sondern auch zum „liberalen Laisser-faire“. Blocher verpflichtet die Partei damit auf die Fortführung der nationalkonservativen Mittelstandsideologie des 19. und frühen 20. Jahrhunderts, aus der die Partei hervorgegangen sei. Er knüpft an die Ressentiments an, die der bäuerliche Nationalismus der BGB gegenüber urbanen und modernen Lebensformen kultivierte. Seine Rede erinnert an die nationalistische Tradition der BGB, die noch in der Nachkriegszeit sowohl das heimat- und besitzlose Proletariat als auch das dekadente, kosmopolitisch orientierte Großbürgertum als zersetzende, überfremdende Bedrohung der Schweiz besprach. ${ }^{36}$

Blocher \& Co befürworten jedoch nicht die etatistischen Forderungen nach „staats- und wirtschaftspolitischen Massnahmen“, welche die BGB als Kraft der Mitte gegen den Marktradikalismus des dominierenden Freisinns artikulierte, um „die inländische Arbeit und Produktion“ zu fördern und das „werktätige Volk“ zu schützen. ${ }^{37}$ Vielmehr werden sie die traditionelle, doppelte Frontstellung der Mittelstandspartei gegenüber den beiden internationalen Großideologien Liberalismus und Sozialismus in einer Weise reartikulieren, welche ,die Mitte' vom sozialdemokratischen Ausbau des Wohlfahrtsstaates, einer sozialliberalen Sicherheitspolitik und einer kosmopolitisch ausgerichteten Kulturpolitik dissoziieren wird, wie sie Ende der 1970er Jahre nicht nur von der SP, der CVP und der FDP, sondern auch vom Berner Flügel der eigenen Partei favorisiert wurden.

Der gegenhegemoniale Diskurs, der mit der parteiinternen Auseinandersetzung um die Zukunft der kriselnden SVP und den Kämpfen um die Hegemonisierung der leeren Identifikationsbegriffe ,Mitte' und ,Mittelstand' ansetzt, wird indes nicht nur die SVP spalten, sondern das gesamte politische System in Frage stellen. Denn im Unterschied zur affirmativen politischen Strategie der Schweizer SVP, deren Mittebegriff die gegebene sozioökonomische Gruppendifferenzierung symbolisch aktualisiert, ist das politische Projekt der Zürcher Sektion transformativ ausgerichtet. Es zielt darauf, die gemäßigt pluralistische und konkordanzdemokratisch integrierte Struktur des politischen Raumes zu Gunsten eines dichotomen Freund-Feind-Modells zu suspendieren, indem es Differenzen

36 Vgl. Skenderovic 2013: 55 u. 57ff.; Tanner 2009.

37 BGB-Parteiprogramm 1943, zit. in Somm 2009: $213 f$. 
aus vielfältigen politischen Kontroversen absorbiert und diese entweder als legitime Forderungen eines eigenverantwortlichen ,Wir' oder als illegitime Ansprüche eines unzulänglichen ,Sie' sinnhaft macht. Allein durch die antagonistische Grenzziehung gegenüber einer sozialliberalen politischen Klasse und vielfältigen ,schmarotzenden“ Randgruppen können sich unterschiedliche Lebensformen (Konservative und Neoliberale, Modernisierungsverlierer und -gewinner, Stadtund Landbevölkerung, Arbeiter, Angestellte, Bauern, Selbstständige, Gewerbetreibende und Unternehmer) mit dem Phantasma eines kulturell und moralisch geeinten Mittelstandes identifizieren. Das Szenario erzeugt eine binärantagonistisch strukturierte, hoch politisierte Zivilgesellschaft und unterhöhlt die Hegemonie des konkordanzdemokratisch-korporatistischen Paradigmas der politischen Schweiz.

Die ersten Tentativen dieser gegenhegemonialen Offensive lassen sich während des Wahlkampfes der Zürcher SVP zu den Kantons- und Regierungsratswahlen von 1979 beobachten. Mit der Devise „Mehr Menschlichkeit - weniger Bürokratie“ und unter der Losung, den ,roten Sturm auf die Zürcher Regierungsburg“ abzuwehren, kündigten Blocher \& Co einen ,aggressiven Wahlkampf" an und brachen mit der kooperativen und klientelistischen Tradition der SVP. ${ }^{38}$ In ihrer Wahlkampfzeitung präsentiert sich die Zürcher SVP als eine „Volkspartei“, die weder Klassen noch Klassengegensätze kenne, die „Volksmeinung und die Anliegen der breiten Bevölkerung" vertrete und keineswegs von „Intellektuellen oder grossen Herren“ geführt werde, sondern von „Mitbürgerinnen und Mitbürgern, die auf beiden Füssen im Alltag stehen“. Zudem sei sie eine „Bürgerpartei“, welche Vermögen und Eigentum als den zentralen bürgerlichen Werten vor der „Übermacht des Staates und gewisser Wirtschaftskreise“ schütze. Sie sei die „,andere Arbeitnehmerpartei“, die Werktätige nicht als Proletarier, sondern als verantwortungsvolle Bürger behandle. Sie sei eine „Dorfpartei“, die sich zu „Volkstümlichkeit“ bekenne und einer „,bürgernahen Politik“ verpflichte. Sie sei die „Mittelstandspartei“, die sich für tiefe Steuern einsetze, um dem Mittelstand „,in seinem Existenzkampf“ zu unterstützen. Schließlich sei man „die traditionelle Partei des Landvolkes“ und damit eine „grüne Partei“, die sich „seit mehr als einem halben Jahrhundert“ um die Umwelt und „die Interessen der Allgemeinheit“ kümmere. ${ }^{39}$

Auch wenn die Selbstbeschreibungen der Partei hier lediglich enumerativen Charakter besitzen - und die Äquivalenz von Bürgertum, Volkstümlichkeit, Mit-

38 Blocher 1979, zit. in: Hartmann/Horvath 1994: 60; [o.A.] Die Mitte 13/1979, zit. in: ebd.

39 Vgl. SVP-Bezirksparteien Winterthur und Andelfingen [o.J.], zit. in: ebd. 
telstand, Arbeitnehmerschaft, Ökologie und Gemeinwohl im Innen respektive Bürokratie, Wohlfahrtsstaatlichkeit und Intellektualismus im Außen noch nicht durch diskursive Topoi konsolidiert sind, kündigt diese Selbstbeschreibung bereits an, dass das traditionell vorherrschende klientelistische Repräsentationsverständnis innerhalb eines ständisch und religiös strukturierten Parteiensystems durch einen universellen Repräsentationsanspruch abgelöst wird. Der Mythos eines tief in der eidgenössisch-bäuerlichen Alltagskultur verwurzelten bürgerlichrepublikanischen Egalitarismus, den die Partei durch den Antagonismus ,Mitbürger, die auf beiden Füßen im Alltag stehen' vs. ,Intellektuelle bzw. grosse Herren' aufruft, wendet sich sowohl gegen die elitäre FDP und CVP, als auch gegen die „Chefideologen“40 der SP. Er konstruiert eine vertikale Konfliktlinie, welche die ,einfachen, integren Bürger' und die ,abgehobene, moralisch korrumpierte politische Klasse' voneinander separiert und ein integratives rechtes Sammlungsprojekts begründet.

Die Paradoxie zwischen der wirtschaftspolitischen Ausrichtung der SVP, die das gewinnmaximierende Individuum aus seinen Verpflichtungen gegenüber der sozialstaatlich oktroyierten Solidargesellschaft befreien will, und ihrer konservativen Gesellschaftspolitik, die individuelle Emanzipation und Selbstverwirklichung der nationalen Schicksals- und Willensgemeinschaft unterordnen möchte, wird durch eine liberal-konservative Äquivalenz überbrückt. Diese Äquivalenz gründet ihrerseits auf der Frontstellung gegenüber einem machtvollen Außen, das sowohl die Individuen als auch die Gemeinschaft bedroht. ${ }^{41}$ Nur aufgrund der Präsenz dieses antagonistischen Anderen transformieren sich die potentiellen inneren Antagonismen der liberalkonservativen Äquivalenz in einfache Differenzen einer verhinderten mittelständischen Ganzheit. Damit adressiert die Reartikulation des Mittelstandsbegriffes die Erfahrung des Mangels, indem sie die Fülle einer Gemeinschaft von gleichgestellten, selbstverantwortlichen Bürgern und Bürgerinnen imaginiert, die durch ein Anderes blockiert sei.

Ende der 1970er Jahre sind entscheidende Weichen für die Desartikulation des konkordanzdemokratischen und multikulturalistischen Diskurses und die Errichtung einer neukonservativen Gegenhegemonie zum Sozialliberalismus gestellt. Doch handelt es sich bei der Wir-Gruppe des radikalen Zürcher Flügels bis hierhin um ein loses Kollektiv, dessen Selbstbeschreibungen, das zeigt etwa das oben paraphrasierte Wahlprogramm, eher einer listenartigen Enumeration als einer konsolidierten Äquivalenzkette gleicht.

40 Blocher 1979, zit. in: ebd.

41 Vgl. Hartmann/Horvath 1995: 90. 
Die Artikulation der Identifikationsbegriffe ,Mitte“ und ,Mittelstand“ dokumentieren den universellen Repräsentationsanspruch der neukonservativen Zürcher SVP. Doch fehlt ihnen Ende der 1970er Jahre noch der gemeinsame politisch-weltanschauliche Rahmen, der sie integriert. Die Orientierung, die Blocher als Präsident der Zürcher SVP zu stiften versprach, geht der Kantonssektion noch ab. Sein ordnungspolitisches Hauptanliegen, die Wirtschaftsfreundlichkeit, ist keineswegs unumstritten. ${ }^{42}$ Umwelt- und familienpolitische Fragen drohen die Partei zu spalten. ${ }^{43}$ Und Blochers strategische Positionierung gegenüber der Konkordanz stößt selbst in Zürich auf parteiinternen Widerstand. Immer wieder kommt es vor, dass Mitglieder der Kantonssektion öffentlich gegen Blochers Oppositionskurs polemisieren. ${ }^{44}$

Auf der anderen Seite sind grundlegende Schritte getan. Mit der Intensivierung der Jugendarbeit und dem Zuwachs aus der Jungen SVP-Zürich ist der Grundstein gelegt, die Partei auch personell für gegenhegemoniale Zwecke umzubesetzen. ${ }^{45}$ Die regelmäßig stattfindenden Diskussionsveranstaltungen erweisen sich ebenfalls als Erfolge. Sie stoßen auf hohes Interesse, verbreiten die ideologischen Aussagenkomplexe der Partei und lassen sie als bürgernahe Alternative zu einer elitären FDP und zu einer farblosen CVP erscheinen. Mit neugeschaffenen vereinsartigen Institutionen wie dem SVP Töff-Club (dem SVPMotorradclub) oder den regelmäßig stattfindenden SVP-Buure-Zmorge (dem SVP-Bauern-Frühstück) verwandelte sich die Mitgliedschaft bei der Zürcher SVP in eine Lebensform, die nicht nur auf politisch-programmatische Übereinstimmungen gründet, sondern ein gemeinsames Leben, Arbeiten und Feiern der Mitglieder und Sympathisanten inszeniert.

Eine deutliche Mehrheit in der Zürcher Sektion der SVP glaubt an das Potential eines politischen Projektes, das die Forderung nach einem starken Sicherheits- und Ordnungsstaat mit neoliberalen Reformen wie der Beendigung des Arbeitsfriedens, der Deregulierung und Flexibilisierung des Arbeitsmarktes, sowie der Beschneidung wohlfahrtsstaatlicher Leistungen $\mathrm{zu}$ Gunsten privater Vermögensbildung verbindet und diese Forderungen gegen den Berner Parteienkonsens wendet. ${ }^{46}$ Aber von einem historischen Block, in dem eine fortschritts-

42 Ebd.: 104.

43 Für eine ausführliche Darstellung des Dissenses innerhalb der Kantonspartei vgl. ebd.: $134 \mathrm{ff}$.

44 Vgl. ebd.: 143f.

45 Vgl. ebd.: 123ff.

46 Vgl. ebd.: 144. 
zugewandte Wirtschaftsfreundlichkeit und ein volkstümlicher Nationalkonservatismus fusionieren, kann Ende der 1970er Jahre noch keine Rede sein.

\subsection{DiE KONSTRUKTION EINER LIBERALKONSERVATIVEN ÄQUIVALENZ}

Der Weg zur Verwirklichung dieser Kollektividentität und die politischen Auseinandersetzung an seinen kritischen Kreuzungspunkten werden im Folgenden nachgezeichnet. Den Ausgangspunkt bilden zwei Politikfelder, die der Zürcher Flügel besonders aktiv bearbeitet: die Wirtschafts- und Sozialpolitik, wo man einen protestantisches Arbeitsethos mit einer neoliberalen ordnungspolitischen Agenda artikuliert, um nach dem Vorbild Reagans und Thatchers ${ }^{47}$ gegen Bürokratie, Etatismus und die postmaterielle Wachstumskritik der Neuen Sozialen Bewegungen zu politisieren; und die Asyl- und Sicherheitspolitik, die der nationalkonservative Diskurs als ein und dasselbe Politikfeld konstruiert. Auf diesem Feld zeichnet sich ab, dass die antagonistische Figur des ,inkompatiblen Fremden', auf die ich später im Rahmen der Analyse der Minarett-Initiative detailliert eingehe, bereits Mitte der 1980er Jahre einen Knotenpunkt des SVP-Populismus konstituiert. In ihm verbinden sich ein neoliberaler und ein nationalkonservativer Diskursstrang zu einer populistischen Krisendiagnostik, die den beiden antagonistischen Polen eine Vielzahl weiterer Differenzen einzuverleiben vermag.

\subsubsection{Neoliberalismus - die ordnungspolitische Offensive}

Im Unterschied zum modernisierungskritischen Erzkonservatismus Schwarzenbachs $^{48}$, mit dem sich in den 1970er Jahren bedeutende Teile der SVPStammwähler identifizierten, formuliert die populistische Avantgarde der Zürcher-SVP keine allgemeine Kritik der Moderne. Schuld an gesellschaftlichen Krisenphänomenen sind aus Blochers Sicht keineswegs die durch die ökonomische Entwicklung induzierten Rationalisierungs-, Flexibilisierungs-, Individualisierungs- und Migrationsprozesse, die eine ursprüngliche schweizerische Identität ,überfremdeten', sondern der hegemoniale Sozialliberalismus der 1970er Jah-

47 Vgl. Somm 2009: 44ff.

48 Vgl. Buomberger 2003; Buomberger 2004: 202 ff.; Drews 2005. 
re, der die Menschen von der protestantischen Arbeits- und Pflichtethik entbinde und ihren ,natürlichen Hang zur Bequemlichkeit' katalysiere. ${ }^{49}$

„Der Mensch - nicht mehr durch Entbehrung und Verzicht herausgefordert - nahm vieles als selbstverständlich hin, wurde bequem und war nicht mehr bereit, seine vom Leben auferlegten Lasten und Nöte zu tragen. Er begann jede Mühsal abzuschütteln. Parallel dazu lief eine Säkularisierung sämtlicher Lebensbereiche: Arbeit war nicht mehr Lebensinhalt, sondern ein verdammenswertes Übel. Freizeit galt als Sinn des Lebens. Dieses Leben entpuppte sich aber bald als sinnentleert, was sofort in einen Wirtschaftshass umschlug. “50

Wie Schwarzenbach rekonstruiert Blocher die Nachkriegsgeschichte der schweizerischen Gesellschaft als Geschichte von Dekadenz und Depravation. Seine Krisendiagnostik beginnt mit einer Art ,Sündenfall‘. Der fatale Regelbruch besteht indes keineswegs in einem systemimmanenten Profitstreben und der damit verbundenen Anwerbung von geringverdienenden ,Gastarbeitern', sondern im Ausbau des Sozialstaates, dessen Institutionen die negativen Eigenschaften des Menschen forcierten. Begleitet wird diese Entwicklung laut Blocher von einem säkularisierten Zeitgeist, der Arbeit, Verzicht und Anstrengung nicht als tieferen Sinn einer guten Lebensführung begreift, sondern als bloßes Mittel zur Qualitätssteigerung der Freizeit entweiht.

Blocher differenziert Schwarzenbachs umfassende Kritik am maßlosen Materialismus der Moderne, um die Idee des ökonomischen Fortschritts mit der Erzählung einer historisch gewachsenen Schweizer Identität zu versöhnen. Die Scharnierfunktion zwischen der konservativen Vergangenheits- und der neoliberalen Zukunftsorientierung übernimmt eine protestantische Arbeitsethik, die durch die Stichworte ,Lasten und Nöte', ,Mühsal', ,Arbeit als Lebensinhalt“ aufgerufen wird. Sie sakralisiert Bescheidenheit, Entsagung, Arbeit und Berufserfolg als Dienst für eine höhere Sache und diszipliniert eine an sich invariabel negative menschliche Natur zum Wohl der Gemeinschaft. Die sogenannten bürgerlichen Sekundärtugenden (wie etwa Disziplin, Fleiß, Strebsamkeit, Ordnungssinn, Folgsamkeit etc.), welche die Neue Linke für ethisch belanglos erklärt, erhalten damit eine tiefere Bedeutung für das Gemeinwohl.

Da die sozialliberale Bildungs- und Sozialpolitik diese sinn- und gemeinschaftsstiftenden Wissensbestände zugunsten der postmaterialistischen Wertori-

49 Diese Argumentation wird sich Jahre später in der metaphorischen Figur „des süßen Giftes des Sozialismus“ verdichten (exemplarisch vgl. SVP-Parteiprogramm 1999; Blocher 1999b u. 2006).

50 Blocher 1983, zit. in Hartmann/Horvath 1995: 106. 
entierungen und Forderungen der Neuen Sozialen Bewegungen marginalisierte, ließen sich mit der Nobilitierung der Sekundärtugenden eine Gegenposition zum Sozialliberalismus formulieren. Die besagten bürgerlichen Sekundärtugenden, mit denen die klassen-, schichten- und milieuübergreifende Einheit des Volkes begründet wird, entfalten ihre politische Dimension erst, indem sie mit einem parasitären Anderen konfrontiert werden, das für die Depravation, Entfremdung und die Zersetzung der sittlichen Gemeinschaft verantwortlich ist. Auf Grundlage dieser komplexen Artikulation von Erwerbsarbeit und Moral stellt Blocher die Wirtschafts- und Wachstumskritik des politischen Gegners als „Krankheitserscheinung einer degenerierten Modernität “51 dar. Diese Diagnose leitet eine Krisenanalyse ein, die nicht das Weber'sche Motiv der Rationalisierung, sondern die sozialliberale Kultur-, Bildungs-, Sozial- und Wirtschaftspolitik als Ursache einer gesellschaftlichen Krisensituation konstruiert. Blocher substituiert den im Diskurs von Schwarzenbach konstituierten Antagonismus von traditioneller Lebenswelt und zügellosem Wirtschaftswachstum durch den Antagonismus von Tradition und Sozialliberalismus. Die für den Diskurs der SVP zentrale Äquivalenz aus mittelständischer Tradition und neoliberaler Reformagenda gründet somit auf einem antagonistischen Anderen, das beide blockiert. Die so konstruierte Einheit aus kapitalistischer Moderne und schweizerischer Tradition, die im konservativen Überfremdungsdiskurs Schwarzenbachs noch als zentraler Widerspruch dargestellt worden war, sorgt dafür, dass die Kritik des sozialliberalen Wohlfahrtsstaates und der daran geknüpften Bürokratie, die die Zürcher SVP vorbereit und nach der erfolgreichen Volksabstimmung über den Beitritt zum EWR wirkungsvoll lanciert, als Verteidigung eines ,ursprünglichen, selbstgenügsamen Schweizervolkes' diskursiviert werden kann.

Auch wenn die politischen Konturen dieser Identität hier noch nicht deutlich hervortreten, lässt sich die oben zitierte Passage doch als frühes Kondensat der wirtschafts- und sozialpolitischen Ausrichtung des SVP Populismus lesen: Es wird ein binärer Antagonismus zwischen einem ,historisch-gewachsenen, eigenverantwortlichen und gesunden Volk` und einem ,nicht-lebensfähigen sozialliberalen Andern' konstruiert, das die staatlichen Institutionen kolonialisiere, um mit allerhand Gesetzen und Paragraphen die Verwirklichung der Prosperität des ,Volkes' zu verhindern. Die skizzierte binäre ideologische Matrix wird durch die Metaphorik des Parasitären strukturiert. Dieses zentrale Deutungs- und Ordnungsschema des SVP Populismus kombiniert die beiden Dichotomien ,nützlich/schädlich“ und , eigen/fremd“ und ordnet soziale Praktiken, politische Ideologien oder Gruppen von Menschen dem einen oder anderen Pol zu. Die Macht 
der rhetorischen Figur besteht darin, dass ihr ein politisches Programm immanent ist: Denn die Metaphorik des Parasitären imaginiert die Beziehung zwischen ,eigen' und ,fremd' als primordialen Konflikt zwischen zwei gegensätzlichen, aber vollen und in sich homogenen Entitäten. Dabei unterscheidet sie nicht nur ein organisches, nützliches und gesundes Innen von einem fremden, für sich genommen nicht überlebensfähigen, infektiösen und daher bedrohlichen Außen, sondern auch das ,gesunde Mark ${ }^{62}$ des politischen Körpers von seinen befallenen Arealen. Die Metapher koppelt das Überleben des politischen Gemeinwesens nicht mehr an die konkordanzdemokratische Absorption und Ausbalancierung interner Differenzen, sondern an die Immunisierung des politischen Körpers gegen nicht-zugehörige Feinde. Die neoliberale wirtschaftspolitische Agenda der Zürcher SVP erscheint infolgedessen nicht etwa als schmerzhafter, aber notwendiger Reformprozess, sondern als politisch gewollte Befreiungsideologie eines organischen Ganzen, das sich eines parasitären Fremden entledigen muss, um mit sich selbst identisch zu werden und eine vermeintlich originäre Fülle wiederzuerlangen. $^{53}$

\subsubsection{Konservatismus - die sicherheitspolitische Offensive}

Neben der Wirtschafts- und Sozialpolitik versuchte die Zürcher SVP, insbesondere auf den Politikfeldern Asyl, Sicherheit und Drogen politische Akzente zu setzen. Eine erste Gelegenheit, das politische Profil der Partei im Bereich ,innere Sicherheit' zu schärfen, bot sich den Hardlinern, als die sogenannten Jugendunruhen zu Beginn der 1980er Jahre gewaltförmig eskalierten. ${ }^{54}$ Nachdem sich die

52 So die Formulierung Christoph Blochers (1991) in einem zum Nationalfeiertag 1991 erschienen Artikel in der Schweizerzeit.

53 Reaktiviert wurde diese ideologische Figur beispielsweise in der ersten heftig umstrittenen Inseratenkampagne „Achtung vor dem rot-grünen Filz“ (vgl. Hartmann/Horvath 1995: 108), welche die Zürcher SVP im Vorfeld der Nationalratswahlen von 1991 schaltete. Vor dem Hintergrund der schwachen Konjunktur politisierte die Zürcher SVP damals mit der Angst vor Arbeitslosigkeit für ihre Deregulierungspolitik und gegen die staatszentrierte Linke, die die soziale Marktwirtschaft schrittweise in eine bürokratisch gelenkte Planwirtschaft überführe. Die einschlägige Abbildung zeigte eine rote und eine grüne Filzlaus, die sich zu Lasten des Wirtschaftsstandortes und des arbeitenden Volkes in einem aufgeblähten Staatsapparat eingenistet haben.

54 Vgl. Hartmann/Horvath 1995: 64; für eine kompakte Darstellung der Jugendunruhen vgl. Tackenberg 2011. 
Kantonssektion in den ersten Wochen nach dem Zürcher ,Opernhauskrawall ${ }^{\circ}$ vom 30. Mai 1980 über die Deutung der Jugendunruhen keineswegs einig war, setzten sich im Spätsommer 1980 diejenigen durch, die in den bewegten Jugendlichen nicht harmlose „Klamaukgesellen ${ }^{\text {“55 }}$ mit unkonventionellen aber durchaus legitimen politischen Anliegen, sondern „Extremisten, Randalierer, Chaoten und Nihilisten ${ }^{\text {“56 }}$ sahen. Blocher erkannte im Autonomen Jugendzentrum von Zürich einen „Hort krimineller Elemente“ ${ }^{\text {(57 }}$. Der SVP-Regierungsrat Konrad Gisler

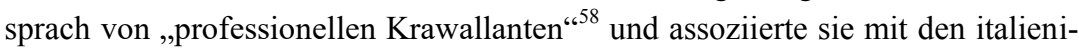
schen Brigate Rosse. Sein Kollege Jakob Stucki identifizierte einen „harten Kern von Anarchisten ${ }^{\text {c59 }}$, der die gesamte Jugend in Misskredit brächte. Ein Jahr später konstruierten Kommentatoren der Mitte die Bewegung als Teil einer linksfaschistischen, international operierenden Terrorszene. ${ }^{60}$

Bis hierhin könnte man denken, dass die Diskursivierung der Jugendunruhen von Seiten der Zürcher SVP allenfalls graduell von derjenigen des bürgerlichen Mainstreams abwich. Im Mittelpunkt der Kritik standen jedoch nicht nur die bewegten Jugendlichen. Die SVP war seit 1978 nicht mehr Teil der Stadtzürcher Regierung und nutzte die mit der Oppositionsrolle verbundene Freiheit, um der Regierung und allen voran der SP, die Elemente des Forderungskataloges der Protestierenden zu integrieren versuchte, die Verantwortung für die anhaltende Gewalt zuzuschreiben. Die Regierung sei nicht in der Lage, den „Schutz des Bürgers“ zu gewährleisten, sodass dieser „zur legalen Selbstverteidigung gezwungen werde", bilanzierte Blocher und befürwortete die Forderung von Kleingewerblern, Bürgerwehren und Patrouillen zu gründen, um gegen die randalierenden Jugendlichen vorzugehen. ${ }^{61}$

Die Bedeutung, die der Diskurs der Zürcher SVP den Jugendunruhen verlieh, changiert zwischen ,sinnloser Gewalt ${ }^{\star}$ als Ausdrucksmittel eines gewaltverherrlichendem Rowdytums, mit dem die überforderte Mitte-Links-Regierung nicht fertig wird, und zielgerichtetem linksextremistischem Terror, mit dem die SP insgeheim sympathisiere. Folglich erscheint die dialogorientierte, integrative Po-

55 So zum Beispiel der damalige Parteisekretär Rudolf Bolliger, der kurz darauf aus dem Amt schied und durch den radikalen PR-Mann Fredy Kradolfer ersetzt wurde. Vgl. [o.A.] Die Mitte 29/1980, zit. in: ebd.: 65.

56 Reichling 1980, zit. in: ebd.

57 Blocher 1980, zit. in: ebd.

58 Gisler 1980, zit. in: ebd.

59 Stucki 1981, zit. in: ebd.

60 Vgl. ebd. sowie: [o.A.] Die Mitte 27/1981 und 30/1981, zit. in: ebd.

61 Blocher 1980, zit. in: ebd.: 66. 
litik der Stadtzürcher Regierung entweder als erpresster Beschwichtigungsversuch und damit als Zeichen von Hilflosigkeit und Schwäche oder aber als politische Kollaboration mit den ,terroristischen“ Feinden von Arbeit, Recht und Ordnung.

Zudem nutzte die Zürcher SVP die Unruhen, um das konservative Schema der Intellektuellenfeindlichkeit zu aktualisieren und gegen Studierende und Professoren zu polemisieren. ${ }^{62}$ Gisler forderte die zuständigen Behörden auf, ,aus präventiven Gründen Wachsamkeit und Präsenz ${ }^{\text {“63 }}$ an der Universität zu zeigen. Die Mitte attackierte die ,scheinheiligen Linksintellektuellen“, die offiziell für einen Dialog warben, in Wirklichkeit jedoch die geistige Vorhut der „Anarchofaschisten “64 bildeten. Blocher machte insbesondere die Geistes- und Sozialwissenschaften verantwortlich für den Verfall von „Lebensbegriffen“ wie Elternschaft, Ehe, Familie und Arbeit. Ursächlich für die Probleme mit der Jugend sei das „Versagen der Theorien [...] von Soziologen und Psychologen“65. Für den Vorstand der Züricher SVP und die Delegiertenversammlung stand fest, dass der jugendlich-universitäre „Müßiggang früher oder später zwangsläufig in der Kriminalität oder im Rauschgift" ${ }^{\text {"66 }}$ ende. Die Unruhen waren demnach nur die Spitze des Eisberges tieferliegender gesellschaftlicher Fehlentwicklungen, die als Folge der Auflösung traditioneller Bindungen verstanden wurden.

Parteiintern diente die neukonservative Polemik gegen die Regierenden und die linksintellektuellen Deutungseliten der Legitimierung des von Blocher favorisierten Oppositionskurses. Nach außen konstituierte sie eine antagonistischen Frontlinie, die ,Blochers Mitte' politische Konturen verlieh, indem sie diese nicht nur von den wenigen gewalttätigen Jugendlichen, sondern auch von dialogorientierten Regierungsvertretern, den Soziologie- und Psychologieprofessoren und Linksintellektuellen dissoziierte. Angesichts des antagonistischen Bedrohungskomplexes aus ,sinnloser' Jugendgewalt, politisch-ideologisch motiviertem Terror, einem ,universitären, lebensfernem Intellektualismus ' und einer sozialliberalen politischen Klasse erscheint ,Blochers Mitte' als gesellschaftlicher underdog, der über den Willen und die Mittel verfügt, die zersetzten Bindungen zu restaurieren.

62 Zur Tradition des konservativen Antiintellektualismus vgl. Lang 2000: 98f.

63 Gisler 1980, zit. in: Hartmann/Horvath 1995: 67.

64 [o.A.] Die Mitte 1/1981, zit. in: ebd.: 68.

65 Blocher 1981, zit. in: Hartmann/Horvath 1995: 69.

66 Aus Deklarationen des SVP-Vorstandes und der Delegiertenversammlung, in: [o.A.]

Die Mitte 3/1981 und [o.A.] Die Mitte 27/1981, zit. in ebd.: 69. 
Während die gemäßigten politischen Kräfte auf eine Mischung aus Eindämmung und Beschwichtigung setzen, die gewisse Forderungen und Praktiken der Protestierenden zertifiziert und andere dezertifiziert, um die Gewalttätigen zu isolieren und die Forderungen der friedlichen Demonstranten differenzlogisch zu resorbieren, verschiebt der Diskurs der Zürcher SVP den Antagonismus gen Mitte. Seine Gefährdungsthese beginnt zwar ebenfalls bei den ,Chaoten“ und ,Extremisten', beschränkt sich jedoch nicht auf eine Äquivalenzierung von Linksextremismus und Gewalt. Die Mutmaßungen über eine heimliche Allianz zwischen ,Universität‘ und den gewalttätigen Protesten, die Behauptung, die Regierungsvertreter der Zürcher SP würden insgeheim mit den Gewalttätern sympathisieren, sowie die Ursachenanalyse, nach der die antiautoritäre, auf ,psychologische“ und ,soziologische Theorien` gestützte Umgestaltung des Bildungs- und Erziehungssystem schuld sei an der gewaltförmigen Desintegration der Gemeinschaft, dehnen die antagonistische Äquivalenzkette auf sozialliberale Positionen aus.

Die Jugendunruhen avancieren zum Zeichen einer allgemeinen Krise, deren Wurzeln tiefer liegen. Sie sind der oberflächliche Ausdruck einer gesellschaftlichen und politischen Entwicklung, in der ein ,universitäres, schulisches, administratives und politisches Establishment' die soziomoralischen Ressourcen der Gemeinschaft zersetzt. Die Zürcher SVP steht damit nicht nur für ein hartes Durchgreifen gegenüber politischen ,Extremisten“ und ,Chaoten“. Sie nutzt die Jugendunruhen, um die Bildungs-, Forschungs- und Sicherheitspolitik en général zur Disposition zu stellen und sich eine Vielzahl unerfüllter Forderungen und marginalisierter ideologischer Elemente einzuverleiben.

Im Kontext der Jugendunruhen aktualisiert der Zürcher Flügel die Vorstellung einer in zwei Teile gespaltenen Gesellschaft, von der sein Repräsentationsanspruch abhängt. Denn nur in einer Situation, in der die Ordnung von einem einheitlichen Außen bedroht ist, dessen Forderungen sich nicht als weitere Differenzen der politischen Gemeinschaft integrieren lassen, kann Blochers neukonservatives Projekt zur gegenhegemonialen Synekdoche avancieren. Nur unter dieser Voraussetzung hat die partikulare politische Agenda das Potential, sich zu hegemonisieren und die abwesende Fülle der Gemeinschaft zu symbolisieren. ${ }^{67}$

Diesen Repräsentationsanspruch konnte die Zürcher SVP im Kontext der Jungendunruhen allerdings nicht verwirklichen. Man kann ihr zwar attestieren, ihre Oppositionsrolle effektiv genutzt zu haben und die Regierung zu einer konsequenten Durchsetzung der Rechtsordnung gezwungen zu haben. Die Hegemonie der Konkordanz und des gemäßigten Pluralismus der politischen Schweiz blieb jedoch bestehen, weil sich die Strategie der Regierenden mittelfristig als 
erfolgreich erwies. Einmal mehr gelang es der konkordanzdemokratischen Mischung aus Eindämmung und Beschwichtigung, eine Krise zu beenden. Für die als legitim anerkannten Forderungen zeigte die Regierung Verständnis, verleibte sie als einfache Differenzen der korporatistischen Verhandlungsdemokratie ein und erneuerte etwa durch die Einrichtung kantonaler Jugendkommissionen das konkordanzdemokratische operative Paradigma der Integration qua Kompromiss. Dieser differenzlogisch dominierte sozialliberale Diskurs dekonstruierte nicht nur die gegen eine vermeintlich bürgerlich-reaktionäre Schweiz errichtete Äquivalenzkette, welche die bewegten Jugendlichen zusammenhielt, sondern unterminierte auch die antagonistische Äquivalenz, die der reaktionäre Diskurs der Zürcher SVP zu konstruieren versuchte. ${ }^{68}$

Als wesentlich erfolgreicher und nachhaltiger sollte sich die zweite sicherheitspolitische Offensive der Zürcher-SVP entpuppen. Sie nahm ihren Ausgang auf dem Gebiet der Asylpolitik. Die liberale Tradition in der Schweizer Asylpolitik wurde Anfang der 1980er Jahre zum Politikum, als sich die Zahl der Asylbegehren binnen kurzer Zeit von etwa zweitausend in den 1970er Jahren auf über viertausend im Jahr 1981 und schließlich auf über siebentausend 1982 erhöhte. Um zu verhindern, dass die Asylfrage Gegenstand des Überfremdungsdiskurses würde, führte der Bundesrat die Unterscheidung von „echten“ und „unechten Flüchtlingen“" ein. ${ }^{69}$ Und auch die Zürcher SVP betonte, dass nicht die altbekannten, ,echten“ Flüchtlinge, sondern die neuen ,unechten“ Wirtschaftsflüchtlinge das Problem seien. ${ }^{70}$ Mit dem Ziel, erstere von letzteren zu unterscheiden, beschlossen Bundesrat und Parlament, die Asylanträge in Zukunft strenger prüfen zu lassen. Doch schien die Revision des Asylgesetzes das Eidgenössische Justiz- und Polizeidepartement zu überfordern: 1982 waren bereits achttausend Gesuche noch nicht entschieden, ein Jahr später doppelt und 1984 fast dreimal so viele. ${ }^{71}$

Angesichts der Tatsache, dass der Neo-Rassismus der Nationalen Aktion im Kontext der Überfremdungsinitiativen der 1970er Jahre insbesondere im traditionellen Milieu der SVP auf Zustimmung stieß, war die Partei für den drohenden Konflikt zwischen humanitärem Selbstverständnis und völkischem Abwehrdenken hoch sensibilisiert. Fritz Hofmann, der Berner Parteipräsident der SVP Schweiz, warnte in einem Artikel im Zürcher Boten, „[u]nechte Flüchtlinge überfluten die Schweiz" und forderte den Bundesrat zu raschem Handeln auf, da

68 Vgl. Criblez 2008.

69 Vgl. Hartmann/Horvath 1995.

70 Vgl. [o.A.] Der Zürcher Bote 5/1982, zit. in: ebd.: 150.

71 Vgl. Hartmann/Horvath 1995: 150f. 
man anderenfalls Gefahr laufe, dass die Flüchtlingsproblematik von einem „nicht bewältigten Überfremdungsproblem“ überlagert werde. ${ }^{72}$ Hofmann übernahm die Flutmetaphorik des Überfremdungsdiskurses. Er versuchte aber die Kontinuität der liberalen Asylpolitik zu wahren: Obwohl Schlepperorganisationen den „Asylfrieden“ gefährdeten, so Hofmanns Argument, müsse man an der „humanen Aufnahmepraxis“ festhalten. ${ }^{73}$ Die gegenwärtige Fremdenfeindlichkeit in der Schweiz liege darin begründet, dass ,wir die Fremdlinge untätig auf den Plätzen und Bahnhöfen herumstehen lassen", anstatt sie wirtschaftlich zu integrieren. ${ }^{74}$ Ähnliche Argumente waren auch aus den Reihen der Zürcher SVP zu hören. Dass die meisten Flüchtlinge nicht mehr aus den autoritären Ostblockstaaten, sondern aus ,anderen Kulturen in fernen Kontinenten“ stammten, konstatierte die Kantonsrätin Christine Ungricht, dürfe nicht als Argument für eine generelle Asylverweigerung herhalten. ${ }^{75}$ Die Bedrohung geht hier nicht von ,unechten, teuren, nicht-integrierbaren und kriminellen Asylanten' aus. Bedroht ist der locus amoenus allenfalls von ,Schlepperbanden' und insbesondere von einer desintegrativen Asylpolitik, wohingegen die Asylbewerber selbst als eine Differenz unter vielen integriert werden könnten.

Anders stellte sich die Situation für die Chefideologen der Zürcher SVP dar. Hans Fehr konstatierte, dass die SVP nur durch ein „Umdenken“ in der Frage weitere Verluste vermeiden und den Einfluss „extreme[r] Gruppierungen“ eindämmen könne. ${ }^{76}$ Wie dieses „Umdenken“ von statten ging, zeigte Blocher in Zusammenhang mit dem Kirchenasyl von Zürich-Seebach ${ }^{77}$. Blocher knüpfte dabei zunächst an den Überfremdungsdiskurs Schwarzenbachs an. Das „Problem der Asylanten“ laste schwer auf dem Volk, stellte er fest. Anstatt die Belastung näher zu erläutern, fährt er mit einer Generalisierung fort: „Ein Land von der Kleinheit der Schweiz, umgeben von grossen, bedeutenden Staaten“, habe naturgemäß Angst vor der „Überfremdung“. Der „urtümliche Trieb zur Behauptung

72 Hofmann 1982, zit. in: ebd.: 151.

73 Hofmann 1984, zit. in: ebd.: 177.

74 Hofmann 1985, zit. in: ebd.: 152.

75 Des Weiteren hob Ungricht hervor, dass die Flüchtlingsproblematik nicht durch repressive Maßnahmen, wie sie der Bundesrat vorantrieb, sondern nur durch ein stärkeres Engagement in der Entwicklungspolitik gelöst werden könne (vgl. Ungricht 1984, zit. in: ebd.: 152f.).

76 Fehr 1986, zit. in ebd.: 153.

77 Der Pfarrer der Gemeinde Zürich-Seebach Peter Wals gewährte chilenischen Flüchtlingen, denen die Schweizer Behörden das Bleiberecht verweigert hatten, Kirchenasyl (vgl. ebd.: 152). 
von Arbeitsplatz und Einkommen“ sorge dafür, dass bei den „Hiesigen“" in Zeiten gesellschaftlicher Unsicherheit Fremdenhass entstünde. Folglich könne nur eine rigide Asylpraxis verhindern, dass sich die ,,primitiven Seiten der menschlichen Natur: Unanständigkeit, Rücksichtslosigkeit und Brutalität“ entfalteten. Es sei daher die Aufgabe des Staates, nicht nur den ,echten', politischen Flüchtlingen einen Zufluchtsort zu gewähren, sondern auch den ,unkontrollierte[n] Zustrom“ von Wirtschaftsflüchtlingen abzuwehren. Dazu seien die Amtsträger aus Furcht vor unpopulären Maßnahmen indes nicht in der Lage. Auch wenn die „üble Gesinnung des Fremdenhasses“ die Asylpolitik nicht bestimmen dürfe, seien „die wilden Aktionen der Humanität“ ebenso falsch. Schließlich tragen nicht die „kirchlichen Propagandisten der Humanität“, sondern „,der Arbeiter in Aussersihl, der sich in seiner Umgebung und Existenz bedroht fühlt“, die Kosten der Mitmenschlichkeit. $^{78}$

Abgesehen von der Kritik an der Regierung scheint sich Blochers Position zunächst nur geringfügig von derjenigen des bürgerlichen Lagers zu unterscheiden. Er wiederholt die Differenzierung von unproblematischen ,echten“ und problematischen ,unechten' Flüchtlingen und pflichtet damit dem bürgerlichen Konsens in der Asylpolitik bei. Mit Hofmann teilt Blocher die Befürchtung, die rechtsextreme Nationale Aktion könne von den Missständen, die eine nicht mehr zeitgemäße Asylpolitik verursacht habe, profitieren. Indem Blocher jedoch ein gewisses $\mathrm{Maß}$ an Fremdenfeindlichkeit als unvermeidlichen Bestandteil der menschlichen Natur konstruiert, die Überfremdungsproblematik in der Schweiz auf die geostrategische Lage des Kleinstaates zurückführt und damit zentrale Elemente des Überfremdungsdiskurses reartikuliert, bietet er den ehemaligen Anhänger Schwarzenbachs eine neue politische Identifikationsfläche. Ihr Unbehagen mit der liberalen Einwanderungs- und Asylpolitik, das von den etablierten politischen Eliten zumeist als Ausdruck irratonaler Ressentiments diffamiert wurde, wird von Blocher als gleichsam natürliche Sorge und legitime politische Forderung rehabilitiert. Wenn es gute Gründe für neo-rassistische Ressentiments gibt und diese Ressentiments schnell in Hass und Brutalität kippen, kann Blocher auf Grundlage dieser Setzung für eine harte Asylpraxis plädieren, um zu verhindern, dass sich ein „,ausgewachsener Fremdenhass“ entwickelt. Umgekehrt ebneten diejenigen, die das ,Asylproblem“ aus ,humanitären“ oder ,moralischen“ Gründen tabuisierten, den Rassisten der Nationalen Aktion in Wirklichkeit den Weg. Die „Vergötterung“ der Asylsuchenden führe „,rascher und intensiver zum

78 Die Zitate des Abschnitts entstammen Blocher 1985, zit. in: ebd.: $153 \mathrm{ff}$. 
Fremdenhass als ihre Beschimpfung“, brachte Blocher seinen Argumentationsgang auf den Punkt. ${ }^{79}$

Die Sinnverkehrungsthese ${ }^{80}$, mit der Blocher hier operiert, konstruiert einen doppelten Antagonismus: Im Rahmen der Asylfrage gibt Blocher vor, in erster Linie den kruden Rassismus der Nationalen Aktion zu bekämpfen: Es gelte zu verhindern, dass das Thema von Politikern hegemonisiert werde, die „den eisernen Besen auf ihrer Fahne tragen“" ${ }^{\text {“1 }}$. Zugleich polemisiert er gegen die „pharisäerhaften Menschenfreunde“882, die ,das Asylproblem‘ zu verharmlosen suchen. Sie würden das Phänomen des Fremdenhasses, den sie zu bekämpfen vorgeben, in Wirklichkeit forcieren. Blochers Polemik gegen die sozialliberalen Kräfte kulminiert schließlich in der These, dass sie die Gewinne ihres Handelns in Form von politischer Macht und kulturellem Kapital gewissermaßen privatisierten, die Kosten dagegen der Allgemeinheit und insbesondere dem ,kleinen Mann` aufbürdeten.

Blochers Asyldiskurs mündet im Glauben, dass die rigide Asylpraxis, für die sich die Zürcher SVP ausspricht, und die humanitäre Tradition der Schweiz nicht im Widerspruch stünden, sondern sie in Wahrheit vor ihren Feinden schützten. Dadurch dass die politische Ordnung nicht nur durch die extremistische Nationalen Aktion, sondern zumindest indirekt auch durch die Befürworter einer linksliberalen Asylpolitik bedroht ist, stilisiert sich die Zürcher SVP als staatstragende Kraft der bürgerlichen Mitte. Der durch die Sinnverkehrungsthese instituierte doppelte Antagonismus ermöglicht der Zürcher SVP, den ideologischen Graben gegenüber dem Linksliberalismus zu vertiefen, die rassistischen Elemente des Überfremdungsdiskurses von Schwarzenbach zu reartikulieren und sich gleichzeitig des Vorwurfes zu erwehren, das schweizerische Humanitätsgebot zu verletzen und mit rechtsextremistischen Positionen auf Wählerfang zu sein. ${ }^{83}$

Zur gleichen Zeit entwickelte die Zürcher SVP eine rigide Position in der Drogenpolitik. Die Drogensucht sei „ein Grundübel unserer Zeit“ und könne nur wirkungsvoll bekämpft werden, indem man „Angebot und Nachfrage gleichermaßen konsequent" sanktioniere, lancierte der Staatsanwalt und spätere Präsi-

79 Blocher 1987, zit. in: ebd.: 154.

80 Zur Sinnverkehrungsthese als Kernstück konservativen Denkens vgl. Hirschmann 1992.

81 Blocher 1987, zit. in: Hartmann/Horvath 1995: 155.

82 Ebd.

83 Der Sinnverkehrungstopos ist eines der zentralen Deutungsmuster des Asyl- und Migrationsdiskurses der SVP. Vgl. die Feinanalyse der Albisgüetlirede von 1993 im folgenden Kapitel. 
dent der SVP-Sektion Pfäffikon Christian Huber die Offensive gegen die liberale Drogenpolitik, in der Blocher eine „konsequente Fortsetzung verwahrlosten Denkens“ erkannte. Sie gründe auf der „falschen Lebensauffassung“, deren Absicht es sei, „den Menschen ein Leben ohne Lasten, ohne Verzicht und Hindernisse zu ermöglichen“. Nicht „Schmerzfreiheit“, sondern „Suchtfreiheit, Schutz der Gesunden und Schutz der Bürger vor Drogendelikten“, müsse das politische Ziel sein. $^{84}$

Der Konsum von Drogen wird hier, ähnlich dem Wirtschaftshass, als Folgeerscheinung des sozialliberalen Zeitgeistes konstruiert. Als in der zweiten Hälfte der 1980er Jahre die ersten staatlich finanzierten Fixerstuben in Schweizer Großstädten eingerichtet wurden, um der Drogenkriminalität entgegenzuwirken, die Konsummengen zu regulieren und die Abhängigen vor Infektionen zu schützen, avancierte die staatliche Drogenpolitik zum Knotenpunkt eines sozialliberalen und etatistischen Anderen, das den Menschen in Abhängigkeit halte, anstatt ihm die Härten des Lebens zuzumuten und sich um die Interessen der „Verwahrlosten“ ${ }^{85}$, nicht aber um die Belange der ,eigenverantwortlichen“ Bürger/innen kümmere.

Im Vorfeld der Kantonalratswahlen von 1987 wurden die Politikfelder Kriminalität, Drogen und Asyl schließlich erstmals gemeinsam artikuliert. Anlässlich eines Wahlparteitages zum Thema Mehr Sicherheit für alle forderten die Hauptredner die Durchsetzung des Betäubungsmittelgesetzes, stärkere Grenzkontrollen und die Ausschaffung krimineller Ausländer. Blocher bilanzierte, dass es auch unter den Asylanten Drogenhändler und Kriminelle gebe, weswegen die Asylpolitik ein wichtiger Aspekt der Sicherheitspolitik sei. ${ }^{86}$ In den folgenden Jahren verknüpfte die Zürcher SVP die Drogenprohibition, die Verschärfung des Asylrechts und rigider Kriminalitätsbekämpfung zu einer Sicherheitsideologie, die fortan als ideologische Klammer ihres populistischoppositionellen Sammlungsprojektes diente. ${ }^{87}$ Denn durch die gemeinsame Artikulation der drei Politikfelder gelang es, nicht nur kulturrassistische Ressentiments zu rationalisieren und zu legitimieren, sondern ein antagonistisches Kollektiv aus sozialliberalen Amtsträgern, linken Deutungseliten, neuen Jugendund Subkulturen, Immigranten und gewöhnlichen Delinquenten zu konstruieren,

84 Die Zitate des Abschnitts entstammen Huber 1987, zit. in: Hartmann/Horvath 1995: 155.

85 Ebd.

86 [o.A.] Der Zürcher Bote 4/1987, zit. in: Hartmann/Horvath 1995: $155 f$.

87 Vgl. Hartmann/Horvath 1995: 157. 
die verantwortlich für die Desintegrationserfahrungen vieler Menschen gemacht werden konnten.

Hierbei deuten bereits die ersten Tentativen in der Sicherheitspolitik darauf hin, dass der neukonservative Diskurs die Figur des ,kriminellen Ausländers' als Knotenpunkt des antagonistischen Außen fungieren lässt. In ihm verschmelzen fünf Stränge des politischen Diskurses der SVP: (1) Aufgrund seiner ethnischen Fremd- und Andersartigkeit konterkariert er das Ideal einer nativen Gemeinschaft; (2) als ,unechter Flüchtling' belastet er den Staatshaushalt, die Steuerzahlenden und den Wirtschaftsstandort Schweiz; (3) als Drogendealer vergiftet er die Jugend und gefährdet die Zukunft der Gemeinschaft; (4) als Delinquent bedroht er Sicherheit und Eigentum der Bürger/innen; (5) dabei kann er bei all diesen Aktivitäten auf das milde Urteil der linken Meinungsmacher und die schützende Hand der sozialliberalen Amtsträger rechnen. Die antagonistische Äquivalenzkette (aus Überfremdung, Steuererhöhungen, Drogenkonsum, Unsicherheit und Linksliberalismus), die der Zürcher Flügel um dieses Anti-Subjekt konstruiert, lässt sich nicht auf einen spiegelbildlichen Ausdruck der Aggregation unerfüllter Forderungen reduzieren. Vielmehr imaginiert die Artikulationsleistung eine binäre Spaltung der Gesellschaft. Sie sorgt dafür, dass die unerfüllten Forderungen in einem popularen Diskurs fusionieren und eine antisystemische Identität annehmen.

Die Zentralität der Asylpolitik im Diskurs der Zürcher SVP liegt folglich nicht ausschließlich darin begründet, dass es sich um ein brisantes und tabuisiertes Thema mit hohem Mobilisierungspotential handelt. Die Asyl- und Migrationspolitik avancierte deswegen zu einem privilegierten Politikfeld der SVP, weil es der Konstruktion einer Freund-Feind-Unterscheidung dient, die das Politikfeld ,Einwanderung ${ }^{6}$ transzendiert. ${ }^{88}$ Nach dem Vorbild der nationalkonservativen „Restabilisierung der bürgerlichen Schweiz nach dem Ersten Weltkrieg ${ }^{489}$ identifiziert sie den sozialliberalen Feind im Innern des Staates mit der Bedrohung durch das Fremde. Durch die Figur des kriminellen Ausländers werden die Bedrohung von außen und jene von innen miteinander verwoben. Der „Kampf gegen die Linke“ erscheint so als tiefer „Ausdruck schweizerischer Lebensart“. ${ }^{90}$ Ein nationalkonservativer und ein neoliberaler Diskursstrang fusionieren zur Quintessenz des Schweizerischen.

88 Für eine ausführliche Analyse des Einwanderungsdiskurses der SVP ab dem Jahr 2003 vgl. Geden 2006: insb. 96ff.

89 Ernst/Wigger 1993.

90 Ebd.: 167. 


\section{Zwischenbilanz und Vorausblick: Von der subkulturellen Enklave zum nationalpopularen politischen Projekt}

Es wurde gezeigt, wie das politische Projekt der Zürcher SVP die ständischkonservative Parteitradition mit den neoliberalen Forderungen nach Steuersenkungen und Bürokratieabbau artikuliert. Der ideologische Mittelstandsbegriff, der die Einheit von neoliberaler Zukunft und konservativem Traditionsbewusstsein symbolisiert, konstituiert sich nicht primär durch die Abgrenzung zu den politischen Extremisten rechts und links der eigenen Identität, sondern durch den Antagonismus zu marginalisierten Gruppen. Diese werden als unzulängliche und unersättliche Profiteure des sozialliberalen Parteienkonsenses und als Bedrohung des ,eigenverantwortlichen Mittelstandes‘ präsentiert. Der Diskurs der Zürcher SVP zielt auf eine dichotomische Vereinfachung des Sozialen, die quer sowohl zum Multikulturalismus als auch zu sozioökonomischen Schichtenanalysen steht und die einschlägigen Gruppendifferenzierungen unterläuft.

Mit den Offensiven in der Asyl-, Drogen- und Sicherheitspolitik sowie mit der Polemik gegen Steuern und Bürokratie gelang es der Zürcher SVP, ihrem Diskurs neue Gegenstände zu geben, den Gegensatz zum Sozialliberalismus zu vertiefen und die neukonservative Ausrichtung der eigenen politischen Formation zu schärfen. Die Zürcher SVP brachte eine Ideologie auf den Weg, die den Widerspruch zwischen dem Erzkonservatismus der Schweizer Demokraten und dem Ultraliberalismus der Auto Partei zu überwinden vermochte ${ }^{1}$ und über ein

1 Diese Konfliktlinie zwischen einem traditionsorientierten, sozialen Nationalismus und einem progressiven, neoliberalen Nationalismus spaltete das Lager der extremen Rechten in der Schweiz (vgl. Gentile/Kriesi 1998; Skenderovic 2009). 
schichten-, ethnien- und konfessionsübergreifendes Integrationspotential verfügte.

Gleichwohl befindet sich der Populismus der Zürcher SVP Ende der 1980er Jahre nach wie vor in einem Initialstadium. Zwar fand sie in der Asylpolitik ein Politikfeld, mit dem sich die neue Rollenauslegung als fundamentaloppositionelle Partei legitimieren ließ, doch glich der unter dem jungen Parteipräsidenten Blocher angeschlagene politische Kurs der Kantonalsektion eher einer tentativen Suche nach potentiellen Dislokationen als einem kohärenten politischen Projekt. Obwohl bereits in den 1980er Jahren jene rhetorischen Figuren und Schlagworte auftauchen, die den politischen Raum in den 1990ern reorganisieren werden, versteht sich die Zürcher SVP noch als Teil des bürgerlichen Lagers - wenngleich als dessen rechte Avantgarde. Ein universeller Repräsentationsanspruch des Bürgertums oder gar des Schweizervolkes wird nur selten erhoben. Die Angriffe des Zürcher Flügels gelten zumeist der SP sowie den sozialliberalen und ökologischen Strömungen in der eigenen Partei, aber keineswegs einem umfassenden, verschwörungstheoretisch imaginierten Bevormundungskartell aus Parteien, Medien und Wissenschaft. Zudem finden sich im Diskurs des Zürcher Flügels zu diesem Zeitpunkt keine gegenhegemonialen Artikulationen zentraler leerer Signifikanten der politischen Schweiz. Die universellen Identifikationsbegriffe ,Schweiz', ,Sonderfall', ,Demokratie“ oder ,Freiheit‘, welche die neue SVP im Laufe der 1990er Jahre usurpieren sollte, werden noch nicht systematisch besprochen.

Um die Zürcher SVP als legitime Nachfolgerin und programmatische Erneuererin der BGB Geltung zu verschaffen, kam es zunächst darauf an, die sedimentierten Identifikationsbegriffe der Partei ,Mitte', ,Mittelstand“ und ,werktätig‘ mit der neoliberalen Reformagenda zu verschmelzen. Hier konnte die Zürcher SVP erste Erfolge verbuchen. Der Zürcher Weg hatte sich als Alternative zum maßvollen Klientelismus und dem sozialliberalen Modernisierungsbestrebungen der Berner Sektion etabliert. Die neuen Kantonssektionen, die ab Ende der 1980er in der Deutschschweiz gegründet wurden, orientierten sich weit stärker am radikalen Kurs der Zürcher als an der gemäßigten Politik der Berner Parteiführung. Auch sie verstanden sich nicht als ergänzende Klientelparteien, sondern als rechtskonservative Alternative. ${ }^{2}$ Die auf Bundesebene nach wie vor tonangebenden Bündner und Berner Kantonssektionen hielten jedoch an der sozialliberalen Reform der Parteiagenda fest. Und als die SVP bei den Nationalratswahlen

2 Vgl. Rinderknecht 1993: 342. 
von 1987 zwei zusätzliche Parlamentssitze gewann, wurde dieser Erfolg auf die sozialliberale Öffnungspolitik ihres Präsidenten Adolf Ogi zurückgeführt. ${ }^{3}$

Außerhalb des Kantons Zürich schlug die programmatische Neuprofilierung der Zürcher SVP keine hohen Wellen. Die Radikalisierung in Zürich hatte kaum Auswirkungen auf das nationale Parteiensystem. Denn auf Bundesebene handelte die Partei nach wie vor als kooperativer Partner der beiden großen bürgerlichen Parteien. So konnten die populistischen Tendenzen in der Kantonssektion nach wie vor als „Einsprengsel in das Konkordanzsystem“ ${ }^{4}$ marginalisiert werden, zumal die von Blocher vorangetriebene wirtschaftsfreundliche Profilierung den Zürcher Flügel zum verlässlichen Komplizen der dominanten FDP machte. Das landesweite Image der Partei, ,anständig, bieder, behäbig, traditionell und langweilig“5 ${ }^{6 \mathrm{zu}}$ sein, hatte sich trotz der populistischen Tendenzen in der Zürcher Kantonssektion kaum gewandelt.

Die Wahrnehmung der Partei sollte sich im Verlauf der 1990er Jahre in grundlegender Weise ändern. Die Zürcher SVP avancierte zur stärksten Partei des Kantons und übertraf dabei die Ergebnisse der traditionell starken Bündner und Berner SVP-Sektionen. Durch ihre Wahlerfolge geriet die moderate Parteiführung um den Berner Bundespräsidenten Adolf Ogi immer stärker unter Druck. Mitte der 1990er Jahre verfolgten lediglich die machtvollen Sektionen der Kantone Graubünden, Bern, Glarus und Waadt weiterhin einen liberaldemokratischen Zentrumskurs. Die neugegründeten Kantonssektionen in der Ostschweiz und in den katholischen, ehemals CVP geprägten innerschweizerischen Kantonen schlossen sich der von Blocher vorgegebenen Richtung an.

Zeitgleich etablierte sich die ehemalige Klientelpartei als nationale Partei. Die SVP expandierte zunächst in die katholische Zentralschweiz und schließlich - wenngleich mit geringeren Zuwachsraten - auch in die Romandie. Sie steigerte ihren Stimmenanteil von 11,9 Prozent im Jahr 1991 sukzessive auf 28,9 Prozent im Jahr 2007. Obwohl sie an den Wahlen von 2011 mehr als zwei Prozent einbüßte, konnte sie sich mit 26,6 Prozent erneut als deutlich stärkste politische Kraft behaupten. Zeitgleich musste insbesondere das gemäßigte bürgerliche Lager Einbußen hinnehmen, wohingegen sich die SP trotz der neuen Konkurrenz der ökologischen Parteien bei etwa 20 Prozent halten konnte. Im internationalen Vergleich mögen diese Machtverschiebungen und die Zugewinne der SVP nicht außergewöhnlich erscheinen, vor dem Hintergrund der außerordentlichen Stabilität des Schweizer Parteiensystems und der konkordanzdemokratischen politi-

3 Buomberger 2004: 206.

4 Armingeon 1996: 72.

5 Buomberger 2004: 206. 
schen Kultur lässt sich die politische Karriere der Partei jedoch durchaus als „fulminant ${ }^{\text {“6 }}$ bezeichnen.

Dieser Aufstieg soll im Folgenden nicht auf demoskopische Bedingungsfaktoren zurückgeführt werden, sondern diskursanalytisch begründet werden. ${ }^{7} \mathrm{Da}-$ mit wird keineswegs negiert, dass sich ein spezifisches sozialstrukturelles Profil der SVP-Wählerschaft zeichnen lässt. ${ }^{8}$ Zurückgewiesen wird lediglich, dass die Erfolgsbedingungen einer rechtspopulistischen Partei mit dem Vorhandensein bestimmter sozialstrukturell definierter Gruppen gleichgesetzt werden können. Bedingung für den Erfolg sind nicht spezifische Eigenschaften als solche, sondern die semantische Transformation, die diese Differenzen erfahren, indem sie gemeinsam gegen ein antagonistisches Außen artikuliert werden und zu Elementen eines ,unterdrückten Volkes' werden. Untersucht werden soll daher, wie der SVP-Populismus eine populare Wir-Gruppe performativ konstituiert, die sich mit der partikularen politischen Programmatik, den Zielen und Strategien der Partei identifiziert.

Wie im Methodenkapitel angekündigt, lanciere ich hierzu Tiefenbohrungen um vier bedeutsame historische Ereignisse: (1) die Volksabstimmung über den Beitritt zur Europäischen Union im Jahr 1992, (2) die Nationalratswahlen von 1999, (3) die Abwahl Christoph Blochers als Nationalrat 2007 und (4) die Minarett-Initiative, die 2007 auf den Weg gebracht und 2009 zur Abstimmung kam. Dabei geht es zunächst jeweils darum, die Ereignisse als Dislokationen des konkordanzdemokratisch-korporatistischen hegemonialen Imaginären zu rekonstruieren. Sodann soll die Analyse zeigen, wie der SVP-Populismus konkrete Fragen und Entscheidungen einer umfassenden binären Wir-Sie-Matrix einverleibt, die quer zum tradierten Selbstverständnis der politischen Schweiz steht.

6 Kriesi u.a. 2005b: vii.

7 Für eine demoskopische und sozialstrukturelle Analyse der SVP-Wählerschaft vgl. Kriesi u.a. 2005a.

8 Gemäß den Ergebnissen der demoskopischen Wahlstudie SELECTS haben vor allem Bauern, Erwerbstätige in traditionellen Berufen und ungelernte Arbeiter eine höhere Wahlwahrscheinlichkeit für die SVP als etwa Manager oder gar soziokulturelle Spezialisten (vgl. Lachat/Selb 2005: 57). 


\section{Der populare Bruch: Der Konflikt um die europäische Integration und die Konstruktion eines nationalpopularen Neoliberalismus}

Im Kontext der EWR-Abstimmung gelang es der Zürcher SVP, universelle Identifikationsbegriffe der politischen Schweiz wie Sonderfall, Demokratie und Föderalismus mit partikularen Leitbegriffen des eigenen politischen Programms wie Selbstverantwortung, Sicherheit, Arbeit und Wettbewerb zu verknüpfen. Dabei gründen die äquivalenzlogische Artikulation dieser Differenzen zu einem ,wahrhaft schweizerischen Wir' und die Usurpation des hegemonialen Imaginären der politischen Schweiz auf der synchronen Konstruktion eines Antagonismus gegenüber der EG und ihren Befürwortern. Um diesen Prozess zu rekonstruieren, präsentiere ich die EWR-Abstimmung zunächst als dislozierendes Ereignis des konkordanzdemokratischen Imaginären (5.1). Nach einem Einschub zur allgemeinen Bedeutung der Albisgüetli-Tagung (5.2) analysiere ich anhand von Blochers Albisgüetli-Rede von 1992, wie der SVP-Populismus die Europapolitik mit anderen Politikfeldern verband und das hegemoniale Imaginäre der politischen Schweiz zu transformieren beginnt (5.3). Sodann werde ich die Artikulationen der Rede mit der Europa-Kritik des nationalkonservativen Lagers unterfüttern (5.4), um schließlich die Persistenz der EU im SVP-Populismus hegemonietheoretisch zu erklären (5.5). 


\subsection{Das NeIn zUM EUROPÄISCHEN WiRTSChAfTRAUM. URSACHEN UND FOLGEN DER VOLKSABSTIMMUNG VOM 6. DEZEMBER 1992}

\section{A) Das Ereignis}

Am 17. Januar 1989 stellte der damalige Präsident der Europäischen Kommission Jacques Delors den EFTA-Staaten mit dem Europäischen Wirtschaftsraum (EWR) eine spezifische Form der Anbindung an die Europäische Wirtschaftsgemeinschaft in Aussicht. ${ }^{1}$ Portugal, Österreich, Dänemark, Norwegen, Schweden, Island, Finnland, Großbritannien und die Schweiz sollten am gemeinsamen Binnenmarkt teilhaben, ohne jedoch formell Mitglieder der Gemeinschaft zu werden und über ihre zukünftige Form mitentscheiden zu können. Im Zentrum des Vertrages steht die Nichtdiskriminierung anderer Staatsangehöriger, die durch die vier ökonomischen Grundfreiheiten (freien Warenverkehr, freien Personenverkehr, freien Dienstleistungsverkehr und freien Kapitalverkehr) verwirklicht werden sollte. Ferner sieht der EWR eine Vertiefung der Zusammenarbeit im Bildungswesen und einheitliche Regelungen in der Sozialpolitik und im Umweltschutz vor. $^{2}$

Nach dem Zusammenbruch des Ostblocks zeichnete sich eine Vertiefung und Erweiterung der Europäischen Gemeinschaft (EG) ab. Während die EFTA einen Großteil ihrer Mitglieder verlor, war die EG im Begriff, der Hegemon in Europa zu werden. ${ }^{3}$ Vor diesem Hintergrund war der Bundesrat davon überzeugt, dass die Schweiz mit der traditionell zurückhaltenden Integrationspolitik brechen müsse. Angesichts der zunehmenden wirtschaftlichen Verflechtung sei der etablierte sektorielle Bilateralismus nicht mehr zielführend. ${ }^{4}$ Zudem sprachen nicht nur strategische Gründe für die EG, auch der Zeitgeist war auf der Seite der europäischen Integration: Europa bot den langersehnten Ausweg aus dem vielzitierten „Unbehagen im Kleinstaat“" ${ }^{* 5}$, dem von Karl Schmid diagnostizierten Komplex, der die Schweizer Linksintellektuellen in den 1960er und 70er Jahren nach Berlin emigrieren ließ, um der intellektuellen Provinzialität und der geistigen Enge ihrer Heimat zu entfliehen. Bürgerliche wie Linke erkannten in dem

1 Vgl. Linder 2010: 14ff.; Moser 2001: 78.

2 Vgl. Menzi 2010: 499.

3 Vgl. Moser 2001: 73 u. 82ff.

4 Vgl. ausführlich ebd.: 82ff.

5 Schmid 1978; sowie zum Topos der Enge vgl. Nizon 1990. 
,beispiellosen Friedensprojekt“ das Gegenmodell einer schweizerischen „Selbstbezogenheit" ${ }^{6}$. Sinngemäß lautete der politische Slogan der Befürworter der europäischen Integration ,Öffnung‘. Die Vorstellung der insularen Felsenbastion, die den Schweizer Exzeptionalismus während des Ost-West-Konfliktes geprägt hatte, schien in einer nunmehr befriedeten, vollends globalisierten Welt anachronistisch. $^{7}$ Aus Sicht der Europabefürworter war die Welt nicht mehr eine von ideologischen Konflikten zerrissene Umwelt, vor der sich der friedvolle, wohlgeordnete Kleinstaat schützen musste. Mit dem Bedeutungsverlust des realexistierenden Sozialismus schien der Sonderfall hinfällig. Der Neutralismus, der über mehrere Jahrzehnte die Schweizer Außenpolitik bestimmte, sollte einem hoffnungsvollen Kosmopolitismus Platz machen. Die Rede vom ,Sonderfall Schweiz' war den Europa-Befürwortern ein Dorn im Auge und der damalige sozialdemokratische Außenminister René Felber belegte den Begriff Anfang der 1990er sogar mit einem Tabu, als er gegenüber seinem Mitarbeiterstab erklärte: „Le mot ,Sonderfall“ - je ne veux plus l'entendre“"8.

Im Winter 1992, als die Mitgliedstaaten der EG durch die Unterzeichnung des Vertrages von Maastricht die europäische Integration weiter vorantrieben, akzeptierte die Schweizer Regierung nach schwierigen Verhandlungen über das Mitbestimmungsrecht der EFTA-Staaten Delors' Initiative. ${ }^{9}$ Im Kontext der drohenden Rezession gewichtete man die Chancen des gemeinsamen Binnenmarktes stärker als das fehlende Mitbestimmungsrecht beim sogenannten Acquis Communautaire, des noch genauer zu bestimmenden Teilumfanges EG-internen Rechtes, das die Mitgliedstaaten des EWR zu übernehmen hätten. Insbesondere der Freisinn, die erste staatstragende Kraft, und die machtvollen Wirtschaftsverbände erhofften sich von den Liberalisierungs- und Deregulierungsmaßnahmen des Vertrages einen Reformschub für der kriselnden Schweizer Wirtschaft, den man im Inland gegen den Widerstand von SP und CVP nicht hatte durchsetzen können.

Sowohl der Nationalrat als auch der Ständerat folgten der Regierung und verabschiedeten den Vertrag mit deutlichen Mehrheiten. ${ }^{10}$ Als einzige der vier regierungstragenden Fraktionen stellte sich die SVP nach langwierigen parteiinternen Auseinandersetzungen gegen den Bundesrat. So unterzeichnete der

6 Guggenbühl 1998: 45.

7 Vgl. Rehberg 2007: 65.

8 Felber 1992, zit. nach: Widmer 2008: 13.

9 Vgl. Linder 2010: 15f. Für eine chronologische Rekonstruktion der Vorverhandlungen vgl. Huth-Spiess 1996: 108ff. sowie Moser 2001.

10 Vgl. Menzi 2010: 499f. 
Vorsitzende des eidgenössischen Volkswirtschaftsdepartements Jean-Pascal Delamuraz am 2. Mai 1992 stellvertretend für den Bundesrat den Vertrag. ${ }^{11}$ Mit der Unterschrift des Bundesrates war der EWR-Beitritt jedoch nicht besiegelt, da die Schweizer Verfassung die Entscheidung über den Beitritt zu einer supranationalen Gemeinschaft einem obligatorischen Referendum unterwirft. Die Chancen, dass Volk und Stände Regierung und Parlament folgen würden, standen im Frühjahr aber gut.

Die Stimmungslage änderte sich am 18. Mai, als der Bundesrat mit vier zu drei Stimmen beschloss, ein Gesuch um die Aufnahme von EG-Beitrittsverhandlungen zu stellen. ${ }^{12}$ Dieser Entschluss war folgenreich. Er spaltete die Anhänger des EWR: Den einen galt der Vertrag als bloße Vorstufe zur EGVollmitgliedschaft, welche die fehlenden Mitbestimmungsrechte kompensieren würde. Die anderen befürworteten den EWR-Beitritt, scheuten aber die Vollmitgliedschaft, weil sie fürchteten, dafür keine Mehrheit im Volk zu finden. ${ }^{13}$ Die strategischen Gegner der EG-Vollmitgliedschaft mahnten, dass das isolationistische Selbstverständnis des neutralen, unabhängigen Sonderfalls das bundesrätliche Ziel der europäischen Integration konterkarieren würde. Die Befürworter dagegen knüpften an das nationale Selbstverständnis als aufgeklärte Musterrepublik an und stellten in Aussicht, die EG nach dem Vorbild des föderalistischen Bundesstaates von Innen erneuern zu können.

Danach begann die eigentliche Abstimmungskampagne. ${ }^{14}$ Für die Annahme des Bundesratsbeschlusses warben neben der Regierung und den drei großen Parteien auch andere deutungsmächtige Akteure. Die führenden Tageszeitungen, der staatliche Rundfunk und die großen Wirtschafts- und Gewerkschaftsverbände politisierten mehr oder weniger offen für die europäische Integration. Im Vordergrund standen zunächst wirtschaftliche Motive. Nur mit dem EWR sei die Schweiz in der Lage, sich von der schwachen Konjunktur der frühen 1990er Jah-

11 Vgl. Linder 2010: 16.

12 Ernst 2012.

13 Vgl. Linder 2010: 16. Vielen Befürwortern des EWR-Beitritts gilt der 18.5.1992 deswegen noch heute als folgenschwerer taktischer Fehler (vgl. exemplarisch Ernst 2012 sowie Bütler 2002: 837).

14 Für eine ausführliche Prozessanalyse des Abstimmungskampfes vgl. Huth-Spiess 1996. Die Politologin macht insbesondere die unzureichende Politikvermittlung des Bundesrates für das spätere Scheitern des Vertrages verantwortlich. Ähnlich argumentiert bereits Goetschel 1994. 
re zu erholen, und ohne den EWR drohten Isolation, Stagnation und Arbeitslosigkeit, mahnte beispielsweise der Bundesrat in einer Informationsbroschüre. ${ }^{15}$

Während die drei anderen Bundesratsparteien sich darüber verständigen konnten, nach außen geschlossen für den EWR zu politisieren, sorgte die EWRFrage bei der SVP für eine heftige Kontroverse. ${ }^{16}$ Das Parteiprogramm von 1991 hatte in der Frage der europäischen Integration einen relativ großen Interpretationsspielraum gelassen, da die Delegierten in der Außenpolitik gegenüber der EG weit auseinanderlagen. ${ }^{17}$ Die liberale Berner und Bündner Führungsriege der SVP Schweiz, die Junge SVP und allen voran der SVP-Bundesrat Adolf Ogi befürworteten den Beitritt zum EWR. Entgegen der Skepsis vieler Parteimitglieder setzte diese Faktion durch, dass sich die SVP in der Populärfassung des Parteiprogramms festlegte, gegen ,eine zentralistische und undemokratische EG ohne Mitbestimmung der Staaten und Regionen“, gegen „die Aufgabe der Selbstbestimmung und der Volksrechte zugunsten Europas und gegen „den Beitritt der Schweiz zur heutigen EG“, aber „für die Beteiligung der Schweiz an einem Europäischen Wirtschaftsraum" einzutreten. ${ }^{18}$

Gegen diese Entscheidung politisierte hauptsächlich die SVP-Zürich. Unterstützung erfuhr sie von Seiten der neugegründeten deutschschweizerischen Kantonssektionen und der Aktion für eine unabhängige und neutrale Schweiz (AUNS), die 1986, im Vorfeld der Abstimmung über den UNO-Beitritt von Christoph Blocher, Otto Fischer (FDP) und anderen namhaften Konservativen als überparteiliche Organisation gegründet worden war und den UNI-Beitritt tatsächlich verhindern konnte. Als Präsident der SVP-Zürich und der AUNS avancierte Blocher früh zum Wortführer der EWR-Gegner. Er finanzierte Zeitungsinserate, publizierte beinahe in jeder Ausgabe der nationalkonservativen Wochenzeitung Schweizerzeit, tourte über mehrere Monate durch das Land und stand beinahe täglich am Rednerpult und setzte sich im parteiinternen Duell gegen Ogi schließlich durch. Auf dem anberaumten Parteitag sprach sich eine deutliche Mehrheit gegen den Vertrag aus. Wenngleich die Kantonssektionen Waadt und

15 Vgl. dazu die Erläuterungen des Bundesrates zur Volksabstimmung vom 6. Dezember (Bundesrat 1992).

16 Neben der SVP stand insbesondere die SP nicht vorbehaltlos hinter dem Vertrag. Viele SP-Parlamentarier/innen warnten vor Lohndumping und einem etwaigen Anstieg der Mieten (vgl. Menzi 2010: 499). Doch hofften viele, eine spätere EG-Vollmitgliedschaft würde dies mittelfristig wettmachen.

17 Vgl. Rinderknecht 1993: 343.

18 Vgl. zudem: SVP-Parteiprogramm für die eidgenössische Legislaturperiode 19911994 (Populärfassung). 
Bern trotzdem für ein Ja mobilisierten, war die SVP damit die einzige bedeutende politische Kraft, die gegen den EWR politisierte.

Nachdem sich in Umfragen abzeichnete, dass der EWR vom Volk angenommen werden würde, konnten die Gegner die Abstimmung doch noch für sich entscheiden. Bei einer Wahlbeteiligung von über 78 Prozent stimmten am 6. Dezember 1992 50,3 Prozent der Stimmbürger/innen gegen den Beitritt. In 16 der 23 Kantone lag die Mehrheit bei den Gegnern des Vertrages. Die Vertragsunterzeichnung und das Parlamentsmehr waren hinfällig. Zwar hatten die welschen Kantone, wie erwartet, geschlossen zugestimmt, doch sprachen sich die deutschsprachigen und insbesondere die ostschweizerischen Kantone mit zum Teil deutlichen Mehrheiten gegen den EWR aus.

Obwohl das Abstimmungsergebnis unterschiedliche Konfliktlinien widerspiegelte, ${ }^{19}$ deuteten die Medien die Stimmverteilung primär als Ausdruck des sogenannten ,Röstigrabens', der Mentalitätsunterschiede zwischen einer isolationistischen Deutschschweiz und einer weltoffenen Romandie. ${ }^{20}$ Der FDPBundesrat Jean-Pascal Delamuraz warnte am Tag nach der verlorengegangenen Abstimmung gar vor einer Spaltung von Welschen und Deutschschweizern. Sein Urteil, der Abstimmungssonntag sei ein „schwarzer Sonntag“ gewesen, prägte das Medienecho der folgenden Tage. ${ }^{21}$

\section{B) Die EWR-Abstimmung als dislozierendes Ereignis und als Geburtsstunde des SVP-Populismus}

Die Tragweite und die Sprengkraft der Abstimmung waren unstrittig. Das Nein zum EWR brach mit dem außenpolitischen Kurs der schrittweisen Integration in

19 Vgl. Kriesi u.a. 1993: 3. Sie unterscheiden fünf Konfliktlinien, die die Entscheidung pro oder kontra EWR beeinflusst hätten: „die populistische (die zwischen den misstrauischen Bürgern und jenen, verläuft, welche dem Bundesrat vertrauen), die sprachliche, den Stadt/Land-Gegensatz, den Gegensatz aufgrund des Ausbildungsstandes und den Rechts/Links-Gegensatz" (ebd.).

20 Das gilt insbesondere für die französischsprachige Presse.

21 „Ce clivage n'est pas fait sur une question accessoire. C'est notre destin qui se joue. Avec des majorités aussi nettes, tant d'un côté que de l'autre, je vois noir pour notre avenir.“ In der deutschen Übersetzung: „Dieser Bruch betrifft nicht eine nebensächliche Frage. Unser Schicksal steht auf dem Spiel. Angesichts so deutlicher Mehrheiten auf der einen wie auf der anderen Seite sehe ich schwarz für unsere Zukunft.“ (Delamuraz, zit. in: [o.A.] 24 heures, 7.12.1992). 
internationale Organisationen, den die Regierung nach dem Fall des Eisernen Vorhangs einschlagen wollte. Aus Sicht der Wirtschaftsverbände gefährdete das Abstimmungsergebnis die Prosperität einer nunmehr isolierten Schweizer Volkswirtschaft, zumal die ökonomische Globalisierung die politischen Gestaltungsmöglichkeiten gerade des Kleinstaates aushöhle und daher transnationale Regierungsformen erfordere. ${ }^{22}$ Schließlich bedeutete die Absage an die europäische Integration eine Wiedergeburt des nationalen Selbstbildes als inselartige Alpenfestung. So sind es mindestens vier Aspekte, die den Volksentscheid zu einem dislozierenden Ereignis machen:

(1) Das Duell, aus dem Blocher \& Co als Sieger hervorgingen, glich einem David-gegen-Goliath-Szenario. Die machtvollen Deutungseliten (die drei stärksten Parteien, der Bundesrat, die wichtigsten Arbeitgeber- und Arbeitnehmerverbände, die Landeskirchen und die Leitmedien) hatten sich im Vorfeld der Abstimmung geschlossen für den Beitritt eingesetzt. Das Nein zum EWR stellte insofern die Responsivität des politischen Systems in Frage. Es bot Blocher, der AUNS und der Zürcher-SVP die Chance, sich zur Avantgarde einer vielfältigen oppositionellen Bewegung emporzustilisieren, die sich zu Beginn der Kampagne auf verlorenem Posten wähnte, in der Zukunft aber den Willen einer politisch entfremdeten Mehrheit zum Ausdruck bringen sollte.

(2) Die EWR-Abstimmung stellte die SVP vor eine erneute Zerreißprobe und wiederum hießen die Pole Zürich und Bern bzw. Christoph Blocher und Adolf Ogi. Der Berner SVP-Bundesrat war einer der Bundesräte, die den EWR als Vorstufe zur Vollmitgliedschaft wahrnahmen und sich für die Aufnahme von Beitrittsverhandlungen einsetzten. ${ }^{23}$ Da Blocher in der Europa-Frage im Unterschied zu wirtschaftspolitischen Fragen innerhalb der SVP nicht nur die Zürcher Kantonalsektion hinter sich wusste, sondern auch auf die mehrheitliche Unterstützung der SVP Schweiz zählen konnte, diente der Widerstand gegen die europäische Integration der Schweiz als festes Standbein in der parteiinternen Auseinandersetzung um die zukünftige politische Ausrichtung der Partei.

22 Vgl. Bütler 2002: insb. 830ff.

23 Sein offenes Engagement für die Aufnahme von Beitrittsverhandlungen mit Brüssel entpuppte sich als strategisch verhängnisvoll. Seine Rede vom „Trainingslager EWR“ wurde von den Gegnern des Vertrages aufgegriffen und avancierte bald zum geflügelten Wort (vgl. etwa Ernst 2012). 
(3) Die EWR-Abstimmung stellte nicht nur die Weichen für den Sieg der Zürcher im innerparteilichen Flügelkampf. Blocher hatte bereits Anfang der 1990er Jahre angesichts der Entwicklungen in der Drogen, Asyl- und Verteidigungspolitik zwischen einer, orientierungslosen, kranken Classe politique', ihren ,Helfershelfern in den Schulen und Universitäten' und ihren ,verwahrlosten Klienten' auf der einen und einem ,gesunden Volk und der führungsstarken, beispielgebenden Zürcher SVP' auf der anderen Seite unterschieden. ${ }^{24}$ Die EWR-Frage bot Gelegenheit diese überdeterminierte Konfliktkonstellation zwischen einem ,starken, charakterfesten Wir ${ }^{6}$ und einem ,richtungslosen, schwachen Sie`zu konsolidieren und zu intensivieren. Denn im Unterschied zum Konflikt mit ,dem Kommunismus', dem realexistierenden Sozialismus und einer ihm insgeheim nacheifernden schweizerischen Linken, als dem identitätsstiftenden Antagonismus der bürgerlichen Allianz hatte die SVP in der Europapolitik das Monopol auf die Kritik des ,unschweizerischen Gebildes'. Da auch die anderen beiden bürgerlichen Parteien, die europäische Integration favorisierten, bot die Europafrage Gelegenheit, die Naht zwischen der Nationalgeschichte und der oppositionellen Neuausrichtung der Zürcher SVP zu schließen und die Gründungsmythen der Schweiz und den Sonderfallgedanken zu resignifizieren. So führte der EWR-Abstimmungskampf zu einem „renversement des alliances, einer Umkehrung der Allianzen“'25: Der sozialdemokratische Tages-Anzeiger und die freisinnige Neue Zürcher Zeitung stimmten darin überein, dass man dieselben, verstockten Nein-Sager' vor sich selbst beschützen müsse; die SP unter ihrem kapitalismuskritischen Präsidenten Peter Bodenmann und die Economiesuisse verbündeten sich; letztere distanzierte sich vom Gewerbe und der Landwirtschaft. ${ }^{26}$ Die neue Konfliktlinie verlief zwischen Öffnung und Schließung. Sie brachte die Konfliktlinien zwischen Romandie und Deutschschweiz und zwischen Stadt und Land auf einen Nenner. Der neue fundamentale Antagonismus überprägte jenen zwischen Arbeit und Kapital und zwischen Katholizismus und Protestantismus und wirbelte die zugehörigen Partei-Wähler-Bindungen durcheinander. Die Folge war eine Sprengung des bürgerlichen Lagers und eine dichotomische Restrukturierung der politischen Schweiz, die quer zur tradierten, gemäßigt pluralistischen Selbstbeschreibung der konkordanzdemokratischen Schweiz stand.

24 Blocher 1991.

25 Somm 2009: 293.

26 Vgl. Somm 2009: 313. 
(4) Da der Bundesrat und die anderen beiden bürgerlichen Regierungsparteien trotz der Niederlage vom 6. Dezember 1992 bis etwa 2002 am Ziel der Europäischen Integration der Schweiz festhielten, verlor die Europapolitik auch in den folgenden Jahren nicht an Aktualität und avancierte zum privilegierten Politikfeld des SVP-Populismus. Retrospektiv kann die EWRAbstimmung daher tatsächlich als das Schlüsselereignis der politischen Schweiz begriffen werden, zu dem sie sowohl die Gegner als auch die Befürworter der europäischen Integration stilisiert hatten. Daher überrascht es auch nicht, wenn Blocher \& Co den 6. Dezember 1992 als politisches Erweckungserlebnis eines marginalisierten Volkes darstellen. ${ }^{27}$

\section{C) Die Ursache des Scheiterns des EWR-Vertrages: Die diskursive Universalisierungsleistung der Zürcher SVP}

Aus Sicht der Wahlanalysten Hanspeter Kriesi, Claude Longchamp, Florence Passy und Pascal Sciarini ist das Scheitern der Vorlage des Bundesrates im Wesentlichen darauf zurückzuführen, dass es den Gegnern gelungen sei, die Abstimmung als ideologische Grundsatzentscheidung darzustellen, welche die begrenzte Sachfrage nach der ökonomischen Integration in den gemeinsamen Europäischen Binnenmarkt transzendiert. ${ }^{28}$ Sowohl bei den Befürwortern als auch bei den Gegnern hätten am Ende nicht „die kalte und rationale Auswertung der Kosten und Gewinne des EWR den Ausschlag gegeben“"29. Vielmehr seien „,sich am 6. Dezember [...] zwei Vorstellungen über die Schweiz und ihre Zukunft gegenüber[ge]standen““30. Die Niederlage der Befürworter des EWR sei der Tatsache geschuldet, dass sie die Kompatibilität der europäischen Integration mit dem Selbstverständnis der Schweiz nicht plausibilisieren konnten, während die SVP und die AUNS mit Argumenten aufgewartet hätten, die ,tief verwurzelten Überzeugungen und Werten der SchweizerInnen entsprochen haben“31, so das Fazit der Politologen. Demnach lag der Schlüssel für den Erfolg von Blocher \& Co in der diskursiven Strategie, die Diskussion vom konkreten „Inhalt der Vorlage“ auf die universellere „Bedeutung der Abstimmung“ zu verlagern. ${ }^{32}$

27 Vgl. Blocher 2004: 8.

28 Kriesi u.a. $1993: 4$ f.

29 Ebd.: 4.

30 Ebd.

31 Ebd.: 4f.

32 Ebd.: 4. 
Vor dem Hintergrund dieser Analyse stellt sich die Frage, wie sich eine partikulare außen- und wirtschaftspolitische Differenz in eine politikfeldübergreifende Wir-Sie-Unterscheidung transformieren konnte. Des Weiteren gilt es zu rekonstruieren, wie die im Rahmen der EWR-Abstimmung geschmiedete Konfliktlinie zwischen ,Öffnung und Schließung ‘ zur prägenden Konfliktlinie der politischen Schweiz avancierte ${ }^{33}$ und wie ausgehend vom 6. Dezember 1992 das „politische Momentum“34 erzeugt wurde, das der Zürcher SVP und Blocher zum Durchbruch verhalf. Mit anderen Worten: Folgt man der Diagnose, dass der EWR nicht aufgrund partikularer Vertragsdetails und individueller Interessenkalküle, sondern in erster Linie aufgrund seiner allgemeinen Bedeutung abgelehnt wurde, so müssen die diskursiven Strategien ausfindig gemacht werden, die diese Universalisierungsleistung vollziehen. Es gilt zu analysieren, wie der von der Zürcher SVP propagierte „Gegensatz zwischen den Vertretern einer offenen, kulturell liberalen Schweiz und den Verteidigern der Schweizer Traditionen ${ }^{\text {‘35 }}$ zum grundlegenden politischen Konflikt avancieren konnte. Denn auf dieser Transformation gründet nicht nur das Scheitern des EWR und der europäischen Integration, sondern auch die Hegemonisierung des ,Sonderfalls Schweiz', dem die die ehemalige Klientelpartei ihren Aufstieg zur stärksten politischen Kraft verdankt.

\section{D) Die Folgen der EWR-Abstimmung: Die politische Polarisierung der Schweiz}

Wohingegen die drei großen Regierungsparteien mehr oder minder geschlossen für den EWR-Vertrag politisierten, war die SVP in der EWR-Frage gespalten. Obwohl sich die Partei im Frühsommer auf ein Nein festgelegt hatte, unterstützte der liberale Berner Flügel weiterhin die Europapolitik des Bundesrates. Mit dem Streit über die Parolenfassung war eine Debatte über den Stellenwert des EWR verbunden. Als sich zeigte, dass der offensiv proeuropäische Kurs des SVP-

33 Zur Konfliktlinie zwischen Öffnung und Abgrenzung als der strukturierenden Konfliktlinie des Schweizer Parteiensystems vgl. Brunner/Sciarini 2002 u. Bornschier/ Helbing 2005: 32ff. Die Politologen begründen die Dominanz dieser Konfliktlinie jedoch nicht diskurstheoretisch, sondern führen sie auf eine vorpolitische Transformation von Werten sowie auf Einstellungen, Interessen und Zukunftserwartungen zurück, die sie bestimmten sozialen Schichten und Milieus zuordnen.

34 Altermatt 2013: 29.

35 Kriesi 2005: 5. 
Bundesrates Adolf Ogi innerhalb der Partei nicht mehrheitsfähig war, versuchten Vertreter des liberalen Flügels, die Bedeutung der anstehenden Abstimmung zu begrenzen. Eine Woche vor der Abstimmung argumentierte beispielsweise der Nationalratspräsident Hans-Rudolf Nebiker, dass im Fall eines Nein zum EWR deutlich weniger Handlungsoptionen blieben als bei einem positiven Votum, weswegen unentschlossene Bürger/innen sich vernünftigerweise zu einem Ja durchringen müssten. Der erfahrene SVP-Politiker stellte die EWR-Abstimmung als eine Abstimmung von vielen dar und warb für ein try-and-error-Verfahren in der Europapolitik. Sollte sich der EWR aus Schweizer Sicht nicht bewähren, könne der Vertrag jederzeit gekündigt werden, so sein zentrales Argument. ${ }^{36}$

Nebikers Plädoyer für ein pragmatisches try-and-error konnte kurz vor der Abstimmung jedoch nicht mehr überzeugen. Die gesellschaftlichen Schreckensszenarien, mit der Gegner und Befürworter für ihr Anliegen geworben hatten, machten die EWR-Abstimmung zur Grundsatzentscheidung. Im Verlauf der Abstimmungskampagne war der EWR weit mehr geworden als ein Freihandelsvertrag zwischen den EFTA-Staaten und der EG. Für die meisten Stimmbürger/innen entsprach die Entscheidung, pro oder contra EWR' einem umfassenden ideologischen Bekenntnis, einer qua politischer Überzeugung entschiedenen Positionierung auf einem polar strukturierten politischen Feld, auf den sich zwei antagonistische historische Blöcke gegenüberstanden: hier die proeuropäischen Schweizer Deutungseliten, dort die als underdog auftretende Zürcher SVP, die sich zur neuen Protagonistin eines transhistorischen nationalen Freiheits- und Unabhängigkeitskampfes stilisierte.

$\mathrm{Zu}$ dieser Polarisierung der Bevölkerung führte nicht nur die Deutung des EWR-Vertrages durch Blocher \& $\mathrm{Co}^{37}{ }^{37}$ sondern auch jene der entschiedenen Befürworter der europäischen Integration. Denn im proeuropäischen Diskurs findet sich wenngleich in spiegelverkehrter Fassung, dieselbe Universalisierung des EWR. Am Tag nach der Abstimmung deutete einer der Wortführer der europäischen Integration auf bürgerlicher Seite, der Freisinnige Peter Tschopp das Ergebnis als Ausdruck eines umfassenden Gegensatzes zwischen einem aufgeklärten und progressiven Lager und einem ideologisch verblendeten und reaktionären Lager. Diejenigen, „die in einer idealisierten Vergangenheit“ leben, hätten sich gegen diejenigen durchgesetzt, die „Sinn für gesellschaftlich relevante Entwicklungen" haben, räsonierte der Ökonom in der Basler Zeitung. ${ }^{38}$ Die vagen

36 Nebiker 1992.

37 Exemplarisch für die ,weittragende Bedeutung“, die Blocher der EWR-Entscheidung zusprach vgl. Blocher 1992b: 3.

38 Tschopp 1992. 
Inhalte und Forderungen, die sich hinter den überdeterminierten Platzhaltern „idealisierte Vergangenheit“ und „gesellschaftlich relevante Entwicklungen“ verbergen, entsprechen - wenngleich unter umgedrehten qualifizierenden Vorzeichen - dem binären Konfliktszenario, das Blocher, die Zürcher SVP und die AUNS im Rahmen der EWR-Abstimmung entworfen hatten. Es imaginiert einen unteilbaren Gegensatz zwischen einem liberalen, universalistischen Kosmopolitismus und einem kommunitaristischen, partikularistischen Ethnonationalismus, dessen Persistenz und Intensität zu einer Krise der operativen Paradigmen der Konkordanzdemokratie führen sollten. ${ }^{39}$

Der Volksentscheid über den EWR markierte den Grundstein für die Hegemonie der binären Ordnungsmatrix des SVP-Populismus, die zunächst das bürgerliche Lager in einen kulturell liberalen und einen nationalkonservativen Teil brach und im langen Nachhall der Abstimmung das gesamte Parteiensystem symbolisch spaltete. Im Rahmen des Widerstandes gegen EWR und EG war es dem Zürcher Flügel gelungen, unterschiedliche politische Positionen und Forderungen gegen die politische Klasse und ihre vermeintliche Klientel in Stellung zu bringen und unter seiner ideologischen Führung engzuführen.

39 An dieser Stelle ließe sich einwenden, dass jedem Volksentscheid eine binäre, dezisionistische und vereinfachende Logik innewohnt. Und in der Tat führt das Plebiszit ein konkurrenzdemokratisches Moment in das Schweizer Konkordanzsystem ein. Es zwingt die politischen Parteien zu einem klaren Bekenntnis und auch den Stimmberechtigten stellt es die Aufgabe, sich zwischen einem schlichten Ja und einem schlichten Nein zu entscheiden. In anderen Worten, das Plebiszit drängt die politische Gemeinschaft zur Entscheidung und unterwirft die öffentliche Deliberation und die parlamentarische Kompromissbildung der blanken Pro-Contra-Entscheidung. Jedoch wurde das polarisierende Momentum der Volksentscheidung in der jüngeren Geschichte der Schweiz von den Trägern des Konkordanzprinzips mittelfristig stets domestiziert. Obwohl das Schweizervolk über bedeutsame politische Fragen per Referendum entschied, gelang es der bürgerlichen Mitte, den offenen Dissens zwischen Mehrheit und Minderheit doch auf ein Politikfeld oder gar eine Sachfrage einzugrenzen, den Volkswillen zu beschwichtigen und eine Intensivierung des Gegensatzes zwischen Gegnern und Befürwortern abzuwenden. Die differenzlogisch komponierte Struktur des politischen Raumes blieb daher stets intakt; die operativen Paradigmen des gemäßigt pluralistischen politischen Systems waren nie gefährdet (Zur wirksamen Einhegung des spaltenden Moments der Volksabstimmung vgl. Kobach 1993). 


\subsection{Einschub: Die Albisgüetli-TAgung der ZÜRCHER SVP}

Ehe ich mich der Albisgüetli-Rede von 1992 zuwende, um zu zeigen, wie die Zürcher SVP diese hegemoniale Repräsentationsleistung vollbringt, möchte ich in einem kurzen Einschub die sinnstiftende Performanz der Institution ,Albisgüetli“ herausarbeiten. ${ }^{40}$ Die erste Albisgüetli-Tagung fand am 3. Februar 1989 statt. Seither lädt die Zürcher Sektion jedes Jahr im Hochwinter Mitglieder und Sympathisanten zu dem politischen Anlass. Die Albisgüetli-Tagung stieß von Beginn an auf hohes massenmediales Interesse und avancierte schnell zu einem publikumswirksamen Höhepunkt des politischen Jahres. Bis 2001 übertrug das erste Schweizer Fernsehen die Veranstaltung direkt und zur besten Sendezeit.

Das Protokoll sieht vor, dass zunächst Christoph Blocher spricht und im Anschluss ein geladener Bundesrat oder ein Spitzenpolitiker einer anderen Partei die Chance zur Gegenrede erhält. ${ }^{41}$ Dieses Format nobilitiert die Zürcher SVP als volksnahe, zutiefst demokratische Partei, die sich für eine faire politische Auseinandersetzung einsetzt; ${ }^{42}$ zugleich strukturiert das Protokoll die politische Debatte als binäre Auseinandersetzung zwischen einem Vertreter der Regierung und Blocher als dem Mann der Opposition.

Darüber hinaus ist der Veranstaltungsort interessant. Die Zürcher SVP tagt nicht etwa in einer modernen Mehrzweckhalle. Beim Albisgüetli handelt es sich um ein Schützenhaus und insofern um ein historisches Motiv von hohem identitätsstiftendem Gehalt. So stellt sich die Partei mit dem Tagungsort in die Tradition der schweizerischen Schützenfeste. Diese Feste bildeten zu Beginn des 19. Jahrhunderts zunächst einen „Knotenpunkt des liberal-radikalen Kommunikationsnetzes“ und spielten eine „wichtige Rolle im politischen Formierungsprozess" des nationalen Imaginären. ${ }^{43}$ In den 1830er und -40er Jahren dienten sie den progressiven, nationalistischen Kräften als Orte des Ideenaustausches. Libe-

40 Vgl. dazu Lukas Zollingers (2002 u. 2004: 46ff.) wissenssoziologisch informierte Analyse der Albisgüetli-Rede von 2000.

41 Bis 2001 waren Blochers Gegenredner stets Bundesräte. Danach wurde beschlossen, dass Bundesräte in Zukunft die Einladung ablehnen sollten. Es handle sich bloß um eine politische Veranstaltung einer Kantonalpartei, weswegen der Bundesrat keine Veranlassung sehe, teilzunehmen (Couchepin zit. in: Somm 2009: 314).

42 Blocher stellt diesen demokratisierenden Impetus der Albisgüetli-Tagung immer wieder aus. Vgl. exemplarisch Blocher 1998.

43 Tanner 2002: 185f.; vgl. auch Hettling 1998. 
rale und Radikale mobilisierten mit Reminiszenzen an die „parareligiöse [Tell]Mythologie“44, ,den Freiheitskampf, die Opferbereitschaft und die Bruderliebe der Väter“45 für ihren Kampf gegen die Jesuiten, den Ultramontanismus der katholischen Kirche und für die Überwindung der alten ständischen Hierarchien in den Kantonen, die der Einheit und Selbstbestimmung der Nation im Weg stünden. Mit den rhetorischen Rückgriffen auf die Gründungsmythen der Alten Eidgenossenschaft

„,stellten [sie] ihre politische Bewegung, ihren Kampf um die nationale Einigung nicht nur in eine Linie mit den ,Befreiungskriegen ' im Spätmittelalter, sondern sie rückten sich und ihre Taten in einer Art mythischen Synchronisierung von Vergangenheit und Gegenwart auch in den Dunstkreis zeitlosen heroischen Strebens. “46

In der ersten Hälfte des 19. Jahrhundert waren die protestantisch-liberal geprägten Schützenfeste noch gegen die katholisch-konservativen Feinde im Innern gerichtet. Nach der Gründung des Bundesstaates im Jahr 1848 machte der Antikatholizismus jedoch einem konsensualen Nationalismus Platz, der die ehemaligen Konfliktparteien integrierte.

„Lange vor der gleichsam offiziellen Versöhnung zwischen freisinniger und katholischer Schweiz am Ende des Jahrhunderts hatten die Schützenfeste ein Forum geschaffen, auf dem sich Radikale und Konservative, Freisinnige und Katholiken gemeinsam als Schweizer Männer im und beim Schiessen treffen und kennenlernen konnten.“47

Neben den historischen Topoi der Reden spielten insbesondere die Rituale der Schützenfeste eine herausragende Rolle für die nationale Vergemeinschaftung. Der Einzug und die Zusammenkunft der Schützen, der Fahnenkult, das hochregulierte Schiessverfahren, die Preisübergabe, das gemeinsame Essen und Singen, aber auch Alltagspraktiken wie der Handschlag und das vertrauliche ,Du' der Schützen ${ }^{48}$ bildeten ein Ensemble von rituellen Praktiken, anhand derer sich das sozial heterogene Teilnehmerfeld als Keimzelle eines neuen und doch historisch begründeten Bundes aus wehrhaften, freien, gleichen, treuen und mutigen Männern identifizieren konnte. Die Schützenfeste symbolisierten, die „innere Einheit

44 Zollinger 2002: 7.

45 Tanner 2002: 189.

46 Ebd.

47 Hettling 1998: 97.

48 Vgl. Zollinger 2002: 7. 
bei äusserer Vielartigkeit und Zerspaltung“, wie Jacob Burckhardt prägnant diagnostizierte. $^{49}$ Angesichts des gemeinsamen Schießens rückten ideologische, kantonale, ständische und konfessionelle Differenzen in den Hintergrund. ${ }^{50}$ „Traf man bei den Schützenfesten als Gruppe ein, verliess man sie im Zusammenschluss zur Nationalgemeinschaft ${ }^{\text {“51 }}$, einem Kollektiv, das die Pluralität seiner Mitglieder nicht suspendiert, sondern im gemeinsamen Kampf gegen fremde Großmächte politisch außer Kraft setzt.

Somit stellt das Arrangement der Albisgüetli-Tagung, die historische Aufladung des Ortes, die Neuinszenierung der Schützen-Symbolik mit gemeinsamem Abendessen, Blasmusik, Fahnen und Wappen, die Zürcher SVP und ihren Präsidenten in die Tradition des liberalen Schweizer Nationalismus ${ }^{52}$. Dessen zentrale Werte Gleichheit, Freiheit, Einheit, Wehrhaftigkeit, Mut und Treue wird Blocher in seinen Reden mit der politischen Agenda der SVP zu einem neukonservativen Block artikulieren.

\subsection{Die Albisgüetlirede von 1992}

In der Albisgüetli-Rede von 1992 polemisiert Blocher gegen Konkordanz und Korporatismus. Der Titel Anpassung und Widerstand ${ }^{53}$, der die Cleavage, Öffnung/Abgrenzung، im Diskurs der EWR-Befürworter aufgreift und variiert, nimmt die polarisierende Stoßrichtung der Rede vorweg. Dieses Deutungsschema, anhand dessen während des Zweiten Weltkrieges und vor allem in der Nachkriegszeit die mit Hitler-Deutschland sympathisierenden, anpasserischen Fröntler' von den ,widerständischen Schweizer Patrioten “ unterschieden wurden, desartikuliert die differenzlogisch komponierte politische Schweiz und begründet das oppositionelle Projekt der Zürcher SVP.

Blochers Argumentationsgang folgt der Struktur ,Exempel, These, Beleg, Fazit' und gibt somit Auskunft über die hegemoniale Funktionsweise der Rhetorik des SVP-Populismus. Blochers Rede oszilliert zwischen konkreten Missständen und partikularen Forderungen einerseits und einer universellen Krisendiagnostik andererseits. Diese Rhetorik verwebt das Singuläre mit dem Allgemeinen.

49 Burckhardt 2008: 492.

50 Vgl. Zollinger 2002: 8.

51 Zollinger 2002: 7.

52 Zum liberalen Schweizer Nationalismus vgl. Kohn 1956: 77.

53 Blocher 1992a. 
Dabei gründet die gemeinsame Artikulation der Forderungen und Missstände im Rahmen des politischen Projekts der Zürcher SVP auf dem Antagonismus gegenüber der als konformistisch und anpasserisch gebrandmarkten Konsenspolitik des politischen Establishments. Die Wir-Gruppe, die in diesem umfassenden Konfliktszenario geschmiedet wird, verfügt nicht etwa über einen gemeinsamen sozialstrukturellen Herkunftsort, sondern kann nur als antagonistisch konstruierte Einheit gedacht werden. Denn die äquivalentielle Verknüpfung der differenten Elemente basiert nicht auf einem tieferliegenden positiven Kern, sondern auf der Konstruktion eines antagonistischen Anderen, der sie allesamt blockiert.

Blocher beginnt, indem er die politischen Entscheidungen in der Asyl-, Sicherheits- und „vor allem“ ${ }^{\text {54 }}$ der Europapolitik als Ausdruck des Konformismus der politischen Klasse liest. Deren tieferliegende Ursache erkennt er wiederum in ihrer persönlichen Charakterschwäche:

„Im vergangenen 700. Jahr der Eidgenossenschaft ist kaum eine offizielle Rede zu Ende gegangen, in welcher nicht Bundesräte, Parlamentspräsidenten, National- und Ständeräte usw. betont hätten, die Schweiz sei kein Sonderfall mehr. Offenbar schämt man sich, etwas Besonderes zu sein. Woher kommt diese krampfhafte dauernde Beteuerung der Politiker, die Schweiz sei kein Sonderfall, könne so nicht mehr existieren? Klar steckt dahinter Schlimmeres als nur alberne Mode: Dahinter sind Unsicherheit, Schwäche auch, Unselbständigkeit, Minderwertigkeitsgefühl, aber vor allem auch die Unfähigkeit, die Probleme im eigenen Land zu lösen. [...] Letztlich - und dies muss mit aller Deutlichkeit festgehalten werden - ist es auch mangelnde Identifikation der führenden Politiker mit dem eigenen Land, dem eigenen Volk, der eigenen Aufgabe. Das geht sogar bis zur Verachtung dieses Landes, bis zur Verachtung des Volkes. “55

Blochers Kritik der politischen Klasse setzt mit dem Hinweis auf das 700. Jubiläum der Eidgenossenschaft ein. Ohne seinen eigenen politischen Standpunkt an dieser Stelle explizit zu machen, schafft der kurze Hinweis eine antagonistische Grenze: Wohingegen die Geschichtsvergessenheit der führenden Politiker/innen soweit reicht, dass sie selbst im Jubiläumsjahr dem Sonderfallgedanken abschwören, erscheint Blochers Position ex negativo als in einer historischen Kontinuität stehend. Darauf folgt eine Reihe von Disqualifikationen der politischen Führung, die den Konformismus der Eliten, die Abkehr vom Sonderfallgedanken ursächlich erklären sollen und Blocher im Umkehrschluss als Anwalt des ,Son-

54 Ebd.

55 Ebd. Die abundanten Kursivsetzungen werden hier und im Folgenden nicht berücksichtigt. 
derfalls‘ und als diametrales Gegenteil einer ,schamvollen, unsicheren, unselbständigen, schwachen und verachtungsvollen Classe politique‘ porträtieren.

Blocher hebt in erster Linie auf die gegensätzlichen Sekundärtugenden der Zürcher SVP und der politischen Klasse ab. Die politischen Positionen der Eliten werden nicht auf spezifische politische Überzeugung, sondern auf ihre allgemeine Charakterschwäche zurückgeführt, die sich in der ,mangelnde[n] Identifikation mit dem eigenen Land, dem eigenen Volk und der eigenen Aufgabe“ ausdrücke und in der „Verachtung“ gegenüber „Land“ und „Volk“ kulminiere. ${ }^{56}$ Diese Klimax spitzt die Kritik des politischen Establishments skandalisierend zu, versinnbildlicht dergestalt die Intensivierung des politischen Konflikts und plausibilisiert die Unüberbrückbarkeit der Differenzen zwischen uns und ihnen. Die inhaltlich überdeterminierten Topoi der Orientierungslosigkeit und der Führungsschwäche stellen so unterschiedliche Gruppen wie Wirtschaftsfunktionäre, Gewerkschaften, Christdemokraten, Freisinnigen und Sozialdemokraten als Elemente eines umfassenden Bedrohungskomplexes vor. Dieses antagonistische Lager wird gleichzeitig mit Begriffen ,Scham' und ,Verachtung' semantisch affiziert. Für Empörung sorgen nicht etwa die falschen politischen Identifikationen der anderen Politiker/innen, sondern der von Impartialität und Konformismus geprägte konkordanzdemokratische Habitus, der als charakterbedingte Unfähigkeit zur politischen Identifikation dargestellt wird.

Folgelogisch erhebt Blocher den Gegensatz von ,Anpassung und Widerstand“ zur zukünftigen „Grundfrage unserer politischen Auseinandersetzung““57 und dekliniert unterschiedliche Politikfelder anhand dieses Deutungsschemas. Damit reduziert er die mannigfaltigen politischen Differenzen der pluralistischen Schweiz auf einen übergreifenden respektive basalen Konflikt zwischen zwei verfeindeten Lagern. Gegenüber stehen sich nicht Nationalkonservative, Liberalkonservative, Marktliberale, Sozialkonservative, Sozialdemokraten, Grüne und Sozialisten, sondern lediglich zwei antagonistische Blöcke: Die widerständische Wir-Gruppe, deren Identität Blocher bis hierhin nicht näher bestimmt, sondern lediglich als bedrohte Entität umrissen hat, trifft auf ,,akademisch getarnte“, „schablonenhafte, stromlinienförmige und anpassungswillige Repräsentationsfiguren“, die Politik, Wissenschaft und Wirtschaft kolonisierten. ${ }^{58}$

Die Vagheit der antagonistisch gruppierten Blöcke geht hier nicht zufällig mit der affektiven Steigerung des Gegensatzes einher. Denn die relative Leere der Begriffe, mit denen sich das ,Wir' bezeichnet, ist die Bedingung für die Ex-

56 Ebd.

57 Ebd.

58 Ebd. 
pansion der Äquivalenz und je weitreichender diese Expansion, desto umfassender und existenzieller muss die Bedrohung für die einzelnen Glieder ausgemalt werden, um eine Implosion der Kette zu verhindern. Dergestalt spiegelt die Intensivierung des Konfliktes die Totalität der Bedrohung und kompensiert zugleich die Heterogenität der gemeinsam artikulierten Elemente.

Nachdem sich der Parteipräsident der Zürcher SVP lange Zeit ausschließlich mit dem politischen Kontrahenten auseinandergesetzt hat, wendet er sich nun der eigenen Kantonssektion zu. In ihren jüngsten Wahlerfolgen erkennt der ein „hoffnungsvoll[es]“ Zeichen der Besserung von der diagnostizierten Malaise. Denn im Gegensatz zur „schaukelhaften Politik der meisten Parteien“59 sei die Zürcher SVP trotz der vehementen Kritik der Medien von den Bürgern für ihren Mut belohnt worden. Darauf folgt der Aufruf zum Widerstand, wobei die ex negativo hergeleiteten Sekundärtugenden der Wir-Gruppe (Entschlossenheit, Überzeugung, Stärke und Mut) nun durch einen konkreten Forderungskatalog ergänzt werden:

„Wir haben anzutreten gegen die verhängnisvolle Regulierung, gegen die ungeheure Gesetzesflut, gegen eine verfehlte rot-grüne Politik, gegen die Verschleuderung von öffentlichen Mitteln, gegen die Freiheitsbeschränkungen an allen Orten, gegen die Zunahme der Verbrechen, gegen die verfehlte Drogen- und Asylpolitik, gegen die konzeptionslose Landwirtschaftspolitik. Widerstand ist hier das Gebot der Stunde! Aber nicht nur Widerstand gegen rot-grüne Gegner, sondern auch gegen die dauernde Anpassung bürgerlicher Politiker, welche sehr oft mit pharisäerhafter Miene und professoralem Gehabe die Anpassung und das Nachgeben geradezu zelebrieren. Dies wird dann noch als ,differenzierte Politik bezeichnet. Dabei ist es aber nichts anderes als Ausdruck fehlender Kraft des Widerstandes und der fehlende Mut, zur eigenen Meinung zu stehen. “60

Blochers Aufruf zum Widerstand beginnt mit einem Angriff auf die ersten Feinde der Zürcher SVP: Erstes Ziel sind die staatliche Bürokratie, die ökologischen und sozialistischen Partei, die Blocher zu einer einheitlichen rot-grünen Linken verschmelzt. Sodann benennt er die Politikfelder, auf denen es gelte, Widerstand zu leisten: die Wirtschafts- und Sozialpolitik, die Triade aus Sicherheits-, Drogen- und Asylpolitik und die Landwirtschaftspolitik. Im Anschluss wird die binär-antagonistische Logik des zentralen Deutungsmusters der Rede wirksam. Die vereinfachende Unterscheidung von Anpassern und Widerständischen dehnt die antagonistische Äquivalenzkette von Rot-Grün auf die bürgerlichen Mitte- 
Parteien aus. Zum gegnerischen Lager gehören damit nicht nur die Linken, sondern auch die Protagonisten der Konkordanz, FDP, CVP und nicht zuletzt der machtvolle Berner SVP-Flügel.

Die Kritik an der konkordanzdemokratischen Konfliktlösung erfolgt nicht als offener Angriff auf die Normen des politischen Systems. Vielmehr deutet Blocher die „Anpassung“ und das „Nachgeben“, die andernorts als konkordanzdemokratisch induzierte, systembedingte Logiken der politischen Schweiz dargestellt werden, als Folge „fehlender Kraft“ und „fehlende[n] Mut[es]“, die bürgerliche Politiker mit ,professoralem Pharisäertum` zu verbergen suchten. ${ }^{61}$ Mit dem Hinweis auf das universitäre Milieu, dem viele Spitzenpolitiker entstammen, wird das Deutungsmuster ,Anpassung und Widerstand' durch den Antiintellektualismus ergänzt, wodurch der Freund-Feind-Gegensatz soweit ausgedehnt und vertieft wird, dass der geführte Kampfbegriff ,Classe politique‘ erst sinnvoll erscheint. Das Zugangskriterium zur gesellschaftlichen und politischen Elite sollte eben nicht eine Frage akademisch zertifizierter Fähigkeiten, sondern eine Frage des Charakters, der Entschlossenheit und Stärke sein.

Entsprechend vehement begegnet Blocher im nächsten Teil dem typisch konkordanzdemokratischen Vorwurf, er sei ein opportunistischer „Neinsager“662 und nicht an konstruktiven Konfliktlösungen interessiert. Nach einem kurzen Exkurs zum Thema Drogen, in dem Blocher den Drogenkonsum Jugendlicher auf eine „Pädagogik, Erziehung, Schulweisheit und Psychologie“ zurückführt, die das ,Jasagen predigte“, betont die Hymne an die Neinsager (so die Kapitelüberschrift), dass es in einer ,politisch schlechten Zeit mit all ihren lebensfremden Lösungen“ darauf ankäme, nein zu sagen, und dass ,[n]ein sagen zu einem schlechten Vorschlag“, stets hieße, zu „etwas Besserem“ ja zu sagen. ${ }^{63}$ Unter diesem Motto listet das Kapitel eine Reihe von Unrechtserfahrungen und Missständen als Belege für die allgemeine Diagnose der Führungsschwäche der politischen Klasse. ${ }^{64}$ Blocher politisiert gegen staatliche „Geldverschleuderung“ und für einen ,ausgeglichenen Bundeshaushalt“, gegen die Entstehung eines „Berufsparlaments“ und für ein „volksnahes Parlament“, gegen das „10-MilliardenAbenteuer des Internationalen Währungsfonds“ und die „Weltbank“, gegen eine „,internationale Entwicklungshilfe“ und für eine „prosperierende Entwicklung dieser Länder auf der Grundlage der Selbstverantwortung“, gegen den „Asylmissbrauch“, für „eine bessere Stimmung gegenüber Ausländern“ und für „den

61 Ebd.

62 Ebd.

63 Ebd.

64 Ebd. 
Kampf gegen die Untätigkeit der Behörden“, gegen die „Vielzahl von Gesetzen, Paragraphen und dergleichen“ und für eine „freiheitliche, konkurrenzfähige Schweiz, in der es den Schweizern gut geht und sie ihre Eigenverantwortung wahrnehmen können" ${ }^{65}$ Die pleonastische Äquivalenz lässt nur einen Schluss zu, er müsste sich allenfalls „einen Vorwurf für [s]eine politische Tätigkeit der letzten Jahren machen“, nämlich den, „,zu wenig nein gesagt“ zu haben. ${ }^{66}$

Nachdem Blocher den EWR und die Auswärtige Politik gegenüber der EG lange Zeit nicht erwähnte, nutzt er die Frage der Europäischen Integration am Ende seiner Rede für einen erneuten Generalangriff auf die politische Elite. Auch dieses Thema wird gleich zu Beginn dem binären Deutungsschema Anpassung und Widerstand unterworfen: „Und nun - meine Damen und Herren - zur Schicksalsfrage für unser Land, ob die Schweiz dem EWR und der EG (im Grunde bedeutet dies dasselbe) beitreten soll oder nicht. Gerade hier geht es um die Frage nach Anpassung oder Widerstand schlechthin. ${ }^{6{ }^{67}}$ Im Unterschied zu „all den Grüppchen und Gruppierungen der Classe politique und der Wirtschaft", welche ihre Stellungnahmen zum EWR allein auf Grund der Präambel abgeben, habe ,die Zürcher SVP diese Frage bereits in den letzten Jahren gründlich vorbereitet" ${ }^{\prime 68}$ In einem parteiinternen Willensbildungsprozess sei man zum Ergebnis gekommen, dass ,ein Beitritt der Schweiz zur EG für die Schweiz wirtschaftlich, politisch und kulturell so nachteilig wäre [...], dass wir hier entschiedenen Widerstand leisten müssen“669. Denn

„gemäss diesem Vertrag müsste unser Land ein durch die EG gesetztes Recht übernehmen! - Ein solcher Vertrag brächte unser Land in eine doppelte Satellisierung. In eine Abhängigkeit von sowohl von der EG als auch von der EFTA. Dieser Vertrag trägt unverkennbar hegemoniale Züge, er gleicht in vielem einem Kolonialvertrag: die Schweiz als Kolonie der EG-Staaten. [...]. Nein - meine Damen und Herren - wir haben nicht 700 Jahre gegen fremde Richter gekämpft, um jetzt unsere Freiheit gegen fremdes Recht und fremde Richter einzutauschen! Soviel Verlust an Souveränität, an demokratischen Rechten, soviel Verlust an Selbstbestimmung lassen wir uns nicht gefallen! [...] Wir wollen weder fremdes Recht noch fremde Richter noch koloniale Verhältnisse! Wir wollen frei und selbstständig bleiben und uns unser Recht selber geben!“70

65 Ebd.

66 Ebd.

67 Ebd.

68 Ebd.

69 Ebd.

70 Ebd. 
Bezeichnete das ,Wir' bis hierhin meistens die Zürcher SVP, taucht im Zusammenhang mit dem EWR ein umfassenderes ,Wir' auf. Dieses ,Wir', in dessen Namen Blocher nun spricht, inkludiert nicht nur Redner, Publikum und abwesende Mitstreiter und Sympathisanten der Partei. Es dient nicht primär ihrer Homogenisierung und Disziplinierung. Vielmehr handelt es sich um eine metonymische Realisierung des ,Wir', um ein historisch expandierendes ,Wir', das Gegenwart und Vergangenheit, die Zürcher SVP und den nationalen Mythos des schweizerischen Freiheits- und Unabhängigkeitskampfes synthetisiert und auf diese Weise eine universelle Identität schöpft. Dieses Wir verdeutlicht den hegemonialen Repräsentationsanspruch, den die Zürcher SVP im Rahmen der EWR-Abstimmung formuliert. Auf dem Spiel stehen nicht nur die korporatistischen Interessen ihrer Klientel, sondern die Identität der Nation. Ein etwaiger Beitritt zum EWR brächte eben nicht nur wirtschaftliche Nachteile für bestimmte Teile der Bevölkerung. Aus Blochers Sicht stehen der Vertrag und die drohende Integration in die supranationale Gemeinschaft im Widerspruch zur historischen Identität der Schweiz und der Souveränität der historisch gewachsenen Willensnation. Blochers partikularer Kampf gegen den EWR erscheint somit als weitere Episode einer Schweizer Universalgeschichte, die vom Kampf eines von fremden Mächten bedrohten, unbeugsamen und souveränen Volkes handelt. ${ }^{71}$

Erneut wird deutlich, dass die gemeinsame Artikulation einer konsistenten Schweizer Universalgeschichte und der partikularen Positionierung der SVP, die Konstruktion eines antagonistischen ,Sie" voraussetzt. Das historisch expandierende politische Kollektiv, das aus dieser Verknüpfung hervorgeht und als ,Wir ${ }^{6}$ angerufen wird, konstituiert sich erst durch die Abgrenzung zur expansiven Kolonialmacht EG, die - ganz im Stile des internationalen Sozialismus - versucht, die Schweiz qua EWR-Vertrag der Souveränität zu berauben und den Kleinstaat in einen von Brüssel, Berlin und Paris aus gesteuerten „Satellitenstaat““72 zu transformieren.

Nachdem Blocher vor den ,grundsätzlichen“733 Folgen des EWR gewarnt hat und die mächtigen Fürsprecher des EWR erneut der Schwäche und des mangelndes Selbstvertrauens bezichtigt hat, wendet er sich nun den Details des Vertrages zu. Zur Zeit der Rede sind diese Details, wie Blocher einräumt, noch nicht bekannt. - Ein Umstand, hinter dem Blocher selbstverständlich das taktische

71 Dieser äquivalentiellen Artikulation der partikularen Identität der SVP mit einer Schweizer Universalgeschichte wende ich mich in Kapitel 6 detaillierter zu.

72 Ebd.

73 Ebd. 
Kalkül einer nicht näher bestimmten Machtelite vermutet, die „uns die Anhänge des Vertrages nicht herausgibt ${ }^{\text {‘674 }}$.

„Bruchstückartig [...] erfahren wir lediglich, dass die Schweiz das europäische Sozialrecht, die Statistik, die Mitbestimmung, die Gleichstellung der Ausländer aus allen EWRStaaten mit den Schweizer Bürgern, die Ausbezahlung der Ergänzungsleistungen der AHV für diese Ausländer, welche je einmal in der Schweiz gearbeitet haben, usw. zu übernehmen hätte. Viele dieser Bestimmungen hat unser Volk durch Volksabstimmungen abgelehnt." 75

Zudem würde der EWR dazu führen, dass sich „unsere schweizerischen Rahmenbedingungen, die politischen und wirtschaftlichen Voraussetzungen [...] verschlechtern“"76. Denn „als ein an sich armes Land“ brauche der Kleinstaat Schweiz „,bessere Rahmenbedingungen als große, reiche Länder““ ${ }^{77}$ Um dieses Argument zu veranschaulichen, greift Blocher auf die von Schwarzenbach geprägte Metapher des „hausgemachten demokratischen Massanzuges“78 zurück, von dessen genauer Passform das Wohl der Schweiz abhinge. Ohne einen selbstgefertigten „massgeschneiderten Anzug“ würde „die Schweiz in der EG zu einer armen Randregion herabsinken“. ${ }^{79}$ Dazu wiederum, führt Blocher seine neoklassische Argumentation fort, „,braucht es gute Schneider, nicht internationale Schwätzer! Es scheint, dass diese Schneider bald nur noch in der Zürcher SVP zu finden sind“" ${ }^{80}$. Die Abwehr des EWR-Vertrages wird als Bedingung der unternehmerfreundlichen Wirtschaftspolitik, der Steuerautonomie der Kantone und des Wettbewerbsföderalismus porträtiert, welche die neoliberale Reformagenda der Zürcher SVP ohnehin verschärfen möchte. Dagegen bedeuteten

„EWR- und EG-Beitritt [...] für die Schweiz: politisch: mehr Abhängigkeit, weniger Volksrechte, mehr Fremdbestimmung, fremdes Recht, fremde Richter, Verlust der Souveränität, Aufgabe der Neutralität; wirtschaftlich: verschlechterte wirtschaftliche Bedingungen, unsichere Arbeitsplätze, mehr Arbeitslosigkeit, kleinere Saläre, höhere Steuern, lang-

74 Ebd.

75 Ebd.

76 Ebd.

77 Ebd.

78 Schwarzenbach 1974: 52.

79 Blocher 1992a.

80 Ebd. 
fristige Abwanderung unserer Volkswirtschaft in die europäischen Zentren, eine Landwirtschaft, welche diesen Namen nicht mehr verdient. “ ${ }^{81}$

Sieht man von der Stärkung der Landwirtschaft ab, die lediglich peripher gestreift wird, dann handelt es sich bei den genannten negativen Auswirkungen eines etwaigen EWR- und EG-Beitritts keineswegs um traditionelle Kernbelange der SVP. Erst die Auseinandersetzung mit der europäischen Integration erlaubt Blocher, nationalkonservative, freisinnige und insbesondere sozialdemokratische Themen $\mathrm{zu}$ besetzen und miteinander zu verbinden. Der von der politischen Klasse vorangetriebene EWR- und EG-Beitritt gefährde nicht nur die demokratische Selbstbestimmung der Nation, für welche die Eidgenossen und Eidgenossinnen über 700 Jahre gekämpft hätten; die Entflexibilisierung der Standortpolitik, die mit der Ratifizierung des Vertrages einherginge, führe auch zu einem wirtschaftlichen Niedergang, zu höheren Steuern, zur Abwanderung der Unternehmen in die europäischen Zentren, schließlich zu Lohnsenkungen und Arbeitslosigkeit.

Die oben zitierte Passage enthält zwar keine expliziten Forderungen, doch verweisen die gemeinsam artikulierten negativen Aspekte eines etwaigen Beitritts zum EWR und zur EG implizit auf ihre positiven Pendants. Der von Blocher angeführte Widerstand gegen die europäische Integration der Schweiz ist gleichbedeutend mit dem Schutz der Volksrechte, der Souveränität, Unabhängigkeit und Autonomie des Landes und dem Kampf für eine florierende Wirtschaft, standorttreue Unternehmen, niedrige Steuern, hohe Löhne und sichere Arbeitsplätze.

Diese Äquivalenzkette, die gegenüber der europäischen Integration geknüpft wird, stärkt Blocher sodann, indem er aus einem Brief eines ihm „bekannten, währschaften Sozialdemokraten“" ${ }^{82}$ zitiert, der sich in der Frage der Europäischen Integration mit ihm solidarisiert:

„Sie haben - vielleicht gerade in unserer Partei (er meint die SP) - viele Anhänger. Ich kann mich nicht so exponieren, aber sie sollen wissen, dass Sie gar nicht so allein stehen mit Ihrer Meinung, dass der Beitritt zum EWR und zur EG eine grosse Schwächung für die Schweiz darstelle. Insbesondere das arbeitende Volk spürt dies zu Recht.“ ${ }^{83}$

81 Ebd.

82 Ebd.

83 Ebd. 
Dem fügt Blocher nur noch hinzu, dass ,[e]s ist nicht das erste Mal [sei], dass die Zürcher SVP das arbeitende Volk vertritt. “84 Denn im Unterschied zu den Kantonalsektionen anderer Parteien sei die Zürcher SVP ,unabhängig`. Deswegen sei sie „so stark, aber für den Gegner und die Neider auch so gefährlich“ ${ }^{\text {(85 }}$. Damit stilisiert Blocher die Zürcher SVP nicht nur zur Gefahr für ihre politischen Gegner, sondern postuliert auch, dass die Kritik des politischen Establishments an seiner Partei durch das partikulare Interesse des Machterhalts motiviert sei, wohingegen die eigene Politik auf Überzeugungen beruhe. Entsprechend ruft das „Schlusswort“ ${ }^{486}$ Parteimitglieder und Sympathisanten dazu auf, der medialen Aburteilung zu trotzen, zu den eigenen Überzeugungen zu stehen und an der Oppositionsrolle festzuhalten:

„Lassen wir uns nicht einschüchtern, wenn unsere Partei $[\ldots]$ angegriffen wird. Man versucht uns zwar damit in eine bestimmte Ecke zu stellen, die Ecke der Fremdenfeindlichen und der Neinsager, dann der Nationalkonservativen, dann der extremen Rechten usw. Aber trösten Sie sich. In dieser Ecke können wir ja gar nicht stehen, sonst müsste man uns nicht erst hineinstellen. Nein, wir gehen unseren Weg und setzen uns ein für unsere politischen Anliegen. Für unser Land und unser Volk. “687

Blocher weist die Fremdbezeichnungen zurück, welche die Zürcher SVP als ,fremdenfeindliche und notorisch nein-sagende Partei der extremen Rechten' peripherisieren. Stattdessen bezieht er sich auf die vagen Identifikationsbegriffe ,Wir', ,Land' und ,Volk'. Die Fixierung dieser leeren Signifikanten ist die notwendige Bedingung dafür, dass die Zürcher SVP sich programmatisch am rechten Rand des politischen Spektrums positioniert und gleichzeitig einen Anspruch auf die Repräsentation des universellen Imaginären der politischen Schweiz erheben kann.

Die Feinanalyse der Albisgüetli-Rede von 1992 hat gezeigt, wie Blocher einen binär strukturierten politischen Raum entstehen lässt. Mit dem zentralen Deutungsmuster ,Anpassung vs. Widerstand ' konstruiert er zwei antagonistische Pole, deren inhaltliche Offenheit es ermöglicht, vielfältige Differenzen gemeinsam zu artikulieren und anhand dieses binären Schemas zu fixieren.

In der Auseinandersetzung mit dem EWR schafft Blocher einen bipolar strukturierten Identifikationsraum. Ein , anpassungswilliges, machthungriges po-

84 Ebd.

85 Ebd.

86 Ebd.

87 Ebd. 
litisches Establishment‘ steht für allerlei Missstände, die ,widerständische, entschlossene und charakterfeste Zürcher SVP“ hingegen für Wohlstand, Eigenverantwortung, Wachstum, Arbeitsplätze, Souveränität, Volksrechte und Selbstbestimmung. Die populare Äquivalenzkette, aus der ,Volk‘ und ,Land“ hervorgehen, verknüpft die traditionelle Parteidomäne (intakte Landwirtschaft), mit einer neoliberalen Deregulierungspolitik (,niedrige Steuern, florierende Ökonomie und standorttreue Unternehmen durch maßgeschneiderte Wirtschaftspolitik'), einer wohlfahrtstaatlichen Gemeinwohlorientierung (hohe Löhne und Arbeitsplätze) und den tradierten Leitbegriffen der demokratischen Willensnation (,Souveränität, Unabhängigkeit, Volksrechte`). Für die Kohäsion dieser Differenzen sorgt die antagonistische Grenze zu einem bedrohlichen Außen, dem EWR und seinen Befürwortern. Die hegemoniale Repräsentationsfunktion der Zürcher SVP hängt von der Präsenz des Anti-Subjekts ab. Denn nur wenn der EWR die Schweizer Demokratie und die wirtschaftliche Prosperität des Landes bedroht, kann die Zürcher SVP, die den Widerstand gegen diese Bedrohung anführt, die artikulierten Differenzen repräsentieren und vereinen. Dieses antagonistische Andere ist einerseits die notwendige Bedingung für die Okkupation der universellen Identifikationsbegriffe ,Volk' und ,Land“; es dokumentiert andererseits den unreinen, politisch verfassten Charakter dieser Identitäten.

Im Folgenden werden die aus der Feinanalyse der Albisgüetlirede von 1992 gewonnenen Ergebnisse durch weitere Diskursfragmente ergänzt. Exponiert werden soll insbesondere, wie Neoliberalismus und Nationalkonservatismus vor dem Hintergrund der Bedrohung durch die EG fusionieren und wie das so entstandene ideologische Amalgam die identitätsstiftenden leeren Signifikanten ,Land', ,Volk‘, ,Schweiz' und ,Demokratie‘ zu hegemonisieren beginnt.

\subsection{Die EG ALS SOZIALISTISCHES REZIDIV UND DIE LIBERAL-KONSERVATIVE USURPATION DES ,SCHWEIZER SONDERFALLS“}

Betrachtet man den EWR-kritischen Diskurs in der Schweiz, lassen sich zunächst zwei Diskursstränge identifizieren, die zu Beginn kaum miteinander in Verbindung gesetzt werden. Zum einen argumentieren die Kritiker des EWR als Anwälte des ,Sonderfalls Schweiz' und deuten die europäische Integration als Gefährdung der historischen Identität des Landes. Aus Sicht nationalliberaler Intellektueller würde die Integration in ein ,supranationales, intellektuelles Groß- 
gebilde EG` die Souveränität des neutralen, föderalistischen und direktdemokratischen Kleinstaates Schweiz unterlaufen. ${ }^{88}$ Zum anderen finden sich EWRkritische Stimmen, welche die volkswirtschaftlichen Gewinnerwartungen der Befürworter des Freihandelsvertrages infrage stellen und vor Masseneinwanderung, Nivellierung des schweizerischen Qualitätsstandards, Steuererhöhungen und Arbeitsplatzverlust warnen und im voranschreitenden Integrationsprozess der EG einen Abschied vom freien Wettbewerb erkennen. ${ }^{89}$

Blochers enumerative Unterscheidung von wirtschaftlichen und politischen Konsequenzen des EWR in der Albisgüetlirede von 1992 ist insofern einschlägig für das Initialstadium der Kritik an EWR und EG. Zwar listet er sowohl wirtschaftliche Kosten als auch politische Nachteile des EWR auf, doch stehen diese Kosten und Nachteile assoziativ nebeneinander und sind noch nicht zu Momenten eines homogenen Anti-Subjekts der Schweiz geronnen.

Die Repräsentation der EG als diametrales Gegenteil der Schweiz konnte die Zürcher SVP jedoch im Verlauf der EWR-Kampagne und insbesondere in der retrospektiven Diskursivierung der Abstimmung schrittweise verwirklichen. Indem die Zürcher SVP Elemente wie Zentralisierung, Umverteilung, Bürokratie, Sozialismus, niedrige Löhne, Arbeitslosigkeit und Kriminalität mit der EG und ihren Befürwortern assoziierte, konnte sie diese Elemente als , unschweizerisch ${ }^{\circ}$ verwerfen und im Innen ein historisch gewachsenes, monolithisches, Volk ${ }^{`}$ und ,Land' imaginieren, das sich mit dem eigenen politischen Programm identifiziert. Denn in dem Maße wie EWR und EG zum antagonistischen Anderen des Schweizerischen werden, wird die Zürcher SVP, die den Kampf gegen die europäische Integration anführt, zur Repräsentantin dieser Identität.

Um diese bipolar-antagonistische Strukturierung des politischen Raumes zu verwirklichen, musste nicht nur der ,Sonderfall Schweiz' gegen den EWR und die EG profiliert werden; es galt auch, den proeuropäischen Argumenten liberaler Provenienz entgegenzutreten. Der EWR und die europäische Integration sollten weder als Freihandelsvertrag und Mittel gegen die Rezession der frühen 1990er Jahre noch als friedenspolitischer Meilenstein in der Geschichte Europas erscheinen, sondern als rezidives Äquivalent des jüngst gescheiterten Sozialismus.

Als Schlüssel für die Konstruktion dieser Äquivalenz erwies sich die sogenannte ,Harmonisierung'. Die Angleichung von nationalem Recht an geltendes und zukünftiges EG-Recht, die der EWR-Vertrag vorsah, um faire Handelsbe-

88 Vgl. exemplarisch etwa die Schweizerzeit-Artikel von Walthard 1992a; Roederer 1992; Bonny 1992; Chevallaz 1992.

89 Vgl. exemplarisch Schiltknecht 1992; Furrer 1992. 
dingungen zu schaffen, wurde von Blocher \& Co als Gleichschaltungspolitik einer bürokratisch-zentralistisch organisierten Kolonialmacht besprochen:

\begin{abstract}
„Damit wir deutlich, was die oft beschworene EG-Harmonisierung bewirken wird. Eine umfassende Umverteilung wird Tatsache werden, die dem Tüchtigen wegnimmt, um dem weniger tüchtigen zu geben. Ein leistungsorientiertes, um wirtschaftliche Spitzenpositionen bemühtes Land wird durch die bürokratische EG-Harmonisierung in seinem Wachstum beschränkt, nach unten nivelliert. Damit lässt sich das Schicksal der Schweizer Wirtschaft ablesen: Die schweizerische Wirtschaft konnte ihre Spitzenposition auf dem Weltmarkt immer nur dank besonderer Leistungsfähigkeit und besonderem Leistungswillen der Schweizer behaupten. Kein anderes Land in der EG konnte einen ähnlich hohen Standard erreichen wie die Schweiz. [...] Ein solches Land kann auch in Zukunft nur bestehen, wenn die politischen Rahmenbedingungen die Erreichung weiterer qualitativer Spitzenleistungen ermöglichen. Wer Qualität nach unten nivelliert, der beraubt dieses Land, der beraubt die Schweiz ihrer wirtschaftlichen, ja ihrer existentiellen Grundlage.“ ${ }^{90}$
\end{abstract}

Blocher erkennt in der ,Harmonisierung nicht nur die ,imperiale“ Geste eines ,supranationalen, zentralistischen, bürokratisch gesteuerten Riesengebildes` gegenüber dem ,direktdemokratischen, föderalistisch aufgebauten Kleinstaat Schweiz‘. „Harmonisierung' wird als „Nivellierung nach unten“ und als ,umfassende Umverteilungsmaßnahme“ konkretisiert, zur „reglementierten Vereinheitlichung aller Lebensbereiche“, zur „Gleichmacherei“ und „Gleichschaltung“ gesteigert und somit mit den Totalitarismen des 20. Jahrhunderts assoziiert. ${ }^{91}$ Die Harmonisierung, durch die sich die machtvolle EU-Bürokratie mit den ,weniger Tüchtigen“" 92 verbündet, ist umso bedrohlicher und fremder, als der , beispiellose" sozioökonomische Aufstieg der Schweiz im 20. Jahrhundert auf eine liberale Wirtschaftsordnung zurückgeführt wird, die ihrerseits wiederum der direktdemokratischen Verfasstheit der Schweiz entwachsen sei:

„Die direkte Demokratie erscheint heute manchem als Hindernis für raschen Fortschritt. Diese direkte Demokratie hat aber für ein kleines, viersprachiges Land mit schlechten natürlichen Voraussetzungen einen Rahmen geschaffen, in dem sich wirtschaftliche Leistungen entfalten, in dem diese Leistungen auch beeindruckende Resultate erzielen konnte.

90 Blocher 1992b: 22 u. 1992a.

91 Vgl. Blocher 1992b: 23.

92 Ebd. 
Gerade diese Fähigkeit geht grossen zentralistisch strukturierten Staaten ab. Kleine Staaten sind ökonomisch effizienter als Grossgebilde.“`33

Die positive Korrelation zwischen den Normen des politischen Systems, der wirtschaftsliberalen Ordnungspolitik und der außerordentlichen Leistungsbilanz des Wirtschaftsplatzes Schweiz unterstreicht auch der SVP-Nationalrat und Großunternehmer Walter Frey, neben Blocher der zweite finanzkräftige Mäzen der Zürcher SVP:

„Kleinräumigkeit, Überblickbarkeit, direkte Demokratie, direkte Einflussnahme und unmittelbare Überwachung des Staates durch das Volk - durch ein Volk, das sich bezüglich Steuern der Regierung gegenüber als betont geizig erweist - sorgten dafür, dass sich der Staatsapparat nicht unmässig aufzublähen vermochte. “94

Die EG habe dagegen nichts mit dem Europa der Vaterländer gemein, das Churchill, de Gaulle und Thatcher vertreten hätten, so Frey weiter. ${ }^{95}$ Obgleich von Protagonisten des Konservatismus angestoßen und vorangetrieben, erscheint die heutige EG als Projekt einer etatistischen Linken, „eine Konstruktion von Intellektuellen“, „ohne Demokratie, ohne Föderalismus“, ein „zentralistisches Grossgebilde“, das genauso zum Scheitern verurteilt sei wie „das römische Reich, das karolingische Reich, das napoleonische Reich, das Dritte Reich [und] das sowjetische Reich“. ${ }^{96}$ Diese Diskursfragmente veranschaulichen, wie die EWR-Frage mit der Schweizer Demokratie und der antisozialistischen Agenda der Zürcher SVP artikuliert wird. Der EWR erscheint als bürokratischgleichschalterische Entmachtung der ,tüchtigen und leistungsorientierten Schweizer Volkswirtschaft ${ }^{\star}$ und des föderalistischen und direktdemokratischen Kleinstaates. ${ }^{97}$

Diesen Antagonismus gegenüber dem Europäischen Zentralismus spitzt der Chefredakteur der Schweizerzeit und spätere SVP-Nationalrat Ulrich Schlüer zu. In einem Kommentar diagnostiziert er: „Die Brüsseler Bürokratie, deren Brotkorb auf Gedeih und Verderb mit dem Zentralismusmodell verknüpft ist, verteidigt ihre zentrale Stellung mit Klauen und Zähnen und baut ihre dirigistische

93 Ebd.: 24.

94 Frey 1992: 27, Hervorhebungen M.H.

95 Ebd.: $37 f$.

96 Ebd.

97 Ähnlich argumentiert beispielsweise Christoph Blocher (1992c). 
Kontrollfunktion beharrlich [...] aus.“ ${ }^{\text {“98 }}$ Die bürokratische Bedrohung des Wirtschaftsstandortes Schweiz, die einst mit den ,roten und grünen Filzläusen' assoziiert worden war, geht nunmehr vom EWR und der EG aus. ${ }^{99}$ Für EWR und europäische Integration zu politisieren, bedeutet daher, die Schweizer Wirtschaft und Politik den schikanösen Regulierungen einer fremden Bürokratie zu unterwerfen, ${ }^{100}$ die mittelständischen Unternehmen in Gefahr zu bringen, ${ }^{101}$ den Wohlstand und die Lebensqualität aufs Spiel zu setzen, die Qualität der Bildungssystems nach unten zu nivellieren, die erprobte Schweizer Sozialpartnerschaft für staatliche Mindestlöhne zu opfern, ${ }^{102}$ den „Zustrom ausländischer Arbeitskräfte" ${ }^{\text {“103 }} \mathrm{zu}$ forcieren und damit hohe Löhne und sichere Arbeitsplätze zu gefährden. Widerstand gegen EWR und EG bedeutet dagegen Widerstand gegen Bürokratie, gegen Zentralismus, gegen Regulierungen im Arbeits-, Sozial- und Umweltrecht. Wer gegen die europäische Integration kämpft, kämpft für das Subsidiaritätsprinzip, den Wettbewerbsföderalismus und das direktdemokratische Selbstbestimmungsrecht des Kleinstaates, für eine liberale Wirtschafts- und Finanzpolitik, das Selbstverantwortungsprinzip, Arbeitsplätze, den Schweizer Qualitätsstandart in Produktion und Bildung und damit für eine ökonomisch prosperierende Schweiz.

Die antagonistische Äquivalenzkette aus der EG und der Schweizer Linken untermauerte die Zürcher SVP, indem sie die europäische Integration als Rezidiv des Sowjet-Kommunismus deutete: „Die Linke sieht, dass der real gelebte Sozialismus ausgespielt hat; nun propagiert sie ein von Bürokraten gegängeltes Europa“'104, räsonierte Walter Frey bereits vor dem Volksentscheid. Und Willy Futterknecht, ein Nationalökonom und Wirtschaftsberater, konstatierte:

„Dass keine zentralistische und dirigistische Bürokratie mit ihren Strömen supranationaler Reglementiererei Völker und Nationen zusammenhalten kann, hat in jüngster Zeit der von den Völkerschaften eben zertrümmerte Ostblock bewiesen. [...] Was in Moskau und Belgrad kläglich gescheitert ist, wird nun in ähnlicher Form und mit sozialistischer Vorherrschaft in Brüssel versucht." ${ }^{105}$

98 Schlüer 1992b.

99 Vgl. Hartmann/Horvath 1995: 128.

100 Vgl. Blocher 1992b: 16 u. 1992c.

101 Vgl. Blocher, 1992b: 15.

102 Vgl. Schlüer 1992a.

103 Vgl. Blocher 1992b: 14.

104 Frey, zit. in: Ryser 2008.

105 Futterknecht 1992: 20f. 
Nach der Abstimmung wurde die gemeinsame Artikulation von Sowjetkommunismus, der EG und der nationalen Linken weiterverfolgt - so unter anderem auf der Herbsttagung der Schweizerzeit im Jahr 1993. Als Hauptredner hatte die nationalkonservative Wochenzeitung den bayerischen FDP-Politiker und EGInsider Manfred Brunner eingeladen. Der ehemalige Kabinettschef Martin Bangemanns bei der EG-Kommission war zu einem vehementen Kritiker der neu entstandenen EU geworden und hatte vor dem Bundesverfassungsgericht gegen den Vertrag von Maastricht geklagt. Brunner postuliert, dass sich Europa zu einem „Spiegelbild des totalitären Ostblocks“"106 gewandelt habe, gegen den es einst errichtet wurde. Entstanden sei ein ,supranationaler, zentralistisch-

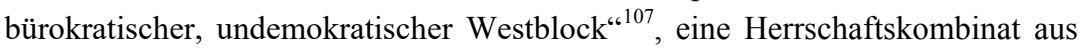
großindustriellem Lobbyismus und Bürokratie, das abgeschirmt von demokratischen Kontrollmechanismen auf eine „Gleichschaltung in allen Lebensbereichen “108 abziele. Gegen dieses Brüsseler Modell Europas stellt Brunner den „Wettbewerb der Modelle“109, eine wettbewerbsorientierte europäische „Konföderation “"110 souveräner, föderalistisch organisierter Nationalstaaten, die - ganz nach Schweizer Vorbild - „das Prinzip der gegenseitigen Anerkennung und Vielfalt in den Mittelpunkt ${ }^{\star 111}$ stellt.

Auf dem anschließenden Podium nahm Blocher die EU-Kritik Brunners auf. Er plädiert ebenfalls für einen „lockeren Staatendbund, der allen Ländern und Völkern Autonomie und Eigenleben belässt" ${ }^{\star 112}$. Zudem postuliert er ein positives Feedback zwischen der bürokratisch-zentralistischen Vertiefung der europäischen Integration und der Frustration der Beherrschten:

„Je stärker die Integration vertieft wird, je mehr Souveränität die europäischen Staaten nach Brüssel abtreten müssen, je zentralistischer die EU wird, je mehr Identität die Menschen in den EU-Mitgliedsländern preisgeben müssen, desto schwerer wiegen die Missstände in der EU, desto bewusster werden diese Missstände wahrgenommen." “113

106 Brunner 1993: 16.

107 Ebd.

108 Ebd.: 12.

109 Ebd.

110 Ebd.: 39.

111 Ebd.: 23.

112 Ebd.: 24.

113 Brunner/Blocher/Schlüer 1993: 50. 
Was in den Medien als transiente Krise der EU besprochen würde, seien „in Wahrheit [...] die schweren Nachteile des bürokratischen Zentralismus "114

Im Unterschied zu Brunner, der das Identitätsmodell der ,aufgeklärten Musterrepublik‘ bediente, knüpft Blocher an das Identitätsmodell der „,heilen Insel in einer heillosen Welt ${ }^{\text {“115 }}$ an. Er akzentuiert die Unvereinbarkeit der Schweiz und der EU und begründet den Gegensatz zwischen dem wettbewerbsorientierten, subsidiären Schweizer Föderalismus und der europäischen Gleichschaltungspolitik $^{116}$ durch einen historischer Topos, der die Schweiz zu einer substantiell anderen politischen Gemeinschaft stilisiert als die EU und ihre Mitgliedstaaten: „Eine EU-Mitgliedschaft wäre für die Schweiz, einen jahrhundertealten Staat, noch weit problematischer als sie für die teilweise jungen Staaten in Europa ist." “117 Die Schweiz sei nämlich ,ein durch und durch und in Jahrhunderten gewachsenes Gebilde“"118; die EU dagegen ein „Produkt intellektueller Einbildungskraft“, „eine von Intellektuellen ausgeheckte“, volkswirtschaftlich und währungspolitisch zum Scheitern verurteilte „Fehlkonstruktion“, die „,verschiedene Länder mit je verschiedener Geschichte, verschiedenen Kulturen und verschiedenen Identitäten in eine einheitliche Form zwingen will - eine Form, die aus unserer Sicht extrem undemokratisch ist". ${ }^{119}$ Wenngleich es sich bei der zentralistischen EU um einen universellen ,Konstruktionsfehler ${ }^{\star}$ handelt, dessen negative Konsequenzen alle Mitgliedstaaten gleichermaßen treffen werden, sei dieses Konstrukt für die Schweiz nicht nur verfassungsmäßig, sondern auch mentalitätsgeschichtlich fremder als für andere Länder:

„Gerade wir Schweizer begegneten grossen politischen Gebilden in Europa immer mit Bedenken, ja mit Angst. Nie hat diese Angst uns allerdings verleitet, uns in diese Grossgebilde zu integrieren. Immer wieder kommen wir auf die alte Feststellung zurück: Die Schweiz hat solange Bestand gehabt als sicheres Gebilde mit guter Rechtstradition, mit von vielen bewunderte Prosperität, als sie den Mut gehabt hat, anders zu sein als andere

\section{Ebd.}

115 Langejürgen 1993: 17.

116 „Vollständige Vereinheitlichung, Totalharmonisierung und Subsidiarität - das sind zwei Konzepte, die sich gegenseitig ausschließen. Die EU-Bürokratie will ja gerade den Wettbewerb unter den EU-Ländern aufheben. [...] Solche Gleichschaltungspolitik ist für jeden Schweizer schlechthin unerträglich. Denn die Schweiz ist entweder föderalistisch - oder es gibt sie nicht.“ (Brunner/Blocher/Schlüer 1993: 51)

117 Ebd.: 42.

118 Ebd.

119 Ebd.: 42f. 
Länder, bessere Lösungen zu suchen und zu verwirklichen, als andere Länder sie gesucht und verwirklicht haben. “120

Über die Kritik an der europäischen Harmonisierung führte der Zürcher Flügel eine Reihe von binären Unterscheidungen ein, welche die EG und die Schweiz miteinander kontrastieren: ,zentralistisch`vs. ,föderalistisch', ,umverteilend‘ vs. ,selbstverantwortlich“, ,bürokratisch“ vs. ,direktdemokratisch‘, ,groß‘ vs. ,kleinräumig', ,expansiv‘ vs. ,friedlich‘, ,gleichmacherisch`vs. ,pluralistisch', ,künstlich-leblos‘ vs. ,organisch-vital', ,krank'vs. ,gesund‘, ,intellektuell‘ vs. ,bodenständig‘. Betrachtet man die Attribute der Schweiz, dann handelt es sich einerseits um Gemeinplätze des Schweizer Patriotismus (föderalistisch, direktdemokratisch, kleinräumig, friedlich, pluralistisch), andererseits um die liberalkonservativen Leitbegriffe der Zürcher SVP (selbstverantwortlich, gewachsen, gesund, bodenständig). Die Äquivalenz dieser Elemente ist eine rein negative. Sie ist bedingt durch die antagonistische Bedrohung durch die EU und die europhilen Eliten. Vor dem Hintergrund dieser Bedrohung durch ein zentralistisches, umverteilendes, bürokratisches und künstlich-lebloses Riesengebilde erscheint die Schweiz nicht nur als föderalistischer, direktdemokratischer Kleinstaat, sondern auch als eigenverantwortliche, vitale Gemeinschaft. Diese äquivalenzlogische Verflechtung unterschiedlicher Diskursstränge und ihrer Elemente konstituiert eine Organizität aus interdependenten Momenten. Föderalismus und direkte Demokratie werden zu Bedingungen des Selbstverantwortungsprinzips. Beide wurzeln in einer kontinuierlich gewachsenen, lebendigen Volksgemeinschaft, deren Fortbestehen die Zürcher SVP garantiert.

Um die Zürcher SVP war eine gegenhegemoniale Alternative zum europäischen Kosmopolitismus entstanden: ein selbstbewusster, wirtschaftsliberaler, föderalistischer und demokratischer Nationalismus, der die Unvereinbarkeit historisch gewachsener, organischer Volkskulturen postuliert und sie in einem freien ökonomischen Wettbewerb aufeinandertreffen lassen möchte. Im Rahmen dieses Diskurses erfüllt die EU die Funktion, die einst der realexistierende Sozialismus für die Konstruktion der bürgerlichen Schweiz besaß. Als ,zentralistisches, expansives, egalitäres und bürokratisches Kunstgebilde" konstituiert sie das inkompatible Andere einer, naturwüchsig-organischen, direktdemokratischen, föderalistischen und bürgerlich-freiheitlichen Schweizer Lebensform`. 


\subsection{Missionarische Politik UNd POPULARER BrUCH}

Der Widerstand gegen die europäische Integration steht einerseits in der Tradition der antisozialistischen Rhetorik, mit der Blocher \& Co die Zürcher SVP auf einen liberal-konservativen Kurs brachten, weißt andererseits jedoch über den Antikommunismus hinaus. Während der antikommunistische Konsens das bürgerliche Lager aus CVP, SVP und FDP einte, sprengte die Frage der europäischen Integration dieses Kollektiv. Da die CVP, die Freisinnigen und nicht zuletzt die Berner Parteiführung der SVP für den EWR politisierten und bis zum deutlichen Scheitern der Volksabstimmung „Ja zu Europa“ im Jahr 2001 mehrheitlich am strategischen Ziel der EU-Mitgliedschaft festhielten, ließ sich plausibilisieren, dass sich auch die bürgerlichen Parteien auf die Seite der minoritären Linken geschlagen hatten, die sich quasi ,naturgemäß für die ,supranationale bürokratisch-zentralistische EG' begeisterte. Die Gefahr ging nunmehr nicht mehr von Sozialdemokraten und Grünen alleine aus, auch die bürgerlichen Parteien wollten die Schweiz unterwandern und ausliefern.

Die Europapolitik erwies sich insofern als prädestiniert dafür, die Kritik an einer staatszentrierten und egalitären Linken auf die gesamte politische Klasse $\mathrm{zu}$ übertragen und einen popularen Antagonismus zu konstruieren, der die etablierten Konfliktlinien des politischen Raumes absorbierte und überprägte. Der Antagonismus zwischen politischer Klasse und Schweizervolk, den die Zürcher SVP im Rahmen der Asyl-, Drogen- und Sicherheitspolitik bereits in den 1980er Jahren eingeführt hatte, fand in der Europapolitik neue Nahrung. Im Unterschied zur Asyl-, Drogen- und Sicherheitspolitik, welche die Zürcher SVP zwar als drängende, aber nicht als identitätsstiftende oder zukunftsentscheidende Politikfelder diskursivieren konnte, avancierte der EWR im Verlauf des Abstimmungskampfes zur richtungsweisenden, nicht korrigierbaren Schicksalsfrage der Nation. Am 6. Dezember ging es nicht nur um wichtige Aspekte wie Sicherheit und Wohlstand, sondern auch darum, die Identität des direktdemokratischen, föderalistischen, bürgerlich-freiheitlichen und ökonomisch prosperierenden Kleinstaates gegen eine politische Klasse zu verteidigen, hinter deren Kosmopolitismus sich Eigennutz, Ruhmsucht und Großmachtstreben verbergen.

Eineinhalb Monate nach der Volksabstimmung stilisierte Blocher die EWRAbstimmung, den ,Schwarzen Sonntag“ des freisinnigen Bundesrates JeanPascal Delamuraz, zum ,großartigen [...] historischen Ereignis““121. 
„Diese Volksabstimmung hat nahezu achtzig Prozent der Stimmberechtigten zu mobilisieren vermocht. Sie hat Tausende von Bürgerinnen und Bürgern dazu bewegen können, über Monate hinweg Abend für Abend in überfüllten Sälen über die Gegenwart und die $\mathrm{Zu}$ kunft des eigenen Volkes nachzudenken und engagiert zu diskutieren. Ein Volk, das über die Vitalität und die Lebenskraft für eine derart tiefgreifende Auseinandersetzung um seine Zukunft verfügt - das ist ein gesundes Volk. Diese Feststellung müsste doch zuallererst sowohl Gegner als auch Befürworter des EWR zutiefst befriedigen.“ ${ }^{122}$

Die Bedeutung der Abstimmung wird zunächst weder mit den vermeintlichen ökonomischen Konsequenzen noch mit Blochers persönlichen politischen Zielen und Motiven in Verbindung gesetzt. Es geht um die allgemeine Bedeutung des 6. Dezembers 1992. Das Ereignis steht für die tiefgreifende politische Auseinandersetzung über die Zukunft der Schweiz, die im Rahmen der EWR-Debatte stattgefunden hätte; Der 6. Dezember bezeugt die ,Vitalität und Lebenskraft` eines ,gesunden Volkes'.

Bezieht sich dieser Volksbegriff noch auf das gesamte Stimmvolk, lässt Blocher im Folgenden ein anderes ,Volk' auftauchen. Das ,Volk‘ umfasst nunmehr ausschließlich diejenigen, die am 6. Dezember mit Nein gestimmt haben; diejenigen, die ,ein Bekenntnis für die Unabhängigkeit unseres Kleinstaates geleistet“ hätten, die sich ,gegen die Brüsseler Bürokratie, gegen undemokratische, gleichschalterische Tendenzen“ entschieden hätten und deren „Glaube an überblickbare, demokratische, freiheitliche Verhältnisse [...] gesiegt" habe. ${ }^{123} \mathrm{Im}$ Anschluss projiziert Blocher den Antagonismus zwischen diesem Volk und der politischen Klasse in die Zukunft:

„Der Entscheid ist gefallen. Trotzdem müssen sich heute sehr viele Schweizerinnen und Schweizer mit wachsender Besorgnis fragen: Ist der Entscheid auch wirklich gefallen? [...] Wird der Entscheid des Souveräns vom 6. Dezember 1992 wirklich als unumstößlich und verbindlich anerkannt? Dass diese Frage überhaupt gestellt werden muss, ist an sich bereits bedenklich. Denn es stellt sich damit die Frage nach der Gültigkeit unserer demokratischen Ordnung. Mit Besorgnis stellen wir fest, was sich das Schweizervolk an Kommentaren in den vergangenen Wochen gefallen lassen musste. [...] Öffentlich Zensuren wurden dem Schweizervolk ausgeteilt. Ein Bundesrat sprach vom ,schwarzen Sonntag‘. Ganz offen wurden durchsichtige Tricks vorgeschlagen, mit welchen sich der Entscheid vom 6. Dezember 1992 umgehen liesse. [...] Es ist offenkundig: Die Achtung vor den 
demokratischen Spielregeln ist in der Politik, in der Gesellschaft, in den Medien, aber auch in der Wirtschaft teilweise bedenklich geschwunden. “124

Dieser Verdacht unterstreicht die Äquivalenz zwischen der nationalen politischen Klasse und der EG: Nicht nur dass die politischen Eliten, die Schweiz einem undemokratischen Gebilde einverleiben wollten. Die Tatsache, dass die etablierten politischen Kräfte selbst nach dem Nein zum EWR an der europäischen Integration festhielten, lässt auf ihre Missachtung der Demokratie schließen:

„In manchem EG-Land hat der Abbau geradezu System. Manche Regierung, manche Staatsverwaltung von EG-Ländern scheinen den Respekt vor der Demokratie überhaupt zu verlieren. In der Schweiz - nicht nur eine der ältesten, sondern auch die direkteste Demokratie der Welt - sind Anfänge von Demokratie-Missachtung ebenfalls bereits festzustellen. “125

Die partikulare Streitfrage des EWR wird an die Frage nach dem Allgemeinzustand der Schweizer Demokratie angeschlossen. Die drohende Missachtung des demokratischen Souveräns in der Europapolitik steht exemplarisch für die Demokratie- und Volksverachtung der politischen Klasse. Wenn Bundesrat und Parlament, die Presse und selbst freisinnige Professoren die „Aushöhlung der Demokratie und die Missachtung von Volksrechten und Volkswillen“ propagieren, es bereits heute „Überzeugungen [gibt], die sich, obwohl in unserem Volk tief verankert, nur noch in Leserbriefen oder Inseraten äussern können“, ${ }^{126}$ dann werden „wir in den kommenden Jahren [mehr denn je] unsere Demokratie zu verteidigen haben" ${ }^{127}$.

Dass die Partei für den Kampf gegen dieses antidemokratische Bevormundungskartell aus Politikern und Doxosophen gerüstet ist, hat Blocher bereits zu Beginn der Rede klargestellt. Die Partei ergebe sich nämlich nicht in „kleinkariertem Parteiengezänk“, sondern habe sich selbst den „Auftrag“ gestellt,

„mit Überzeugungskraft und Durchsetzungswillen und orientiert an der Wirklichkeit sich nachdrücklich für unser Volk, für unser Land, für eine freie und prosperierende Schweiz einzusetzen. Diesem Auftrag hat sich alles unterzuordnen. Getreu diesem Auftrag hat die

124 Ebd.: 7ff.

125 Ebd.: 9f.

126 Ebd.:10f.

127 Ebd.: 9. 
Zürcher SVP im vergangenen Jahr dringende politische Probleme angepackt. [...] Die Zürcher SVP hat in diesem Sinne eigentliche politische Pionierarbeit geleistet in der Asylfrage, zur Verhinderung des Berufsparlaments, in der Drogenpolitik, zur Sicherung der Arbeitsplätze und vor allem - und dies in eindrücklicher, unermüdlicher Anstrengung - im Kampf gegen den EWR. Unser Einsatz erfolgte im Dienst der Schweizerinnen und Schweizer. Es war ein Kampf für die Freiheit, gegen den Verlust der Selbstständigkeit für die Wahrung der Volksrechte und für die Wohlfahrt von Land und Volk. [...] Es war die Liebe zu unserem Land und zu unserem Volk, die uns die Kraft für diese ausserordentliche Anstrengung verliehen hat, die uns auch alle in dieser schwierigen Auseinandersetzung erlebten Unannehmlichkeiten ertragen liess.“" ${ }^{\text {(128 }}$

Werben andere Parteien mit ihrer Problemlösungskompetenz, beschreibt Blocher seine Partei als pflichtethisch vereinte und politisch überzeugte Kraft. Der konkordanzdemokratische Prototyp des ausbalancierenden Gesellschaftsingenieurs macht dem charakterfesten Überzeugungstäter Platz, der sich über den Kampf gegen die EU und das proeuropäische Kartell aus Politikern, Wissenschaftlerinnen, Wirtschaftsfunktionären und Medienvertreterinnen zum Repräsentanten des nationalen Imaginären und Märtyrer der politischen Schweiz stilisiert.

Besonders interessant ist hierbei, wie diese Repräsentationsleistung partikulare und universelle Semantiken miteinander vernäht. Die partikulare Kritik der politischen Eliten in Fragen der Asylpolitik, der Wirtschaftspolitik und der Auswärtigen Politik dient nicht nur als Beleg für die allgemeine Existenz einer ,abgehobenen, überheblichen und volksverachtenden Kaste von Berufspolitikern“. Durch die stetige Reproduktion der Äquivalenzkette ,Asyl - Kriminalität - Drogen - EU - Etatismus` wird die populistische Universalkritik an den herrschenden Verhältnissen, den Politikern, den Doxosophen und ihrem tabuisierenden Diskurs, gleichzeitig begrenzt. Auf der Seite des unterdrückten ,Schweizervolkes' ist nur, wer diesen umfassenden Bedrohungszusammenhang auch erkennt.

Auch die Abgrenzung gegenüber extremistischen Strömungen im In- und Ausland wird an die Vertiefung der europäischen Integration und der ,gleichschalterischen, bürokratischen Eliten' rückgekoppelt:

„Nationalismus und Rechtsextremismus werden in Europa dann zur Gefahr, wenn Länder, Kulturen und geschichtlich gewachsene Gemeinschaften von Bürokraten rücksichtslos übergangen und gleichgeschaltet werden. [...] Extremismus gedeiht dort, wo die klare po- 
litische Linie fehlt, wo persönliche Einbildung und Arroganz die politische Führung dazu verleiten, über das Volk hinwegzuregieren.“129

„Ein Gebilde, das nationale Identitäten unterdrückt, das europäische Völker ihrer Solidarität beraubt, beschwört grosse Gefahren für Europa, weil es nationalistischen Strömungen Auftrieb geben könnte. Übersteigerter Nationalismus entsteht [...] vor allem dort, wo nationale Gefühle unterdrückt, wo man seine Liebe zur Heimat nicht mehr offen aussprechen darf. Dort entstehen gefährliche, oft kaum mehr kontrollierbare Gegenbewegungen, aus welchen die Neigung zu Bürgerkriegen gefährlich wachsen dürfte.“130

Nationalismus und Extremismus erscheinen als übersteigerte Abwehrreaktionen auf eine bürokratisch-zentralistische EU, einem Klientelsystem von Politikern, die sich ihrer Verantwortung gegenüber den europäischen Völkern entzögen. Mit der Vertiefung der Integration im Rahmen der EU habe sich Europa in sein Gegenteil verkehrt. Das antinationalistische Friedensprojekt de Gaulles und Adenauers sei zur Triebfeder eines ,übersteigerten Nationalismus` geworden, so Blocher weiter. ${ }^{131}$

Vor dem Hintergrund dieser Sinnverkehrungsthese erscheint die Zürcher SVP erneut als Gegenmodell: Sie kämpft für die Rechte des Volkes, sie vertraut „auf die innovative, initiative Kraft unseres Volkes“"132, übernimmt Verantwortung für ihre Entscheidungen, ,popularisiert Politik' und kultiviert auf diese Weise ein gesundes nationales Selbstvertrauen, das Extremisten den Nährboden entzieht. Dieser Argumentationsgang fixiert den Rechtsextremismus nicht als das konstitutive Andere der politischen Schweiz, sondern lediglich als Folge, als eine untergeordnete Differenz des imperialen Zentralismus der EU und ihrer Agenten. Der entscheidende Effekt dieser Argumentation besteht darin, dass sie den SVP-Populismus des Extremismusverdachts entledigt und gleichzeitig seine Integrationsfähigkeit gegenüber den unerfüllten Forderungen steigert, die zuvor mit der extremen Rechten assoziiert waren, indem sie sie als Momente eines legitimen nationalen Selbstbewusstseins nobilitiert, das der Gefahr eines extremistischen Nationalismus präventiv entgegenwirkt.

Dieses Selbstbewusstsein strukturiert auch das neoliberale Plädoyer für eine deregulierte, wirtschaftliche Konkurrenz zwischen Individuen, Gemeinden, Kan-

129 Ebd.: 17f.

130 Brunner/Blocher/Schlüer 1993: 61.

131 Ebd.: 56f.

132 Blocher 1993: 12 u. 17f. 
tonen und Staaten. Denn auch das Bekenntnis zu einer neoliberalen Ordnungspolitik ist durch Stärke, Selbstvertrauen und Leistungsbereitschaft motiviert:

„Wird der Weg auch nicht einfach sein, so ist [...] auf die Vitalität zu vertrauen, mit der sich das Volk für diese Alternative entschieden hat. [...] Wir müssen endlich erkennen: Die Zukunft unseres Landes und das Wohl unseres Volkes hängen weitgehend von unseren eigenen Anstrengungen, von unseren eigenen Leistungen ab.“133

Folglich dürfe man nicht zulassen, wenn „Nicht-Könner in der Wirtschaft" ${ }^{\text {“134 }}$ sich mit dem Nein zum EWR herausredeten. Sowohl die politische Krise als auch die wirtschaftliche Rezession der frühen 1990er Jahre ist personell und nicht strukturell bedingt, wie die Wirtschaftseliten glauben machen wollten. Blochers Diskurs ist durchweg personen- und handlungszentriert. Denn nicht nur für die Krise werden handelnde Personen in die Verantwortung genommen. Es sind auch konkrete Akteure, denen die Fähigkeiten zugesprochen werden, den diagnostizierten Mangel zu kompensieren. Da sind ein ,vitales Volk', die „eigentlichen, persönlich für ihren Betrieb verantwortlichen Unternehmer “'135, die von ,den Managern der Grosskonzerne' differenziert werden müssen, und natürlich die auftragsgebundene Zürcher SVP und ihr standfester Führer.

Mit dem erfolgreichen Kampf gegen den EWR ist die Zürcher SVP zur politischen Protagonistin eines konservativen Nationalbewusstseins geworden, das zuvor insbesondere von der CVP hegemonisiert worden war. ${ }^{136}$ Entgegen des tradierten Selbstverständnisses der politischen Schweiz als multikulturelle, konkordanzdemokratisch integrierte Nation führte die Abstimmungskampagne im Vorfeld des Volksentscheids zu einer binären Spaltung des politischen Raumes, welche die Zürcher SVP in den folgenden Jahren erfolgreich perpetuierte. Wohingegen die EWR-Befürworter eine sich entwickelnde, konkordanzdemokratisch prozeduralisierende Schweizer Identität propagierten, die sich der veränderten geostrategischen Lage in Europa anpassen könne und müsse, konstruierten die Gegner des EWR zwei antagonistische, historisch verankerte Entitäten, deren imaginäre Organizität auf dem Antagonismus gründet, der sie voneinander trennt. Dabei transformiert der SVP-Populismus die partikulare politische Differenz ,pro-oder-contra-EWR' in eine antagonistische Grenze, die zwei unvereinbare Lebensformen voneinander trennt.

133 Ebd.: 16.

134 Blocher zit. in Hartmann/Horvath 1995: 117.

135 Brunner/Blocher/Schlüer 1993: 84.

136 Vgl. Lang 2000: 97. 
Der Strategie, die Debatte über den EWR vom konkreten ,Inhalt der Vorlage“ auf die universellere „Bedeutung der Abstimmung“ zu verlagern, die zu Beginn des EWR-Kapitels als Schlüssel für den Erfolg von Blocher \& Co präsentiert wurde, ${ }^{137}$ liegt demnach eine antagonistische Konstruktionslogik zugrunde, welche die Bedeutung der Europäischen Integration als bedrohliche Antinomie einer blockierten schweizerischen Selbstidentität fixiert. Der SVP-Diskurs gruppiert die Eigenschaften der politischen Systeme, die physisch-moralischen Konditionen und die ideologischen Leitdifferenzen innerhalb zweier antagonistischer Matrizen. Anhand der EWR-Frage eröffnet er einen diskursiven Verweisraum, der in der Lage ist, vielfältige Differenzen zu einer Wir-Gruppe zusammenzuschließen. Die Kohäsion dieses ,Wir‘ ist dabei abhängig von der Präsenz der SieGruppe. Ihre Einheit gründet darauf, dass gewisse Differenzen (Sozialismus, Intellektualität, Krankheit, Schwäche, Bürokratie etc.) als ,bedrohlich‘, ,europäisch' und ,unschweizerisch' ausgeschlossen werden. Auf diese Weise konstituiert der Mythos des Sonderfalls, den die Zürcher SVP in der Auseinandersetzung mit einer uniformierenden EG aktualisiert, eine subjektiv begehrenswerte populare Identität eines ökonomisch starken, unabhängigen, eigenverantwortlichen, bodenständigen und sich selbst regierenden Schweizervolkes, dessen volle Realisierung durch eine antagonistische Sie-Gruppe blockiert ist.

Quantitative Wahlanalysen wie jene von Kriesi u.a. ${ }^{138}$ sind selbstverständlich in der Lage, die Korrelationen zwischen der Ablehnung des EWR und den politischen Einstellungen gegenüber den enummerierten Differenzen zu belegen. Ihnen entgeht jedoch, dass diese Korrelationen ihrerseits politisch konstruiert sind und dass die gemeinsam artikulierten Differenzen im Zuge dieser Artikulation ihre begrenzte Bedeutung transzendieren. Denn durch die äquivalenzlogisch erwirkte Überdeterminierung verwandeln sich die Differenzen in Symptome einer tieferliegenden, allgemeinen Malaise. Partikulare Entscheidungen, die bestimmte Erwartungen nicht erfüllen oder widersprechen, werden so zu Eponymen eines universellen Konfliktes zwischen einer ,dekadenten, unschweizerischen, sozialistisch-totalitären und machthungrigen politischen Klasse“ und einer , auftragsgebundenen, gesunden und starken Zürcher SVP‘. Durch die Konstruktion dieses Konfliktszenarios avanciert Blochers Partei zum Repräsentanten des popularen Allgemeinen, der blockierten Identität des Schweizervolkes. 


\subsection{ZUSAMMENFASSUNG: DIE , ORIENTIERUNGSLOSE POLITISCHE KLASSE“ UND DIE ÜBERDETERMINIERUNG DER POPULAREN ÄQUIVALENZ}

Die skizzierte Hegemonisierung der abwesenden Fülle, die sich im Zuge der Debatte um die europäische Integration vollzieht, verdichtet sich im Slogan der ,orientierungslosen politischen Elite'. Bemerkenswert ist dieser Slogan in zweierlei Hinsicht.

Erstens schließt er an die konservative Modernekritik an, wie sie etwa der Schweizer Rechtsintellektuelle Eduard Stäuble in seiner historisch-genetischen Krisendiagnose der schweizerischen Gesellschaft aktualisiert. ${ }^{139}$ Demnach habe die Entfremdung von identitätsstiftenden Werten und Traditionen die Allgemeinverbindlichkeit der autoritativen Institutionen (Kirche, Staat, Ehe, Familie, Beruf) untergraben und eine ,allgemeine Orientierungskrise“, eine „totale Verunsicherung“" ausgelöst. ${ }^{140}$ Als Wurzel allen Übels fungiert der nihilistische Zeitgeist. Die verschiedenartigen Pathologien der modernen Gesellschaft werden hingegen lediglich als Symptome respektive Kompensationsversuche gelesen: Ein „grenzenlos entarteter Individualismus“, „egoistische Selbstverwirklichung“ und ein „krankhafter [...] Narzissmus“ veranlasse die Menschen, die „nihilistische Leere“ mit „Geld und Macht" zu tarnen, durch maßlosen Konsum und eine ebenso maßlose Freizeitgestaltung zu kompensieren, um sich schließlich in Drogen und den neumodischen Hochrisikosportarten zu verlieren, so Stäubles Argument. ${ }^{141}$

Diese äquivalenzlogische Artikulation von Dekadenz, Egoismus, Hedonismus, Maßlosigkeit, Langeweile und Sucht, die in der konservativen Kritik der Moderne als Spätfolgen eines anonymen Zeitgeists gefasst werden, variiert der SVP-Populismus im Slogan der orientierungslosen politischen Klasse. Die Depravation liegt nicht in erster Linie in den von Stäuble anvisierten Modernisierungs- und Laizisierungsprozessen begründet, das absolute Übel rührt von einer politische Klasse her, die nicht nur selbst von der modernen Orientierungskrise betroffen ist, sondern diese Unwerte propagiert und politisch subventioniert, die Tugenden des Schweizervolkes dagegen verlacht, seine Substanz zu zersetzen versucht, um es schließlich im Rahmen der europäischen Integration vollends zu

139 Stäuble 1999.

140 Ebd.: $13 \mathrm{ff}$.

141 Ebd.: $14 \mathrm{ff}$. 
entwurzeln und zu entmachten. Strukturbildend wirkt auch hier die Trias ,Dekadenz, Apokalypse, Heroismus‘. Denn auf die Dekadenz (Nihilismus, Orientierungskrise, Maßlosigkeit, Narzissmus, etc.) folgt angesichts der drohenden Apokalypse (EU-Beitritt und Verlust der lokalen Selbstbestimmung) die heroische Geste. Erweckt durch den auftragsgebundenen Widerstand Blochers besinnt sich eine im Grunde parochiale, allenfalls subsidiär organisierte Bürgerschaft ihrer gemeinsamen nationalen Identität, ihrer Vitalität und ihres Mutes. Der Widerstand gegen den EWR dient also nicht nur der Abwehr einer internationalen Organisation mit weitreichenden politischen Steuerungskompetenzen und dem Erhalt der Souveränität des Schweizervolkes. Die Kritik einer orientierungslosen politischen Klasse stilisiert Blocher und seine Partei zugleich zu jenen politischen Autoritäten, die allein aufgrund der Tatsache, dass sie eine bestimmte Richtung vorgeben, den Glauben erwecken, sie allein seien in der Lage, einen allgemeinen Mangel zu kompensieren.

Zweitens erlaubt der Vorwurf der Orientierungslosigkeit aufgrund seiner inhaltlichen Vagheit das bürgerliche Lager zu spalten. Das antagonistische Andere der Zürcher SVP beschränkt sich nicht mehr auf die Sozialdemokratie, die mit dem realexistierenden Sozialismus sympathisiere, und die Neue Linke, deren Wachstumskritik zu Faulheit und Sinnverlust führe. Es umfasst nun auch die bürgerliche, staatstragende Allianz. Auf der einen Seite konstituiert diese Verschiebung der Wir-Sie-Grenze das Anti-Subjekt des Volkes: eine politische Klasse, deren interne Differenzen nur Facetten ein und derselben ,unschweizerischen' Alterität sind. ${ }^{142}$ Auf der anderen Seite begründet dieser Antagonismus eine populare Identifikationsschablone, die ebenfalls vielfältige Differenzen absorbiert. Dieses inklusive ,Wir ${ }^{6}$ umfasst neoliberale Forderungen nach Deregulierung, Flexibilisierung und Steuersenkungen, protektionistische Interessen wie die Subvention der Landwirtschaft und die steuerlichen Privilegien des heimischen Kleingewerbes, migrations-, sicherheits- und außenpolitische Aspekte wie die Begrenzung der Zuwanderung, die Wahrung der Neutralität, der direkten Demokratie und der Unabhängigkeit, die Erhöhung der Ausgaben im Sicherheitssektor und härtere Strafmaßnahmen für Delinquenten. Gegen die Orientierungslosigkeit der politischen Klasse formieren sich ferner wertkonservative Forderungen wie eine ,geistig-moralischen Erneuerung“, eine Erziehungspolitik, die nicht auf ökonomisches Wachstum und Effizienz zielt, sondern das „Wesen des Menschen“ ins Zentrum stellt, eine Wirtschaftspolitik, die akzeptiert, „dass in einer endlichen Welt unendliches Wachstum schlechterdings nicht möglich ist“, eine Beschäftigungspolitik, die Arbeit nicht lediglich auf einen „Kostenfak- 
tor“ reduziert, sondern als „,integrierenden Bestandteil der menschlichen Existenz" begreift. ${ }^{143}$ Nicht zuletzt artikulierte die nationalkonservative Oppositionspolitik, die der Zürcher Flügel mit seinen Angriffen auf den moralistischen Duktus der ,Heimatmüden ${ }^{144}$ und der ,Linken und Netten ${ }^{6145}$ sowie auf den Imperialismus der EU fortführte, auch Elemente, die ehedem mit der extremen Rechten assoziiert waren. So tauchten am Rande von Blochers öffentlichen Auftritten immer häufiger Rechtsextremisten auf, die den Präsidenten der Zürcher SVP zu ihrer Führerfigur stilisierten. ${ }^{146}$ Und auch personell manifestierte sich der Rechtsruck der Partei. Mit Pascal Junod, einem antisemitischen Protagonisten der Neuen Rechten, und Roger Etter, der sich öffentlich mit der Waffen-SS sympathisierte, waren im Verlauf der 1990er Figuren zur SVP gestoßen, die das kulturelle Kapital der langjährigen Regierungspartei gefährdeten und Blochers Idee, mit einem ,maßvollen, gesunden Patriotismus' dem ,gefährlichen Extremismus' den Nährboden zu entziehen, ad absurdum führten. ${ }^{147}$

Der leere Signifikant der ,orientierungslosen politischen Klasse‘ impliziert keineswegs zwangsläufig eine liberal-konservative Reformagenda, auch wenn Blocher diese Bedeutung mit seiner Kritik an einer bürokratisch-zentralistischen und insofern sozialistisch-totalitären EU zu fixieren versuchte. Der Slogan zeigte sich vielmehr anschlussfähig für ein heterogenes Spektrum von politischen

143 Ebd.

144 Dieser Slogan prägte den SVP-Wahlkampf zu den Nationalratswahlen 1995.

145 Mit diesem Slogan politisierte die Zürcher SVP erstmals im Herbst 1993, nachdem eine 20-jährige Pfadführerin im Kanton Zürich erstochen wurde (vgl. Hartmann/ Horvath 1995: 136). Neben den Umrissen eines Messerstechers stand zu lesen „Das haben wir den Linken und Netten zu verdanken: mehr Kriminalität, mehr Drogen, mehr Angst“. Der tradierte Antagonismus gegenüber den Sozialdemokraten wurde mit dieser Formel ausgebaut; von nun an grenzte sich die Partei nicht nur gegen die ,Linken', sondern auch gegen die ,Netten` der bürgerliche Mitteparteien ab.

146 Für die in Deutschland erscheinende rechtsextremistische Zeitschrift „Sprung auf ... Marsch, marsch“ war Blocher der ,mit Abstand nationalste und mutigste Redner“, zit. nach: [o.A.] FACTS, 21.10.1999.

147 So warnte etwa Hanspeter Kriesi (1999b) in einem Interview mit dem Bieler Tagblatt vor dem sukzessiven Rechtsruck der Partei: „Rechtsradikale Elemente schleichen sich in die Partei ein, die dadurch instrumentalisiert und radikalisiert zu werden droht.“ Der Rechtsextremismus-Experte Jürg Frischknecht (1991: 257) warnte bereits 1991 vor einer ,unheiligen Symbiose“ zwischen Rechtsradikalen und den reaktionären Strömungen in der SVP. Gegen Junod und Etter leitete die SVP auf öffentlichen Druck hin Parteiausschlussverfahren ein. 
Standpunkten, das von einer staatsinterventionistischen Beschäftigungspolitik, über eine konservativ-ökologische Wachstumskritik, einen antietatistischen Neoliberalismus bis hin zu rechtsextremistischen Positionen reichte. Die SVP verwandelte sich in der Folge zum ideologischen Auffangbecken für marginalisierte Forderungen und Ideologien unterschiedlicher Couleur. 



\section{Die Heydays des SVP-Populismus und die rechtspopulistische Hegemonisierung des nationalpopularen Imaginären}

Die zuletzt konstatierte Heterogenität der gemeinsam artikulierten Differenzen verweist auf das grundlegende Dilemma populistischer Projekte. Zum einen hängt ihr Erfolg davon ab, dass sie möglichst viele Standpunkte, Forderungen und Ziele in sich vereinigen. Nur unter der Bedingung einer weitreichenden, integrativen Äquivalenz können sich ihre partikularen Agenden semantisch in ein subjektiv begehrtes, abwesendes Allgemeines transformieren. Zum anderen droht bei Ausuferung der Äquivalenz und zunehmender Inkompatibilität der verknüpften Differenzen die Zersplitterung in unterschiedliche Lager. Wenn die Äquivalenz gegen unendlich läuft, wird sie unbeherrschbar, die Zahl potentieller innerer Antagonismen und mit ihr die Wahrscheinlichkeit der Implosion steigt. Begrenzt ein politisches Projekt dagegen die Äquivalenz, indem es bestimmte Momente ausschließt, erhöht sich zwar seine Kohärenz, doch reduziert sich seine Integrationskraft gegenüber unerfüllten Forderungen und marginalisierten Positionen. Die folgende Analyse, die bei den Nationalratswahlen von 1999 ansetzt, soll zeigen, mit welchen Strategien die SVP diesem Dilemma begegnet, um einen außerordentlich stabilen populistischen Diskurs zu kreieren.

\subsection{Die Nationalratswahlen 1999}

\section{A) Das Ereignis}

Trotz des sensationellen Erfolgs bei der EWR-Abstimmung hatte die SVP bei den Nationalratswahlen von 1995 nur vergleichsweise geringe Zuwächse erzielt. Mit 14,9 Prozent war sie hinter der SP, der FDP und der CVP die schwächste im 
Bundesrat vertretene Partei geblieben. Fünf Jahre später, bei den Nationalratswahlen am 24. Oktober 1999 verbuchte sie einen ,erdrutschartigen Sieg“"1. Die Partei erreichte 22,5 Prozent. Sie konnte ihren Stimmanteil um 7,6 Prozentpunkte steigern und war gemeinsam mit der SP die stärkste politische Kraft des Landes. Erstmals konnte sie landesweit reüssieren. Auch dort, wo die Partei bis dahin kaum oder gar nicht präsent war, in großstädtischen Kantonen wie Basel und Genf oder in der Westschweiz, in den Kantonen Freiburg, Waadt und Wallis, verbuchte sie signifikante Stimmzuwächse. In den neuen Hochburgen der Ostund Zentralschweiz erreichten die Blocher-treuen Kantonssektionen bis zu 40 Prozent.

Das Wahlprogramm war erstmals maßgeblich vom Zürcher Flügel geprägt. Die SVP forderte eine Senkung der Staatsquote, mehr Freiheit und Selbstverantwortung, mehr Polizeipräsenz, die Wahrung einer unabhängigen, neutralen und souveränen Schweiz, sowie die Reduktion der Fürsorgeleistungen für Asylbewerber. ${ }^{2}$ Nach der Wahl war sich daher nicht nur Blocher sicher, dass der Erfolg der SVP im Wesentlichen von der Kantonssektion Zürich ausginge; auch für mittelinksgerichtete Zeitungen wie etwa die französischsprachige Le Temps stand fest, dass die SVP ihren Wahlsieg auf der nationalen Ebene der politischen Arbeit des Zürcher Flügels zu verdanken habe. Schließlich hatte die Zürcher Sektion bereits im April, bei den Kantonsratswahlen für ein politisches Vorbeben gesorgt, als sie 60 der 180 Sitze holte. ${ }^{3}$

Der Stimmzuwachs der SVP ging in erster Linie zu Lasten der bürgerlichen Mitte $^{4}$ sowie zu Lasten der Kleinst- und Kleinparteien des rechten Randes. ${ }^{5}$ Trotz des Rechtsrucks der Partei strömten die Wähler/innen also von beiden Seiten zur SVP.

Aufgrund der signifikanten Machtverschiebungen beanspruchte die SVP nach den Nationalratswahlen einen zweiten Bundesratssitz und die anderen Parteien erkannten diese Forderung prinzipiell an. Als die SVP jedoch beschloss,

1 Longchamp 2000: 394.

2 SVP-Parteiprogramm 1999.

3 Blocher zit. in: Banz 1999 u. Hans 1999.

4 Die FDP verpasste erstmals in ihrer Geschichte die 20 Prozentmarke, die CVP erreichte nur 15,9 Prozent.

5 Vgl. Longchamp 2000: 409. Vergleicht man die Wählerwanderungen mit anderen europäischen Staaten, fällt auf, dass relativ wenige Wähler von der SP zur SVP wechseln, wohingegen sich die Wähler/innen anderer rechtspopulistischer Parteien zu großen Teilen aus einem sozialdemokratischen Milieu rekrutieren (vgl. Longchamp 2000: 409). 
mit der Kampfkandidatur Christoph Blochers nicht gegen die Bundesräte der stark geschwächten CVP, sondern gegen die SP und ihre Bundesräte Moritz Leuenberger und Ruth Dreifuss anzutreten, stimmten auch die Fraktionen der bürgerlichen Parteien mit dem Verweis auf die Unantastbarkeit des Konkordanzprinzips mehrheitlich für Leuenberger und Dreifuss. Somit änderte sich die Zusammensetzung der Regierung trotz der außerordentlichen Wählerbewegungen nicht: Die SP, die FDP und die CVP stellten jeweils zwei Bundesräte, die SVP als Wahlsiegerin lediglich einen Bundesrat, der weiterhin durch Blochers wichtigsten innerparteilichen Gegenspieler, den moderaten Berner Adolf Ogi eingenommen wurde. ${ }^{6}$

Der nationalkonservative Parteiflügel drohte daraufhin mit dem Gang in die Opposition und als Ursula Koch, die Präsidentin der SP, die Bildung einer „Koalition der Vernunft" (aus FDP, CVP und SP) vorschlug, ${ }^{7}$ griffen Blocher \& Co diese politische Kampfansage gerne auf. Denn entgegen anderer Vorstöße innerhalb der SP, die auch um eine scharfe Abgrenzung von den Freisinnigen bemüht waren, leistete dieser Slogan nichts anderes, als die von der Zürcher SVP vorangetriebene Spaltung des politischen Raumes zu affirmieren. ${ }^{8}$ In Kochs Selbstbeschreibung fand der populistische SVP-Flügel sein ideales politisches Pendant: ein in ,Orientierungslosigkeit, Internationalismus und Staatsgläubigkeit geeintes kosmopolitisches Anderes', das sich als rationales und progressives Anderes stilisiert. Für die SVP galt es lediglich, die antagonistische Leitdifferenz des Sozialliberalismus ,fortschrittlich-vernünftig/reaktionär-unaufgeklärt' in die eigene Leitdifferenz, fremd/heimisch` zu übersetzen.

6 Ogi trat bereits ein Jahr später, im Dezember 2000 zurück. Das Parlament lehnte die offiziellen Bundesratskandidaten der SVP, die Zürcher Regierungsrätin Rita Fuhrer und den Thurgauer Regierungsrat Roland Eberle ab und wählte mit Samuel Schmid erneut einen Vertreter des Berner Flügels in den Bundesrat.

7 Vgl. Bürgi 1999: 182.

8 Der Fraktionsvorsitzende der SP, Franco Cavalli, räumte dagegen ein, dass die Sozialdemokratie genau mit derlei Formeln wie sie im Rahmen der Konzeptionen des Dritten Weges, der Neuen Mitte und der Politik der Mitte zuhauf finden, mitverantwortlich für den Aufstieg des Rechtspopulismus in Europa sei (Cavalli, zit. nach: [o.A.] NZZ 148/2000). Für eine linke Kritik an der Mitte-Orientierung der SP vgl. Lang 2000: 108 . 


\section{B) Kontext und Wahlkampf: Die Polarisierung des gemäßigt pluralistischen Parteiensystems}

Wohingegen die SVP Schweiz in der Wirtschafts- und Sozialpolitik sowie in der Außen-, Migrations- und Sicherheitspolitik dem Zürcher Kurs folgte, schoben die Delegierten der Akzentuierung des populistisch-oppositionellen Profils, die Blocher mit seinen Vorschlägen zur Stärkung der direkten Demokratie fortführte, einen Riegel vor. Bereits im Vorjahr war Blocher innerparteilich heftig kritisiert worden, nachdem er auf dem Albisgüetli für die Direktwahl des Bundesrates geworben hatte, um den ,verkommenen, undurchsichtigen Ränkespielereien der Parlamentarier“ zu beenden und die ,heutige Scheinkontrolle durch Parlament und Medien“ durch eine ,wirkungsvollere Kontrolle unserer Regierung durch das Volk“ zu ersetzen. ${ }^{9}$ Als er im Wahljahr gemeinsam mit Vertretern der Schweizer Demokraten, der Freiheitspartei und der Lega eine Initiative ankündigte, nach der eingereichte Initiativen künftig innerhalb einer verbindlichen Frist von sechs Monaten der Abstimmung zu unterbreiten sind, fand er dafür ebenfalls keine Mehrheit in der Partei. ${ }^{10}$ Zumal er sich mit dem Untertitel der einschlägigen Annonce Wenn in der Schweiz das Volk spricht, haben Politiker zu schweigen den Vorwurf einhandelte, die etablierten checks and balances der Schweizer Demokratie aus dem Gleichgewicht zu bringen. ${ }^{11}$

Als strategisch kluger Schachzug erwies sich dagegen der Plan, unter Ausschluss der SP eine bürgerliche Regierung zu bilden. ${ }^{12}$ Zwar hatte Blochers Vorhaben keine Aussicht auf Erfolg, da die FDP, die CVP und auch der gemäßigte SVP-Flügel nicht bereit waren, die SP von der Regierung auszuschließen und mit der Zauberformel und der Konkordanz zu brechen, doch verlangte es der bürgerlichen Mitte $a b$, sich innerhalb des von Blocher entworfenen binären Dis-

9 Blocher 1998.

10 Die Initiative für die Direktwahl des Bundesrates brachte die SVP erst im Jahr 2013 vors Volk und wurde mit 76,3 zu 23,7 Prozent deutlich abgelehnt. Die sogenannte Maulkorb-Initiative wurde 2003 von dem rechten Verein Bürger für Bürger unter dem Namen „Volkssouveränität statt Behördenpropaganda“ neu aufgelegt, scheiterte aber beim Referendum trotz der Unterstützung der SVP mit 75,2 zu 24,8 Prozent ebenfalls deutlich.

11 So etwa seitens des FDP-Bundesrates Pascal Couchepin (Blocher/Couchepin 1999). Die von ihren Gegnern als „Maulkorb-Initiative“ titulierte Volksbegehren verbot Bundesrat und Parlament zwar nicht etwa die Stellungnahme zu künftigen Initiativen, doch schränkte es die Reaktionsmöglichkeiten des Parlamentes stark ein.

12 Blocher 1999a. 
sens-Szenarios zu positionieren. Die kalkulierte Absage von Seiten der CVP, der FDP und Teilen der eigenen Partei führte den Wählern vor Augen, dass die bürgerliche Mitte lieber mit der SP kooperierte, als mit der Zürcher SVP für eine bürgerliche Schweiz zu politisieren.

\section{C) Folgen der Nationalratswahlen: Die Radikalisierung der SVP und die Dislokation des Konkordanzsystems}

Zusammenfassend lassen sich folgende vier Punkte festhalten:

(1) Die SVP Schweiz stimmte inzwischen mit der Mehrzahl der politischen Forderungen des Zürcher Flügels überein. Die Partei sah ihre Zukunft als rechte Alternative zu CVP und FDP. Strittig war dagegen die strategische Positionierung gegenüber den politischen Gegnern: Nach wie vor warnten die Spitzen der Berner SVP vor der harten Oppositionspolitik des Zürcher Flügels, ihrem ,chronischen Neinsager-Kurs', vor der Allianz mit der AUNS und ihrem vehementen politischen Stil. Blocher warf den Bernern dagegen „die Verachtung des Volkes“"13 vor und profilierte die Partei als bedingungslose Oppositionspartei.

(2) Nach der Nationalratswahl, als sich die SVP hinter Blochers Plan stellte, gegen die SP-Bundesräte zu kandidieren, spiegelten die anderen Parteien die von der Zürcher SVP intendierte Vereinfachung des politischen Raumes erneut, indem sie sich selbst als pragmatisch-problemlösende ,Koalition der Vernunft', die SVP als ideologisch verbohrte Partei präsentierten.

(3) Die Nationalratswahlen bewirkten, wie Claude Longchamp in seiner Wahlanalyse treffend konstatiert, in erster Linie eine „Umgruppierung des bürgerlichen Lagers“. Aus drei „kulturell determinierten und regional definierten Repräsentationsparteien", die sich ihre Machtanteile nicht streitig machen, seien politische Richtungsparteien geworden, die miteinander konkurrieren. $^{14}$

(4) Im Zuge dieser Transformation des bürgerlichen Lagers ging auch der gemäßigt pluralistische Charakter des Parteiensystems verloren, wodurch wiederum das Konkordanzsystem zur Disposition stand. Denn Kompromisse, Verlässlichkeit und Kollegialität schienen mit einer fundamentaloppositionellen SVP nicht mehr praktikabel.

13 Zit. nach: Institut für Politikwissenschaft der Universität Bern [o.J.]: 14.

14 Longchamp 2000: 415. 


\section{D) Politologische Ursachenanalysen des SVP-Wahlerfolges}

Die von Claude Longchamp geleitete quantitative Wahlanalyse der Gesellschaft für praktische Sozialforschung macht deutlich, dass der Erfolg der SVP keineswegs auf einer klientelpolitischen Strategie gründet. ${ }^{15}$ Wenngleich die Partei bei ihren traditionellen Stammwählern (Protestanten, Mittelständlern, Bürgern mit geringem Einkommen, Männern und Bewohnern des ländlichen Raumes) nach wie vor überproportional erfolgreich ist und bei bestimmten Wählergruppen, wie etwa den Katholiken besonders große Zuwächse verbuchen konnte, büßte sie bei keiner der untersuchten Bevölkerungsgruppen (auch nicht bei den Arbeitnehmern, Bürgern mit hohem Einkommen, Frauen und Städtern) Stimmen ein. ${ }^{16}$ Vielmehr bilde die radikalisierte SVP aus Longchamps Sicht ein „neues und starkes Gravitationszentrum im bürgerlichen Lager“'17, das „,verschiedenartige, volatile Potentiale der schweizerischen Wählerschaft ${ }^{\star 18}$ angesprochen habe. Der Aufschwung der SVP sei auf ein „Zusammenspiel von Unzufriedenheit und Protestverhalten“"19 zurückzuführen, dabei habe die Partei von „spezifischen Umständen im Wahljahr“'20 profitieren können.

Wenngleich die SVP bei den Nationalratswahlen 1999 von besonderen Umständen profitiert haben mag, lässt sich das Wahlergebnis aus heutiger Sicht, vor dem Hintergrund der außerordentlichen Kontinuität ihrer Erfolge seit 2000 weder durch „,volatile Potentiale، ${ }^{، 21}$ erklären noch als ephemerer Ausschlag bagatellisieren.

15 Vgl. Longchamp 2000.

16 Vgl. ebd.: 405ff. Zu den markanten Stimmzuwächsen der SVP in der katholischen Wählerschaft vgl. Hirter 2000: 17.

17 Longchamp 2000: 415.

18 Ebd.: 408.

19 Ebd.: 408.

20 Ebd.: 416. Zu nennen sind in erster Linie drei Ereignisse: (1) Die gewaltsame Eskalation des Kosovokonflikts erhöhte die Virulenz von zwei privilegierten Politikfeldern der SVP : Außen- und Sicherheitspolitik sowie die Asylpolitik (vgl. SVP 1999a). (2) Zudem profitierte die SVP davon, dass sich die FDP stärker in der Mitte des politischen Spektrums positionieren wollte und sich dabei an der von Schröder und Blair verkörperten Idee der Neuen Mitte orientierte. (3) Schließlich konnte die SVP den Skandal um Blochers „unbewusstes“ Lob eines Holocaust-Leugners für sich nutzen, indem sie die Affäre als „Schmutzkampagne“ diskursivierte.

21 Longchamp 2000: 408. 
In diese Richtung argumentierte der Politologe Hanspeter Kriesi bereits im Jahr 2002. Kriesi geht davon aus, dass die Identitätskrise, in welche die Schweiz im Zuge der Debatten um den Eizenstat-Bericht und die Infragestellung der Rolle der Schweiz im Zweiten Weltkrieg in der zweiten Hälfte der 1990er Jahre geraten war, den Hintergrund für den Durchbruch der SVP darstellt. Er belegt, dass die verbreitete Identifikation mit der Geschichte der Schweizer Nation den Ausschlag für den Wahlerfolg der SVP gab, wobei er die nationale Identität der Schweiz anhand des Nationalstolzes und der Rechtmäßigkeit der Kritik an der Rolle der Schweiz im Zweiten Weltkrieg messbar zu machen versucht. ${ }^{22}$

Der Schwachpunkt dieser Argumentation besteht indes nicht nur in einer streitbaren Operationalisierung nationaler Identität. Das Problem dieser Analyse ist vielmehr theoretischer Natur. Wenn Kriesi nationale Identität als maßgebliche unabhängige Variable für die Wahlentscheidung begreift, dann präsupponiert er ein stabiles Nationalbewusstsein, einen vorpolitischen Modus des Selbstverstehens der Schweizer/innen, der immer schon als solcher existent war, aber erst im Wahljahr 1999 politisch virulent wurde. Diese Perspektivierung lässt den Erfolg der SVP als Ausdruck einer vermeintlich monolithischen und primordialen Entität erscheinen und blendet aus, dass nationale Identität erst im Zuge eines konfliktimmanenten Konstruktionsprozesses hergestellt und aktualisiert wird. Und mehr noch: Indem sie diese Kollektividentität nicht als Effekt, sondern als Basis der Rhetorik der SVP konzipiert, läuft sie Gefahr, die identitätspolitische Hegemonie der SVP schlichtweg zu reproduzieren. ${ }^{23}$

Ähnliches gilt für die Untersuchung von Matthias Brunner und Pascal Sciarini sowie für jene von Simon Bornschier und Marc Helbing. ${ }^{24}$ Die Politologen belegen anhand empirischer Umfragen, dass die Konfliktlinie zwischen ,Öffnung und Abgrenzung', mit der die SVP politisiert, zur strukturierenden Konfliktlinie des Schweizer Parteiensystems avanciert ist. Sie fragen jedoch nicht nach der Einrichtung dieser Cleavage, sondern führen sie auf eine vorpolitische Transformation von Werten, Einstellungen, Interessen und Zukunftserwartungen zurück. Auch hier suggeriert das Erklärungsmodell, die Identitätspolitik der Zürcher SVP sei nichts weiter als das kongruente politische Abbild eines ge-

22 Vgl. Kriesi 2002.

23 Die Tatsache, dass Kriesi nationale Identität anhand des Nationalstolzes und der Zurückweisung der Kritik der Schweiz im Zweiten Weltkrieg operationalisiert (Kriesi 2002: 569f.), lässt darauf schließen, dass er der Identitätspolitik der SVP auch praktisch aufsitzt.

24 Vgl. Brunner/Sciarini 2002 u. Bornschier/Helbing 2005: 32ff. 
gebenen Willens, ihre Rhetorik nichts weiter als der opportunistische Versuch, eine milieu- oder schichtenspezifische Nachfrage zu saturieren. ${ }^{25}$

\title{
5.2 Geschichtspolitik: Die Konstruktion EINES HEARTLAND
}

\author{
„Meine Damen und Herren, die Gegenwart ist \\ nichts anderes als eine Fortsetzung dieser ewi- \\ gen Auseinandersetzungen zwischen Freiheit \\ und Unfreiheit.“
}

BLOCHER 2011A: 12

Im Unterschied zu diesen Erklärungsansätzen beschäftige ich mich nicht mit der sozialstrukturell bedingten Nachfrage nach dem Politikangebot der SVP, sondern fokussiere den performativen Effekt ihrer Rhetorik. Mir geht es um die diskursive Organisation des besagten „Zusammenspiels von Unzufriedenheit und Protestverhalten“26. Denn erst aufgrund dieser Organisation konnte die SVP zum besagten politischen „Gravitationszentrum“27 innerhalb des bürgerlichen Lagers avancieren und die rural geprägten, ehemals CVP-dominierten „katholischen Stammlande ${ }^{628}$ der Schweiz erobern. Die von Brunner, Sciarini, Bornschier und Helbing konstatierte Virulenz der Konfliktlinie zwischen ,Öffnung und Abgrenzung' spielt dabei eine ebenso zentrale Rolle wie die von Kriesi fokussierte Krise und Restauration der nationalen Identität, doch werden sie nicht schlichtweg vorausgesetzt. Es wird vielmehr gezeigt, wie der SVP-Populismus die Bedeu-

25 Marc Helbing (2011) und Simon Bornschier (2009 u. 2010) machen dieses Problem in späteren Publikationen explizit. So betont etwa Helbing, dass rechtspopulistische Parteien diese Konfliktlinie „mitstrukturieren“ und „traditionelle kollektive Identitäten, die auf Klasse und Religion basierten, spalten“ (2011: 14f.). Simon Borschier (2009: 14) argumentiert, dass sich die zukünftige Forschung politischen Akteuren mehr Bedeutung bei der Kreation der Konfliktlinien zusprechen müsse. Dagegen wurde hier argumentiert, dass das Struktur-Akteurs-Modell, an dem Helbing und Bornschier festhalten, die sozialperformative Quintessenz von populistischer Politik im Spezifischen und von Politik im Allgemeinen systematisch verfehlt.

26 Longchamp 2000: 408.

27 Ebd. : 415.

28 Lang 2000: 97. 
tung der Nation im Rahmen eines populistischen Gemeinschaftsmythos fixierte und als milieu- und schichtenübergreifende identitätsstiftende Instanz revitalisierte.

In den Mittelpunkt rückt damit in erster Linie die Reinterpretation der Schweizer Geschichte. Denn im Rahmen der Geschichtspolitik gelang es Blocher \& Co, die traditionell identitätsstiftenden Begriffe der politischen Schweiz mit dem eigenen ideologischen Repertoire zu verweben und sich zu den neuen Helden einer Schweizer Universalgeschichte zu stilisieren. Mein Erkenntnisinteresse richtet sich daher erneut auf die Hegemonie der Zürcher SVP in der Konstruktion nationaler Identität.

Im Zentrum steht hierbei in erster Linie der Begriff des ,Schweizer Sonderfalls'. Denn dieser Begriff, der auch für den ehemals vorherrschenden konkordanzdemokratischen Diskurs einen Ausgangspunkt in der Konstruktion der Willensnation konstituierte, bildet auch im SVP-Populismus den Knotenpunkt, in dem die partikulare Identität des Zürcher Flügels mit der allgemeinen Geschichte der Schweiz vernäht wird. Doch im Unterschied zum konkordanzdemokratischen Diskurs liegt Blochers Diskursivierung des Sonderfalls nicht etwa die Vorstellung einer heterogenen Bevölkerung zugrunde, die nur durch Konsens und Kompromiss integriert werden könne. Die Zürcher SVP postuliert vielmehr eine organisch-natürliche Gemeinschaft. Konstitutiv für diesen Gemeinschaftsmythos ist die Abgrenzung von einem in unterschiedlicher Gestalt wiederkehrenden Bedrohungskomplex, der sich aus einer europäischen Großmacht im Außen und aus zersetzenden Kräften im Innen zusammensetzt. Die Schweiz erscheint in diesem Diskurs nicht als vorbildhafte, konkordanzdemokratisch integrierte Musterrepublik - nicht als spezifische Differenz innerhalb der Gemeinschaft westlicher Demokratien, sondern als letzte Bastion von Freiheit, Pluralismus, Demokratie und Gemeinschaftlichkeit, die durch ein halbtotalitäres, halbchaotisches politisches Umfeld bedroht ist.

Im Zuge dieser Diskursivierung des Sonderfalls wandeln sich auch die Semantiken etablierter Identifikationsbegriffe der politischen Schweiz. Der Pluralismus beispielsweise erscheint angesichts der Bedrohung durch ein europäisches, bürokratisch-zentralistisches und sozialistisch-gleichmacherisches Außen nicht in erster Linie als innenpolitische Herausforderung, der konkordanzdemokratisch begegnet werden muss, sondern als bedrohtes Gut, das es gemeinsam zu beschützen gilt. Das evozierte Konfliktszenario lässt insofern die paradoxale Eventualität eines pluralistischen Populismus erscheinen, dessen kohäsive Wirkung nicht auf einem substantiellen Homogenitätspostulat, sondern auf der Bedrohung durch einen vermeintlich antipluralistischen Antagonisten gründet. Jedoch wird diese Eventualität im Fall des SVP-Populismus durch die geschichtspolitische 
Konstruktion einer parochial-selbstbezogenen, hierarchisch geordneten und harmonischen ,Schweizer Urgesellschaft ${ }^{\star}$ konterkariert, die anstelle von Demokraten „politisierte Nicht-Bürger ${ }^{\text {“29 }}$ hervorbringt.

Im Folgenden versuche ich diese These zu untermauern, indem ich die Geschichtspolitik des SVP-Populismus anhand einer Reihe von Feinanalysen rekonstruiere. Im Mittelpunkt des folgenden Kapitels (5.2.1) steht Blochers Rede „Die Schweiz und der Zweite Weltkrieg“ aus dem Jahr 1997. Ich möchte zeigen, inwiefern die Vorstellung einer ursprünglichen, organischen Gemeinschaft auf die simultane Konstruktion einer anorganischen, zersetzenden Gegengemeinschaft angewiesen ist. Im darauffolgenden Kapitel (5.2.2) folgt sodann eine Analyse der geschichtspolitischen Passagen aus den Albisgüetli-Reden der Jahre $1998^{30}$ und $1999^{31}$, die offenlegt, dass die Hegemonisierung des nationalen Imaginären durch die Zürcher SVP auf einer zyklisch-periodischen Geschichtstheorie gründet, die Vergangenheit, Gegenwart und Zukunft in einem transhistorischen, binär-antagonistisch strukturierten Szenario synchronisiert.

\subsubsection{Das Organische und das Zersetzende}

Im Jahr 1995 erhob der Präsident des Jüdischen Weltkongresses Edgar Bronfmann erstmals öffentlich den Vorwurf, die Schweizer Nationalbank hätte während des Zweiten Weltkrieges Gold gekauft, das von Holocaust-Opfern stammte, und verlangte die Einrichtung eines Fonds für die Hinterbliebenen. Die Nationalbank beteuerte, nichts von der Herkunft etwaiger herrenloser Vermögen gewusst zu haben, räumte aber auch ein, dies nicht ausreichend geprüft zu haben. Um den Vorwürfen auf den Grund zu gehen und die Schweizer Außenhandelspolitik mit Nazi-Deutschland zu untersuchen, setzte die US-Regierung eine Expertenkommission unter dem Vorsitz von Stuart Eizenstat ein. Die Schweizer Regierung beauftragte ihrerseits die Bergier-Kommission, die Außen- und Flüchtlingspolitik der Schweiz während des Zweiten Weltkrieges aufzuarbeiten.

Die Diskussion über das Raub- und Totengold in den Tresoren der Nationalbank weitete sich zu einer Debatte über die allgemeine Rolle der Schweiz im Zweiten Weltkrieg aus. Dabei wurde das ehedem vorherrschende Selbstbild des demokratischen Kleinstaates, der den faschistischen Achsenmächte die Stirn geboten hatte und seine humanitäre Tradition wahren konnte, durch die zeitgenös-

29 Greven 1999: 205.

30 Blocher 1998.

31 Blocher 1999b. 
sische Geschichtsschreibung teilweise infrage gestellt. ${ }^{32}$ Der in der BergierKommission vertretene linke Historiker Jakob Tanner interpretierte das einstige Symbol des nationalen Widerstandswillens des Réduit als Rückzug und attackierte das Neutralitätsprinzip als opportunistische Geste. ${ }^{33}$ Ausländische Medien und Schweizer Intellektuelle wie Adolf Muschg und Jean Ziegler hielten der Identität des hehren, wehrhaften Musterstaates die hässliche Fratze des mitschuldigen Hehlers und Kriegsgewinners entgegen. ${ }^{34}$ Die Historiker Philipp Sarasin und Regina Wecker diagnostizierten „das Ende der Réduit Schweiz“635 und forderten eine „Neuorientierung ${ }^{\text {“36 }}$ eines Schweizbildes. Und auch für die Leitmedien der politischen Mitte stand fest, dass die „tiefen Verstrickungen der Schweizer Wirtschaft“ mit den Achsenmächten den ,selbstgerechten Mythos“ einer neutralen, wehrhaften und unabhängigen Schweiz ein für alle Mal disqualifiziert hätten. ${ }^{37}$

Der Bundesrat äußerte sich zwar kritisch zu einzelnen Vorwürfen Bronfmans und den harschen Wertungen in der Einleitung des Eizenstat-Berichts, zeigte sich aber offen für eine internationale Aufarbeitung der Schweizer Geschichte. ${ }^{38}$ Die diplomatisch-kooperative Position der Regierung bot der Zürcher SVP die Gelegenheit, sich als einzig verbliebene Kraft zu präsentieren, die der Identitätskrise trotze und das positive Selbstbild der Schweizer Nation aufrecht erhielt, indem sie sich der psychologischen Kriegsführung des feindlichen Auslands als den primären Feinden sowie den ,Nestbeschmutzern' und den ,Orientierungslosen“ im Inland als den sekundären Feinden entschlossen entgegenstellte. ${ }^{39}$

Blocher schaltete sich mit zwei längeren Reden in die Debatte ein: Am 1. März 1997 hielt er in Zürich-Oerlikon das Referat Die Schweiz und der Zweite Weltkrieg, am 21. Juni 1997 im Kursaal Bern folgte das Referat Die Schweiz und der Eizenstat-Bericht. ${ }^{40}$ Die folgende Analyse der Geschichtspolitik der Zürcher SVP stützt sich in erster Linie auf die erste Rede, greift aber auch auf die zweite

32 Vgl. Sarasin/Wecker 1998; vgl. auch NZZ-Verlag 1997.

33 Tanner 1998.

34 Muschg 1997a u. 1997b; Ziegler 1998; exemplarisch für die ausländische Berichterstattung vgl. [o.A] Der Spiegel 1997/12.

35 Sarasin/Wecker 1998: 7.

36 Ebd.: 11.

37 Vgl. Berthoud 2001.

38 Vgl. Bundesrat 1997.

39 Die Differenzierung von primären und sekundären Feinden ist inspiriert durch Anton Pelinkas (2012: 17) Begriff der „sekundären Schuldigen“.

40 Blocher 1997a u. 1997b. 
Rede und weitere Artikel zurück, die im Kontext der Debatte in der Schweizerzeit publiziert wurden.

$\mathrm{Zu}$ Beginn des Vortrages Die Schweiz und der Zweite Weltkrieg deutet Blocher die Forschungsergebnisse der Eizenstat- und der Bergier-Kommission als Rezidive:

„Die grossspurig als historische Neuigkeiten angekündigten Sensationen sind allen einigermassen informierten Zeitgenossen längst bekannt. Bis heute ist überhaupt nichts Neues zum Vorschein gekommen, was Interessierten, speziell aber den Verantwortlichen in Politik, Wirtschaft und Gesellschaft nicht längst hätte bekannt sein müssen. Ein Teil davon war schon im Weltkrieg, vor allem aber in den Nachkriegsjahren bei Presse, Parlament und Volk Gegenstand leidenschaftlicher Diskussionen. Die Neutralität im Zweiten Weltkrieg, die Handelspolitik, die Verteidigung des Landes, die Aussen- und die Flüchtlingspolitik, sind und waren Gegenstand zahlreicher historischer Betrachtungen und geschichtlicher Expertisen. In allen neueren Geschichtsbüchern und im Geschichtsunterricht der heutigen Schulen wird all das gesagt, was heute naiverweise als Neuigkeit verkündet und angeprangert wird.“41

Performativ wirksam ist das Deutungsmuster des Rezidivs in zweierlei Hinsicht: Zum einen sorgt es dafür, dass Blocher in seiner Rekonstruktion der Schweizer Geschichte sich nicht an den konkreten Aussagen des Eizenstat-Berichts und der Bergier-Kommission abarbeiten muss, sondern sich mit deren Rezeption, Interpretation und Bewertung befassen kann. Zum anderen wohnt dem Rezidiv selbst eine binär-antagonistische Stoßrichtung inne: Denn es unterscheidet die „Verantwortlichen in Politik, Wirtschaft und Gesellschaft ${ }^{\text {“42 }}$, deren Ignoranz das Neue so erscheinen lässt, von dem historisch Gelehrten Blocher, der das vermeintlich Neue zu enttarnen weiß.

Blochers Gelehrsamkeit trägt indes keineswegs elitäre oder akademische Züge. Nach seiner Darstellung handelt es sich vielmehr um ein populares Allgemeinwissen. Blocher spricht als primus inter pares, als Mann aus dem Volk. Ihn zeichnen Mut, Entschlossenheit und Aufopferungsbereitschaft und nicht primär sein außergewöhnlicher Intellekt aus. Aus dieser Sprecherposition entlarvt er die neuen Erkenntnisse der Experten als Neuauflagen längst bekannten Wissens, wodurch deren Rezeption durch die politische Klasse und die Medien entweder als Zeichen von Inkompetenz oder als politisch motivierte Effekthascherei erscheint.

41 Blocher 1997a: 5f.

42 Ebd.: 5. 
„Die Classe politique verhält sich bei den heutigen schwerwiegenden Angriffen auf unser Land, unser Volk und unser Verhalten während des Zweiten Weltkrieges in etwa so überlegt und gefasst, wie Hühner in einem Hühnerhof, wenn der Fuchs ums Gehege schleicht. Der Grund dafür dürfte in einer krassen, generellen Missachtung der Geschichte durch die verantwortlichen Leute in unserem Staate liegen, als ob man ohne Geschichtskenntnisse Gegenwart und Zukunft gestalten könnte. Diese Weisheit wurde in den letzten Jahren in politischen Kreisen geradezu verlacht und verhöhnt. Unsere Landesregierung und namhafte Wirtschaftsvertreter [...] agieren - oder besser reagieren - höchst widersprüchlich und unglücklich. Sie haben mit ihrem Verhalten, jenen Kreisen, die uns unentwegt attackieren, ständig Auftrieb gegeben. Ein grosser Teil der inländischen Presse hat die Stimmung der Verunsicherung mit fetten Sensationsmeldungen, mit gezielten Indiskretionen zusätzlich geschürt und für eine miesmacherische, selbstzerfleischende Untergangsstimmung gesorgt. Unzählige Bürgerinnen und Bürger werden dabei in ihren Gefühlen zu unserer Heimat, die älteren unter ihnen in ihrer Lebensleistung für unser Land, ständig aufs Neue verletzt. “43

Gegenüber diesem apologetischen Lager der ,Selbstzerfleischung' profiliert das Rezidiv Blocher als standfesten Geschichtskenner, der über die Kompetenz verfügt, das von Linksintellektuellen, Historikern und ausländischen Medien ramponierte Selbstbild der Schweiz zu restaurieren. Die darauffolgende detaillierte Rehabilitierung der Schweizer Außenhandels- und Flüchtlingspolitik während des Zweiten Weltkrieges, durch die Blocher die Vorhaltung der Kollektivschuld zu entkräften versucht, sei im Folgenden nur in ihren Grundzügen widergegeben. Dem Vorwurf, die Schweiz habe rege Handelsbeziehungen mit den Achsenmächten unterhalten, begegnet Blocher mit einer Sinnverkehrungsthese, an die er ein verantwortungsethisches Argument knüpft: Gewisse Handelskompromisse seien notwendig gewesen, um die Rohstoffversorgung, die Wohlfahrt, die innere Stabilität, die Wehrhaftigkeit und die Unabhängigkeit des eingekeilten Kleinstaates aufrechtzuerhalten und Arbeitslosigkeit, Hungersnöte, Generalstreiks und schließlich die Annektierung durch Deutschland und Italien zu verhindern. So hätten die von Eizenstat kritisierte Neutralität und das von Jakob Tanner als Beschwichtigungspolitik herabgestufte Réduit nicht nur den unabhängigen und souveränen Kleinstaat, sondern auch die bereits immigrierten Juden gerettet.

Einige nationalkonservative Autoren machen dieses verantwortungsethische Argument auch in Bezug auf die Flüchtlingspolitik geltend. ${ }^{44}$ Blocher dagegen

43 Ebd.: 6.

44 So etwa von Hans R. Herdener (1997), dem Präsidenten der Schweizerischen Gesellschaft für militärische Studienreisen: „Hätten unsere Behörden die Grenzen für die 
spricht die Schweiz in dieser Frage keineswegs von Verantwortung und Schuld frei. Stattdessen differenziert er die Schuldfrage nach wohlbekanntem Muster. Teile der politischen Eliten, Blocher nennt explizit die „Behörden“, „lebensfremde, eigenmächtige Bürokraten", den freisinnigen Außenminister Marcel Pilet-Golaz, „führende Kreise in der Wirtschaft“, „Vertreter der Gewerkschaften“, hätten nicht „,die Kraft [gehabt] der Gefahr und dem Druck von aussen standzuhalten". ${ }^{45}$ Das ethische und politische Versagen in der Flüchtlingspolitik geht folglich auf die Rechnung der "Schwachen, der „Anpasser und Leisetreter", denen Mut und Widerstandswille gefehlt habe und die mitunter mit dem ,,neuen Europa“" Hitlers und Goebbels sympathisiert hätten. ${ }^{46}$ Widerstand leisteten nach Blochers Erzählung dagegen die Kirchen, das Militär sowie die politischen Parteien, und insbesondere „[d]as Volk war weit widerstandswilliger und verteidigte die Souveränität weit entschlossener als viele Leute in den führenden Kreisen “47. So geschah trotz einer schwachen und anpasserischen politischen Führung „das Wunderbare: Die Schweiz hielt durch, trotz zeitweiligem Wankelmut auf höchster Ebene ${ }^{\text {“48 }}$. In der zur Diskussion gestellten Gesamtbetrachtung ist die Schweiz damit rehabilitiert.

Indes ermöglicht die Leitdifferenz, Widerstand/Anpassung', die hier um ein „neues Europa“ herum organisiert wird, nicht nur eine Rehabilitierung der Schweizer Außenpolitik, sondern auch eine Analogie von Geschichte und Gegenwart, die den Diskurs der Zürcher SVP um die Jahrtausendwende prägen

Flüchtlinge weit geöffnet, wäre ein militärische Aktion Hitlers nicht auszuschliessen gewesen. Das dürfte der Hauptgrund für die zeitweise Zurückweisung der Juden gewesen sein. Wenn Hitler die Schweiz wegen der zu hohen Anzahl jüdischer Flüchtlinge angegriffen hätte, wäre unser Land verwüstet worden, Tausende von Schweizer Soldaten wären gefallen und sowohl die bereits ansässigen als auch die zu uns geflüchteten Juden wären höchstwahrscheinlich in Ausschwitz gelandet.“ In dasselbe Horn stößt Ulrich Schlüers (1997) Schlussfolgerung, die er in seiner Abrechnung mit den als Junghistoriker stigmatisierten kritischen Schweizer Historikern zieht: „Ob es denn eine Alternative gegeben hat zum Handeln der damals Verantwortlichen? Darüber schweigen sich die Junghistoriker aus - wohl wissend, dass die Alternative nur in der Auslieferung des Landes an den Nationalsozialismus bestanden hätte - mit all den damit verbundenen Schrecken sowohl für die Schweizer als auch für die hier lebenden Juden und Flüchtlinge.“

45 Blocher 1997a: 11ff.

46 Ebd.: 12.

47 Ebd.: $11 \mathrm{ff}$.

48 Ebd.: 11. 
wird. Diese geschichtspolitische Analogisierung realisiert Blocher in der folgenden Passage. Nachdem er den Bundesrat für die damalige Beschränkung der Volksrechte und Pilet-Golat für sein „elitäres“ und antidemokratisches Denken gescholten hat, zieht er die Lehre aus der Geschichte:

„Die Tendenz der Regierenden, sich bei ihrer ,höheren Einsicht“ vom Volke höchst ungern dreinschwatzen zu lassen, Volksentscheide möglichst zu umgehen, kennen wir noch heute! [...] Wollen nicht auch heute führende Kreise auf anpasserische Weise wesentliche demokratische Rechte an eine zentralistische Bürokratie in Brüssel abtreten? Es ist aber zu hoffen, dass solche Tendenzen heute ebenso scheitern wie damals; scheitern am Selbständigkeitsdrang, am Widerspruchsgeist, an einer gewissen Eigenbrötlerei des Schweizers, scheitern an der vielfältigen politischen Kultur unseres Landes, am Föderalismus und an der Volkssouveränität, die wir nicht preisgeben dürfen. Aber auch ein Teil der führenden Kreise der Wirtschaft forderte damals die Anpassung an die uns umgebende Grossmacht, eine sofortige und stramme Ausrichtung an das sogenannte ,neue Europa' (wie oft wurde doch in der Geschichte und - auch heute wieder - mit einem ,neuen Europa' hantiert). [...] Entscheidend aber ist wieder - und das ist das Wunderbare - keine dieser ,massgebenden" Stimmen konnte sich damals durchsetzen. Der Widerstandswille blieb bestehen. “49

Das Dritte Reich und die EU, die im kosmopolitisch-europhilen Diskurs als Gegenmodelle konstruiert werden - als rassistisch und nationalistisch motivierter Bellizismus einerseits und als multikulturelles Friedensprojekt andererseits, erscheinen im Diskurs des Zürcher Flügels als Varianten ein und desselben Bedrohungskomplexes. Konstitutiv für diese antagonistische Äquivalenz ist wiederum der Topos von ,Anpassung und Widerstand‘. Er verschmilzt das vermeintliche Gegensatzpaar zu einem bedrohlichen Außen und verlängert die antagonistische Äquivalenz nach innen und lässt so ein bedrohliches ,Sie' aus primären und sekundären Schuldigen entstehen, das vielfältige Gruppen (Jüdische Organisationen, den Faschismus, die EU, den ,Großen Bruder USA ${ }^{60}$, sowie die Schweizer Eliten, Interessenverbände, Behörden, geschichtsvergessene Bundesräte, Historiker und die Linksintellektuellen) umschließt und gegen das sich entsprechend viele Differenzen zu einem ,Wir‘ zusammenschließen lassen. Das einschlägige Argument lautet, dass es angesichts einer äußeren Bedrohung durch einen übermächtigen Feind (den Faschismus, die EU oder jüngst die Vereinigten Staaten)

49 Ebd.: $11 \mathrm{ff}$.

50 Als solchen bezeichnet Blocher (1997b) die USA eingangs seines Vortrages „Die Schweiz und der Eizenstat-Bericht". 
darauf ankäme, als widerstandswillige und geeinte Nation zu handeln, zumal wenn die geforderte Geschlossenheit durch zersetzende Elemente im Innern torpediert werde.

Diese Äquivalenz aus primären und sekundären Feinden wird vertieft, indem die vielzitierte Führungsschwäche einer ,rückgratlosen, orientierungslosen politischen Elite' mit der konservativen Leitdifferenz ,bodenständig/intellektuell' artikuliert wird, die wir bereits aus den Pionierzeiten des Zürcher Flügels kennen. Die Gegnerschaft gegen die politischen Eliten im engen Sinn wird mit einer Frontstellung gegen die Intellektuellen und Kulturschaffenden als weitere Elemente des Anderen der Gemeinschaft verbunden. Gemeinsam bilden sie die Demarkationslinie, die den politischen Raum entzweit, indem sie eine organische Gemeinschaft und ihre natürlichen Bindungen von einem heimatlosen, weltfremden und zersetzenden Außen unterscheidet. ${ }^{51}$

Die Diffamierung der Schweiz durch die Intellektuellen und Kulturschaffenden hat ihre Ursache aus Blochers Sicht zunächst in einer den „masochistischen“ Deutungseliten eigenen Psychopathologie. ${ }^{52}$ Demnach sind die geschichtspolitischen Gegenspieler Blochers von einer autoaggressiven Immunkrankheit befallen. Aufgrund dieser pathologischen Konstitution verschwören sie sich mit den „ausländischen jüdischen Organisationen “53 gegen das Schweizervolk. Blocher diagnostiziert seinen geschichtspolitischen Gegenspielern aber nicht nur Unwissenheit und Krankheit. Er radikalisiert diese Diagnose, indem er die antagonistische Äquivalenz des Jüdischen Weltkongresses sowie der Schweizer Intellektuellen und Kulturschaffenden unter der Überschrift Von Selbstgerechten, Heuchlern und anderen Moralisten ${ }^{54}$ subsumiert. So wie es den ,jüdischen Organisationen" laut Blocher ums Geld gehe, ${ }^{55}$ zielten diejenigen, die sich von der Schweizer Geschichte distanzieren, darauf ab, die ,eigene unbefleckte Weste, [...] ihr

51 Zur Tradition der Intellektuellenfeindlichkeit des Schweizer Konservatismus und der Unterscheidung, bindend/zersetzend“ vgl. Lang 2000: $98 \mathrm{f}$.

52 Blocher 1997a: 33f. Der Historiker Hans-Georg Bandi (1999) brachte diese Perversion zwei Jahre später auf den Begriff des ,helvetischen Masochismus“, der ,,in vorgestellten oder wirklichen Demütigungen, in Qualen und krankhaftem Schuldbedürfnis Befriedigung findet".

53 Blocher 1997a: 20.

54 Ebd.

55 Auf diese Passage der Rede, in der Blocher die Figur des heuchlerischen geldgierigen Juden aufruft, stürzte sich dann auch die mediale Kritik. Die Boulevard-Zeitung Sonntags-Blick titelte etwa „Blocher: Den Juden geht es nur ums Geld“ ([o.A] Sonntagszeitung, zit. in: Somm 2009: 339.) 
eigenes politisches Ansehen“ zu wahren, anstatt ,[t] $[$ rotz der eigenen Unvollkommenheit“ „den Kopf hinzuhalten“, um „einen schwierigen Auftrag zu erfüllen“ und „für andere ein gutes, tragbares oder bestmögliches Ergebnis zu erzielen und durchzusetzen. ${ }^{\text {" }}{ }^{56}$ Was die ,geldgierigen jüdischen Organisationen " und die ,moralistischen Intellektuellen` demnach eint, ist ihr Egoismus, das eigennützige Ziel, ihr ökonomisches respektive symbolisches Kapital auf Kosten der Gemeinschaft zu maximieren.

Wohingegen die Rede vom ,helvetischen Masochismus‘ den Gedanken evoziert, die Bedrohung käme von Innen, von pathologischen Subjekten, die es zu isolieren gelte, spitzt Blochers Rede von ,Selbstgerechten, Heuchlern und anderen Moralisten“ diese Diagnose dahingehend zu, dass diese egoistische Gruppen aus der Diffamierung einer verantwortungsethisch geeinten Gemeinschaft kulturelles Kapital zu schlagen versuche. Die Forschungen der Historiker, die Gesellschaftskritik der Intellektuellen und die ethischen Problematisierungen der Kulturschaffenden mutieren insofern zu selbstsüchtigen Sabotageakten.

Wenn der Verlust des gemeinschaftlichen locus amoenus hier nicht auf Migrations-, Suburbanisierungs- und Anonymisierungsprozesse zurückgeführt, sondern konkreten gemeinschaftszersetzenden Agenten angelastet wird, dann erfährt das Spektrum der nationalkonservativen Elitenkritik hier eine Zuspitzung, die dem kognitiven Schema des Parasitären folgt: Weder leiden die kranken Deutungseliten unter ihrer pathologischen Konstitution, noch handelt es bei ihrem Tun um eine bloße Schädigung der Gemeinschaft. Vielmehr zehren sie von dem Schaden, den sie der Gemeinschaft zufügen. ,Unser Schaden ist ihr Nutzen, ihr Erstarken ist identisch mit unserer Schwächung. Wir müssen herrschen, um nicht selbst beherrscht zu werden', so die Nietzscheanische Moral der Metaphorik des Parasitären. Die zwischen Fremdheit, Pathologie und Egoismus einerseits und Zugehörigkeit, Verantwortung und Aufopferungsbereitschaft andererseits unterscheidende Metapher lässt keine Abstufung zu. Jede Relativierung des schweizerischen Widerstandes verwandelt sich in einen egoistischen Anschlag gegen die Gemeinschaft - in eine Variante der antagonistische Trias aus ,Selbstgerechtigkeit, Heuchelei und Moralismus'.

Die Tatsache, dass die erneute Aufarbeitung der Schweizer Geschichte im Rahmen der Bergier-Kommission und des Eizenstat-Berichtes ein differenziertes Bild zeichnet und keineswegs im Widerspruch zur vorherigen Geschichtsschreibung steht, wie Blocher zu Beginn der Rede selbst einräumt, ist Makulatur angesichts des Schadens, den US-amerikanische Spitzenpolitiker, jüdische Weltorganisationen und die eigenen Intellektuellen der Schweiz zufügen wollen. Denn die 
polarisierende Wirkung des verantwortungsethischen Arguments zehrt von der Virulenz des Antagonismus. Angesichts der Ungeheuerlichkeit der Bedrohung, so die Botschaft, gelte es bedingungslos und selbstbewusst zur Schweiz zu stehen. In einer derartigen Situation gibt es nur schwarz und weiß: entweder an der Seite von Blocher für die Gemeinschaft einstehen oder an der Seite der ,geldgierigen Juden', der ,übergriffigen Weltmacht USA', den ,intellektuellen Nestbeschmutzern' und ,selbstsüchtigen Kulturschaffenden` gegen die Gemeinschaft agitieren. Wenn CVP und FDP zuließen, dass die Linken „eine bürgerliche Erfolgsgeschichte“ in eine „Morität des Versagens" umdeuteten, dann gehören auch sie zum Lager der Selbstgerechten, Heuchler und Moralisten ${ }^{6}{ }^{57}$ Blocher \& Co dagegen sind die einzig verbliebenen politischen Kräfte, die für das politische Ansehen des Schweizervolkes eintreten, das es sich als letzte antifaschistische Bastion in Mitteleuropa verdient habe.

Wie der Zürcher Flügel diese hegemoniale Stellung in der Repräsentation der politischen Schweiz untermauert und das nationale Imaginäre modifiziert, wird das folgende Kapitel anhand der Analyse der Albisgüetli-Reden von 1998 und 1999 zeigen. Im Zentrum steht dabei die Konstruktion einer zyklischperiodischen Geschichtstheorie, die Vergangenheit, Gegenwart und Zukunft synchronisiert und Blochers, unschweizerische“ Attitüde des ,rigorosen Neinsagers' als gegenwärtige Variante eines genuin schweizerischen Widerstandsgeistes nobilitiert.

\subsubsection{Blocher \& Co als Helden einer zyklisch-periodisch verlaufenden Geschichte. Von ,schweizerischen Gemeinschaften“ und europäischen Massengesellschaften“}

Blochers Albisgüetli-Rede von 1998 beginnt mit der Aufzählung der vier Jubiläen, die es zu feiern gelte: (1) „1648: 350 Jahre Loslösung vom Deutschen Reich und damit 350 Jahre formelle schweizerische Souveränität und Unabhängigkeit", (2) „1798: 200 Jahre Helvetik und damit Freiheit und Gleichheit aller Bürger“, (3) „1848: 150 Jahre Schweizerischer Bundesstaat“ und schließlich (4) „1988: 10 Jahre Albisgüetli-Tagung der Zürcher SVP“ ${ }^{58}$ Blocher fügt den drei allgemeinen Jahresfeiern das Partei-Jubiläum der Albisgüetli-Tagung hinzu. Diese

57 Somm, zit. in: Lang 2009.

58 Blocher 1998: 2. 
Parallelisierung der Jubiläen nimmt die hegemoniale Funktionslogik der Rede vorweg. Es geht darum, das eigene politische Projekt (hier repräsentiert durch die Albisgüetli-Tagung) als Fortführung einer wechselvollen und doch gleichsam organisch verankerten Nationalgeschichte zu nobilitieren.

Blocher verfährt chronologisch und beginnt mit 1648 und den ,erfolgreichen Verhandlungen eines Schweizers “59. Gemeint ist der ehemalige Baseler Bürgermeister Rudolf Wettstein, der 1646/47 in „mühsamsten bilateralen Verhandlungen und unzähligen Einzelgesprächen“ die Bedingungen für die formelle Anerkennung der Unabhängigkeit und Souveränität der Schweiz im Rahmen des Westfälischen Friedens geschaffen habe. „Der tüchtige Wettstein hatte die weltgeschichtlichen Auswirkungen des westfälischen Friedenskongresses erkannt. Er nahm das Recht ernst und setzte es kraftvoll gegen aristokratische Gemütlichkeit und obrigkeitlichen Schlendrian durch. “60 Dieser „diplomatische Erfolg“661 war indes nur möglich, weil sich die Eidgenossenschaft gegen den Willen einiger „unüberlegte[r] Politiker und hohe[r] Militärs“ „mit grosser Weitsicht“ die „strikte Neutralität auferlegt und eine gemeinsame Wehrordnung zu deren bewaffnetem Schutz erlassen hatte“. 62

Blochers Würdigung Wettsteins konstituiert die beiden politischen Pole, deren Konflikt die politische Schweiz aus seiner Sicht bis heute prägen. Auf der einen Seite bildet die Äquivalenz aus ,Aristokratie‘, ,Gemütlichkeit‘, ,Obrigkeitsstaatlichkeit', ,Schlendrian', und ,militärischem Engagement' ein dekadentes antagonistisches ,Sie'; auf der anderen Seite konstituiert die Äquivalenz aus ,Tüchtigkeit‘, ,Weitsicht', ,politischer Klugheit‘, ,Souveränität‘, ,Neutralität", ,Wehrhaftigkeit' und ,Frieden' ein ,Wir', das sich aus den einfachen Leute und einer „wahren Elite“633 (Wettstein und seine politischen Nachfolger) zusammensetzt. Die Tatsache, dass dieselbe bipolare Struktur auch heute virulent ist, wird an dieser Stelle durch den Hinweis belegt, dass Bundesrat und Parlament wohl aus Angst und Scham, sich zur Eigenständigkeit zu bekennen, den SVP-Antrag, das Jahr $1648 \mathrm{zu}$ feiern, zurückgewiesen haben. ${ }^{64}$

Das Jubiläum von 1798 bedarf einer weitaus komplexeren Artikulation als 1648. Denn im Unterschied zur 1648 errungenen Souveränität ging die Helvetik gerade nicht aus der Schweizer Eidgenossenschaft selbst hervor, sondern wurde

59 Ebd.: 3.

60 Ebd.

61 Ebd.

62 Ebd.: 2.

63 Zum Begriff der ,wahren Elite“ vgl. Blocher 2002.

64 Blocher 1998: 3. 
von Frankreich oktroyiert. Folglich kann Blocher die Verwirklichung von Freiheits- und Gleichheitsprinzipien nicht als autochthone, gegen die Interessen ausländischer Großmächte durchgesetzte Leistung darstellen. Er versucht daher, die französische Intervention als schädlich und imperialistisch zu deuten, ohne ihren demokratisierenden Effekt zu negieren. Das primäre Übel rührt daher nicht von außerhalb, sondern von einem Feind im Innen. Eine korrumpierte, durch ,Ehrgeiz, Geltungssucht und Wichtigtuerei‘ getriebene politische Elite, die „enge Kontakte zu immer unverschämter und erpresserischer auftretenden französischen Gesandten ${ }^{\text {“65 }}$ pflegte, habe eine Schweiz geschwächt, die ob der langanhaltenden Vernachlässigung des Militärwesens ohnehin wehrlos gewesen sei.

„Freilich versetzten die französischen Truppen keinem gesunden und schon gar keinem modernen Staat den Todesstoß. In der alten Eidgenossenschaft herrschte damals eine kleine aristokratische Oberschicht über die Untertanen; große Teile der Bevölkerung waren von der Beteiligung an Politik [...] ausgeschlossen. Die Politik war dumpf, langweilig und muffig, alle Staatsgeschäfte umgab eine große Geheimnistuerei. Die Regierenden vor 1798 waren in erschreckendem Masse selbstgefällig, realitätsfremd, dünkelhaft und borniert; sie fühlten sich über die breite Volksmasse weit erhaben. “66

Darauf folgt die Pointe: „Solche Figuren finden sich in der Schweizer Politik noch heute, auch wenn sie keine gepuderten Perücken mehr tragen. “67 Einmalmehr erscheint die konkordanzdemokratische Verhandlungspolitik, auf die Blocher mit den Attributen „dumpf“, „langweilig“, „muffig“ und „Geheimnistuerei“ anspielt, nicht als bewährte, systemisch induzierte Handlungslogik, sondern als aristokratische Geste einer politischen Elite, die sich selbst die Rolle der politisch befugten Experten zuspricht, das Volk hingegen als unbefugte Laien wahrnimmt. Als exemplarischer Beleg für die Synchronie von Geschichte und Gegenwart fungiert der FDP-Nationalrat und Vizepräsident der Freisinnigen Peter Tschopp, der im Kampf für die europäische Integration der Schweiz das „Informationsmonopol des Staates" wiederherstellen wolle, um die feudalistische Aristokratie zu restaurieren. ${ }^{68}$ Denn durch die EU, so Blochers Argumentation weiter, soll

65 Blocher 1998: 4.

66 Ebd.

67 Ebd.

68 Ebd. 
„[d]er vor 200 Jahren überwundene Feudalismus - die Herrschaft weniger über viele wieder auferstehen. Der bürokratische Brüsseler Zentralismus bedeutet nichts anderes als eine Rückkehr Europas zu feudalistischen Zuständen in der Politik, nämlich die Verminderung der Zahl der Entscheidungsträger und die Einschränkung der Mitsprecherechte des Volkes. “69

Nach dieser analogisierenden Prolepse kehrt Blocher zu 1798 zurück, um den positiven, demokratisierenden Effekt der französischen Machtpolitik zu relativieren: Die zu Beginn noch ,,als angebliche Befreier“ bejubelten Franzosen hätten Hab und Gut der Bevölkerung geplündert und die Staatsschätze nach Paris transportiert. „Ohne Rücksicht auf die Geschichte wurde 1798 das in langsamer Entwicklung Gewordene auf einen Schlag ersetzt durch das Organisierte und Geplante.“70 Der „,neue - nach französischem Muster - zentralistischbürokratisch regierte Zentralstaat verleugnete jeden Föderalismus“" ${ }^{\text {71 }}$, führte schließlich zu einer Serie von Staatsstreichen und stellte die Schweiz vor eine innere Zerreißprobe. Nun folgt die Moral der Geschichte: Aus 1798 sei zu lernen,

„was herauskommt, wenn gewisse Kreise die notwendigen Reformen in Politik und Wirtschaft nicht von der eigenen Kraft, sondern von der Einmischung fremder Mächte erwarten. [...], ,[D]ie faktische Integration in eine europäische Grossmacht [bedeutete] vor allem eines: zahlen, zahlen und nochmals zahlen! [...],,[L]ebensfremde politische Experimente [sind gefährlich] für unsere vielsprachige, föderalistische Schweiz. Die am grünen Tisch entworfenen Staatsplanungen, die uns durch Fremde aufgezwungen werden, die unsere politischen Zustände, unsere Geschichte nicht kennen und unser Land nicht gern haben, sind für die Schweiz gefährlich. ${ }^{\text {“72 }}$

Angeschlossen wird hier an den Antagonismus, den die Zürcher SVP im Laufe des EWR-Abstimmungskampfes als die zentrale Konfliktlinie der politischen Schweiz instituieren konnte: die Inkommensurabilität zwischen dem ,organisch gewachsenen, föderalistisch organisierten, vitalen, florierenden und kraftvollen Kleinstaat Schweiz' und der ,intellektuell geplanten, zentralistischbürokratischen und parasitär-epidemischen Großmacht EU‘. Durch die Kontinuation des napoleonischen Frankreichs und der Brüsseler EU konstituiert

69 Ebd.

70 Ebd.: 5.

71 Ebd.

72 Ebd. 
Blocher ein zyklisch-periodisches Geschichtsverständnis, das der Bedrohung durch die EU eine quasi-universelle Bedeutung verleiht. Die transhistorische Äquivalenz ,Napoleon-Brüssel‘ lässt Blocher \& Co als die einzig legitimen politischen Erben des ,Schweizer Sonderfalls‘ erscheinen.

Auf diesen hegemonialen Effekt zielt auch die Diskursivierung von 1848, mit der Blocher fortfährt. Den Ausgangspunkt bildet erneut das antagonistische Verhältnis zwischen der Schweiz und den europäischen Großmächten:

„Im Gegensatz zu den Verfassungen von Helvetik (1798), Mediation (1803) und Restauration (1814) entstand die Bundesverfassung von 1848 ohne Einmischung fremder Mächte, allein aus dem Willen der Mehrheit des Schweizervolkes. Die Schweiz musste damals nicht dem politischen und wirtschaftlichen Druck von aussen nachgeben, sondern tat in voller Eigenständigkeit und Souveränität das ihr richtig Scheinende. Das übrige Europa betrachtete die Schweizer Entwicklung auch damals mit Skepsis, mit Misstrauen und sogar mit ausgesprochenem Widerwillen. [...] Unser Land hatte $1848 \mathrm{mehr}$ als genug von den Zumutungen, den Einmischungen und den Erpressungsversuchen fremder Regierungen. Die Schweiz blieb als demokratische Republik in Europa noch bis ins 20. Jahrhundert ein europäischer Sonderfall. Was den Föderalismus, die direkte Demokratie, die Neutralität und die Gemeindeautonomie betrifft, so ist sie es bis heute geblieben. Sogar ein weltweiter Sonderfall! Wer heute die nationale staatliche Souveränität aufgeben will, verrät die Idee des Bundesstaates von 1848،“73

Der mit 1848 geschaffene Sonderfall, den die SVP hier für sich reklamiert, bezieht sich jedoch nicht nur auf die besondere politische Verfassung der Schweiz. Zu 1848 gehört auch eine liberale Wirtschaftspolitik. Denn nur

„[d]ank eines freiheitliches Systems, eines schlanken Staates, der die Verantwortung des Einzelnen in den Mittelpunkt und sich in nichts einmischte, was Private besser tun können, dank wagemutiger, risikobereiter Unternehmer - entwickelte sich die Schweiz zu einem der wohlhabendsten, stabilsten und industrialisierten Länder der Welt. Wer heute Unternehmer anpöbelt [...] verrät die Idee des Bundesstaates von 1848.“774

Dasselbe gilt für die Außenpolitik, die Asylpolitik und die geplante Föderalismusreform. Auf all diesen Feldern gefährden die politischen Gegner des Zürcher Flügels nicht nur den Status quo, sondern zugleich die mit 1848 begründete Identität der Schweiz: „Wer heute unsere Soldaten ins Ausland schicken will“, 
„[w]er heute die tägliche und nächtliche illegale Masseneinwanderung und die damit verbundene Kriminalität duldet und mit Direktzahlungen belohnt", [w]er heute das Ständemehr oder den Ständerat abschaffen will“", übt zugleich Verrat an $1848 .^{75}$

Um die eigene Reformagenda von diesen ketzerischen Anschlägen auf den Sonderfall zu unterscheiden, konstatiert Blocher, „dass die Entwicklung der Eidgenossenschaft damit [mit der Bundesverfassung von 1848] nicht zum Stillstand kam“, sondern durch die „sogenannte ,Demokratische Bewegung““ vorangetrieben wurde. ${ }^{76}$ Die geplante Initiative zur Volkswahl des Bundesrates, für die Blocher im folgenden Abschnitt der Rede wirbt, erscheint dergestalt nicht als Bruch mit dem etablierten parlamentarischen Konkordanzsystem, sondern als Fortführung eines Verfassungsbildungsprozesses, der in den 1850er und -60er Jahren ,zum gezielten Weiterausbau der Volksrechte, der direkten Demokratie zur Volkssouveränität“"77 führte.

Diese demokratisierende Tradition, in die sich Blocher stellt, manifestiere sich gewissermaßen in actu, in der Albisgüetli-Tagung selbst, auf deren Jubiläum Blocher zum Ende der Rede eingeht. Denn auf die gängige Stilisierung der Albisgüetli-Tagung als ,bodenständige, kraftvolle, richtungsweisende und substanzreiche Veranstaltung', lässt Blocher ein demokratietheoretisches Argument folgen, das die eigene oppositionelle Ausrichtung adelt:

„Der Bundesrat hat diskussionslos immer das letzte Wort. Es zeugt vom grossartigen demokratischen Geist unserer Mitglieder, dass sie sich die Stellungnahmen des Bundesrates auch dann ohne Pfeifen anhören, wenn sie anderer Meinung sind. Wir wissen, dass die Demokratie von der Auseinandersetzung lebt. Mindestens war es in der Vergangenheit so - dass die Schweiz durch eine intensive politische Auseinandersetzung - das wichtigste Kennzeichen einer guten politischen Kultur - gekennzeichnet war.“78

Nicht die Integration möglichst vieler Interessen qua Kompromiss und Konsens, sondern die auf dem Albisgüetli inszenierte agonale ,Auseinandersetzung ' wird hier zum Kernstück und Erfolgsrezept der Schweizer Demokratie. So stellt sich die Zürcher SVP nicht zuletzt mit der auf dem Albisgüetli inszenierten Kontroverse in den Dienst einer höheren Sache, der Verteidigung und Kultivierung der Schweizer Demokratie.

75 Ebd.: $6 f$.

76 Ebd.: 7.

77 Ebd.

78 Ebd.: 15 . 
Blochers Geschichtspolitik findet ein Jahr später an selber Stelle eine eindrückliche Fortführung. Auch der Blick in die Zukunft, den der Titel Unsere Politik im 21. Jahrhundert ${ }^{79}$ ankündigt, beginnt mit einem Blick in die Vergangenheit. Unter der Kapitelüberschrift Ein Jubiläum im Elfenbeinturm geht Blocher zum Einstieg mit den offiziellen Jubiläumsfeierlichkeiten ins Gericht. Wie von ihm prophezeit, sei das Jubiläum ,150 Jahre Bundesstaat‘ dazu „missbraucht“ worden, „dem Schweizervolk den EU-Beitritt schmackhaft zu machen “" ${ }^{\text {“80. Doch }}$ nicht nur das. Die Propaganda für die EU, die Blocher parodistisch nacherzählt, läuft in seiner Rekapitulation der Feierlichkeiten parallel mit der Ignoranz und der Geringschätzung der Eliten gegenüber dem Schweizervolk.

Als exemplarisches Beispiel fungiert der ,sogenannte ,Tag der internationalen Beziehungen““ als einem der drei offiziellen Festveranstaltungen: Auf „dem von unzähligen Polizisten bewachten, menschenleeren Bundesplatz“ begrüßten die Bundesräte „ausländische Fürsten, Exzellenzen und Präsidenten“, während ein „armer Bauer“ als Verkörperung der Schweizer Geschichte „vor den Augen der Staatsgäste barfuss Heu auf einen Karren laden [musste], das vorher dekorativ auf dem Bundesplatz ausgelegt worden war" - so die gekürzte Zusammenfassung der von Blocher geschilderten „Szenerie“, die ihn nach eigenem Bekunden ,an frühere Völkerschauen und Tierschauen in zoologischen Gärten“ erinnert. ${ }^{81}$ Dass die „handverlesenen Gäste [...] nur durch eine Hochsicherheitssperre mit Metalldetektoren zum Staatsakt dieses einstigen Landes der Freiheit [gelangten]“, während „,[i]m Innern des Hauses [...] der Nationalratspräsident - als höchster Schweizer und Vertreter der Sozialdemokraten - den Ansprachereigen mit dem Wort ,Durchlaucht“ [eröffnete]", dass sich bei einer weiteren Festveranstaltung ,auserlesene Gäste aus Politik, Wirtschaft und Gesellschaft“ einer ,für teures Geld eigens komponierten modernen Musik“ lauschen, während das „Volk [...] durch Abschrankungen und Polizei konsequent ausgeschlossen [blieb]“, dass Blocher eine Fülle von Fahnen“, aber „,keine einzige Schweizerfahne“ erspähen konnte, aber ,ein Fallschirmspringer im EU-Tenue in unanständigster Weise mitten in die Rede der Genfer Regierungsrätin“ platzte, vervollständigt das Bild eines Jubiläums unter Ausschluss des Schweizervolkes: elitär, abgehoben, undemokratisch, internationalistisch und zugleich unprofessionell und beschämend. ${ }^{82}$

79 Blocher 1999b.

80 Ebd.: 3.

81 Ebd.

82 Ebd. 
Mit den unechten Feierlichkeiten der Herrschenden kontrastiert das einzigartige Potential der authentischen Sitten und Bräuche der Beherrschten:

„Wenn wir bedenken, welche Möglichkeiten die Kultur unseres mehrsprachigen Landes, unser Brauchtum, unsere Chöre, unsere Orchester, unsere Schauspielbühnen bieten würden, wenn wir bedenken, welche kulturellen Leistungen unser Volk hauptberuflich oder in der Freizeit erbringt - sofern sich keine eidgenössischen Kulturfunktionäre mit unseren Steuergeldern einmischen -, dann erlauben die Jubiläumsveranstaltungen von 1998 nur zwei Schlüsse: Entweder die [...] verantwortlichen Personen in Bern sind vollständig am Verblöden oder man will dem Schweizervolk das Land bewusst so sehr verleiden, dass jede Identifikation, jedes Heimatgefühl, jede Geborgenheit zerstört wird. Wenn dem hintersten und letzten eingebläut ist, dass wir Schweizer ganz genau gleich und noch etwas schlechter sind als alle übrigen Menschen und Staaten dieser Welt, dann - so glaubt man wohl in Bern - haben wir den Sonderfall mitsamt seiner Neutralität und direkten Demokratie erledigt, und dann endlich kann man unser Land getrost in die EU, in die UNO und in die NATO führen." ${ }^{83}$

Bemerkenswert an dieser Passage ist die Überblendung von Fülle und Mangel. Einerseits stellt Blocher das Potential des Volkes in Form der repetierenden Aufzählung ,unser mehrsprachiges Land, unsere Chöre, unsere Orchester, unsere Schauspielbühnen' als nahezu unerschöpflich vor, andererseits ist dieser pleonastisch imaginierte locus amoenus auf einem Mangel gegründet. Die Heimat bezeichnet eine inhibierte Fülle, eine antagonistisch blockierte Identität, die in der zitierten Passage verschwörungstheoretisch imaginiert wird. Es ist die Präsenz des antagonistischen Anderen (,die offizielle Schweiz', die verantwortlichen Personen in Bern' und ,die Kulturfunktionäre‘), welche die ,Kultur unseres mehrsprachigen Landes' als Einheit imaginiert und zugleich die Realisierung ihrer vollständigen Prosperität verhindert. Die Illusion einer wesenhaften, innerlichen Substanz wird in einem antagonistischen Außen konstruiert, das die volle Entfaltung dieser Substanz als gelebte Heimatliebe und -pflege blockiert.

Die Verschwörung, die Blocher am Ende der Passage wittert, macht diesem antagonistischen Anderen nicht nur seine diskriminierenden Gesten zum Vorwurf, sondern unterstellt ihm heimtückische Absichten. Blocher mutmaßt, dass die Feierlichkeiten deswegen so beschämend ausfielen und eine miefige, unattraktive Schweiz gezeigt hätten, um ,jedes Heimatgefühl, jede Geborgenheit“ zu zerstören, dem Schweizervolk sein nationales Selbstbewusstsein zu nehmen, den Souverän schließlich im Rahmen von EU, UNO und NATO zu entmachten und 
seiner Identität zu berauben ${ }^{84}$ Erneut überführt Blochers Rede den „,helvetischen Masochismus ${ }^{\text {“85 }}$ in eine gezielte politische Strategie des Machtkartells. Das Pathologische, das fehlende Bekenntnis zum ,Sonderfall Schweiz', wohnt nicht nur dort, wo es den größten Schaden verursacht, nämlich an der Spitze des Staates. Die Autoimmunkrankheit entpuppt sich als eine politische Strategie, um die Schweiz zu zersetzen, sie,scheibchenweise und durch die ,Hintertüre' ihrer Unabhängigkeit und Neutralität zu berauben.

Das dritte Jubiläum, das 1998 an der Reihe gewesen wäre, den 350. Jahrestag des Westfälischen Friedens und die „Loslösung der Schweiz vom römischdeutschen Reich“ hätten die Regierenden "stillschweigend übergangen“. ${ }^{86}$ Blocher glaubt auch schon zu wissen, dass die politische Klasse auch das diesjährige 500. Jubiläum des Schwabenkriegs, in dem ,sich die Eidgenossen erfolgreich geweigert [hatten], sich der Reichssteuer, dem Reichsgericht und der habsburgisch-europäischen Machtpolitik zu unterwerfen“887, entweder missachten oder für ihre Zwecke nutzen werde. Denn

„[d]iese Feier dürfte Bern noch viel peinlicher sein als der Westfälische Frieden. Also wird man sie - ganz nach dem Vorbild diktatorischer Staaten, welche die nicht genehmen Jubiläen auch verdrängen - entweder unter den Tisch wischen oder zur Propaganda für einen EU-Beitritt (und damit zur Unterwerfung unter neue Reichssteuern, ein neues Reichsgericht und eine europäische Machtpolitik) missbrauchen.“ ${ }^{88}$

Und ein Jahr später propagiert Blocher an selber Stelle:

„Es gehört heute zum guten Ton, die Erfolgsgeheimnisse der Schweiz als veraltet zu erklären und lächerlich zu machen. Die ,Classe politique' überschüttete hierzulande die eigenen Bürger in den letzten Jahren tonnenweise mit Selbstkritik [...]. Damit sollen die Bürger verunsichert werden, um sie für grosse internationale Organisationen gefügig zu machen und um ihre persönlichen und wirtschaftlichen Freiheiten einschränken zu können. Folgerichtig müssen dieser Kreise auch die schweizerischen Staatsmythen zerstören oder - wie sie sagen - ,kritisch aufarbeiten'. Fantasielos und jeder Tiefe entbehrend, haben sie nicht begriffen, dass zum Beispiel hinter den Geschichten Wilhelm Tells, des Rütlischwurs, Winkelrieds und zahlreicherer anderer Sagen und Mythen aus der Schweizer

84 Ebd.

85 Bandi 1999.

86 Blocher 1999b: 4.

87 Ebd.

88 Ebd.: 5. 
Geschichte viel mehr Wahrheit steckt als in sogenannten Tatsachenberichten der gestrigen Tageszeitungen. [...] Bei ihrem Schwur auf dem Rütli haben die alten Eidgenossen 1291 eine Genossenschaft gegründet. Sie haben sich für Selbstverantwortung entschieden und damit jedem Anspruch des hierarchischen, zentralistischen habsburgischen Verwaltungsstaates eine Absage erteilt.، ${ }^{\text {(89 }}$

Während sich die Kritik der europäischen Integration im Rahmen der EWRKampagne abgesehen von wenigen Anspielungen noch auf die Äquivalenz des realexistierenden Sozialismus, der EU und des eigenen politischen Establishments begrenzt hat, wird die antagonistische Äquivalenzkette nun explizit an die Gründungsmythen der Eidgenossenschaft rückgebunden. Das europäische Andere mutiert zu einem periodisch wiederkehrenden monarchischen und totalitären Bedrohungskomplex, der die Habsburger Monarchie, das absolutistische und das napoleonische Frankreich, den italienischen und den deutschen Faschismus, sowie den totalitären Kommunismus umfasst und zu dem heute die Spitzenpolitiker der EU, aber auch die proeuropäischen Schweizer Eliten gerechnet werden. Die gegenwärtige politische Auseinandersetzung ist daher nichts anderes als eine Variante einer stets widerkehrenden politischen Konstellation: Dort die korrumpierten Eliten, die an der Seite des feindlichen Auslands gegen die Selbstbestimmung des eigenen Volkes agitieren; hier die tapferen, einfachen Leute, die sich an der Seite einer wahren, verantwortungsvollen Elite einer historisch verankerten Essenz der Schweizer Nation verpflichten.

In den folgenden Kapiteln „Nach einem Jahrhundert der staatlichen Allmacht“, „Bleibt die Schweiz Hort von Freiheit und Selbstverantwortung?“ und „Kampf dem Sozialismus“ beschäftigt sich Blocher mit dem 20. Jahrhundert und seinen Hauptgegner, dem Sozialismus. ${ }^{90}$ Dabei ist Blochers Sozialismusbegriff nicht nur für den realexistierenden Sozialismus oder die Schweizer Sozialdemokraten reserviert. Sozialistisch sind für Blocher der Sowjetkommunismus, der Nationalsozialismus, die EU und nicht zuletzt die ,ehemals bürgerlichen Partner" der SVP, die er unter der Etikette der „Linken und Netten“ ebenfalls dem sozialistischen Lager zurechnet. ${ }^{91}$ Die folgende Analyse der drei genannten Kapitel aus Blochers Rede veranschaulicht, wie der SVP-Populismus diese expandierende Äquivalenzkette knüpft und wie der Sozialismus zum leeren Signifikanten avanciert, der die unterschiedlichen Gegenspieler der SVP bündelt, als ,un-

89 Blocher 2000a: 11.

90 Blocher 1999b: 5ff.

91 Ebd.: 6. 
schweizerisch` und bedrohlich diskursiviert und von dem legitimen Kampf um die Repräsentation der Gesellschaft ausschließt.

Das „Jahrhundert der staatlichen Allmacht“ beginnt mit der Äquivalenz von Sozialismus und Nationalsozialismus. Blochers Argumentation fügt hier Versatzstücke der Totalitarismustheorien André Glucksmanns, François Furets, Karl Poppers und Friedrich August Hayeks aneinander. ${ }^{92}$ Die von Blochers konstruierte Äquivalenz fokussiert jedoch weniger das sogenannte Primärphänomen des Totalitarismus, den unbedingten Wahrheitsanspruch, den die neue Gesellschaftsordnung verwirklichen soll, als vielmehr die Sekundärphänomene respektive die Folgen der beiden Totalitarismen, „aggressive Eroberungskriege“, „die brutale Unterdrückung von inneren und äusseren Gegnern“, „ein Terror mit vielen Millionen Menschenopfern - der braune und der rote Holocaust - sowie schließlich der völlige wirtschaftliche, gesellschaftliche und geistige Zusammenbruch". Dass ,beide Ideologien - zeitweise sogar vertraglich verbündet und in der Namensgebung zusammengeschlossen - Werte wie Freiheit und Demokratie zerstört haben“, in beiden Systemen, „[e]in allmächtiger Zentralstaat [...] alles lenken, diktieren und regulieren wollte“, dass sowohl ,unter der braunen“ als auch „unter der roten Herrschaft" das „Individuum“ durch „das Kollektiv, die Masse“ verdrängt worden sei, ,[d]er Einzelne [...] nichts, die Gesamtheit alles [galt]“, belegt die Wesensgleichheit von „Naziherrschaft und real existierendem Sozialismus". ${ }^{93}$

Blocher bringt den Antagonismus zwischen sozialistischer Diktatur und liberaler Demokratie auf die Formel, sozialistischer, allmächtiger Zentralstaat ' versus ,selbstbestimmten Individuum'. Der Antagonismus wird dadurch so sehr entleert und verallgemeinert, dass auch die EU und die Schweizer Sozialdemokraten als Momente des sozialistischen locus terribilis geltend gemacht werden können. Damit kann Blocher argumentieren, dass die Virulenz des Antagonismus auch nach dem Zerfall der Sowjetunion und der vermeintlich unaufhaltsamen Globalisierung von Marktwirtschaft und liberaler Demokratie persistent bleibt. Nach wie vor und ungeachtet der katastrophalen Konsequenzen des Sozialismus sei der Glaube an die Allmacht des Staates ungebrochen:

„Die allgemeine Tendenz geht in Richtung Zentralismus, Kollektivierung, Vermassung, Zwangsregulierung, gleichmacherischen Sozialismus, gigantische Staatsgebilde, die dem Einfluss des Bürgers möglichst entzogen sein sollen. Die politische Macht wird dem ein-

92 Explizit macht Blocher (2000b) diese Bezüge in seinem Aufsatz „Freiheit statt Sozialismus. Aufruf an die Sozialisten in allen Parteien“.

93 Blocher 1999b: 5. 
zelnen Bürger weggenommen und auf anonyme Bürokraten und Funktionäre übertragen: Wie ehedem sollen einige wenige über viele herrschen. Um die Zustimmung einer Mehrheit zu bekommen, wird umverteilt, wird das Eigentum missachtet, wird der gleichmacherische Wohlfahrtsstaat propagiert, wird auf Pump gelebt, werden Schulden gemacht, wird dem sicheren Ruin entgegengesteuert. Arbeitslosigkeit, Armut und Resignation sind die Folgen. “94

Die EU wird hier nicht explizit genannt, durch die Attribute ,zentralistisch, gigantisch, Staatsgebilde, gleichmacherisch', die seit der EWR-Kampagne zum festen semantischen Inventar der Diskursivierung des europäischen Staatenbundes gehören, aber aufgerufen. Blocher deutet das Brüsseler Europa erneut als gegenwärtige Variante des sozialistischen Bedrohungskomplexes, um die kleine, seit jeher antisozialistische Schweiz, die während des Zweiten Weltkrieges ,als praktisch einziger Staat auf dem europäischen Festland, völlig umzingelt von einer feindlichen Umgebung" der totalitären Bedrohung die Stirn geboten habe, als letzte Bastion „der Freiheit, der Menschlichkeit, der Demokratie und des Rechts“ zu singularisieren. ${ }^{95}$

Diese letzte Bastion, die ein „leuchtende[s] Vorbild einer menschenwürdigen Gesellschaftsordnung" sein könnte, ist nicht nur von außen, durch die feindliche Übernahme der EU, sondern auch durch die „Versozialisierung“ von Innen bedroht. ${ }^{96}$ Und hierfür macht Blocher nicht nur die Schweizer Sozialdemokraten, die ihren Glauben an den Sozialismus erst vor wenigen Jahren mit ihren ,Pilgerreisen' in die DDR bekräftigten, sondern auch die anderen bürgerlichen Parteien verantwortlich:

„Es wäre zu einfach, die Verantwortung für diese katastrophale Entwicklung [gemeint sind die wachsende Verschuldung und die ansteigende Staatsquote, die Blocher im Anschluss an Milton Friedman als Indiz dafür betrachtet, dass die Schweiz inzwischen ein sozialistischer Staat sei; Anm. M.H.] allein den Sozialisten in die Schuhe zu schieben: Sozialisten gibt es leider in allen Parteien, auch in den bürgerlichen. Diese Versozialisierung haben wir den Linken und den Netten zu verdanken. “97

94 Ebd.

95 Ebd.: 6.

96 Ebd.: 7. Blocher kombiniert hier die beiden traditionellen Selbstverständnisse der Schweiz als Felsenbastion und aufgeklärte Musterrepublik (vgl. Langejürgen 1993: 17).

97 Ebd.: 5 
Der ,Sozialismus' der ,Linken und Netten' ist für Blocher nicht nur ein parteiübergreifendes „falsches politisches Programm ${ }^{\text {“98 }}$. Die sozialistische „,Vision“ eines weniger mühsamen, lasten- und risikoärmeren Lebens" entpuppt sich als „verhängnisvolle Lebensphilosophie“, als „süsses Gift, von dem nur schwer wegzukommen ist" ${ }^{99}{ }^{99}$ Die wiederkehrende Metapher des ,süssen Giftes ${ }^{100}$ konzipiert den Sozialismus als köperfremde, von außen zugeführte Droge, die Profiteure sozialistischer Politik als Abhängige und die Politiker als Dealer, die ihren Kundenkreis erweitern, indem sie unabhängige Bürger in abhängige Untertanen verwandeln. Sie verschmilzt somit die unterschiedlichen Protagonisten des Außen zu einem gemeinschaftsgefährdenden symbiotischen Bedrohungskomplex.

„Die Bürger hoffen auf ein sorg- und müheloses Leben, und die Politiker können ihre Bedeutung hervorheben und ihre Macht sichern, indem sie durch Umverteilung und Ausgabenbeschlüsse ein solches Leben zu garantieren vorgeben. [...] Nicht nur den Schwachen und Hilflosen wird gegeben, sondern auch und gerade den Gesunden und Starken.“101

Die wohlfahrtsstaatliche Umverteilungspolitik entspricht nicht etwa dem Willen einer solidarischen Ausgleichsgesellschaft, die es sich zum Ziel setzt, auch marginalisierten Gruppen einen gewissen Lebensstandard zu ermöglichen und die desintegrativen Effekte von Modernisierungsprozessen abzufedern. Die Metapher des süßen Giftes konzipiert den aktiven Wohlfahrtsstaat als Herrschaftsinstrument und verleiht Blochers Antisozialismus eine dezidiert populistische, gegen die Herrschenden gerichtete Stoßrichtung. Denn, wie in der Drogenpolitik, bezahlen auch hier die Nicht-Abhängigen: Die „Leistungswillige[n] werden zu Abgaben gezwungen, ausgenützt, für dumm verkauft und für ihren Einsatz bestraft ${ }^{\star 102}$.

Entsprechend wird der geforderte Rückbau des Wohlfahrtsstaates nicht in erster Linie volkswirtschaftlich, sondern moralisch begründet. Die Verwirklichung des Selbstverantwortungsprinzip bezeichnet hier nicht etwa eine alternativlose Anpassung an eine veränderte Umwelt, die in den Diskursen der neuen Mitte als überfällige Reaktion auf einen global gewordenen Wettbewerbsdruck geltend gemacht wird, sondern die Verwirklichung einer moralisch richtigen Politik. Die Leitdifferenz lautet nicht ,Gewinn/Verlust", sondern ,hart arbei-

98 Ebd.

99 Ebd.: 7f.

100 Vgl. auch Blocher 2000b: 5.

101 Blocher 1999b: 8.

102 Ebd. 
tend/faul'. Es ist dieser moralische Antagonismus, der den Widerspruch zwischen einer etatistischen Position in der Agrarpolitik (der Forderung nach einer starken staatlichen Subventionierung der Schweizer Landwirtschaft) und einer neoliberalen Position auf allen anderen Politikfeldern (der Forderung nach einer konsequenten Verschlankung eines ,teuren, ineffizienten Staates') überbrückt. Denn nur unter dieser Voraussetzung, lassen sich die im europäischen Vergleich üppigen Agrarsubventionen, mit denen der Schweizer Staat die heimische Landwirtschaft protegieren soll, mit dem konsequenten Rückbau des Wohlfahrtsstaates vereinbaren. Wenngleich die Bauern aufgrund ungünstiger Standortfaktoren nicht rentabel wirtschaften können und staatlicher Protektion bedürfen, gehören sie selbstverständlich der Wir-Gruppe der Werktätigen an. ${ }^{103}$

Aufgrund des moralischen Charakters des Selbstverantwortungsprinzips wird seine Legitimität nicht daran gemessen, ob es sein Versprechen, Leistung würde mit sozialem Aufstieg honoriert, tatsächlich einlöst. Die neoliberalen Forderungen nach Deregulierung, Privatisierung und Steuersenkungen werden keineswegs auf einen egoistischen Einzelnen bezogen, dessen Streben nach Glück weder protegiert noch begrenzt werden soll, sondern als Restauration eines archepolitischen, wohlgeordneten Gemeinwesens diskursiviert, in dem jeder den ihm qua Natur zugewiesenen Platz einnimmt.

Die Akzeptanz dieser organisch gewachsenen Hierarchien konstituiert gleichzeitig die antagonistische Grenze, welche die „wahre Elite“ von der „falschen Elite" und das ,arbeitssame Volk' von denjenigen unterscheidet, die , das süße Gift' des europäisch-massengesellschaftlichen Sozialismus entweder verbreiten oder ihm verfallen sind. ${ }^{104}$ Diese Subversion ermöglicht eine semantische Transformation von Identitätsmarkern: Riten, Kleidungsstile oder das gebrochene Hochdeutsch der Dialektsprecher, die in anderen Diskursen als Zeichen von Folklore, Rückständigkeit oder Bildungsferne erscheinen, verwandeln sich in Essenzen des Volkes als einer, wahren, blockierten Elite‘.

So bringt Blocher nicht nur die zentralen Identifikationsbegriffe der bürgerlichen Schweiz (Freiheit, Selbstverantwortung, Leistungswille, Menschlichkeit, Demokratie, Recht) gegen ein moralisch korrumpiertes, sozialistisches Anderes

103 Dieser Widerspruch (zwischen der etatistischen Forderungen eines aktiven Staates in der Landwirtschaft auf der neoliberalen Forderung des Rückbaus eines ,teuren, ineffizienten Staates' in anderen Sektoren) wird als einer der zentralen Widersprüche der SVP betrachtet (vgl. Betz 2012; Wirz 2011), indes wird nicht gefragt, wie es der SVP gelang, diesen Widerspruch in eine schlichte Differenz zu transformieren.

104 Explizit vollzieht Blocher diese Trennung etwa in der Albisgüetli-Rede von 2002 (vgl. Blocher 2002). 
in Anschlag, sondern verleiht dieser Wir-Sie-Unterscheidung eine bemerkenswerte historisierende Rückversicherung:

„Schon Jeremias Gotthelf hat geschrieben: ,Nimmer und nimmer dürfen wir vergessen, und das ist ein Unterschied, der sein soll zwischen uns und den anderen Völkern, solang wir Schweizer sein wollen (...); dass die Kraft bei uns im Einzelnen liegt und jedes einzelnen Wiege das Haus ist, während andere Völker ihre Kraft in der Masse suchen und der Masse Kraft in ihrer Grösse und Verkittung. ““105

Blochers Rückgriff auf den konservativen Schweizer Literaten Jeremias Gotthelf ist keineswegs singulär für den Diskurs des SVP-Populismus. Ende der 1990er Jahre avancieren Gotthelf und der auf der Flucht vor den Nazis in die Schweiz emigrierte Ökonom und Sozialphilosoph Wilhelm Röpke zu den wichtigsten Gewährsmännern der SVP. Gotthelf und Röpke belegen die Inkompatibilität zwischen einer genuin schweizerisch-freiheitlichen politischen Kultur, die den in kleinräumig-organisch Gemeinschaften verwurzelten Einzelnen zum Ausgangsund Bezugspunkt von Politik und Gesellschaft erklärt, und einer europäischsozialistischen politischen Kultur des Großräumigen und der Masse. ${ }^{106}$ Die Kritik der (zentralistisch-technokratischen) Verfassung der EU, die Blocher \& Co im Rahmen der Kampagne gegen den EWR formulierte, verwandelt sich in einen unhintergehbaren Mentalitätsunterschied zwischen der Schweiz und dem europäischen Ausland. In der Brüsseler Bürokratie und dem Vertrag von Maastricht findet dieser Unterschied bloß seinen aktuellen Ausdruck. In Wirklichkeit aber wurzelt er in zwei diametralen soziokulturellen Substraten: einem massengesellschaftlichen, sozialistisch-europäischen Untertanenkultur, die aus den zentralstaatlich organisierten, absolutistischen Monarchien hervorging und einer demokratischen, selbstverantwortlichen schweizerischen Kultur, die parochialen, autarken Kleingemeinschaften entwuchs.

Der Gegensatz von Masse und Einzelnem, den Blocher mit Gotthelf ins Feld führt, dient insofern nicht nur der Unterscheidung zwischen der Schweiz und den anderen europäischen Staaten. Der Topos der Masse ${ }^{107}$ fungiert als Knotenpunkt des antagonistischen Außen. Dabei sind es drei Diskursstränge, die in der ,Masse' zusammenlaufen: (1) der bereits nachgezeichnete ethnonationalistischer Diskursstrang, der die Masse als europäisch, den in organischen Gemeinschaften

105 Blocher 1999b: 6.

106 Vgl. exemplarisch Blocher 1997c; Blocher 2000b: 4; Baader u.a. 1999: 53.

107 Zur Bedeutung und Funktion des Topos der Masse in konservativen Kulturkritiken vgl. Thies 2013. 
verwurzelten, selbstverantwortlichen Einzelnen hingegen als schweizerisch vorstellt; (2) ein konservativ-kulturkritischer Diskursstrang, laut dem die moderne, von tradierten Autoritäten entfesselte Massengesellschaft die Menschen in anonyme, indifferente, bindungslose Nomaden verwandle, die nur durch die Wiederbelebung der vor-staatlichen, mikrosozialen und ,natürlichen' Sozialisationsorte (Hof, Familie, Verein, Gemeinde) reintegriert werden können; und (3) ein neoliberaler Diskursstrang, der das selbstverantwortliche Individuum ins Zentrum von Wirtschaft, Politik und Gesellschaft rückt und den egalisierenden Wohlfahrtsstaat als politische Apparatur des massengesellschaftlichen Zwangs zu Konformität und Mittelmäßigkeit abbauen möchte.

Im Knotenpunkt der ,Masse“ fusionieren das neoliberale Selbstverantwortungsprinzip, für dessen Durchsetzung die Partei in der Wirtschafts- und Sozialpolitik streitet, und die nationalkonservative Rehabilitierung der organischen Mikrogemeinschaften mit ihren ,vorpolitischen, natürlichen' Hierarchien und Pflichten, an der die Partei gesellschaftspolitisch festhält. Wie diese Fusion genau funktioniert, illustriert das folgende Röpke-Zitat, mit dem Eduard Stäuble seine Kritik der modernen Gesellschaft auf den Punkt bringt:

„Masse und Konzentration auf jedem Gebiet geben der modernen Gesellschaft das Gesicht. Sie ersticken mehr und mehr den Bereich der Eigenverantwortung, des Eigenlebens und des Eigendenkens und geben dem kollektiven Denken und Fühlen stärksten Auftrieb. Jene kleinen Kreise - von der Familie angefangen - mit ihrer menschlichen Wärme und ihrer natürlichen Solidarität, weichen der Masse, der Konzentration, der gestaltlosen Menschenanhäufung in den Grossstädten und Industriezentren, der Entwurzelung, den Massenorganisationen, der anonymen Bürokratie, der Riesenunternehmungen und schliesslich des Staates, der diese in Individuen zerbröckelnde Gesellschaft mit dem Zwangsapparat des Wohlfahrtsstaates, der Polizei und den Steuerbehörden zusammenfasst. [...] Es muss alles getan werden, um den Schwerpunkt der Lebensverantwortung wieder zu verlegen vom staatlichen Zentrum an die Stelle, die gesundes Denken und geschichtliche Erfahrung als die natürliche Stelle verlangt, hin zum Einzelnen inmitten seiner Familie, zu den dezentralisierten staatsfreien Organisationen, zu den breiten Schichten der Völker.“ ${ }^{108}$

Röpkes respektive Stäubles Argumentation zeigt: Der „phänomenale Spagat“ ${ }^{\star 109}$ des SVP-Populismus, der den potentiell antagonistische Differenz zwischen der nationalkonservativen Restauration vor-staatlicher, organisch-solidarischer Gemeinschaften und der neoliberalen Stilisierung des selbstverantwortlichen Indi- 
viduums als äquivalente Momente ein und derselben Identität artikuliert, konstituiert sich im Außen. Das massengesellschaftliche Andere ermöglicht es, kommunitaristische Gemeinschaftssemantiken mit dem neoliberalen Prinzip der Selbstverantwortung des Einzelnen zu artikulieren und diverse flottierende Elemente entweder einem liberal-konservativen ,Wir ${ }^{6}$ oder einem sozialistischmassengesellschaftlichen ,Sie' zuzuordnen. Die paradoxale Äquivalenz aus neoliberalen und nationalkonservativen Momenten im SVP-Populismus gründet auf der Abgrenzung von einer europäischen, in Individuen zerbröckelten und durch den Wohlfahrtsstaat gleichgeschalteten sozialistischen Massengesellschaft. Im Topos der Masse fallen die sozialstaatliche Angleichung und die anonymisierende Vereinzelung zusammen. ${ }^{110}$ Sie werden zu Teilaspekten eines europäischsozialistischen Anderen und lassen den neoliberalen Angriff auf den Wohlfahrtsstaat als politischem Überbau der Massengesellschaft und die konservative Revitalisierung von Familie und Gemeinde als äquivalente Willensakte ein und derselben autochthonen Schweiz erscheinen. Somit verwandelt die antagonistisch komponierte Essenz des Sonderfalls die partikularen politischen Forderungen der Zürcher SVP, die Blocher im Mittelteil der Rede auflistet (der Ausbau der direkten Demokratie durch die Volkswahl des Bundespräsidenten, die Wahrung des Wettbewerbsföderalismus und der bewaffneten Neutralität, der Kampf gegen Kriminalität und illegale Masseneinwanderung sowie der Rückbau des Sozialstaates) in universelle Ziele des Schweizervolkes.

Zum Abschluss der Rede blickt Blocher in die Zukunft. Für das 21. Jahrhundert prognostiziert er eine Polarisierung des Parteiensystems. Und während er seinem politisch-ideologischen Gegner, dem Sozialismus, eine Zukunft einräumt, prognostiziert er seinen strategischen Gegnern, den Parteien der bürgerlichen Mitte, die baldige Auflösung:

„Auf der linken Seite wird es stets die Sozialisten geben. Sozialisten gibt es künftig, weil der Sozialismus eine so bequeme Politik ist. [...] Auf der anderen Seite wird die SVP [...] das grosse Gegengewicht bilden. Auch die freiheitlichen und verantwortungsvollen Wähler anderer bürgerlicher Parteien - namentlich der FDP und der CVP - werden sich unserer Partei anschliessen. Diese neue Partei [...] würde wohl am besten den Namen SelbstVerantwortungs-Partei tragen, oder ganz neu: SVP. Der linke Flügel der FDP, der CVP auch einzelne aus der heutigen SVP - werden dann eine neue Partei namens WWP gründen. Die WWP ist dann die Partei, die - wie Franz Steinegger sagt - weder links noch rechts steht. Die grosse Frage, was der Staat tun soll, die grosse Frage Sozialismus oder Freiheit stellt sich für diese Leute nicht mehr [...]. Dann werden wir eine Schweiz mit drei 
Parteien haben: der SVP, der SP und der WWP. (Ich merke, dass nicht alle in der Politik so bewandert sind, dass sie wissen, was WWP eigentlich heisst. Aber es ist doch klar: es ist die ,Wischi-Waschi-Partei‘!) ‘111

Der transhistorische Konflikt zwischen dem artifiziellen und allmächtigen Zentralstaat des Sozialismus und der organischen Gemeinschaft selbstverantwortlicher Schweizer Bürger wird demnach auch die Zukunft prägen. Die Passage zeigt, dass durch die Entleerung und Verallgemeinerung der Alternative ,(europäischer) Sozialismus oder (schweizerische) Selbstverantwortung', mit der Blocher \& Co den politischen Raum entzweien, der politischen Mitte, die einst den ,konkordanzdemokratischen Sonderfall Schweiz' für sich beanspruchen konnte, nunmehr jede politische Existenzberechtigung abgesprochen wird. In diesem Freund-Feind-Szenario erscheint jeder Versuch der Aktualisierung der Konkordanz und des Austarierens von wohlfahrtsstaatlich gesicherten Gleichheits- und individuellen Freiheitsrechten als opportunistische Geste eines ,orientierungslosen Establishments“, das lediglich „Pöstchen in Verwaltung und Behörden“"112 anstrebt, aber unfähig ist, sich politisch zu identifizieren.

Der Diskurs der SVP ist weder dialektisch noch eschatologisch: Es wird weder ein post-politisches Ende von Geschichte imaginiert noch eine harmonische Gesellschaftsordnung in Aussicht gestellt, die in der Lage wäre, den transhistorischen Antagonismus zwischen ,Freiheit' und ,Sozialismus' zu synthetisieren. Gleichwohl ist dem SVP-Populismus ein utopisches Moment immanent - wenngleich in einer arche-politischen, rückwärtsgewandt-nostalgischen Variante. Dieses Moment artikuliert sich neben dem Gemeinschaftsbegriff auch im Begriff der Heimat:

„Wir verstehen unter Heimat nicht nur ein Stückchen Erde, sondern auch die Geschichte, die sich darauf abgespielt hat, die Gemeinschaft von Menschen, die sich kennen, das Geborgensein in Landschaft, Dörfern und Städten. Wer uns das schmälert oder wegnimmt, tut etwas Furchtbares, denn er mordet ein Stück unserer Seele und vergiftet die geistige Luft, die wir atmen." ${ }^{113}$

Der Heimatbegriff stellt ein vorpolitisches, parochiales, in organischen Kleingemeinschaften wurzelndes und allenfalls subsidiär organisiertes Heartland vor. Die Heimat ist ein widerspruchsfreier Raum, ein ursprünglicher, natürlich-

111 Blocher 1999b: 17.

112 Vgl. Blocher 2000a: 7.

113 Ebd.: 14. 
wohlgeordneter, autarker und widerständiger locus amoenus, in dem jeder seinen Platz einnimmt und auf „unterschiedlichen Stufen unseres Gemeinwesens Verantwortung ${ }^{\text {‘114 }}$ trägt. Dieser differenzlogisch komponierte Mythos imaginiert eine Ur-Schweiz als hierarchisch strukturierte Gesellschaft ohne Antagonismus, deren natürliches Gleichgewicht erst durch den Sündenfall des ,europäischen Sozialismus' und seine Nachahmer im Inland gestört wurde. Dieses archepolitische Heartland ist das notwendige Pendant der „Antipolitik“115 des SVPPopulismus. Denn erst vor dem Hintergrund dieses vorpolitischen Originals ist jeder politische Steuerungsversuch nicht nur ökonomisch ineffizient, sondern zugleich fremdartig und gemeinschaftszersetzend. Der Antipolitik und dem Antietatismus des SVP-Populismus liegt keineswegs ein volkswirtschaftlich begründetes Alternativlosigkeits-Argument zugrunde, sie sind moralisch angezeigt.

In diesem moralischen Diskurs fungiert die von Politik und Staat seit jeher bedrohte Ur-Schweiz, die mit dem Heimatbegriff evoziert wird, als objet $a .{ }^{116}$ Sie steht für ein bedrohtes und zu großen Teilen bereits verlorengegangenes $\mathrm{He}$ artland, dessen Restauration eine Kompensation des (irreduziblen) Mangels der Subjekte verspricht. Die Heimat vermittelt nicht nur Zugehörigkeit und Gemeinschaft. Sie ist gleichzeitig ursprünglich, natürlich-organisch, gerecht und zukunftsfähig. Sie symbolisiert eine antagonistisch blockierte Fülle, auf die sich die libidinösen Energien der Subjekte richten.

Der Affizierung des Heimatbegriffs (und seiner Bilderwelt) liegt ein diskursiv respektive antagonistisch organisierter Konstruktionsprozess zugrunde. Der Antagonismus gegenüber den wohlfahrtsstaatlich organisierten europäischen Massengesellschaften konstituiert die parochiale Ordnung der Heimat als spezifische Differenz der politischen Kultur der Schweiz. Dabei kontrastiert die Vagheit des Heimatbegriffs mit der postulierten Gegenständlichkeit der Sie-Gruppe, die für unterschiedliche Krisenphänomene verantwortlich gemacht wird. Die Identifizierbarkeit des inkompatiblen Anderen ist konstitutiv für die Stabilisierung der Wir-Identität. Sie kompensiert die Offenheit des Heimatbegriffs. Denn erst die stetige Schließung gegenüber konkreten antagonistischen Anderen verleiht dem kommunitaristischen Heartland-Mythos stabile politische Konturen, ohne ihre semantische Offenheit und ihr Integrationspotential zu sehr einzuschränken.

114 Mörgeli 1999.

115 Zum Begriff vgl. Diehl 2011: 27; mit Blick auf die SVP vgl. Hartmann/Gross 1995: 32.

116 Zur Semantik des Heimatbegriffs in der Ideologie der SVP vgl. auch Zollinger 2004: $80 \mathrm{ff}$. 


\subsubsection{Zusammenfassung: Die geschichtspolitische Hegemonisierung des, Sonderfalls“}

Im vorhergehenden Unterkapitel konnte gezeigt werden, dass der geschichtspolitische Diskurs der Zürcher SVP die Vergangenheit als eine Serie kritischer Kreuzungspunkte diskursiviert, an denen der ,Sonderfall Schweiz' jeweils auf dem Spiel stand. Staat und Politik sind nicht nur ökonomisch ineffizient, sondern spielen auch eine gemeinschaftszersetzende Rolle. Entsprechend behaupten Blocher \& Co keineswegs, Neues zu begründen. Die Zürcher SVP hat ,die den umliegenden Nationen diametral entgegengesetzte Kultur und Lebensweise' und ,die Tüchtigkeit und Weisheit des Schweizervolkes' nicht erfunden, sondern wiederentdeckt und vom sozialliberalen Schutt der 1970er und 1980er Jahre befreit. ${ }^{117}$ Die Legitimität ihres politischen Projektes zehrt von dieser vermeintlich defensiven Orientierung. ${ }^{118}$ So wird auch dort, wo die SVP für Reformen politisiert, diesen Reformen ein restaurativer Charakter zugesprochen. Grundlegend für diese neokonservative Position ist die essentialistische Vorstellung eines originären Schweizervolkes, das jene Werte, mit denen es sich bis heute identifiziert, in zahlreichen Konflikten gegen ein selbstidentisches Europa und seine etatistischen Kollaborateure im Inland wahren konnte. Stets verteidigt sich ein ,moralisches, widerständiges und arbeitsames Wir', angeführt durch eine ,wahre, auftragsgebundene Elite' gegen ein ,korrumpiertes, parasitäres und machtpolitisch denkendes Sie'.

Dieses geschichtspolitische Szenario lässt den Widerstand der Zürcher SVP als weitere Episode einer „Schweizerischen Gegenläufigkeit“"119 erscheinen: Im gegenwärtigen Kampf gegen die europäische Integration, gegen die gesellschaftlichen Eliten und etablierten Repräsentationsorgane und für den Rückbau des Wohlfahrtsstaates und die Wahrung der Unabhängigkeit steht derselbe Sonderfall auf dem Spiel, für den die Eidgenossen bereits 1291, 1499, 1648, 1792 und 1848 stritten, den sie zwischen 1939 bis 1945 gegen die ,faschistische Umzingelung ${ }^{6} \mathrm{zu}$ verteidigen wussten und der sie während des Kalten Krieges zur antisozialistischen Bastion machte. Im Rahmen dieser Analogisierung von Geschichte, Gegenwart und Zukunft erscheint die Oppositionspolitik der SVP als Fortfüh-

117 Ähnliches stellt Stuart Hall (1986: 101) für den Thatcherismus fest.

118 Zur defensiven Selbstbeschreibung Blochers vgl. Altwegg 2004: 88.

119 Blocher 1999b: 13. Blocher paraphrasiert hier das berühmte Diktum des Schweizer Politologen Karl Schmids, wonach eben jene Gegenläufigkeit konstitutiv für den Erfolg der Schweiz sei. 
rung eines Zweikampfes, der die Schweizer Geschichte seit jeher prägte. Diese zyklisch-periodische und binär-antagonistisch strukturierte Repräsentation der Schweizer Geschichte ermöglicht dem politischen Projekt der Zürcher SVP sich zu universalisieren und die ,partikularistische Selbstbezogenheit zum Schweizer Nationalcharakter von Freiheit und Unabhängigkeit ${ }^{\star 120} \mathrm{zu}$ stilisieren. Denn erst die Repräsentation eines transhistorischen Bedrohungskomplexes, der aus der äquivalenzlogischen Artikulation von absolutistischen, (national-)sozialistischen, europäischen und intellektuellen Momenten hervorgeht, lässt die Äquivalenz aus konservativen, neoliberalen, oppositionellen und plebiszitären Momenten zur Essenz der Schweizer Nation avancieren.

Zugleich unterminiert diese Repräsentation der Schweizer Geschichte die politische Kultur der Konkordanz. Der geschichtspolitische Diskurs der Zürcher SVP bewirkt sozusagen einen Seitenwechsel des Sonderfallbegriffs: Konstituierte sich der konkordanzdemokratische Exzeptionalismus einst durch eine Vielzahl peripherer Antagonismen gegenüber diversen, irrationalen, extremistischen und unschweizerischen fundamentaloppositionellen Gruppen“, deren „schwarzweiß polarisierten Zukunftserwartungen ““121 er Vernünftigkeit und Legitimität absprach, fixiert der SVP-Populismus den Sonderfall Schweiz fortan innerhalb einer binär strukturierten Matrix. Dadurch mutiert Blochers Attitude des ,standhaften, rigorosen und wenn nötig sturen Neinsagers', für die ihn der konkordanzdemokratische Diskurs als , unschweizerisch` disqualifiziert, zum Symbol eines genuin schweizerischen, dem Exzeptionalismus verpflichteten Widerstandsgeistes.

Dieser Hegemonisierung des Sonderfalls liegt die Konstruktion eines transhistorischen Antagonismus zugrunde. Denn nur die Imagination eines Bedrohungskomplexes kann die (potentiell antagonistischen) Differenzen unter dem Dach des Sonderfallbegriffs äquivalent setzen. Erst die Präsenz dieser übergeordneten antagonistischen Differenz transformiert die inneren Antagonismen in schlichte Differenzen einer politischen Entität und sorgt dafür, dass die innere Heterogenität des Sonderfallbegriffs nicht zu seiner Dissolution führt.

Die Momente der beiden Äquivalenzketten (Freiheit, Föderalismus, Demokratie und Bodenständigkeit respektive Monarchie, Zentralismus, Bürokratie, Intellektualismus, Sozialismus und Totalitarismus) werden gerade nicht als kontingent artikulierte Elemente, sondern als Epiphänomene zweier diametraler organisch gewachsener Einheiten vorgestellt. So gehen die Schweizer Momente ,Freiheit, Föderalismus, Demokratie und Bodenständigkeit‘ auf einen genuin 
schweizerischen, selbstverantwortlichen Einzelnen zurück, den allein die SVP vertritt, wohingegen die europäischen Momente ,Monarchie, Zentralismus, Bürokratie, Intellektualismus, Sozialismus und Totalitarismus' den genuin europäischen Massengesellschaften entwachsen, deren politische Erben die ,Linken und Netten' sind.

Die Restrukturierung des politischen Raumes, die mit der Konstruktion der beiden diametralen Äquivalenzketten verbunden ist, führt $\mathrm{zu}$ semantischen Transformationen der artikulierten Momente. Es handelt sich eben nicht um eine schlichte Okkupation des Schweizer Exzeptionalismus, sondern um eine hegemoniale Reartikulation, welche die Semantik des Sonderfalls durch neue Singularisierungsstrategien modifiziert: Dadurch dass die EU beispielweise, die in der EWR-Kampagne noch als künstliche, von Intellektuellen ausgeheckte Bedrohung der organisch gewachsenen europäischen Nationen und Völker erschien, als Fortführung der massengesellschaftlich-zentralstaatlichen Traditionen dieser Nationen repräsentiert wird, erscheint der ,Sonderfall Schweiz' nicht mehr als primus inter pares, als die pluralistische, konkordanzdemokratisch integrierte Musterrepublik, die allen anderen Staaten ein Vorbild sein könnte, sondern als ein umstelltes, ideologisch geeintes und wehrhaftes Eiland inmitten eines zentralistisch gleichgeschalteten Europas. Die Kontinuation im Außen erwirkt eine transhistorische Singularisierung des Schweizervolkes und der Schweizer Nation, die es der Zürcher SVP erlaubt, vielfältige Differenzen gemeinsam zu artikulieren und unter ihrer Ägide zu vereinen.

\subsection{Demokratie und Pluralismus. ZUR SEMANTISCHEN TRANSFORMATION IDENTITÄTSSTIFTENDER BEGRIFFE IM SVP-POPULISMUS}

Im vorangegangenen Kapitel habe ich mich hauptsächlich mit der Äquivalenzkette im Außen beschäftigt und gezeigt, dass die Hegemonisierung des Schweizer Sonderfalls durch die SVP nur durch die Konstruktion eines multiplen Bedrohungskomplexes aus konkreten, identifizierbaren Entitäten möglich wurde. Im Folgenden leuchte ich in die Worthülse ,Sonderfall' hinein und beschäftige mich mit den Bedeutungsverschiebungen, die seine Momente im Zuge ihrer Reartikulation erfahren.

Ich konzentriere mich dabei in erster Linie auf die gemeinsame Artikulation von Demokratie und Pluralismus. Denn diese beiden Elemente sind aus zwei Gründen besonders interessant. Erstens handelt es sich um sedimentierte leere 
Signifikanten, die von allen bedeutungsvollen politischen Kräften in Anspruch genommen und bei der Konstruktion des ,Sonderfalls Schweiz' seit jeher maßgeblich involviert sind. Zweitens ist ihre gemeinsame Artikulation eine paradoxale. Wohingegen der Demokratiebegriff der Zürcher SVP einen positiven Freiheitsbegriff und ein bejahendes Verhältnis zu Politik kolportiert, konstruiert die Artikulation eines parochialen Pluralismus- und Freiheitsbegriffs Politik als per se parasitäres Moment.

Der konkordanzdemokratische Diskurs artikuliert Demokratie in erster Linie als Modus der konsensförmigen Integration einer multikulturellen Gesellschaft, die sich in den verfassungsmäßig forcierten Aushandlungsprozessen zwischen den etablierten politischen Repräsentanten vollzieht. Gegen diesen hegemonialen Diskurs verflechtet der von der Zürcher SVP geführte Demokratiebegriff drei Traditionen: Erstens eine liberale Tradition, in der Demokratie als temporale Gewaltenteilung gedacht wird; zweitens eine agonistische Tradition, in der Demokratie als umkämpfte Selbstinstituierung einer pluralistischen Gesellschaft betrachtet wird und drittens eine kommunitaristisch-identitäre Tradition, in der Demokratie als unmittelbarer Ausdruck einer substantiell begründeten Willensgemeinschaft bzw. als Herrschaft einer in einer geteilten Sittlichkeitsvorstellung begründeten volonté générale vorgestellt wird.

Bemerkenswert ist insbesondere das Verhältnis zwischen der zweiten und der dritten Tradition. Hierin zeigt sich nämlich, dass der SVP-Populismus zwischen einem integrativen politischen Pluralismus und einer Negation desselben oszilliert, die den exklusiven ,,antiliberalen und vormodernen“122 Demokratiebegriff der alteidgenössischen Landsgemeinden aktualisiert. Auf der einen Seite argumentiert Blocher, dass die konkordanzdemokratische Aberkennung einer systematischen Opposition der demokratischen Qualität des politischen Gemeinwesens nicht zuträglich sei. „Eine funktionierende Demokratie setzt nämlich Alternativen voraus.“ Weil ,[d] as Eintrichtern von Einheitsmeinungen und angeblich Zwangsläufigem von oben [...] undemokratisch [ist]", sei es so wichtig, dass ,[w]ir nicht davor zurückgestreckt [sind], das ,Undenkbare“ zu denken, [...] neue Anstöße und auch Zündstoff für die politische Diskussion geliefert [haben] “. ${ }^{123}$ Die Auseinandersetzung über grundsätzliche und zukunftsweisende Fragen des gesellschaftlichen Zusammenlebens wie etwa den Beitritt zum EWR ist für Blocher Kernstück und Sternstunde der Demokratie. Die ,intensive politische Auseinandersetzung“ ist „das wichtigste Kennzeichen einer guten politi- 
schen Kultur“. ${ }^{124}$ Natürlich versucht Blocher, mit solchen Aussagen die politische Oppositionsstrategie des Zürcher Flügels als Dienst an der größeren Sache der Demokratie zu nobilitieren. Zugleich ist diese Argumentation aber demokratietheoretisch gehaltvoll. Im Gegensatz zum konkordanzdemokratischen Imaginären, dem die Illusion einer vollkommen integrierten Gesellschaft zugrunde liegt und das jede Manifestation des Politischen unter Extremismus-Verdacht stellt und als ,unvernünftig ' und ,unschweizerisch ${ }^{`} \mathrm{zu}$ dezertifizieren versucht, betont Blocher, dass demokratische Politik die Konstruktion von Wir-SieUnterscheidungen voraussetzt. Er plädiert für einen politischen Pluralismus und wirbt für ein demokratisches Imaginäres, das Politik als Kampf um die Selbstinstituierung der Gesellschaft begreift und nicht-konsensfähige Elemente inkludiert. Nicht der deliberativ erzeugte Elitenkonsens, sondern die antagonistische Auseinandersetzung jenseits des konkordanzdemokratischen Imperativs der pragmatischen Konfliktlösung erscheint als die adäquate politische Inszenierung einer pluralistischen Gesellschaft.

Gleichzeitig jedoch erscheint Politik im SVP-Diskurs als parasitär und überflüssig. Denn auf der anderen Seite des europäisch-sozialistischen Anderen lassen Blocher \& Co das arche-politische Heartland einer differenzlogisch komponierten, idyllischen Ur-Schweiz erscheinen, in der das Prinzip der Selbstverantwortung dafür Sorge trage, dass jedem das Seinige zu Teil werde, jede Differenz die für sie vorgesehene Position einnimmt. Politik ist weder die Folge von gesellschaftlichem Pluralismus noch der Versuch, den Pluralismus konsensual zu transzendieren. Sie ist im Grunde illegitim und überall dort in ihre Schranken zu weisen, wo die ursprüngliche, natürliche und gerechte Ordnung infrage gestellt wird.

Der Heartland-Mythos der SVP ist also nicht nur konstitutiv für die Konstruktion der popularen Äquivalenz. Indem er ein europäisch-sozialistisches Außen vorstellt, das der Schweiz prinzipiell fremd sei, sorgt er für die Stabilisierung der Äquivalenzkette. Er wirkt apodiktisch. Denn der Antagonismus wird hier nicht als intrinsisches Element der demokratischen Gesellschaft, sondern als externe Entität vorgestellt. Das antagonistische Andere ist eben nicht das notwendige Komplement des Systems. Für seine Blockade müssen vielmehr fremde, nicht-zugehörige Phänomene haften, die das einst ,gute und gesunde System“ korrumpiert haben. ${ }^{125}$ In dieser Konstruktionslogik des antagonistischen Anderen manifestiert sich ein Grundzug des SVP-Populismus: Seine Kontinuität geht da-

\section{Blocher 1998: 15}

125 Vgl. hierzu auch die Kritik der Laclau'schen Populismustheorie von Slavoj Žižek (2009: 278ff.) sowie für eine knappe Zusammenfassung vgl. Casula 2012: $58 \mathrm{f}$. 
rauf zurück, dass der Mangel, den etwa der vage Heimatsbegriff zum Ausdruck bringt, einem multiplen Bedrohungskomplex aus positiven Gruppen angelastet wird, durch deren Ausschluss ein vorpolitisch-originäres Gleichgewicht wiederhergestellt werden könne.

Der Topos des ursprünglichen Gleichgewichts begründet ein politisches Szenario, das Jacques Rancière als das „doppelte Spiel“126 eines ethnisch begründeten Rechtspopulismus bezeichnet: Die SVP-Populismus fordert „einerseits, gegen die Demokratie, eine Fundierung der Politik" in der Tradition und der Geschichte und postuliert ,andererseits, gegen den herrschenden Konsens, eine Bejahung der Befähigung des Volkes zur Politik“ ${ }^{127}$ Damit dieser Matchplan aufgeht, wird die relative Leere des Volksbegriffs durch eine essentialisierende Geschichtspolitik verfüllt, die das Volk und seine Zukunft im Rahmen einer zyklischen Geschichtsphilosophie gefangen nimmt.

Demokratietheoretisch problematisch ist, dass sich durch diese Imagination das Prinzip der Volkssouveränität in der Verteidigung von Normen erschöpft, die von den Bürgern als zeit- und geschichtslose Essenzen des Gemeinwesens betrachtet werden. Das Phantasma eines vorpolitischen, wohlgeordneten Urzustandes avanciert zum universellen Bezugspunkt politischer Legitimität, sodass jede Politik, die gegen die Normen dieser vermeintlichen Ur-Schweiz verstößt, als ketzerische Abweichung wahrgenommen wird. Der geschichtspolitische Diskurs des SVP-Populismus schafft somit antipolitische politische Subjekte, die Politik nur dann als legitim anerkennen, wenn sie als Restauration dieser UrSchweiz geltend gemacht wird. Sein Staatsbürgerschaftskonzept entspricht dem von „politisierten Nicht-Bürgern““128, die vermeintlich ursprünglichen Normen folgen, anstatt darüber zu beraten und zu entscheiden, unter welchen Gesetzen und in welcher Gesellschaft sie leben möchten. „Die Beschwörung traditioneller Sittlichkeit geht einher mit einem starken Misstrauen gegen ,die Politik', die mehr als Gefahr für das private Leben und Geschäften denn als Chance für die Gestaltung der Öffentlichkeit begriffen wird.““129

Was mit Rancière als „doppeltes Spiel“ bezeichnet wurde, lässt sich hegemonietheoretisch auch als Ineinandergreifen von Äquivalenz- und Differenzlogik beschreiben. Einerseits sind die artikulierten Elemente äquivalent, da sie alle von Politik und Staat bedroht sind: Fleiß, Bescheidenheit, Selbstbehauptung, Eigenständigkeit, Verantwortlichkeit, Unabhängigkeit, Selbstbestimmung bezeich-

126 Rancière 2006.

127 Ebd.

128 Greven 1999: 205; vgl. auch Sauer 2002: 133.

129 Lang 2000: 101. 
nen alle dasselbe, nämlich die Zugehörigkeit zu einer abwesenden harmonischen Schweizer Urgesellschaft. Andererseits wird ihre äquivalenzlogische Überdeterminierung differenzlogisch eingehegt, indem ihnen ein fester Platz in dieser originären Gemeinschaft zugewiesen wird, an dem sie sich vollkommen entfalten könnten. Das oben zitierte Ideal Christoph Mörgelis, jeder möge „,auf unterschiedlichen Stufen unseres Gemeinwesens Verantwortung übernehmen“"130, ist paradigmatisch für die „Antipolitik“"131 des SVP-Diskurses. Sie zehrt von der Vorstellung eines Heartland, in dem die quasi-natürliche Prädetermination nicht durch politische Eingriffe gestört werde, sodass jedem das Seinige zu Teil werde.

Die äquivalenzlogische Überdeterminierung erwirkt eine Politisierung nach außen. Jede sektorielle Unrechtserfahrung avanciert zum Ausdruck eines universellen Unterdrückungsverhältnisses. Auf der anderen Seite sorgt der differenzlogisch komponierte Heartland-Mythos für eine Entpolitisierung nach innen. Die Differenzen werden strukturell absorbiert und arretiert. Der Heartland-Mythos stabilisiert den Diskurs. Er limitiert die Möglichkeiten der Reartikulation seiner Elemente, indem er sie dem Selbstverantwortungsprinzip unterwirft. Somit lässt sich die für populistische politische Projekte außergewöhnliche programmatische und stimmenmäßige Kontinuität des SVP-Populismus als Effekt eines archepolitischen Mythos verstehen, welcher der äquivalenzlogisch erwirkten Überdeterminierung der Elemente entgegenwirkt, ohne sie ihrer gemeinsamen antagonistischen Ausrichtung zu berauben.

Wie der konkordanzdemokratische Mythos stellt auch der SVP-Mythos die Möglichkeit einer pluralistischen Gesellschaft ohne Antagonismus in Aussicht. In beiden Diskursen beruht die Essentialisierung dieser Vorstellung zum genuin Schweizerischen auf der Externalisierung inkompatibler Differenzen. Der konkordanzdemokratische Mythos exkludiert die Bürgerinnen und Bürger, deren politische Positionen nicht konsensual integriert werden können, als unvernünftig und unschweizerisch; der SVP-Mythos diskursiviert diejenigen, deren Lebensweise seine Allgemeingültigkeit konterkarieren, als parasitäre Elemente und Kollaborateure eines transhistorischen Bedrohungskomplexes, der die Habsburger Monarchie, das napoleonische Frankreich, die faschistischen Achsenmächte, die Sowjetunion und die Europäische Union mit Migranten, Drogenabhängigen, Intellektuellen und sozial Schwachen zusammenschließt. ${ }^{132}$ 
Im Unterschied zur Äquivalenzkette des konkordanzdemokratischen Diskurses gründet jene des SVP-Populismus nicht auf der Akzeptanz vermeintlich neutraler oder adäquater Verfahren der Entscheidungsfindung, sondern auf der Imagination der organisch gewachsenen Einheit eines eigentlichen Volkes, dessen Willen im Selbstverantwortungsprinzip zum Ausdruck käme. Die Kohäsion des Volkes wird nicht mehr als Effekt einer konkordanzdemokratischprozeduralisierenden Form von Politik gedacht. Im Gegenteil, das komplexe Institutionengefüge ist eigentlich obsolet. Denn es wird geltend gemacht, dass das Volk vor aller Politik existiere und in der SVP lediglich politisch Gestalt annehme. Die Herausforderung, eine pluralistische Gesellschaft zu integrieren, die im konkordanzdemokratischen Diskurs als Grund des proportionalen Repräsentationsregimes und der konsensorientierten Konfliktlösung fungiert, wird im SVPDiskurs zugunsten der Vorstellung eines selbstidentischen, durch gemeinsame geschichtliche Erfahrungen und den gesunden Menschenverstand geeintes Volk suspendiert. Die Bevölkerung mag pluralistisch sein, zum Schweizervolk gehören aber nur diejenigen, die das Selbstverantwortungsprinzip gegen die Kolonialisierungstendenzen aus Bern und Brüssel verteidigen und gewillt sind, mit der SVP eine originäre, gerechte, wettbewerbsfähige und von fremden Elementen gereinigte Heimat zu restaurieren, in der jede Politik überflüssig sei.

Wie der SVP-Populismus diesen vermeintlich unvereinbaren Widerspruch zwischen der agonistischen und der kommunitaristisch-identitären Tradition in einem gemeinsamen Kampf vereinigt, werde ich im Kontext der MinarettInitiative vorführen. Zunächst folgen jedoch ein kurzer Exkurs zu zwei gegenhegemonialen politischen Projekten und ein Kapitel zur zentralen Stellung Christoph Blochers im SVP-Populismus. 


\section{Gegenhegemonien: Swissness oder Sonderfall. Post-politische Restauration der multikulturellen Schweiz oder linkspopulistische Gegenhegemonie}

Im vorangegangenen Kapitel wurde die Hegemonisierung des ,Sonderfalls Schweiz' durch die SVP analysiert. Es wurde gezeigt, wie der SVP-Diskurs die Nation artikuliert, wie die liberal-konservative Repräsentation des Sonderfalls zur dominanten wurde und welche semantischen Transformationen die Identifikationsbegriffe der politischen Schweiz im Rahmen dieser Monopolisierung erfahren.

In den 1990er Jahren galt der ,Sonderfall Schweiz' vielen als erledigt. Die Ergebnisse des Eizenstat-Berichtes und der Bergier-Kommission erschütterten den Mythos des neutralen Kleinstaates, der sich moralisch schadlos gehalten und als einziger liberaldemokratischer Staat auf dem europäischen Festland den Achsenmächten getrotzt habe. Zudem hatte die Globalisierung durch das friedliche Ende des Ost-West-Konflikts jenen Schub erhalten, der das Ende des Nationalstaates und der kriegerischen Nationalismen des 19. und 20. Jahrhunderts besiegeln sollte. Es waren keineswegs nur SP-Politiker, sondern auch Politiker der staatstragenden bürgerlichen Parteien, die den ,Sonderfall Schweiz' einst hegemonisiert hatten, die nunmehr auf dessen Verabschiedung drängten. ${ }^{1}$ Die SVP war die einzig bedeutsame politische Kraft, die sich gegen die kritischen Relativierungen und die Abgesänge auf den Sonderfall zur Wehr setzte und sich ,entschieden zur Schweiz bekannte', wie Blocher nicht müde wurde zu betonen mit monumentalem politischem Erfolg. Im SVP-Populismus avancierte der ,Sonderfall Schweiz' zu einem mythischen Horizont, einem fixen Bezugspunkt 
des Politischen, den auch Blocher nur „erahnen“ kann, wie er auf der Albisgüetli-Tagung im Januar 2000 formulierte. $^{2}$

Entgegen den Prognosen der 1990er Jahre und der Krise der SonderfallIdeologie mussten auch linksliberale Intellektuelle anerkennen, dass das Nationale in den 2000er Jahren ein eigentümliches Revival erlebte. ${ }^{3}$ Die negativen Auswirkungen des Scheiterns der europäischen Integration bleiben aus; der unabhängige, neutrale Kleinstaat erwies sich entgegen den Prognosen als ökonomisch und politisch zukunftsfähig; und auch die emotionale Identifikation mit der Schweiz, die Ende der 1990er durch die Debatte um die Rolle der Schweiz im Zweiten Weltkrieg belastet war und 2001 durch den Konkurs der Swissair, dem Symbol der modernen Nationalökonomie, weiteren Schaden genommen hatte, geriet wieder intakt.

Das wiedererstarkende Selbstbewusstsein, eine besondere, anderen Nationen überlegenes Gemeinwesen zu sein, manifestierte sich nicht nur in der parteiübergreifenden Wiederentdeckung des ,Sonderfalls', sondern im Erfolg der sogenannten Swissness, einer heterogenen Qualitätsmarke, die das Schweizerische zum trendigen, nachhaltigen und qualitätsbewussten Lebensstil stilisierte. Junge Städter schmückten sich mit T-Shirts und Handtaschen mit dem Schweizer Kreuz; Pop-Bands reüssierten mit Liedern in Mundart über Heimat, Heimatliebe und Heimweh; moderne Heimatfilme wie „Tell“, „Heimatklänge“ oder „Achtung, fertig, Charlie!" wurden Kassenschlager und variierten die Bedeutung der Heimat; die Arteplages der EXPO 2002 stiftete eine nie dagewesene „Leichtigkeit des Schweizerseins“"4; und auch politisch wurde das Bekenntnis zur Schweiz zum Gebot der Stunde: So zeigt das neue Logo der SP etwa die Konturen des Matterhorns und die Freisinnigen zitierten die nationale Emblematik, indem sie die Buchstaben FDP in die Form eines dreidimensionalen Schweizer Kreuzes brachten. Galt der Exzeptionalismus in den 1990er Jahren allen bedeutenden politischen Akteuren mit Ausnahme der SVP als Anachronismus, wurde er nunmehr zu einem scheinbar unvermeidbaren Ausgangs- und Bezugspunkt politischen Handelns.

Vor diesem Hintergrund entstanden im Jahr 2007 gegen die Hegemonie der SVP als „Sonderfall-Partei“ ${ }^{\text {“5 }}$ zwei diametrale Initiativen: eine linkspopulistische

2 Blocher 2000a: 10.

3 Vgl. Meier-Dallach u.a. 2003; Eberle 2007; Imhof 2007; Tanner 2007.

4 [o.A.] NZZ, zit. in: Daum, Matthias (2014): Schafft neue Bilder! Die Schweiz nach dem 9. Februar, in: ZeitOnline, 20.2.2014.

5 Imhof 2007: 28. 
mit dem Wortführer Kurt Imhof und ein kosmopolitische mit dem Wortführer Jakob Tanner. ${ }^{6}$

Imhof bescheinigt dem Sonderfall-Diskurs ein Potential der nationalen Neubesinnung. Aus Sicht des Soziologen ist die Rede vom ,Sonderfall Schweiz، trotz vieler Parallelen zu anderen europäischen Nationen nicht nur legitim, sondern auch politisch angezeigt. Imhof geht davon aus, dass ,jede historische oder biographische Sinnstiftung jeder sozialen Einheit zwanghaft in einem Sonderfall [mündet] ${ }^{\text {“7 }}$. Die Abgrenzung von einer Normalität, welche die eigene Besonderheit gefährdet, sei die notwendige Bedingung, um ein Identitäts- und Zugehörigkeitsgefühl zu entwickeln. ${ }^{8}$ Hierzu versucht Imhof, jene Knotenpunkte des konkordanzdemokratischen Sonderfall-Diskurses zu restaurieren, die der SVPPopulismus als ,wohlklingende Feigenblätter' einer abgehobenen und klüngelnden Elite diskreditierte. Imhof ist überzeugt, dass die drei Bausteine des Sonderfall-Gedankens (das Bedrohungsgefühl, der Wille zur Selbstbestimmung und das Verlangen nach Konkordanz), die er als gegeben erachtet, gewisse Pfadabhängigkeiten erzeugten, die nicht notwendig SVP-like seien. Dabei geht es dem Soziologen darum, den Schweizer Exzeptionalismus als Legitimationsressource eines Etatismus zu instituieren, der dem „,,internationalistischen“ Deregulierungsdogma“" die Stirn zu bieten vermag, wofür es einer geteilten „Bedrohungswahrnehmung ${ }^{\text {“10 }}$ bedürfe. Imhof polemisiert damit nicht in erster Linie gegen die SVP und die AUNS als „Hardcore-Vertretern“" ${ }^{11}$ des Sonderfalls, sondern gegen die „revisionistische Dekonstruktion des Sonderfalls“, die „keinerlei Orientierung“" stifte, ${ }^{12}$ sowie gegen den ,,internationalistischen“ Antietatismus der ,Neuen Linken““'13, für die ,,in ihrer Multikulti-, Gender- und Umwelt-Ära alles Nationale und Patriotische des Teufels [war] ${ }^{614}$. Denn nur wenn die politische Mitte und die politische Linke ihren „dogmatischen Antietatismus“ ablegten und sich aktiv in den schweizerischen Sonderfalldiskurs einschalteten, bestünde ein Chance, dass sich der Wille zur nationalen Selbstbestimmung ,im Zeichen eines zunehmend globalisierungskritischen Standortnationalismus“ mit einem funktio-

\footnotetext{
6 Vgl. Nussbaumer 2007.

7 Imhof 2007: 26.

8 Ebd.

9 Ebd: 47.

10 Ebd: 45.

11 Ebd: 52.

12 Ebd: 47.

13 Ebd: 45.

14 Ebd: 47.
} 
nierenden Staatswesen und dem schweizerischen Ideal eines autonomen Service public artikulieren ließe. ${ }^{15}$

Gegenüber einem antietatistischen Kosmopolitismus, der einer linken Identifikation mit dem Nationalstaat den Boden entzogen und der neoliberalen und ethnonationalistischen Hegemonisierung des Sonderfalls Tür und Tor geöffnet habe, betont Imhof die Möglichkeiten einer gegenhegemonialen Reokkupation des Sonderfallbegriffs, der das Ideal der nationalen Selbstbestimmung nicht der SVP überlässt. Grundlegend ist dabei, dass der Antagonismus, den Blocher \& Co gegen alles Fremde und Staatliche artikulieren, durch den Antagonismus gegenüber der „, Globalisierungsbedrohung “" ${ }^{\text {“16 }}$ substituiert wird.

Während Imhof den ,Sonderfall Schweiz ' von links einfordert, ist der Schweizer Exzeptionalismus für den Historiker Tanner zutiefst reaktionär. Nicht die Reartikulation des Sonderfalls, sondern allein die Swissness ermögliche eine zeitgemäße, ,kreative Neuaneignung nationaler oder lokaler Traditionen“17. Die Marke und ihr Image fungieren als ideologische „Klammer“ eines „,neue[n] Wohlbehagen[s] im Kleinstaat “ ${ }^{18}$ War die Konjunktur der Swissness und des „leichtfüssigen Schweizpatriotismus “'19, den sie produziert, für Imhof eine bloße Gelegenheit für eine gegenhegemoniale Usurpation des Sonderfallbegriffs, bildet die Swissness aus Tanners Sicht das neue Rückgrat eines gegenhegemonialen Diskurses, der den eigentümlichen Aufschwung des Nationalen in andere politische Bahnen lenken sollte als die Sonderfall-Ideologie der SVP. Und mehr noch: Tanner postuliert, dass ,der Höhenflug der Swissness das Grounding der Sonderfall-Ideologie ${ }^{\text {“20 }}$ besiegle. Die Swissness degradiere das nationale Emblem des Schweizer Kreuzes zu einer Marke unter vielen; sie „depotenziert die Bedrohungskomplexe und die Ausgrenzungsgewalt, die in der nationalen Befreiungssaga der Schweiz angelegt sind“21.

Tanners Plädoyer für eine merkantile Swissness bleibt jedoch in einem entscheidenden Punkt hinter dem Sonderfall-Diskurs Imhofs (und demjenigen der SVP) zurück: Indem die Swissness das Schweizerkreuz mit neuen Elementen kombiniert, produziert sie zwar vielfältige Schweiz-Bilder, doch handelt es sich beim Swissness-Diskurs im Unterschied zu den Sonderfall-Diskursen nicht um

15 Vgl. ebd.: 51.

16 Ebd: 50.

17 Tanner 2007.

18 Ebd.

19 Imhof 2007: 51.

20 Tanner 2007.

21 Ebd. 
einen politisierenden, sondern um einen entpolitisierenden Diskurs. Tanner räumt dieses politische Defizit der Swissness ein:

„Swissness schürt keinen neuen Nationalismus. Sie ist vielmehr Ausdruck eines globalisierten Kapitalismus, der alles und jedes in Märkte und Moden integriert. [...] Auf die sozialpolitischen Herausforderungen der Gegenwart - zunehmende Ungleichheit, neue Armut und soziale Diskriminierung - vermag Swissness jedenfalls keine effektive Antwort zu geben. “22

Es sei dahingestellt, ob die Swissness wirklich keinen neuen Nationalismus schürt oder ob sie nicht vielmehr die Gefahr birgt, den Kulturrassimus des SVPSonderfall-Diskurses durch einen konsumorientierten Chauvinismus zu ersetzen. In jedem Fall aber beschränkt sich der Swissness-Diskurs darauf, den von der SVP vorgestellten Bedrohungskomplex als irrational zu verwerfen. Er trifft keine eigenen Freund-Feind-Unterscheidungen, sondern repliziert nur jene der SVP. Da sich ohne Antagonismus Identität nicht gestalten, geschweige denn umgestalten lässt, verharrt die Swissness in einem politisch blinden Lifestyle-Patriotismus. Die Swissness favorisiert einen post-politischen Kosmopolitismus. Sie imaginiert eine teilungsfreie Gesellschaft, die in der Lage ist, jede Differenz zu integrieren und läuft dadurch Gefahr, die äquivalentielle Artikulation der subalternen Positionen, denen die Teilhabe am schweizerischen high-end-Kapitalismus verwehrt ist, der SVP zu überlassen.

Die Swissness sorgt für eine Pluralisierung der vorgestellten Schweiz, sie unterläuft das Monopol der SVP auf die Repräsentation des Nationalen und produziert vielfältige Anknüpfungspunkte für einen anderen Exzeptionalismus. Im Unterschied zu Imhofs Reartikulation des Sonderfallbegriffs konfrontiert der Swissness-Diskurs die populistische Spaltung des SVP-Diskurses aber nicht mit einer dritten Alternative. Vielmehr imaginiert er einen differenzlogisch komponierten Raum, in dem alles ,schweizerisch“ werden könne. Seine antagonistische Grenze findet dieser Diskurs im SVP-Patriotismus, der als skurriler Anachronismus rekonstruiert wird. ${ }^{23}$ Die von der SVP instituierte Konfliktlinie zwischen einem ,orientierungslosen, elitären Kosmopolitismus ‘ und einem ,orientierungsstiftenden, popularen Ethno-Kommunitarismus' wird auf diese Weise jedoch nicht infrage gestellt, sondern reproduziert: hier das sorgenvolle und hart arbeitende

22 Ebd.

23 Exemplarisch für diese exotistische Perspektivierung der SVP vgl. Biasio/Sprecher 2007. 
Volk der nativen Kleingemeinschaften, dort die sorgenbefreite und hedonistische Dekadenz der parasitären multikulturellen Massengesellschaft.

Entsprechend kontert der SVP-Populismus Tanners Swissness durch eine Umkehrung der Adjektivierungen unter Beibehaltung der dichotomischen Struk-

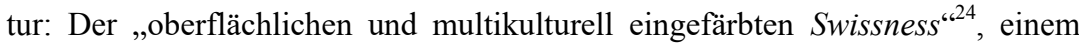
„Patriotismus à la carte - substanzfrei, unverbindlich, inhaltslos" ${ }^{\text {“25 }}$, hält er einen

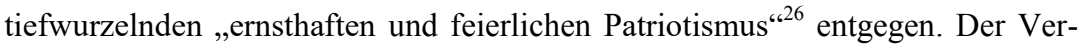
such, das verlorengegangene „linksliberale Deutungsmonopol“ mit dieser unglaubwürdigen „Avance an den Zeitgeist“ zu erneuern, sei ein „grotesker“ Taschenspielertrick. $^{27}$

Wenn aus dem nationalen Ideen- und Bilderreservoir, das die Swissness angelegt hat, ein linkes politisches Projekt entstehen soll, das die subalternen Forderungen zu einem gegenhegemonialen Selbstbestimmungswillen artikuliert, dann muss es sich auf die Dialektik von Identität und Alterität einlassen, die dem ,Sonderfall Schweiz' innewohnt. Einem radikaldemokratischen Projekt, das die Heimatbilder der Swissness politisiert, ginge es nicht darum, den nationalen Bedrohungskomplex zu überwinden, sondern einen Bedrohungskomplex zu konstruieren, der es erlaubt, aus dem heterogenen Lager der „Enttäuschten, Erfolglosen und Einsamen ${ }^{\text {‘28 }}$, die heute bei der SVP Schutz suchen, ein anderes Schweizervolk zu schmieden und einen anderen ,Sonderfall' als Sehnsuchtsort der Subjekte des Mangels zu installieren. Imhofs Intervention skizziert eine derartige gegenhegemoniale Strategie, wurde von der politischen Linken jedoch nicht systematisch weiterverfolgt, da sie quer zur negativen Konnotation des Nationalen liegt.

24 Brunner 2008.

25 Gut 2007.

26 Brunner 2008.

27 Gut 2007.

28 Biasio/Sprecher 2007: Kap. 1. 


\section{7. ,Blocherismus"}

„Liberalismus und Konservatismus sind in der Tat Gegensätze. [...] Ich bringe die beiden Elemente sauber zusammen.“

BLOCHER 1995

In den letzten Kapiteln wurde an einigen Stellen bereits die zentrale Stellung Christoph Blochers im SVP-Diskurs thematisiert. Im Kapitel über die Geschichtspolitik erschien Blocher etwa als defensiver Aufrührer, dessen politisches Handeln in der Kontinuität der historischen Freiheits- und Unabhängigkeitskämpfe steht, sowie als organischer Intellektueller, der aufgrund seiner erfahrungsgesättigten Lebens- und Menschenführung das abwesende Allgemeine, die gefährdete, natürlich gewachsene und in historischen Kämpfen errungene Ordnung zurückbringen könnte.

In diesem Kapitel soll die Funktion des Signifikanten ,Blocher“ in den Vordergrund gerückt werden. Es gilt den Bonapartismus, die populismustypische Führerzentrierung hegemonietheoretisch zu analysieren und als Grundlage des missionarischen Politikmodells des SVP-Diskurses in den Blick zu nehmen. ${ }^{1}$ Den Hintergrund bilden der erneute Wahlerfolg der SVP bei den Nationalratswahlen 2007 und die anschließende Abwahl Christoph Blochers als Bundesrat.

1 Zum Bonapartismus als zentralem Element des SVP-Populismus vgl. Priester 2012a; zum missionaristischen Aspekt des Populismus vgl. Zúquete 2011. 


\subsection{Das Ereignis: Die Nationalratswahlen 2007 UND DIE ABWAhl Christoph Blochers ALS BUNDESRAT}

Ehe ich auf die Abwahl Blochers als Bundesrat im Nachgang der Nationalratswahlen von 2007 eingehe, sei kurz auf die strategischen Überlegungen der Bundesratsparteien eingegangen, die vier Jahre zuvor zur Wahl Blochers als Justizminister geführt hatten.

Nachdem Blocher 1999 mit seiner Kandidatur gegen Moritz Leuenberger und Ruth Dreifuss (SP) scheiterte und nach wie vor Vertreter des Berner Flügels (zunächst Adolf Ogi und nach dessen Rücktritt Samuel Schmid) den einzigen SVP-Bundesratssitz bekleideten, zeigte sich spätestens bei den Nationalratswahlen von 2003, dass die ,Koalition der Vernunft ${ }^{{ }^{2}}$ bei den Bundesratswahlen 1999 einen Pyrrhus-Sieg gegen Blocher errungen hatte. Nicht nur, dass der Zürcher Flügel im parteiinternen Richtungsstreit endgültig die Oberhand über den gemäBigten Berner Flügel um Ogi und Schmid gewann, die konsequent populistische Ausrichtung der SVP Schweiz bescherte ihr bei den darauffolgenden Nationalratswahlen im Oktober 2003 mit 26,7 Prozent den nächsten Wahlerfolg. ${ }^{3}$ Nachdem die SVP für den Fall einer erneuten Nicht-Berücksichtigung Blochers mit der Aufkündigung der Konkordanz drohte, entschieden sich CVP und FDP im Dezember 2003 zu einem Strategiewechsel: Der Versuch, den SVP-Exponenten von der Regierung auszuschließen und als proto-faschistische Gefahr der Schweizer Demokratie zu marginalisieren, war gescheitert. Nun sollte dem fundamentaloppositionellen Diskurs des Zürcher Flügels der Wind aus den Segeln genommen werden. Blocher sollte in den Bundesrat eingebunden werden. Der starke Mann der SVP übernahm das Justiz- und Polizeidepartement von Ruth Metzler (CVP). CVP und FDP, aber auch einige Nationalräte der SP erhofften sich von dieser Maßnahme, dem Diskurs des Zürcher SVP-Flügels den Nährboden zu entziehen. Das Kollegialitätsprinzip sollte Blocher dazu zwingen, Verantwortung für die gemeinsam getroffenen Entscheidungen zu übernehmen. ${ }^{4}$

2 Zur Geschichte des Begriffs vgl. Bürgi 1999: 182.

3 Die konsequent populistische Ausrichtung der SVP manifestierte sich unter anderem im dem 2003 verabschiedeten Parteiprogramm, in dem sich die SVP Schweiz als Partei vorstellte, die ,praktisch allein gegen alle andern“ kämpfe, und als einzige „Alternative zu den vereinigten Regierungsparteien SP, FDP und CVP“ charakterisierte, die allesamt an der ,desolaten Situation“ der Schweiz schuld seien (SVP 2003: 7).

4 Vgl. Hämmerle 2011: 17. 
Die Strategie, den Aufschwung der SVP durch Beschwichtigung und Einbindung zu bremsen, scheiterte jedoch ebenfalls. Sie bot Blocher die Gelegenheit, zwischen dem bewährten Anti-Establishment-Gestus und einem staatstragenden Habitus des verantwortungsvollen und akribischen Staatsdieners hinund herzuwechseln. Der zuverlässige und arbeitssame Justizminister Blocher schloss nicht nur „die Reihen der SVP“5, indem er den moderaten Bündnern und Bernern vor Augen führte, dass die programmatische Radikalisierung und die scharfe Kritik der politischen Klasse keineswegs mit einem Abschied von der Regierungsmacht nach sich zog. Auch für die Wähler der bürgerlichen MitteParteien belegte der Bundesrat Blocher die Wählbarkeit der ,neuen SVP‘. Selbst seine stärksten politischen Gegner stellten Blocher für seine Expertise und Detailbesessenheit ein gutes Arbeitszeugnis aus. ${ }^{6}$ Und sein wichtigstes politisches Projekt als Justizminister, die Verschärfung des Asylrechts, fand eine breite Mehrheit sowohl im Parlament als auch bei der Volksabstimmung, die von einer breiten Allianz linker Parteien und Organisationen initiiert worden war.

So musste die Prognose, ,Blochers SVP“ hätte ihr Potential bei den Nationalratswahlen 2003 voll ausgeschöpft, abermals korrigiert werden. Die Partei konnte ihren Stimmanteil erneut steigern. Sie erreichte 28,9 Prozent, nochmals 2,2 Prozentpunkte mehr als 2003 und nur einen Prozentpunkt weniger als FDP und CVP zusammen. ${ }^{7}$ Die SP, die im Wahlkampf gegen Blocher politisierte, wurde schwer getroffen, verlor 3,8 Prozentpunkte und fiel um beinahe zehn Prozentpunkte hinter die SVP $(19,4)$ zurück. Die Grünen, die sich ebenfalls gegen eine Wiederwahl Blochers stellten, konnten hingegen zulegen und verfehlten die zehn Prozent-Marke nur knapp. Einmal mehr war die SVP der Wahlsieger. In einigen Gemeinden der Ostschweizer Hochburgen erreichte die Partei mitunter 50 Prozent. Signifikante Zuwächse erzielte sie aber insbesondere in der Westschweiz und dort insbesondere in Modernisierungsregionen, so etwa in Avenches, Payerne und Önsingen. ${ }^{8}$ Die ,SVP-Welle ${ }^{{ }^{69}}$ hatte das gesamte Land erfasst. Die Partei homogenisierte ihre Wahlergebnisse und konnte sich aufgrund ihrer erneut mar-

5 Vgl. Seitz 2007.

6 So etwa vom SP-Nationalrat Andrea Hämmerle (2011: 18), der Blochers Abwahl als Bundesrat initiierte, und dem langjährigen SP-Präsidenten Helmut Hubacher (2014: 134).

7 Die CVP konnte sich auf konstant niedrigem Niveau stabilisieren und erreichte 14,5 Prozent. Die FDP verlor erneut und erreichte lediglich 15,8 Prozent.

8 Vgl. Schuler, zit. in: [o.A.] Le Temps 24.10.2007.

9 [o.A.] Le Temps 24.10.2007. 
kanten Stimmzuwächse in der Romandie und der katholischen Innerschweiz endgültig als gesamtschweizerische Partei etablieren.

Im Vergleich zu früheren Wahlkämpfen, als in jedem Kanton einzelne, unabhängige Wahlkämpfe geführt wurden, bei denen vielfach konkrete, kantonsspezifische Fragen im Vordergrund standen, wurde der Wahlkampf 2007 national geführt. ${ }^{10}$ Obwohl das SVP-Thema Nummer eins, die Bedrohung der von den politischen Eliten vorangetriebenen europäischen Integration und des damit verbundenen Souveränitätsverlust des demokratischen, föderalistischen Kleinstaates gegenüber dem ,bürokratisch-zentralistischen Kunstgebilde', nicht mehr akut war, nachdem auch die anderen bürgerlichen Parteien von der europäischen Integration Abstand genommen hatten, gelang es der SVP auch in diesem Wahlkampf, die beiden zentralen Themen des Wahlkampfes zu bestimmen. Da ist zum einen die Kontroverse um die Eignung Christoph Blochers als Bundesrat und zum anderen die Themen innere Sicherheit und Migration, die der Zürcher Flügel insbesondere im Kontext der im Sommer 2007 lancierten Ausschaffungsinitiative in eine Debatte über das grundlegende Verhältnis zwischen Demokratie und Rechtsstaatlichkeit überführte. ${ }^{11}$

,Keine Stimme für Blocher druckte die SP auf Plakate. In einem Sammelband Fahrplanwechsel - Für mehr Demokratie und Solidarität und weniger Blocher $^{12}$ warnen SP-Politiker und linke Intellektuelle vor der „Blocherisierung der Schweiz“'13. Unter diesem Schlagwort kritisierte die SP nicht mehr die Positionen von rechten CVP- und FDP-Politikern als solche, sondern den zunehmenden Einfluss Blochers auf die Politik des bürgerlichen Lagers. ${ }^{14}$ Die SVP konterte, indem sie den Linken unterstellte, an einem „Anti-Blocher-Reflex“'15 zu leiden. Der ursprünglich geplante Wahlkampfslogan „Schweiz stärken, SVP wählen“ wurde in „Blocher stärken, SVP wählen“ umgeändert. ${ }^{16}$ Nie zuvor hatte eine Schweizer Partei ihren Wahlkampf derart auf ihren Spitzenkandidaten zugespitzt $^{17}$ und nie zuvor war der Wahlkampf auch der anderen Parteien derart per-

10 Vgl. Seitz 2007.

11 Diese Universalisierungsleistung wird auch für die Minarett-Initiative, die ich im nächsten Kapitel detailliert analysiere, kennzeichnend sein und wird deswegen zunächst nicht weiterverfolgt.

12 Gross u.a. 2007a.

13 Vgl. Gross u.a. 2007a.

14 Gross u.a. 2007b: 21ff. u. Gross 2007: 253.

15 Vgl. Hubacher 2014: 78.

16 Vgl. Brunner 2007.

17 Somm 2009: 494. 
sonenzentriert. ${ }^{18}$ Die konsequente Anti-Blocher-Kampagne, die insbesondere SP und Grüne betrieben, reflektierte den binären Antagonismus, den Blocher \& Co zu instituieren versuchten.

Nachdem das Projekt der europäischen Integration, das in den 1990er Jahren SP, CVP und FDP zur ,Koalition der Vernunft ' zusammengeschlossen hatte, gescheitert war, war es nunmehr die gemeinsame Ablehnung Blochers und seiner Partei, auf der die kosmopolitische Einheit der bürgerlichen Mitte und der Linken beruhte. Während die drei Parteien die politischen Inhalte und die Agenda der SVP unterschiedlich bewerteten, trafen sie sich in der Kritik des Stils von Blocher \& Co: Dass der Habitus der SVP-Exponenten ,unschweizerisch ‘ und das Schäfchen-Plakat krypto-faschistisch sei, Blochers Insistieren auf das Grundsätzliche die pragmatische Kompromissfindung torpediere, seine ,protes-

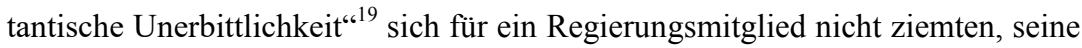
offene Skepsis gegenüber Kompromissen und sein notorisches Aufbegehren gegen das Konsensprinzip weder zum politischen System noch zur politischen Kultur passten, - darin waren sich auch die marktliberalsten Freisinnigen und die regulierungsfreudigsten Sozialdemokraten einig. Diejenigen, die von der SVP als ,Linke und Nette' tituliert wurden, affirmierten ihre Zusammengehörigkeit, indem sie sich in gemeinsamer Stilkritik übten.

Blocher avancierte zum Mythos, den es familiengeschichtlich zu ergründen galt. Dieses politische Talent musste einer ganz besonderen familiären „Binnenkultur ${ }^{620}$ entwachsen sein, die durch die lebenstüchtige und widerstandsfähige Mutter von elf Kindern und den schwermütigen und rigorosen Vater geprägt wurden. Für die einen war Blocher der ur-schweizerische, von allen Seiten attackierte Messias, der die Sorgen und Ängste der einfachen Leute ernst nimmt; für die anderen der totalitäre Demagoge ${ }^{21}$, der rassistische Ressentiments salonfähig und die „Borniertheit und Fremdenfeindlichkeit [...] der Deutschschweizer Provinz ${ }^{\text {،22 }}$ zur Essenz des Schweizerischen zu machen versucht.

Die Kontroverse um Blocher sollte ihren Höhepunkt jedoch erst bei den Bundesratswahlen, eineinhalb Monate nach dem triumphalen Erfolg der SVP bei den Nationalratswahlen finden. Normalerweise ist die Bundesratswahl ein spannungsarmes Zeremoniell, bei dem die amtierenden Bundesräte, sofern sie nicht freiwillig, aus gesundheitlichen Gründen oder unter Druck der eigenen Fraktion

18 Vgl. Seitz 2007.

19 Somm 2007.

20 Somm 2009: 69.

21 Vgl. Gross 2007.

22 Riva 2004. 
zurücktreten, im Amt bestätigt werden. Doch dieses Mal wählten Grüne, SP, CVP und einige Freisinnige anstelle des amtierenden Justizministers und offiziellen SVP-Kandidaten Christoph Blocher die SVP-Politikerin und Bündner Regierungsrätin Eveline Widmer-Schlumpf ins Amt.

SP und Grüne hatten bereits vor den Nationalratswahlen kein Geheimnis daraus gemacht, dass sie Blocher unabhängig vom Ausgang der Nationalratswahl nicht im Amt bestätigen würden. Die Grünen entschlossen sich nach den Wahlen sogar dazu, mit Luc Recordon einen eigenen Gegenkandidaten ins Rennen gegen Blocher zu schicken. Die Ankündigung der beiden wichtigsten linken Parteien schien jedoch nicht mehr als eine leere Drohung und Recordons Kandidatur war nicht mehr als ein symbolischer Akt des Widerstandes. Ein Gegenkandidat aus dem linken Lager würde keine Chance haben, Blocher zu beerben. Einen grünen Bundesrat oder einen dritten Sozialdemokrat zu Lasten der stärksten Partei ins Amt zu wählen, hätte einen Bruch mit dem Proporzsstem bedeutet und dafür war weder die SP noch die CVP zu gewinnen. Auch wenn sich die CVP in Bezug auf Blocher gespalten zeigte, schien doch kein Weg an seiner Wiederwahl vorbeizuführen. ${ }^{23}$ Die einzig realistische Option war, anstelle Blochers einen gemäßigten Vertreter der SVP in den Bundesrat zu wählen. Doch schien diese Möglichkeit, die der Präsident der SP-Schweiz Hans-Jürg Fehr in einem „Sonntags-Blick“Interview ins Spiel gebracht hatte, vollkommen unrealistisch, weil sich der etwaige SVP-Spitzenpolitiker mit seiner Kampfkandidatur gegen die eigene Fraktion und Partei stellen müsste. ${ }^{24}$

Doch genau dieses Szenario sollte eintreten: SP, Grüne und CVP fanden in Eveline Widmer-Schlumpf, einer renommierten SVP-Regierungsrätin aus Graubünden, die gesuchte Dissidentin. Offiziell wurde Widmer-Schlumpf von keiner Partei für die Wahl vorgeschlagen, weil die Initianten fürchteten, der innerparteiliche Druck auf Widmer-Schlumpf würde ansonsten zu groß werden. ${ }^{25}$ Erst unmittelbar vor der Wahl verriet Josef Zisyadis, der als einziger Nationalrat der kommunistischen Partei der Arbeit Mitglied der Fraktion der Grünen war, den Namen Widmer-Schlumpfs aus. ${ }^{26}$ Die Panne brachte die Wahl der Bündnerin

23 Vgl. Hämmerle 2011: 33f.

24 Vgl. ebd.: $28 \mathrm{ff}$.

25 Erst unmittelbar vor der Wahl posaunte Josef Zisyadis den Namen WidmerSchlumpfs aus. Der einzige Nationalrat der kommunistischen Partei der Arbeit (PdA) hatte bei der Einfädelung des Coups gar keine Rolle gespielt. Doch brachte auch diese Panne die Wahl der Bündnerin nicht mehr in Gefahr.

26 Zisyadis hatte bei der Einfädelung des Coups keine Rolle gespielt (vgl. Hämmerle 2011: 49). 
aber nicht mehr in Gefahr. Bereits im ersten Wahlgang lag Widmer-Schlumpf mit 116 zu 111 Stimmen vor Blocher. Im zweiten holte sie die notwendige absolute Mehrheit und setzte sich mit 125 zu 115 gegen den amtierenden Justizminister durch. Am Tag darauf nahm sie die Wahl an. ${ }^{27}$ Blocher war abgewählt. Grüne, SP, CVP und einige Mitglieder der FDP-Fraktion und allen voran natürlich Widmer-Schlumpf, die sich bis zuletzt sowohl gegenüber den Initianten des Coups als auch gegenüber der Spitze der eigenen Partei bedeckt hielt, waren ihm in den Rücken gefallen.

Die Reaktion der SVP-Parteispitze fiel entsprechend heftig aus. Der Parteipräsident Ueli Maurer kündigte an, man werde als geschlossene Fraktion in die Opposition gehen und unabhängig vom Bundesrat und den regierungstragenden Parteien politisieren. ${ }^{28}$ Der Zürcher Flügel setzte eine harte Linie gegen die Dissidenten durch. Und als die Bündner SVP sich weigerte, Widmer-Schlumpf aus der Partei auszuschließen, wurde die traditionsreiche Kantonssektion ausgeschlossen. Der verbliebene SVP-Bundesrat Samuel Schmid, der die Oppositionsstrategie durch die Annahme seiner Wiederwahl torpedierte, wurde der Fraktion verwiesen.

Widmer-Schlumpfs Aufstand gegen Blocher und die Reaktion der Parteiführung stellte die SVP vor eine Zerreißprobe, der die Partei nicht standhielt. Die dissidente Bündnerin gründete mit der ehemaligen Bündner SVP und anderen SVP-Politkern, die mit dem Zürcher Kurs ebenfalls nicht einverstanden waren, die Bürgerlich-Demokratische Partei (BDP), die programmatisch und strategisch an die alte, kollegiale SVP erinnert. Maurer und Blocher erkannten, dass der strikte Oppositionskurs, den sie Fraktion und Partei verordnen wollten, weitere SVP-Wähler und -Nationalräte in die Hände der BDP treiben könnte. So wurde etwa den Berner Parlamentariern gestattet, eine Unterfraktion zu bilden und sich mit Samuel Schmid zu besprechen. Die Entscheidung, von nun an als systematische Opposition zu agieren, wurde jedoch nicht infrage gestellt. Die stärkste Partei nahm eine Rolle ein, die das politische System der Schweiz eigentlich gar nicht vorsieht.

Folglich wurde erneut die Konkordanz zur Disposition gestellt. Blocher skandierte in seiner Abschiedsrede als Bundesrat: „Konkordanz - fast ein heiliger Tempel; Toleranz - die grösste Tugend; Kollegialität - bis zur Selbstverleugnung; Amtsgeheimnis - sehr oft um viel Dreck und Dinge zuzudecken, die

27 Vgl. ebd.: 49ff.

28 Vgl. Maurer, zit. in: [o.A.] Tages-Anzeiger 19.12.2007 u. Maurer 2007. 
niemand sehen durfte. ${ }^{29}$ Und Emil Grabher deutete im Zürcher Boten die Abwahl Blochers als Zeichen für den Abschied von der Demokratie:

„Konkordanz heisst plötzlich nicht mehr, dass die drei (sic!) grössten Parteien Regierungsverantwortung übernehmen. Für etwas gerade stehen. ,Verantwortung', ein teuflischer Begriff. Nein, jetzt bedeutet es nur noch, dass die Gewählten ein harmonisches Grüppchen von Friede, Freude, Eierkuchen sein müssen, welches vorab im stillen Kämmerlein jene Entscheide gutheisst, die durch Linke, Scheinheilige und Nette fein säuberlich zurecht gezimmert wurden, wenn möglich noch EU-kompatibel. Fort mit den Regeln der Demokratie. Schluss mit der Offenheit gegenüber dem Volk. Schluss mit Eigenverantwortung und Selbstbestimmung. ${ }^{\text {“30 }}$

Im Folgenden soll jedoch nicht erneut die Kritik der Konkordanz, sondern Blochers herausgehobene Stellung im SVP-Populismus in den Blick genommen werden. Der außergewöhnliche berufliche Werdegang Blochers spielt hierfür eine maßgebliche Rolle. Um dessen Bedeutung herauszuarbeiten, gilt es, die jeweiligen Stationen nicht als charakterprägende Sozialisationsorte des Politikers zu analysieren, sondern nach ihren kulturellen Bedeutungen und ihrer jeweiligen hegemonialen Funktion zu fragen.

\subsection{Christoph Blocher: BaUer, Jurist, Oberst, UNTERNEHMER, KUNSTSAMMLER. DIE KARRIERE DES POLITISCHEN VERSORGERS UND Gesetzgebers}

Christoph Blocher wuchs als siebtes von elf Kindern in einer Pfarrfamilie im ostschweizerischen Laufen auf. Mit 15 Jahren eröffnete Christoph Blocher seinem Vater, er wolle eine Lehre als Landwirt machen, die er zwei Jahre später auch begann. Blocher absolvierte die Lehre zum Landwirt in Ossingen, in dem ehedem agrarisch geprägten Weinland nahe Zürich. Wenngleich agrarpolitische Forderungen für den SVP-Populismus keineswegs zentral sind, die üppig subventionierte Landwirtschaft vielmehr quer zum Marktradikalismus des Zürcher Flügels liegt, entstammen die wichtigsten Requisiten für Blocher Selbstinszenierungen der bäuerlichen Bilderwelt: Bauern in traditioneller Arbeitskleidung

29 Blocher, zit. in Somm 2009: 32.

30 Grabherr 2007. 
säumen die Bühne; Heuballen dienen ihm als Rednerpult; mit Trychlern zog Blocher durch die Zürcher Innenstadt, um gegen den Beitritt der Schweiz zum EWR zu protestieren; auf den Covers von Parteiprogrammen schwingen Sennen ihre Sensen; andere zeigen Kleinfamilien, die durch das typisch schweizerische, von Wiesen und Weiden geprägte Kulturland streifen; dieselbe Landschaft dient Blocher in Interviews als Hintergrund.

Sicherlich lässt sich die Tatsache, dass Blochers rigide Deregulierungsagenda die Landwirtschaft ausspart, als inkonsequente Interessenpolitik zugunsten der eigenen, vom Strukturwandel gebeutelten Klientel kritisieren. ${ }^{31}$ Dieser Deutung entgeht jedoch, dass der SVP-Populismus der Landwirtschaft eine quasiuniverselle Bedeutung für die Konstitution der bürgerlichen Schweizer Gesellschaft zuerkennt und damit an eine Vorstellung anknüpft, die tief im Selbstverständnis des Bauernstandes verankert ist. Selbst im frühindustrialisierten Mittelland begreifen sich die Schweizer Bauern bis weit ins 20. Jahrhundert als Keimzelle der nationalen Leitkultur. ${ }^{32}$ Diese Aura der erfahrungsgesättigten bäuerlichen Lebensweise hat Blocher laut seinem Biographen, dem WeltwocheRedakteur Markus Somm während seiner Lehrjahre aufgesogen:

„Das Land, die Bauern: Darin erkennt er [Blocher, m. Anm.] den Kern dessen, was die Schweiz ausmacht. Dass die Bauern gut organisiert sind, dass sie in gewissen Parteien übervertreten sind, reicht als Erklärung nicht aus. Das magische Moment ist entscheidend: Sie sind die Verwalter der Tradition eines Landes, sie sitzen länger als alle andern auf ihren Böden. Sie kleben an der Erde. Als Eigentümer konservativ, da Aufruhr die Besitzenden gefährdet, sind die heutigen Bauern die Abkömmlinge jener, die überlebt haben. Vor einigen Jahrhunderten waren fast alle Schweizer Bauern.“33

„Zwar lebten auch die Bauern von Ossingen in der Moderne - in den Fünfzigerjahren kamen Traktoren auf, künstlicher Dünger, wissenschaftlich erprobte Anbaumethoden, und selbst in den Bauernstuben meldete das Radio die Nachrichten,. Trotzdem hatte sich das Leben der Bauern im Vergleich zu allen anderen Berufsgruppen weniger geändert. Worauf es in der Landwirtschaft ankam - die Jahreszeiten, das Wetter, die Fruchtbarkeit des Bodens, Leben und Sterben der Tiere - all diese Dinge waren unverändert gültig - seit Jahrtausenden.“34

31 Vgl. exemplarisch Wirz 2011.

32 Vgl. Jost 2007: 27; Skenderovic 2013.

33 Somm 2009: 103.

34 Ebd.: 101. 
„Die Gegenwart war für ihn [Blocher, Anm. M.H.] relativ. Während die neuen Linken, die er an der Universität kennenlernen sollte, den Status quo in Frage stellten, weil sie ihn für überholt hielten, kam Blocher von der anderen Seite her - aus Ossingen und Laufen am Rheinfall, aus der Vergangenheit. Dem Aktuellen begegnete er mit der Reserviertheit desjenigen, der bezweifelt, ob alles, was aufkam, Bestand hatte. Bei den Bauern hatte er erfahren, dass manche Gesetzmäßigkeiten galten, ganz gleich, was der Zeitgeist sagte. Den Boden bearbeitend hört er die Grundwasserströme des Landes und seiner Geschichte fliessen. ${ }^{* 35}$

Als ausgebildeter Landwirt repräsentiert Blocher nicht nur den körperlich arbeitenden Menschen, der in der Lage ist, sich selbst und die Seinigen zu versorgen. Als Bauer kennt Blocher die Lebenswirklichkeit der ,eigentlichen Welt ${ }^{6}$ - nicht aus Büchern oder der Theorie, sondern aus der konkreten Erfahrung. Die bäuerliche Lebenswelt ist bei Somm und Blocher die natürliche Keimzelle eines Konservatismus, der das Gewordene mit dem Schleier des Ewigen ummantelt. Sie ist die konservative Bastion einer ursprünglichen erfahrungsgesättigten Beständigkeit und Bescheidenheit, die den Moden des Zeitgeists und dem intellektuellen Denken in Möglichkeiten trotzt. Blochers Konservatismus, die Privilegierung der Erfahrung gegenüber dem Wissen, des Handelns gegenüber dem Theoretisieren, des Kontinuierlichen gegenüber dem Neuen, findet hier sein ideologisches Widerlager. Der Bauer ist derjenige, der die Mühen des Arbeitslebens wacker erträgt, wissend, dass die Ideale und Versprechen des Zeitgeistes angesichts der eigentliche Beschaffenheit der Welt nicht einzulösen sind.

Somm und Blocher rezitieren damit Kurt Guggisbergs Stilisierung des „traditions- und naturverbundenen“"36 Bauernstandes als Kernstück eines „gesunden Volkes“37, auf dem das Selbstbewusstsein der BGB gründete. Wie bei Guggisberg ist der Bauer bei Somm und Blocher der „Archetyp des Schweizerischen““38; ein „Schutzwall“ gegen die ,zersetzende Überindustrialisierung und Landflucht“, sowie gegen ,die Grossstadt als glänzende Verführerin“. ${ }^{39}$ Jedoch fungiert das bäuerliche Leben anders als bei dem BGB-Chefideologen der 1950er und 60er Jahre nicht als Vorlage für die Restauration einer vorindustriellen, dörflichen und landwirtschaftlich geprägten Schweiz. Vielmehr destillieren Blocher und Somm aus der bäuerlichen Lebens- und Arbeitsweise eine Essenz, die als

35 Ebd.

36 Guggisberg, zit. in: Skenderovic 2013: 59.

37 Ebd.

38 Scheidegger 2012: 138.

39 Gruner 1977: 155. 
Richtschnur für Blochers Modernisierung fungiert. Die rezitierten Elemente bäuerlichen Lebens, die in anderen Diskursen als Eponyme der Rückständigkeit erscheinen, erfahren eine semantische Transformation. Der traditionell wirtschaftende Bauer ist nicht vorrangig der Verlierer eines Strukturwandels, den es zu bekämpfen gilt, sondern der tiefere Grund für die wirtschaftliche und politische Erfolgsbilanz der Schweiz und insofern die Quintessenz der Modernisierung, die es zu bewerkstelligen gelte. Was Kritiker als irrational, inkonsistent oder paradoxal interpretieren und von Somm als „magischer Moment ${ }^{\star 40}$ verstanden wird, die Protektion der Landwirtschaft durch eine neoliberale Partei, ist der Effekt einer Universalisierung des bäuerlichen Lebens durch die Entleerung landwirtschaftlicher Praktiken: „Den Boden bearbeitet hört er [der Bauer] die Grundwasserströme des Landes und seiner Geschichte fließen." ${ }^{41}$ Der Bauer verkörpert nicht bloß ,eine Ansammlung von altmodischen oder reaktionären oder egositischen Vorstellungen“42. Er fungiert als Knotenpunkt in der Konstruktion eines Gemeinsinns, der als erfahrungsgesättigt und historisch informiert nobilitiert wird.

Jedoch gründet die herausgehobene Stellung Blochers nicht ausschließlich auf dem für SVP-Politiker typischen agrarischen Hintergrund. Weil seine Familie keinen Boden besaß, den der junge Landwirt hätte bewirtschaften können, entschloss er sich, die Matura nachzuholen, um sich in Zürich zunächst für Agronomie zu immatrikulieren und bald darauf an die juristische Fakultät zu wechseln. An der Universität wurde Blocher politisiert. Gegen die 68er-Generation gründete er gemeinsam mit Harro von Senger den antikommunistischen Studentenring und wurde so ,zum $68 \mathrm{er}$ - aber von der falschen Seite“ ${ }^{“ 43}$, wie er selbst sagte.

Bereits auf dem Gymnasium hatte Blocher Freundschaft mit Werner Oswald geschlossen, über den er dessen gleichnamigen Vater, den Besitzer der EMSChemie, kennengelernt hatte. Der junge Christoph Blocher wusste den Patriarchen zu beeindrucken. Als Blocher sein Jura-Studium abgeschlossen hatte, entschied er sich gegen die Richterlaufbahn, nahm stattdessen die Halbtagesstelle im Rechtsdienst bei der EMS-Chemie an, promovierte nebenbei, heiratete und wurde vierfacher Vater. Während sich seine Frau Silvia um die Kinder kümmerte, stieg Blocher binnen zwei Jahren zum Vizedirektor der EMS-Chemie auf.

40 Somm 2009: 103.

41 Ebd.: 101.

42 Ebd.: 40.

43 Blocher, zit. in: Somm 2009: 115. 
Zehn Jahre später starb Werner Oswald. Die EMS-Chemie befand sich damals in einer schweren Krise. Das Hauptgeschäftsfeld der Firma lag in der Produktion von Kunststofffasern für Textilien und die ließen sich woanders billiger herstellen. Oswalds Söhne wollten die Firma verkaufen und Blocher suchte in ihrem Auftrag nach einem Verkäufer, der die Firma weiterführen würde. Die Suche blieb erfolglos. Schließlich entschloss sich Blocher, die Firma mit Hilfe eines Kredits der Schweizerischen Bankgesellschaft selbst zu kaufen. Blocher führte die EMS-Chemie zum Erfolg. Er ließ die Fertigung von Textilfasern auslaufen und verlagerte das Geschäft auf die technisch anspruchsvolle Produktion von hochspezialisierten Kunststoffen, die insbesondere in der Automobilindustrie zur Anwendung kamen.

Auch wenn Blocher das meiste Geld mit Aktiengeschäften verdiente, zeugt sein wirtschaftlicher Leistungsausweis als Retter der EMS-Chemie aus Sicht seiner Anhänger von einer außergewöhnlichen Führungskompetenz, persönlichem Engagement und Verantwortlichkeit. Nachlesen lässt sich dies in dem vier Monate vor der Nationalratswahl erschienen Buch Das Blocher-Prinzip ${ }^{44}$, in dem der Journalist Matthias Ackeret Blocher befragt, um die Erfolgsgeheimnisse seiner Karriere zu ergründen. Für Ackeret ist es Blochers ,einheitliches Führungskonzept", das ihm „in allen wesentlichen Bereichen (Wirtschaft, Militär, Politik, Familie)“ Erfolg verleiht. ${ }^{45}$ Das „Führungsbuch“ ist zugleich ein Lebensführungsbuch und der Wirtschaftsführer zugleich ein Lebensgesetzgeber. Ackeret inszeniert Blocher als erfolgreichen Unternehmer alter Schule, nicht als Karrierist, sondern als benevolenten Patriarch und selbstlosen Versorger seiner Untergebenen und ihrer Familien. Blocher hat die EMS-Chemie nicht geerbt und erfolgreich weitergeführt. Blocher ist ein Selfmademan. Er hat sich verschuldet, um sie zu kaufen und zu retten. Er geht die nötigen Risiken ein und trifft mitunter schmerzhafte Entscheidungen, um sein Unternehmen dem Wettbewerb anzupassen und die Arbeitsplätze im peripheren Graubünden, wo die EMS-Chemie ihren Hauptsitz hat, zu erhalten. Blocher ist bereit, alles Notwendige zu tun, um seinen Auftrag zu erfüllen. ${ }^{46}$ Seine wirtschaftliche Expertise ist weder akademisch zertifiziert, noch gründet sie auf modernen Managementstrategien. Sie wurzelt vielmehr in Blochers erfahrungsgesättigtem Wissen. Der Erfolg und die Innovationsfähigkeit der EMS-Chemie basiert nicht auf kreativen Menschen, sondern auf Fleiß und Pflichtbewusstsein, auf klaren Hierarchien und unumstößlichen Prinzipien. Der Unternehmer Blocher inszeniert sich niemals als Genie.

44 Vgl. Ackeret 2007.

45 Ebd.: 7.

46 Zur Zentralität des Auftrages vgl. Blocher in ebd.: 29ff. 
Nicht er, seine Ziele und sein Wille, sondern der Auftrag steht im Zentrum und dem sind alle untergeordnet. Blocher ist lediglich der Chef, weil er die allgemeinen Grundsätze der richtigen Auftragserfüllung kennt. Er ist der Erste unter Gleichen. Seine herausgehobene Stellung gründet nicht auf singulären Eigenschaften. Sie wird nicht mit absoluten, sondern mit relationalen Aussagen untermauert: Blocher ist der „Fähigste ${ }^{“ 47}$. Er teilt das Schicksal seiner Angestellten und vereint ihre besten Eigenschaften.

Während des Jura-Studiums schlug Blocher beim Militär die Offizierslaufbahn ein und brachte es bis zum Oberst im Luftschutz. Wenngleich das Militär in den 1960er und 70er Jahren die Bedeutung einbüßte, zehrte die Milizarmee in bürgerlichen Kreisen nach wie vor von dem Prestige, das ihm der sogenannte ,Landi-Geist“ verliehen hatte. Das Militär war die „Schule der Nation“, in der „nicht bloss Disziplin, sondern Nationalbewusstsein“ vermittelt wurden. ${ }^{48}$ Der „nationale Schulterschluss“ ${ }^{49}$ gegen den Sozialismus, den man als Soldat der Schweizer Armee leistete, versöhnte die beiden Konfessionen und schloss ihre politischen Repräsentanten zum bürgerlichen Lager zusammen. Als sich die außenpolitische Bedrohung nach dem Untergang der Sowjetunion auflöste und der innenpolitische Antikommunismus im Zuge des Fichen-Skandals litt, verlor die „nationalpädagogische Staatsideologie ${ }^{\text {“50 }}$ des bedrohten, militärisch wehrhaften Kleinstaates ihre Existenzgrundlage. Angesichts des globalen Siegeszuges von Marktwirtschaft und Demokratie und der friedlichen Integration Europas galten die rituellen Jubiläumsfeierlichkeiten der wehrhaften, unabhängigen Schweiz auch in bürgerlichen Kreisen als antiquiert. In einem nunmehr befriedeten Europa würde eine reine Verteidigungsarmee bedeutungslos werden.

Im Unterschied zu CVP und FDP hielt die Zürcher SVP an der Rezitationen und Neuinszenierungen des Militärischen fest. Nachdem sich die Bedrohung durch die Sowjetunion aufgelöst hatte, stilisierte Blocher im Kampf gegen die europäische Integration den unbeugsamen Milizionär zum Sinnbild des schweizerischen Selbstbestimmungswillens. So verabschiedete Blocher als Oberst im Februar 1992 sein Regiment auf der Zürcher Sechseläuten-Wiese. Mitten in Zürich marschierten und salutierten 750 Mann in Uniform. Blocher hob die Bedeutung des Militärs in „Zeiten der Verunsicherung ${ }^{* 51}$ hervor. Militärische Tugenden wie Pflichterfüllung, Auftragsgebundenheit, Disziplin, Leistung und Aus-

47 Blocher, zit. in: Zeller 2008.

48 Somm 2009: 144.

49 Maissen 2010: 281.

50 Guggenbühl 1998: 45.

51 Blocher, zit. in: Somm 2009: 177. 
dauer spielen für den Diskurs der SVP eine Schlüsselrolle. Nicht nur dass die Rhetorik des Zürcher Flügels militärisch informiert ist, als ranghoher Militär unterstreicht Blocher auch die Relevanz und den Nutzen des Militärischen für Politik und Gesellschaft. ${ }^{52}$

Blocher ist außerdem Kunstsammler. Er sammelt im Wesentlichen Gemälde von Ferdinand Hoderer und Albert Anker, zwei Schweizer Künstlern des 19. Jahrhundert. Insbesondere Anker hat es ihm angetan, - nicht weil er andere Künstler geringschätzt, sondern weil „man nicht alles sammeln kann“653 und weil Anker „,nach wie vor unterschätzt, sozusagen als Verklärer verklärt" ${ }^{* 54}$ werde. Ankers Bilder zeigen nicht Adelige oder Großbürger bei außerordentlichen Anlässen. Anker malt das Volksleben. $\mathrm{Zu}$ sehen sind meist arme Bauersfamilien in Alltagssituationen: Männer beim Pfeiferauchen, Frauen bei der Hausarbeit, Kinder bei den Schulaufgaben und Mädchen auf dem Nachhauseweg vom Einkaufen. Blocher interpretiert Anker zugleich als Realisten und als protestantischen Symbolisten:

„Anker bedurfte des Symbolismus nicht, um das Leben darzustellen. [...] Er nimmt alltägliche Szenen und zeigt immer wieder aufs Neue, dass der Alltag uns geschenkt, gegeben ist. [...] Er zeigt das Leben, wie es ist. [...] Er idealisiert nicht. Er beschönigt nicht. Er blickt vielmehr genau hin und stellt dar, was er sieht. “55

„[D]ie Menschen in Ankers Bildern sind geborgen, aufgehoben, nicht verloren trotz des auch bei ihm überall aufscheinenden Elends. ${ }^{* 656}$

„Das gefällt mir. Denn er wendet sich damit gegen all jene selbsternannten Retter der Welt, die vom Machbarkeitswahn befallen sind." ${ }^{\text {"57 }}$

„Das Leben hat es mit ihnen [zwei Mädchen auf Gemälden Ankers] nicht gut gemeint. [...] Und doch - sie bestehen! Sie haben nicht ein Leben ohne Schwierigkeiten, aber die Schwierigkeiten sind überwindbar, die Lasten des Lebens sind tragbar. [...] Du wirst dein

52 Vgl. Blocher, in: Ackeret 2007: 18.

53 Blocher 2011b: 62.

54 Ebd.: 61.

55 Ebd.: 61 u. 62.

56 Ebd.: 61.

57 Ebd. 
Brot [das eine Mädchen trägt einen großen Laib Brot] essen - wenn auch im Schweisse Deines Angesichts. Man wird hart arbeiten, aber verheissen ist Brot - das Leben. ${ }^{\text {“58 }}$

„Bei Anker geht es um einfache, zutiefst menschliche Einsichten.“ ${ }^{\text {59 }}$

Hier zeigt sich, wie Blocher den partikularen Darstellungen eine allgemeingültige Botschaft abgewinnt. Hinter den vielfältigen Bildoberflächen liegt die Quintessenz menschlichen Seins. Um diese Essenz durscheinen zu lassen, bedürfe es eben keiner komplexen Bildersprache, die nur von Experten gelesen werden könne. Im Gegenteil: Anker ist Realist, er malt „das Leben, wie es ist" ${ }^{\text {60 }}$ und verzichtet auf entfremdende Effekte. Dies macht Ankers Bilder zu popularen, leicht zugänglichen Werken. Doch verortet Blocher just hinter dieser vermeintlichen Einfachheit und der realistischen Objektivität des hoffnungsvollen Existentialisten, den er in Anker erkennt, ein philosophisches Wissen, das die dargestellten Alltagssituationen transzendiert und das profane (Arbeits-)Leben des Volkes sakralisiert. Das Unbestimmbare des menschlichen Lebens wird verfüllt mit einem protestantisch-konservativen Weltbild, in dem jeder, von der göttlichen Prädestination getragen, seinen Platz einnimmt und den Widrigkeiten des Lebens trotzt. $^{61}$ Das Andere, das diesem Diskurs politische Konturen verleiht und die Grenze des Universalitätsversprechens markiert, sind die „vom Machbarkeitswahn“62 befallenen „Retter der Welt“63, die utopischen Etatisten, die Ankers unumstößliche Gesetzmäßigkeiten nicht anerkennen und seinem religiös begründeten Optimismus angesichts des ,Aufgehobenseins ‘ in den natürlich-organischen Hierarchien der kleingemeinschaftlichen Lebenswelten skeptisch gegenüberstehen. ,Blochers Albert Anker' reflektiert die arche-politische Suspension des Politische Dimension im Diskurs der SVP. Sein ,Aufgehobensein“ fungiert als Knotenpunkt eines reaktionären, antipolitischen Heartland-Mythos, der dem Projekt der SVP einen legitimationsstiftenden Grund verleiht, indem es konkrete gesellschaftliche Hierarchien als quasi-natürliche Universalien menschlichen Lebens deklariert.

Auch als Kunstsammler changiert Blocher zwischen elitärem und popularem Gestus. Als Kunstsammler hebt er sich ab; die Gemäldesammlung symbolisiert

58 Ebd.: 61 u. 62.

59 Ebd.: 62.

60 Ebd.

61 Ebd.

62 Ebd.

63 Ebd.: 61. 
seinen sozialen Aufstieg. Ankers Werke repräsentieren Blochers Selbstverständnis, Teil der Führungselite zu sein. Mit Anker stilisiert sich Blocher erneut zum Gesetzgeber des menschlichen Lebens. Gleichzeitig verkörpert die AnkerSammlung den popularen Widerstandsgeist ihres Besitzers. Der Kunstsammler Blocher mag auch van Gogh, Manet und Monet, sammelt aber in erster Linie Anker, einen bekannten Schweizer Künstler, der in der modernen Kunstszene nicht besonders hoch im Kurs stehe, wie Blocher mehrfach betont. Blocher achtet die Meinung von Experten, lässt sich aber von ihrem Urteil nicht beeinflussen ${ }^{64}$ Für ihn ist der marginalisierte Volksmaler ein großer Künstler. Abermals schlägt sich Blocher auf die Seite des Geringgeschätzten und erklärt es zum Hochwertigen.

Blochers berufliche Karriere korrespondiert mit dem „Baukasten-Prinzip“655 seiner Rhetorik, die komplexe Bedrohungsszenarien schafft, indem sie die immer gleichen Elemente (die EU, die ,Classe politique', den Bundesrat, die Verwaltung, die Ausländer, den Islam, den Kulturbetrieb, die direkte Demokratie und das unabhängige, selbstverantwortliche Schweizervolk) kombiniert. Als erfolgreicher Unternehmer kritisiert er die unverantwortlichen Manager genauso wie den Etatismus der Linken. Als bodenständiger Bauer stellt er sich gegen die abgehobenen Theorien der Intellektuellen. Als Offizier steht er in der Tradition der widerständigen, unabhängigen Schweiz. Seine wissenschaftliche Qualifikation bezeugt seine eigene Expertise. Seine Ankersammlung macht ihn zum Teil einer kulturellen Elite und bringt ihn zugleich in Stellung gegen den Zeitgeist, den sie produziert.

,Blocher' repräsentiert das Periphere gegen das Zentrale, das Ewiggültige gegen das Transiente, die Erfahrung gegen den Zeitgeist, das Bäuerliche gegen das Städtische, das Praktische gegen das Theoretische, den freien Markt gegen den Staat, den gesunden Menschenverstand gegen das komplexe Expertenwissen. Und seine wirtschaftliche Erfolgsbilanz belegt, dass das vermeintlich Unterlegene und Anachronistische das Höherwertige und Zukunftsweisende ist.

64 Vgl. ebd.

65 Hubacher 2014: 47. 


\subsection{Der AbgeWÄhlte als Verhinderter HEILSBRINGER. CHARISMA, POLITISCHE REPRÄSENTATION UND MISSIONARISCHE POLITIK}

Blochers vielfältige Qualifikationen machen ihn zum idealen Repräsentant eines heterogenen Kollektivs. Blocher ist nicht nur Landwirt und Politiker, Militär und Politiker, Kunstsammler und Politiker oder Unternehmer und Politiker, sondern alles zugleich. Diese Gleichzeitigkeit erwirkt eine Überdeterminierung des Signifikanten ,Blocher', die ihn in die Lage versetzt, die potentiell antagonistischen Differenzen im Diskurs der SVP zu synthetisieren, eine Implosion der popularen Äquivalenz zu verhindern und der antagonistischen Negativität des Volkes eine positive Form zu verleihen. In Blocher fusionieren das Moderne (der globale Wettbewerbs- und Innovationsdruck) und das Bewährte und Ewiggültige (das Militärische, das Bäuerliche, Albert Ankers tiefe Einsichten und Blochers Führungsprinzipien). ,Blocher' personifiziert die Widerständigkeit und die Vitalität des Marginalisierten, die er mit seinen „wenig eleganten Gesten“, einer „leicht grobe[n], volksnahe[n] Sprache“ und seiner ,warme[n] Bodenständigkeit“ reinszeniert. ${ }^{66}$ Insofern gründet Blochers Charisma nicht allein auf seinem natürlichen politischen Talent, sondern auf seiner Bedeutung als universeller Heilsbringer, der gesetzgebende, heldenhafte und versorgende Funktionen auf sich vereint. $^{67}$

Diese hegemoniale Stellung Blochers wird nach seiner Abwahl als Bundesrat manifest. So behauptet Markus Somm etwa:

„Im öffentlichen Sektor, wo Leute arbeiten, die sich durch Blochers Staatsrückbau-Politik bedroht fühlen mussten, machte sich Triumph breit - während in den Zürcher Banken, in Industriebetrieben und kleinen Unternehmen, wo der Wohlstand dieses Landes generiert wird, wo man sich mit Gesetzen rumschlägt und die Steuern zahlt, die die jetzt Jubelnden dann verteilen: Hier verfiel man in stille Depression. “68

Blocher erscheint hier als neoliberaler Held, als Außenseiter, der sich in die Höhle des Löwen, den öffentlichen Sektor, begibt, um für die Interessen der Leistungsträger des Landes zu streiten. Nicht Blocher und die radikalisierte SVP,

66 Somm 2009: 10.

67 Vgl. zur Funktion politischer Führer als Versorger, Gesetzgeber und Held die interaktive Theorie politischen Charisma von Ron van Dooren (1994).

68 Somm 2007. 
sondern die ,Werktätigen', die gegen einen parasitären und aufgeblähten öffentlichen Sektor konturiert werden, sind die eigentlichen Verlierer der Abwahl. Blochers Repräsentationsfunktion resultiert aus dem reziprok-antagonistischen Verhältnis gegenüber den parasitären Institutionen des öffentlichen Sektors. Das partikulare Schicksal des abgewählten Bundesrates steht für die allgemeine Verfasstheit des politischen Betriebs. Der öffentliche Sektor entledigt sich des popularen Helden, der ihm entgegentrat.

Während Somm nach Blochers Abwahl das, werktätige Volk` gegen den öffentlichen Sektor laufen lässt, fallen in Blochers Albisgüetli-Rede 2008, einen Monat nach der Abwahl, alle Attribute des Volkes weg, die diese Identifikationsschablone begrenzen würden. Der abgewählte Bundesrat verortet sich „,[a]uf der Seite des Volkes ${ }^{\text {“69 }}$ und nimmt sich im ersten Teil der Rede viel Zeit, um dessen Gefühlslage zu rezitieren:

„[D]as riesige Echo, das meine Abwahl mit sich brachte, zeigt, dass viele Bürgerinnen und Bürger das Ganze nicht verstehen können. Sie sind traurig und empört. Sie reden von Intrigen, von hinterhältigem Verhalten der Parlamentarier. Von Entwürdigung des Parlamentes. Viele schreiben, sie hätten den Schlaf nicht mehr gefunden. Sie schämen sich und wenden sich ab von ihren Volksvertretern. “70

„Das Volk habe man aus dem Bundesrat geworfen. Volkes Seele sei tief verletzt, schreibt mir ein Sekundarlehrer aus dem Kanton Graubünden. Das Parlament habe sich vor laufender Kamera selbst entwürdigt, obwohl das gleiche Parlament bei jeder passenden und unpassenden Gelegenheit die ,Würde des Parlaments“ und die ,Würde der Institution“ hochleben liesse - schreibt eine Mutter mit fünf Kindern! Wenn ich die zahllosen empörten Briefe aus der Bevölkerung lese, sehe ich die Leute vor mir, wie sie über die Festtage an ihren Stuben- und Küchentischen sitzen. Auch viele einfache Leute sind darunter! Sie schreiben - zwei-, dreiseitige Briefe. Viele von Hand. Mit tiefen und erwägenswerten Gedanken über unser Land - schöne Gedanken. Über die Politiker - weniger schöne Gedanken. Die Leute schämen sich für die Parlamentarier. Sie haben die Abwahl am Fernsehen mitverfolgen können. Hinterhältigkeit, Neid und Hass seien aus den Gesichtern der Parlamentarier gequollen. “71

Während sich Somm auf die vergleichsweise konkrete Gruppe der in der freien Wirtschaft Beschäftigten bezieht, ist in Blochers Rede lediglich von „Bürgerin-

69 So der Titel von Blochers Albisgüetli-Rede von 2008 (Blocher 2008).

70 Ebd.: 3.

71 Ebd.: 6. 
nen und Bürgern“, von „,vielen“, und von „Leuten an Stuben- und Küchentischen" die Rede. ${ }^{72}$ Exemplarisch werden die Gedanken eines Sekundarlehrers und einer fünffachen Mutter rekapituliert. Nicht die Tatsache, dass ihre singulären Interessen nicht mehr vertreten werden, ist das Motiv ihrer Empörung. Ihre „Betroffenheit" ${ }^{\text {‘73 }}$ resultiert aus der skandalösen Abwahl Blochers. Das Ereignis wird zum Sinnbild einer ,heuchlerischen, hinterhältigen, neidvollen und hasserfüllten Classe politique‘, die das Parlament entwürdigt, um ihren Widersacher zu entmachten. Jedoch sorgt diese Entwürdigung der Politik durch die Politik bei den ,einfachen Leuten' keineswegs für Resignation, sondern für eine tiefgreifende Politisierung, die Blocher skizziert, indem er die Lebenswelt imaginiert, der die Briefe entstammen. Die Briefeschreiber besitzen weder einen Schreibtisch noch einen Computer; sie schreiben ,,an ihren Stuben- und Küchentischen“74 von Hand. Nicht im Öffentlichen, im Parlament als der Arena der dekadenten Politik, sondern im Privaten, an den familiären Küchen- und Stubentischen als den zentralen Orten der organischen Mikrogemeinschaften werden die „tiefen und erwägenswerten Gedanken über unser Land“" ${ }^{\text {75 }}$ produziert.

Diese Diskursierung der Abwahl verwandelt das Ereignis in die Spitze des Eisberges. Sie schafft einen originären Antagonismus zwischen einer moralisch intakten privaten Sphäre und einer moralisch korrumpierten öffentlichen Sphäre. Die missionarische Dimension populistischer Politik, das „Zusammenspiel““76 aus Verschwörungstheorie, Erlösungsnarrativ, Führerzentrierung und der Kreation einer unterdrückten, moralisch überlegenen Wertegemeinschaft, entfaltet sich erst durch das politische Komplott gegen Blocher. Erst im Moment des Antagonismus transformieren sich die parochialen Identitäten in politisierte Identitäten, werden die ,untergeordneten, einfachen Leute ${ }^{\natural} \mathrm{zu}$,widerständischen, engagierten Bürgern'. Und erst als Opfer der parlamentarischen Intrige repräsentiert der Abgewählte die Unvollständigkeit der moralischen Gemeinschaft. Die antagonistische Blockade der popularen Fülle, die sich in Blochers Abwahl manifestiert, evoziert Affekte, die als „Wut“, „Scham“ und „Empörung“ rhetorisch reinszeniert werden. Was andernorts als irrationale Heilserwartung gefasst wird, entpuppt sich als Effekt einer semantischen Überdeterminierung/Entleerung des Signifikanten ,Blocher', durch die er zum Platzhalter einer abwesenden Universalität wird.

72 Ebd.: 3 u. 6.

73 Ebd.: 5.

74 Ebd.: 6.

75 Ebd.

76 Zúquete 2011: 93. 
Gleichzeitig bedeutete die Abwahl Blochers zugunsten Widmer-Schlumpfs aber eine Krise für den SVP-Diskurs. Das Ministeramt ermöglichte Blocher zwischen staatsmännischer Regierungsverantwortung und fallweiser Opposition hinund herzuwechseln. Als Bundesrat konnte Blocher zugleich Teil der bürgerlichen Mehrheit und ihr schärfster Kritiker sein. Der Bundesrat Blocher schloss damit nicht nur die Reihen der eigenen Partei. Er gewann auch ehemalige Stammwähler der Mitte-Parteien hinzu.

Einerseits verliehen die Abwahl Blochers und der anschließende Gang in die Opposition dem Blocher-Kult neue Nahrung. Andererseits stellten sie die SVP vor eine interne Zerreißprobe. Schließlich hatte der Ausschluss der Bündner SVP zur Gründung der BDP geführt, die das liberal-konservative Projekt in konkordanzdemokratischer Weise weiterführte, Kernforderungen der SVP (beispielsweise in der Landwirtschaftspolitik, in der Bildungspolitik und der Verkehrspolitik) differenzlogisch, im Rahmen einer „lösungsorientierten Sachpolitik“" ${ }^{\text {77 }}$ reartikulierte und viele pragmatische SVP-Politiker und gemäßigte SVP-Wähler für sich gewann.

Verschärft wurde die Krise der parteiinternen Hegemonie Blochers dadurch, dass sie nicht nur von der politischen Mitte unter Druck geriet, sondern im Zuge des Minarett-Streits auch von rechts, durch einen antiislamisch fundierten populistischen Diskurs herausgefordert wurde, der die SVP mit anderen rechtspopulistischen Parteien in Europa identifizierte. Mit diesem Diskurs beschäftige ich mich im folgenden Kapitel. 


\section{Der Minarett-Streit. Der SVP-Populismus zwischen Zersplitterung und Hegemonisierung des demokratischen Imaginären}

Nachdem sich auch die Parteien der bürgerlichen Mitte von der europäischen Integration der Schweiz distanziert hatten, war es schwieriger geworden, die Virulenz der Bedrohung des Sonderfalls durch eine imperiale EU und eine ,europhile Classe politique' zu plausibilisieren. Infolgedessen lässt sich beobachten, dass das Thema europäische Integration durch das Thema Migration abgelöst wird, ${ }^{1}$ wobei die vakant gewordene Position des Primärfeindes sukzessive durch einen ,nicht-integrierbaren Islam‘ verfüllt wurde. Nahm der Antiislamismus zunächst eine periphere Stellung im SVP-Diskurs ein, avancierte er nach den Terroranschlägen vom 11. September 2001 sukzessive zu einem Knotenpunkt des SVPDiskurses, indem sich sicherheits-, migrations- und integrationspolitische Diskursstränge überschneiden. Seinen vorläufigen Höhepunkt fand er im Rahmen des Minarett-Streits zwischen 2006 und 2010.

Der Minarett-Streit stellt daher den Hintergrund für die folgende Tiefenbohrung dar. Ihr Hauptziel ist es, die populistische Verbindung zwischen einem antiislamisch begründeten „differenzialistischen Nativismus“2 ${ }^{\text {'2 }}$ und einem emphatischen Demokratiebegriff zu analysieren, mit dem die SVP für das Primat der Volksrechte gegenüber dem internationalen Völkerrecht und den Menschenrechten politisierte. Nachdem der Minarett-Streit und die Minarett-Initiative zusammengefasst und als dislozierende Ereignisse der politischen Schweiz und des SVP-Populismus geltend gemacht werden (9.1), gilt es im ersten analytischen

1 Vgl. Skenderovic/D’Amato 2008: 223; Betz 2012: 100f.

2 Betz 2003: insb. 195. 
Kapitel herauszuarbeiten, wie der populistische, vertikale Antagonismus zwischen dem Schweizervolk und den europafreundlichen Eliten zugunsten eines horizontalen Antagonismus zwischen einem ,christlich-aufgeklärten, liberalen und humanen Europa' und dem, voraufklärerischen, intoleranten und unmenschlichen Islam' in den Hintergrund tritt (9.2). Darauf aufbauend soll im folgenden Unterkapitel (9.3) analysiert werden, wie der SVP-Populismus diese kulturelle Konfliktlinie nach der Abstimmung zu resorbieren und zu variieren versucht. Gezeigt wird, wie der SVP-Diskurs den Minarett-Streit dem Sonderfallgedanken einverleibt, indem er das demokratische Prinzip der umkämpften Selbstinstituierung von Gesellschaft als genuin schweizerische Errungenschaft gegen internationalistische Verrechtlichungs- und Bürokratisierungstendenzen verteidigt und das für liberale Demokratien zentrale Spannungsverhältnis von Demokratie und Liberalismus politisiert. ${ }^{3}$ Dabei bleibt der Islam als inkompatible Differenz präsent, wird in seiner Funktion als Primärfeind aber durch eine ,volks- und demokratieverachtende politische Klasse` ersetzt.

\subsection{MinaRetT-STREIT UND MinARETT-INITIATIVE}

\section{A) Das Ereignis}

Der Minarett-Streit begann im Januar 2006 mit lokalen Protesten gegen Baugesuche von Minaretten in Wangen bei Olten (Solothurn), Wil (St. Gallen) und Langenthal (Bern). ${ }^{4}$ Weiteren Zündstoff erhielt die Debatte, als der bernische Dachverband der muslimischen Vereine Umma im April 2007 mit dem Plan in die Öffentlichkeit trat, in Bern-Wankdorf für 60 bis 80 Millionen Schweizerfranken das größte islamische Zentrum Europas zu errichten. In den drei deutschschweizerischen Kleinstädten sammelten SVP-Kommunalpolitiker Unterschriften gegen die Genehmigung der Gesuche und reichten bei den zuständigen Baukommissionen Petitionen ein. In Zürich und St. Gallen trugen die SVPFraktionen die Proteste in die kantonalen Parlamente. Unter der Führung der Kantonsrätin Barbara Steinemann legte die Zürcher SVP-Fraktion eine Motion vor, um ein generelles Minarett-Verbot im kantonalen Baurecht zu verankern. In

3 Allgemein zu diesem Spannungsverhältnis vgl. Mouffe 2008; im Hinblick auf die Minarett-Initiative vgl. Linder 2014.

4 Für eine Rekonstruktion der Ereignisse vgl. Müller/Tanner 2009: 36ff. 
St. Gallen zog der junge SVP-Kantonsrat Lukas Reimann nach. Jedoch wurden beide Vorstöße in den Kantonsräten mit deutlichen Mehrheiten abgewiesen. Nach dem Willen der Parlamentarier sollte über den Bau von Minaretten nach wie vor fallweise, nach den geltenden baurechtlichen Kriterien entschieden werden. So kam es in Wangen, Wil und Langenthal zu langwierigen juristischen Auseinandersetzungen zwischen den muslimischen Vereinen, den Gemeinden und den Kantonen, wobei die unterschiedlichen Instanzen die Baugesuche unterschiedlich beurteilten. Schließlich wurde nur in Wangen, wo sich der Kulturverein nach einem vierjährigen Rechtsstreit gegen die Gemeinde durchgesetzt hatte, ein Minarett gebaut. In Wil und Langenthal setzte der Volksentscheid den Verhandlungen ein abruptes Ende.

Da die SVP Schweiz zwar Sympathie für die Protestierenden bekundete, einer etwaigen Volksinitiative, die den Bau von Minaretten verfassungsmäßig verbieten wollte, aber skeptisch gegenüber, sahen sich die entschlossenen MinarettGegner innerhalb der SVP gezwungen, unabhängig von ihrer Partei eine Volksinititative auf den Weg zu bringen. Mit diesem Ziel gründeten sie das sogenannte Egerkinger-Komitee. Es setzte sich aus 16 Politikern zusammen. Zu 14 zur damaligen Zeit größtenteils eher unbekannten Vertretern der SVP - neben Steinemann und Reimann engagierten sich u.a. Ulrich Schlüer, Walter Wobmann, Oskar Freysinger und Jasmin Hutter - gesellten sich zwei Vertreter der Eidgenössisch-Demokratischen Union (EDU), einer evangelikalen Kleinstpartei. Die Leitung des Komitees übernahmen Wobmann, Schlüer und der EDU-Nationalrat Christian Waber. Auf der anderen Seite stand eine vermeintlich übermächtige Allianz: Der Bundesrat, die linken Parteien und die Mitte-Parteien plädierten allesamt für ein Nein, ebenso die Landeskirchen, die Gewerkschaften, die Economiesuisse, die großen Tageszeitungen und die öffentlich-rechtlichen Medien. Die meisten Spitzenpolitiker der SVP begrüßten die Initiative zwar grundsätzlich, entschieden sich aber aus taktischen und inhaltlichen Gründen gegen ein direktes Engagement. ${ }^{5}$ Christoph Blocher verweigerte jede Stellungnahme in puncto Minarett-Verbot und ließ bis zuletzt offen, ob er für oder gegen die Initiative sei. $^{6}$

Offiziell gestartet wurde die Initiative am 1. Mai 2007. Am 8. Juli 2008 reichten die Initianten die nötigen Unterschriften für eine Volksinitiative ein. Der Bundesrat genehmigte die Initiative, da sie nicht gegen zwingendes Völkerrecht verstoße, betonte jedoch, dass ein generelles Minarett-Verbot inkompatibel mit den Menschenrechtsgarantien der Bundesverfassung sei, und auch international

5 Keller 2005.

6 Vgl. Blocher 2009b. 
garantierte Menschenrechte, so etwa die Religionsfreiheit und das Diskriminierungsverbot der Europäischen Menschenrechtskonvention, unterlaufe, und beantragte dem Nationalrat die Ablehnung der Initiative. ${ }^{7}$ Die Parlamentarier teilten die Position des Bundesrates stark mehrheitlich. Sowohl der Nationalrat (mit 131 zu 51 bei 11 Enthaltungen) als auch der Ständerat ( 36 zu 3) lehnten die Initiative ab. Da ein Antrag auf Ungültigkeitserklärung in beiden Kammern scheiterte, wurde die Initiative dem Volk und den Ständen vorgelegt.

Im Abstimmungskampf spielte das Plakat des Egerkinger-Komitees eine Hauptrolle. Es zeigte eine Frau im schwarzen Niqab, im Hintergrund auf einem Schweizer Kreuz positionierte Minarette, darüber den Slogan ,Stopp - Ja zum Minarettverbot ${ }^{8}$. Auf Anfrage mehrerer Städte nahm die Eidgenössische Kommission gegen Rassismus Stellung zu dem Plakat und hob hervor, dass das Plakat eine „hetzerische Wirkung“ entfalte, indem es die in der Schweiz lebenden Muslime diabolisiere und „eine Islamisierung der Schweiz" suggeriere, „die es so nicht gibt“. ${ }^{9}$ Daraufhin beschlossen einige Städte und Kantone, den Aushang des Plakats zu verbieten, worin hauptsächlich SVP-Politiker, aber auch Sozialdemokraten und Freisinnige einen illegitimen Angriff auf die Meinungsfreiheit erkannten. ${ }^{10}$ Schließlich wurde am 29. November 2009 abgestimmt. Die Wahlbeteiligung lag bei bemerkenswerten 53,4 Prozent. 57,5 Prozent stimmten zu und auch bei den Ständen erreichte die Initiative eine Mehrheit. Das Verbot des Baus von Minaretten wurde in der Verfassung verankert.

Mit diesem Abstimmungsergebnis hatte im Vorfeld kaum jemand gerechnet. Alle Umfragen hatten der Initiative ein deutliches Scheitern vorausgesagt. Entsprechend konsterniert reagierte die Seite der Verlierer. Stellvertretend für den Bundesrat beteuerte Justizministerin Widmer-Schlumpf, man respektiere den Volksentscheid, ${ }^{11}$ betonte jedoch, dass man zutiefst bedauere, dass Menschenrechte aufgrund „diffuser Ängste“"12 eingeschränkt worden seien. Die allermeisten FDP- und BDP-Politiker folgten der bundesrätlichen Losung: Bedauern ja,

7 Für eine detailliertere Rekonstruktion der Position des Bundesrates vgl. Kley 2014: $37 \mathrm{f}$.

8 Das Plakat ist etwa auf der folgenden Seite abgebildet: http://www.patriot.ch/morgar ten/islam/minarettverbot.htm, 11.9.2014.

9 Eidgenössische Kommission gegen Rassismus 2009: 4f.

10 Vgl. etwa Schlüer 2009a; Köppel 2009a.

11 Widmer-Schlumpf, zit. in: Engeler/Gut 2009.

12 Ebd. 
Widerstand nein. Die CVP war gespalten. ${ }^{13}$ Auf der linken Seite wollte man sich dagegen nicht mit der Niederlage abfinden. Der Club Hélvetique, eine im Jahr 2005 ins Leben gerufene Vereinigung von Schweizer Intellektuellen, brachte eine „Toleranz-Initiative“ ins Spiel, die das Minarett-Verbot per Volksentscheid rückgängig machen solle. ${ }^{14}$ Insbesondere grüne Politiker und Rechtswissenschaftler argumentierten, dass das Minarett-Verbot der Europäischen Menschenrechtskonvention widerspreche und betonten, dass sich der Entscheid durch eine Klage vor dem Europäischen Gerichtshof für Menschenrechte rückgängig machen ließe. ${ }^{15}$ Die Schweiz stünde dann vor der Wahl, stellte der Berner Staatsund Völkerrechtler Walter Kälin gegenüber der nationalen Nachrichtenagentur der Schweiz SDA klar: „Entweder entscheidet [sie] sich zu einem Rechtsbruch, kündigt die Europäische Menschenrechtskonvention, oder sie hebt das Minarettverbot auf."16

Die europäische extreme Rechte reagierte erwartungsgemäß euphorisiert auf das Abstimmungsergebnis. ${ }^{17}$ „,Das ist ein klares Signal aus der Schweiz auch für uns “'18, forderte etwa der Lega-Nord-Minister für vereinfachte Gesetzgebung in der italienischen Regierung, Roberto Calderoli. Sein Parteifreund, der Europaabgeordnete Mario Borghezio bewunderte die „mutige Schweiz, die christlich bleiben will“"19. Geert Wilders betonte, die Holländer würde genauso abstimmen wie die Schweizer und würdigte das Ergebnis als Durchbruch: „Zum ersten Mal haben sich Menschen in Europa der Islamisierung widersetzt. “20 Der Front National gab in einer Pressemitteilung bekannt, dass ,die sogenannten Eliten endlich aufhören [sollten], die Befürchtungen der Menschen in Europa zu ignorieren“‘21 und variierte im März 2010 - sehr zum Unwillen der SVP-Führung - das Abstimmungsplakat der Initianten: Die Minarette waren nun mehr auf der Schwei-

13 Einen Überblick über die Reaktionen der Nationalräte der unterschiedlichen Parteien liefert der Weltwoche-Redakteur Urs Paul Engeler, freilich aus Perspektive der Minarett-Gegner (Engeler 2009b).

14 Vgl. Kreis 2009.

15 So etwa der Parteipräsident der Grünen Ueli Leuenberger (vgl. Engeler 2009b; Engeler/Gut 2009). Eine Zusammenfassung der juristischen Diskussion über die Legalität der Initiative findet sich bei Kley 2014.

16 Kälin, zit. in: Engeler/Gut 2009.

17 Für einen Überblick vgl. [o.A.] Spiegelonline 30.11.2009.

18 Calderoli, zit. in: ebd.

19 Borghezio, zit. in: ebd.

20 Wilders, zit. in: ebd.

21 Front National, zit. in: ebd. 
zerflagge, sondern auf dem französischen Hexagon stationiert - unterlegt von einer algerischen Flagge - gleichsam, um darauf aufmerksam zu machen, dass die Islamisierung in Frankreich ja noch weiter vorangeschritten sei als in der Schweiz. ${ }^{22}$

Wohingegen die meisten schweizerischen Medien das Ergebnis als Folge von „Angst und Unwissen“'23 deuteten und in erster Linie um den ImageSchaden und den Glaubwürdigkeitsverlust fürchteten, den der Finanzplatz und die Tourismusdestination Schweiz erleiden würde, fiel die Kritik ausländischer Medien harsch aus. ${ }^{24}$ Die Süddeutsche Zeitung erkannte der Volksentscheidung eine „Katastrophe“ und bilanzierte: „So kann es kommen, wenn das Volk nicht nur über Turnhallen und Transrapidbahnen abstimmt, sondern über alles. ${ }^{\text {“25 }}$ Der Berliner Tagesspiegel deutete den Volksentscheid als „Rückfall hinter die Errungenschaften der Aufklärung, eine Rückschritt in eine Zeit der Ideologien, Glaubensdogmen und Vorurteile, eine krachender Tritt gegen Vernunft und Wis-

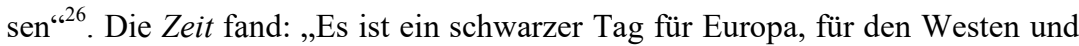
die Freiheit. “27 Die Dokumentation der begeisterten Reaktionen europäischer Rechtspopulisten dienten gleichsam als ultimative Beweise, dass sich die SVP mit der Minarett-Initiative endgültig aus der Riege der ,normalen Parteien ' verabschiedet hatte. ${ }^{28}$

Während Politiker, Wirtschafts- und Tourismusverbände und die Medien den Imageschaden beklagten, den das Land durch den antiislamischen Entscheid erlitten habe, ${ }^{29}$ transzendierte die politische Debatte bereits kurz nach der Abstimmung die Antiislamismus-Frage. Gestritten wurde nunmehr in erster Linie über den Vorschlag, die Volksentscheidung durch ein Urteil des Europäischen Gerichtshofs für Menschenrechte zu kippen, den Schweizer Jura-Professoren ins Spiel gebracht hatten. Die Befürworter des Minarett-Verbots reagierten empört. Und nunmehr schaltete sich auch SVP-Politiker und SVP-nahe Stimmen ein, die

22 Die beiden Plakate sind auf der folgenden Internetseite gemeinsam abgebildet: http:// www.europe1.fr/politique/quand-les-minarets-inspirent-le-fn-146312, 10.10.2014.

23 Vgl. exemplarisch Modoux 2009.

24 Für einen Überblick vgl. Schrader 2009. Der SVP-Populismus nahm diese Kritik seinerseits dankbar auf und so sind die folgenden Ausschnitte nach einem WeltwocheArtikel von Paul Urs Engeler und Philip Gut zitiert (Engeler/Gut 2009).

25 [o.A.] Süddeutsche Zeitung, zit. in: Engeler/Gut 2009.

26 [o.A.] Der Tagesspiegel, zit. in: Engeler/Gut 2009.

27 [o.A.] Die Zeit, zit. in: Engeler/Gut 2009.

28 Vgl. exemplarisch: [o.A.] Spiegelonline 30.11.2009.

29 Vgl. Waltz 2009. 
der Minarett-Initiative skeptisch gegenüberstanden. So zeigte die Titelseite der rechtskonservativen Weltwoche unter der Überschrift Totengräber der Demokra$\mathrm{tie}^{30}$ die Konterfeis von sechs Schweizer Politikern und Professoren, die den Minarett-Entscheid mit Hilfe des Europäischen Gerichtshofes für Menschenrechte revidieren wollten. Das Erwägen einer Klage in Straßburg deutete sie als typische, machtpolitisch und antidemokratisch motivierte Geste einer ,abgehoben wirkenden Elite“, die ,per Bandentrick [...] Vorstellungen, die in der Schweiz keine Chance haben, von aussen wieder ins helvetische Spielfeld“"31 ${ }^{\text {zu werfen }}$ versuche und nahm damit die Überdeterminierung vorweg, die der Volksentscheid im SVP-Populismus erfahren sollte.

\section{B) Ursachenanalysen des Abstimmungsergebnisses}

Die VOX-Analyse der Abstimmung ergab, dass die Befürworter in erster Linie beabsichtigten, ,ein Zeichen gegen die Ausbreitung des Islam und des von ihm propagierten Gesellschaftmodells [zu] setzen““.32 Das Argument der Gegenseite, ein generelles Bauverbot von Minaretten schränke die verfassungsrechtlich garantierte Religionsfreiheit ein, konnte die Befürworter dagegen nicht überzeugen, weil Minarette aus ihrer Sicht, „nichts mit der Religionsausübung zu tun hätten“333. Eine nachrangige Rolle spielten dagegen die Absicht, der Diskriminierung christlicher Gemeinden in islamisch geprägten Ländern mit einer reziproken Diskriminierung islamischer Gemeinden zu antworten, und die negativen Einstellungen gegenüber der muslimischen Bevölkerung in der Schweiz, weswegen die Umfrageergebnisse, so Hirter und Vatter, ,auf jeden Fall nicht als generelle Ablehnung der in der Schweiz lebenden Muslime interpretiert werden“634 dürften. Entsprechend ,erklärten 64 Prozent aller Stimmenden, dass sich die schweizerische und die islamische Lebensweise gut vertragen“" ${ }^{\text {35 }}$. Doch räumen die beiden Politologen dieser positiven Einschätzung nur geringen Einfluss auf die Wahlentscheidung ein: Selbst „diejenigen, die „,von einer sehr guten Verträg-

30 Vgl. den Titel der Weltwoche 49/2009.

31 Vgl. Engeler 2009a.

32 Hirter/Vatter 2010: 2. Grundlage der Analyse ist eine repräsentative Nachbefragung in Form von Telefoninterviews mit geschlossenen Fragen.

33 Ebd.

34 Ebd.: 2f.

35 Ebd.: 3 . 
lichkeit ausgingen, stimmten dem Verbot des Baus neuer Minarette mit einem Ja-Anteil von 49 Prozent zu' ${ }^{\text {‘36. }}$.

Sieht man davon ab, dass die Telefoninterview-basierte Umfrage, die der VOX-Analyse zugrunde liegt, strukturelle Verzerrungen produzieren, die von der sozialen Erwünschtheit und der Suggestiv-Wirkung geschlossener Fragen herrühren, deuten diese Ergebnisse darauf hin, dass die Befürworter der Initiative nicht konkrete Minarette oder konkrete muslimische Gemeinden, sondern die Bedeutung des Minaretts als Symbol des Machtanspruch eines grundverschiedenen Gesellschaftmodells im Sinn hatten.

In diese Richtung deuten auch die Thesen der „Blitzanalyse“ des Religionshistorikers Jean-François Mayer und die Forschung der Religionswissenschaftler Martin Baumann und Andreas Tungert-Zanetti. ${ }^{37}$ Mayer enummeriert die vielfältigen Motive des antiislamischen Abstimmungsverhaltens. Seine Liste reicht von der Sorge um die Geltung von Frauenrechten in muslimischen Parallelgesellschaften, über die Stereotypisierung des Islam als einem gewaltverherrlichenden Glaubenssystem bis hin zu einer diffusen Angst vor Überfremdung angesichts der vermeintlichen Islamisierung der Schweiz. Baumann und Tungert-Zanetti reflektieren dagegen die Bedeutung, die religiöse Bauwerke im Kontext gesellschaftlicher Pluralisierungsprozesse erhalten. Hierzu begreifen sie den öffentlichen Raum als

„sensibles und umkämpftes Terrain [...], in dem neue Religionsbauten von gesellschaftlich ausgegrenzten religiösen Gruppen zu Kristallisationspunkten von Protest und Abwehr werden. Religiöse Symbole von neu hinzutretenden Religionsgemeinschaften im öffentlichen Raum stellen etablierte Verhältnisse auf die Probe. Sie sind Zeichen der Neuverhandlung gesellschaftlicher Repräsentanz und Teilhabe.“38

Demnach rührt die politische Brisanz religiöser Bauwerke daher, dass sie die Absicht der als ,fremd“ und ,nicht-zugehörig‘ konnotierten Religionsgemeinschaft manifestieren, dauerhaft zu bleiben, öffentlich wahrgenommen und anerkannt zu werden. ${ }^{39}$ Die politische Dimension der Minarett-Frage, die Baumann und Tungert-Zanetti in positiven Begriffen von gesellschaftlicher Repräsentanz, Teilhabe und Anerkennung formulieren, kippt in dem Moment, wo die religiöse Minderheit als inkompatibel und bedrohlich konstruiert wird. Denn in diesem

36 Ebd.

37 Mayer 2009; Baumann/Tungert-Zanetti 2011.

38 Baumann/Tungert-Zanetti 2011: 154.

39 Ebd.: 179. 
Moment komme ein frühneuzeitlich-konservativer Antipluralismus zum Zug, der die Politik zu präventivem Handeln anhält, sobald die religiöse Homogenität des Staates gefährdet sei. ${ }^{40}$

Demzufolge basiert der Erfolg der Minarett-Gegner darauf, dass der Islam nicht mehr als eine Differenz unter vielen (wie etwa die Freikirchen, die Anthroposophen oder die hinduistischen Gemeinden), sondern als ein zentraler Knotenpunkt eines antagonistischen Bedrohungskomplexes artikuliert wird. Eine sozialwissenschaftliche Analyse sollte daher weder bei der Diagnose ,diffuser Ängste' oder einem tief verwurzelten, nunmehr antiislamisch aktualisierten Rassismus stehen bleiben, noch sollte sie sich in der Gewichtung der aufgelisteten Motive der Minarett-Gegner erschöpfen. Vielmehr sollte sie die Motive der MinarettGegner als Elemente behandeln, um zu rekonstruieren, wie Diskursivierung des Islam als absolutes Übel die äquivalentielle Artikulation dieser Elemente erst ermöglicht, wie der neue Knotenpunkt Islam innerhalb des antagonistischen Außen die populare Identität verformt und wie diese Verformung durch den SVPPopulismus resorbiert wird.

\section{C) Die Minarett-Initiative als dislozierendes Ereignis der politischen Schweiz und des SVP-Populismus}

Der deutliche Erfolg des Egerkinger-Komitees überraschte nicht nur die Verlierer, die sich auf die Prognosen der Meinungsforscher/innen verlassen hatten, sondern auch die Initianten. ${ }^{41}$ Wie bei der EWR-Abstimmung 1992 hatte eine kleine Gruppe entgegen aller Prognosen im Alleingang über die wichtigsten politischen und religiösen Organisationen der Schweiz triumphiert. Nicht nur die Initianten, sondern auch Medienvertreter konstatierten im Anschluss eine ,riesige Kluft zwischen veröffentlichter und öffentlicher Meinung “42. So fand der liberale Religionshistoriker Jean-François Mayer keinen Grund, Oskar Freysinger zu widersprechen, als der SVP-Hardliner im Vorfeld der Abstimmung klarstellte, dass ein etwaiges Ja zum Minarett-Verbot gleichbedeutend mit einer Zurückweisung des gesamten politischen Establishments sei. ${ }^{43}$

40 Ebd.: 181.

41 Vgl. Baumann 2009: 1; Mayer 2009: 1.

42 Jakobs 2009; exemplarisch für die Seite der Initianten vgl. Steinemann 2009.

43 Vgl. Mayer 2009: 2. 
Die VOX-Analyse der Abstimmung ergab, dass es die bürgerlichen MitteParteien am härtesten traf. ${ }^{44}$ Während sich der Stammwähler der SP, der Grünen und der SVP ihren Parteien anschlossen und mit deutlichen Mehrheiten gegen respektive für die Initiative stimmten, folgten die Mitte-Wähler der von CVP und FDP ausgegebenen Nein-Parole mehrheitlich nicht. ${ }^{45}$ Erneut war es einer Gruppe von SVP-Politikern gelungen, weit ins bürgerliche Lager hineinzustoßen und den Repräsentationsanspruch von CVP und FDP zu unterhöhlen.

In der Annahme der Minarett-Initiative manifestierten sich aber nicht nur die gebrochenen Partei-Wählerbindungen in der Mitte des politischen Spektrums. Das Ereignis dislozierte nicht nur die konkordanzdemokratisch-korporatistische Schweiz. Der Antiislamismus der Minarett-Initiative stellte auch die SVP vor eine erneute Zerreißprobe. Nachdem in Folge der Abwahl Blochers als Bundesrat im Jahr 2007 ein konkordanzorientierter Flügel gegen die offizielle oppositionelle Parteilinie aufbegehrte und unter der Führung Widmer-Schlumpfs zu einer neuen Partei zusammenfand, war es diesmal der radikale Flügel, der aufzusplittern drohte. Denn im Zuge der Minarett-Debatte wurde die migrationspolitische Agenda der SVP, die bislang in erster Linie mit ökonomischen und sicherheitspolitischen Argumenten begründet wurde, kulturalistisch generalisiert. Dem national-populistischen Antagonismus zwischen der ,europhilen, linken und netten Elite' und dem ,Volk' als mentaler Bastion des Sonderfalls wurde ein horizontaler Antagonismus an die Seite gestellt, der eine islamische Zivilisation und eine abendländisch-christliche, aufgeklärte und liberale europäische Zivilisation unterschied. So entstand in partieller Konkurrenz zu einem um Blocher und den neuen Parteipräsidenten Toni Brunner zentrierten, etablierten SonderfallDiskurs, der die Schweiz von allem Europäischen - vom zentralistisch organisierten, sozialliberalen Wohlfahrtsstaat bis hin zum linken und rechten Extremismus - abzugrenzen versucht, ein um Oskar Freysinger zentrierter, internationalistisch orientierter Diskurs, der das Schweizervolk nicht in erster Linie gegen das europäische Ausland, sondern gegen den Islam konturiert.

Der hegemoniale Blocherismus läuft seit der Minarett-Initiative Gefahr, von zwei Seiten zerrieben zu werden: Von der Mitte setzt ihm ein konkordanzdemokratisch orientierter Parteiflügel zu, der mit der lösungsorientierten BDP der dissidenten Eveline Widmer-Schlumpf sympathisiert; von der rechten Seite gerät er durch einen antiislamischen Parteiflügel unter Druck, der sich mit der extremen europäischen Rechten solidarisiert, von der Blocher \& Co die SVP seit jeher ab- 
zugrenzen versuchen. ${ }^{46}$ Umso willkommener war die Drohung der Abstimmungsverlierer, vor dem Europäischen Gerichtshof für Menschenrechte gegen das Minarett-Verbot zu klagen. Denn dieser Vorschlag bot dem SVP-Populismus die Vorlage, um den neuen Antagonismus Islam-Europa dem alten Antagonismus Schweiz-EU unterzuordnen. In der Folge rückte der neo-rassistisch begründete Antiislamismus zugunsten des liberaldemokratischen Spannungsverhältnisses von Volkssouveränität und Rechtsstaatlichkeit in den Hintergrund. Die SVP politisierte damit nicht nur am rechten Rand des politischen Spektrums, sondern zugleich entlang des Spannungsverhältnisses zwischen Demokratie und Liberalismus.

\subsection{Der AntilsLamismus UNd die EURopäIsierung DES POPULAREN BRUCHS}

Während des Minarett-Streits entwickelte sich der Islam im SVP-Populismus von einer Differenz des antagonistischen Bedrohungskomplexes zu der antagonistischen Differenz par excellence. Insofern gilt es in diesem Kapitel anhand des Diskurses der Initianten diese Primatstellung des Islam in der Konstruktion des Anderen zu rekonstruieren. Indes sollen hier nicht die symbolische Gewalt und die Kultur des Verdachts, die von der pauschalisierenden und stereotypisierenden Repräsentation des Islam und der Muslime im Diskurs der MinarettGegner ausgeht, ins Zentrum gerückt werden. ${ }^{47}$ Es soll analysiert werden, welche Verschiebungen der Islam als neuer Knotenpunkt des antagonistischen AuBen im Innen des popularen Diskurses produziert.

Antiislamische Ressentiments sind keineswegs neue Elemente des SVPPopulismus. ${ }^{48}$ In einem migrationspolitischen Positionspapier aus dem Jahr 1998 konstatiert die Zürcher SVP, dass sich der Islam „,mehr und mehr als eigentliches Integrationshemmnis “49 erweise. Nach den terroristischen Anschlägen vom 11. September 2001 hielten antiislamische Ressentiments auch in SVP-nahen Medien Einzug. Bereits drei Monate vor 9/11 erschien in der Schweizerzeit eine Rezension zu einem Buch des islamkritischen Orientalisten Hans-Peter-Raddatz,

46 Vgl. etwa Engeler 2012.

47 Vgl. mit Fokus auf die Schweiz Behloul 2009: insb. 108; Mayer 2009; allgemein Attia 2009.

48 Vgl. Betz 2003 u. 2012; Baumann/Tungert-Zanetti 2011.

49 SVP Zürich, zit. in Betz 2012: 100. 
welche die Konstellation des Anti-Minarett-Diskurses vorwegnimmt: dort ein ,bedrohlicher, inkompatibler Islam', hier ein christlich-liberales Europa, dessen Eliten, einem dogmatischen Multikulturalismus folgend, die Bedrohung der Unterwanderung durch die religiös-politische Ideologie tabuisierten. ${ }^{50}$ Nach den Anschlägen beschuldigte Raddatz die politische Klasse westlicher Staaten in der Schweizerzeit, einem „Dialog-Fetischismus ${ }^{\text {“51 }} \mathrm{zu}$ betreiben und auch historisch fundierte Kritiken des Islam auszuschließen.

Die Zürcher SVP griff diese Argumentationskette eineinhalb Jahre später auf und begann ab etwa 2003, auf den Politikfeldern Migration und Staatsbürgerschaft mit der drohenden Überfremdung durch den Islam zu politisieren. Gegen die Vorlage zur öffentlich-rechtlichen Anerkennung von nicht-christlichen Religionsgemeinschaften im Jahr 2003 und zur Erleichterung der Einbürgerung von Angehörigen der zweiten Ausländergeneration im Jahr 2004 polemisierte sie mit rhetorischen Fragen wie „Steuergelder für Koranschulen?“ respektive „Dank automatischer Einbürgerung: Muslime bald in der Mehrheit?،“52 Diese Aspekte sollte das Egerkinger Komitee im Minarett-Streit engführen.

Bevor ich mich mit dem Diskurs der Minarett-Gegner befasse, möchte ich zunächst das Argumentarium des Bundesrates in groben Zügen skizzieren. Der Bundesrat konstatierte, dass ein generelles Verbot ,ein völlig unverhältnismässiger Eingriff nicht nur in zentrale Grundrechte, sondern auch in die kantonalen Kompetenzen [wäre] ${ }^{653}$. Denn nicht die Bürger oder der Bund, sondern die zuständigen „lokalen Behörden sind am besten in der Lage, über die Zulässigkeit oder Unzulässigkeit der Errichtung solcher Bauten zu entscheiden “ ${ }^{\text {54 }}$. Demzufolge sei jeder einzelne Antrag auf den Bau eines Minaretts anhand der geltenden Bestimmungen des kantonalen und kommunalen Bau- und Raumplanungsrechts zu prüfen. ${ }^{55}$ Ferner schütze ein etwaiges Minarett-Verbot, anders als die Befürworter suggerierten, keineswegs vor „,[v]erfassungsfeindlichen, gewalttätigen Aktivitäten von Kreisen, die sich auf den Islam berufen “56. Im Gegenteil, ,[e]in Verbot im Sinne der Initiative könnte [...] den religiösen Frieden gefährden, da sie [sic!] von der muslimischen Bevölkerung als diskriminierender Akt aufge-

50 Vgl. Eysz 2001.

51 Vgl. Raddatz 2001.

52 Vgl. Baumann/Tungert-Zanetti 2011: 152.

53 Bundesrat 2008.

54 Ebd.

55 Ebd.

56 Ebd. 
fasst werden müsste““ ${ }^{57}$ Muslime könnten ,,in rechtlicher Hinsicht keinen Sonderstatus beanspruchen“, hätten umgekehrt ,aber selbstverständlich das Recht auf gleiche Behandlung mit anderen hier lebenden Personen und Religionsgemeinschaften“. ${ }^{58}$ Schließlich würde ,ein Bauverbot im Sinne der Initiative [...] auch im Ausland auf Unverständnis stossen und dem Ansehen der Schweiz schaden“, was sich „negativ auf die Sicherheit schweizerischer Einrichtungen und die ökonomischen Interessen unseres Landes auswirken [könnte]“. 59

Der Bundesrat artikuliert die Minarett-Frage differenzlogisch. Über den Bau eines Minaretts lässt sich nicht allgemein entscheiden. Ein Minarett ist weder ein Symbol für den Integrationswillen der Muslime noch eine Landmarke eines aggressiven islamischen Imperialismus. Ein Minarett ist ein Bauwerk und über Bauwerke entscheiden Kommunen und Kantone anhand des geltenden Baurechts. Ferner schütze ein Bauverbot von Minaretten keineswegs vor islamischen Fundamentalisten. Im Gegenteil, ein etwaiges Verbot könnte radikalen Strömungen Auftrieb verleihen, schweizerische Auslandsvertretungen in Gefahr bringen und der Ökonomie und dem Ansehen des Landes schaden. Damit greift der Bundesrat vielfältige Argumente der Gegenseite auf, vermeidet es aber, rund um die religionspolitische Neutralität des liberalen Verfassungsstaat ein ,Wir ${ }^{6} \mathrm{zu}$ formieren, das sich offensiv für den Bau von Minaretten stark macht und das Ziel des Egerkinger Komitees als unmittelbaren Angriff auf die eigene Identität wahrnimmt. Stattdessen argumentiert der Bundesrat konsequentialistisch. Er negiert nicht die Motive der Minarett-Gegner, sondern fokussiert die Risiken eines etwaigen Verbotes und zielt auf eine pragmatische Lösung.

Im Gegensatz zum differenzlogischen Absorptionsversuch des MinarettStreits im bundesrätlichen Diskurs entwirft der um das Egerkinger-Komitee zentrierte Diskurs rund um die Minarett-Frage ein binäres Konfliktszenario. Grundlage dieses Unterfangens ist die Essentialisierung des Islam als geschlossene Totalität, die einem festen, invariablen Kern entspringt. So formuliert beispielsweise der Chefredakteur der Weltwoche Roger Köppel: „Der Islam ist nicht toleranzwillig. Es mag gemässigte Strömungen geben, aber daneben gibt es nach wie vor einen militanten, auf Eroberung, Verdrängung und Zerstörung angelegten glühenden Kern, der gefährlich auf die äusseren Schichten abstrahlt.“" ${ }^{60}$ In der Schweizerzeit wird der Islam als „komplettes System [...] mit religiösen,

57 Ebd.

58 Ebd.

59 Ebd.

60 Köppel 2009b. 
rechtlichen, politischen, wirtschaftlichen und militärischen Komponenten “61 vorgestellt. Unterschiedliche Formen der Islamkritik werden damit in einem antimuslimischen Neo-Rassismus zusammengeführt, der Menschen muslimischen Glaubens aufgrund des singulären Merkmals ihrer Religionszugehörigkeit totalisiert und als inkompatibel, integrationsresistent und potentiell gefährlich diskursiviert. Die vielfältigen negativen Eigenschaften (Zwangsheirat, Ehrenmord, ,Vielweiberei', weibliche Genitalverstümmelung, Steinigung, die Unterordnung der Frau, Terrorismus, Ghettoisierung, Kriminalität, die Verfolgung religiöser und sexueller Minderheiten), die der Diskurs des Egerkinger Komitees diesem System zuschreibt, erscheinen als Epiphänomene einer tieferliegenden, unhintergehbaren Eigentlichkeit einer seit jeher intoleranten, archaischen, voraufklärerischen, fundamentalistischen, fanatischen, gewaltverherrlichenden und daher nicht-integrierbaren, „politreligiösen Eroberungsbewegung ${ }^{\text {“62 }}$, deren Ziele das Minarett als ,imperiale Landmarke' symbolisch zum Ausdruck bringe. ${ }^{63}$ So führt etwa Oskar Freysinger das Wort ,Minarett` etymologisch auf ,El Manar (der Leuchtturm) zurück und argumentiert, Minarette hätten mit der Religionsausübung nichts zu tun. Es handle sich um „Leuchttürme des Jihad“, um „vorgeschobene Brückenköpfe“ der Islamisierung. Ein Minarett sei „ein weit herum sichtbares Symbol der völligen religiösen Unterwerfung unter eine Doktrin und der damit zusammenhängenden Intoleranz, die auch innerhalb der verschiedenen Strömungen des Islam umstritten ist ${ }^{\text {“ }}$. $^{44}$

Der essentialisierende Topos der Eigentlichkeit konstruiert eine primordiale Diversität zwischen zwei wesenhaften, in sich homogenen Entitäten - einer aufgeklärten europäisch-westlichen und einer aufklärungsresistenten, gefährlichen oder zumindest verdächtigen islamischen Identität. So postuliert beispielsweise Ulrich Schlüer, dass der Islam „im Gegensatz zu anderen Weltreligionen [...] verbindliche Rechts- und Gesellschaftsnormen [auferlegt], die in Vielem [...] in unauflösbarem Widerspruch zu den Grund- und Freiheitsrechten stehen, wie sie die Schweizerische Bundesverfassung jedem in der Schweiz lebenden Menschen zusichert. “65 Für die Minarett-Gegner ist „,[d]as Minarett [...] gleichsam die Speerspitze der Scharia - eine andere, unserem demokratisch geschaffenen

61 [o.A.] Schweizerzeit 24.10.2008; vgl. auch Raddatz 2009.

62 Gut 2009.

63 Vgl. Behloul 2009: 106f.; Baumann/Tungert-Zanetti 2011: insb. 177. Exemplarisch für den Topos der Eigentlichkeit im Diskurs der Minarett-Gegner vgl. Suter 2007.

64 Freysinger 2009.

65 Schlüer 2010. 
Recht diametral widersprechende Rechtsordnung "66 ${ }^{\text {6 }}$. Am 29. November ginge es daher nicht um „baurechtliche Erwägungen“"67, sondern um ein Entscheidung zwischen zwei inkompatiblen Rechtsordnungen - dem ,weltlichen, demokratischen Schweizer Recht ${ }^{6}$ und dem ,totalitären, islamischen Scharia-Recht'. ${ }^{68}$ Dass die demographische Entwicklung in allen europäischen Staaten auf Seiten des Islam ist, verleiht dem Bedrohungsszenario eine objektive Komponente. ${ }^{69}$ Der Kampf gegen Minarette ist ein symbolischer Kampf gegen die ,Islamisierung“. Und der Kampf gegen die ,Islamisierung‘ ist ein Kampf gegen die Unterordnung der Frau, gegen die Diskriminierung sexueller und religiöser Minderheiten, gegen Fanatismus, Terrorismus, Bellizismus, gegen Männlichkeitswahn, Ghettoisierung und Bandenkriminalität, die allesamt dem ,System Islam‘ zugeschrieben werden.

Insofern ist Hans-Georg Betz zuzustimmen, wenn er diagnostiziert, dass der so diskursivierte Islam perfekt in den neurechten Deutungsrahmen des „differenzialistischen Nativismus“" ${ }^{\text {“70 }}$ passt. Das ,geschlossene System Islam‘ dient als ultimativer Beweis für die Unmöglichkeit des Zusammenlebens unterschiedlicher, in sich homogener kultureller Entitäten. Es fungiert als antagonistisches Pendant eines ,Wir', das spiegelbildlich als quasi-natürliches, organisches Ganzes imaginiert werden kann. Demnach korrespondiert die antagonistische Differenz ,Islam/Westen“ als dominantes „Medium der Operationalisierung und monokausale[n] Erklärung von [...] komplexen sozio-kulturellen Prozessen“"71 einerseits mit dem grundlegenden Deutungsmuster des SVP-Populismus, einem ,indigenen Multikulturalismus“"72, der ausschließlich native Minoritäten für integrierbar erklärt.

Andererseits lässt sich anhand des Schweizer Minarett-Diskurses beobachten, dass ,der inkompatible und bedrohliche Islam' die sedimentierten Identitäten des SVP-Populismus erschüttert, indem er die innereuropäischen Grenzziehungen des SVP-Sonderfalldiskurses überprägt. Als neues Außen unterminiert der Islam den antieuropäischen Sonderfall-Diskurs. Die Heimat ist zwar nach wie vor der zentrale leere Signifikant, aber die liberal-konservativen Knotenpunkte (Föderalismus, Neutralität, Selbstverantwortung, unternehmerfreundliche Poli-

66 Egerkinger Komitee, zit. in Behloul 2009: 107.

67 Ebd.

68 Vgl. exemplarisch Reimann 2007; Biffiger 2007; Raddatz 2009.

69 Für das demographische Argument vgl. Reimann 2007; Ulfkotte 2009.

70 Betz 2003: insb. 200.

71 Behloul 2009: 120.

72 Skenderovic 2003: 201. 
tik), die die populare Äquivalenz einst in Schach hielten und das semantische Spektrum der Heimat begrenzten, treten zurück. Angesichts der vermeintlichen ,Islamisierung Europas' lösen sich die Antagonismen, die der geschichtspolitische Diskurs der SVP zwischen der Schweiz und den zentral- und wohlfahrtsstaatlich organisierten europäischen Massengesellschaften instituierte, in schlichte Differenzen auf. Infolgedessen wird der ,Sonderfall Schweiz' nach der Volksabstimmung nicht mehr ausschließlich als antisozialistische und antieuropäische Bastion selbstverantwortlicher, autonomer Bürger, sondern in zunehmenden Maße als antiislamische, europäische Musterrepublik besprochen, die dank der direkten Demokratie eine Vorreiterrolle im Kampf gegen die ,Islamisierung des Abendlandes ' und ,den dogmatischen Multikulturalismus' des Establishments habe übernehmen können.

Das ethnokulturalistische Begründungsmuster bleibt bestehen, wendet sich nunmehr aber nicht gegen ,obrigkeitsstaatliche Deutsche', ,zentralistische Franzosen` oder ,monarchische Österreicher' oder eine EU, die das Großmachtstreben ihrer Mitgliedstaaten verwirklichen soll. Der geschichtspolitische Mythos einer einzigartigen schweizerischen Mentalität und die einschlägigen kommunitaristischen Bezüge auf Gemeinschaft, Volk und Heimat weichen zugunsten einer europäischen, westlichen, christlichen und liberalen Identität zurück. Angesichts der gemeinsamen Bedrohung durch den Islam transformiert sich der geschichtspolitisch imaginierte Antagonismus zwischen der Schweiz und den EUMitgliedsstaaten zu einer schlichten Differenz innerhalb eines wehrhaften okzidentalen ,Wir', das Elemente europäischer, westlicher, laizistischer, zionistischer und christlich-abendländischer Diskurse bündelt.

Einerseits erlaubt der Antagonismus gegenüber dem Islam dem SVPPopulismus, sich neue Forderungen einzuverleiben, die zuvor entweder gar keine oder kaum eine Rolle spielten. So finden Elemente aus feministischen Diskursen, Forderungen sexueller und religiöser Minderheiten, aber auch radikal laizistische Ziele und rassistische Motive Eingang in den populistischen Diskurs. ${ }^{73}$ Andererseits scheint die populare Äquivalenz dem nationalkonservativen Zürcher Flügel um Blocher im Zuge des Minarett-Streits zum ersten Mal zu entgleiten. Der von Blocher propagierte und verkörperte nationalpopulare HeartlandMythos der autochthonen, genügsamen, hart arbeitenden, freien und widerständischen Schweizer, der das Identitätsspektrum des Popularen lange Zeit limitierte, bekommt Konkurrenz durch einen Antiislamismus, der die SVP und die

73 Vgl. Behloul 2009: 107. Zur Illustration der Artikulation von Frauenrechten vgl. Egerkinger Komitee [o.J.]. 
Schweiz nicht als diametrales Gegenteil von allem Europäischen, sondern als primus inter pares innerhalb einer paneuropäischen Rechten positioniert. ${ }^{74}$

Im folgenden Kapitel soll daher untersucht werden, wie der Diskurs des Zürcher Flügels der Europäisierung der Äquivalenz entgegenwirkt, um den alten Sonderfall-Diskurs und seine Grenzen zu konservieren.

\subsection{VOLKSSOUVERÄNITÄT GEGEN ,FREMDES RECHT‘. DIE POPULISTISCHE GENERALISIERUNG DER BEDROHUNG UND DIE VARIATION DES ,SONDERFALLS“}

Von Beginn an fokussierte der antiislamische Diskurs der Minarett-Gegner nicht den Islam allein. Ziel der Kritik sind auch die international orientierten Deutungseliten, deren ,dogmatischer Multikulturalismus' die Toleranz verabsolutiere, ,unsere Kultur' entwaffne und der islamischen Unterwanderung ausliefere. ${ }^{75}$ So formulierte etwa der Orientalist Hans-Peter-Raddatz in der Schweizerzeit einen europäisch-islamischen Bedrohungszusammenhang, in dem die EU als „Islam-Vehikel“"76 fungiere:

„Ein erheblicher Teil der Brüsseler Aussenpolitik besteht darin, islamische Interessen zur Kernforderung der Politik zu erheben, sozusagen den Islam als Zentralstern in die Eurofahne zu stellen. Mithin werden die politisch entkernten EU-Staaten zu quasi-religiösen Motoren, die den Impetus der islamischen Kulturkolonien in Europa mit zielstrebiger Energie unterstützen. “77

Raddatz fokussiert die EU, andere Kommentatoren bezichtigen die Medien, Kirchen, „linke Parteien“ und „weltfremde Gerichte“. ${ }^{78}$ Aktiviert wird die typisch

74 So betont etwa das Egerkinger Komitee (2010) anlässlich der Publikation des Manifests „Nein zur Islamisierung der Schweiz“ genau ein Jahr nach der MinarettAbstimmung: „Dank der direkten Demokratie konnte sich der Volkswille in der Schweiz durchsetzen. Entsprechend strahlte das Schweizer Abstimmungsresultat in alle Länder Europas aus.“

75 Vgl. exemplarisch Farwick 2009; Gstrein 2009; Kelek 2007.

76 Raddatz 2009.

77 Ebd.

78 Vgl. exemplarisch Nieth 2009; Schlüer 2009a. 
populistische Vorstellung eines „homogenen Bevormundungskartells“"79 , das die Bedrohung durch den Islam nicht nur verdränge und verleugne, sondern unter Verweis auf das ,gutmenschliche“ Toleranz-Dogma zu tabuisieren und den Volkswillen mithilfe übergeordneten, international geltenden Rechts strategisch zu umgehen versuche. ${ }^{80}$

Für diese Artikulation des Antiislamismus mit dem Antagonismus zwischen Schweizervolk und einem ,international orientierten Establishment` lieferte die Reaktion der Wahlverlierer eine Steilvorlage. Während im Abstimmungskampf noch damit argumentiert wurde, dass die Initiative illiberal und daher unschweizerisch und obendrein nutzlos, wenn nicht gar kontraproduktiv sei, traten diese pragmatischen und identitätspolitischen Argumente nach der Abstimmung zurück. Im Zentrum stand nunmehr das juristische Argument, nach dem ein generelles Bauverbot von Minaretten gegen die im Völkerrecht und der Europäischen Menschenrechtskonvention verankerte Religionsfreiheit verstoße und der Mehrheitsentscheid durch eine Klage vor dem Europäischen Gerichtshof für Menschenrechte revidiert werden könnte. ${ }^{81}$

Dieses Argument der Gegenseite sollte der SVP-Populismus aufgreifen, wodurch er den antieuropäisch begründeten Sonderfall-Diskurs gegen die Judizialisierung der Politik konturiert. Die Hauptgefahr geht nun nicht mehr von einer gewaltverherrlichenden und totalitären Religion, sondern von einer ,minoritären Herrscherkaste' aus, welche die Volksrechte mit dem Verweis auf übergeordnetes, internationales Recht auszuhebeln versuche. ${ }^{82}$ Der Islam und die internationalistisch orientierte Elite tauschen sozusagen die Plätze. Das Establishment, der Sekundärfeind der Minarett-Gegner, wird zum Primärfeind; der Islam, die Hauptgefahr der Minarett-Gegner, wird zu einem sekundären Teilaspekt eines internationalen Bedrohungskomplexes. Somit transzendierte der MinarettStreit die neo-rassistische Essentialisierung des Islam. Er indiziert eine grundlegende Bedrohung der Schweizer Demokratie, die prinzipiell jedes Politikfeld tangiert. Gegenüber diesem Bedrohungsszenario konnte sich der SVPPopulismus, der in der Minarett-Frage selbst ja durchaus gespalten war, als Einheit rekonstituieren und auch Blocher konnte seine Rolle als Oppositionsführer wieder übernehmen.

79 Vgl. Priester 2012a: 9.

80 Vgl. exemplarisch Engeler/Gut 2009.

81 Dieser Vorschlag ging insbesondere von den Grünen und Völkerrechts-Professoren aus (vgl. Engeler 2009a).

82 Vgl. exemplarisch Engeler 2009a; Engeler/Gut 2009. 
Dieses Konfliktfeld hatte Blocher nämlich bereits 2007 für die SVP abgesteckt. Als amtierender Justizminister hatte er in seiner aufsehenerregenden 1 . August-Rede darauf hingewiesen, dass die Ausweitung internationalen Rechts die Volksrechte gefährde. ${ }^{83}$ „Es darf nicht sein, dass sogenanntes ,höheres“ Recht, oder ,internationales Recht', oder ,Völkerrecht' das demokratisch bestimmte Recht der eigenen Staatsbürger leichtfertig beschränkt oder gar ausser Kraft setzt. ${ }^{\text {" } 84}$ Schließlich sei der Bundesbrief, dessen Jubiläum am 1. August gefeiert wird, eine „Absage an unkontrollierte staatliche Macht und eine geradezu rebellische Absage an die Einschränkung des Volkswillens“" ${ }^{\text {85 }}$, auf die einst „Vögte“ und heute „,internationale Experten, hochkarätige Juristen, angesehene Professoren, Kongresse, internationale Foren, internationale Organisationen, Regierungen" abzielten. ${ }^{86}$

Genau dieses Argument sollte den Minarett-Streit nach der Abstimmung hegemonisieren. In einem Artikel des ehemaligen Generalsekretärs der SVP Schweiz und Vizepräsident der Zürcher SVP-Sektion Gregor A. Rutz erscheint der Minarett-Streit sozusagen als Lackmustest für den Sonderfall des liberaldemokratischen Schweizer Bundesstaates. ${ }^{87}$ Dass bestimmte Kreise erwägen, mit juristischen Mitteln gegen den Entscheid zu klagen, steht für Rutz exemplarisch für einen etatistischen Paternalismus, der dem Souverän immer mehr Kompetenzen entziehe, um ihn vor sich selbst zu schützen. ${ }^{88}$ Zur Minarett-Initiative, so Rutz‘ zentrale These, könne man ,stehen, wie man will - zum Resultat von Volksabstimmungen jedoch nicht. “" ${ }^{89}$ Denn der politische ,Sonderfall Schweiz“ zeichne sich im Unterschied etwa zur Bundesrepublik Deutschland dadurch aus, dass er keine dem Stimmbürger übergeordnete rechtsetzende Instanz anerkenne. Dieser Exzeptionalismus sei durch die allgemeine Tendenz der Judizialisierung der Politik gefährdet, die Rutz als Ausdruck einer „bevormundenden“, demokratieverachtenden und freiheitsgefährdenden „Staatsgläubigkeit“ geltend macht und auf diese Weise die neoliberale Hegemonisierung des Freiheits- und Demokratiebegriffs aktualisiert. ${ }^{90}$

83 Blocher 2007b.

84 Ebd.

85 Ebd.

86 Ebd.

87 Rutz 2009, vgl. auch Engeler/Gut 2009.

88 Vgl. Rutz 2009.

89 Ebd.

90 Ebd. 
Wie diese Artikulation mit dem bewährten antagonistischen Bedrohungskomplex aus dem schweizerischen Establishment und der Bedrohung von außen kombiniert wird, lässt sich exemplarisch in dem Artikel „Die Gewalt fremden Rechts" ${ }^{\text {“91 }}$ des Weltwoche-Journalisten Urs P. Engeler beobachten. Engeler diskursiviert die Judizialisierung nicht als anonyme Tendenz, sondern als politische Waffe des Establishments zur Entmachtung des Souveräns. ${ }^{92}$ Das Völkerrecht „,thront“ als „Götze [...] über der demokratisch gebildeten Mehrheit ${ }^{*} .{ }^{93}$ Es ,,verlangt nichts weniger als die [...] Unterwerfung der Ja-Sager unter sein universelles Gesetz. [...] Das Völkerrecht ist der ärgste Feind der direkten Demokratie, die Keule, mit der Professoren, linke und grüne Politiker [...] eigenwilliges Volk in die Knie prügeln wollen. “94

Bereits in der vorherigen Ausgabe hatte Engeler gemeinsam mit Philip Gut gewarnt:

„Der Prozess, das Schweizer Recht und die freie Entscheidung nicht nur zu relativieren, sondern auf den ausländischen Altären zu opfern, beschleunigt sich. [...] Eine politische und juristische Elite, die, angespornt und unterstützt vom Geheul der unterlegenen Linken, Volksentscheide auf dem Umweg via Ausland umstossen will, verrät und meuchelt die Demokratie. “95

Die durchgehende Gewalt- und Herrschaftsmetaphorik schöpft ein umfassendes Konfliktszenario. Auf dem Spiel stehen nicht mehr nur integrationsresistente Muslime, geschweige denn religiöse Bauwerke. Es geht um die Schweizer Demokratie und das Vertrauen eines braven Volkes.

„[D]as Votum fremder Richter [hätte] die Sprengkraft einer politischen Bombe. Der Bruch wäre definitiv zwischen dem Volk, das noch an demokratische Entscheide geglaubt hat, das leidenschaftlich debattiert, treu an die Urnen marschiert und auf das Resultat wartet, und einer Führungskaste, die sich - auch im Hinblick auf einen EU-Anschluss - einer Politik von oben und aussen verschrieben hat.“96

91 Engeler 2009.

92 Ebd.

93 Ebd.

94 Ebd.

95 Ebd.

96 Ebd. 
Die Generalisierung des Minarett-Streits und die binär antagonistische Spaltung des politischen Raumes gehen miteinander Hand in Hand. Der Versuch das Minarett-Verbot per Völkerrecht rückgängig zu machen, erscheint keineswegs als singuläre Option, um die Religionsfreiheit zu wahren, sondern als Moment der Wahrheit, in dem die Maske der „Führungskaste“ fällt und hinter vermeintlich edlen Motiven wie Menschenrechten, political correctness und Toleranz die totalitäre Allüre einer demokratiegefährdenden „Politik von oben und von aussen“97 zum Erscheinen kommt.

Der populare Antagonismus gegenüber dem Establishment und den internationalen Organisationen absorbiert den Minarett-Streit und verwandelt ihn in einen symbolischen Verdichtungspunkt des grundlegenden Konflikts. Somit durchläuft das Minarett einen zweistufigen Generalisierungsprozess. Im Diskurs des Egerkinger Komitees bringt es zunächst das aggressive und totalitäre Wesen des ,kompletten System“ Islam zum Ausdruck und symbolisiert damit die Inkompatibilität nicht nur des Islam, sondern auch der Muslime. Nach dem Erfolg der Initianten repräsentiert es schließlich den allgemeinen Gegensatz zwischen dem freiheitlichen ,Schweizervolk' und einem ,etatistisch und internationalistisch orientierten Establishment", das nunmehr, da es auf Druck des Volkes die europäische Integration von der politischen Agenda streichen musste, übergeordnetes Menschen- und Völkerrecht bemüht, um den demokratischen Souverän zu entmachten.

So lässt sich anhand von Blochers Albisgüetli-Rede 2010 beobachten, wie der SVP-Diskurs das populistische Konfliktszenario ausgehend von der Minarett-Abstimmung rekonstituiert. Auch hier indiziert der Minarett-Entscheid den undemokratischen Charakter der unterlegenen politischen, juristischen und kulturellen Eliten:

„Geradezu peinlich waren die Reaktionen von Regierungsmitgliedern, Politikern, Professoren und Journalisten nach Annahme der Minarett-Initiative. Sie erklärten und entschuldigten sich im Ausland für den Volksentscheid und sagten augenblicklich, man dürfe diesen nicht umsetzen. Überhaupt würden die fremden Richter in Strassburg, dann schon dafür sorgen, unsere direkte Demokratie auszuhebeln.“"98

Gegen diese Elite stellt Blocher, ähnlich wie Rutz, die historische Zweckbestimmung des ,Sonderfalls Schweiz‘ und der dort verankerten Volksrechte:

97 Ebd.

98 Blocher 2010: 5. 
„[D]ie Schöpfer unseres Bundesstaates haben sehr wohl gewusst, welches die beiden wichtigsten Grundsäulen unseres Staates sind! Die Souveränität gegen Innen und Aussen. Darum sind die Bürger in den Mittelpunkt zu stellen. Sie und nicht die Regierenden und nicht die Verwaltungsbeamten! [...] Darum stehen die Freiheitsrechte des Einzelnen im Mittelpunkt der Verfassung: also die Meinungsfreiheit, Pressefreiheit, Gedanken- und Gewissenfreiheit, Handels- und Gewerbefreiheit, die Niederlassungsfreiheit, die Eigentumsfreiheit, die Glaubens- und Gewissensfreiheit. [...] All dies sind in erster Linie Rechte der Bürger gegenüber der staatlichen Obrigkeit. Darum soll die Freiheit der Bürger geschützt werden gegenüber den staatlichen Eingriffen - auch und gerade der Richter." ${ }^{\text {999 }}$

Entscheidend ist, dass die liberalen Freiheitsrechte hier nicht dem Schutz vor der politischen Gewalt einer demokratischen Mehrheit dienen. Im Gegenteil, die potentiell antagonistische Differenz zwischen der demokratischen Tradition und der liberalen Tradition wird durch den Antagonismus gegenüber der undemokratischen und unfreiheitlichen ,staatlichen Obrigkeit“ synthetisiert. Die liberaldemokratische Äquivalenz basiert auf der Präsenz eines antagonistischen Anderen, der sowohl die liberalen Freiheitsrechte als auch das demokratische Recht der Selbstgesetzgebung der Bürger gefährdet. Hierzu wird die Judikative als neues Exekutivorgan einer parasitären Staatskaste besprochen, die sich die „Zurschaustellung ihres Gutmenschentums ${ }^{\text {“ } 100}$ von den Bürgern, die sie besteuert, finanzieren ließen. Letztlich aber, so Blochers Zwischenfazit, geht es ihnen aber darum, „die Demokratie abzuschaffen“"101. Sie wollen „weniger Freiheit der Bürger und dafür mehr Macht für den Staat, d.h. mehr Sozialismus“" ${ }^{\text {102 }}$. Denn, so Blocher weiter,

„[d]as Störendste in unserem Land ist für unsere Gegner [...] die direkte Demokratie. [...] Am besten man bemüht die Gerichte, das wirkt so schön ,rechtsstaatlich`. Und da unsere Gesetze nicht dazu taugen, die Demokratie abzuschaffen, beruft man sich auf fremdes Recht. Völkerrecht und Menschenrecht werden sie genannt. Diese Begriffe kann man nach Lust und Laune biegen. Und sicher werden sie nicht vom verfassungsmässig vorgesehenen Gesetzgeber - also nicht durch die Stimmbürger - erlassen. “103

99 Ebd.

100 Vgl. ebd.: 7.

101 Ebd.: 7.

102 Ebd.

103 Ebd.: 10. 
Blochers Albisgüetli-Rede zeigt exemplarisch, wie der SVP-Populismus die durch die Minarett-Initiative ausgelöste Dislozierung näht. Der Minarett-Streit wird generalisiert. Er symbolisiert die allgemeine Bedrohung des direktdemokratischen Sonderfalls durch die Judikative und insbesondere durch das Völkerrecht. Die Absorption der Minarett-Debatte erwirkt aber nicht nur eine Extension der antagonistischen Äquivalenz, sondern auch eine Reorganisation des popularen Lagers. Denn dadurch, dass die populare Äquivalenz nunmehr gegen die Judikative in Stellung gebracht wird, avanciert die direkte Demokratie, die im Kampf gegen die europäische Integration noch eines von vielen gleichrangig gewichteten Momenten war, zum zentralen Knotenpunkt des SVP-Populismus. Die direkte Demokratie kanalisiert den popularen Widerstand. Sie fungiert nicht bloß als dynamisierendes konkurrenzdemokratisches Komplement des konkordanzdemokratischen Elitenkonsenses. Sie ist gleichzeitig Essenz, Bastion und Medium des ,Sonderfalls‘ und des popularen Widerstandes. Die direkte Demokratie (und nicht die Konkordanz) repräsentiert die Einzigartigkeit der politischen Schweiz.

Zugleich wird versucht, das Bedeutungsspektrum dieser genuin populistischen Artikulation der direkten Demokratie durch den Antagonismus gegenüber dem Wohlfahrtsstaat im Rahmen der eigenen politischen Ideologie abzustecken. Denn im SVP-Diskurs ist die direkte Demokratie in erster Linie der Garant der Freiheitsrechte, welche die Agenten der staatlichen Obrigkeit mit ausländischer Hilfe auszuhebeln versuchten. ${ }^{104}$ Die eigentliche Zweckbestimmung der direkten Demokratie wird hier nicht in einem politisch sensiblen „Könnens-Bewusstsein“"105 der Bürger verortet, sondern in der Abwehr der ,ausufernden Sozialindustrien“ des interventionistischen Wohlfahrtsstaates der ,vereinigten Linken“ und seiner vielfältigen parasitären Agenten und Profiteure. Innerhalb dieser antagonistischen Äquivalenz konstituiert die Figur des ,nicht-integrierbaren Moslems` einen privilegierten Knotenpunkt. Denn in diesem Anti-Subjekt vernähen sich drei wichtige Diskursstränge des SVP-Populismus: ein neu-rechter Überfremdungsdiskurs, der ethnische und kulturelle Differenzen als ,inkompatibel ${ }^{*}$ verwirft; ein neoliberaler Krisen-Diskurs, der das „,Unfähige“ und das ,Unnütze“،106 als absolutes Übel wahrnimmt; und ein neo-rassistischer SicherheitsDiskurs, der Muslime unter Generalverdacht stellt.

Der antietatistische Auftrag, den die SVP der direkten Demokratie zuschreibt, ist kein politisch gewählter. Vielmehr entspringt er der arche-

104 Für diese Argumentationskette vgl. exemplarisch Schlüer 2009a.

105 Meier 1980: 469.

106 Balibar 2008: 23. 
politischen Vorstellung des Heartland, das es gegen alles ,Fremde' abzuschirmen gilt - gegen die Asylsuchenden, die unter- und die überqualifizierten Arbeitsmigranten ${ }^{107}$, die ,Muslime mit ihren Ghettos und Parallelgesellschaften', gegen das Völkerrecht und die Europäische Union, aber auch gegen die Intellektuellen, gegen den ,bürokratischen Wohlfahrtsstaat", das ,schleichende Gift des Sozialismus' und die ,wohltönende Toleranz und Solidarität der Gutmenschen'. Das Bedeutungsspektrum der popularen Äquivalenz variiert in Abhängigkeit davon, welche dieser antagonistischen Figuren in den Vordergrund gerückt wird, erfährt durch die ständigen Rekurse auf das von Blocher verkörperte Heartland der ,selbstverantwortlichen nativen Schweizer' als antisozialistischer Bastion aber eine gewisse Begrenzung.

Diese für den SVP-Populismus charakteristische Begrenzung der popularen Äquivalenz qua Historisierung und Essentialisierung bildet den Ausgangspunkt für die abschließende kritische Diskussion der Populismuskonzeption Laclaus.

107 Seit Ende 2009 lässt sich beobachten, dass insbesondere die Zürcher SVP nicht nur gesellschaftlich marginalisierte Zuwanderer, sondern auch hochqualifizierte Zuwanderer als Bedrohung bespricht. Eine Inseratenkampagne diagnostiziert: „Ausländische Ellbögler drängen sich an unsere Arbeitsplätze“ und „Deutscher Filz macht sich breit: Denn Deutsche stellen vor allem Deutsche an - an der Uni und in den Spitälern“ (SVP-Inserat in der NZZ, 15.12.2009). Die Zürcher SVP-Politikerin Nathalie Rickli schließt die Argumentationskette: „Deutsche nähmen nicht nur SchweizerInnen die Arbeit weg, sie verdrängten auch andere ausländische Arbeitskräfte und belasteten damit indirekt die Sozialwerke“ (Rickli, paraphrasiert nach Betz 2012: 105). 


\section{Schluss:}

Antipolitischer Populismus 



\section{Die Kontinuität des SVP-Populismus und die Externalisierung innerer Grenzen}

Zum Abschluss möchte ich auf die außerordentliche programmatische Konstanz und elektorale Kontinuität des SVP-Populismus eingehen, die diesen Diskurs trotz der jüngsten Dislozierungen kennzeichnet. Vor dem Hintergrund dieses Diskurses werde ich anschließend die von Laclau postulierte Anschlussfähigkeit seiner Populismustheorie für demokratietheoretische Überlegungen diskutieren. ${ }^{1}$ Im Zentrum steht dabei die Frage, inwiefern die streng formale Konzeption des Phänomens eine Unterscheidung zwischen einem popular-demokratischen und einem autoritären Populismus bzw. einem politischen und einem antipolitischen Populismus zulässt. ${ }^{2}$

Die Forschung zur SVP hat zu Recht darauf hingewiesen, dass die Partei bei ihrem Aufstieg von einer Reihe struktureller Faktoren profitiert hat:

- Das Konkordanzsystem induziert langwierige, mitunter intransparente politische Entscheidungsfindungsprozesse. Es perpetuiert eine kollaborierende politische Elite und schwächt somit drei fundamentale Prinzipien demokratischer Repräsentation: die Zurechenbarkeit politischer Entscheidungen, die Verantwortlichkeit für die Folgen der getroffenen Entscheidung und die Responsivität gegenüber subalternen Forderungen. Konkordanzdemokratien bieten damit besonders günstige Bedingungen für den Erfolg populistischer Parteien, da die systemisch bedingten Willensbildungs- und Entscheidungsfindungsprozesse

1 Laclau 2005a: insb. 167.

2 Zur Unterscheidung dieser beiden vgl. Hall 1986. Was die spezifische Differenz des einen gegenüber dem anderen ausmacht, bleibt bei Hall jedoch vage. 
das populistische Verschwörungsszenario eines ,homogenen politischen Establishments " plausibilisieren. ${ }^{3}$

- Da der Regierungsbildung im Proporzsystem keine Koalitionsvereinbarungen vorausgehen, ist die SVP nicht gezwungen, sich auf inhaltliche Kompromisse festzulegen. ${ }^{4}$ Vielmehr ermöglicht die Tatsache, dass im politischen System der Schweiz das Konkordanzprinzip durch Referendums- und Initiativrechte flankiert wird, der Partei trotz gleichzeitiger Regierungsbeteiligung mit Referenden gegen den Parteienkonsens zu politisieren und so die oppositionelle Grundhaltung zu untermauern, ohne das symbolische Kapital einer verantwortungsvollen Regierungspartei einzubüßen. ${ }^{5}$

- Im Gegensatz zu neugegründeten, europäischen rechtspopulistischen Parteien konnte die SVP von ihrem kulturellen Kapital als langjährige, verlässliche Regierungspartei zehren. So wird der vonseiten der Mitte- und Links-Parteien erhobene Rechtsextremismus-Vorwurf auch dadurch entkräftet, dass die SVP sich als verantwortungsvolle Mitregierungspartei verdient gemacht hat. ${ }^{6}$

- Gerade in der Pionierphase des SVP-Populismus begünstigten der relativ schwache Organisationsgrad der Schweizer Parteien und die relative Autonomie der Kantonalparteien die Dissidenz der Zürcher Sektion, die der SVP Schweiz einen neuen ideologischen Kurs aufprägte. ${ }^{7}$

- Zudem profitierte die SVP von der ,ideologischen Elastizität ${ }^{\text {“8 }}$ der CVP und der FDP gegenüber sozialdemokratischen und postmateriellen Forderungen. Insbesondere der Freisinn, der engste programmatische Verbündete der SVP und die prägende Kraft der bürgerlichen Schweiz, rückte in den 1990er Jahren

3 Zum positiven Zusammenhang zwischen Konkordanzdemokratien und dem Aufstieg rechtspopulistischer Parteien vgl. Taggart 1996: 113ff., 2002 u. 2004; Mouffe 2005; Caramani/Mény 2005: 41ff.; vergleichend anhand der Beispielländer Österreich, Schweiz und den Niederlanden vgl. Fröhlich-Steffen 2006, mit Blick auf die Schweiz: Papadopoulos 2005 u. Albertazzi 2008: 107ff.

4 Vgl. Geden 2005a, Papadopoulos 2005.

5 Vgl. Geden 2005b u. 2006. In der Regel erodiert das populistische Parteienprofil, sobald die Partei Teil der regierungstragenden Koalition wird (vgl. Fröhlich-Steffen/ Rensmann 2006).

6 Skenderovic 2007b: 58.

7 Vgl. allgemein zur relativen Autonomie der Kantonalparteien Ladner 2004; mit Blick auf die SVP und Abspaltung des Zürcher Flügels vgl. Albertazzi 2008: 116.

8 Somm 2009: 141. 
unter der Führung Franz Steineggers in die Mitte und überließ das liberalkonservative Wählerspektrum der SVP. ${ }^{9}$

- Die SVP profitierte auch davon, dass die Schweizer Politik seit den 1990er Jahren durch den Erfolg der Politsendung Arena des öffentlich-rechtlichen Senders SRF1 eine starke Mediatisierung erfuhr. ${ }^{10}$ Die Arena hat die Debattenkultur drastisch verschärft. Sie privilegiert die kontroversen Themen der SVP und reinszeniert damit die vom SVP-Diskurs propagierte Polarisierung. ${ }^{11}$

- Schließlich bot der Mythos des ,Sonderfalls Schweiz‘ als neutralem und unabhängigem Kleinstaat dem SVP-Populismus gerade im Kampf gegen die europäische Integration der Schweiz vielfältige Anknüpfungspunkte. ${ }^{12}$

Obwohl diese Opportunitätsstrukturen den Aufstieg der SVP maßgeblich bedingten, wurden sie in dieser Arbeit lediglich tangiert und nicht systematisch beforscht. Fokussiert wurde vielmehr die Rhetorik der SVP und ihr nahestehender Akteure. Dabei wurde das Rhetorische nicht im Rahmen eines Struktur-AkteursModells als schlichtes Politikangebot betrachtet, das eine unbefriedigte, sozialstrukturell bedingte Nachfrage im Tausch gegen politische Macht zu stillen versucht, sondern als sozial performativer und politisch formgebender Diskurs konzipiert. $^{13}$

Die theoretische Grundlage dieses Unterfangens bildete die postfundamentalistische Hegemonie- und Populismustheorie von Ernesto Laclau und Chantal Mouffe. Verworfen wurde damit sowohl eine nomothetische Lektüre, die den SVP-Populismus im Rahmen eines pathogenetischen Ursache-WirkungsZusammenhangs auf ein politisches Epiphänomen einer gegebenen sozialstruk-

9 Vgl. Longchamp 2000: 410; Somm 2009: 392ff.

10 Zum allgemeinen Zusammenhang zwischen Populismus und Mediatisierung vgl. Diehl 2011 u. 2012; Misik 2012.

11 Vgl. Albertazzi 2008: 115.

12 Vgl. zur Persistenz des Sonderfallbewusstseins Meier-Dallach u.a. 1980; Eberle 2007; Imhof 2007.

13 Dahinter steht die Überzeugung, dass der Aufstieg (rechts-)populistischer Parteien gerade nicht auf ein politisches Überbauphänomen reduziert werden kann, das durch einen ökonomischen Strukturwandel, wenn nicht determiniert, so doch bedingt wird, sondern als Resultat einer erfolgreichen Identitätspolitik zu rekonstruieren ist, welche die dominanten Identitäten und Konfliktlinien der Schweizer Gesellschaft überprägt, indem sie gewisse Traditionen, Elemente und Forderungen zu einem popularen Imaginären verknüpft. 
turell begründeten Basis reduzieren würde,$^{14}$ als auch eine ideologiekritische Lektüre, ${ }^{15}$ die den SVP-Populismus - im Rekurs auf universelle Teilungs- und Organisationsprinzipien von Gesellschaft - als Anomalie wahrnimmt und ihm entweder ein baldiges Ende prognostiziert oder ihn dafür kritisiert, dass er die präsupponierten Ordnungsprinzipien verletzt und eine ,normale, anerkennungswürdige Sozialisation` verhindere.

Anstatt den SVP-Populismus a priori als pathologisch zu begreifen und seine Paradoxien und Inkonsistenzen als inkompatible Widersprüche zu thematisieren ${ }^{16}$ wurde mit der Hegemonie- und Populismustheorie ein konzeptuelles Instrumentarium entfaltet, das es erlaubt, die Funktionslogik der diskursiven Repräsentationsleistungen zu analysieren, die diese scheinbaren Widersprüche durch kontingente Artikulationen synthetisieren und im Rahmen einer popularen Identität homogenisieren. Die relative Vagheit/Leere der zentralen Knotenpunkte dieser Identität (,Demokratie‘, ,Heimat‘, ,Freiheit‘ und ,Sonderfall Schweiz') wurde nicht als Beleg einer unterentwickelten, „dünnen Ideologie“17, sondern als Effekt universalisierender Operationen verstanden, welche die vielfältigen vakanten Elemente/Forderungen zu einer Identität bündeln und gegen den Status quo in Stellung bringen. Auf diese Weise konnte das Postulat der Unvereinbarkeit von Pluralismus und Populismus im Anschluss an Laclau zurückgewiesen und durch einen konstruktivistischen Theorierahmen ersetzt werden, der das Verhältnis der beiden vermeintlich widersprüchlichen Phänomene prozeduralisiert und Pluralismus und Populismus als zwei konkurrierende politische Selbstbeschreibungen von Gesellschaft liest.

Auf dieser Grundlage ließ sich rekonstruieren, auf welche Weise der äquivalenzlogisch dominierte SVP-Populismus die differenzlogisch dominierte Selbstbeschreibung der Schweiz als gemäßigt pluralistische, multikulturelle und konkordanzdemokratisch integrierte Totalität herausfordert und überprägt. Die diagnostizierte Polarisierung der Schweizer Gesellschaft und des Parteiensystems ${ }^{18}$ und die vielzitierte Krise der Konkordanz ${ }^{19}$ wurden nicht auf vorpolitische gesellschaftliche Entwicklungen zurückgeführt, sondern als Effekte der dichotomisierenden Rhetorik des SVP-Populismus gelesen. Die im Verhältnis zu anderen

14 Vgl. hierzu etwa Lachat/Selb 2005.

15 Vgl. grundlegend Eagleton 1993.

16 Vgl. exemplarisch Betz 2012: $105 \mathrm{ff}$.

17 Mudde 2004: 543.

18 Vgl. Longchamp/Rousselot 2010; Ladner u.a. 2010; Ladner 2010 u. 2013.

19 Vgl. Mazzoleni/Skenderovic 2007; Longchamp/Rousselot 2010; Longchamp u.a. 2003; Ladner 2004; Ladner u.a. 2010; Betz 2012. 
rechtspopulistischen Bewegungen in Europa außergewöhnliche Stabilität des SVP-Populismus erklärt sich aus dieser theoretischen Perspektive nicht durch persistent günstige Rahmenbedingungen, sondern durch die stetige Reproduktion einer spezifischen Repräsentation der Schweizer Gesellschaft. Der Cleavage zwischen „Öffnung und Schließung“20 respektive zwischen Kosmopolitismus und Ethno-Kommunitarismus ${ }^{21}$ wurde daher diskurstheoretisch auf den Grund gegangen.

Es wurde zunächst argumentiert, dass der Schweizer Exzeptionalismus nach der Einbindung der Sozialdemokratie durch einen differenzlogisch komponierten, konkordanzdemokratischen Diskurses hegemonisiert wird und in Form einer konsensorientierten politischen Kultur und einer gemäßigt pluralistischen „Ausgleichsgesellschaft“ ${ }^{622}$ sedimentiert, die sich anhand ,ganzheitlicher und teilungsfreier Repertoires ${ }^{\text {‘23 }}$ wahrnimmt. Dabei wurde herausgearbeitet, dass sich dieser Diskurs durch die Einrichtung peripherer Antagonismen gegenüber nichtkompromissfähigen Kräften konstituiert: Indem er fundamentaloppositionelle Diskurse und „schwarzweiß polarisierten Zukunftserwartungen“24 ${ }^{\text {“24 }}$ als ,ideologisch', ,extremistisch', ,unvernünftig' und ,unschweizerisch'verwirft, nobilitiert er die Politik der Mitte und den Elitenkonsens der vier Bundesratsparteien als ,vernünftig' und ,genuin schweizerisch'. Die außerordentliche Stabilität des Parteiensystems und der Partei-Wählerbindungen erklärt sich vor diesem Hintergrund als Effekt der Hegemonie des konkordanzdemokratischen SonderfallDiskurses, der die politische Schweiz gegen alle binären Spaltungsversuche immunisierte.

Im Anschluss habe ich anhand ausgewählter Ereignisse rekonstruiert, wie der SVP-Populismus von der innerparteilichen Zürcher Opposition gegen die sozialliberalen Modernisierungspläne der machtvollen Berner und Bündner Sektionen zum oppositionellen Projekt schlechthin und schließlich zum Repräsentanten des ,Sonderfalls Schweiz' avancierte. Hierbei habe ich herausgearbeitet, wie der SVP-Populismus die konkordanzdemokratisch integrierten Differenzen des gemäßigten Pluralismus überprägt und die pluralistische Gesellschaft entlang der Demarkationslinien der eigenen politischen Ideologie spaltet. Somit wurde die Dominanz der Konfliktlinie zwischen „Öffnung und Abgrenzung “25 in der Orga-

20 Brunner/Sciarini 2002; Bornschier/Helbing 2005.

21 Betz 2002 u. 2004.

22 Rehberg 2007.

23 Meier-Dallach 1988: 127; vgl. auch Meier-Dallach u.a. 1980: 44ff.

24 Meier-Dallach 1988: 113.

25 Vgl. Brunner/Sciarini 2002 sowie Bornschier/Helbing 2005: 32ff. 
nisation des politischen Raumes als Effekt einer hegemonialen DesorganisationReorganisation des politischen Raumes gefasst. Der SVP-Diskurs transzendiert die sozial sedimentierten Konfliktlinien ,Arbeit/Kapital', ,Staat/Kirche', ,Romandie/Deutschschweiz‘ sowie zwischen ,Peripherie/Zentrum', indem er den Antagonismus in die Mitte der Gesellschaft verschiebt. Er unterscheidet eine ,widerständische, autochthone und selbstverantwortliche populare Äquivalenzkette' von einer ,parasitären, anpasserischen und etatistischen Äquivalenzkette', welche die etablierten Repräsentationsorgane der politischen Schweiz mit dem Fremden und dem Marginalisierten assoziiert. Aus dieser binären Repräsentation der Gesellschaft entsteht ein ,Volk' im Sinne einer antagonistisch blockierten Identität, die einen universellen Anspruch auf die Repräsentation der Nation postuliert.

Während der konkordanzdemokratische Exzeptionalismus alles Polarisierende als ,unschweizerisch ' verwirft, fixiert der SVP-Populismus den ,Sonderfall Schweiz' nunmehr innerhalb einer binär strukturierten Matrix. Der ,Sonderfall' wechselt sozusagen die Seiten und die fundamentaloppositionelle Praxis des Widerstands wird zum genuin Schweizerischen. Der Antagonismus zwischen, Öffnung und Schließung ${ }^{6}$, Orientierungslosigkeit und Orientierung ${ }^{6}$ respektive zwischen ,Anpassung und Widerstand" konstituiert eine Wir-Sie-Matrix, die den politischen Raum in zwei Teil spaltet und eine Vielzahl heterogener Elemente/Forderungen (antiislamische, bäuerliche, rassistische, militärische, pazifistische, protektionistische, neoliberale, radikaldemokratische und zuletzt sogar feministische) miteinander artikuliert.

Infolgedessen ist der populistische Diskurs der ,neuen“ SVP mit einem Dilemma konfrontiert, das alle äquivalenzlogisch dominierten Projekte gleichermaßen betrifft: Einerseits ist die Expansion der popularen Äquivalenz die notwendige Bedingung für die binäre Repräsentation der Gesellschaft. Andererseits setzt ein Diskurs, der die Äquivalenz gegen unendlich laufen lässt, seine Hegemoniefunktion aufs Spiel. Der Diskurs droht unbeherrschbar zu werden und durch interne Antagonismen zu implodieren.

Mithilfe der Ergänzung des deduktiv gewonnen hegemonietheoretischen Begriffsinstrumentariums durch induktiv gewonnen Analysebegriffe konnte gezeigt werden, dass der SVP-Populismus diesem Dilemma im Wesentlichen durch drei diskursive Praktiken begegnet: (1) durch das Präsenthalten eines übergeordneten Antagonismus gegenüber einem sozialistisch-europhilen Anderen, (2) durch die Verdinglichung der Freund-Feind-Unterscheidung qua Naturalisierung und Historisierung der antagonistischen Grenze und (3) durch die konsequente Hierarchisierung von Politikfeldern durch die Konstruktion von Knotenpunkten und leeren Signifikanten, welche die gemeinsam artikulierten Differenzen hierarchi- 
sieren und um einen konstitutiven Mangel organisieren. So werden sämtliche Politikfelder an die drei Kernforderungen ,Wahrung der Unabhängigkeit‘, ,Verwirklichung des Selbstverantwortungsprinzips‘ sowie ,rigide Asyl- und Migrationspolitik' rückgekoppelt. $^{26}$

Diese miteinander verwobenen Praktiken begründen die außerordentliche Stabilität des SVP-Populismus. Sie schöpfen ein integratives und robustes $\mathrm{He}$ artland, einen nationalpopularen Ursprungs- und Sehnsuchtsort, der politisierend und entpolitisierend zugleich wirkt: Einerseits stellt er die Hegemonie einer rationalen Mitte infrage, kritisiert die korporatische Arkanpolitik und entfacht eine Konfliktualität, die durch die konkordanzdemokratischen politischen Tugenden ,Vernunft', ,Kompromissfähigkeit‘ und ,Pragmatismus‘ erstickt wurde. Andererseits propagiert dieser Heartland-Mythos eine vorpolitische Gemeinschaft, wodurch er die Kontingenz von Kultur negiert und die Restauration einer differenzlogisch komponierten, hierarchisch gegliederten Gemeinschaft ohne Antagonismus in Aussicht stellt. Somit repräsentiert er die internen Grenzen, die der SVP-Populismus zieht, als externe Grenzen, die vermeintlich substantielle Entitäten voneinander separieren. Die möglichen Anknüpfungspunkte der popularen Äquivalenz werden reduziert und gegenhegemoniale Artikulationen des ,Volkes“ erschwert. So wird etwa die direkte Demokratie, eine der zentralen Knotenpunkte des SVP-Diskurses, als Medium zur Abwehr per se fremder Einflüsse artikuliert.

Die Imagination einer organischen, quasi-natürlichen Gemeinschaft löscht die Kontingenz der eigenen Identität und begründet eine anti-politische politische Identität ${ }^{27}$, die ihren kontingenten Charakter leugnet und Politik als Störung einer vorpolitischen Harmonie wahrnimmt. Die politisierende Dimension, die dem SVP-Populismus durchaus immanent ist, wird durch eine arche-politische Verleugnung des Politischen unterminiert. Der Schlüssel für die Kontinuität des SVP-Populismus und die konstante Reproduktion der Wir-Sie-Grenze liegt somit in der Repräsentation der internen Grenzen des Diskurses als externe Gren$z e$. Von großer Bedeutung sind daher Topoi wie jene der Masse oder die Metaphorik des Parasitären, welche die Feinde innerhalb der Gemeinschaft mit den Feinden außerhalb der Gemeinschaft assoziieren. Die Metaphorik des Parasitären erweist sich gar als diskursstrukturierend. Denn sie schließt das ,Organische‘, das ,Eigenständige‘ und das ,Nützliche‘ gegen das ,Fremde‘, das ,Abhängige‘ und das ,Schädliche“ zusammen und imaginiert die politische Grenze, die der SVP-Populismus einzieht, als natürliche Grenze. Die parasitären Anti- 
Subjekte (,die Gutmenschen, die sich ihre zur Schau gestellte Gesinnungsethik vom Volk bezahlen lassen', ,die integrationsresistenten Muslime', , die kriminellen Asylanten' und die ,europhilen Kulturschaffenden') blenden die antagonistische Spaltung (,nützlich/schädlich') und die essentialistische Vorstellung einer vorpolitischen Diversität (,organisch/fremd') ineinander. Dadurch lassen sich die beiden Hauptstränge des SVP-Populismus - der neoliberaler Antietatismus und der nationalkonservative Kommunitarismus - im Rahmen eines originären und autochthonen Heartland überhaupt erst verknüpfen.

Im SVP-Diskurs werden die dominanten leeren Signifikanten ,Mittelstand', ,Heimat‘ oder ,Sonderfall Schweiz‘ zu vorgängigen Originalen geschlossen. Für die Elemente der popularen Äquivalenz sind sie nicht nur ein Ort der Sehnsucht, sondern auch ein Ort des Ursprungs. Der hegemoniale Repräsentationsanspruch des SVP-Populismus zehrt weniger von der Entleerung seiner Knotenpunkte, als vielmehr von der geschichtspolitisch begründeten Externalisierung heterogener inkompatibler Elemente. Dabei fungiert das Heartland sozusagen als Gatekeeper: Es entscheidet, welche Elemente/Forderungen als legitim anerkannt werden und welche als ,fremd“ essentialisiert werden und dem antagonistischen Bedrohungskomplex zugeschlagen werden. Das Heartland limitiert die universalisierende Logik des leeren Signifikanten. Und auch die expansive Äquivalenzlogik wirkt weniger auf Seiten des popularen Lagers, als vielmehr auf Seiten des Bedrohungskomplexes: Im Heartland tut ,jeder das Seinige ; alle übernehmen ,auf unterschiedlichen Stufen unseres Gemeinwesens Verantwortung ${ }^{\text {(28 }}$. Dagegen signifizieren die politischen Eliten, die EU, die Manager, die Funktionäre, die Habsburger Monarchie, der französische Absolutismus, die Drogenabhängigen, die Kriminellen, die Muslime, die ,Scheininvaliden' und die Intellektuellen alle dasselbe: ein unschweizerisches Anderes, vor dem es den ,Sonderfall Schweiz‘ zu beschützen gilt.

Indes ist der populistische Balanceakt zwischen der äquivalentiellen Artikulation flottierender Elemente und der damit verbundenen Überdeterminierung des Diskurses auf der einen und der Fixierung dieser Elemente im Rahmen des Heartland auf der anderen Seite eng mit ,Blocher' verbunden. ,Blocher' fungiert in diesem Diskurs gleichzeitig als Gesetzgeber, Versorger und Held des, Vol$\mathrm{kes}^{6}{ }^{29}$ Aufgrund seiner vielfältigen Karriere ist er in der Lage, die potentiell antagonistischen Stränge des SVP-Diskurses zusammenzuhalten und die Einheit der liberalkonservativen Äquivalenz zu repräsentieren. ,Blocher' ist aber nicht nur das überdeterminierte objet a, auf das sich die Hoffnungen und Sehnsüchte

28 Mörgeli 1999.

29 Vgl. zur dreifachen Funktion charismatischer Führer vgl. Doreen 1994. 
heterogener, subalterner Positionen projizieren; auch er fungiert als Gatekeeper der popularen Äquivalenz, indem er selbst die Werte des Heartland verkörpert. Damit lässt sich verstehen, dass die einheitliche politische Strategie seit dem partiellen Rückzug Blochers Risse bekommen hat, ${ }^{30}$ und dass die Hoffnungen auf eine Reintegration der Flügelkämpfe an Blocher geknüpft werden. ${ }^{31}$

30 So wurde ab Dezember 2008, nach der Abspaltung der Bündner SVP um die Bundesrätin Eveline Widmer-Schlumpf nicht nur die konsequent populistische Ausrichtung der Partei herausgefordert. Auch der populistische Flügel selbst droht seither aufzusplittern: da ist auf der einen Seite ein rechtsextremer, anti-islamisch fundierter Diskurs, der das SVP-Projekt mit einer paneuropäischen Rechten assoziiert und somit den Sonderfallgedanken verletzt; und da ist auf der anderen Seite, ein um die schweizerische Umweltschutzorganisation ECOPOP zentrierter Diskurs, der die SVP-Themen ,Migration“ und ,Überbevölkerung', mit Ökologie und Wachstumskritik artikuliert und bei der Volksabstimmung Stopp der Überbevölkerung - zur Sicherung der natürlichen Lebensgrundlagen im Alleingang gegen alle Parteien ein respektables Ergebnis von 25,9 Prozent erzielen konnte (vgl. Longchamp 2014).

31 Vgl. exemplarisch Engeler 2012. 



\section{Popular-demokratischer oder autoritärer Populismus. Das ethische Moment der politischen Ontologie und die Grenzen des Formalismus}

Die Stärke der Populismustheorie Laclaus besteht darin, dass sie das Phänomen ,Populismus‘ nicht anhand inhaltlicher Merkmale definiert, sondern über seine Funktionslogik begreift. Kernstück des Ansatzes ist die Überlegung, dass sich der hegemoniale Übergang von den partikularen Elementen der plebs zur Universalität des populus durch die Entleerung von Signifikanten der plebejischen Äquivalenz vollzieht. Diese entleerten Signifikanten sind in der Lage, vielfältige Forderungen zu bündeln und gegen den Status quo in Stellung zu bringen, lassen dabei jedoch unterschiedliche Identifikationen und Aneignungen zu. Politische Integration gründet daher nicht auf einem Homogenitätspostulat oder einem fundamentalen Organisationsprinzip, sondern vollzieht sich im Rahmen dieser polysemischen Signifikanten. Sie ermöglichen, dass ,sich alle auf etwas Identisches

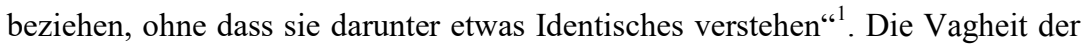
zentralen Identifikationsbegriffe populistischer Diskurse ist demnach die Voraussetzung für die Kreation einer weitreichenden popularen Äquivalenz. Der Populismus ist bei Laclau eben nicht notwendig inkompatibel mit dem Pluralismus. Im Gegenteil: Der Pluralismus wird politisch, indem unterschiedliche politische Projekte versuchen, die durch die leeren Signifikanten bezeichnete, abwesende Fülle der Gemeinschaft zu signifizieren. ${ }^{2}$

Die Gefährdung der Demokratie geht für Laclau daher keineswegs von populistischer Politik, sondern - im Gegenteil - von ihrer Verunmöglichung aus: "The consequence is unavoidable: the construction of a ,people" is the sine qua

1 Bonacker/Brodocz 2001: 182.

2 Vgl. Laclau 2007a: 144. 
non of democratic functioning. Without production of emptiness there is no ,people', no populism, but no democracy either." ${ }^{33}$ An diesem Punkt fließen populistische und demokratische Politik ineinander. ${ }^{4}$ Die leere Identität des Volkes, welche die moderne Demokratie als Quelle der Souveränität instituiert, ist die Ermöglichungsbedingung des Populismus. Populismus ist umgekehrt der Modus, in dem dieser Ort partiell hegemonisiert und mit konkreten Inhalten gefüllt wird. Die Kämpfe um die provisorische Bezeichnung der unbezeichenbaren Identität des ,Volkes' (und nicht etwa die Verwirklichung bestimmter Gerechtigkeitsprinzipien, deliberativer Prozeduren oder institutioneller Arrangements) werden damit zum Brennpunkt der Demokratie. Demokratische Politik setzt die antagonistische Konstruktion eines ,Volkes' voraus. Sie braucht einen Begriff von Universalität. Denn ohne Bezug auf ein Allgemeines mutiert sie zu einer schieren Aggregation sozialstrukturell verfasster Positionsdifferenzen, in der das Ideal einer umkämpften Selbstinstituierung von Gesellschaft verloren geht.

Demokratietheoretisch entscheidend ist für Laclau nicht, dass das ,Volk' anhand leerer Signifikanten aus dem liberaldemokratischen Spektrum (Demokratie, Freiheit, Menschenrechte) oder aus dem linken politischen Spektrum (Gerechtigkeit, Solidarität, Verletzlichkeit) verkörpert wird, ${ }^{5}$ sondern allein die Tatsache, dass das ,Volk“ nicht im Rahmen einer „spezifischen symbolischen Matrix“6 fixiert wird - seine Identität nicht im Rekurs auf einen ultimativen Grund oder eine wesenhafte Substanz arretiert wird. Da weder der Führerkult noch die Affizierung der Wir-Sie-Unterscheidung geschweige denn das dezisionistische Moment des Antagonismus dieses Prinzip verletzten, geht aus Laclaus Sicht die Gefahr für die Demokratie keineswegs von populistischen Projekten als solchen aus.

Vielmehr beginnt die Gefahr für die Demokratie dort, wo sich ein demos wie im SVP-Diskurs - um eine voll-konstituierte Identität zu schließen beginnt, indem er den Antagonismus externalisiert und seine hybride, kontingente Natur negiert. Die Unterscheidung zwischen einem radikaldemokratischen Populismus und einem autoritären Populismus ist daher auf der Achse interner Antagonismus - externer Antagonismus zu verorten. Denn die konsequente Externalisierung des Feindes zieht die Antipolitik des autoritären Heartland-Populismus

3 Laclau 2005a: 169.

4 Entsprechend heißt es bei Laclau (2005a: 169): ,[W]e reach a point at which the notion of democratic identity is practically indistinguishable from what I have called popular identity.“

5 Für den Vorschlag, ,Verletzlichkeit‘ als Knotenpunkt einer linken Gegenhegemonie zu instituieren vgl. Butler 2014.

6 Laclau 2005a: 169. 
nach. Und vice versa, nur wenn der Antagonismus nicht als Manifestation einer vordiskursiven Diversität, sondern als kontingente Entscheidung präsent gehalten wird, durch die sich die jeweiligen Identitäten erst konstituieren, kann populistische Politik radikaldemokratisch sein.

Wenngleich Laclau eine „Ethisierung“" der Unentscheidbarkeit ablehnt und dem subjektiven Begehren nach Schließung und voller Identität eine zentrale Rolle in der Konstruktion eines ,Volkes' einräumt, erschöpft sich seine Populismustheorie weder in einem ethisch blinden „Dezisionismus“ noch in einem erkenntnistheoretisch haltlosen „Relativismus“, wie Karin Priester meint. ${ }^{8}$ Sie führt auch nicht zu einer „Hypostasierung“ beliebiger gesellschaftlicher Konflikte zum „Sinn des Politischen und Kennzeichen wirklicher Pluralität“, wie Michael Hirsch kritisiert. ${ }^{9}$ Solchen Vorwürfen entgeht, dass die politische Ontologie Laclaus trotz ihrer Vorbehalte gegenüber einer präskriptiven Ethik, die den Spalt zwischen Unentscheidbarkeit und Entscheidung füllen würde, keineswegs ethisch folgenlos ist. ${ }^{10}$ So ist die politische Ontologie, die Verankerung einer irreduziblen Kontingenz von Gesellschaft als paradigmatischem Bezugspunkt der Gesellschaftsanalyse, als politische Intervention zu lesen. Sie fordert dazu auf, die totalitären Phantasmen von Harmonie und Fülle zu verabschieden und leitet dazu an, verdinglichte Identitäten als essentialisierende Schließungen des Popularen zu dekonstruieren und Hegemonisierungen heterogener Forderungen im Rahmen hybrider Identitäten ins Auge zu fassen.

Nichtsdestotrotz entpuppt sich der Formalismus Laclaus vor dem Hintergrund des SVP-Populismus als problematisch. Denn Laclaus demokratietheoretische Würdigung des Populismus vermeidet ausgerechnet die Frage nach der ,Internalisierung-Externalisierung des Feindes' und blendet das damit verbundene Spannungsverhältnis zwischen einer Ethik der Politisierung und der Visibilisierung von Kontingenz auf der einen Seite und hegemonialen Entpolitisierungseffekten andererseits aus. ${ }^{11}$ Das Problem wurzelt darin, dass Laclau die Logik des leeren Signifikanten und jene der Reifikation nicht nur theoretisch, sondern auch empirisch getrennt halten will:

7 Laclau 1999: 134f.; Stäheli 2001: 222.

8 Priester 2012b: 116.

9 Hirsch 2007: 200.

10 Vgl. Devenney 2004: 138; Stanley Aronowitz (1989: 52) spricht in diesem Zusammenhang treffend von einem ,ethical a priori“ des Postfundamentalismus.

11 Ich knüpfe hier an Slavoj Žižeks (2006a u. 2006b) kritische Replik der Populismustheorie Laclaus an, ohne für seine Unterscheidung von Kommunismus und Populismus zu plädieren. 
„In reification we have [...] an inversion in the relation between true and distorted expression, while here the opposition true/distorted does not make any sense; given that the equivalential link is established between radically heterogeneous demands, their ,homogenization" through an empty signifier is a pure passage à l'acte, the construction of something essentially new and not the revelation of any underlying ,true identity." ${ }^{\text {"12 }}$

In der Tat muss der Verdinglichungsbegriff orthodox marxistischer Prägung aus einer postfundamentalistischen Perspektive abgelehnt werden. Wenn Unentscheidbarkeit radikal gedacht wird, es keine ,privilegierte epistemologische Stelle“"13 gibt, von der aus richtige Repräsentationen und falsche Repräsentation sozialer Wirklichkeit unterschieden werden können, dann machen die Gegensatzpaare verdinglicht/nicht-verdinglicht respektive wahr/verzerrt keinen Sinn. Der fundamentale Unterschied zwischen Reifikation und leerem Signifikant besteht folglich darin, dass es bei dem letzteren nicht um wahres oder falsches Bewusstsein, sondern um ,the contingent construction of a consciousness tout court" ${ }^{\text {" }}{ }^{\text {}}$ geht. Leere Signifikanten offenbaren gerade nicht „eine grundlegende ,wahre“ Identität“, sondern konstruieren etwas „,wesenhaft Neues“"15. Die synekdochische Verkörperung der abwesenden Universalität des ,Volkes‘ durch ein partikulares Element der popularen Äquivalenz resultiert aus einer „creatio ex nihilo, die sich gerade nicht auf irgendeinen vorgängigen oder ultimativen Wortsinn [literality] reduzieren lässt" ${ }^{\text {16 }}$.

Damit wird der Prozess der Hegemonisierung von allem essentialistischen Ballast befreit, die Konstruktion eines, Volkes' durch einen leeren Signifikanten als kontingenter und anfechtbarer Prozess gefasst. Doch stellt sich vor dem Hintergrund der Analyse des SVP-Populismus die Frage, ob dieser theoretisch stringenten Konzeption des leeren Signifikanten nicht eine Quintessenz der rechtspopulistischen Identitätspolitik entgeht. Denn hier gründet die populistische Hegemonie auf der Imagination eines vorgängigen Wortsinns - einer invariablen, dinghaften Identität des ,Schweizervolkes‘. Die theoretisch als offen gefasste Signifikation des popularen Kollektivs, wird im SVP-Populismus geschichtspolitisch geschlossen. Dadurch bleibt die Äquivalenzlogik dominant und die binäre Spaltung der Gesellschaft wird aufrechterhalten. Indes werden den Bedeutungsspektren der leeren Signifikanten ,Schweizervolk‘, ,Sonderfall‘ und ,Heimat“

12 Laclau 2006:653.

13 Laclau/Mouffe 2006 [1985]: 28.

14 Vgl. Laclau 2006: 651.

15 Ebd.: 653.

16 Ebd.: 653 . 
von Beginn an gewisse Grenzen aufgelegt. Bestimmte Elemente/Forderungen werden unter Verweis auf eine organische Diversität verworfen und einem antagonistischen Bedrohungskomplex zugeschlagen. ${ }^{17}$

Diese Prozesse lassen sich hegemonietheoretisch als antagonistische Schließungen analysieren, wobei die leeren Signifikanten, die das Eingeschlossene und das Ausgeschlossene bezeichnen, diese Entitäten erst hervorbringen. Das bedeutet aber gerade nicht, dass die leeren Signifikanten die Logik der Verdinglichung außer Kraft setzten, wie Laclau gegen Žižek argumentiert. ${ }^{18}$ Die Artikulation leerer Signifikanten kann vielmehr Verdinglichungen und Essentialisierungen implizieren.

An anderer Stelle ist sich Laclau dessen durchaus bewusst, wenn er etwa den Begriff des „Ideologischen“ einführt, um die Naturalisierung hegemonialer Projekte beschreiben zu können. ${ }^{19}$ Der Analogisierung von Populismus und radikaler Demokratie in On Populist Reason liegt aber eine mangelnde Sensiblität für die totalisierenden Effekte populistischer Schließungen zugrunde. Laclau denkt das Wechselspiel von Essentialisierung respektive Schließung versus Entleerung respektive Öffnung nicht konsequent zu Ende. Stattdessen verabsolutiert er den Moment des popularen Bruchs mit dem Status quo, die expansive Logik der popularen Äquivalenz und die Offenheit und Resignifizierbarkeit der leeren Signifikanten des Popularen, blendet das stabilisierende Moment der Schließung durch Naturalisierung und seine antipolitischen Effekte jedoch aus. ${ }^{20}$

An diesem Punkt findet die streng formale Populismustheorie Laclaus ihre Grenze: Die Analogie von populistischer Politik und demokratischer Politik kann nur aufrechterhalten werden, wenn bestimmte Verkörperungen des ,Volkes` zugelassen, andere dagegen inkrementiert werden. Dazu müsste man nicht so weit gehen wie Chantal Mouffe, die im Rahmen ihres agonistischen Pluralismus die Unentscheidbarkeit des Politischen mit einer partikularen Ethik der wechselseitigen Anerkennung Andersdenkender füllt, um ultimative Schließun-

17 Die Forderungen von streikenden Arbeitern, gesellschaftlich marginalisierten Migranten und prekär beschäftigten Akademikern sind innerhalb dieses Mythos genauso illegitim wie biorassistische und technokratische Forderungen.

18 Vgl. Laclau 2006: 651ff.

19 Vgl. Laclau 2007b: 38f.; auch Kapitel 4.5 des Theorieteils dieser Arbeit.

20 Darauf weist auch Francisco Panizza (2005b: 28) hin: „The unified people at one with its leader, as represented in the populist imaginary, defines the end of history as much as liberalism's illusion of pluralism without antagonism, the social order of Hobbes' Leviathan and Marx's classless society.“ 
gen des Politischen zu verhindern. ${ }^{21}$ Es gilt aber, den strengen Formalismus Laclaus partiell zu überwinden und nicht nur die politische Ontologie antagonistischer Sinnfixierungen aufzudecken, sondern auch die Topoi herauszuarbeiten, die diese Schließung stabilisieren. Denn nur auf diese Weise kann graduell zwischen demokratischeren Populismen und autoritäreren Populismen unterschieden werden.

Das ethisch-politische Anliegen Laclaus ist indes grundlegender: Mithilfe seiner Hegemonie- und Populismustheorie lässt sich in Erinnerung halten, dass auch die, vermeintliche Ur-Schweiz der selbstverantwortlichen Bürger und der organischen Hierarchien', die der Heartland-Mythos der SVP vorstellt, um das semantische Feld des ,Schweizervolkes` zu begrenzen, aus kontingenten SchlieBungen hervorgeht und dass trotz der Robustheit dieser Schließungen andere Schließungen und andere Konstruktionen des ,Schweizervolkes' möglich sind. Eine Hegemonieanalyse eröffnet daher immer auch einen politischen Möglichkeits- und Handlungsraum, um den fatalen Antagonismus zwischen technokratischer Post-Politik und neo-rassistischer Arche-Politik mit einem anderen demokratischeren Populismus zu konfrontieren.

21 Mouffe 2008: 85ff.; erläuternd Hildebrand/Séville 2015: insb. 38. 


\section{Bibliographie}

\section{LITERATUR}

Agamben, Giorgio (2004): What is a people? online abgerufen: http://www.16 beavergroup.org/articles/2004/05/01/rene-agamben-what-is-a-people, 9.6.2015.

Akerstrom Andersen, Niels (2003): Discursive Analytical Strategies. Understanding Foucault, Koselleck, Laclau, Luhmann, Bristol.

Albertazzi, Daniele (2008): Switzerland: Yet Another Populist Paradise, in: Ders./McDonnell, Duncan (Hg.) (2008a): Twenty-First-Century Populism: The Spectre of Western European Democracy, Basingstoke, S. 100-118.

Albertazzi, Daniele/McDonnell, Duncan (Hg.) (2008a): Twenty-First-Century Populism: The Spectre of Western European Democracy, Basingstoke.

Albertazzi, Daniele/McDonnell, Duncan (2008b): Introduction: the Scepter and the Spectre, in: Dies. (Hg.): Twenty-First-Century Populism: The Spectre of Western European Democracy, Basingstoke, S. 1-14.

Almond, Gabriel/Verba, Sidney (1963): The Civic Culture, Boston.

Altermatt, Urs (1994): Ausbruchsversuche aus dem Korsett der Konkordanz. Essay zur Schweizer Politik am Ende des 20. Jahrhunderts, in: Ders. u.a. (Hg.): Rechte und linke Fundamentalopposition. Studien zur Schweizer Politik 1965-1990, Basel, S. 3-29.

Altermatt, Urs u.a. (Hg.) (1994): Rechte und linke Fundamentalopposition. Studien zur Schweizer Politik 1965-1990, Basel.

Altermatt, Urs/Furrer, Markus (1994): Die Autopartei: Protest für Freiheit, Wohlstand und das Auto, in: Altermatt, Urs et. al. (Hg.): Rechte und linke Fundamentalopposition. Studien zur Schweizer Politik 1965-1990, Basel, S. $135-151$.

Altermatt, Urs/Bosshart-Pfluger, Catherine/Tanner, Albert (1998): Einleitung. Nation und Nationalisierung in der Schweiz, in: Dies. (Hg.): Die Konstrukti- 
on einer Nation. Nation und Nationalisierung in der Schweiz. 18.-20. Jahrhundert, Zürich, S. 11-18.

Altermatt, Urs (2013): CVP. Von der katholischen Milieupartei zur Partei der bürgerlichen Mitte, in: Mazzoleni, Oscar/Meuwly, Olivier (Hg.): Die Parteien in Bewegung. Nachbarschaft und Konflikte, Zürich, S. 21-48.

Althusser, Louis (1977): Ideologie und ideologische Staatsapparate Aufsätze zur marxistischen Theorie, Hamburg.

Altwegg, Jürg (2004): Une Suisse en crise. De Ziegler à Blocher, Lausanne.

Anderson, Benedict (1996): Die Erfindung der Nation, Frankfurt.

Angermüller, Johannes (2007a): Nach dem Strukturalismus, Bielefeld.

Angermüller, Johannes (2007b): Was fordert die Hegemonietheorie?, in: Nonhoff, Martin (Hg.): Diskurs, radikale Demokratie, Hegemonie, Bielefeld, S. $170-184$.

Antonio, Roberto (2000): After Postmodernism: Reactionary Tribalism, in: American Journal of Sociology 106/2, S. 40-87.

Arditi, Benjamin (2003): Populism, or, Politics at the Edges of Democracy, in: Contemporary Politics 9/1, S. 17-31.

Armingeon, Klaus (1995): Der Schweizer Rechtsextremismus im internationalen Vergleich, in: Schweizerische Zeitschrift für Politikwissenschaft 1/1, S. 4164.

Armingeon, Klaus (1996): Konkordanz, Sozialpartnerschaft und wohlfahrtstaatliche Politik in der Schweiz im internationalen Vergleich, in: Linder, Wolf/Lanfranchi, Prisca/Weibel, Ewald R. (Hg.): Schweizer Eigenart - eigenartige Schweiz. Der Kleinstaat im Kräftefeld der europäischen Integration, Bern u.a., S. 69-84.

Aronowitz, Stanley (1989): Postmodernism and Politics, in: Ross, Andrew (Hg.): Universal Abandon? The Politics of Postmodernism, Edinburgh, S. 46-62.

Asbach, Olaf (2002): Von der Geschichte politischer Ideen zur „History of Political Discourse“? - Skinner, Pocock und die „Cambridge-School“, in: Zeitschrift für Politikwissenschaft 12/2, S. 637-667.

Attia, Iman (2009): Die „,westliche Kultur“ und ihr Anderes. Zur Rekonstruktion von Orientalismus und antimuslimischem Rassismus, Bielefeld.

Auer, Dirk (2008): Die Konflikttheorie der Hegemonietheorie, in: Bonacker, Thorsten (Hg.): Sozialwissenschaftliche Konflikttheorien. Eine Einführung, Wiesbaden, S. 249-266.

Austin, John L. (1968): Performative und konstatierende Aussagen, in: Bubner, Rüdiger (Hg.): Sprache und Analysis. Texte zur englischen Philosophie der Gegenwart, Göttingen, S. 140-153.

Austin, John L. (1972): Zur Theorie der Sprechakte, Stuttgart. 
Bachmann-Medick, Doris (2006): Cultural Turns. Neuorientierungen in den Kulturwissenschaften, Reinbek bei Hamburg.

Balibar, Étienne (1991): Is there a Neo-Racism?, in: Dies./Wallerstein, Immanuel (Hg.): Race, Nation, Class - Ambiguous Identities, London, S. 17-28.

Balibar, Étienne (2008): Die Rückkehr des Konzeptes „Rasse“. Zur Umwandlung der Wahnvorstellungen Rasse und Rassismus durch die Neuschaffung eines Intimfeindes - häufig unter dem Deckmantel des Universalismus, in: Springerin 3/2008, S. 18-24.

Banz, Claudia (1999): Die SVP feiert sich und ihren Wortführer, in: TagesAnzeiger, 25.10.1999.

Baschek, Nicklas (2010): Anfeindungen. Carl Schmitts „Begriff des Politischen“ aus der Perspektive der Systemtheorie Niklas Luhmanns, Darmstadt.

Baumann, Martin (2009): Anxieties, Banning Minarets and Populist Politics in Switzerland - a Preliminary Analysis, online abgerufen: http://www.pluralism.org/affiliates/baumann/index.php, 29.12.2014.

Baumann, Martin/Tungert-Zanetti, Andreas (2011): Wenn Religionen Häuser bauen. Sakralbauten, Kontroversen und öffentlicher Raum in der Schweizer Demokratie, in: Baumann, Martin/Neubert, Frank (Hg.): Religionspolitik Öffentlichkeit - Wissenschaft: Studien zur Neuformierung von Religion in der Gegenwart, Zürich, S. 151-188.

Bathke, Peter/Hoffstadt, Anke (2013): Vorwort, in: Dies. (Hg.): Die neuen Rechten in Europa. Zwischen Neoliberalismus und Rassismus, Köln, S. 7-18.

Bech Dyrberg, Torben (1998): Diskursanalyse als postmoderne politische Theorie, in: Marchart, Oliver (Hg.): Das Undarstellbare der Politik. Zur Hegemonietheorie Ernesto Laclaus, Wien, S. 23-51.

Becher, Phillip (2013): Rechtspopulismus, Köln.

Behloul, Samuel M. (2009): Minarett-Initiative. Im Spannungsfeld zwischen Abwehr-Reflex und impliziter Anerkennung neuer gesellschaftlicher Fakten, in: Tanner, Matthias u.a. (Hg.): Streit um das Minarett. Zusammenleben in der religiös pluralistischen Gesellschaft, Zürich, S. 103-122.

Benoist, Alain de (1985): Kulturrevolution von rechts. Gramsci und die Nouvelle Droite, Krefeld.

Berger, Peter L./Luckmann, Thomas (2010): Die gesellschaftliche Konstruktion der Wirklichkeit. Eine Theorie der Wissenssoziologie. Mit einer Einleitung zur deutschen Ausgabe von Helmuth Plessner, Frankfurt a. M.

Berthoud, Jean-Michel (2001): Reaktion auf Bergier-Bericht: Positiv bis kritisch, online abgerufen: http://www.swissinfo.ch/ger/reaktion-auf-bergier-berichtpositiv-bis-kritisch/2220598, 21.11.2014. 
Betz, Hans-Georg (1994): Radical Right Wing Populism in Western Europe, Basingstoke.

Betz, Hans-Georg (2001): Exclusionary Populism in Austria, Italy, and Switzerland, in: International Journal 56/3, S. 393-420.

Betz, Hans-Georg (2003): Xenophobia, Identity Politics and Exclusionary Populism in Western Europe, in: Panitch, Leo/Leys, Colin (Hg.): Socialist Register 2003. Fighting Identities: Race, Religion and Ethno-Nationalism, London, S. 193-210.

Betz, Hans-Georg (2004): La droite populiste en Europe: extrème et démocrate?, Paris.

Betz, Hans Georg (2005): Mobilising Resentment in the Alps: the Swiss SVP, the Italian Lega Nord, and the Austrian FPÖ, in: Caramani, Daniele/Mény, Yves (Hg.): Challenges to consensual politics. Democracy, Identity, and Populist Protest in the Alpine Region, Bruxelles, S. 147-166.

Betz, Hans-Georg (2012): Zwischen Fundamentalopposition und Konkordanz: Die Schweizer Volkspartei seit 1991, in: Sir Peter Ustinov Institut (Hg.): Populismus. Herausforderung oder Gefahr für die Demokratie?, Wien, S. 91110.

Betz, Hans-Georg/Johnson, Carol (2004): Against the Current - Stemming the Tide: The Nostalgic Ideology of the Contemporary Radical Populist Right, in: Journal of Political Ideologies 9/3, S. 311-327.

Beyme, Klaus von (2012): Der Rechtspopulismus in der Postdemokratie. Die Erosion der Parteien, der Aufstieg der ExpertInnen und der Medien, die Organisation des „Wutbürgers“, in: Sir Peter Ustinov Institut (Hg.): Populismus. Herausforderung oder Gefahr für die Demokratie?, Wien, S. 33-56.

BDP (o.J.): BDP - Engagement für eine lösungsorientierte Sachpolitik, online abgerufen: http://www.bdp.info/data/uploads/schweiz/deutsch-unterlagen/ bdp-informationen/dafuer-steht-die-bdp_150117.pdf, 12.2.2015.

Bhabha, Homi K. (1990): Introduction: Narrating the Nation, in: Bhabha, Homi K. (Hg.): Nation and Narration, London, S. 1-7.

Bhabha, Homi K. (2000): Die Verortung der Kultur, Tübingen.

Biasio, Fabian/Sprecher, Margrit (2007): Die Mitte des Volkes, Zürich.

Bichsel, Peter (2010): „Blocher will die ganze Schweiz“. Interview mit Marie Josée-Kuhn, in: Work. Die Zeitung der Gewerkschaft, 19.11.2010, online abgerufen: http://www.workzeitung.ch/tiki-read_article.php?articleId=1322, 9.10.2014.

Bieling, Hans-Jürgen (2006): Die politische Theorie des Neo-Marxismus: Antonio Gramsci, in: Brodocz, André/Schaal, Gary S. (Hg.): Politische Theorien der Gegenwart. Eine Einführung. Opladen, S. 440-470. 
Bobbio, Norberto (1988): Gramsci and the Concept of Civil Society, in: Keane, John (Hg.): Civil Society and the State: New European Perspectives, London, S. 73-99.

Bonacker, Thorsten (2008): Gesellschaft: Warum die Einheit der Gesellschaft aufgeschoben wird, in: Moebius, Stephan/Reckwitz, Andreas (Hg.): Poststrukturalistische Sozialwissenschaften, Frankfurt a. M., S. 27-42.

Bonacker, Thorsten/Brodocz, André (2001): Im Namen der Menschenrechte. Zur symbolischen Integration der Internationalen Gemeinschaft durch Normen, in: Zeitschrift für Internationale Beziehungen 8, S. 178-208.

Bornschier, Simon (2009): Cleavage Politics in Old and New Democracies: A Review of the Literature and Avenues for Future Research, in: European University Institute, Max Weber Programme, online abgerufen: http://cadmus.eui.eu/handle/1814/11151, 12.5.2014.

Bornschier, Simon (2010): Cleavage Politics and the Populist Right: The New Cultural Conflict in Western Europe, Philadelphia.

Bornschier, Simon/Helbing, Marc (2005): Stabilität und Wandel von Parteiensystemen und die Konfliktlinie zwischen Öffnung und Abgrenzung. Der theoretische Ansatz, in: Kriesi, Hanspeter/Lachat, Romain/Selb, Peter/Bornschier, Simon/Helbing, Marc (Hg.) (2005): Der Aufstieg der SVP. Acht Kantone im Vergleich, Zürich, S. 11-40.

Bourdieu, Pierre (2001): Das politische Feld. Zur Kritik der politischen Vernunft, Konstanz.

Brodocz, André (2000): Zwischen Dekonstruktion und Pragmatismus: Die philosophische Position von Ernesto Laclau, in: Information Philosophie 2/2000, S. 36-39.

Brubaker, Rogers (2007): Ethnizität ohne Gruppen, in: Ders. (Hg.): Ethnizität ohne Gruppen, Hamburg, S. 17-45.

Brubaker, Rogers/Cooper, Frederick (2007): Jenseits der „Identität”, in: Brubaker, Rogers (Hg.): Ethnizität ohne Gruppen, Hamburg, S. 46-95.

Brug, Wouter van der/Meindert, Fennema/Tillie, Jean (2000): Anti-Immigrant Parties in Europe: Ideological or Protest Vote, in: European Journal for Political Research 37/1, S. 77-102.

Brunner, Matthias/Sciarini, Pascal (2002): L'opposition ouverture-traditions, in: Hug, Simon/Sciarini, Pascal (Hg.): Changements de valeurs et nouveaux clivages politiques en Suisse, Paris, S. 29-94.

Bublitz, Hannelore/Bührmann, Andrea D./Hanke, Christine/Seier, Andrea (1999): Diskursanalyse - (k)eine Methode? Eine Einleitung, in: Dies. (Hg.): Das Wuchern der Diskurse. Perspektiven der Diskursanalyse Foucaults, Frankfurt a.M., S. 10-21. 
Buchstein, Hubertus/Jörke, Dirk (2003): Das Unbehagen der Demokratietheorie, in: Leviathan 31/4, S. 470-495.

Buomberger, Thomas (2003): Blochers Vorläufer, in: Basler Magazin 32/2003, 9.8.2003.

Buomberger, Thomas (2004): Kampf gegen unerwünschte Fremde. Von James Schwarzenbach bis Christoph Blocher, Zürich.

Burckhardt, Jacob (2008): Das schweizerische Schützenfest, in: Ders.: Werke. Kritische Gesamtausgabe. Band 9. Herausgegeben von der Jacob Burckhardt-Stiftung Basel, München/Basel, S. 487-493.

Bürgi, Jürg von (1997): Brandstifter als Biedermann, in: Der Spiegel 29/1997, 14.7.1997, online abgerufen: http://www.spiegel.de/spiegel/print/d-8743171. html, 12.12.2012.

Bürgi, Jürg von (1999): Schlaue Verrenkungen, in: Der Spiegel 44/1999, 1.11.1999, online abgerufen: http://www.spiegel.de/spiegel/print/d-150140 02.html, 12.12.2012.

Butler, Judith (1993): Für ein sorgfältiges Lesen, in: Benhabib, Seyla (Hg.): Der Streit um Differenz. Feminismus und Postmoderne in der Gegenwart, Frankfurt a. M., S. 122-132.

Butler, Judith (1997): Körper von Gewicht. Die diskursiven Grenzen des Geschlechts, Frankfurt a. M.

Butler; Judith (2001): Psyche der Macht. Das Subjekt der Unterwerfung, Frankfurt a. M.

Butler, Judith (2002): What is Critique? An Essay on Foucault's Virtue, in: Ingram, David (Hg.): The Political: Readings in Continental Philosophy, London, S. 212-228.

Butler, Judith (2014): Körperliche Verletzbarkeit, Bündnisse und Street Politics, in: Westend 11/1, S. 3-24.

Bütler, Hugo (2002): Nationalstaat, Integration und Globalisierung. Schweizer Politik angesichts von Denationalisierung und Demokratiedefiziten, in: Bosshart, Pfluger, Catherine/Jung, Joseph/Metzger, Franziska (Hg.): Nation und Nationalismus in Europa. Kulturelle Konstruktion von Identitäten. Festschrift für Urs Altermatt, Frauenfeld/Stuttgart/Wien, S. 827-842.

Canovan, Margret (1981): Populism, New York.

Canovan, Margret (1999): Trust the People! Populism and the Two Faces of Democracy, in: Political Studies 47/1, S. 2-16.

Canovan, Margaret (2002): Taking Politics to the People. Populism and the Identity of Democracy, in: Mény, Yves/Surel, Yves (Hg.): Democracies and the Populist Challenge, Houndmills/New York, S. 25-44. 
Canovan, Margaret (2004): Populism for Political Theorists?, in: Journal of Political Ideologies 9/3, S. 241-252.

Caramani, Daniele/Mény, Yves (2005): Introduction: The Alpine Challenge to Identity, Consensus, and European Integration, in: Dies. (Hg.): Challenges to Consensual Politics. Democracy, Identity, and Populist Protest in the Alpine Region, Bruxelles, S. 21-52.

Casula, Philipp (2012): Hegemonie und Populismus in Putins Russland, Bielefeld.

Claussen, Detlev (1993): Die missglückte Säkularisierung. Über Xenophobie, Antisemitismus und Nationalismus als Bestandteile einer modernen Alltagsreligion, in: Widerspruch 26/1993, S. 5-14.

Collins, Randall (2000): Über die mikrosozialen Grundlagen der Makrosoziologie, in: Müller, Hans-Peter/Sigmund, Steffen (Hg.): Zeitgenössische amerikanische Soziologie, Opladen, S. 99-134.

Coser, Lewis A. (1972): Theorie sozialer Konflikte, Neuwied/Berlin.

Criblez, Lucien (2008): Jugendpolitik, in: Historisches Lexikon der Schweiz (HLS), online abgerufen: http://www.hls-dhs-dss.ch/textes/d/D16587.php, 20.11.12.

Critchley, Simon (2004): Is there a Normative Deficit in the Theory of Hegemony?, in: Ders./Marchart, Oliver (Hg.): Laclau. A Critical Reader, London, S. $113-122$.

Critchley, Simon (2008): Unendlich fordernd. Ethik der Verpflichtung, Politik des Widerstands, Zürich/Berlin.

Critchley, Simon /Marchart, Oliver (Hg.) (2004): Laclau. A Critical Reader. London.

Dahrendorf, Ralf (1972): Konflikt und Freiheit. Auf dem Weg zur Dienstklassengesellschaft, München.

Dahrendorf, Ralf (2003): Acht Anmerkungen zum Populismus, in: Transit. Europäische Revue 25, online angerufen: http:/www.eurozine.com/articles/ 2007-09-18-dahrendorf-de.html, 14.09.2014.

Daum, Matthias (2014): Schafft neue Bilder! Die Schweiz nach dem 9. Februar, in: Zeit Online, online abgerufen: http://www.zeit.de/2014/09/schweizmasseneinwanderungsinitiative-neue-bilder, 10.11.2014.

Decker, Frank (2000): Parteien unter Druck. Der neue Rechtspopulismus in den westlichen Demokratien, Opladen.

Decker, Frank (2004): Der neue Rechtspopulismus, Opladen.

Decker, Frank (Hg.) (2006a): Populismus. Gefahr für die Demokratie oder nützliches Korrektiv?, Wiesbaden. 
Decker, Frank (2006b): Die populistische Herausforderung. Theoretische und ländervergleichende Perspektiven, in: Ders. (Hg.): Populismus. Gefahr für die Demokratie oder nützliches Korrektiv?, Wiesbaden, S. 9-32.

Decker, Frank (2006c): Neuere Entwicklungen in der Rechtspopulismusforschung, online abgerufen: http://www.dvpw.de/fileadmin/docs/2006xDecker. pdf, 12.7.2010.

Decker, Frank (2012): Populismus und der Gestaltwandel des Parteienwettbewerbs, in: APUZ. Aus Politik und Zeitgeschichte 62/5-6, S. 9-15.

Decker, Frank (2013): Wenn die Populisten kommen. Beiträge zum Zustand der Demokratie und des Parteiensystems, Wiesbaden.

Decker, Frank/Lewandowsky, Marcel (2009): Populismus - Erscheinungsformen, Entstehungshintergründe und Folgen eines politischen Phänomens, online abgerufen: http://www.bpb.de/themen/85B6F3,0,Populismus.html, 1.3. 2011.

Degen, Bernhard (1991): Von „Ausbeutern“ und „Scharfmachern“ zu „Sozialpartnern". Beziehungen zwischen Gewerkschaften und Unternehmern im Wandel, in: Schweizerisches Sozialarchiv (Hg.): Bilder und Leitbilder im sozialen Wandel, Zürich, S. 231-290.

Degen, Bernhard (1993): Sozialdemokratie: Gegenmacht? Opposition? Bundesratspartei? Die Geschichte der Regierungsbeteiligung der schweizerischen Sozialdemokraten, Zürich.

Demirovic, Alex (2007): Politische Gesellschaft - zivile Gesellschaft. Zur Theorie des integralen Staates bei Antonio Gramsci, in: Buckel, Sonja/FischerLescano, Andreas (Hg.): Hegemonie gepanzert mit Zwang. Zivilgesellschaft und Politik im Staatsverständnis Antonio Gramscis, Baden-Baden, S. 21-41.

Derrida, Jacques (1974): Of Grammatology. Baltimore.

Derrida, Jacques (1990a): Die différance, in: Engelmann, Peter (Hg.): Postmoderne und Dekonstruktion. Texte französischer Philosophen der Gegenwart, Stuttgart, S. 76-113.

Derrida, Jacques (1990b): Die Struktur, das Zeichen und das Spiel im Diskurs der Wissenschaften vom Menschen, in: Engelmann, Peter (Hg.): Postmoderne und Dekonstruktion. Texte französischer Philosophen der Gegenwart, Stuttgart, S. 114-139.

Derrida, Jacques (1999): Bemerkungen zu Dekonstruktion und Pragmatismus, in: Mouffe, Chantal (Hg.): Dekonstruktion und Pragmatismus: Demokratie, Wahrheit und Vernunft, Wien, S. 171-195.

Derrida, Jacques (2000): Politik der Freundschaft, Frankfurt a. M.

Deutsch, Karl W. (1976): Die Schweiz als ein paradigmatischer Fall politischer Integration, Bern. 
Devenney, Mark (2004): Ethics and Politics in Discourse Theory, in: Critchley, Simon/Marchart, Oliver (Hg.): Laclau. A Critical Reader. London/New York, S. 123-139.

Diehl, Paula (2011): Populismus, Antipolitik, Politainment. Neue Tendenzen der Kommunikation, in: Berliner Debatte Initial 22/1, S. 27-39.

Diehl, Paula (2012): Populismus und Massenmedien, in: APUZ. Aus Politik und Zeitgeschichte 62/5-6, S. 16-22.

Diestelhorst, Lars (2007): Umkämpfte Differenz. Hegemonietheoretische Perspektiven der Geschlechterpolitik mit Butler und Laclau, Berlin.

Dooren, Ron van (1994): Messenger form the Promised Land. An Interactive Theory of Political Charisma, Den Haag.

Dorna, Alexandre (2003): Wer ist Populist?, online abgerufen: www.eurozine.com/pdf/2003-11-25-dorna-de.pdf, 14.12.2011.

Downs, Anthony (1968): Ökonomische Theorie der Politik, Tübingen.

Drews, Isabel (2005): „Schweizer erwache!“ Der Rechtspopulist James Schwarzenbach (1967-1978), Frauenfeld/Stuttgart/Wien.

Dubiel, Helmut (1986): Das Gespenst des Populismus, in: Ders. (Hg.): Populismus und Aufklärung, Frankfurt a. M., S. 33-50.

Eagleton, Terry (1993): Ideologie. Eine Einführung, Stuttgart/Weimar.

Eberle, Thomas S. (2007): Der Sonderfall Schweiz aus soziologischer Perspektive, in: Ders./Imhof, Kurt (Hg.) (2007): Sonderfall Schweiz, Zürich, S. 7-24.

Eberle, Thomas S./Imhof, Kurt (Hg.) (2007): Sonderfall Schweiz, Zürich.

Eidgenössische Kommission gegen Rassismus (2009): Stellungnahme der EKR zum Aushang von Plakaten der Initiative „Gegen den Bau von Minaretten“ im öffentlichen Raum, online abgerufen: http://www.ekr.admin.ch/pdf/0910 06_StellungnahmeEKR_PlakateMinarettinitiativea4cf.pdf, 5.12.2014.

Eisenstadt, Shmuel N. (2006): Multiple Modernities in the Framework of a Comparative Evolutionary Perspective, in: Wimmer, Andreas/Kössler, Reinhart (Hg.): Understanding change, models, methodologies and metaphors, Houndmills, Basingstoke, S. 199-218.

Eisenstadt, Shmuel N. (2009): Cultural Programmes, the Construction of Collective Identities and the Continual Reconstruction of Primordiality, in: Preyer, Gerhard (Hg.): Neuer Mensch und kollektive Identität in der Kommunikationsgesellschaft, Wiesbaden, S. 135-184.

Elliker, Florian (2011): Demokratie, Rechtsstaat und Integration. Zur diskursiven Strukturierung gesellschaftlicher Zugehörigkeit am Beispiel einer Schweizer Volksinititative, Bamberg.

Ernst, Synes (2012): Der schwarze Montag, in: Handelszeitung 19, 10.5.2012. 
Ernst, Andreas/Wigger, Erich (1993): Innovation und Repression: Die Restabilisierung der bürgerlichen Schweiz nach dem Ersten Weltkrieg, in: Imhof, Kurt/Kleger, Heinz/Romano, Gaetano (Hg.): Zwischen Konflikt und Konkordanz. Analysen von Medienereignissen in der Schweiz der Vor- und Zwischenkriegszeit. Krise und sozialer Wandel. Band 1, Zürich, S. 109-171.

Errejón, Iñigo/Mouffe, Chantal (2015): Construir pueblo. Hegemonía y radicalización de la democracía, Barcelona.

Fairclough, Norman (2007): Introduction, in: Ders./Cortese, Giuseppina/Ardizzone, Patrizia (Hg.): Discourse and Contemporary Change, Bern u.a., S. 9-24.

Fairclough, Norman/Wodak, Ruth (1997): Critical Discourse Analysis, in: Van Dijk, Teun A. (Hg.): Discourse Studies. A Multidisciplinary Introduction, Vol. 2. Discourse as Social Interaction, London, S. 258-284.

Fanon, Frantz (1981): Die Verdammten dieser Erde. Vorwort von Jean-Paul Sartre, Frankfurt a. M.

Foucault, Michel (1987): Das Subjekt und die Macht, in: Dreyfus, Hubert L./Rabinow, Paul (Hg.): Michel Foucault. Jenseits von Strukturalismus und Hermeneutik, Frankfurt a. M., S. 241-261.

Foucault, Michel (1988): Die Archäologie des Wissens, Frankfurt a. M.

Foucault, Michel (1991): Die Ordnung des Diskurses, Frankfurt a. M.

Flügel, Oliver/Heil, Reinhard/Hetzel, Andreas (Hg.) (2004): Die Rückkehr des Politischen. Demokratietheorien heute, Darmstadt, S. 7-16.

Fraenkel, Ernst (2011): Deutschland und die westlichen Demokratien, BadenBaden.

Freeden, Michael (1998): Is Nationalism a Distinct Ideology?, in: Political Studies 46 , S. 748-765.

Frischknecht, Jürg (1991): Schweiz wir kommen. Die neuen Fröntler und Rassisten, Zürich.

Fröhlich-Steffen, Susanne/Rensmann, Lars (Hg.) (2005): Populisten an der Macht. Populistische Regierungsparteien in West- und Osteuropa. Mit einem Nachwort von Cas Mudde, Wien.

Fröhlich-Steffen, Susanne (2006): Rechtspopulistische Herausforderer in Konkordanzdemokratien. Erfahrungen aus Österreich, der Schweiz und den Niederlanden, in: Decker, Frank (Hg.): Populismus. Gefahr für die Demokratie oder nützliches Korrektiv?, Wiesbaden, S. 144-164.

Ganguillet, Gilbert (1986): Le Conflit Jurassien. Un cas de mobilisation ethnorégionale en Suisse, Zürich.

Geden, Oliver (2005a): Blochers Schweiz, in: Blätter für deutsche und internationale Politik 4/2005, S. 404-406. 
Geden, Oliver (2005b): Identitätsdiskurs und politische Macht: Die rechtspopulistische Mobilisierung von Ethnozentrismus im Spannungsfeld von Oppositionspolitik und Regierung am Beispiel von FPÖ und SVP, in: FröhlichSteffen, Susanne/Rensmann, Lars (Hg.): Populisten an der Macht. Populistische Regierungsparteien in West- und Osteuropa. Mit einem Nachwort von Cas Mudde, Wien, S. 69-84.

Geden, Oliver (2006): Diskursstrategien im Rechtspopulismus. Freiheitliche Partei Österreichs und Schweizer Volkspartei zwischen Opposition und Regierungsbeteiligung, Wiesbaden.

Gellner, Ernest (1991): Nationalismus und Moderne, Berlin.

Gentile, Emilio (2006): Politics as Religion, Princeton.

Gentile, Pierre/Kriesi, Hanspeter (1998): Contemporary Radical Right Parties in Switzerland: History of a Divided Family, in: Betz, Hans-Georg/Immerfall, Stefan (Hg.): The New Politics of the Right, Neo-populist Parties and Movements in Established Democracies, New York, S. 125-142.

Geras, Norman (1987): Post-Marxism?, in: New Left Review 163, S. 40-82.

Giddens, Anthony (1991): Consequences of Modernity, Cambridge.

Giddens, Anthony (1998): The Third Way. The Renewal of Social Democracy, Cambridge.

Giddens, Anthony (2007): Europe in the Global Age, Cambridge.

Glaser, Barney G./Strauss, Anselm (1967): The Discovery of Grounded Theory. Strategies for Qualitative Research, New York.

Glasze, Georg (2007): Vorschläge zur Operationalisierung der Diskurstheorie von Laclau und Mouffe in einer Triangulation von lexikometrischen und interpretativen Methoden, in: Forum Qualitative Sozialforschung 8/2, online abgerufen: http://www.qualitative-research.net/index.php/fqs/article/view/23 9/529, 7.1.12.

Goetschel, Laurent (1994): Zwischen Effizienz und Akzeptanz. Die Information der Schweizer Behörden im Hinblick auf die Volksabstimmung über den 6 . Dezember 1992, Bern.

Goodwyn, Lawrence (1978): The Populist Moment, New York.

Greven, Michael T. (1999): Die politische Gesellschaft. Kontingenz und Dezision als Probleme des Regierens und der Demokratie, Opladen.

Griffin, Roger (2005): Cloister or Cluster? The Implications of Emilio Gentile's Ecumenial Theory of Political Religion for the Study of Extremism, in: Totalitarian Movements and Political Religions 6/1, S. 33-52.

Gross, Andreas (2007): Die kleine Chance der kleinen Konkordanz, in: Ders./Krebs, Fredi/Lautenschlager, Felix/Stohler, Martin (Hg.): Fahrplan- 
wechsel - Für mehr Demokratie und Solidarität und weniger Blocher, St. Ursanne, S. 251-259.

Gross, Andreas/Krebs, Fredi/Lautenschlager, Felix/Stohler, Martin (Hg.) (2007a): Fahrplanwechsel- Für mehr Demokratie und Solidarität und weniger Blocher, St. Ursanne.

Gross, Andreas/Krebs, Fredi/Lautenschlager, Felix/Stohler, Martin (2007b): Anregung zu mehr gemeinsamem Nachdenken, Gespräch mit Adrian Vieli, in: Ders./Krebs, Fredi/Lautenschlager, Felix/Stohler, Martin (Hg.): Fahrplanwechsel - Für mehr Demokratie und Solidarität und weniger Blocher, St. Ursanne, S. 17-32.

Gruner, Erich (1977): Die Parteien in der Schweiz, Bern.

Gsteiger, Fredy (2002): Blocher. Ein unschweizerisches Phänomen, Basel.

Guggenbühl, Christoph (1998): Von Untertanen zu Staatsbürgern. Voraussetzungen der Bundesstaatsgründung aus längerfristiger Perspektive, in: Schweizerisches Landesmuseum Zürich (Hg.): Die Erfindung der Schweiz. Bildentwürfe einer Nation, Zürich, S. 34-45.

Guissani, Bruno (1995): Populistischer Anti-Populismus. Ein runder Tisch mit Beat Allenbacher, Roger Friederich, Bruno Guissani und Georges Plomb, Interview mit Christian Gross und Franz Horvath, in: Hartmann, Hans/Gross, Andreas (Hg.): Heile Welt Schweiz. Die nationalkonservative Bewegung in der Diskussion, Zürich, S. 223-236.

Hall, Stuart (1986): Popular-demokratischer oder autoritärer Populismus, in: Dubiel, Helmut (Hg.): Populismus und Aufklärung, Frankfurt a. M., S. 84105.

Hall, Stuart (1994a): Kulturelle Identität und Diaspora, in: Ders.: Rassismus und kulturelle Identität. Ausgewählte Schriften 2, Hamburg, S. 26-43.

Hall, Stuart (1994b): Alte und neue Identitäten, alte und neue Ethnizitäten, in: Ders.: Rassismus und kulturelle Identität. Ausgewählte Schriften 2, Hamburg, S. 66-88.

Hall, Stuart (1994c): Die Frage der kulturellen Identität, in: Ders.: Rassismus und kulturelle Identität. Ausgewählte Schriften 2, Hamburg, S. 180-222.

Hall, Stuart (2002): Gramsci's Relevance for the Study of Race and Ethnicity, in: Martin, James (Hg.): Antonio Gramsci. Critical Assessments of Leading Political Philosophers. Volume IV. Contemporary Applications, London/New York, S. 281-309.

Hämmerle, Andrea (2011): Die Abwahl. Fakten \& Figuren, Glarus.

Hans, Christophe (1999): La victoire de l'UDC nationale est avant tout celle de l'aile zurichoise, in: Le Temps, 26.10.1999. 
Hartleb, Florian (2005): Populismus - ein Hindernis für politische Sozialisation, in: APUZ. Aus Politik und Zeitgeschichte 41, S. 32-38.

Hartleb, Florian (2012): Totengräber oder Korrektiv der Demokratie? in: APUZ. Aus Politik und Zeitgeschichte 5-6, S. 22-29.

Hartleb, Florian (2013): Populismus. „Es gibt einen europaweiten Trend zum Anti-Elitarismus“, in: Zeit Online, online angerufen: http://www.zeit.de/politik/ausland/2013-02/interview-populismus-hartleb/komplettansicht?print= true, 27.02.2013.

Hartmann, Hans/Horvath, Franz (1995): Der (un-)heimliche Aufstieg der Zürcher SVP, Zürich.

Hartmann, Hans/Gross, Andreas (1995): Epizentrum: Der nationalkonservative Kern, in: Dies. (Hg.): Heile Welt Schweiz. Die nationalkonservative Bewegung in der Diskussion, Zürich, S. 30-33.

Heer, Sebastian (2013): Politischer Mythos, Legitimität und Ordnungskonstruktion, in: Patzelt, Werner J. (Hg.): Die Machbarkeit politischer Ordnung, Bielefeld, S. 99-126.

Heinrich-Böll-Stiftung (Hg.) (2012): Rechtspopulismus in Europa, Wien,

Helbing, Marc (2011): Rechtspopulismus als Ideologie und der neue Integrations-Exklusions-Cleavage in Westeuropa, in: Berliner Debatte Initial 22/1, S. $12-26$.

Helms, Ludger (1996): Rechtspopulismus in Österreich und der Schweiz im Vergleich, in: Journal für Sozialforschung 36, S. 23-42.

Hennecke, Hans Jörg (2003): Das Salz in den Wunden der Konkordanz. Christoph Blocher und die Schweizer Politik, in: Werz, Nikolaus (Hg.): Populismus. Populisten in Übersee und Europa, Opladen, S. 145-162.

Hettling, Manfred (1998): Die Fähnlein der Treffsicheren. Die eidgenössischen Schützenfeste im 19. und 20. Jahrhundert, in: Blattmann, Lynn/Meier, Irène (Hg.): Männerbund und Bundesstaat. Über die politische Kultur der Schweiz, Zürich, S. 97-119.

Hildebrand, Marius/Lluis Martell, Conrad (2012): The Negation of Power: from Structuration Theory to the Politics of the Third Way, in: Distinktion: Scandinavian Journal of Social Theory 13/2, S. 187-207.

Hildebrand, Marius/Séville, Astrid (2015): Populismus oder agonale Demokratie? Bruchlinien der theoretischen Symbiose zwischen Laclau und Mouffe, in: Politische Vierteljahresschrift 1/2015, S. 27-43.

Hilty, Carl (1875): Vorlesungen über die Politik der Eidgenossenschaft, Bern. Hirsch, Michael (2007): Die zwei Seiten der Entpolitisierung. Zur politischen Theorie der Gegenwart, Stuttgart. 
Hirschman, Albert O. (1992): Denken gegen die Zukunft. Die Rhetorik der Reaktion, München.

Hirschman, Albert O. (1994): Wie viel Gemeinsinn braucht die liberale Gesellschaft?, in: Leviathan 2/1994, S. 293-304.

Hirseland, Andreas/Schneider, Werner (2011): Wahrheit, Ideologie und Diskurse. Zum Verhältnis von Diskursanalyse und Ideologiekritik, in: Keller, Reiner/Hirseland, Andreas/Schneider, Werner/Viehöver, Willy (Hg.): Handbuch Sozialwissenschaftliche Diskursanalyse. Band 1: Theorien und Methoden, Wiesbaden, S. 401-432.

Hirter, Hans (2000): Wahlen 1999. Zusammensetzung und politische Orientierung der Wählerschaft bei den eidgenössischen Wahlen 1999. Swiss Electoral Studies. Band 4, Bern/Genf/Zürich.

Hirter, Hans/Vatter, Adrian (2010): Analyse der eidgenössischen Abstimmung vom 29. November 2009. Vox-Analyse des Forschungsinstituts gfs.bern und Institut für Politikwissenschaft, Universität Bern, online abgerufen: http://www.polittrends.ch/abstimmungen/abstimmungsanalysen/vox-analysen/2009-11-28_VoxS.pdf, 21.1.2015.

Hobsbawm, Eric (1991): Nationen und Nationalismus. Mythos und Realität seit 1780, Frankfurt/New York.

Hobsbawm, Eric (1995): Das Zeitalter der Extreme. Weltgeschichte des 20. Jahrhunderts, München.

Hoffer, Eric (1966): The True Believer. Thoughts on the Nature of Mass Movements, New York.

Hoheneder, Barbara (2012): Die Politik von Angst und Zugehörigkeit. Der Nährboden des Populismus, in: Heinrich-Böll-Stiftung (Hg.): Rechtspopulismus in Europa, Wien, S. 185-196.

Horatschek, Annegreth (2005): Kollektive Identität, in: Nünning, Ansgar (Hg.): Grundbegriffe der Kulturtheorie und Kulturwissenschaften, Stuttgart/Weimar, S. 71-72.

Howarth, David (2000): Discourse, Buckinghamshire.

Howarth, David (2004): Hegemony, Political Subjectivity and Radical Democracy, in: Critchley, Simon/Marchart, Oliver (Hg.): Laclau. A Critical Reader. London/New York, S. 256-276.

Howarth, David/Norval, Aletta J./Stavrakakis, Yannis (Hg.) (2000): Discourse Theory and Political Analysis. Identities, Hegemonies and Social Change, Manchester.

Howarth, David/Stavrakakis, Yannis (2000): Introducing Discourse Theory and Political Analyses, in: Dies./Norval, Aletta J. (Hg.): Introducing Discourse 
Theory and Political Analyses. Identities, Hegemonies and Social Change, Manchester, S. 1-23.

Hubacher, Helmut (2014): Hubachers Blocher, Oberhofen.

Huth-Spiess, Petra (1996): Europäisierung oder „Entschweizerung“? Der Abstimmungskampf der Schweiz um den Beitritt zum EWR, Bern u.a.

Imbusch, Peter (1998): Einleitung, in: Ders. (Hg.): Macht und Herrschaft. Sozialwissenschaftliche Konzeptionen und Theorien. Opladen, S. 9-36.

Imhof, Kurt (1996a): Das kurze Leben der geistigen Landesverteidigung. Von der „Volksgemeinschaft“ vor dem Krieg zum Streit über die „Nachkriegsschweiz“ im Krieg, in: Ders./Kleger, Heinz/Romano, Gaetano (Hg.): Krise und sozialer Wandel. Band 2. Konkordanz und Kalter Krieg. Analyse von Medienereignissen in der Schweiz der Zwischen- und Nachkriegszeit, Zürich, S. 19-84.

Imhof, Kurt (1996b): Wiedergeburt der geistigen Landesverteidigung: Kalter Krieg in der Schweiz, in: Ders./Kleger, Heinz/Romano, Gaetano (Hg.): Krise und sozialer Wandel. Band 2. Konkordanz und Kalter Krieg, Analyse von Medienereignissen in der Schweiz der Zwischen- und Nachkriegszeit, Zürich, S. 173-248.

Imhof, Kurt (2007): Sonderfalldiskurse und Pfadabhängigkeit: Der Fall Schweiz, in: Eberle, Thomas S. (Hg.): Sonderfall Schweiz, Zürich, S. 25-55.

Institut für Politikwissenschaft der Universität Bern (o.J.): Année Politique. Schweizerische Politik. Schweizerische Volkspartei (1987-2005), online abgerufen, http://www.anneepolitique.ch/docu/HP-SVP.pdf, 20.05.2014.

Jäger, Margarete/Jäger, Siegfried (2007): Deutungskämpfe. Theorie und Praxis Kritischer Diskursanalyse, Wiesbaden.

Jäger, Siegfried (2007): In der Falle der Synthetisierung von Diskursanalyse und soziologischer Feldtheorie, in: Forum. Qualitative Social Research 8/2, online abgerufen: http://nbn-resolving.de/urn:nbn:de:0114-fqs070278, 14.8. 2014.

Jäger, Wolfgang (2011): Die Kultur der Demokratie braucht permanente Pflege, in: Badische Zeitung, 9.4.2011, online abgerufen: http://www.badischezeitung.de/kommentare-1/die-kultur-der-demokratie-braucht-permanentepflege-43993574.html, 15.5.2011.

Jakobs, Hans-Jürgen (2009): Wenn der Staat das Volk nicht mehr versteht, in: Süddeutsche Zeitung, online abgerufen: http://www.sueddeutsche.de/politik /minarett-verbot-wenn-der-staat-das-volk-nicht-mehr-versteht-1.133875, 14. 1.2015. 
Jorio, Marco (2006): Geistige Landesverteidigung, in: Historisches Lexikon der Schweiz (HLS), online abgerufen: http://www.hls-dhs-dss.ch/textes/d/D17 426.php, 20.4.2014.

Jost, Hans-Ulrich (2007): Tradition und Moderne in der SVP, in: Traverse: Zeitschrift für Geschichte 1/1, S. 25-44.

Jost, Hans-Ulrich/Imhof, Kurt (1998): Geistige Landesverteidigung: Helvetischer Totalitarismus oder antitotalitärer Basiskompromiss? Ein Streitgespräch. Gesprächsleitung Schweizerisches Landesmuseum Zürich, in: Schweizerisches Landesmuseum Zürich (Hg.): Die Erfindung der Schweiz. Bildentwürfe einer Nation, Zürich, S. 365-379.

Jun, Uwe (2006): Populismus als Regierungsstil in westeuropäischen Parteiendemokratien: Deutschland, Frankreich und Großbritannien, in: Decker, Frank (Hg.): Populismus. Gefahr für die Demokratie oder nützliches Korrektiv?, Wiesbaden, S. 233-254.

Kaindl, Christina (2013): Neoliberalismus und Rechtsextremismus im Wandel, in: Bathke, Peter/Hoffstadt, Anke (Hg.): Die neuen Rechten in Europa. Zwischen Neoliberalismus und Rassismus, Köln, S. 20-30.

Kaschuba, Wolfgang (1995): Kulturalismus. Vom Verschwinden des Sozialen im gesellschaftlichen Diskurs, in: Ders. (Hg.): Kulturen - Identitäten - Diskurse, Berlin, S. 11-30.

Katz, Daniel (1973): Patterns of Leadership, in: Knutson J. Jeanne (Hg.): Handbook of Political Psychology, San Francisco, S. 203-233.

Keller, Reiner (2005): Wissenssoziologische Diskursanalyse. Grundlegung eines Forschungsprogramms, Wiesbaden.

Keohane, Robert O. (1984): After Hegemony. Cooperation and Discord in the World Political Economy, Princeton, New Jersey.

Keohane, Robert O./Nye, Joseph S. (1977): Power and Interdependence. World Politics in Transition, Boston.

Kitschelt, Herbert (1986): Opportunity Structures and Political Protest: Antinuclear Movements in four Democracies, in: British Journal of Political Science $16 / 1$, S. 57-85.

Kitschelt, Herbert/McGann, Anthony (1995): The Radical Right in Western Europe. A Comparative Analysis, Ann Arbor.

Klapp, Orrin E. (1964): Symbolic Leaders. Public Dramas and Public Men, Chicago.

Kley, Andreas (2014): Direkte Demokratie und Menschenrechte - ein Spannungsfeld, in: Werder, Hans/Lauber, Anina (Hg.): Bedrohte Werte? Europa und der Nahe Osten unter Globalisierungsdruck, Bern, S. 29-36. 
Klöti, Ulrich (2001): Consensual Governement in a Heterogenous Polity, in: West European Politics 24/2, S. 19-34.

Kobach, Kris W. (1993): The Referendum. Direct Democracy in Switzerland, Darmouth.

Kohn, Hans (1956): Nationalism and Liberty. The Swiss Example, London.

Koller, Arnold (1995): Die Schweiz an der Schwelle zum 21.Jahrhundert, in: Haraibi, Najib (Hg.): Wettlauf um die Schweiz 2000. Herausforderungen für eine innerlich zerrissene Schweiz, S. 3-23.

Koopmans, Ruud/Statham, Paul (2000): Migration and Ethnic Relations as a Field of Political Contention. An Opportunity Structure Approach, in: Koopmans, Ruud/Statham Paul (Hg.): Challenging Immigration and Ethnic Relations Politics. Comparative European Perspectives, Oxford, S. 13-56.

Koschorke, Albrecht (2007): Zur Logik kultureller Gründungserzählungen, in: Zeitschrift für Ideengeschichte 1/2, S. 5-12.

Kreis, Georg (1993): Die Schweiz unterwegs. Schlussbericht des Nationalen Forschungsprogramms 21 „Kulturelle Vielfalt und nationale Identität“, Basel/Frankfurt a. M.

Kreis, Georg (2009): Die Einheit einer Wolke. Wie weiter nach dem Ja zum Minarett-Verbot, in: Basler Zeitung, 9.12.2009, online abgerufen: http://www.clubhelvetique.ch/clubhelv/index.php?CH-Block, 5.2.2015.

Kriesi, Hanspeter/Longchamp, Claude/Passy, Florence/Sciarini, Pascal (1993): Analyse der eidgenössischen Abstimmung vom 6. Dezember 1992, Bern.

Kriesi, Hanspeter (1999a): Movements of the Left, Movements of the Right: Putting the Mobilization of two New Types of Social Movements into Political Context, in: Kitschelt, Herbert/Lange, Peter/Marks, Gary/Stephens, John D. (Hg.): Continuity and Change in Contemporary Capitalism, New York, S. 398-425.

Kriesi, Hanspeter (1999b): Kampf mit SVP-Mitteln. Interview mit Hanspeter Kriesi, in: Bieler Tagblatt, 19.10.1999, online abgerufen: http://www.bielertagblatt.ch/nachrichten/vermischtes/kampf-mit-svp-mitteln, 15.03.2014

Kriesi, Hanspeter (2002): Politische Folgen nationaler Identität. Das Beispiel der eidgenössischen Wahlen von 1999, in: Bosshart, Pfluger, Catherine/Jung, Joseph/Metzger, Franziska (Hg.): Nation und Nationalismus in Europa. Kulturelle Konstruktion von Identitäten. Festschrift für Urs Altermatt, Frauenfeld/Stuttgart/Wien, S. 565-586.

Kriesi, Hanspeter (2005): Einleitung, in: Ders./Lachat, Romain/Selb, Peter/Bornschier, Simon/Helbing, Marc (Hg.) (2005): Der Aufstieg der SVP. Acht Kantone im Vergleich, Zürich, S. 1-10. 
Kriesi, Hanspeter/Lachat, Romain/Selb, Peter/Bornschier, Simon/Helbing, Marc (Hg.) (2005a): Der Aufstieg der SVP. Acht Kantone im Vergleich, Zürich.

Kriesi, Hanspeter/Lachat, Romain/Selb, Peter/Bornschier, Simon/Helbing, Marc (2005b): Vorwort, in: Dies. (Hg.): Der Aufstieg der SVP. Acht Kantone im Vergleich, Zürich, S. vii-viii.

Kriesi, Hanspeter/Grande, Edgar/Lachat, Romain/Dolezal, Martin/Bornschier, Simon/Frey, Timotheos (Hg.) (2008): West European Politics in the Age of Globalization, Cambridge.

Küng, Hans (1992): Die Schweiz ohne Orientierung? Europäische Perspektiven, Zürich.

Küng, Thomas (2014): Gebrauchsanweisung für die Schweiz, München/Zürich.

Lachat, Romain/Selb, Peter (2005): Schweiz, in: Dies./Kriesi, Hanspeter/Bornschier, Simon/Helbing, Marc (Hg.): Der Aufstieg der SVP. Acht Kantone im Vergleich, Zürich, S. 41-58.

Laclau, Ernesto (1981): Politik und Ideologie im Marxismus. Kapitalismus - Faschismus - Populismus, Berlin.

Laclau, Ernesto (1982): Diskurs, Hegemonie und Politik, in: Haug, Fritz (Hg.): Neue soziale Bewegungen und Marxismus. Internationale SozialismusDiskussion 2, Das Argument: Argument Sonderband 78, S. 6-22.

Laclau, Ernesto (1989): Politics and the Limits of Modernity, in: Ross, Andrew (Hg.): Universal Abandon? The Politics of Postmodernism, Edinburgh, S. 63-89.

Laclau, Ernesto (1990a): New Reflections on the Revolution of Our Time, in: Ders.: New Reflections on the Revolution of Our Time, London/New York, S. 3-85.

Laclau, Ernesto (1990b): The Impossibility of Society, in: Ders.: New Reflections on the Revolution of Our Time, London/New York, S. 89-92.

Laclau, Ernesto (1997): Inklusion, Exklusion und die Logik der Äquivalenz. Über das Funktionieren ideologischer Schließungen, in: Weibel, Peter/Žižek, Slavoj (Hg.): Inklusion: Exklusion. Probleme des Postkolonialismus und der globalen Migration, Wien, S. 45-74.

Laclau, Ernesto (1999): Dekonstruktion, Pragmatismus, Hegemonie, in: Mouffe, Chantal (Hg.): Dekonstruktion und Pragmatismus. Demokratie, Wahrheit und Vernunft, Wien, S. 111-154.

Laclau, Ernesto (2000): Identity and Hegemony. The Role of Universality in the Constitution of Political Logics, in: Ders./Butler, Judith/Žižek, Slavoj: Contingency, Hegemony, Universality. Contemporary Dialogues on the Left, London, S. 44-89. 
Laclau, Ernesto (2003): Discourse, in: Goodin, Robert E./Pettit, Philip (Hg.): A Companion to Contemporary Political Philosophy, Oxford, S. 431-437.

Laclau, Ernesto (2004): Glimpsing the Future, in: Critchley, Simon/Marchart, Oliver (Hg.): Laclau. A Critical Reader. London/New York, S. 279-328.

Laclau, Ernesto (2005a): On Populist Reason, London.

Laclau, Ernesto (2005b): What's in a Name?, in: Panizza, Francisco (Hg.): Populism and the Mirror of Democracy, London, S. 32-49.

Laclau, Ernesto (2006): Why Constructing a People is the Main Task of Radical Politics, in: Critical Inquiry 32/4, S. 646-680.

Laclau, Ernesto (2007a): Emanzipation und Differenz, Wien.

Laclau, Ernesto (2007b): Ideologie und Post-Marxismus, in: Nonhoff, Martin

(Hg.): Diskurs - radikale Demokratie - Hegemonie. Zum politischen Denken von Ernesto Laclau und Chantal Mouffe, Bielefeld, S. 25-40.

Laclau, Ernesto (2010): El legado de Nestor Kirchner, in: Pagina 12, 4.11.2010, online abgerufen: http://www.pagina12.com.ar/diario/elpais/subnotas/156 246-50159-2010-11-04.html, 10.02.2014.

Laclau, Ernesto/Mouffe, Chantal (1990): Post-Marxism without Apologies, in: Laclau, Ernesto: New Reflections on the Revolution of our Time, London, S. 97-134.

Laclau, Ernesto/Mouffe, Chantal (2006)[1985]: Hegemonie und radikale Demokratie. Zur Dekonstruktion des Marxismus, Wien.

Laclau, Ernesto/Zac, Lilian (1994): Minding the Gap: the Subject of Politics, in: Laclau, Ernesto (Hg.): The making of Political Identities, London/New York, S. 11-39.

Ladner, Andreas (1999): Das Schweizer Parteiensystem und seine Parteien, in: Klöti, Ulrich/Knoepfel, Peter/Kriesi, Hanspeter/Linder, Wolf/Papadopoulos, Yannis (Hg.): Handbuch der Schweizer Politik. Manuel de la politique suisse, Zürich, S. 213-260.

Ladner, Andreas (2001): Swiss Political Parties: Between Persistency and Change, in: West European Politics, 24/2, S. 124-144.

Ladner, Andreas (2004): Stabilität und Wandel in Parteiensystemen. Eine vergleichende Analyse von Konfliktlinien, Parteien und Parteiensystemen in den Schweizer Kantonen, Wiesbaden.

Ladner, Andreas (2010): Schweizer Parteienlandschaft ist im Europa-Vergleich am „Extremsten“, in: Sonntag 17, 2. Mai 2010, S. 17.

Ladner, Andreas (2013): Die Positionierung der Schweizer Parteien im internationalen Vergleich, in: Mazzoleni, Oscar/Meuwly, Olivier (Hg.): Die Parteien in Bewegung. Nachbarschaft und Konflikte, S. 201-228. 
Ladner, Andreas u.a. (2010): Die politische Positionierung der europäischen Parteien im Vergleich. Eine Analyse der politischen Positionen der europäischen Parteien anlässlich der Wahlen des Europäischen Parlaments 2009 mit besonderer Berücksichtigung der Schweizer Parteien, Cahier de l'IDHEAP 252/2010.

Lang, Josef (2000): Blocher, SVP und der Nationalkonservatismus. Historische und ideologische Kontinuitäten, in: Widerspruch. Beiträge zur sozialistischen Politik 20/39, S. 97-113.

Lang, Josef (2009): Ein Mann, ein Buch. Der Sonderfall Blocher - in der ersten autorisierten Biografie wird der SVP-Politiker grotesk überhöht, in: Die Zeit $8 / 2009$, 12.2.2009, online abgerufen: http://www.zeit.de/2009/08/ChChristoph-Blocher, 18.2.2014.

Langejürgen, Ralf (1993): Die Eidgenossenschaft zwischen Rütli und EWR. Der Versuch einer Neuorientierung der Schweizer Außenpolitik, Zürich.

Lefort, Claude (1990): Die Frage der Demokratie, in: Rödel, Ulrich/Frankenberg, Günther/Dubiel, Helmut (Hg.): Autonome Gesellschaft und libertäre Demokratie, Frankfurt a. M., S. 281-297.

Lehmbruch, Gerhard (1967): Proporzdemokratie. Politisches System und politische Kultur in der Schweiz und in Österreich, Tübingen.

Lehmbruch, Gerhard (1996): Die korporative Verhandlungsdemokratie in Westmitteleuropa, in: Schweizerische Zeitschrift für Politische Wissenschaft 2/4, S. 19-41.

Lenk, Kurt (2005): Das Problem der Dekadenz seit Georges Sorel, in: Kauffmann, Heiko/Kellershohn, Helmut/Paul, Jobst (Hg.): Völkische Bande. Dekadenz und Wiedergeburt. Analysen rechter Ideologie, Münster, S.49-63.

Lewandowsky, Marcel (2011): Demagogen von rechts und Provokateure aus der Mitte. Rechtspopulismus in Westeuropa, in: Berliner Debatte Initial 22/1, S. $40-53$.

Linder, Wolf (1994): Swiss Democracy. Possible Solutions to Conflict in Multicultural Societies, New York/London.

Linder, Wolf (2010): Europäisierung ohne Mitgliedschaft. Zum politischen Handlungsspielraum der Schweiz ausserhalb der EU, in: Freiburghaus, Dieter/Epinay, Astrid (Hg.): Beziehungen Schweiz - EU: Standortbestimmungen und Perspektiven, Zürich, S. 13-39.

Linder, Wolf (2012): Schweizerische Demokratie. Institutionen - Prozesse Perspektiven. 3. Auflage, Bern.

Linder, Wolf (2014): Direkte Demokratie, Menschenrechte und Europäisierung - ein wachsendes politisches Spannungsfeld, in: Werder, Hans/Lauber, Ani- 
na (Hg.): Bedrohte Werte? Europa und der Nahe Osten unter Globalisierungsdruck, Bern, S. 29-36.

Linder, Wolf/Steffen, Isabelle (2006): Politische Kultur, in: Klöti, U1rich/Knoepfel, Peter/Kriesi, Hanspeter/Linder, Wolf/Papadopoulos, Yannis (Hg.): Handbuch der Schweizer Politik. Manuel de la politique suisse, Zürich, S. 13-34.

Link, Jürgen (2008): Diskurstheoretische Überlegungen zur neuesten Konjunktur des „Populismus“-Begriffs (mit Bezug auf Ernesto Laclau), in: Faber, Richard/Unger, Frank (Hg.): Populismus in Geschichte und Gegenwart, Würzburg, S. 17-30.

Lipset, Seymour M./Rokkan, Stein (1967): Cleavage Structures, Party Systems, and Voter Alignement, in: Dies. (Hg.): Party Systems and Voter Alignments: Cross-National Perspectives, New York, S. 1-64.

Longchamp, Claude (2000): Die nationalkonservative Revolte in Gestalt der SVP. Eine Analyse der Nationalratswahlen 1999 in der Schweiz, in: Plasser, Fritz/Ulram, Peter A./Sommer, Franz (Hg.): Das österreichische Wahlverhalten, Schriftenreihe des Zentrums für angewandte Politikforschung. Band 21, Wien, S. 393-423.

Longchamp, Claude (2014): Ja-Mehrheit für Ecopop-Initiative! - oder doch nicht? Auszug aus der Forschungsarbeit von gfs.bern, online abgerufen: http://www.gfsbern.ch/de-ch/Detail/ja-mehrheit-zur-ecopop-initiative-oderdoch-nicht, 25.2.2015.

Longchamp, Claude/Bieri, Urs/Golder, Lukas/Bösch, Luca (2003): Folgen der Polarisierung. Medienbericht zur Nachanalyse der Wahlen 03. Erstellt durch das GFS-Forschungsinstitut, Politik und Staat, Bern, online abgerufen: http://www.gfsbern.ch/Neuigkeiten/tabid/177/itemid/376/amid/1151/folgender-polarisierung.aspx, 24.05.2012

Longchamp, Claude/Rousselot, Bianca (2010): Bürger und Politik in der Schweiz, in: Gabriel, Oscar W./Plasser Fritz (Hg.): Deutschland, Österreich und die Schweiz in Europa. Bürger und Politik, Baden-Baden, S. 217-264.

Lluis Martell, Conrad (2013): Die Zivilgesellschaft als politischer Raum. Ein diskurstheoretisches Konzept von Zivilgesellschaft. Unveröffentlichte Masterarbeit, Hamburg.

Mair, Peter (2002): Populist Democracy vs. Party Democracy, in: Mény, Yves/Surel, Yves: Democracies and the Populist Challenge, Basingstoke, S. 81-98.

Maissen, Thomas (2010): Geschichte der Schweiz, Baden.

Marchal, Guy P. (1992): Das „Schweizeralpenland“. Eine imagologische Bastelei, in: Ders./Mattioli, Adam (Hg.): Erfundene Schweiz. Konstruktionen na- 
tionaler Identität/La Suisse imaginée. Bricolage d'une identité nationale, Zürich, S. 37-49.

Marchart, Oliver (Hg.) (1998): Das Undarstellbare der Politik. Zur Hegemonietheorie Ernesto Laclaus, Wien.

Marchart, Oliver (2000): The ,Fourth Way' of the Ultra-right: Austria, Europe, and the End of Neo-Corporatism, in: Capital \& Class 73, S. 7-14.

Marchart, Oliver (2002): „Austrifying“ Europe: Ultra-right Populism and the New Culture of Resistence, in: Cultural Studies 16, S. 809-819.

Marchart, Oliver (2004): Politics and the Ontological Difference: on the „Strictly Philosophical“" in Laclau's Work, in: Ders./Critchley, Simon (Hg.): Laclau. A Critical Reader, London/New York, S. 54-72.

Marchart, Oliver (2005): Symbol und leerer Signifikant. Zum Verhältnis von Kulturtheorie, Diskurstheorie und politischer Theorie, in: Berndt, Frauke/Brecht, Christoph (Hg.): Aktualität des Symbols, Freiburg, S. 245-268.

Marchart, Oliver (2007): Post-Foundational Political Thought. Political Difference in Nancy, Lefort, Badiou and Laclau, Edinburgh.

Marchart, Oliver (2008): Cultural Studies, Konstanz.

Marchart, Oliver (2010): Die politische Differenz - Zum Denken des Politischen bei Nancy, Lefort, Badiou, Laclau und Agamben, Frankfurt a. M.

Marchart, Oliver (2011): The Second Return of the Political: Democracy and the Syllogism of Equality, in: Bowman, Paul/Stamp, Richard (Hg.): Reading Rancière, London/New York, S. 128-147.

Martin, Pierre (2000): Comprendre les évolutions électorales. La théorie de réalignement revisitée, Paris.

Mayer, Jean-François (2009): Analysis: A Majority of Swiss Voters decide to ban the Building of Minarets, in: Religioscope, online abgerufen: http://religion.info/english/articles/article_455.shtml, 29.12.2014.

Mazzoleni, Oscar (2003): Nationalisme et populisme en Suisse. La radicalisation de la „nouvelle“ UDC, Lausanne.

Mazzoleni, Oscar (2005): Multi-level Populism and Centre-Periphery Cleavage in Switzerland. The Case of Lega dei Ticinesi, in: Caramani, Daniele/Mény, Yves (Hg.): Challenges to Consensual Politics. Democracy, Identity, and Populist Protest in the Alpine Region, Bruxelles, S. 209-228.

Mazzoleni, Oscar/Meuwly, Olivier (2013): Einleitung, in: Dies. (Hg.): Die Parteien in Bewegung. Nachbarschaft und Konflikte, S. 7-18.

Mazzoleni, Oscar/Skenderovic, Damir (2007): The Rise and Impact of the Swiss People's Party. Challenging the Rules of Governance in Switzerland, in: Delwit, Pascal/Poirier, Philipe (Hg.): Extrême droite et pouvoir en Europe. The Extreme Right Parties and Power in Europe, Brüssel, S. 85-116. 
McAdam, Doug/Tarrow, Sidney/Tilly, Charles (2008): Dynamics of Contention, Cambridge.

McGann, Anthony/Kitschelt, Herbert (2005): The Radical Right in the Alps. Evolution of Support for the Swiss SVP and Austrian ÖVP, in: Party Politics 11/2, S. 147-171.

Meier, Christian (1980): Die Entstehung des Politischen bei den Griechen, Frankfurt a. M.

Meier-Dallach, Hans-Peter (1988): Die Schweiz zwischen Traditionalität und Modernität, in: Landeszentrale für politische Bildung Baden-Württemberg (Hg.): Die Schweiz, Stuttgart u.a., S. 100-127.

Meier-Dallach, Hans-Peter/Rosenmund, Moritz/Ritschert, Rolf (1980): Wandel und Konstanz des Bildes Schweiz. Methode, Instrumente und ausgewählte Ergebnisse. Soziologisches Institut der Universität Zürich, Bulletin 38, Zürich.

Meier-Dallach, Hans-Peter/Hohermuth, Susanne/Walter, Therese (2003): Isola helvetica. Das Bild der Schweiz im Zeitalter der Globalisierung - L'image de la Suisse à l'ère de la mondialisation - L'immagine della Svizerra nell'era della globalizzazione, Zürich.

Mény, Yves/Surel, Yves (Hg.) (2002a): Democracies and the Populist Challenge, Houndmills/New York.

Mény, Yves/Surel, Yves (2002b): The Constitutive Ambiguity of Populism, in: Dies. (Hg.): Democracies and the Populist Challenge, Houndmills/New York, S. 1-21.

Menzi, Brigitte (2010): Schicksalshafte Europafrage: Das Volk sagt Nein zum EWR, in: Linder, Wolf/Bolliger, Christian/Rielle, Yvan (Hg.): Handbuch der Eidgenössischen Volksabstimmungen, Bern u.a., S. 499-502.

Minkenberg, Michael (2001): The Radical Right in Public Office. AgendaSetting and Policy Effects, in: West European Politics 4, S. 1-21.

Misik, Robert: Eine Spirale von Lärm und Aufmerksamkeit. Über die nicht immer ganz widerwillige Symbiose von Rechtspopulismus und Medien, in: Heinrich-Böll-Stiftung (Hg.): Rechtspopulismus in Europa, Wien, S. 155170.

Modoux, François (2009): La peur et l'ignorance, in: Le Temps, 30.11.2009, online abgerufen: http://www.letemps.ch/Page/Uuid/9cce2ca2-dd30-11debc20cbd5d36bc26f/La_peur_et_lignorance, 12.12.2014.

Moebius, Stephan (2003): Die soziale Konstituierung des Anderen. Grundrisse einer poststrukturalistischen Sozialwissenschaft nach Lévinas und Derrida, Frankfurt a. M./New York.

Moebius, Stephan (2009): Kultur, Bielefeld. 
Moebius, Stephan/Quadflieg, Dirk (2006): Jacques Derrida (1930-2004). Kultur als Kultur des Anderen, in: Hofmann, Martin L./Korta, Tobias F./Niekisch, Sybille (Hg.): Culture Club II. Klassiker der Kulturtheorie, Frankfurt a. M., S. 293-311.

Moebius, Stephan/Reckwitz, Andreas (2008): Einleitung. Poststrukturalismus und Sozialwissenschaften: Eine Standortbestimmung, in: Dies. (Hg.): Poststrukturalistische Sozialwissenschaften, Frankfurt a. M., S. 7-23.

Moser, Peter (2001): Schweizerische Aussenpolitik in der Zeit des Umbruchs 1989-1992. Die EWR-Verhandlung und die Reaktion auf die Deutsche Wiedervereinigung aus einer Foreign-Policy-Analysis-Perspektive, Zürich.

Mouffe, Chantal (1979): Hegemony and Ideology in Gramsci, in: Dies. (Hg.): Gramsci and Marxist Theory, London, S. 168-204.

Mouffe, Chantal (1999): Dekonstruktion, Pragmatismus und die Politik der Demokratie, in: Dies. (Hg.): Dekonstruktion und Pragmatismus: Demokratie, Wahrheit und Vernunft, Wien, S. 11-36.

Mouffe, Chantal (2005): The „End of Politics“ and the Challenge of Right-Wing Populism, in: Panizza, Francisco (Hg.): Populism and the Mirror of democracy, London, S. 50-71.

Mouffe, Chantal (2007a): Über das Politische. Wider die kosmopolitische Illusion, Frankfurt a. M.

Mouffe, Chantal (2007b): Pluralismus, Dissens und demokratische Staatsbürgerschaft, in: Nonhoff, Martin (Hg.): Diskurs - radikale Demokratie - Hegemonie. Zum politischen Denken von Ernesto Laclau und Chantal, Bielefeld, S. 41-54.

Mouffe, Chantal (2008): Das demokratische Paradox, Wien.

Mouffe, Chantal (2011): „Postdemokratie“ und die wachsende Entpolitisierung, in: APUZ. Aus Politik und Zeitgeschichte 1-2/2011, S. 3-5.

Müller, Felix/Tanner, Matthias (2009): Muslime, Minarette und die MinarettInitiative in der Schweiz: Grundlagen, in: Dies./Mathwig, Frank/Lienemann, Wolfgang (Hg.): Streit um das Minarett. Zusammenleben in der religiös pluralistischen Gesellschaft, Zürich, S. 21-45.

Müller, Jan Werner (2012): Wir! Sind! Das! Volk!, in: Die Zeit 17/2012, 22.4.2012, online abgerufen: http://www.zeit.de/2012/17/P-Populismus, 12. 3.2015 .

Müller, Jan-Werner (2015): Was ist Populismus?, Frankfurt a. M.

Mudde, Cas (2004): The Populist Zeitgeist, in: Government and Opposition 39/4, S. 541-563.

Mudde, Cas (2007): Populist Radical Right Parties in Europe, Cambridge. 
Mudde, Cas (2010): The Populist Radical Right: A Pathological Normalcy, in: West European Politics 36/86, S. 1167-1186.

Muschg, Adolf (1997a): Die Teilnahms-Ferne, in: Die Zeit 7/1997, 7.2.1997.

Muschg, Adolf (1997b): Wenn Auschwitz in der Schweiz liegt, Frankfurt a. M.

Neidhart, Leonhard (2002): Die politische Schweiz. Fundamente und Institutionen, Zürich.

Nizon, Paul (1990): Diskurs in der Enge, Frankfurt a. M.

Nohlen, Dieter (2011): Populismus, in: Ders./Grotz, Florian (Hg.): Kleines Lexikon der Politik, Bonn, S. 489-499.

Nonhoff, Martin (2004): Zwei Begriffe des Diskurses, in: Goehler, Gerhard (Hg.): Politische Theorie. 22 umkämpfte Begriffe zur Einführung, Wiesbaden, S. 67-80.

Nonhoff, Martin (2006): Politischer Diskurs und Hegemonie: Das Projekt soziale Marktwirtschaft, Bielefeld.

Nonhoff, Martin (2007a) (Hg.): Diskurs - radikale Demokratie - Hegemonie. Zum politischen Denken von Ernesto Laclau und Chantal Mouffe, Bielefeld.

Nonhoff, Martin (2007b): Diskurs, radikale Demokratie, Hegemonie - Einleitung, in: Ders. (Hg.): Diskurs - radikale Demokratie - Hegemonie. Zum politischen Denken von Ernesto Laclau und Chantal Mouffe, Bielefeld, S. $7-$ 25.

Nonhoff, Martin (2010): Hegemonieanalyse: Theorie, Methode und Forschungspraxis, in: Keller, Reiner/Hirseland, Andreas/Schneider, Werner/Viehöver, Willy (Hg.): Handbuch Sozialwissenschaftliche Diskursanalyse. Band 2: Forschungspraxis, Wiesbaden, S. 299-331.

Nonnenmacher, Günther (2014): Die Stunde der Populisten, in: Frankfurter Allgemeine Zeitung, 29.11.2014, online abgerufen: http://www.faz.net/aktuell/ politik/europaeische-union/europa-skepsis-die-stunde-der-populisten-132922 43.html, 2.12.2014.

Norval, Aletta (1996): Deconstructing Apartheid Discourse, London.

Norval, Aletta (2000): Trajectories of Future Research in Discourse Theory, in: Dies./Howarth, David/Stavrakakis, Yannis (Hg.): Introducing Discourse Theory and Political Analyses. Identities, Hegemonies and Social Change, Manchester, S. 219-236.

Nullmeier, Frank (2006): Politikwissenschaft auf dem Weg zur Diskursanalyse?, in: Keller, Reiner/Hirseland, Andreas/Schneider, Werner/Viehöver, Willy (Hg.): Handbuch sozialwissenschaftliche Diskursanalyse. Band 1: Theorien und Methoden, Wiesbaden, S. $287-314$.

NZZ-Verlag (Hg.) (1997): Schatten des Zweiten Weltkriegs: Nazigold und Shoa-Gelder - Opfer als Ankläger, NZZ-Fokus. 
Ortega y Gasset, José (1957): Der Aufstand der Massen, München.

Osborne, Peter (1991): Radicalism without Limit, in: Ders. (Hg.): Socialism and the Limits of Liberalism, London, S. 201-227.

Oudenampsen, Merijn (2012): Populistischer Realismus. Vox Populi und das Postpolitische, in: Heinrich-Böll-Stiftung (Hg.): Rechtspopulismus in Europa, Wien, S. 137-154.

Panizza, Francisco (Hg.) (2005a): Populism and the Mirror of Democracy, London.

Panizza, Francisco (2005b): Introduction - Populism and the Mirror of Democracy, in: Ders. (Hg.): Populism and the Mirror of Democracy, London, S. 131.

Papadopoulos, Yannis (2005): Populism as the Other Side of Consociational Multi-Level Democracies, in: Caramani, Daniele/Mény, Yves (Hg.): Challenges to Consensual Politics. Democracy, Identity, and Populist Protest in the Alpine Region, Brüssel, S. 71-82.

Priester, Karin (2011): Definitionen und Typologien des Populismus, in: Soziale Welt 62, S. 185-198.

Priester, Karin (2012a): Wesensmerkmale des Populismus, in: APUZ. Aus Politik und Zeitgeschichte 62/5-6, S. 3-8.

Priester, Karin (2012b): Die Stunde der Entscheidung. Radikale Linke im Geiste Carl Schmitts, in: Blätter für deutsche und internationale Politik 6/2012, S. 108-119.

Patzelt, Werner J. (1999): Politikverdrossenheit, populäres Parlamentsverständnis und die Aufgaben der politischen Bildung, in: APUZ. Aus Politik und Zeitgeschichte 7-8, S. 31-38.

Patzelt, Werner J. (2003): Einführung in die Politikwissenschaft. Grundriß des Fachs und studienbegleitende Orientierung, Passau.

Patzelt, Werner J. (2013a): Die Machbarkeit politischer Ordnung. Transzendenz und Konstruktion, Bielefeld.

Patzelt, Werner J. (2013b): Transzendenz, politische Ordnung und beider Konstruktion, in: Ders. (Hg.): Die Machbarkeit politischer Ordnung. Transzendenz und Gemeinsinn, Bielefeld, S. 9-42.

Pelinka, Anton (2012): Populismus - zur Karriere eines Begriffs, in: Sir Peter Ustinov Institut (Hg.): Populismus. Herausforderung oder Gefahr für die Demokratie?, Wien, S. 9-21.

Pieper, Marianne (2006): Diskursanalysen - Kritische Analytik der Gegenwart und wissenspolitische Deutungsmusteranalyse. Ein Kommentar zu den Beiträgen von Susanne Krassmann und Julia Lepperhoff, in: Kerchner, Brigit- 
te/Schneider, Silke (Hg.): Foucault: Diskursanalyse der Politik. Eine Einführung, Wiesbaden, S. 269-286.

Pierson, Paul (2004): Politics in Time. History, Institutions and Social Analysis, Princeton New Jersey.

Rancière, Jacques (2002): Das Unvernehmen. Politik und Philosophie, Frankfurt a. M.

Rancière, Jacques (2006): Politik gibt es nur als Ausnahme. Interview mit Robin Celikates und Bertram Keller, in: polar, online abgerufen: http://www.polarzeitschrift.de/polar_01.php?id=21, 12.4.2014.

Rancière, Jacques (2007): Die Entsorgung der Demokratie. Interview mit Christian Höller, online abgerufen: http://www.eurozine.com/pdf/2007-11-30ranciere-de.pdf, 1.3.2013.

Rauber, Andre (2003): Formierter Widerstand. Geschichte der kommunistischen Bewegung in der Schweiz 1944-1991, Zürich.

Rear, David (o.J.): Laclau and Mouffe's Discourse Theory and Fairclough's Critical Discourse Analysis: An Introduction and Comparision, online abgerufen: https://www.academia.edu/5635811/Operationalising_Laclau_ and_Mouffes_Discourse_Theory_as_a_Practical_Method_of_Text_Analysis _Discursive_struggle_and_contested_signifiers_in_education_policy_and_w ork_skills_in_Japan, 5.1.2014.

Reckwitz, Andreas (2000): Die Transformation der Kulturtheorien - Zur Entwicklung eines Theorieprogramms, Weilerswist.

Reckwitz, Andreas (2001): Der Identitätsdiskurs. Zum Bedeutungswandel einer sozialwissenschaftlichen Semantik, in: Rammert, Werner/Knauthe, Gunter/Buchenau, Klaus/Altenhöner, Florian (Hg.) Kollektive Identitäten und kulturelle Innovationen. Ethnologische, soziologische und historische Studien, Leipzig, S. 21-38.

Reckwitz, Andreas (2006): Ernesto Laclau: Diskurse, Hegemonien, Antagonismen, in: Moebius, Stephan/Quadflieg, Dirk (Hg.): Kultur. Theorien der Gegenwart, Wiesbaden, S. 339-349.

Reckwitz, Andreas (2008a): Subjekt/Identität: Die Produktion und Subversion des Individuums, in: Moebius, Stephan/Reckwitz, Andreas (Hg.): Poststrukturalistische Sozialwissenschaften, Frankfurt a. M., S. 75-92.

Reckwitz, Andreas (2008b): Praktiken und Diskurse. Eine sozialtheoretische und methodologische Relation, in: Kalthoff, Herbert/Hirschauer, Stefan/Lindemann, Gesa (Hg.): Theoretische Empirie. Zur Relevanz qualitativer Forschung, Frankfurt a. M., S. 188-209.

Reckwitz, Andreas (2010): Das hybride Subjekt. Eine Theorie der Subjektkulturen von der bürgerlichen Moderne zur Postmoderne, Weilerswist. 
Reinfeldt, Sebastian (2013): „Wir für Euch!“ Die Wirksamkeit des Rechtspopulismus in Zeiten der Krise, Münster.

Rehberg, Karl-Siegbert (2007): „Insula helvetica“ als Gleichgewichtsgesellschaft. Mythisierung als Krisenbewältigung, in: Eberle, Thomas S./Imhof, Kurt (Hg.): Sonderfall Schweiz, Zürich, S. 56-81.

Rensmann, Lars (2006): Populismus und Ideologie, in: Decker, Frank (Hg.): Populismus. Gefahr für die Demokratie oder nützliches Korrektiv?, Wiesbaden, S. 59-80.

Riva, Alex (2004): Blocher regiert. Erfolg und Ideologie der Schweizerischen Volkspartei, in: Kontext 1/04, online abgerufen: http://www.contextxxi. at/context/content/view/100/77/index.html, 21.3. 2014.

Rinderknecht, Matthias (1993): Parteien - Partis, in: Forschungszentrum für schweizerische Politik an der Universität Bern (Hg.): Année politique suisse. Schweizerische Politik 1992, Bern, S. 338-350.

Rosa, Hartmut (1994): Ideengeschichte und Gesellschaftstheorie. Der Beitrag der "Cambridge School“ zur Metatheorie, in: Politische Vierteljahresschrift 35/2, S. 197-223.

Rosa, Hartmut (1999): Politische Theorie im Spiegel der Herausforderungen der Politik. Einige zusammenfassende Überlegungen, in: Greven, Michael Th./Schmalz-Bruns, Rainer (Hg.): Politische Theorie - heute, Baden-Baden, S. 447-471.

Rosa, Hartmut (2007): Identität, in: Straub, Jürgen/Weidemann, Arne/Weidemann, Doris (Hg.): Handbuch interkulturelle Kommunikation und Kompetenz, Stuttgart/Weimar, S. 47-56.

Rosanvallon, Pierre (2008): Counter-Democracy. Politics in the Age of Distrust, Cambridge.

Rosenberger, Sieglinde Katharina (2001): Demokratie und/versus Populismus, in: Dies./Andrei Markovits, Andrei (Hg.): Demokratie. Modus und Telos. Beiträge für Anton Pelinka, Wien, S. 101-116.

Rosenberger, Sieglinde Katharina (2005): Rechtspopulismus: Kurzfristige Mobilisierung der vox populi oder anhaltende Herausforderung der repräsentativen Demokratie? in: Fröhlich-Steffen, Susanne/Rensmann, Lars (Hg.): Populisten an der Macht. Populistische Regierungsparteien in West- und Osteuropa, Wien, S. 35-50.

Rössel, Jörg (2008): Die Konflikttheorie der Theorie der Interaktionsrituale, in: Bonacker, Thorsten (Hg.): Konflikttheorien, Wiesbaden, S. 427-446.

Rovira Kaltwasser, Cristóbal (2011): Populismus in vergleichender Perspektive, in: Berliner Debatte Initial 22/1, S. 4-11. 
Rüdiger, Anja (1996): Dekonstruktion und Demokratisierung. Emanzipatorische Politiktheorie im Kontext der Postmoderne, Opladen.

Rustin, Michel (1988): Absolute Voluntarism: Critique of a Post-Marxist Concept of Hegemony, in: New German Critique 43, S. 146-173.

Rydgren, Jens (2004): The Populist Challenge - Political Protest and EthnoNationalist Mobilization in France, New York/Oxford.

Ryser, Daniel (2008): Halb sank er hin. Walter Frey und die SVP, in: Wochenzeitung 13/2008, 27.3.2008, online abgerufen: http:/www.woz.ch/0813/wal ter-frey-und-die-svp/halb-sank-er-hin, 23.12. 2014

Saint-Just, Louis A. L. de (1957) : Discours et Rapports, Paris.

Sarasin, Philipp (2001): Die Wirklichkeit der Fiktion. Zum Konzept der ,imagined communities“, in: Jureit, Ulrike (Hg.): Politische Kollektive. Die Konstruktion nationaler, rassischer und ethnischer Gemeinschaften, Münster, S. $22-45$.

Sarasin, Philipp/Ernst, Andreas/Kübler, Christoph/Lang, Paul (1998): ImagiNation. Eine Einleitung, in: Schweizerisches Landesmuseum Zürich (Hg.): Die Erfindung der Schweiz. Bildentwürfe einer Nation, Zürich, S. 19-31.

Sarasin, Philipp/Wecker, Regina (1998): Einleitung, in: Sarasin, Philipp/Wecker, Regina (Hg.): Raubgold - Reduit - Flüchtlinge, Zürich, S. 7-11.

Sartori, Giovanni (1976): Parties and Party Systems, Cambridge.

Sauer, Birgit (2002): Direkte Demokratie und politische Deregulierung. Anmerkungen zum rechten Politikstil, in: Rossade, Werner/Sauer, Birgit/Schirmer, Dietmar (Hg.): Politik und Kultur. Studien zu den kulturellen Grundlagen politischen Handelns und politischer Institutionen, Wiesbaden, S. 125-134.

Saussure, Ferdinand de (1967): Grundfragen der Allgemeinen Sprachwissenschaft. Herausgegeben von Charles Bally und Albert Sechehaye. Mit einem Nachwort von Peter von Polenz, Berlin.

Schäfer, Himar (2013): Die Instabilität der Praxis. Reproduktion und Transformation des Sozialen in der Praxistheorie, Weilerswist.

Scharsach, Hans-Henning (2002): Christoph Blocher. Polarisierung als politisches System, in: Ders. (Hg.): Rückwärts nach rechts. Europas Populisten, Wien, S. 140-148.

Scheidegger, Tobias (2012): Vom Schweizerbauern zum Produzenten authentischer Swissness: Historische Annäherung an Bilder der bäuerlichen Schweiz im aktuellen Nahrungsmittel-Marketing, in: Decorzant, Yann/Heiniger, Alix/Reubi, Sege/Vernat, Anne (Hg.): Le Made in Switzerland: mythes, fonctions et réalités, Basel, S. 137-157.

Schilling, Christoph (1994): Blocher. Aufstieg und Mission eines Schweizer Politikers und Unternehmers, Zürich. 
Schmid, Karl (1978): Unbehagen im Kleinstaat. Untersuchungen über Conrad Ferdinand Meser, Henri-Frederic Amiel, Jakob Schaffner, Max Frisch, Jacob Burckhardt, Zürich.

Schmid, Karl (1998) [1957]: Versuch über die schweizerische Nationalität, in: Sprecher, Thomas/Niederberger, Judith (Hg.): Karl Schmid. Gesammelte Werke. Band 2, S. 332-346.

Schmidtke, Oliver (1996): Politics of Identity: Ethnicity, Territories, and the Political Opportunity Structure in Modern Italian Society, Sinzheim.

Schmitt, Carl (1991): Der Begriff des Politischen, Berlin.

Schrader, Martin (2009): Presseschau: So etwas wie ein Angstschrei, in: Deutsche Welle, 30.11.2009, online abgerufen: http:/www.dw.com/de/presse schau-so-etwas-wie-ein-angstschrei/a-49463 32, 11.10.2014.

Schwarzenbach, James (1974): Die Überfremdung der Schweiz, wie ich sie sehe, Zürich.

Searle, John R. (1969): Speech Acts. An Essay in the Philosophy of Language, Cambridge.

Seitz, Werner (2006): Elemente der politischen Kultur der Schweiz. Eine Annäherung, in: Blum Roger/Meier, Peter/Gysin, Nicole (Hg.): Wes Land ich bin, des Lied ich sing? Medien und politische Kultur. Berner Texte zur Kommunikations- und Medienwissenschaft. Band 10, Bern 2006, S. 51-64.

Seitz, Werner (2007): Mit Blocher schliesst die SVP ihre Reihen. Interview: Peter Granwehr, in: Der Landbote, 12.9.2007.

Seitz, Werner (2008): „Melonengrüne“ und „Gurkengrüne“. Die Geschichte der Grünen in der Schweiz, in: Baer, Matthias/Seitz, Werner (Hg.): Die Grünen in der Schweiz, Zürich/Chur, S. 7-14.

Segert, Dieter (2011): Populismus in Ostmitteleuropa. Stimme der Transformationsverlierer oder Gefährdung der Demokratie?, in: Berliner Debatte Initial 22/1, S. 53-65.

Seyd, Benjamin C. (2014): Das vertraute Gespenst - Ernesto Laclau zum Populismus, in: theorieblog, 27.5.2014, online abgerufen: http://www.theorieblog. de/index.php/2014/05/das-vertraute-gespenst-ernes-to-laclau-populismus/ print, 29.05.2014.

Sieyès, Emmanuel J. (2010): Was ist der Dritte Stand?, in: Ausgewählte Schriften. Herausgegeben von Oliver W. Lembcke und Florian Weber, Hamburg, S. 111-175.

Sigglow, Astrid (2009): Emanzipation und Kontingenz. Poststrukturalistische Demokratietheorie bei Chantal Mouffe, Ernesto Laclau und Jacques Derrida. Unveröffentlichte Magisterarbeit, Freiburg im Breisgau. 
Sir Peter Ustinov Institut (Hg.) (2012): Populismus. Herausforderung oder Gefahr für die Demokratie? Wien.

Skenderovic, Damir (2003): Constructing Boundaries in a Multicultural Nation: the Discourse of ,Overforeignization“ in Switzerland, in: Ohliger, Rainer/Schönwalder, Karen/Triadafilopoulos, Triadafilos (Hg.): European Encounters, Burlington, S. 186-209.

Skenderovic, Damir (2007a): Immigration and the Radical Right in Switzerland: Ideology, Discourse and Opportunities, in: Patterns of Prejudice 41/2, S. $155-176$.

Skenderovic, Damir (2007b): Das rechtspopulistische Parteienlager in der Schweiz. Von den Splitterparteien zur Volkspartei, in: Traverse. Zeitschrift für Geschichte 1, S. 45-63.

Skenderovic, Damir (2009): The Radical Right in Switzerland. Continuity and Change. 1945-2000, New York/Oxford.

Skenderovic, Damir (2013): Bauern, Mittelstand, Nation. Imagination und Metamorphosen der Schweizerischen Volkspartei im 20. Jahrhundert, in: Mazzoleni, Oscar/Meuwly, Olivier (Hg.): Die Parteien in Bewegung. Nachbarschaft und Konflikte, S. 49-76.

Skenderovic, Damir/D’Amato, Gianni (2008): Mit dem Fremden politisieren. Rechtspopulistische Parteien und Migrationspolitik in der Schweiz seit den 1960er Jahren, Zürich.

Spivak, Gayatari Chakravorty (1996): Subaltern studies. Deconstructing Historiography, in: Landry, Donna/MacLean, Gerald $(\mathrm{Hg})$ : The Spivak Reader, London, S. 203-236.

Smith, Anna Marie (1994): New Right Discourse on Race and Sexuality, Britain 1968-1990, Cambridge.

Smith, Anna Marie (1998): Laclau and Mouffe - the Radical Democratic Imaginary, New York.

Spier, Tim (2006): Populismus und Modernisierung, in: Decker, Frank (Hg.): Populismus. Gefahr für die Demokratie oder nützliches Korrektiv?, Wiesbaden, S. 33-58.

Spier, Tim (2010): Modernisierungsverlierer? Die Wählerschaft rechtspopulistischer Parteien in Westeuropa, Wiesbaden.

Stäheli, Urs (2000): Poststrukturalistische Soziologien, Bielefeld.

Stäheli, Urs (2001): Die politische Theorie der Hegemonie. Ernesto Laclau und Chantal Mouffe, in: Brodocz, André/Schaal Gary S. (Hg.): Politische Theorien der Gegenwart. Band 2, Opladen, S. 193-224.

Stanley, Ben (2008): The Thin Ideology of Populism, in: Journal of Political Ideologies 13/1, S. 95-110. 
Stavrakakis, Yannis (1998): Laclau mit Lacan, in: Marchart, Oliver (Hg.): Das Undarstellbare der Politik, Wien, S. 177-189.

Stavrakakis, Yannis (2000): On the Emergence of Green Ideology: The Dislocation Factor in Green Politics, in: Ders./Howarth, David/Norval Aletta J. (Hg.): Introducing Discourse Theory and Political Analyses. Identities, Hegemonies and Social Change, Manchester, S. 100-118.

Stavrakakis, Yannis (2004): Antinomies of Formalism: Laclau's Theory of Populism and the Lessons from Religious Populism in Greece, in: Journal of Political Ideologies 9/3, S. 253-267.

Steiner, Jürg (1970): Gewaltlose Politik und kulturelle Vielfalt. Hypothesen entwickelt am Beispiel der Schweiz. Mit einem Vorwort von Stein Rokkan, Bern/Stuttgart.

Steppacher, Burkard (2012): Knirschende Konkordanz, in: KAS Auslandsinformationen 3/2012, S. 56-71.

Studer, Brigitte (2010): Partei der Arbeit (PdA), in: Historisches Lexikon der Schweiz (HLS), online abgerufen: http://www.hls-dhs-dss.ch/textes/d/D17 401.php, 10.10.2012.

Tackenberg, Marco (2011): Jugendunruhen, in: Historisches Lexikon der Schweiz (HLS), online abgerufen: http://www hls-dhs-dss.ch/textes/d/D173 49.php, 8.10.2012.

Taggart, Paul (1996): The New Populism and the New Politics: New Protest Parties in Sweden in a Comparative Perspective, Basingstoke.

Taggart, Paul (2000): Populism, Buckingham.

Taggart, Paul (2002): Populism and the Pathology of Representative Politics, in:

Mény, Yves/Surel, Yves (Hg.): Democracies and the Populist Challenge, Basingstroke, S. 62-80.

Taggart, Paul (2004): Populism and Representative Politics in Contemporary Europe, in: Journal of Political Ideologies 9/3, S. 269-288.

Taguieff, Pierre-André (1994): From Race to Culture: The New Right's View of European Identity, in: Telos 98/99, S. 99-127.

Taguieff, Pierre-André (1995): Political Science Confronts Populism: Form a Conceptual Mirage to a Real Problem, in: Telos 103, S. 9-43.

Tanneberg, Dag/Rovira Kaltwasser, Cristóbal (Hg.) (2011): Populismus. Berliner Debatte Initial 22/1.

Tanner, Jakob (1998): „Réduit national“ und Aussenwirtschaft: Wechselwirkungen zwischen militärischer Dissuasion und ökonomischer Kooperation mit den Achsenmächten, in: Sarasin, Philipp/Wecker, Regina (Hg.): Raubgold Reduit - Flüchtlinge. Zur Geschichte der Schweiz im Zweiten Weltkrieg, Zürich, S. 81-105. 
Tanner, Albert (2002): Willensnation versus Kulturnation. Nationalbewusstsein und Nationalismus in der Schweiz, in: Bosshart, Pfluger, Catherine/Jung, Joseph/Metzger, Franziska (Hg.): Nation und Nationalismus in Europa. Kulturelle Konstruktion von Identitäten. Festschrift für Urs Altermatt, Frauenfeld/Stuttgart/Wien, S. 179-203.

Tanner, Jakob (2007): Das neue Wohlbehagen im Kleinstaat, in: Tagesanzeiger, 30.11.2007.

Tanner, Jakob (2009): Mittelstand, in: Historisches Lexikon der Schweiz (HLS), online abgerufen: http://www.hls-dhs-dss.ch/textes/d/D13791.php, 19.12. 2012.

Thies, Christian (2013): Die Masse - ein konservativer Topos der Zeitdiagnose? in: Großheim, Michael/Hennecke, Hans J. (Hg.): Staat und Ordnung im konservativen Denken, Baden-Baden, S. 76-91.

Tella, Torcuato S. di (1995): Populism, in: Lipset, Seymour M. (Hg.): The Encyclopedia of Democracy, Washington, D.C, S. 985-989.

Teuwsen, Peer (2012): Zu viel SVP in unseren Köpfen. Die rechtskonservative Geisteshaltung ist in der Mitte der Gesellschaft angekommen. $\mathrm{Zu}$ welchem Preis?, online abgerufen: http://www.zeit.de/2012/26/CH-SVP, 10.06.2013.

Torfing, Jacob (2005): The Linguistic Turn: Foucault, Laclau, Mouffe, and Žižek, in: Janoski, Thomas u. a. (Hg): The Handbook of Political Sociology. States, Civil Societies, and Globalization, Cambridge u. a., S. 153-171.

Tschopp, Peter (1992): Eine Niederlage für die Schweiz, Basler Zeitung, 7.12.1992.

Villiger, Kaspar (2008): Eine Willensnation muss wollen. Die politische Kultur der Schweiz: Zukunfts- oder Auslaufmodell?, Zürich.

Waltz, Christian (2009): Schweizer wollen keine Minarette, in: Deutsche Welle, 30.11.2009, online abgerufen: http://www.dw.com/de/schweizer-wollenkeine-minarette/a-4945813, 11.10.2014.

Watson, Matthew/Hay, Colin (2004): The Discourse of Globalisation and the Logic of No Alternative: Rendering the Contingent Necessary in the Political Economy of New Labour, in: Policy and Politics 30/4, S. 289-305.

Weber, Max (1972): Wirtschaft und Gesellschaft. Grundriss der verstehenden Soziologie, 5. rev. Ausgabe herausgegeben von Johannes Winckelmann, Tübingen.

Wehler, Hans-Ulrich (2011): Nationalismus. Geschichte, Formen, Folgen, München.

Wengeler, Martin (2003): Topos und Diskurs. Begründung einer argumentationsanalytischen Methode und ihre Anwendung auf den Migrationsdiskurs (1960-1985), Tübingen. 
Wenman, Marc Anthony (2003): Laclau or Mouffe? Splitting the Difference, in: Philosophy \& Social Criticism 29, S. 581-605.

Werz, Nikolaus (2011): Populismen in Lateinamerika seit den 1990er Jahren, in: Berliner Debatte Initial 22/1, S. 66-79.

Weyland, Kurt (1996): Neopopulism and Neoliberalism in Latin America: Unexpected Affinities, in: Studies in Comparative International Development 31/1, S. 3-31.

Weyland, Kurt (2001): Clarifying a Contested Concept. Populism in the Study of Latin American Politics, in: Comparative Politics 34/1, S. 1-22.

Widmer, Paul (2008): Die Schweiz als Sonderfall. Grundlagen - Geschichte Gestaltung, Zürich.

Wimmer, Andreas (2005): Kultur als Prozess. Zur Dynamik des Aushandelns von Bedeutungen, Wiesbaden.

Wimmer, Andreas (2011): A Swiss Anomaly? A Relational Account of National Boundary making, in: Nations and Nationalism. Journal of the Association for the Study of Ethnicity and Nationalism 17/4, S. 718-738.

Winkler, Heinrich August (2015): Stunde der Vereinfacher. Was rechte und linke Populisten verbindet, in: Die Zeit 6/2015, 5.2.2015.

Wirz, Claudia (2011): Der Bauer ist König, in: Die Zeit 15/2011, 7.4.2011, online abgerufen: http://www.zeit.de/2001/15/CH-Landwirtschaft, 15.3.2014.

Wodak, Ruth/Cillia, Rudolf de/Reisigl, Martin/Liebhart, Karin/Hofstätter, Klaus/Kargl, Maria (1998): Zur diskursiven Konstruktion nationaler Identität, Frankfurt a. M.

Wodak, Ruth (2001): Politikwissenschaft und Diskursanalyse. Diskurs in/der Politik, in: Markovits, Andrei S./Rosenberger, Sieglinde (Hg.): Demokratie Modus und Telos. Beiträge für Anton Pelinka, Wien, Köln, Weimar, S. 75100.

Wolin, Sheldon (1968): Paradigms and Political Theories, in: Gutting, Gary (Hg.): Paradigms and Revolutions. Appraisals and Applications of Thomas Kuhns Philosophy of Science, London, S. 160-191.

Wrana, Daniel/Langer, Antje (2007): An den Rändern der Diskurs. Jenseits der Unterscheidung diskursiver und nicht-diskursiver Praktiken, in: Forum Qualitative Sozialforschung $8 / 2$, online abgerufen, http://www.qualitativeresearch.net/index.php/fqs/rt/printerFriendly/253/557

Wullweber, Joscha (2012): Konturen eines politischen Analyserahmens - Hegemonie, Diskurs und Antagonismus, in: Ders./Dzudzek, Iris/Kunze, Caren/(Hg.): Diskurs und Hegemonie. Gesellschaftskritische Perspektiven, Bielefeld, S. 29-58. 
Zeller, René (2008): „Weil ich der Fähigste bin!“, in: Neue Zürcher Zeitung, 19.11.2008, online abgerufen: http://www.nzz.ch/aktuell/startseite/weil-ichder-faehigste-bin--1.1287409, 10.10.2014.

Zeller, René (2011): Heimatliebe. Nationale Identität lässt sich nicht monopolisieren, in: Neue Zürcher Zeitung, 30.7.2011, online abgerufen: http://www.nzz.ch/aktuell/international/heimatliebe-1.11702715, 14.11.2014.

Ziegler, Jean (1998): Die Schweiz, das Gold und die Toten, München.

Žižek, Slavoj (1990): Beyond Discourse Analysis, in: Laclau, Ernesto: New Reflections on the Revolution of Our Time, London, S. 249-260.

Žižek, Slavoj (1999): Carl Schmitt in the Age of Post-Politics, in: Mouffe, Chantal (Hg.): The Challenge of Carl Schmitt, London/New York, S. 18-37.

Žižek, Slavoj (2005): Die politische Suspension des Ethischen, Frankfurt a. M.

Žižek, Slavoj (2006a): Against the Populist Temptation, in: Critical Inquiry 32, S. 551-574.

Žižek, Slavoj (2006b): Schlagend, aber nicht treffend!, in: Critical Inquiry 33/1, S. $185-211$.

Žižek, Slavoj (2009): In Defense of Lost Causes, London/New York.

Zollinger, Lukas (2002): „Ich weiss etwas, das du nicht weisst..." Rekonstruktion der politischen Denkweise in der Albisgüetlirede 2000 von Christoph Blocher, in soz:mag 2/2002, S. 6-9.

Zollinger, Zollinger (2004): Der Mittelstand am Rande. Christoph Blocher, das Volk und die Vorstädte, Bern.

Zúquete, José Pedro (2011): Missionarische Politik. Ein Beitrag zur Analyse des Populismus, in: Berliner Debatte Initial 22/1, S. 92-100.

[o.A.] FACTS (1999): Der Tribun wankt, 21.10.1999.

[o.A.] SonntagsZeitung (1999): Die SVP gegen den Rest: An welchen Themen sich der Streit entzünden wird, 31.10.1999.

[o.A.] Le Temps (2007): La vague UDC, irrésistible, 24.10.2007.

[o.A.] NZZ (1997): Cotti für Abschied vom Sonderfall Schweiz. Rede an der „Albisgüetli“-Tagung der kantonalen SVP, 18.1.1997.

[o.A] NZZ (2000): Gespräche am Stammtisch ernst nehmen. Europas Sozialdemokratie auf der Suche nach Antworten auf den Rechtspopulismus, 28.6.2000.

[o.A.] Der Spiegel (1997): Hitlers beflissene Hehler, 1997/12, 17.3.1997, S. 162-178, online abgerufen: http://www.spiegel.de/spiegel/print/d8680325.html, 10.11.2014.

[o.A.] Spiegelonline (2009): Abstimmung in der Schweiz. Europas Rechte bejubeln Minarett-Verbot, 30.11.2009, online abgerufen: http://www.spiegel.de/ 
politik/ausland/abstimmung-in-der-schweiz-europas-rechte-bejubeln-mina rett-verbot-a-664222.html, 10.12.2015.

[o.A.] Tages-Anzeiger (2007): SVP bekräftigt Gang in die Opposition, 19.12.2007.

\section{FRAGMENTE DES SVP-DISKURSES}

Ackeret, Matthias (2007): Das Blocher-Prinzip. Ein Führungsbuch, Schaffhausen.

Baader, Roland/Koblet, Hans/Stäuble, Eduard/Schlüer, Ulrich (1999): Podiumsgespräch, in: „Schweizerzeit“-Schriftenreihe 34, S. 41-55.

Bandi, Hans-Georg (1999): Helvetischer Masochismus, in: Schweizerzeit 21/3, 29.1.1999.

Biffiger, Gregor (2007): Handeln, bevor es zu spät ist! in: Schweizerzeit 29/13, 11.5.2007.

Blocher, Christoph (1991): Die Classe politique in der Krise, in: Schweizerzeit $13 / 15,1.8 .1991$.

Blocher, Christoph (1992a): Anpassung und Widerstand, Schweizerzeit 14/3, 21.2.1992.

Blocher, Christoph (1992b): Der EWR-Vertrag - eines freien Volkes unwürdig!, in: „Schweizerzeit“-Schriftenreihe 12.

Blocher, Christoph (1992c): EWR - das Ende der Unabhängigkeit, in: Schweizerzeit 14/18, 16.10.1992.

Blocher, Christoph (1993): Unser Standort - unser Auftrag! Albisgüetli-Rede 1993, in: Blocher, Christoph/Ogi, Adolf: Politische Standortbestimmung nach dem Nein zum EWR. Die Referate der Albisgüetli-Tagung 1997. Gehalten anderthalb Monate nach dem EWR-Nein des Schweizervolkes, in: „Schweizerzeit"-Schriftenreihe 14, S. 3-22.

Blocher, Christoph (1995): Ein exemplarischer Kampf. Eine Standortbestimmung mit Christoph Blocher. Interview mit Christian Gross und Hans Hartmann, in: Hartmann Hans/Gross, Andreas (Hg.): Heile Welt Schweiz. Die nationalkonservative Bewegung in der Diskussion, Zürich, S. 34-52.

Blocher, Christoph (1997a): Die Schweiz und der Zweite Weltkrieg, Referat in Zürich-Oerlikon 1.3.1997, in: „Schweizerzeit“-Schriftenreihe 26, S. 5-39.

Blocher, Christoph (1997b): Die Schweiz und der Eizenstat-Bericht, Referat im Kursaal Bern 21.6.1997, in: „Schweizerzeit“-Schriftenreihe 28. 
Blocher, Christoph (1997c): Standortbestimmung. Albisgüetli-Rede 1997, 17.1.1997, online abgerufen: http://www.blocher.ch/en/articles/standortbestimmung/7d3de2f4ad413ceb 9c51405b713167b1.html, 10.8.2013.

Blocher, Christoph (1998): Die Schweiz im Jubiläumsjahr 1998. AlbisgüetliRede 1998, 16.1.1998, online abgerufen: http://www.blocher.ch/uploads/me dia/980116albis.pdf, 4.3.2012.

Blocher, Christoph (1999a): Wie SVP, FDP und CVP eine bürgerliche Regierung bilden - mein 7-Punkte-Programm, ohne Publikationsort, 27. Mai 1999, online abgerufen: http://www.blocher.ch/artikel/wie-svp-fdp-und-cvp-einebürgerliche-Regierung-bilden-mein-7-punkte-programm.html, 15.05.2013.

Blocher, Christoph (1999b): Unsere Politik im 21. Jahrhundert. Albisgüetli-Rede 1999, 15.1.1999, online abgerufen: http://www.blocher.ch/uploads/media/99 0115albis.pdf, 3.2.2013.

Blocher, Christoph (2000a): Die sieben Geheimnisse der SVP (streng vertraulich). Albisgüetli-Rede 2000, 21.1.2000, online abgerufen: http://www.blocher.ch/uploads/media/000121albis.pdf, 15.7.2013.

Blocher, Christoph (2000b): Freiheit statt Sozialismus, 3.4.2000, online abgerufen: http://www.blocher.ch/artikel/freiheit-statt-sozialismus.html, 20.7.2013.

Blocher, Christoph (2001): Suchst Du den Krieg, dann kommt er zu Dir! Albisgüetli-Rede 2001, 19.1.2001, online abgerufen: http://www.blocher.ch/uploa ds/media/010119albis.pdf, 15.2.2013.

Blocher, Christoph (2002): Chumm Bueb und lueg dies Ländli aa! Von wahren und falschen Eliten. Albisgüetli-Rede 2002, 18.1.2002, online abgerufen: http://www.blocher.ch/uploads/media/020118albis.pdf, 21.3.2013.

Blocher, Christoph (2003): Dialog mit Abwesenden. Eine Rede in Zitaten. An ihren Worten sollt ihr ihre Taten messen. Albisgütli-Rede 2003, 17.1.2003, online abgerufen: http://www.blocher.ch/uploads/media/030117_blocher_albis_de.pdf, 11.2.2014.

Blocher, Christoph (2004): Die bürgerliche Wende vollziehen. Albisgüetli-Rede 2004, 16.1.2004, online abgerufen: http://www.blocher.ch/artikel/diebuergerliche-wende-vollziehen/915e0602972f8d144b6780e8d733f7ae.html, 10.8.2014.

Blocher, Christoph (2006): Agenda 2006, Albisgüetli-Rede 2006, 20.1.2006, online abgerufen: http://www.blocher.ch/artikel/agenda-2006.html, 5.7.2014.

Blocher, Christoph (2007a): Zum Wohl von Volk und Land. Albisgüetli-Rede 2007, 19.1.2007, online abgerufen: http://www.blocher.ch/artikel/zum-wohlvon-volk-und-land.html, 20.7.2014. 
Blocher, Christoph (2007b): 1. August-Rede in Hallau, online abgerufen: http://blocher.ch/artikel/1-august-rede-2007-in-hallau/55f14e5f300e9fdecb82 18710aa5bf47.html, 10.10.20134.

Blocher, Christoph (2008): „Auf der Seite des Volkes“. Albisgüetli-Rede 2008, 18.1.2008, online abgerufen: http://www.blocher.ch/artikel/auf-der-seite-desvolkes, 2.8.2013.

Blocher, Christoph (2009a): Widerstand statt Anpassung, Albisgüetli-Rede 2009, 16.1.2009, online abgerufen: http://www.blocher.ch/uploads/media/0 90116albisgueetlirede.pdf, 20.7.2013.

Blocher, Christoph (2009b): Anpassung statt Widerstand ist die Antwort der Schwachen. Interview mit Patrick Müller und Othmar von Matt, SonntagsZeitung, 8.11.2009, online abgerufen: http://www.blocher.ch/en/articles/anpassung-statt-widerstand-ist-die-antwort- der-schwachen.html, 11.12.2014.

Blocher, Christoph (2010): Wie die politische Elite die Schweiz zugrunde richtet. Albisgüetli-Rede 2010, 15.1. 2010, online abgerufen: http://www.blocher.ch/artikel/wie-die-politische-elite-die-schweiz-zugrunderichtet/b184d09f930f2844f920415a61b8c605.html, 1.8.2013.

Blocher, Christoph (2011a): Warum wählen Schweizer SVP? Albisgüetli-Rede 2011, 21.1.2011, online abgerufen: http://www.blocher.ch/artikel/warumwaehlen-schweizer-svp/c266494d84b954f4e74c20cf69f96ad7.html, $\quad 2.8$. 2013.

Blocher, Christoph (2011b): Wahre Kunst ist freie Kunst! Interview mit René Scheu, in: Der Schweizer Monat 985, 4/2011, S. 60-63.

Blocher, Christoph/Couchepin, Pascal (1999): Das Duell - Blocher gegen Couchepin. Interview mit Andreas Durrisch und Ottmar von Matt, in: SonntagsZeitung, 4.7.1999, online abgerufen: http://www.blocher.ch/artikel/dasduell-blocher-gegen-couchepin.html, 10.05.2013.

Blocher, Christoph/Gross, Andreas (1999): „Dieser Krieg beseitigt das Elend nicht“. Gespräch mit Martin Furrer und Martin A. Senn, in: Die Weltwoche 16/1999, 15.4.1999, online abgerufen: http://www.blocher.ch/artikel/dieserkrieg-beseitigt-das-elend-nicht.html, 15.04.2014.

Bonny, Jean-Pierre (1992): Brüssel hätte das Sagen, in: Schweizerzeit 14/17, 2.10.1992.

Brunner, Manfred (1993): Unabhängigkeit, Föderalismus, Freiheit - und die EU? Referat gehalten an der „Schweizerzeit“-Herbsttagung vom 13.11.1993, in: „Schweizerzeit"-Schriftenreihe 16, S. 5-40. 
Brunner, Manfred/Blocher, Christoph /Schlüer, Ulrich (1993): Die Europäische Union und die Schweiz. Podiumsgespräch, in: „Schweizerzeit"Schriftenreihe 16, S. 41-89.

Brunner, Toni (2007): Dank Christoph Blocher - SVP weiter gestärkt, in: SVPKlartext 11/2007.

Brunner, Toni (2008): Ewiges Ringen zwischen den Kräften der Freiheit und den Kräften der Unfreiheit, in: Der Zürcher Bote 32/50.

Bundesrat (1992): Volksabstimmung vom 6. Dezember 1992. Erläuterungen des Bundesrates, online abgerufen: http://www.bk.admin.ch/themen/pore/va/19 921206/index.html?lang=de, 15.8.2014.

Bundesrat (1997): Erklärung des Bundesrates vom 22. Mai, online abgerufen: http://www.parlament.ch/d/dokumentation/dossiers/dossiers-archiv/chweltkrieg-2/ch-weltkrieg-2-dokumente/Seiten/erklaerung-bundesrat1997.aspx, 20.10.2014.

Bundesrat (2008): Botschaft zur Volksinitiative „Gegen den Bau von Minaretten“, online abgerufen: https://www.admin.ch/ch/d/ff/2008/7603.pdf, 11.9.014.

Chevellaz, Georges-André (1992): Der Bundesrat will uns einlullen. Ein Interview mit Alt-Bundesrat George-André Chevallaz, in: Schweizerzeit 14/15, 4.9.1992.

Egerkinger Komitee (o.J.): Argumentarium „Frauen gegen eine Islamisierung der Schweiz“, online abgerufen: http://www minarett-verbot.ch/downloads/ argumentarium_frauenfreiheit.pdf, 12.1.2015.

Egerkinger Komitee (2010): Manifest „Nein zur Islamisierung der Schweiz“, 29.11.2010, online abgerufen: http://www.minarett-verbot.ch/downloads/ kein-minarett-kein-muezzin-keine-scharia-29.11.pdf, 14.1.2015.

Engeler, Urs P. (2003): In der Realität angekommen, in: Die Weltwoche 15/2003, 9.4.2003, online abgerufen: http://www.weltwoche.ch/ausgaben/2 003-15/artikel-2003-15-in-der-realitaet.html, 12.9.2014.

Engeler, Urs P. (2009a): Die Gewalt fremden Rechts, in: Die Weltwoche 50/2009, 9.12.2009, online abgerufen: http://www.weltwoche.ch/ausgaben/ 2009-50/artikel-2009-50-die-gewalt-des-f.html, 5.12.2014.

Engeler, Urs P. (2009b): „Binär primitiv-gewickelter Populismus“, in: Die Weltwoche 50/2009, 9.12.2012, online abgerufen:

http://www.weltwoche.ch/ausgaben/2009-50/artikel-2009-50-umfragebinaer-primitiv-gewickelter-populismus.html, 5.12.2014. 
Engeler, Urs P. (2012): La leçon française, in: Die Weltwoche 18/2012, 2.5.2012, online abgerufen: http://www.weltwoche.ch/ausgaben/201218/kommentar-la-lecon-francaise-die-weltwoche-ausgabe-182012.html,

12.1.2015.

Engeler, Urs P./Gut, Philip (2009): Demokratie. Politik aus dem Hinterhalt, in:

Die Weltwoche 49/2009, 2.12.2009, online abgerufen: http://www.weltwoche.ch/ausgaben/2009-49/artikel-2009-49-demokratie-polit.html,

5.12.2014.

Eysz, Matthias von (2001): Der Islam im liberalen Europa: Christlichabendländische Kultur vor der Selbstauflösung, in: Schweizerzeit 21/11, 13.6. 2001.

Farwick, Dieter (2009): Die Demografie wird unsere Kultur zerstören, in: Schweizerzeit 31/28, 27.11.2009.

Frey, Walter (1992): Der Wirtschaftsstandort Schweiz, in: „Schweizerzeit“Schriftenreihe 12.

Freysinger, Oskar (2009): Ja zum Minarett-Verbot, in: Schweizerzeit 31/24, 9.10.2009.

Furrer, Werner (1992): Schweiz und EG: Blendende Zukunft? Eine Streitschrift von Werner Furrer, in: Schweizerzeit 14/18, 16.10.1992.

Futterknecht, Willy (1992): Das EG-Trugbild. Dokumente und Analysen eines Machtkampfes, Schaffhausen.

Grabherr, Emil (2007): Die fremdbestimmte Konkordanz, in: Der Zürcher Bote 49/51, 21.12.2007.

Gstrein, Heinz (2009): Die Bedeutung des Minaretts im Islam, in: Schweizerzeit 31/28, 27.11.2009.

Gut, Philipp (2007): Avancen an den Zeitgeist, in: Die Weltwoche 49/2007, online abgerufen: http://www.weltwoche.ch/ausgaben/2007-49/artikel-200749-avancen-an-den-z.html, 15.10.2014.

Gut, Philip (2009): Ein Ja zur Demokratie. Kommentar zu MinarettAbstimmung, in: Die Weltwoche 48/2009, 29.11.2009, online abgerufen: http://www.weltwoche.ch/ausgaben/2009-48/artikel-2009-11-29-kommentarzur.html, 5.12.2014.

Herdener, Hans R. (1997): Dazu stehen wir! Mehr als fünfzig Jahre danach, in: Schweizerzeit 19/7, 4.4.1997.

Kelek, Necla (2007): Das Minarett ist ein Herrschaftssymbol, in: Schweizerzeit 29/19, 13.6.2007. 
Keller, Peter (2009): Druck von unten, in: Die Weltwoche 49/2009, 2.12.2009, online abgerufen: http://www.weltwoche.ch/ausgaben/2009-49/artikel-200949-politik-druck-vo.html, 14.11.2014.

Köppel, Roger (2009a): Minarette, in: Die Weltwoche 41/2009, 25.6.2009, online abgerufen: http://www.weltwoche.ch/ausgaben/2009-41/artikel-2009-41editorial-minare.html, 2.1.2014.

Köppel, Roger (2009b): Islam, in: Die Weltwoche 42/2009, 1.7.2009, online abgerufen: http://www.weltwoche.ch/ausgaben/2009-42/artikel-2009-42-editorial-islam.html, 2.1.2015.

Maurer, Ueli (2007): Wahlsieger in die Opposition gezwungen, in: SVP-Klartext 12/2007.

Mörgeli, Christoph (1999): Die Arroganz der Wahlverlierer, in: Schweizerzeit 21/26, 2.12.1999.

Mörgeli, Christoph (2000a): Die direkte Demokratie vervollständigen. Unser Land braucht einen stärkeren Bundesrat, der sich direkt auf das Volk abstützen kann, in: Schweizerzeit 22/3, 28.1.2000.

Mörgeli, Christoph (2000b): Der Kleinstaat und die Ideologie des Großräumigen, in: Schweizerzeit 22/27, 24.11.2000, online abgerufen: http://www.schweizerzeit.ch/2700/leit.html, 5.6.2014

Nebiker, Hans-Rudolf (1992): SVP-Communiqué vom 30.11.1992.

Nieth, Robert (2009): Einschränkung bis zur Selbstaufgabe, in Schweizerzeit 32/28, 27.11.2009.

Nussbaumer, Hannes (2007): Den Sonderfall widerbeleben oder entsorgen?, in: Tagesanzeiger, 6.12.2007, online abgerufen: http://archive.today/201210100 44638/http://sc.tagesanzeiger.ch/dyn/news/zuerich/821000.html\#selection78.5-535.78

Raddatz, Hans-Peter (2001): Angriff gegen den Westen. Die Gefahr des fundamentalistischen Islam, in Schweizerzeit 21/19, 5.10.2001.

Raddatz, Hans-Peter (2009): Rechtsstaat und Scharia, in: Schweizerzeit 31/27, 13.11.2009.

Reimann, Lukas (2007): Aufklären statt verschleiern! in: Schweizerzeit 29/13, 11.5.2007.

Roederer, Walter (1992): „Schweizer, lasst euch nicht verkaufen!“‘, in: Schweizerzeit 14/18, 16.10.1992.

Rothenhäusler, Paul (1997): Oberschulmeister der Nation. Offener Brief an Adolf Muschg, in: Schweizerzeit 19/4, 21.2.1997.

Rutz, Gregor A. (2009): Direkte Demokratie am Ende?, in: Der Zürcher Bote $52 / 51,18.12 .2009$. 
Schiltknecht, Kurt (1992): Die wirtschaftlichen und währungspolitischen Auswirkungen eines EWR/EG-Beitritts, in: „Schweizerzeit“-Schriftenreihe 12.

Schlüer, Ulrich (1992a): Ausverkauf, in: Schweizerzeit 14/17, 2.10.1992.

Schlüer, Ulrich (1992b): Le Pen als Partner?, in: Schweizerzeit 14/6, 3.4.1992.

Schlüer, Ulrich (1997): Kollektivschuld der Schweiz? Die Welt der linken Historiker, in: Schweizerzeit 19/9, 2.5.1997.

Schlüer, Ulrich (1999a): Spalte rechts. Majestätsbeleidigung, in: Schweizerzeit 21/19, 24.9.1999.

Schlüer, Ulrich (1999b): Zauberformel am Ende, in: Schweizerzeit 21/24, 19.11.1999.

Schlüer, Ulrich (1999c): Spalte rechts. Sieger, in: Schweizerzeit 21/28, 29.12.1999.

Schlüer, Ulrich (2009a): Ein Abstimmungskampf mit beunruhigenden Merkmalen, in: Der Zürcher Bote 51/44, 30.10.2009.

Schlüer, Ulrich (2009b): Unsere Antwort: Ja zur Schweiz, in: Schweizerzeit 31/30, 21.12.2009.

Schlüer, Ulrich (2010): Das Minarett und die Steinigungs-Gelüste, online abgerufen: http://www.minarett-verbot.ch/downloads/kein-minarett-kein-muezzin -keine-scharia-29.04.pdf, 1.1.2015.

Somm, Markus (2007): Abwahl: Sein wahres Versagen, in: Die Weltwoche 51/2007, online abgerufen: http://www.weltwoche.ch/ausgaben/200751/artikel-2007-51-sein-wahres-vers.html, 10.11.2014.

Somm, Markus (2009): Christoph Blocher. Der konservative Revolutionär, Herisau.

Stäuble, Eduard (1999): Die Schweiz und der die geistige Situation der Gegenwart. Rede, gehalten an der ,Schweizerzeit“-Herbsttagung am 6. November 1999 in Flaach, in: „Schweizerzeit“-Schriftenreihe 34.

Steinemann, Barbara (2009): Eine Nachlese auf die Abstimmung des Jahrzehnts, in: Der Zürcher Bote, 51/49, 4.12.2009.

Suter, Daniel (2007): Keine Religion des Friedens, in: Schweizerzeit 29/14, 28.5.2007.

SVP (1991): SVP-Parteiprogramm für die eidgenössische Legislaturperiode 1991-1994 (Populärfassung), Bern.

SVP (1991): Wohlfahrt - Freiheit - Sicherheit, Parteiprogramm 1999, Bern.

SVP (1999a): SVP-Parteiprogramm 1999, Bern.

SVP (1999b): SVP-Positionspapier Sicherheit ist ein Recht, Bern.

SVP (1999c): SVP-Positionspapier zur Migrationspolitik, Bern.

SVP (2003): Wahlplattform 2003 bis 2007, Bern. 
Ulfkotte, Udo (2009): Die schleichende Islamisierung Europas, in: Schweizerzeit 31/26, 6.11.2009.

Walthard, Frédéric (1992a): Die EG und die Kleinstaaten, in: Schweizerzeit 14/12, 26.6.1992.

Walthard, Frédéric (1992b): Falle für Souveränität und Unabhängigkeit, in: Schweizerzeit 14/14, 14.8.1992.

Walthard, Frédéric (1997a): Hat die Schweiz ihr Rückgrat verloren?, in: Schweizerzeit 19/6, 21.3.1997.

Walthard, Frédéric (1997b): Kompromissler unerwünscht! Zwischen Nationalratswahl und Bundesratswahl, in: Schweizerzeit 21/23, 5.11.1999.

Wartburg, Wolfgang von: Was zu tun wäre. Zur Orientierungslosigkeit der Classe politique, in: Schweizerzeit 16/3, 18.2.1994.

Wartburg, Wolfgang von (1994): Was zu tun wäre. Zur Orientierungslosigkeit der classe politique, in: Schweizerzeit 16/3, 18.2.1994.

[o.A.] Schweizerzeit (2008): Der Islam - ein komplettes System, 30/30, 24.10.2008. 



\section{Danksagung}

Die vorliegende Dissertation ist im Verlauf von vier Jahren an der Universität Hamburg verfasst worden. Ihr Entstehen wäre nicht möglich gewesen ohne die vielfältige Unterstützung, die ich von vielen Seiten erhalten habe.

Der erste Dank gebührt der Hansen-Stiftung für die finanzielle und ideelle Förderung des Forschungsprojekts. Ein besonderer Dank geht dabei an Klaus P. Hansen und Jan-Christoph Marschelke. Meinen beiden Betreuern Urs Stäheli und Marianne Pieper möchte ich dafür danken, dass sie mich während der gesamten Zeit der Dissertation unterstützt und gefördert haben. Den Mitgliedern der Mikro-AG „Hegemonietheorie und soziale Bewegungen“ und des Workshops „Diskurs- und Hegemonietheorie“ danke ich für die produktiven Diskussionen über die Tiefen und Untiefen der politischen Theorie Ernesto Laclaus und Chantal Mouffes. Ferner danke ich den Mitarbeitern des Sozialarchivs in Zürich für ihre Hilfe bei der Suche nach Quellen aus dem Zeitalter vor der Digitalisierung. Beim transcript Verlag - und besonders bei Anke Poppen - bedanke ich mich für die gute Zusammenarbeit.

Meinen Freunden Astrid Sigglow und Conrad Lluis Martell möchte ich an dieser Stelle für die vielen gemeinsamen Theoriediskussionen, ihre Ermutigung, ihre Kritik und für so viel mehr danken. Mit Elisabeth Michelbach und Manuel Scheidegger konnte ich an langen Göttinger Bibliothekstagen erholsame und unterhaltsame Pausen verbringen. Meinen Eltern und Helga Karth - und ganz besonders Doris Zimmermann - danke ich für ihre Unterstützung und ihren Rückhalt. Mit Friederike Schruhl konnte ich Ideen ausprobieren, Perspektiven akzentuieren und viele intensive Diskussionen führen. Ohne sie wäre nicht nur diese Arbeit eine andere. 


\section{Kultur und Kollektiv}

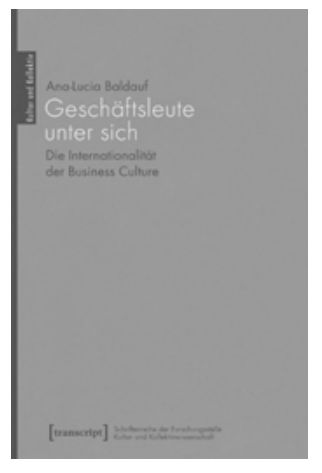

Ana-Lucia Baldauf

Geschäftsleute unter sich

Die Internationalität der Business Culture

2015, 318 Seiten, kart., 34,99€,

ISBN 978-3-8376-3213-2

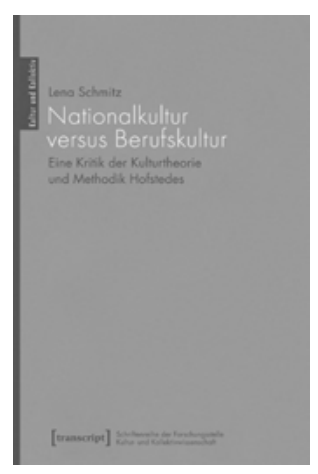

Lena Schmitz

Nationalkultur versus Berufskultur

Eine Kritik der Kulturtheorie

und Methodik Hofstedes

20I5, 276 Seiten, kart., 34,99€,

ISBN 978-3-8376-3II0-4

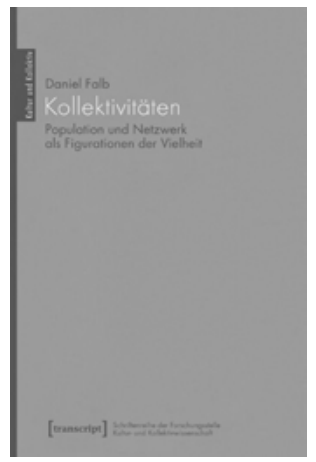

Daniel Falb

Kollektivitäten

Population und Netzwerk

als Figurationen der Vielheit

20I5, 4IO Seiten, kart., 34,99€,

ISBN 978-3-8376-3099-2

Leseproben, weitere Informationen und Bestellmöglichkeiten finden Sie unter www.transcript-verlag.de 